PEDRO CARDOZO DE MELLO

SISTEMA DE AUTOMAÇÃO E CONTROLE PARA TANQUES OCEÂNICOS COM MÚLTIPLOS ATUADORES 
PEDRO CARDOZO DE MELLO

\title{
SISTEMA DE AUTOMAÇÃO E CONTROLE PARA TANQUES OCEÂNICOS COM MÚLTIPLOS ATUADORES
}

\begin{abstract}
Tese de Doutorado apresentada à Escola Politécnica da Universidade de São Paulo como parte dos requisitos para obtenção do título de Doutorado em Engenharia.
\end{abstract}

Área de Concentração:

Engenharia de Controle e Automação Mecânica.

Orientadores:

Prof. Dr. Julio Cezar Adamowski

Prof. Dr. Eduardo Aoun Tannuri

São Paulo 
Este exemplar foi revisado e alterado em relação à versão original, sob responsabilidade única do autor e com a anuência de seu orientador.

São Paulo, de maio de 2012.

Assinatura do autor

Assinatura do orientador

\section{FICHA CATALOGRÁFICA}

Mello, Pedro Cardozo de

Sistema de automação e controle para tanques oceânicos com múltiplos atuadores / P.C. de Mello. -- São Paulo, 2012. $217 \mathrm{p}$.

Tese (Doutorado) - Escola Politécnica da Universidade de São Paulo. Departamento de Engenharia Mecatrônica e de Sistemas Mecânicos.

1.Tanque de provas 2. Ondas (Geração; Ensaios) 3. Controladores programáveis 4. Ondógrafo I. Universidade de São Paulo. Escola Politécnica. Departamento de Engenharia Mecatrônica e de Sistemas Mecânicos II. t. 
Dedico este trabalho à minha família. 


\section{AGRADECIMENTOS}

Ao Prof. Dr. Julio Cezar Adamowski, pelos conhecimentos e experiências compartilhados e pela orientação na elaboração deste trabalho e em diversos assuntos da Engenharia. Ao Prof. Dr. Eduardo Aoun Tannuri, pela objetividade com que me orientou ao longo da pesquisa e pelo incentivo à sua finalização. Agradeço aos meus orientadores pela paciência, incentivo e dedicação com que me auxiliaram em assuntos interdisciplinares.

Aos professores do TPN pelo apoio e pela oportunidade de atuar em um laboratório que muito agregou a meus conhecimentos e, em especial, aos professores Dr. Kazuo Nishimoto, Dr. Alexandre Nicolaos Simos e Dr. André Luís Condino Fujarra. Agradeço também aos alunos do TPN Edgard Malta, Rodolfo Gonçalves, Felipe Ruggeri, Rodrigo Amarante e Rafael Watai, entre outros.

Aos pesquisadores e alunos do Laboratório de Ultrassom da Poli pela ajuda no desenvolvimento dos diversos sistemas eletrônicos e fundamentos teóricos utilizados no trabalho - em especial ao engenheiro Alan Souza, ao Prof. Dr. Flavio Buiochi e ao Dr. Marco Aurélio Brizzotti Andrade - e aos alunos da pós-graduação, em especial Marcelo Matuda, Fausto Kenzo Chinen e Eduardo Bonci Cavalca.

Aos pesquisadores do Departamento de Engenharia Naval da Poli, Carlos Alberto Freire de Souza e Dr. João Alcino Martins, pelos mais variados conhecimentos a mim transmitidos.

Agradeço pela orientação recebida, na concepção do sistema de automação e controle, dos professores Dr. Fuad Kassab Junior e Dr. Ricardo P. Marques do LAC Poli e dos alunos Thiago Contim e Daniel Uehara pelo apoio essencial na integração dos sistemas eletrônicos.

Ao engenheiro Thiago Turcato do Rego, pelo suporte aos equipamentos da Mitsubishi FA, que foram inestimáveis para que o sistema de automação e controle atingisse o desempenho esperado.

Agradeço também ao companheirismo de Mario Luis Carneiro, Oygres Siqueira e Izabela Frazão Alberto nas extensas montagens experimentais utilizadas neste trabalho e também no desenvolvimento e na implementação dos equipamentos no CH-TPN. Sem essa ajuda e suporte esse trabalho não seria possível.

Agradeço em especial ao Dr. Ing. Nicolás Pérez, por acreditar no desenvolvimento da técnica de TR aplicada a um tanque de provas e pelas correções feitas ao longo do trabalho nos conceitos teóricos necessários. 


\section{Resumo}

O presente trabalho aborda o desenvolvimento de um sistema de automação e controle para tanques oceânicos com múltiplos atuadores para possibilitar a geração e absorção ativa de ondas. O desenvolvimento compreende: a implementação e a validação do sistema de automação e controle para o tanque de provas; $o$ desenvolvimento de algoritmos para a geração de ondas com batedores do tipo flap, para atender aos casos tipicamente utilizados em ensaios de estruturas oceânicas, tais como ondas regulares e irregulares, com ou sem espalhamento direcional. O sistema desenvolvido fez uso de controladores do tipo CLP (controlador lógico programável) em rede de comunicação industrial usando troca de dados síncrona, como uma solução robusta de automação.

Os controladores desenvolvidos foram estudados individualmente para a devida caracterização e identificação dos limites de desempenho. Sensores de ondas ultrassônicos foram desenvolvidos e caracterizados para medir ondas nos atuadores e viabilizar a malha de controle de absorção ativa do tanque de provas. Sensores de ondas capacitivos foram desenvolvidos e calibrados para a medição de ondas nos ensaios experimentais.

A validação experimental do funcionamento do sistema de atuação, controle e sensoriamento foi realizada utilizando os equipamentos desenvolvidos. Os testes foram feitos validando o funcionamento dos atuadores, a geração de ondas regulares, a geração de ondas regulares oblíquas e a geração de ondas irregulares de cristas longas. Os testes apontaram que os atuadores dos cantos do tanque, que são fixos, provocam alterações no campo de ondas, tal como a difração de ondas. As flutuações foram avaliadas onde os valores extremos podem chegar a $58 \%$ e foi apresentada uma proposta de medidas paliativas. As ondas regulares e irregulares foram validadas para que o tanque seja capaz de realizar ensaios experimentais reproduzindo as condições ambientais da costa brasileira em ensaios com modelos reduzidos. Foram realizadas medições do coeficiente de reflexão das ondas regulares e irregulares geradas no tanque de provas que mostram valores em torno de $10 \%$. Usando a absorção ativa de ondas em duas laterais opostas do tanque, constatou-se que a segunda reflexão (re-reflexão) afeta fracamente o campo de ondas.

A fim de demonstrar o potencial do controlador do tanque, foi desenvolvida uma nova técnica para focalização de energia de ondas em tanque de provas, fundamentada na técnica de TR (time reversal), para concentrar ondas em pontos específicos do espaço. Esta técnica foi originalmente proposta para aplicações usando ultrassom na forma de ondas de pressão acústica, mas, devido à semelhança do fenômeno físico, a técnica foi aplicada às ondas de superfície livre da água.

Foram realizados três tipos de testes usando TR, e em todos eles a concentração de ondas foi obtida no local e no instante esperados. Concluiu-se, então, que o método funciona mesmo que existam obstáculos à propagação da onda, como difração e reflexão no interior do tanque de provas. Um dos testes estudou as ondas concêntricas geradas por um objeto lançado contra a água; a aplicação de TR resultou em uma onda concentrada no ponto de lançamento. Os fenômenos observados podem servir de paradigma para comparações numéricas e estudos de ondas em meios dispersivos. 


\begin{abstract}
This work discusses the development of an automation and control system for ocean tanks with multiple actuators to enable the generation and active absorption of waves. The development includes: implementation and validation of system automation and control to the ocean wave tank, the development of algorithms for generating waves with flap type wave generator for dealing with cases typically used in tests of ocean structures, such as regular waves and irregular, with or without directional spreading. The developed system used PLC controllers (programmable logic controller) and an industrial communication network with synchronous data exchange, which is a robust automation system solution.

The developed controllers were individually studied for proper performance characterization. Ultrasonic wave sensors have been developed and characterized to measure waves in the face of actuators and enable the control loop active absorption of the ocean wave tank. Capacitive wave sensors have been developed and calibrated to measure wave in experimental tests.

The experimental validation of system actuation, control and sensing system was performed. Validation tests of the operation of the actuators under regular wave generation, irregular wave generation and oblique regular waves were done. The tests showed that the fixed actuators of the corners of the tank cause changes in the wave field such as diffraction waves. The spatial wave field fluctuations can reach 58\% and correction procedures were proposed. Regular and irregular waves were validated for the tank to be able to perform experimental tests reproducing the environmental conditions of the Brazilian coast in reduced model tests of offshore structures. Measurements of the reflection coefficient of regular and irregular waves generated in the test tank indicated values around $10 \%$. Using active absorption of waves in two opposite sides of the tank, it was realized that the re-reflection weakly affects the wave field.

In order to demonstrating the innovative potential applications of tank, it was developed a new technique to focus wave energy, based on the technique of TR (time reversal) to concentrate waves at specific points in space. This was originally proposed for applications using ultrasound acoustic pressure waves, but due to the similarity of the physical phenomenon, the technique was applied to the waves in the free water surface.

Three types of tests were carried out and in each TR concentration wave was obtained in the expected location and the expected time. It was noticed that the method also works even with obstacles to wave propagation, such as diffraction and reflection inside the ocean wave tank. An object thrown against the water, creating concentric waves was studied and after the application of TR resulted in a wave concentrated at the same splash point. The observed phenomena can be considered as a paradigm for numerical comparisons and studies of waves in dispersive media.
\end{abstract}




\section{Sumário}

\section{Lista de Figuras}

\section{Lista de Tabelas}

\section{Lista de Abreviaturas}

\section{Lista de Símbolos}

1 Introdução........................................................................................................... 1

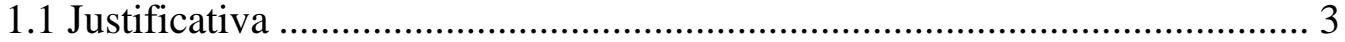

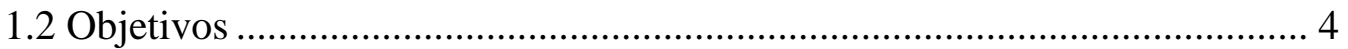

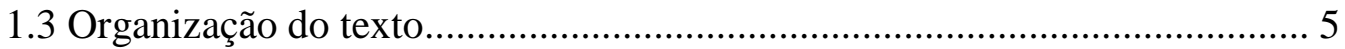

2 Contextualização e revisão bibliográfica .................................................. 6

2.1 Histórico sobre tanques de ensaios hidrodinâmicos...................................... 6

2.2 Sistema de controle e automação ......................................................... 14

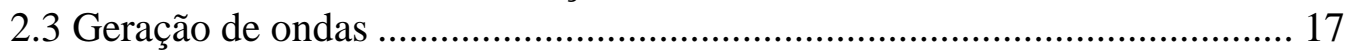

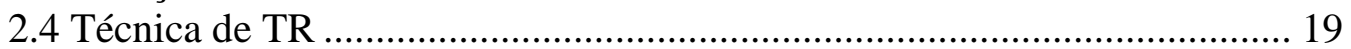

3 Fundamentos teóricos ............................................................................... 20

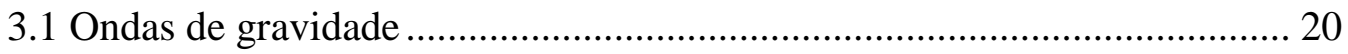

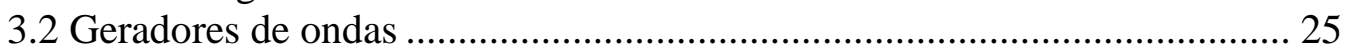

3.2.1 Solução linearizada ..................................................................... 25

3.2.2 Função de transferência mecânica ...................................................... 32

3.2.3 Efeito da largura finita dos batedores de ondas .................................. 33

3.3 TR - Time reversal e focalização espacial ................................................. 36

4 Implementação do tanque de provas.......................................................................... 40

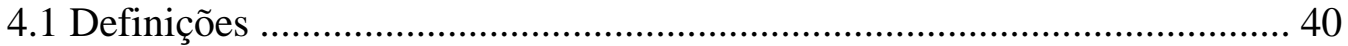

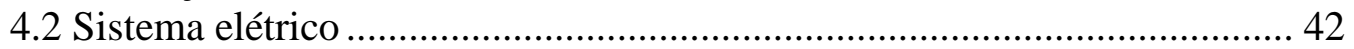

4.2.1 Painel de distribuição de energia ........................................................ 44

4.2.2 Painéis de controle de motores.............................................................. 46

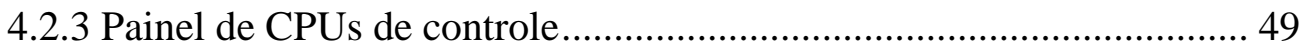

4.3 Sensoriamento de altura de ondas por ultrassom ...................................... 52

4.3.1 Sensor ultrassônico do Calibrador Hidrodinâmico ............................... 54

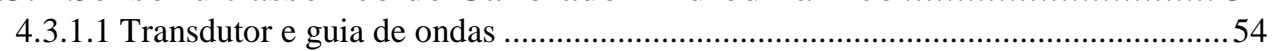

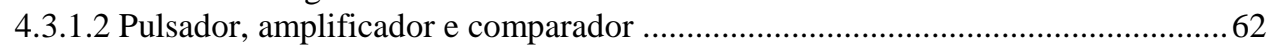

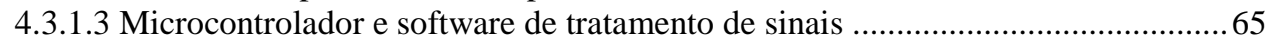

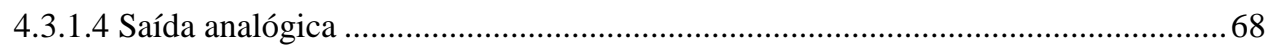

4.4 Automação e controle .......................................................................... 73

4.4.1 Temporização do sistema........................................................... 74

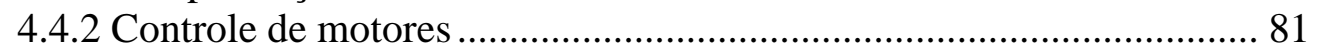

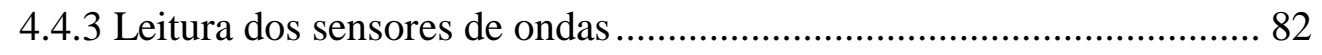

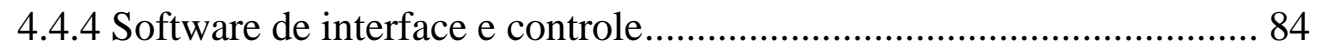

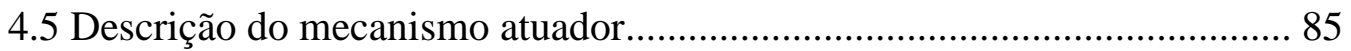

4.6 Sensoriamento de altura de ondas por sensores capacitivos ...................... 88 
5 Procedimentos para a geração de ondas ...................................................93

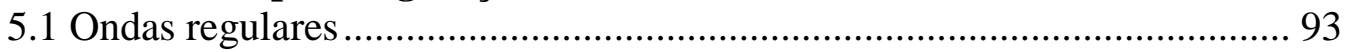

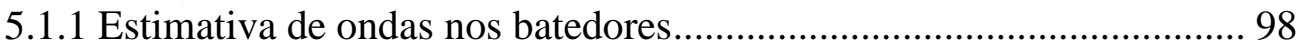

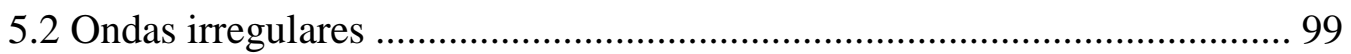

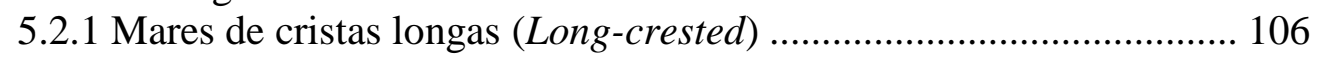

5.2.2 Mares de cristas curtas (Short-crested) ........................................... 108

6 Procedimentos experimentais .......................................................................... 112

6.1 Validação da resposta dinâmica mecânica .............................................. 112

6.2 Validação de geração de ondas regulares............................................... 118

6.2.1 Ondas unidirecionais não-oblíquas .............................................. 118

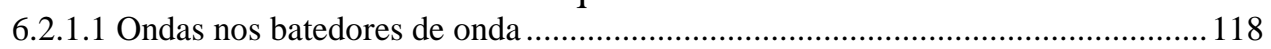

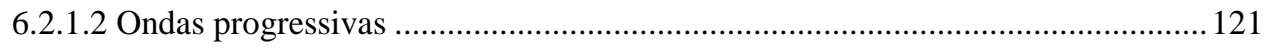

6.2.2 Ondas unidirecionais oblíquas ...................................................... 130

6.3 Validação de geração de ondas irregulares unidirecionais ....................... 148

6.4 Aplicação da técnica de TR no tanque de provas .................................... 159

6.4.1 Lançamento de objeto na superfície da água .................................. 159

6.4.1.1 Tanque de provas sem obstáculo........................................................................ 160

6.4.1.1.1. Correção espacial nos WPC...................................................................... 161

6.4.1.1.2. Reversão temporal dos lançamentos de objeto ......................................... 165

6.4.1.2 Tanque de provas com obstáculo ........................................................................ 171

6.4.2 Fonte impulsiva com um ponto de recepção indireto ........................ 178

6.4.3 Fonte impulsiva feita por um par de batedores ................................ 183

6.4.3.1 Tanque de provas sem obstáculo......................................................................... 183

6.4.3.2 Tanque de provas com obstáculo ........................................................................ 191

6.4.4 Conclusões acerca dos ensaios de TR ............................................. 197

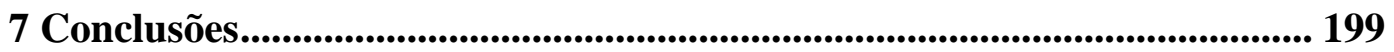

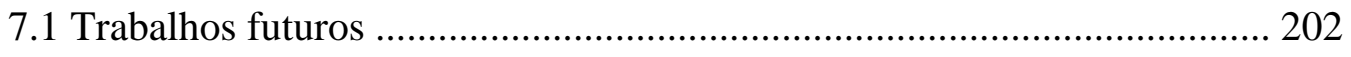

8 Referências bibliográficas ......................................................................... 204

Apêndice A - Absorvedores passivos de ondas ........................................... 213 


\section{LISTA DE FIGURAS}

Figura 1.1. Tanque de provas do TPN batizado como Calibrador Hidrodinâmico. 1

Figura 2.1. Evolução dos tipos de tanques para ensaios hidrodinâmicos. Adaptado de Naito (2006).

Figura 2.2. Exemplo de tanque de testes onshore. Reprodução de Zhang, Schäffer e Jakobsen (2007). 8

Figura 2.3. Foto do tanque Amoeba. Reprodução de Naito, Minoura e Okuyama (2002).

Figura 2.4. Tanque oceânico Deep Sea Basin do NMRI............................................. 12

Figura 2.5. Tanque oceânico Sea Model Basin do NMRI.......................................... 13

Figura 2.6. Sistema de controle do Deep Sea Basin do NMRI. ................................... 16

Figura 3.1. Onda progressiva propagando em local de batimetria constante................ 21

Figura 3.2. Deslocamentos das partículas do fluido em profundidades finita e infinita.

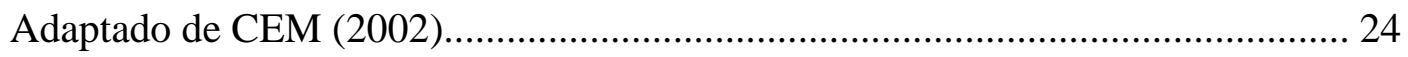

Figura 3.3. Definição de um gerador de ondas do tipo flap ...................................... 26

Figura 3.4. Visão em planta do gerador de ondas. ..................................................... 27

Figura 3.5. Funções de transferência - Influência da quantidade de números de ondas na FT evanescente. 31

Figura 3.6. Funções de transferência - influência da direção de geração de ondas. ...... 31

Figura 3.7. Função de transferência mecânica. ............................................................ 32

Figura 3.8. Discretização espacial dos batedores de ondas........................................ 34

Figura 3.9. Limite de Biesel para o Calibrador Hidrodinâmico. .................................... 35

Figura 4.1. Definições de coordenadas e características do tanque.............................. 41

Figura 4.2. Sistema de coordenadas para modelos em teste ...................................... 41

Figura 4.3. Numeração dos flaps (interna), as caixas de sensores (centro) e CPUs (externa) 
Figura 4.4. Localização dos principais equipamentos elétricos no tanque de ondas...... 44

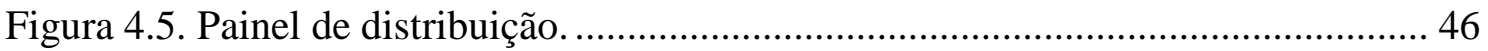

Figura 4.6. Painel de controle de motores (CCM) ........................................................ 48

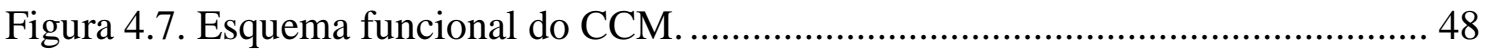

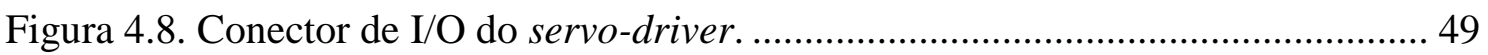

Figura 4.9. Diagrama de atuação da proteção elétrica dos servo-drivers....................... 49

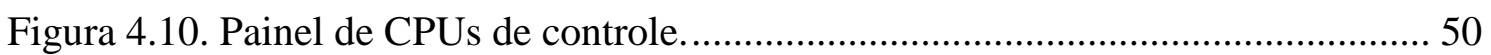

Figura 4.11. Esquema funcional do painel de CPU..................................................... 51

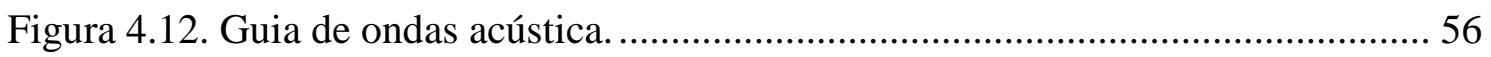

Figura 4.13. Guia de ondas e transdutor (à direita) inicialmente usado no Calibrador Hidrodinâmico.

Figura 4.14. Montagem para testar a atenuação da guia de ondas e visão ampliada da guia de ondas testada, respectivamente. …......................................................... 59

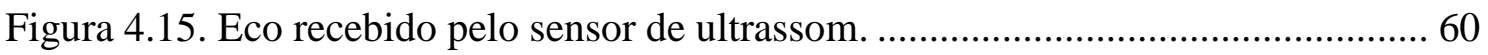

Figura 4.16. Atenuação acústica devida ao uso da guia de ondas................................. 61

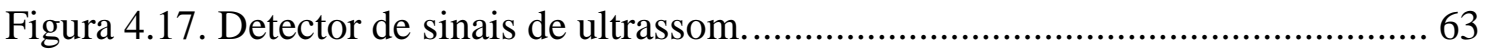

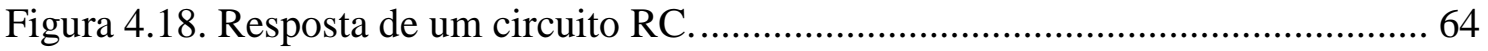

Figura 4.19. Níveis de detecção do eco no condicionador de sinais. ............................ 64

Figura 4.20. Esquema elétrico do circuito condicionador analógico do medidor de ondas por ultrassom.

Figura 4.21. Fluxograma dos microcontroladores dos medidores de ondas por ultrassom.

Figura 4.22. Rampa de conversão dos circuitos do DAC.......................................... 70

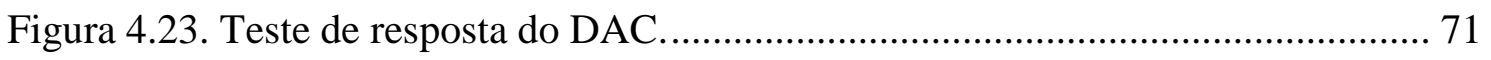

Figura 4.24. Leitura do sensor de ondas observada................................................. 72

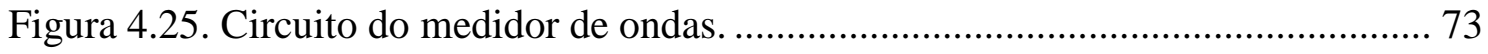

Figura 4.26. Tempos de respostas dos hardwares do gerador de ondas........................ 76 


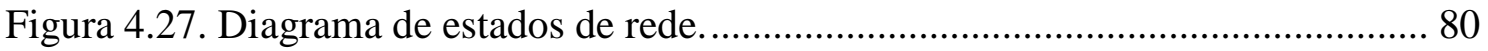

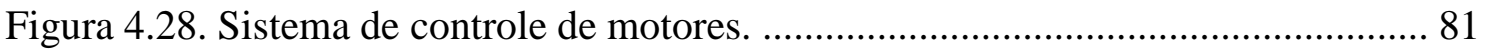

Figura 4.29. Malha de controle de posição dos servo-drivers ....................................... 82

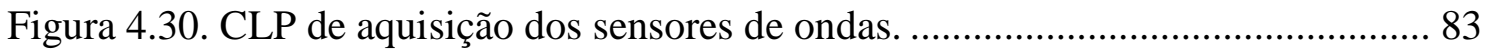

Figura 4.31. Tela do Simulink com controle do gerador de ondas................................ 84

Figura 4.32. Atuador eletromecânico do gerador de ondas............................................ 85

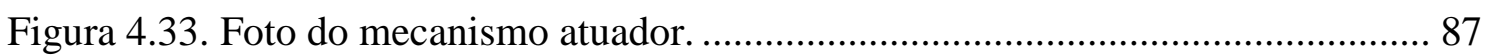

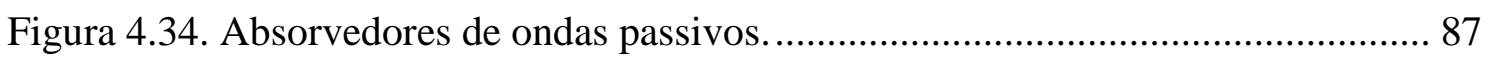

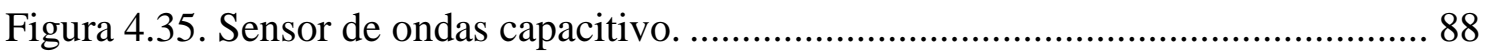

Figura 4.36. Arranjo experimental usado para calibração estática de sensor capacitivo.

Figura 4.37. Regressão linear para ajuste de calibração estática de sensor capacitivo. . 90

Figura 4.38. Arranjo experimental utilizado na avaliação da resposta dinâmica do sensor

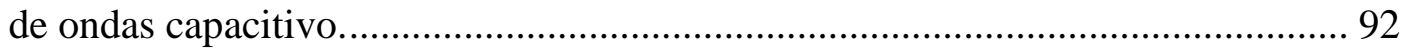

Figura 4.39. Resultado obtido no teste de calibração dinâmica - valor normalizado.... 92

Figura 5.1. Ilustração de geração de ondas no tanque.................................................. 94

Figura 5.2. Onda regular propagando através do tanque oceânico................................ 95

Figura 5.3. Inicialização da onda em geração de onda de $1 \mathrm{~Hz}$ com $40 \mathrm{~mm}$ de altura a $45^{\circ}$ 96

Figura 5.4. Série temporal de deslocamento para 3 flaps com onda de $1 \mathrm{~Hz}$ por $40 \mathrm{~mm}$ a $45^{\circ}$

Figura 5.5. Função de transferência (FT) nos batedores de ondas. 99

Figura 5.6. Espectro do tipo JONSWAP. 103

Figura 5.7. Curvas de $D(f, \theta)$ para diversos $s$ em $\theta 0=0$. 105

Figura 5.8. Função de espalhamento direcional de mar local dependente da frequência. 105

Figura 5.9. Análise de simulação de mar irregular long-crested. 108 
Figura 5.10. Equação $A j(L a, n) \cdot \cos \theta j$ para direção principal de $180^{\circ}$ do referencial do tanque de provas (Figura 4.1)

Figura 5.11. Espectros direcionais.

Figura 6.1. Resposta em degrau dos batedores segundo a sequência da Tabela 6.1 .... 113

Figura 6.2. Função sinc.

Figura 6.3. Resposta impulsiva dos batedores.

Figura 6.4. Resposta em frequência dos batedores

Figura 6.5. Função de transferência (FT) experimental x teórica.

Figura 6.6. Função de transferência (FT) experimental com atrasos temporais x teórica.

Figura 6.7. Resposta do sistema de automação e controle do gerador de ondas.

Figura 6.8. Disposição dos três sensores de ondas (WPx) no interior do tanque para avaliar ondas regulares.

Figura 6.9. Sistema de controle dual mode.

Figura 6.10. Resposta de ondas progressivas do gerador de ondas. 125

Figura 6.11. Análise de reflexão de onda para a frequência de $1.0 \mathrm{~Hz}$ com $\mathrm{H}=52 \mathrm{~mm}$ do ensaio C002.

Figura 6.12. Comparação da estabilidade da onda incidente com uma lateral e duas absorvendo ondas (ensaios C001 e C002).

Figura 6.13. Matriz de sensores 4 x 4 montada no tanque de provas.

Figura 6.14. Elevação de onda dos 16 sensores sincronizados no tempo da onda de $1 \mathrm{~Hz}$ com $2,5 \%$ de declividade (destacado o trecho analisado).

Figura 6.15. Sensores utilizados para medição direcional de ondas. Em destaque o referencial angular adotado.

Figura 6.16. Onda regular de $0,7 \mathrm{~Hz}$ com $2,5 \%$ de declividade. 139

Figura 6.17. Onda regular de $0,7 \mathrm{~Hz}$ com $3,3 \%$ de declividade 140

Figura 6.18. Onda regular de $0,7 \mathrm{~Hz}$ com $5,0 \%$ de declividade. 141

Figura 6.19. Onda regular de $1,0 \mathrm{~Hz}$ com $2,5 \%$ de declividade. 142 
Figura 6.20. Onda regular de $1,0 \mathrm{~Hz}$ com $3,3 \%$ de declividade. 143

Figura 6.21. Onda regular de $1,0 \mathrm{~Hz}$ com $5,0 \%$ de declividade. 144

Figura 6.22. Onda regular de $1,3 \mathrm{~Hz}$ com $2,5 \%$ de declividade. 145

Figura 6.23. Onda regular de $1,3 \mathrm{~Hz}$ com $3,3 \%$ de declividade. 146

Figura 6.24. Onda regular de $1,3 \mathrm{~Hz}$ com $5,0 \%$ de declividade. 147

Figura 6.25. Início de final das séries temporais de $\eta d j$ e $\eta k j$ no flap número $20 \ldots . . . .150$

Figura 6.26. Calibração de mar irregular de cristas largas da Bacia de Campos centenária.

Figura 6.27. Espectros de potências das ondas irregulares calibradas. 153

Figura 6.28. Estatística do mar decenário da Bacia de Campos. 154

Figura 6.29. Estatística do mar centenário da Bacia de Campos. 154

Figura 6.30. Estatística do mar decenário da Bacia de Santos. 155

Figura 6.31. Estatística do mar centenário da Bacia de Santos. 155

Figura 6.32. Análise de reflexão feita para as ondas irregulares 158

Figura 6.33. Arranjo experimental de lançamento (sem escala). 160

Figura 6.34. Atraso temporal em função da frequência nos sensores de ondas capacitivos. 162

Figura 6.35. Onda lida nos sensores capacitivos do lançamento 01. 163

Figura 6.36. Sinais dos sensores de onda com correções espaciais. 164

Figura 6.37. Onda do lançamento 1 adquirida nos sensores de ondas ultrassônico..... 166

Figura 6.38. Deslocamento realizado na reversão temporal do lançamento 01 (trecho de 20 segundos ). 167

Figura 6.39. Onda lida nos sensores capacitivos na reversão temporal do lançamento 01. 168

Figura 6.40. Leitura dos sensores de onda com correções espaciais. 169

Figura 6.41. Onda concentrada no instante $t c=0 s$ usando TR do lançamento $02 \ldots . .170$

Figura 6.42. Arranjo experimental de lançamento (sem escala). 171 
Figura 6.43. Lançamento 04a com a antepara presente no tanque de provas..... 172

Figura 6.44. Onda lida nos sensores capacitivos do lançamento 04.

Figura 6.45. Onda do lançamento 4 adquirida nos sensores de ondas ultrassônico..... 174

Figura 6.46. Ponto de recepção dos lançamentos 3 e 4 com o WP11 medindo a onda concentrada.

Figura 6.47. Elevação de ondas nos sensores de ondas na reversão temporal do lançamento 04 .

Figura 6.48. Elevação de onda no sensor 11 no instante da focalização em todos os testes do lançamento 4 176

Figura 6.49. Função sinc. 178

Figura 6.50. Deslocamento executado no flap 1. 179

Figura 6.51. Leitura do sensor de ondas 15 (WP15). 180

Figura 6.52. Espectro do impulso sinc feito no batedor 1 visto nos sensores WP15 (trecho de 24 a 186 segundos do sensor). 180

Figura 6.53. Imagem de três instantes da concentração do teste T02 destacando as frentes de ondas incidindo no sensor 15.

Figura 6.54. Arranjo experimental de emissão usando o batedor 20 (sem escala). ..... 183

Figura 6.55. Onda impulsiva realizada pelo batedor 20 .

Figura 6.56. Onda emitida no batedor 20 adquirida nos sensores de ondas ultrassônico.

Figura 6.57. Comparação de resultados dos testes de reversão temporal entre dois batedores de ondas. 187

Figura 6.58. Resultado da reversão temporal do teste EM01RetA. 190

Figura 6.59. Arranjo experimental de emissão usando o batedor 20 (sem escala). ..... 192

Figura 6.60. Onda impulsiva realizada pelo batedor 20 .

Figura 6.61. Comparação de resultados dos testes de reversão temporal entre dois batedores de ondas. 194

Figura 6.62. Resultado da reversão temporal do teste EM02RetA. 196 
Figura 6.63. Instantes destacados da concentração de ondas ocorrida no ensaio

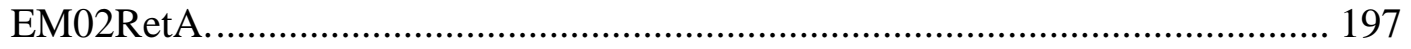




\section{LISTA DE TABELAS}

Tabela 3.1. Relações assintóticas da onda progressiva 25

Tabela 4.1. Medidas adotadas para evitar ruídos eletromagnéticos. 42

Tabela 4.2. Resumo das entradas e saídas usadas no CLP n ${ }^{\circ} 3$. 52

Tabela 4.3. Características dos sensores de ondas do tipo capacitivo, resistivo e ultrassônico. 53

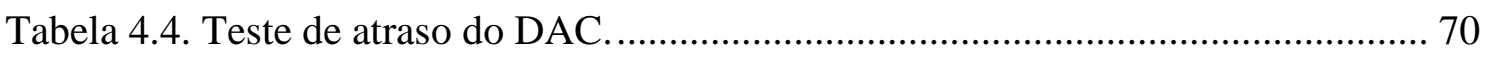

Tabela 4.5. Variáveis de controle da rede ............................................................. 79

Tabela 5.1. Tempo de processamento necessário para se criar séries temporais. ......... 111

Tabela 6.1. Resposta em degrau dos servo-drivers. ............................................... 113

Tabela 6.2. Testes de resposta em frequência dos batedores...................................... 116

Tabela 6.3. Resultado do teste de resposta em frequência dos batedores. .................... 116

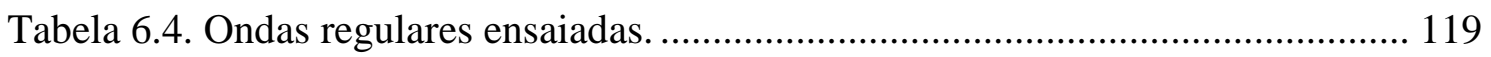

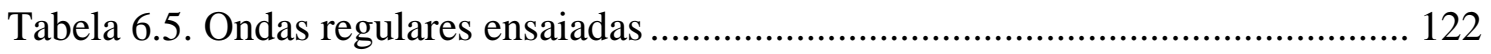

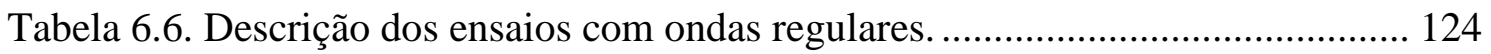

Tabela 6.7. Trecho inicial das ondas regulares - Onda incidente. ............................. 125

Tabela 6.8. Diferença no trecho inicial - Onda incidente. ........................................ 126

Tabela 6.9. Coeficientes de reflexão medidos nos ensaios com onda regular............... 127

Tabela 6.10. Altura de ondas regulares incidentes por trechos temporais. ................. 129

Tabela 6.11. Diferença de altura de ondas regulares incidentes por trechos temporais (medidas em relação às alturas requeridas).

Tabela 6.12. Variação de altura de onda percentual entre a onda incidente inicial e os trechos com uma e duas reflexões. 130

Tabela 6.13. Ondas regulares oblíquas. 132

Tabela 6.14. Posições dos sensores na matriz espacial. 134 
Tabela 6.15. Desvio entre valor de altura requerida e altura média na matriz de sensores.

Tabela 6.16. Ondas irregulares ensaiadas no tanque de provas. 149

Tabela 6.17. Resultados experimentais da calibração das ondas irregulares. 153

Tabela 6.18. Coeficientes de reflexão experimental. 156

Tabela 6.19. Características dos testes de lançamento de objeto na água. 161

Tabela 6.20. Resultado das análises de lançamentos realizados. 164

Tabela 6.21. Resultado da aplicação de TR aos lançamentos 1 e 2 . 169

Tabela 6.22. Características dos testes de lançamento de objeto na água 173

Tabela 6.23. Resultado da aplicação de TR aos lançamentos 3 e 4. 176

Tabela 6.24. Características dos testes com fonte impulsiva. 179

Tabela 6.25. Resultados dos testes com fonte impulsiva no WP15. 181

Tabela 6.26. Testes realizados de emissão e recepção entre batedores de ondas. 184

Tabela 6.27. Resultado dos testes de emissão e recepção por um par de batedores de ondas. 188

Tabela 6.28. Resultado da análise dos sensores capacitivos da reversão temporal entre um batedor de ondas emissor e os demais batedores 191

Tabela 6.29. Testes realizados de emissão e recepção entre batedores de ondas. 192

Tabela 6.30. Resultado dos testes de emissão e recepção por um par de batedores de ondas. 
LISTA DE ABREVIATURAS

\begin{tabular}{|c|c|}
\hline CH-TPN & Calibrador Hidrodinâmico do Tanque de Provas Numérico \\
\hline CLP & Controlador Lógico Programável \\
\hline CPU & Central Processing Unit \\
\hline EPUSP & Escola Politécnica da Universidade de São Paulo \\
\hline FFT & Fast Fourier Transform \\
\hline GPU & Graphics Processing Unit \\
\hline IPT & Instituto de Pesquisa Tecnológicas do Estado de São Paulo \\
\hline ITTC & International Towing Tank Conference \\
\hline JONSWAP & Joint North Sea Wave Project \\
\hline NMRI & National Maritime Research Institute \\
\hline PID & Proporcional integral derivativo \\
\hline RMS & Root Mean Square \\
\hline SFC & Sequential Function Chart \\
\hline SSCNET & Servo System Controller Network \\
\hline TR & Time Reversal \\
\hline WPC & Wave Probe Capacitivo \\
\hline WPU & Wave Probe Ultrassônico \\
\hline
\end{tabular}




\section{LISTA DE SÍMBOLOS}

\section{Alfabeto Romano}

L

$h$

$h_{0}$

$h_{2}$

I

$\mathrm{H}$

$\mathrm{H}_{\mathrm{e}}$

C

$\mathrm{C}_{\mathrm{g}}$

$\mathrm{D}$

$k$

$k_{s}$

$v_{x}$

$v_{z}$

$X_{0}(y, t)$

$X_{0 j}$

$X(y, z, t)$

$x_{0}$

S

$\mathrm{S}_{\mathrm{a}}$

$f(z)$
Comprimento de onda

Profundidade local

Distância entre o ponto de pivotamento e o ponto de acionamento do flap

Distância entre o ponto de pivotamento e a linha de água do flap

Distância entre o ponto de pivotamento e o fundo do tanque

Altura de onda

Altura de ondas evanescente

Velocidade de fase da onda

Velocidade de grupo da onda

Declividade da onda

Número de onda

Número de onda evanescente

Velocidade orbital horizontal no fluido

Velocidade orbital vertical no fluido

Deslocamento horizontal do flap na linha de água

Deslocamento horizontal do flap índice $j$ na linha de água

Deslocamento horizontal do flap em função da profundidade

Amplitude do deslocamento horizontal do flap na linha de água

Altura do deslocamento do flap na linha de água

Altura do deslocamento do flap no acionamento mecânico

Função representativa do movimento do flap 
FT

$\mathrm{FT}_{\mathrm{p}}$

$\mathrm{FT}_{\mathrm{e}}$

$\mathrm{FT}_{\mathrm{M}}$

$l$

NF

dist

$\mathrm{T}_{\mathrm{CLP1M}}, \mathrm{T}_{\mathrm{CLP2M}}$

$\mathrm{T}_{\mathrm{CLP} 3 \mathrm{~S}}$

$\mathrm{T}_{\mathrm{CLP1}}, \mathrm{T}_{\mathrm{CLP} 2}, \mathrm{~T}_{\mathrm{CLP} 3}$

$\mathrm{P}_{\mathrm{xj}}, \mathrm{P}_{\mathrm{yj}}$

$A_{j}\left(L_{a}, k\right)$

$L_{a}$

$n d_{j}$

$\mathrm{S}(\omega)$

$\mathrm{D}(\mathrm{f}, \theta)$

$\mathrm{a}_{\mathrm{m}}, \mathrm{a}_{\mathrm{mn}}$

$\mathrm{T}_{\mathrm{p}}$

$\mathrm{H}_{\mathrm{s}}$

$t_{C_{g}}$
Função de transferência do gerador de ondas

Função de transferência progressiva do gerador de ondas

Função de transferência evanescente do gerador de ondas

Função de transferência mecânica do gerador de ondas

Largura do flap

Zona morta acústica do pistão plano

Distância medida pelo sensor de ondas ultrasônico

Tempo de comunicação entre CLP e motores

Tempo de comunicação entre CLP e sensores ultrasônicos

Tempo de comunicação via rede dos CLPs

Posição do centro do flap índice $j$ em relação ao sistema de coordenadas

Seletor de atuação do flap índice $j$.

Direção normal em planta dos flaps índice $j$

Estimativa de onda no flap índice $j$

Espectro de densidade de energia de ondas

Espalhamento direcional de ondas

Parâmetro que define o espalhamento direcional de ondas do modelo de espalhamneto direcional $\cos ^{2 \mathrm{~s}}$

Amplitude de onda definida a partir do espectro de mar

Período de pico do espectro de densidade de energia do mar

Altura significativa de ondas do mar

Tempo necessário para uma onda percorrer duas vezes a distância do tanque 
$\mathrm{R}_{\mathrm{a}}$

$\phi$

$\phi_{p}$

$\phi_{e}$

$\omega$

$\omega_{\mathrm{n}}$

\section{Simbologia especial}

$\Gamma$

Alfabeto Grego

Superfície livre da água

Frequência angular ordem

Direção de propagação da onda energia JONSWAP
Raio de array de sensores de ondas para medição de direção de ondas proposto em Nwogu (1989)

Ganho de correção de espectro de densidade de energia

Atraso temporal em função da frequência da onda e a posição do sensor de ondas (visto no tópico 6.4.1.1.1)

Atenuação da onda concêntrica em função do raio

Coeficiente de reflexão de ondas

Potencial de velocidades da água

Potencial de velocidades de ondas progressivas da água

Potencial de velocidades de ondas evanescentes da água

Frequência angular não amortecida de sistema dinâmico de $2^{\mathrm{a}}$

Deslocamento orbital horizontal das partículas do fluido

Deslocamento orbital vertical das partículas do fluido

Fator de concentração de energia do espectro de densidade de

Coeficiente de amortecimento de sistema dinâmico de $2^{\mathrm{a}}$ ordem 


\section{Introdução}

No âmbito dos projetos desenvolvidos no Tanque de Provas Numérico do Departamento de Engenharia Naval e Oceânica da Escola Politécnica da Universidade de São Paulo, foi dado início ao desenvolvimento de um tanque oceânico para testes de modelos reduzidos de estruturas offshore. Intitulado Calibrador Hidrodinâmico, é um tanque de formato quadrado, com 14 metros de lado por 4,1 metros de profundidade, que usa um sistema gerador de ondas em todo o perímetro lateral. O gerador de ondas é constituído por múltiplos atuadores conectados a 148 batedores de ondas, de 36 centímetros de largura, que atuam de forma independente. O principal objetivo do tanque é a realização de ensaios experimentais de validação e experimentação de equipamentos offshore para a calibração de modelos numéricos adotados nos simuladores hidrodinâmicos do TPN. Assim sendo, esse tanque de provas recebeu o nome de "Calibrador Hidrodinâmico". O tanque é, portanto, uma ferramenta acoplada para o desenvolvimento de um modelo híbrido hidrodinâmico (numérico e experimental), tendência observada em pesquisas nos últimos anos. A Figura 1.1 mostra uma foto do tanque de provas.

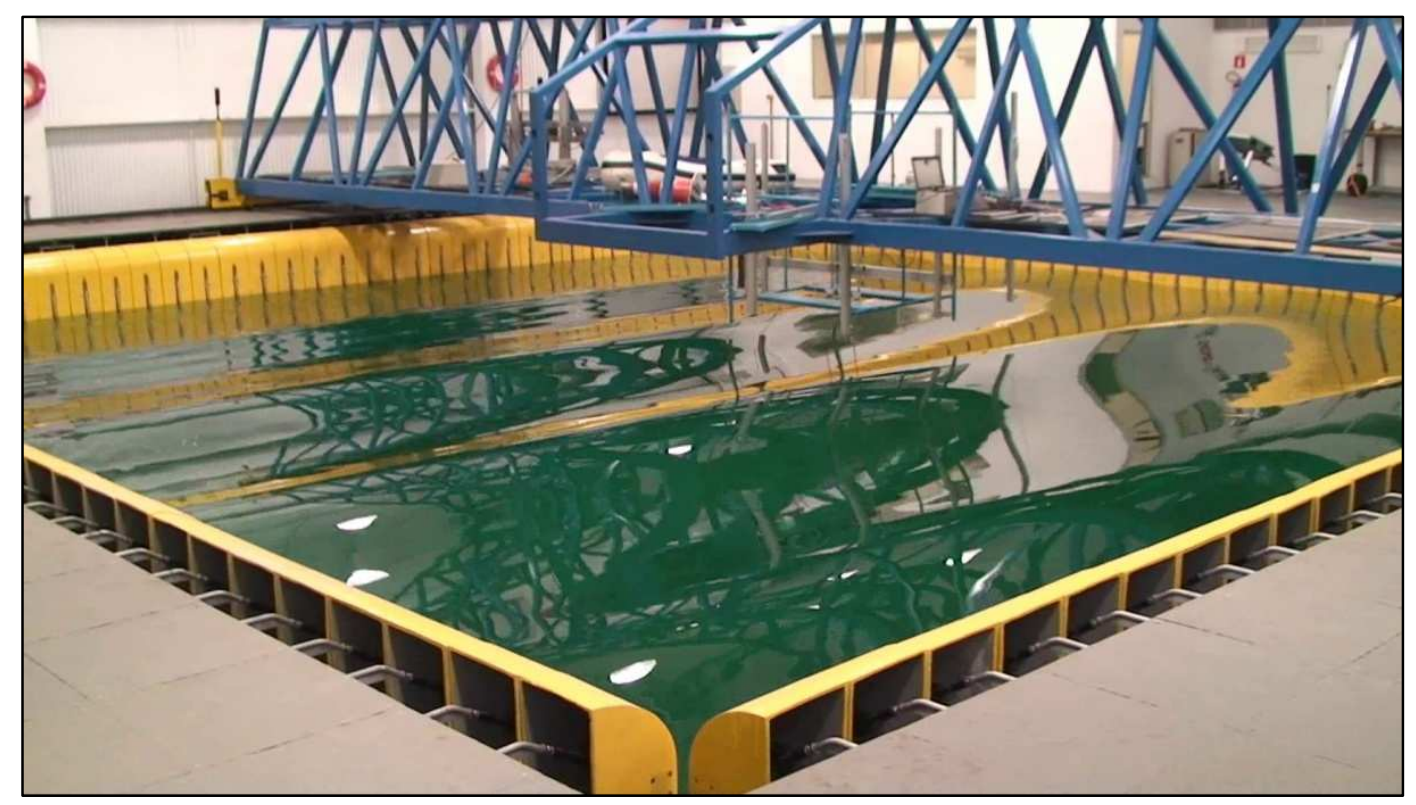

Figura 1.1. Tanque de provas do TPN batizado como Calibrador Hidrodinâmico. 
Quanto aos aspectos hidrodinâmicos envolvidos na concepção do tanque, por possuir todo o perímetro constituído por batedores, ele pode gerar ondas em quaisquer direções. Este fato representa uma vantagem em relação aos tanques convencionais, pois fenômenos de mudança de direção e mares bimodais com direções distintas podem ser ensaiados. Por permitir a absorção de ondas em quaisquer direções, através do controle dos atuadores dos batedores, o tanque permite realizar ensaios com mais tempo de duração, assim como reduzir o tempo de espera entre os ensaios. Há uma grande complexidade envolvida no controlador de absorção ativa de ondas, em inglês AWA (active wave absorption). Uma vez que as paredes do tanque são os próprios batedores e uma fronteira para as ondas, eles devem gerar ondas ao mesmo tempo em que se comportam como fronteiras transparentes para as ondas incidentes. Estas compreendem as ondas efetivamente geradas nas paredes opostas assim como as ondas geradas pelo modelo de embarcação sendo ensaiado. Como todo sistema de controle, a absorção ativa de ondas requer realimentação, que pode ser feita através da medição da elevação da água nos batedores de ondas ou da força sobre os mesmos.

Os mecanismos de acionamento ou atuadores, por sua vez, têm o objetivo de controlar com precisão a posição dos batedores de ondas. As ondas são geradas pela perturbação causada por eles. A sensibilidade dos movimentos dos batedores é grande, pois eles geram grandes perturbações na água. Assim sendo, este trabalho apresenta uma análise detalhada da resposta dinâmica do mecanismo para evitar possíveis problemas de movimentação mecânica, principalmente do ponto de vista dinâmico.

Da mesma maneira que os mecanismos de acionamento, o sistema eletrônico do gerador de ondas deve ter uma resposta adequada, entre outros atributos. Todos os subsistemas desenvolvidos foram analisados para que, ao serem integrados, funcionem de acordo com as especificações do projeto. Os controladores eletrônicos utilizados neste gerador de ondas são usados em automações e controles industriais.

Os tanques de provas existentes em outras instituições usam um hardware de controle desenvolvido especificamente para a aplicação. O Calibrador Hidrodinâmico tem um dos primeiros geradores de ondas que usa equipamentos destinados à automação industrial. Essa abordagem propiciou uma grande flexibilidade no desenvolvimento do controlador e também diminuiu a fase de desenvolvimento de hardware do controlador. Assim sendo, boa parte do trabalho de desenvolvimento do 
gerador de ondas se concentrou na integração dos módulos e no desenvolvimento do software de controle.

Por consequência, a grande flexibilidade do hardware possibilitou o desenvolvimento contínuo para a pesquisa atual e para pesquisas futuras no Calibrador Hidrodinâmico.

\subsection{Justificativa}

O estudo de tanques oceânicos e geradores de ondas não é assunto recente na literatura técnica e científica. Nas últimas duas décadas, a absorção ativa de ondas tem se destacado como um dos temas mais inovadores na literatura especializada. No contexto brasileiro, não há relatos do desenvolvimento de um sistema gerador de ondas com múltiplos atuadores e que faça uso da absorção ativa como alternativa às praias passivas de absorção de ondas. Dessa forma, um sistema de automação e controle de atuadores integrados ao sensoriamento de ondas com processamento de malha de controle ativa em tempo real é um desenvolvimento por si só de grande relevância na Engenharia do país.

A absorção ativa de ondas, ao contrário da absorção passiva em praias, é mais eficiente com ondas longas; assim sendo, pode-se construir um tanque de provas menor para fazer ensaios hidrodinâmicos com fator de escala de modelo semelhante ao de um tanque de grandes dimensões com absorção por praias passivas.

Segundo a literatura, a região de absorção ótima de um sistema ativo é aproximadamente plana, perdendo eficiência em baixa e alta frequência, diferentemente de uma praia passiva que apresente variações de absorção em função da declividade de onda e do comprimento de onda.

Ao utilizar um tanque de dimensões reduzidas e absorção ativa de ondas, o tempo necessário para "acalmar" a água entre ensaios é reduzido, pois a absorção ocorre em todas as direções e o tempo para as ondas se propagarem do centro à lateral, que absorve as ondas, é pequeno se comparado a tanques de dimensões maiores. 
Ao realizar um ensaio com modelo mantido por linhas de amarração, pode-se manter o mesmo aproamento do modelo e o gerador pode executar ondas em diferentes direções de incidências. Caso contrário, ter-se-ia que mudar o aproamento do modelo alterando-se linhas e pontos de fixação na lateral do tanque, o que demandaria muito mais tempo de ensaio.

Outra vantagem em relação a tanques convencionais é a possibilidade de ensaiar fenômenos de mudança de direção e mares bimodais com direções distintas. Por absorver ondas em quaisquer direções, o tanque permite realizar ensaios com mais tempo de duração com campos de ondas estacionários.

A disposição física dos batedores, formando um espaço confinado ou "cavidade", permite estabelecer comparações com ondas de pressão acústica. Em especial, a técnica de TR (time reversal) acústica pode ser aplicada ao tanque oceânico como um meio de focalização de energia de ondas empírico e que resolve o problema inverso de propagação de ondas. $\mathrm{O}$ método é inédito para tanques oceânicos; e devido aos recursos de atuadores e sensores disponíveis, pode resultar em estudos detalhados das suas características e vantagens, se comparado ao método convencional de focalização espacial de ondas.

\subsection{Objetivos}

O objetivo geral deste trabalho é o desenvolvimento de um sistema de automação e controle para tanques oceânicos com múltiplos atuadores para possibilitar a geração e a absorção ativa de ondas. $\mathrm{O}$ desenvolvimento compreende: a implementação e validação do sistema de automação e controle para o tanque de provas; o desenvolvimento de algoritmos para a geração de ondas com batedores do tipo flap, para atender os casos tipicamente utilizados em ensaios de estruturas oceânicas, tais como ondas regulares e irregulares, com ou sem espalhamento direcional.

Com o objetivo específico de demonstrar o potencial do controlador do tanque, foi desenvolvida uma nova técnica para focalização de energia de ondas em tanque de provas, fundamentada na técnica de TR (time reversal) para concentrar ondas em pontos específicos do espaço. Esta técnica foi originalmente proposta para aplicações que usem 
ultrassom na forma de ondas de pressão acústica, mas, devido à semelhança do fenômeno físico, propôs-se estudá-las em ondas de superfície livre da água.

\subsection{Organização do texto}

O presente trabalho foi organizado em sete capítulos.

O capítulo 2 apresenta o contexto da concepção de tanques de provas, incluindo a revisão bibliográfica do problema.

O capítulo 3 apresenta os fundamentos teóricos de geração de ondas.

O capítulo 4 apresenta o desenvolvimento do sistema gerador de ondas, incluindo a concepção dos sistemas e subsistemas eletroeletrônicos de automação, a integração dos sistemas elétricos, o sensoriamento de ondas, o acionamento eletromecânico dos batedores e softwares de controle. No capítulo 4 também são apresentados os métodos utilizados para validar o tanque de ondas, tal como o sensoriamento de ondas.

No capítulo 5 apresentam-se os métodos e algoritmos de geração de ondas aplicados ao Calibrador Hidrodinâmico.

No capítulo 6, são apresentadas as validações experimentais dos métodos de geração de ondas propostos, bem como o resultado da avaliação dos subsistemas que compõem o sistema gerador de ondas. Os ensaios de geração de ondas realizados contemplam ondas regulares, ondas irregulares de cristas largas e ondas com focalização de energia usando a técnica de TR.

O capítulo 7 apresenta um resumo das conclusões do presente trabalho e as propostas de desenvolvimentos futuros. 


\section{Contextualização e revisão bibliográfica}

\subsection{Histórico sobre tanques de ensaios hidrodinâmicos}

Durante a pesquisa sobre tanques oceânicos visando os estudos do Calibrador Hidrodinâmico, foram encontradas muitas fontes de referências. Muitas destas dizem respeito a tanques oceânicos, tanques onshore, tanques de reboque e canais de ondas. Um exemplo dos principais tipos de tanques pode ser visto na Figura 2.1 adaptada de Naito (2006).

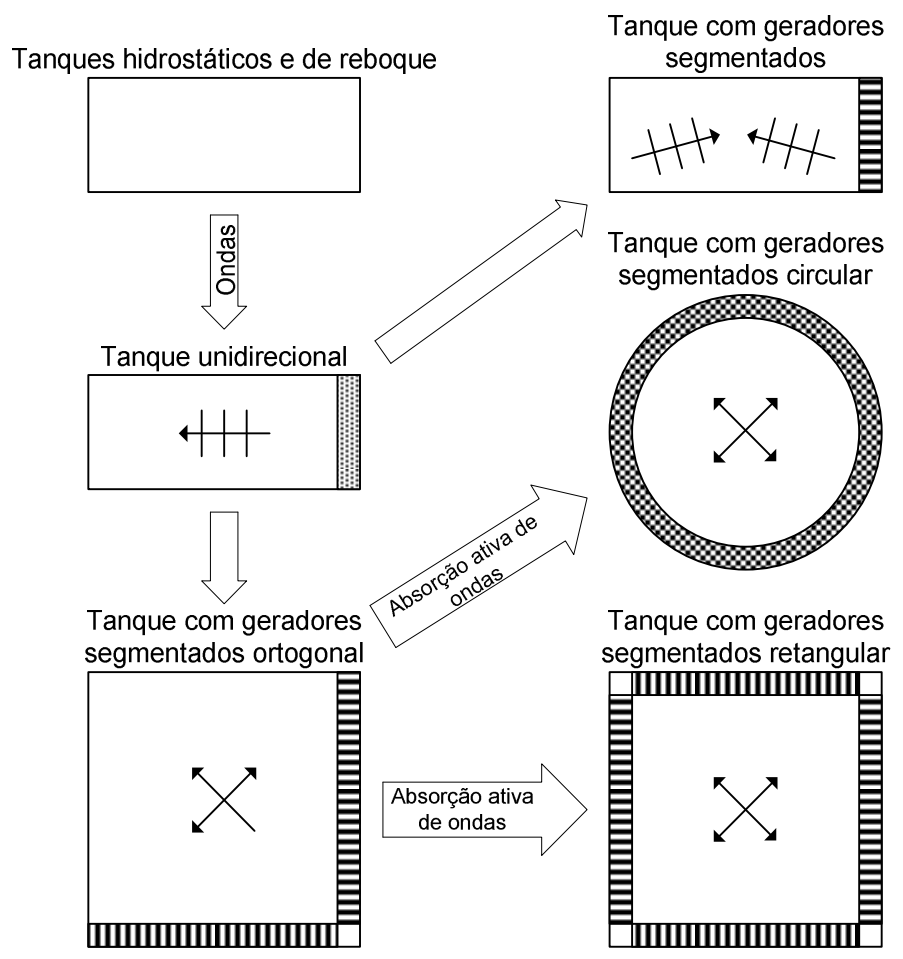

Figura 2.1. Evolução dos tipos de tanques para ensaios hidrodinâmicos. Adaptado de Naito (2006).

Os canais (formato retangular) foram os primeiros tipos de tanques utilizados em testes hidrodinâmicos, concebidos para ensaios hidrostáticos e de reboque para testes de resistência ao avanço, há mais de um século. Depois disso, receberam geradores de ondas, no século passado, e passaram a ser a principal ferramenta para estudos hidrodinâmicos em universidades e institutos de pesquisa. O trabalho de Cerdeira (2006) apresenta um resumo de diversos canais existentes no Brasil, assim como um estudo sobre as características de um canal de ensaios específico. Estudos mais 
detalhados sobre canais podem ser vistos no trabalho de Martins (2003). Nele, a teoria de geradores de ondas foi apresentada e técnicas experimentais foram usadas para a caracterização de um tanque de dimensões reduzidas existente no LENO - Laboratório de Engenharia Naval e Oceânica da Universidade de São Paulo.

Os tanques de reboque e os canais têm grande importância histórica, pois foram usados desde muito tempo em projetos visando a avaliação de coeficientes de arrasto de embarcações. Posteriormente, com a introdução da geração de ondas, passaram a contar com a avaliação do comportamento em ondas e o avanço das embarcações em teste. Geralmente eles possuem o comprimento muito maior que a largura e podem ter trilhos nas laterais, para que um carro dinamométrico possa percorrer o tanque rebocando o modelo em testes de avanço. Este recurso é muito útil, também, para a simulação de correntes, devido à possibilidade de se rebocar o modelo em testes, ao invés de mover o fluido através do tanque.

Os tanques onshore são destinados às pesquisas na engenharia costeira. Costumam apresentar geradores de ondas do tipo pistão translacional, pois estes têm melhor desempenho em lâminas de água menores, ou seja, em águas rasas. O movimento do batedor, ao formar uma parede plana, desloca muito fluido e é mais semelhante ao movimento orbital das partículas do fluido em lâminas de água reduzidas. Nessa condição, a velocidade orbital horizontal das partículas decai pouco com a profundidade. Nos pistões, foram aplicadas teorias de geração de ondas usando modelos que incorporam efeitos de águas rasas. O uso típico destes tanques é para ensaios costeiros fazendo uso de ondas regulares, irregulares, transientes, cnoidais e solitárias. Eles também são usados para ensaios de estudos de casos naturais extremos, tais como impactos de material particulado na água simulando desbarrancamento em encostas e tsunamis incidindo em uma região costeira. Quanto à forma, usualmente apresentam geradores de ondas segmentados multidirecionais, conforme apresentado em Biesel (1954), e podem ter uma ou duas laterais ortogonais formadas por tais geradores. A profundidade geralmente não passa de 2 metros. Como os usos são variados, as outras laterais ou são compostas por absorvedores de ondas ou representam em escala uma região costeira em estudo. Existem diversos trabalhos publicados sobre a geração e propagação de ondas em tais tanques. O trabalho de Zhang, Schäffer e Jakobsen (2007) aplica e compara o modelo de águas rasas de Boussinesq na geração de ondas em um tanque de provas de estudos costeiros numéricos e experimentais. Da 
mesma forma, visando gerar ondas cnoidais em tanques de águas rasas, Zhang, Schäffer e Bingham (2006) aplicaram o mesmo modelo de ondas. Anteriormente, em Wu e Dalrymple (1987) foi realizada uma pesquisa sobre geração de ondas direcionais em águas rasas e a observação de geração de ondas livres parasitas nos batedores de ondas, interferindo no campo de ondas. No trabalho de Madsen, Bingham e Liu (2002) novamente o modelo de ondas para águas rasas foi aplicado e comparado com experimentos para validar a propagação de ondas progredindo de águas profundas para rasas. Outro trabalho sobre o assunto é o de Massel (1996), que analisa a propagação de ondas com profundidade limitada, comparando-a com outros modelos de propagação em águas rasas. Um exemplo de tanque de provas onshore pode ser visto na Figura 2.2.

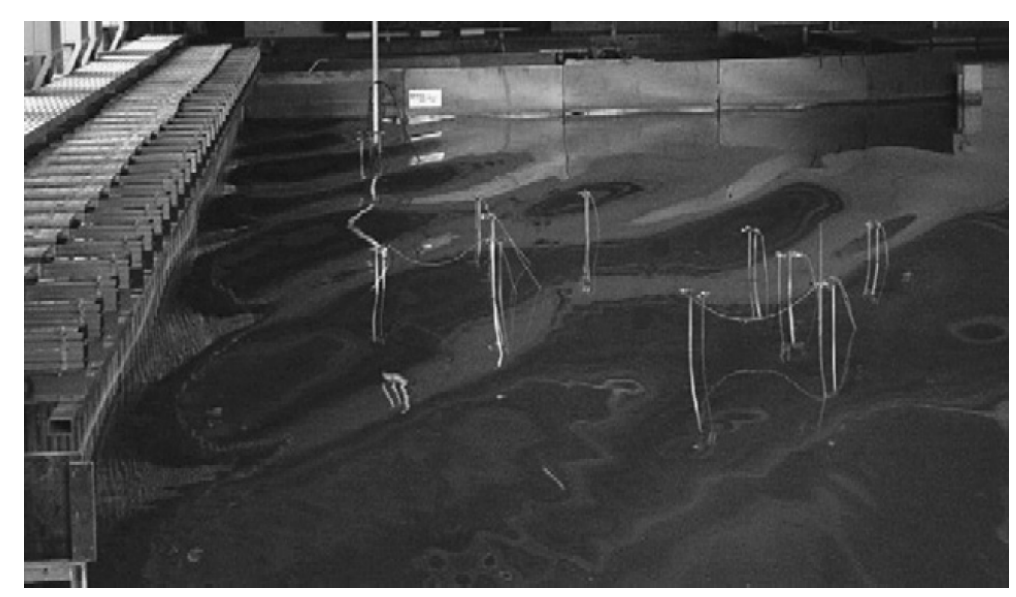

Figura 2.2. Exemplo de tanque de testes onshore. Reprodução de Zhang, Schäffer e Jakobsen (2007).

Os tanques destinados a ensaios oceânicos, por outro lado, usam geradores de ondas do tipo flap articulado, pois apresentam melhor desempenho nestas condições. O movimento orbital da velocidade do fluido abaixo das ondas decai exponencialmente com a profundidade e é mais próximo do movimento que um gerador de ondas do tipo flap possui em comparação ao gerador do tipo pistão. A diferença do movimento do flap decaindo linearmente com a posição vertical e das partículas da água decaindo exponencialmente durante as oscilações provoca a formação de ondas evanescentes locais próximas ao gerador. Este assunto é abordado nesse trabalho, em capítulo subsequente. Tais tanques têm, em geral, profundidade suficiente para que seja possível realizar ensaios com equipamentos offshore flutuantes e submersos. A profundidade tem que ser suficientemente grande para que as ondas geradas não sejam afetadas pelo fundo do tanque e a velocidade orbital apresente comportamento circular. 
Assim como tanques mais rasos, os tanques oceânicos podem ser compostos por geradores de ondas e absorvedores de ondas nas laterais. Existem diversos exemplos de tanques oceânicos pelo mundo. Em Chakrabarti (1994) e Martins (2003) é possível encontrar vários exemplos de tanques desse tipo. Normalmente, eles são compostos por uma ou duas laterais ortogonais geradoras de ondas, sendo as demais compostas por absorvedores de ondas passivos.

Fazendo uso de uma lateral com geração de ondas, é possível gerar ondas até determinado limite direcional imposto pela dimensão do flap e pelo comprimento de onda. Um importante limite empírico foi definido por Biesel (1954) acerca desta questão, que será retomada mais à frente. Pode-se destacar um tanque com tal característica que está em operação no Brasil, o LabOceano (veja em LABOCEANO, 2011). Ele tem 45 metros de comprimento por 30 metros de largura; é equipado com gerador de ondas tipo flap com 75 atuadores de 0,4 metros de largura cada. A profundidade é de até 15 metros (ajustável), com um poço central de 5 metros de diâmetro por 10 metros de profundidade. Ele é usado para realizar testes hidrodinâmicos em escala reduzida de equipamentos offshore.

Fazendo uso de duas laterais geradoras de ondas, é possível ampliar o limite direcional, pois são somadas as direções das duas laterais ortogonais. As outras laterais são compostas por absorvedores passivos. A absorção passiva de ondas usando praias geralmente é utilizada em tanques e não funciona bem para ondas longas em relação ao comprimento da praia. Assim, é necessária uma praia suficientemente grande para um bom desempenho de absorção com ondas longas. Em Chakrabarti (1994) é mostrada uma grande variedade de praias para tais aplicações. Em De Mello (2006), Martins (2003) e Cerdeira (2006) podem ser vistos estudos para medição de reflexão de praias e propostas de melhorias do desempenho aplicado a tanques de ensaios hidrodinâmicos. Da mesma forma que praias, outros tipos de absorvedores passivos têm limitações de desempenho. Em Chakrabarti (1994) e De Mello (2006) são mostrados alguns desses tipos, que são novamente estudados no Apêndice A deste trabalho, para a absorção atrás dos batedores de ondas do Calibrador Hidrodinâmico.

Fora do Brasil, existem inúmeros tanques em operação que apresentam tal característica; podem-se destacar, pela larga experiência em ensaios hidrodinâmicos, os tanques oceânicos do Marin (Maritime Research Institute Netherlands) e do Marintek (Norwegian Marine Technology Research Institute). Os dois institutos contam com 
diversos tipos de tanques de ensaios (veja em MARIN, 2011, e em MARINTEK, 2011), entre os quais tanques oceânicos com geradores de ondas do tipo flap segmentados em duas laterais ortogonais adjacentes. A profundidade máxima dos tanques é de cerca de 10 metros. São utilizados para estudos de equipamentos offshore flutuantes e submersos. Além de ondas, os tanques contam com um sistema gerador de correntezas para simular correntes marinhas e um sistema de geração de ventos para simular rajadas sobre o convés de plataformas e navios.

Tendo todas as laterais do tanque compostas por batedores, pode-se dessa forma gerar ondas em todas as direções (Figura 2.1). Esse é um grande benefício em termos de simulações de complexas condições ambientais, por gerar ondas de mares bimodais com direções distintas e com espalhamento direcional. Nesse caso, os geradores de ondas devem absorver ativamente as ondas que são geradas do lado oposto do tanque. Usando a absorção ativa de ondas, segundo Schäffer e Klopman (2000) e Naito (2006), podemse obter ensaios de maior duração sem interferência de reflexões internas no tanque nos resultados. Em Maeda (2004) é feita uma extensiva avaliação experimental da estabilidade do campo de ondas em tanque circular com batedores tipo flap e absorção ativa pela leitura de sensores de ondas capacitivos nas faces dos batedores. Os experimentos foram realizados no Deep Sea Basin do NMRI (National Maritime Research Institute), no Japão.

Um aspecto importante sobre a absorção é discutido no trabalho de Newman (2008). A estimativa teórica do movimento de cada batedor de ondas pode ser feita de forma simples, para que sejam realizadas a geração e a absorção de ondas no tanque, propagando-se a onda através do tanque, chamada de absorção cinemática. Essa abordagem aplicada a um batedor segmentado é mostrada em Newman (2008) e Schäffer e Klopman (2000). O resultado não tem uma resposta adequada. Problemas numéricos ocorrem, desestabilizando o campo de ondas, e experimentalmente surgem outros problemas. A absorção fica comprometida no caso de existir um modelo em teste dentro do tanque. Nesse caso, ocorreriam a difração e a irradiação de ondas por ele, efeito não previsto pelo modelo teórico. Assim, Newman (2008) mostra numericamente a absorção pela força incidente nos batedores devido ao campo potencial hidrodinâmico como realimentação da posição dos mesmos, a chamada absorção dinâmica. O estudo sugere que a medição da força de acionamento do batedor traz grande benefício de controle. A correta medição de força é de difícil montagem prática em batedores; 
existem diversos estudos, nem todos implementados, que fazem uso desta grandeza física como realimentação, conforme pode ser visto em Salter (1981), Salter (1984), Spinneken e Swan (2009a) e Spinneken e Swan (2009b).

Em outra abordagem usada de forma pioneira para geradores de ondas em tanques, Naito, Nakamura et al. (1996), Naito, Minoura e Okuyama (2002) e Naito (2006) propõem que se utilize um gerador de ondas composto por cunhas flutuantes absorvedoras de ondas com dimensões reduzidas. A partir da dinâmica de $2^{\mathrm{a}}$ ordem de uma cunha flutuante monitorada por sensor de posição (e suas grandezas derivadas), se faz um acionamento de força vertical por motor do tipo bobina (corrente elétrica $\propto$ força). A cunha flutuante absorve a onda incidente, enquanto gera outra onda independentemente. Usando esse artifício, foi possível montar um tanque com dimensões reduzidas e com boa eficiência de geração e absorção de ondas. O tanque Amoeba (Advanced Multiple Organized Experimental Basin) (Figura 2.3) tem cerca de 1,6 metros de diâmetro, profundidade de 0,25 metro e é composto por 50 cunhas. A técnica de absorção é baseada na medição do movimento da cunha e na atuação em força sobre a mesma; assim, não é feita a medição da superfície livre da água e tampouco importa a direção de incidência da onda. A absorção ocorre pela reação da onda nas cunhas. Os trabalhos realizados no Amoeba sugerem que, apesar das dimensões reduzidas do tanque e da elevada escala dos modelos, é possível obter resultados de comportamento de embarcações.

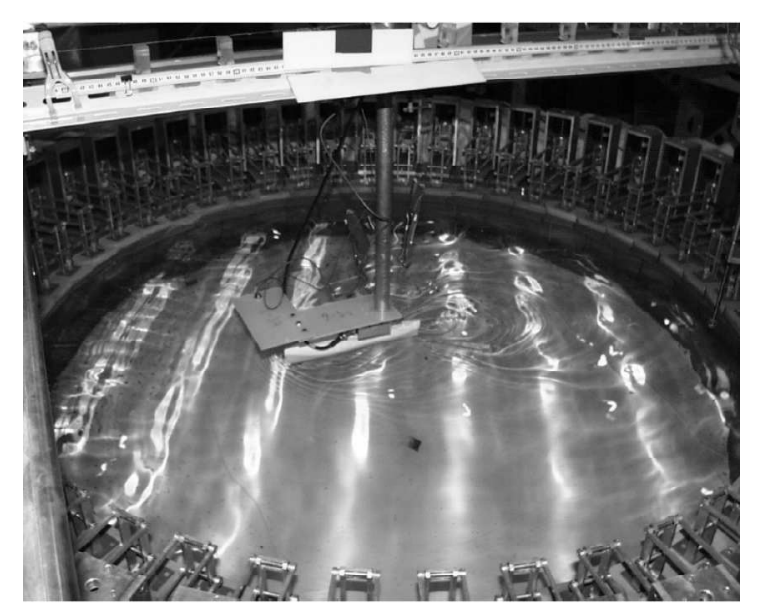

Figura 2.3. Foto do tanque Amoeba. Reprodução de Naito, Minoura e Okuyama (2002).

No entanto, o mais usual é fazer a realimentação por leitura da elevação das ondas na face dos batedores para realizar a absorção ativa de ondas. Citamos novamente o 
exemplo do trabalho de Maeda (2004) sobre o Deep Sea Basin. Na Figura 2.4: o tanque é composto por 128 batedores do tipo flap, possui 14 metros de diâmetro, 5 metros de profundidade (mais poço central de 6 metros de diâmetro e 30 de profundidade) e é equipado com medição da elevação da superfície livre na face dos batedores por sensores capacitivos. Os batedores apresentam um complexo mecanismo que fecha as aberturas entre os flaps mesmo quando estes se movem para frente e para trás. Deste modo, evitam-se as descontinuidades na superfície de contorno lateral do tanque. $\mathrm{O}$ trabalho também apresenta resultados de geração de ondas de diversos tipos no tanque. O algoritmo de absorção estima em tempo real a frequência e o ângulo de incidência da onda, para ajustar a reação da velocidade do flap pela resposta analítica prevista para absorver as ondas.

Após a experiência adquirida com o Deep Sea Basin, o NMRI inaugurou em 2010 um novo tanque oceânico chamado Sea Model Basin, para ser utilizado em manobras de embarcações usando a mesma tecnologia do anterior. O tanque tem formato retangular e mede 40 por 80 metros, com 4,5 metros de profundidade; possui 382 flaps de 0,5 metro de largura e cantos arredondados compostos por flaps (veja em NMRI, 2011). A Figura 2.5 mostra o novo tanque do NMRI, que conta com um sistema de geração de ventos, além do sistema gerador de ondas.

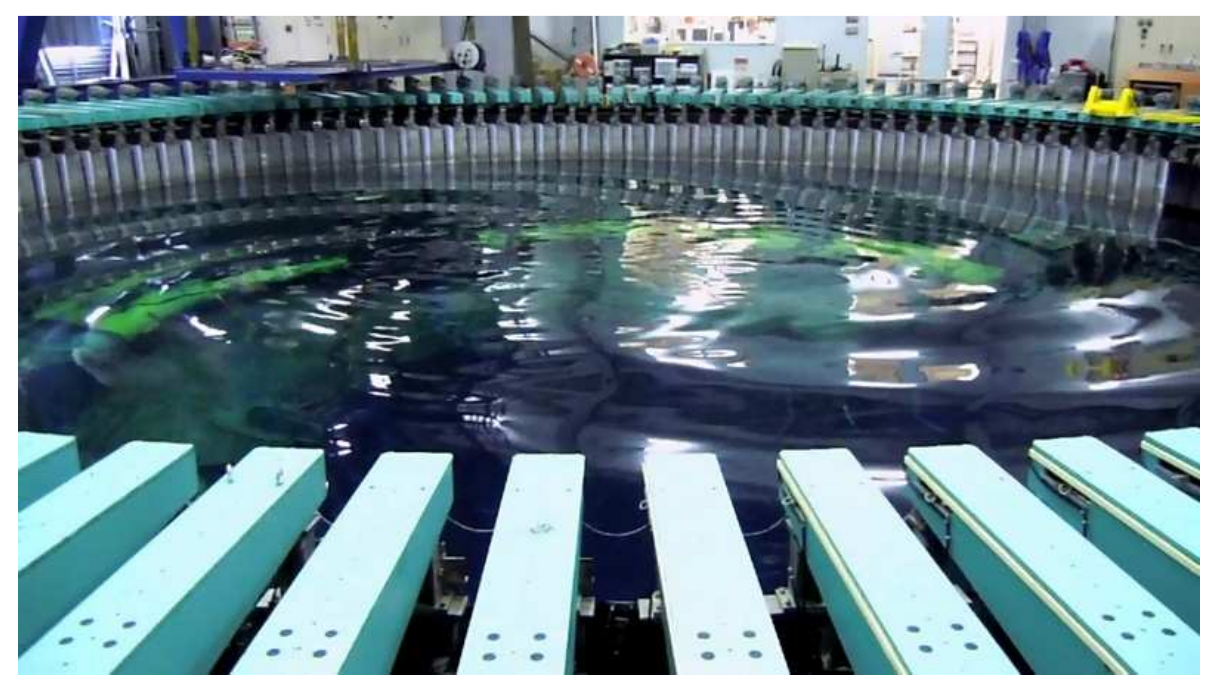

Figura 2.4. Tanque oceânico Deep Sea Basin do NMRI. 


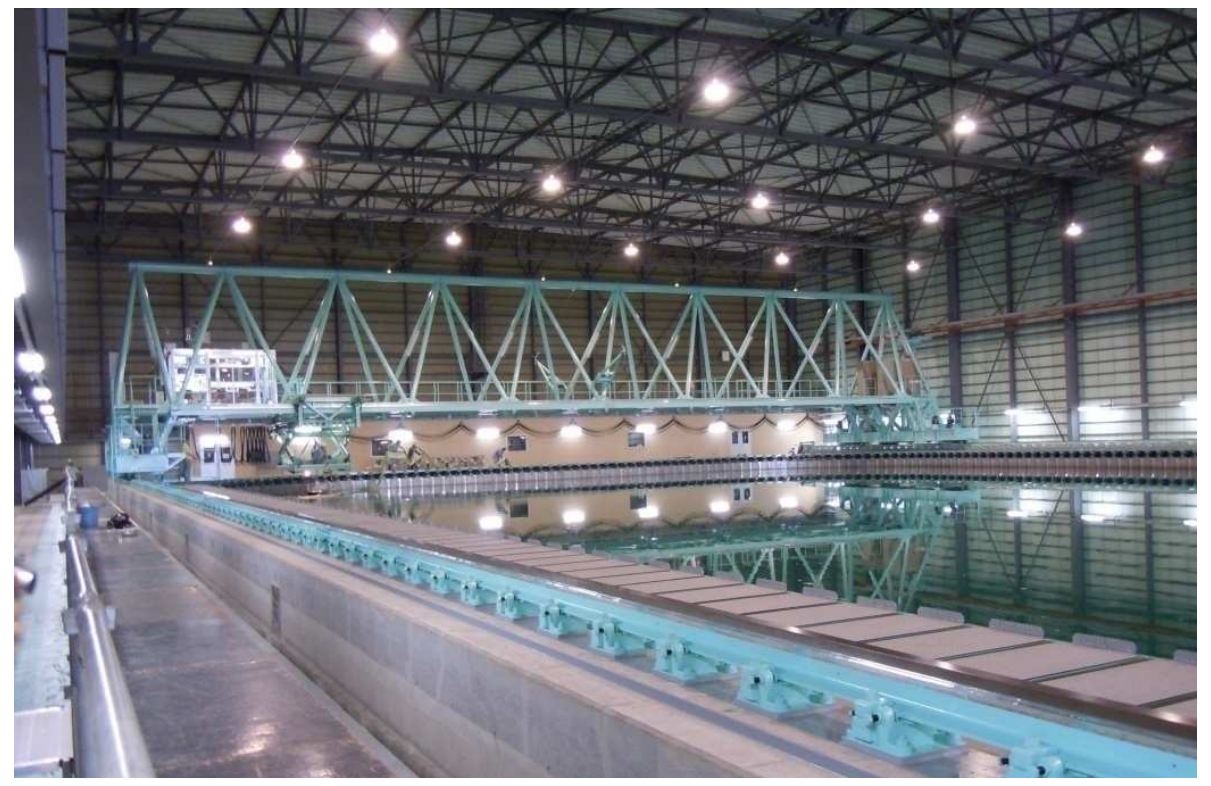

Figura 2.5. Tanque oceânico Sea Model Basin do NMRI.

Outra linha de desenvolvimento usando a medição da onda em frente aos batedores faz uso de filtros digitais para executar a absorção, manipulando a posição do flap. O trabalho pioneiro a respeito é de Milgram (1970), que ajustou um filtro digital para trabalhar no domínio tempo da mesma forma que a função de transferência analítica. Diversos autores abordaram o assunto desde então. Schäffer e Klopman (2000) apresentam uma revisão histórica de diversos autores sobre o assunto e abordam também aspectos da concepção de absorção ativa. Tipos de sensores (medição do nível, força e pressão na face do batedor), distância do sensor ao batedor, considerações sobre onda evanescente no batedor e forma de atuação (posição e velocidade) são discutidos pelos autores.

A revisão bibliográfica sobre a absorção ativa de ondas tem como objetivo balizar o desenvolvimento do sistema de automação e controle do Calibrador Hidrodinâmico, abordado neste trabalho, para que possa atender às pesquisas e desenvolvimentos futuros no tanque de provas. Os aspectos relevantes observados na pesquisa visam definir as necessidades para o sistema e serão apresentados no tópico seguinte. Os resultados das pesquisas realizadas pela equipe envolvida no TPN, incluindo experimentos em canal de ensaios e no tanque do Calibrador Hidrodinâmico, podem ser vistos em De Mello, Carneiro et al. (2007), Carneiro, De Mello et al. (2009) e De Mello, Carneiro et al. (2010). Nesses trabalhos são abordados os métodos de absorção 
de ondas baseados no algoritmo proposto em Maeda (2004) e também a abordagem de Schäffer (1996) e Schäffer (2001).

\subsection{Sistema de controle e automação}

Não existe na literatura específica um conceito padrão estabelecido de sistema de automação para geradores de ondas. Em princípio, os geradores de ondas são projetados para realizar uma determinada gama de ondas. No caso do tanque em estudo, as soluções pesquisadas foram comparadas com estudos realizados anteriormente e com soluções de automação para máquinas multieixos servo-controladas. No entanto, as informações procuradas eram escassas e grande parte delas não é divulgada, pelo fato de resultarem de pesquisas desenvolvidas por empresas privadas. Dessa forma, buscou-se uma arquitetura de controle e de automação usando as poucas informações obtidas e opções que existem com os fabricantes de motores e controladores industriais.

Uma das exceções entre as fontes de informações foi retirada do trabalho de Castro (2009). Ele mostra que o gerador de ondas desenvolvido pela Bosch-Rexroth para a Universidade Texas A\&M usa uma arquitetura baseada em redes que interligam os servo-drivers, que acionam os motores. A rede é do tipo SERCOS, desenvolvida pela Rexroth e que posteriormente teve as especificações abertas a desenvolvedores (Sercos, 2011). A rede interliga os servo-drivers a computadores pessoais (PCs), que usam o sistema operacional Linux com recursos de bibliotecas de tempo real de execução. $\mathrm{O}$ programa no computador executa em tempo real o controle de dois grupos de oito atuadores servo-acionados. Assim, com três computadores, 48 atuadores formam o gerador de ondas. Um quarto computador serve de estação de operação ao usuário e preparação de ondas para ensaios. O computador de operação se comunica com o primeiro dos computadores de controle de motores, que serve de mestre no controle em tempo real de operação. O sistema foi usado no desenvolvimento do trabalho de Castro (2009) sobre absorção ativa de ondas. Neste trabalho, o sensor usado na realimentação das ondas foi do tipo capacitivo, instalado nos batedores do tipo pistão, e não é mostrado como os sinais são adquiridos pelo sistema de automação. 
Outro sistema de controle de gerador de ondas da Bosch-Rexroth que faz uso de um tipo de arquitetura diferente é utilizado no LabOceano. O seu autor trabalhou na operação e manutenção deste sistema - as informações aqui descritas são de fonte pessoal. O sistema é composto por três computadores (PCs). Os dois primeiros computadores servem para gerar as ondas para o ensaio e para a interface de operação, respectivamente. O computador de interface de operação é onde o operador comanda o gerador; nele, os arquivos de ondas são carregados para a execução de ensaios. O computador de operação se comunica por rede ethernet com o computador de controle. O computador de controle executa um software de operação em sistema operacional DOS (Disk Operating System) com tempo real de operação. Este micro tem uma placa de interface de comunicação CAN que controla 10 RTP (Real Time Processor). A RTP é uma placa de controle para 8 atuadores com interface analógica para adquirir a medição de ondas na face dos atuadores usando sensores de ondas capacitivos. Ela tem um DSP, um processador de comunicação em rede óptica SERCOS e outros cinco processadores 8051 de controle de interfaces. A rede SERCOS opera em tempo real e comanda 8 servo-drivers em um laço de rede token-ring. Os servo-drivers ficam dispostos em painéis que abrigam 16 servo-drivers cada, os chamados MCCs. As RTPs ficam abrigadas em dois painéis, chamados de WCC, incluindo fontes e outros circuitos auxiliares.

O sistema utilizado nos dois tanques do NMRI, citados no tópico anterior, faz uso de um sistema semelhante ao da Texas A\&M; usa somente computadores no controle. A partir de informações fornecidas pessoalmente pelo Dr. Katsuya Maeda durante uma visita técnica ao NMRI, pôde ser constatada a arquitetura do sistema utilizado. O tanque Deep Sea Basin tem 128 atuadores do tipo flap controlados por 8 painéis elétricos. Em cada painel existem 16 servo-drivers que controlam 16 motores. Cada grupo de 8 servodrivers é controlado em velocidade por um computador (PC padrão EISA industrial com CPU Pentium I) que executa um software de controle em sistema operacional DOS. Os computadores têm um módulo de 32MB de disco em estado sólido de onde o sistema operacional é carregado e um programa de controle é executado. No computador, diversas placas de interface (em número de 8 canais cada) enviam comandos analógicos de velocidade aos servo-drivers e coletam os encoders dos motores (posições reais dos atuadores) em quadratura de fase (canais A e B) para executar uma malha fechada de controle. Além desta malha, é necessário adquirir os 
sensores de elevação de ondas nas faces dos flaps para executar a malha de absorção de ondas, feita por uma placa que adquire os sinais analógicos dos sensores capacitivos. Os computadores têm interface entre si e com o computador de controle na sala de operação por rede ethernet. O sistema operacional tem tempo real de operação. O que não pôde ser apurado na visita foi se existe uma linha de sincronismo e controle entre os computadores ou se isto é feito inteiramente pela rede ethernet. Foi informado, na oportunidade, que a arquitetura utilizada no Deep Sea Basin foi incorporada em grande parte ao Sea Model Basin, na mesma instituição. A Figura 2.6 mostra o interior de um painel do sistema de controle utilizado no NMRI.

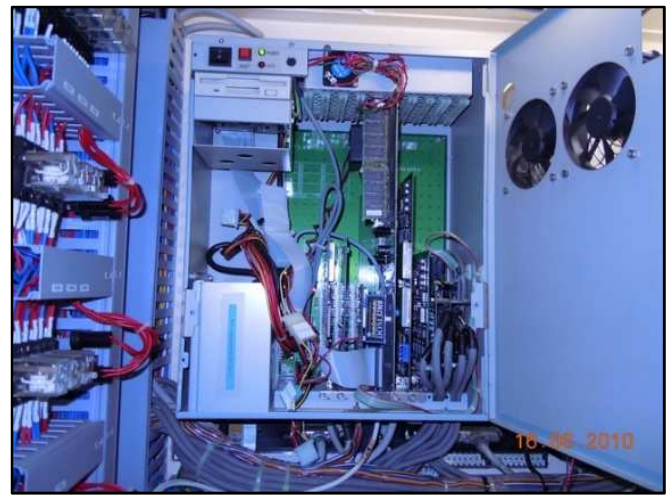

(a) - CPU de controle de 8 atuadores

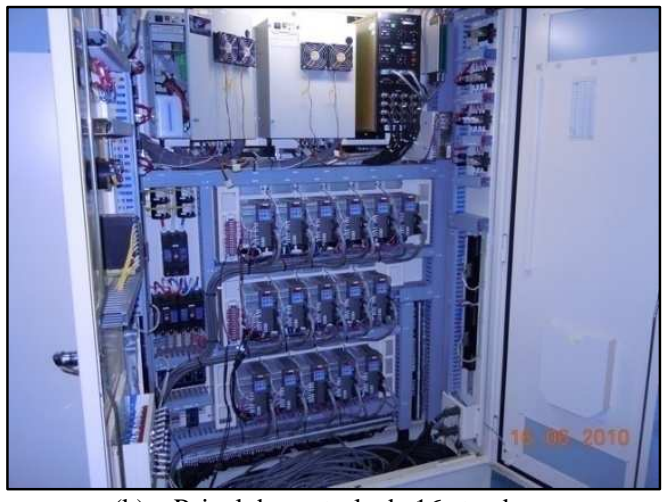

(b) - Painel de controle de 16 atuadores

Figura 2.6. Sistema de controle do Deep Sea Basin do NMRI.

Outra fonte encontrada na pesquisa é da empresa de automação Moog (2008). Foram obtidas, na pesquisa, informações de um tipo de sistema com atuadores hidráulicos. O sistema foi especificado para o tanque oceânico do Marintek, descrito no tópico anterior. O sistema desenvolvido é uma atualização do sistema de acionamento por pistões hidráulicos do gerador de ondas lateral do tanque constituído por 144 flaps. Nele, foi montada uma servo-válvula proporcional por flap; a partir de um sensor de posição no flap, a posição do mesmo é controlada pela válvula. Cada grupo de seis válvulas é controlado por uma rede de comunicação CANopen ligada a controladores industriais chamados MSC (Moog Servo Controller). Cada MSC controla dois grupos de válvulas; com doze destes, controlam-se os 144 flaps do gerador de ondas. No computador de controle de operação foi feita a integração dos sinais necessários para controlar todas as válvulas. Dessa forma, a partir de duas redes de comunicação distintas, o MSC faz a interface do sistema de controle e automação. 
Baseando-se nestas informações levantadas e com as especificações dos fabricantes de equipamentos industriais do mercado, pôde-se concluir que um sistema baseado em redes industriais e controladores operando em tempo real de operação é adequado para o uso em um gerador de ondas. A solução adotada no Calibrador Hidrodinâmico seguiu esta linha, apresentada no capítulo 4. No texto foi feita uma explicação detalhada da implementação e do desempenho obtidos. A solução adotada não faz uso do computador como equipamento responsável pela execução em tempo real, caso da solução do NMRI e da Bosch-Rexroth; o computador é utilizado como interface de operação, executa os cálculos de algoritmos de absorção ativa de ondas em malha fechada e serve de interface de leitura e gravação de dados.

\subsection{Geração de ondas}

Nesta seção, é apresentada uma revisão da geração de ondas, assunto abordado no trabalho. Alguns trabalhos se referem a geradores segmentados e suas variações, teoria de ondas bicromáticas, ondas irregulares unidirecionais ou de cristas longas (chamadas de long-crested) e ondas irregulares com espalhamento direcional ou de cristas curtas (chamadas de short-crested).

O estudo de geradores de ondas remonta ao ano de 1929, no trabalho de Havelock (1929). Foi demonstrada a função de transferência 2D de geradores de ondas, divididos em dois grupos básicos; pistão translacional e flap articulado. Diversos outros trabalhos, desde então, tratam do assunto, como em Biesel (1954), Dean e Dalrymple (1984), Madsen (1974), Castro (2009), Zhang (2005), Nohara, Yamamoto e Matsuura (1996), Wu e Dalrymple (1987) e Naito (2006).

Destes trabalhos, a partir da geração de ondas por geradores segmentados, surgem diversas abordagens para o assunto tendo em vista o tipo de aplicação, para águas rasas ou para águas profundas, por exemplo. Devido à relevância para este trabalho, as fontes bibliográficas estudadas foram de águas profundas e intermediárias.

As referências à geração de ondas em geradores segmentados, também chamados pela literatura de snake, podem ser encontradas primeiramente em Biesel (1954). O autor define uma importante restrição angular de geração de ondas baseada na dimensão 
dos flaps que compõem o gerador de ondas. Em Madsen (1974) podem ser encontradas as teorias de geração de ondas multidirecionais, aspectos sobre a função de transferência progressiva angularmente e fenômenos não lineares relativos à geração de ondas.

Em Zhang (2005) e em Castro (2009) pode ser encontrada a dedução analítica para as ondas progressiva e evanescente de um gerador de ondas usando a teoria linear.

Uma abordagem sobre diversos tipos de geradores de ondas advindos das soluções particulares da teoria linear, aplicada à condição de contornos laterais formadas pelos batedores, pode ser vista em Naito (2006). Neste trabalho, é mostrada a possibilidade de se ter diversos formatos de tanques com teoria de geração e absorção de forma unificada.

Nos trabalhos de Nohara, Yamamoto e Matsuura (1996) e Nohara (2000) podem ser encontrados o método de geração de ondas usando teoria linear aplicada a ondas regulares e irregulares e otimizações numéricas para geração de ondas, além de questões de automação para um tanque de ondas, pois o foco é a implantação de um tanque oceânico.

O trabalho numérico de O`Dea e Newman (2007) visa o aprimoramento da qualidade de um tanque oceânico via simulação numérica de $1^{\text {a }}$ ordem. Nele foram realizadas variações de número de batedores e de configurações de movimentação, bem como efeitos de borda (reflexão e não reflexão nas bordas) para verificar a qualidade do campo de ondas no interior do tanque.

A geração de ondas usando a teoria de ondas de $2^{\mathrm{a}}$ ordem pode representar uma resposta mais adequada quando se estão gerando ondas com grandes declividades usando a solução de $1^{\mathrm{a}}$ ordem ou quando as ondas estão se propagando em águas muito rasas. O assunto é tratado em (Schäffer, 1996). No trabalho, é vista a dedução analítica da geração de ondas para o correto movimento do batedor de ondas, de forma que a espacialidade da forma da onda se mantenha e que não ocorra a formação de ondas subharmônicas e super-harmônicas. O tema também pode ser visto em Sulisz e Hudspeth (1993) e Li e Williams (1998), mas estes autores trabalham com o conceito de expansão harmônica usando autofunções.

Trabalhos sobre a qualidade de síntese de mares irregulares também foram pesquisados. Em Miles e Funke (1989), pode ser vista uma análise de sensibilidade de resolução numérica ao se sintetizar mares irregulares. Em Mitsuyasu, Tasai et al. (1975) 
e em Hasselmann, Dunckel e Ewing (1980) pode ser acompanhada a análise de formato do espalhamento de mares reais a partir de observações para geração de modelo paramétrico de espalhamento.

A qualidade do campo de ondas em tanques oceânicos foi pesquisada nos trabalhos de Briggs (1997) e Hawkes et al. (1993), que mostram as dificuldades em se obter campos de ondas de mares irregulares em diversos tanques oceânicos comparados. Os aspectos que dificultam a obtenção do campo de ondas são enumerados e discutidos desde a geração até a correta medição e estimação das ondas.

\subsection{Técnica de TR}

A teoria de TR (time reversal) pesquisada para o presente trabalho tem sido recentemente desenvolvida na área de ultrassom (ondas de pressão em fluidos) e radiofrequência (ondas eletromagnéticas) para focalização espacial e concentração de energia em meios não homogêneos. O que se propõe no trabalho é a focalização de ondas usando TR, pelo fato de o tanque ser similar a uma cavidade acústica de ultrassom. Este assunto é recente e foi primeiramente abordado em Fink (1992). Por ser um assunto relativamente novo em acústica, em se tratando de ondas de gravidade a pesquisa é mais escassa ainda. Por essa razão, foi encontrada pouca literatura a respeito. Por exemplo, em Fouque, Garnier et al. (2004), Fouque e Nachbin (2003) e em Fouque, Garnier e Nachbin (2004) podem ser encontrados estudos numéricos de propagação de ondas de gravidade por sobre local de batimetria variável. Estudos experimentais são raros sobre o assunto. Dessa forma, sua abordagem no trabalho se deu para estudar a focalização de ondas no interior do tanque de provas. A abordagem realizada fez uso do gerador segmentado, da presença de obstáculos à propagação das ondas e do uso da reflexão interna no tanque para realizar diversos testes experimentais, descritos no trabalho. A ideia é que o método sirva de alternativa para a focalização espacial de ondas em um meio de propagação não homogêneo, condição que exige estudar as alterações que as ondas irão sofrer durante a propagação para que ocorra efetivamente a focalização. 


\section{Fundamentos teóricos}

Neste capítulo, serão apresentados os fundamentos teóricos necessários para o entendimento da hidrodinâmica aplicada à geração de ondas em um tanque oceânico. Primeiramente será apresentada a teoria de ondas de gravidade. A condição de contorno cinemática imposta por um gerador de ondas será apresentada para descrever a geração de ondas. As teorias de geração de onda apresentadas são usadas em diversas aplicações típicas de ensaios em ondas em tanques oceânicos, tais como ondas regulares e mares irregulares de cristas longas e cristas curtas. Ao final, a teoria de TR será apresentada. Esta teoria não tem origem na hidrodinâmica e sim no estudo de acústica. Entretanto, como o tanque oceânico é um ambiente propício para tal estudo experimental, a aplicação é possível, visto existir uma semelhança entre as ondas de pressão acústicas e as ondas de superfície livre. Esta aplicação pode trazer benefícios em estudos futuros

com ondas de gravidade. À frente no capítulo 5, a teoria é aplicada ao caso específíco do Calibrador Hidrodinâmico.

\subsection{Ondas de gravidade}

Ondas de gravidade de superfície são definidas pelo seu período, altura e direção de propagação. O comprimento de onda é resultado da dispersividade da mesma, dada pelo seu período e pela profundidade local em que ela está se propagando. Ao se sobrepor diversas ondas regulares, pode-se recriar um determinado mar irregular dentro do limite da teoria linear para pequenas amplitudes, o que pressupõe a possibilidade da somatória de diversas frequências harmônicas e de diversas direções de propagação.

Por esta razão, as ondas regulares são básicas para depois apresentarmos outras teorias de ondas. A Figura 3.1 ilustra esquematicamente uma onda progressiva propagando na direção $X$ que estende as cristas na direção $Y$, onde $L$ é o comprimento de onda e $T$ o período da onda. Na figura, sob um ponto de vista fixo no tempo, veríamos o comprimento da onda entre dois cruzamentos por zeros descendentes. Sob um ponto de vista fixo no espaço, veríamos um período de onda entre dois cruzamentos por zeros descendentes. Na natureza, qualquer que seja o tipo de escoamento de fluidos 
e ondulações de superfície livre, a modelação do fenômeno tem uma representação adequada através dos princípios da mecânica dos fluidos. No caso de ondas de gravidade em alto-mar, em geral são geradas por vento, na natureza, e por geradores de ondas, em laboratório. Os princípios da Conservação da Massa e da Conservação da Quantidade de Movimento permitem caracterizar o fenômeno. Detalhes sobre os princípios usados podem ser vistos em Dean e Dalrymple (1984). Neste trabalho, a teoria será apresentada de forma suscinta.

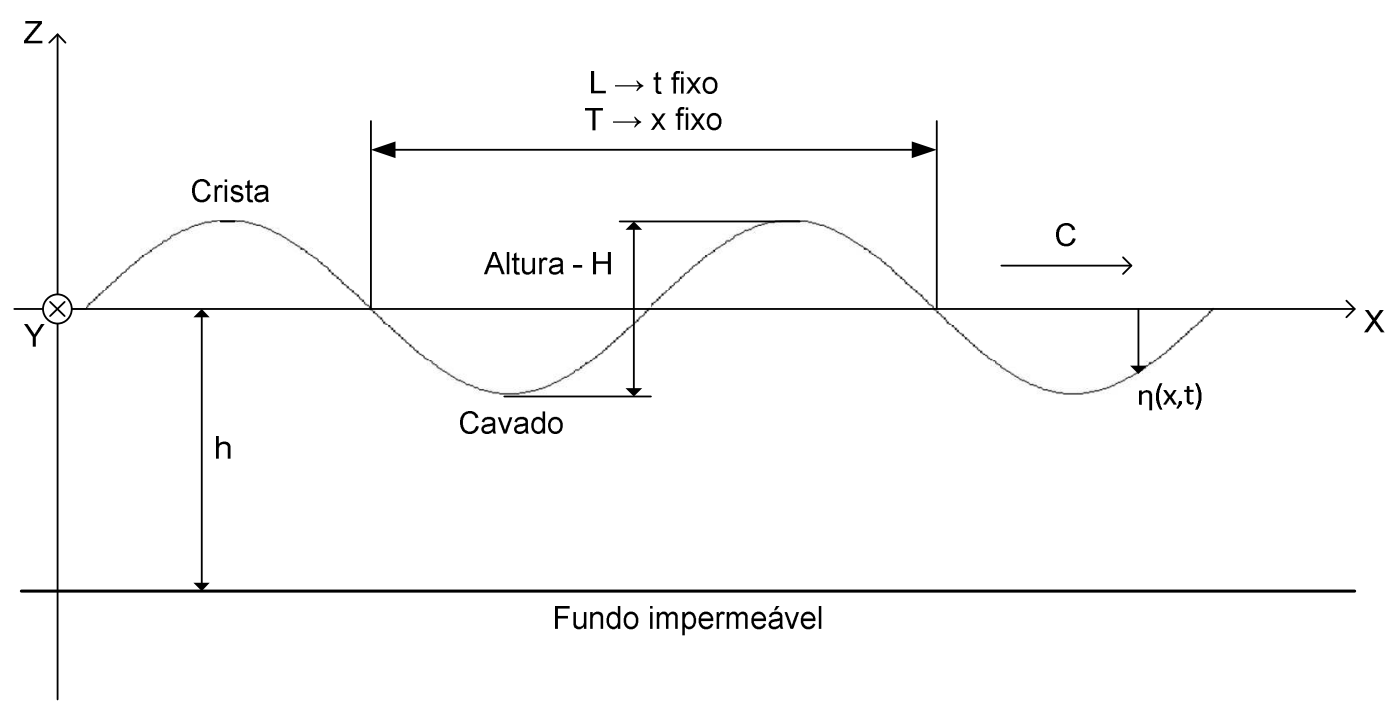

Figura 3.1. Onda progressiva propagando em local de batimetria constante.

A solução do escoamento do fluido pela passagem de ondas de gravidade progressivas é de difícil dedução. Por essa razão, simplificações foram adotadas para a solução do problema. O conjunto de soluções do problema obtido com simplificações de forma linear é chamada de teoria de ondas de Airy ou ondas de pequena amplitude. O escoamento oscilatório das partículas do fluido é dado por um potencial de velocidades $\phi(x, z, t)$; dele se obtêm o campo de velocidades no fluido, a superfície livre $\eta(x, z, t)$ e o campo de pressão no interior do fluido. Algumas hipóteses simplificadoras são feitas; o fluido é irrotacional, incompressível e invíscito. A solução do problema do escoamento é obtida, então, pela equação de Laplace, que atende à condição de Conservação da Massa:

$\nabla^{2} \phi=0$ 
Para a obtenção do potencial de velocidades, devem-se impor as condições de contorno do fluido para resolver o escoamento. Na superfície livre, as partículas do fluido têm trajetória coincidente com a própria superfície, mostrada na Figura 3.1, ou seja, uma condição cinemática para as partículas do fluido:

$\frac{\partial \phi}{\partial z}=\frac{\partial \eta}{\partial t}$, em $z=0$

Na superfície livre, a pressão é constante ao longo das oscilações das ondas; dessa forma, a partir da Equação de Bernoulli pode-se definir a condição de contorno dinâmica na superfície livre e que atende ao princípio da Conservação da Quantidade de Movimento, como:

$\eta=-\frac{1}{g} \cdot \frac{\partial \phi}{\partial t}$, em $z=0$

O fundo impermeável impõe uma condição de contorno no potencial de velocidades em sua face:

$\frac{\partial \phi}{\partial z}=0$ em $z=-h$

Ao combinar as condições de contorno em uma solução harmônica usando o método de separação de variáveis aplicado a $x, z$ e $t$, o potencial de velocidades resulta em:

$\phi(x, z, t)=\frac{\mathrm{H} \cdot \mathrm{g} \cdot \cosh k(h+z)}{2 \cdot \omega \cdot \cosh k h} \cdot \operatorname{sen}(k x-\omega t)$

onde $H$ é a altura da onda, $g$ é a aceleração da gravidade, $\omega=2 \pi / T$ é a frequência angular da onda, $k=2 \pi / L$ é o número de onda e $L$ é o comprimento de onda. Associando $\omega$ e $k$, obtém-se a velocidade de fase da onda (velocidade das cristas e cavados) ou celeridade da onda:

$C=\frac{\omega}{k}=\frac{L}{T}$

À relação entre a altura da onda $(H)$ e o seu comprimento $(L)$ dá-se o nome de declividade de onda: 
$D=\frac{H}{L}$

Usualmente a declividade pode ser expressa por porcentagem do comprimento de ondas ou por valor de zero a um. A declividade é comumente utilizada para definir o limite de validade da teoria de ondas, visto que, quanto maior a declividade, maior é a não-linearidade da onda. A teoria mostrada aqui é válida para pequenas amplitudes.

Aplicando o potencial de velocidades, equação (3.5) nas equações das condições de contorno de superfície livre, equações (3.2) e (3.3) combinadas, resulta na relação de dispersão da onda:

$\omega^{2}=g k \tanh k h$

A relação de dispersão associa a frequência angular da onda $(\omega)$ com o comprimento $(L)$. O resultado mostra que ondas de períodos maiores têm velocidade de fase maior, ou seja, a velocidade de propagação da onda não é constante no meio fluido, varia em função do período da oscilação.

A partir da relação de dispersão, pode-se reescrever o comprimento de ondas e a celeridade por:

$L=\frac{g T^{2}}{2 \pi} \tanh \left(\frac{2 \pi h}{L}\right)$
$C=\frac{g T}{2 \pi} \tanh \left(\frac{2 \pi h}{L}\right)$

Segundo a teoria linear de ondas, a velocidade de propagação da energia das ondas é dada pela chamada velocidade de grupo $\left(C_{g}\right)$ que é menor que $C$. Esta é a velocidade com que um "pacote" de ondas propaga. Quando, a partir do repouso, uma onda regular é gerada, na maioria dos casos a linha imaginária que define o início da onda tem velocidade igual a $C_{g}$. Sendo $C_{g}$ menor que $C$, as cristas das ondas desaparecem quando ultrapassam esta linha. Ao final do "pacote" de ondas, as cristas das ondas parecem surgir da linha com velocidade $C_{g}$. A partir da energia da onda, a celeridade de grupo ou velocidade de grupo é dada por:

$C_{g}=n C=\frac{C}{2}\left(1+\frac{2 k h}{\sinh 2 k h}\right)$ 
As componentes horizontal e vertical das velocidades orbitais no fluido podem ser obtidas pelas derivadas do potencial em relação às coordenadas $x$ e $z$ :

$v_{x}=\frac{\partial \phi}{\partial x}=\frac{H \cdot \omega \cdot \cosh k(h+z)}{2 \cdot \operatorname{senh} k h} \cdot \cos (k x-\omega t)$
$v_{z}=\frac{\partial \phi}{\partial z}=\frac{H \cdot \omega \cdot \operatorname{senh} k(h+z)}{2 \cdot \operatorname{senh} k h} \cdot \operatorname{sen}(k x-\omega t)$

Considerando que as trajetórias das partículas do fluido têm as velocidades definidas acima, ao se fixar uma posição $\left(x_{1}, z_{1}\right)$ e integrando-se em relação ao tempo as velocidades orbitais, obtém-se o deslocamento relativo das partículas do fluido em torno desta posição:

$$
\begin{aligned}
& \xi=-\frac{\mathrm{H} \cdot \omega \cdot \cosh k\left(h+z_{1}\right)}{2 \cdot \cosh k h} \cdot \operatorname{sen}\left(k x_{1}-\omega t\right) \\
& \zeta=\frac{\mathrm{H} \cdot \operatorname{senh} k\left(h+z_{1}\right)}{2 \cdot \operatorname{senh} k h} \cdot \cos \left(k x_{1}-\omega t\right)
\end{aligned}
$$

Nota-se que a trajetória tem, em um ciclo de ondas, uma órbita fechada. Quando a onda está propagando sobre um fundo plano e de profundidade infinita, esta órbita é circular. Quando a profundidade é finita, a órbita tem forma elíptica com deslocamento horizontal maior que o vertical. A Figura 3.2 mostra uma reprodução destas duas situações.
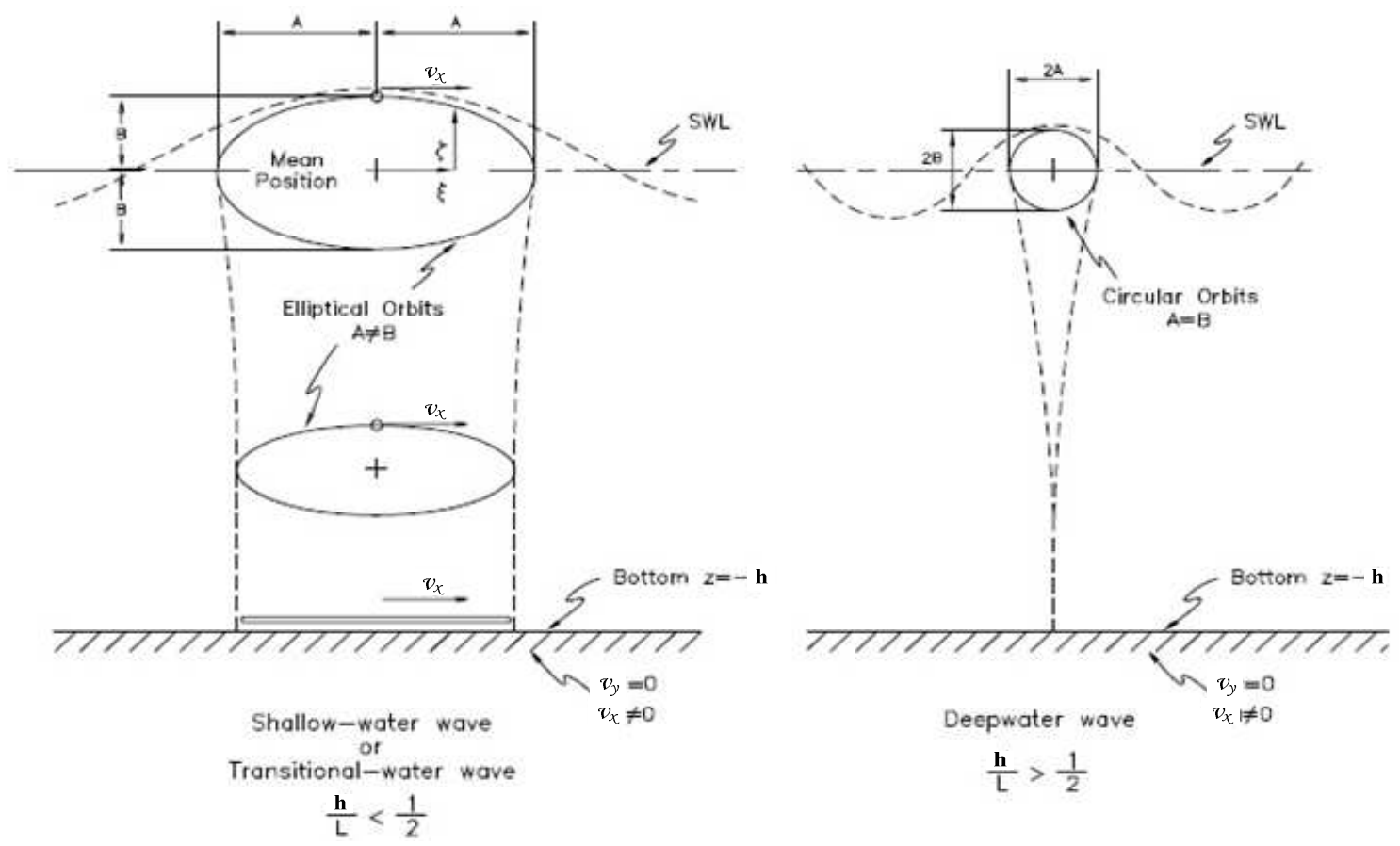

Figura 3.2. Deslocamentos das partículas do fluido em profundidades finita e infinita. Adaptado de CEM (2002). 
A teoria de ondas lineares prevê que se possam fazer simplificações assintóticas em função da profundidade relativa $(h / L)$. Pode ser visto em Dean e Dalrymple (1984) que, em função da profundidade relativa, podemos adotar as simplificações de acordo com a Tabela 3.1.

Tabela 3.1. Relações assintóticas da onda progressiva

\begin{tabular}{|c|c|c|c|c|c|c|}
\hline Condição & Limites & $\begin{array}{c}\text { Simplificação } \\
\text { assintótica }\end{array}$ & $\boldsymbol{L}$ & $\boldsymbol{C}$ & $\boldsymbol{C}_{\boldsymbol{g}}$ & $\begin{array}{c}\text { Trajetórias das } \\
\text { partículas da água }\end{array}$ \\
\hline Águas rasas & $\begin{array}{c}\frac{h}{L}<1 / 20 \\
k h<\pi / 10\end{array}$ & $\tanh k h \approx k h$ & $L=\frac{g T^{2} k h}{2 \pi}$ & $\sqrt{g h}$ & $\boldsymbol{C}_{\boldsymbol{g}}=\boldsymbol{C}$ & $\begin{array}{c}\text { Elipses fechadas } \\
\text { horizontalmente }\end{array}$ \\
\hline $\begin{array}{c}\text { Águas } \\
\text { intermediárias }\end{array}$ & $\begin{array}{c}1 / 20<\frac{h}{L}<1 / 2 \\
\pi / 10<k h<\pi / 2\end{array}$ & $\tanh k h$ & $\begin{array}{c}\text { Equação } \\
(3.9)\end{array}$ & $\begin{array}{c}\text { Equação } \\
(3.10)\end{array}$ & $\begin{array}{c}\text { Equação } \\
(3.11)\end{array}$ & Elipses \\
\hline $\begin{array}{c}\text { Águas } \\
\text { profundas }\end{array}$ & $\begin{array}{c}\frac{h}{L}>1 / 2 \\
k h>\pi / 2\end{array}$ & $\tanh k h \approx 1$ & $L_{0}=\frac{g T^{2}}{2 \pi}$ & $C_{0}=\frac{g T}{2 \pi}$ & $\boldsymbol{C}_{\boldsymbol{g}}=\frac{\boldsymbol{C}}{\mathbf{2}}$ & Circulares \\
\hline
\end{tabular}

\subsection{Geradores de ondas}

\subsubsection{Solução linearizada}

Uma vez definidas as bases da teoria de ondas, podemos demonstrar a mecânica do funcionamento de um gerador de ondas. $\mathrm{O}$ gerador de ondas definido para o uso no Calibrador Hidrodinâmico foi do tipo flap, conforme discutido no capítulo anterior. A Figura 3.3 mostra o arranjo do gerador de ondas. Basicamente o equacionamento tem como meta estimar a altura da onda para um dado deslocamento do flap, ou seja, a função de transferência. No trabalho, será seguida a formulação para o batedor do tipo flap aplicando a função de forma do batedor em questão. 


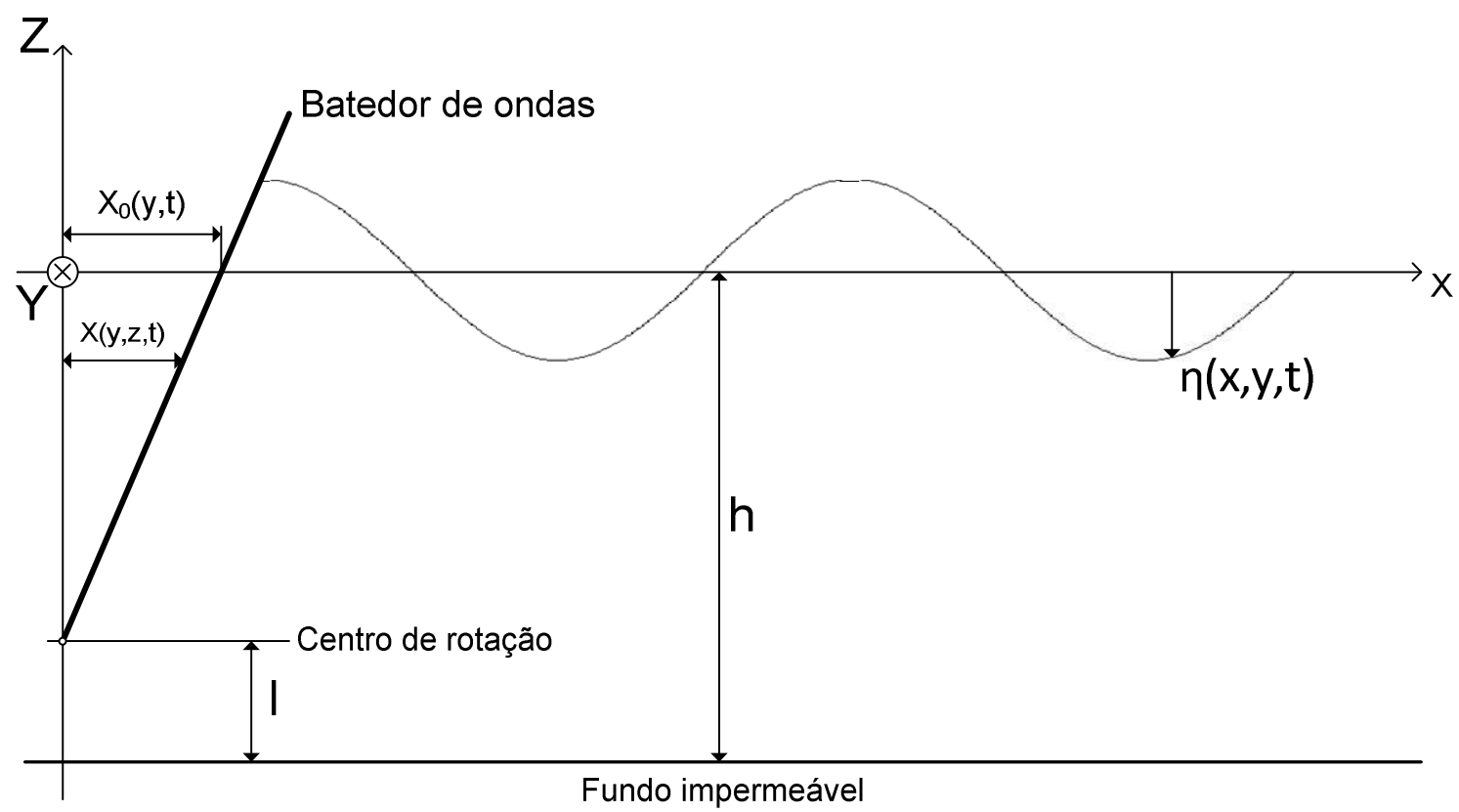

Figura 3.3. Definição de um gerador de ondas do tipo flap.

A teoria apresentada a seguir segue as bases do trabalho de Zhang (2005) e Hughes (1993), mas pode ser visto em Dean e Dalrymple (1984) em 2D (caso de gerador não-segmentado, caso bidimensional com coordenadas $x$ e $z$ ).

Visando incorporar a geração de ondas oblíquas, é preciso definir o arranjo em planta do gerador de ondas. Na prática, temos flaps com largura finita, mas na formulação será considerado que a largura é infinitesimal, ou seja, contínua em y (Figura 3.4). Esta suposição não considera vários problemas na qualidade das ondas geradas e absorvidas. A resolução espacial entre largura do flap e comprimento de onda leva a um limitante de geração de ondas tratado pela primeira vez por Biesel (1954). Estes problemas serão tratados mais adiante. O número de ondas é projetado nos dois eixos do sistema de coordenadas. 


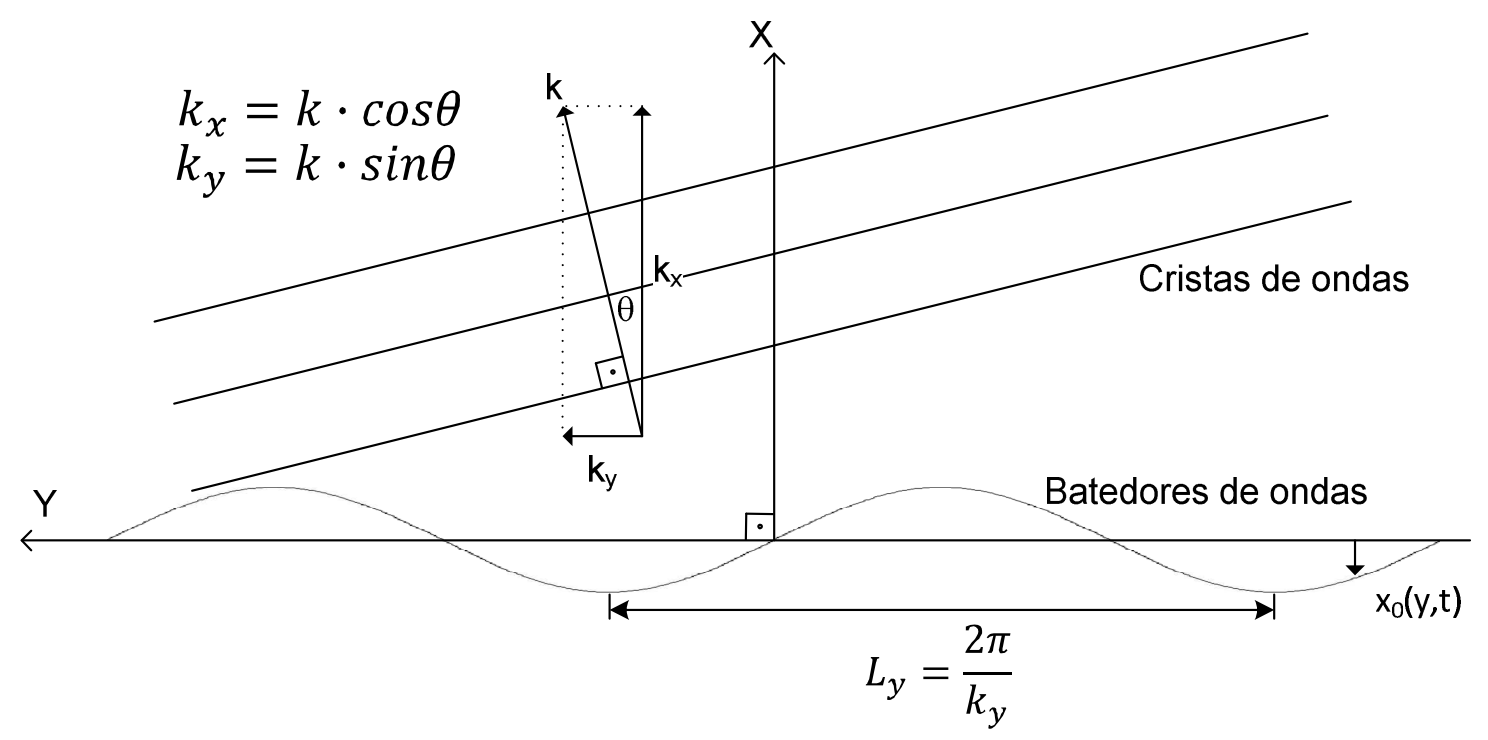

Figura 3.4. Visão em planta do gerador de ondas.

A função que representa o movimento dos flaps é:

$X(y, z, t)=x_{0} f(z) \sin \left(\omega t-k_{y} y\right)$

onde:

$f(z)=\left\{\begin{aligned} 1+\frac{z}{h-l}, & 0 \geq z \geq-(h-l) \\ 0, & -\mathrm{h} \leq z<-(h-l)\end{aligned}\right.$

e $x_{0}$ é a amplitude do deslocamento do flap na linha de água em repouso.

Devem-se impor, além das condições de contorno adotadas para ondas regulares, outras duas condições de contorno. Primeiramente, segundo Biesel (1954) apud, Quadrante (2011), para garantir a unicidade da solução do potencial de velocidades resultante da ação de um gerador de ondas, deve-se garantir que, distante do gerador, uma onda progressiva tenha sido gerada, que não existam ondas em sentido contrário e que não existam ondas estacionárias que se estendam indefinidamente a partir do gerador de ondas. A condição necessária para a solução do problema é uma condição de radiação. Agora as condições de contorno impõem que o potencial seja da forma:

$\phi(x, y, z, t)=C_{p} \cosh k(h+z) \sin \left(k_{x} x+k_{y} y-\omega t\right)+$

$+C_{s} e^{-\left(\sqrt{k_{s}^{2}+k_{y}^{2}}\right) x} \cos k_{s}(h+z) \cos \left(k_{y} y-\omega t\right)$ 
O primeiro termo da equação (3.18) representa o potencial progressivo da onda gerada, onde $k$ é o número de onda dado pela equação (3.8) e $C_{p}$ está associado ao movimento do batedor. $\mathrm{O}$ segundo termo representa as ondas evanescentes, que decaem exponencialmente com o aumento da distância em $x$. O termo $k_{s}$ é o número de onda evanescente, dado por:

$\omega^{2}=-g k_{s} \tan k_{s} h$

A solução do número de onda evanescente tem infinitas raízes reais, tornando o potencial das ondas evanescentes uma somatória infinita de termos. O termo $C_{S}$ está associado ao movimento do batedor de ondas.

A segunda condição de contorno necessária impõe a compatibilidade entre o movimento do flap e o movimento da velocidade horizontal das partículas do fluido, ou seja, uma condição cinemática no flap, garantindo a impermeabilidade do mesmo. A forma linearizada é:

$\frac{\partial \phi}{\partial x}=\frac{\partial X}{\partial t}$, em $x=0$

A posição fixa $x=0$ é uma simplificação a pequenas amplitudes de movimento do flap, visto que simplificadamente as ondas na superfície livre também são consideradas de pequena amplitude.

Primeiramente, o potencial para o caso de ondas progressivas pode ser visto abaixo:

$\phi_{p}(x, y, z, t)=C_{p} \cosh k(h+z) \sin \left(k_{x} x+k_{y} y-\omega t\right)$

O potencial progressivo pode ser deduzido pelo método de separação de variáveis assumindo $k^{2}>0, k_{y} \leq k$ e incluindo o termo referente ao eixo de coordenadas $y$. Agora, usando a condição de contorno cinemática no flap (compatibilidade da velocidade horizontal), a equação do movimento do flap (eq. 3.16), a equação (3.21) e usando dedução algébrica, obtém-se o valor de $C_{p}$ :

$C_{p}=\frac{x_{0} \omega c_{0}}{k_{x} \sinh k h}$ 
na qual $c_{0}$ é:

$c_{0}=\sinh k h \frac{\int_{-h}^{0} f(z) \cosh k(h+z) d z}{\int_{-h}^{0} \cosh ^{2} k(h+z) d z}$

O valor de $c_{0}$ após a integração em duas partes por conta de $f(z)$ é:

$c_{0}=\frac{4 \sinh k h[\cosh k(l)-\cosh k h-k(-2 l) \sinh k(l)+k(h-l) \sinh k h]}{k(h-l)(2 k h+\sinh 2 k h)}$

Aplicando a condição de contorno da superfície livre (eq. 3.3), associamos a elevação da onda com o movimento do flap e assim a superfície livre:

$\eta_{p}(x, y, t)=\mathrm{x}_{0} c_{0} \frac{k}{k_{x}} \cos \left(\omega t-k_{x} x-k_{y} y\right)$

Assim, a função de transferência de altura de ondas $(H)$ pela altura de movimento do flap (deslocamento $S=2 \cdot x_{0}$ ) é:

$F T_{p}=\frac{H}{S}=c_{0} \frac{k}{k_{x}}$

O termo $k / k_{x}$, de acordo com a Figura 3.4, é equivalente ao cosseno entre a direção da onda e a direção normal do gerador de ondas, ou seja:

$F T_{p}=\frac{H}{S}=c_{0} \frac{k}{k_{x}}=c_{0} \frac{1}{\cos \theta}$

A parcela evanescente pode ser deduzida pelo mesmo procedimento adotado para a parcela da onda progressiva. A parcela evanescente é:

$\phi_{e}(x, y, z, t)=C_{s} e^{-\left(\sqrt{k_{s}^{2}+k_{y}^{2}}\right) x} \cos k_{s}(h+z) \cos \left(k_{y} y-w t\right)$

Por conta do número infinito de soluções de $k_{s}$ o potencial evanescente torna-se um somatório: 
$\phi_{e}(x, y, z, t)=\sum_{j=1}^{\infty} C_{j} e^{-\left(\sqrt{k_{s}^{2}+k_{y}^{2}}\right) x} \cos k_{s j}(h+z) \cos \left(k_{y} y-w t\right)$

Assumindo o mesmo método da onda progressiva:

$C_{j}=\frac{-x_{0} \omega c_{s j}}{\sqrt{k_{s j}^{2}+k_{y}^{2}} \sin k_{s j} h}$

onde $c_{s j}$ é:

$c_{s j}=\sin k_{s j} h \frac{\int_{-h}^{0} f(z) \cos k_{s j}(h+z) d z}{\int_{-h}^{0} \cos ^{2} k_{s j}(h+z) d z}$

O valor de $c_{s j}$ após a integração em duas partes por conta de $f(z)$ é:

$c_{s j}=\frac{-4 \sin k_{s j} h\left[\cos k_{s j}(l)-\cos k_{s j} h+k_{s j}(-2 l) \sin k_{s j}(l)-k_{s j}(h-l) \sin k_{s j} h\right]}{k_{s j}(h-l)\left(2 k_{s j} h+\sin 2 k_{s j} h\right)}$

A superfície livre evanescente:

$\eta_{e}(x, y, t)=\sum_{j=1}^{\infty} x_{0} c_{s j} \frac{k_{s j}}{\sqrt{k_{s j}^{2}+k_{y}^{2}}} e^{-\left(\sqrt{k_{s j}^{2}+k_{y}^{2}}\right) x} \sin \left(\omega t-k_{y} y\right)$

Assim, a função de transferência de altura de ondas evanescente pela altura de movimento do flap $($ deslocamento $=$ stroke $=S)$ é:

$F T_{e}=\frac{H_{e}}{S}=\sum_{j=1}^{\infty} c_{s j} \frac{k_{s j}}{\sqrt{k_{s j}^{2}+k_{y}^{2}}} e^{-\left(\sqrt{k_{s j}^{2}+k_{y}^{2}}\right) x}$

Da forma como foi colocado o problema, agora somente deve-se ajustar a fase entre as funções de transferências. A função de transferência progressiva tem fase fixa em $90^{\circ}$ com a altura da onda adiantada em relação à posição do flap. Assim, representando por fasores no plano complexo a função progressiva $H / S$ é multiplicada por i (imaginário $i=\sqrt{-1}$ ). A função evanescente tem fase igual à elevação de onda, portanto, no eixo real. A função de transferência total é, portanto, na forma complexa:

$F T=\frac{H_{e}}{S}+i \cdot \frac{H}{S}=F T_{e}+i \cdot F T_{p}$ 
A Figura 3.5 mostra o módulo das funções de transferências progressiva e evanescente. Em função da quantidade de números de ondas na somatória das ondas evanescentes $(j)$, demonstra-se a sensibilidade na convergência dos valores. Adotou-se 200 números de ondas evanescentes no trabalho como sendo adequado para representar a $F T_{e}$ devido a convergência do valor da somatória.

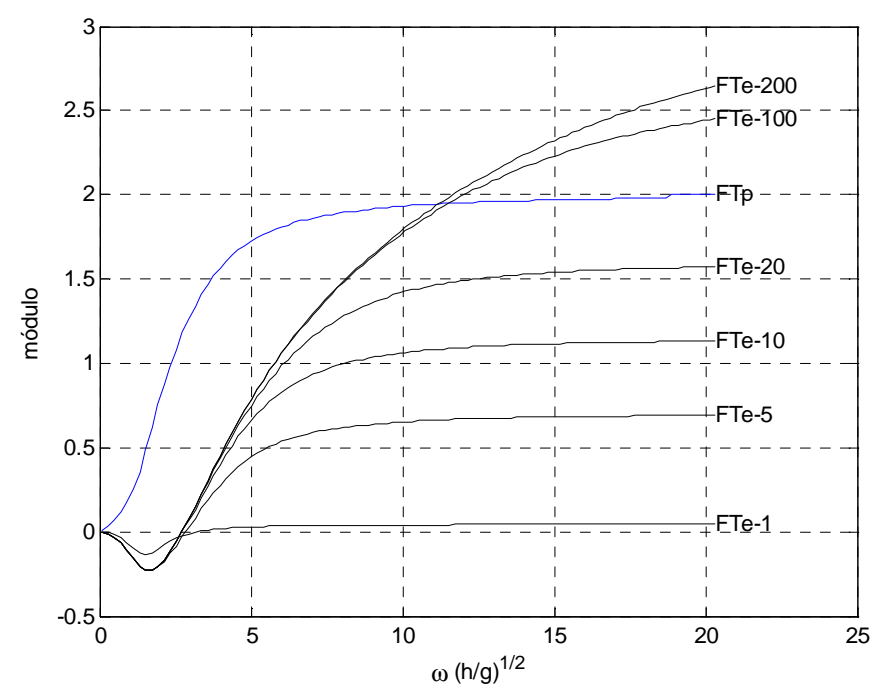

Figura 3.5. Funções de transferência - Influência da quantidade de números de ondas na FT evanescente.

Do mesmo modo, para diferentes direções de geração de onda a Figura 3.6 mostra a forma das funções de transferências. A função de transferência evanescente na figura é mostrada com 200 números de onda por direção.

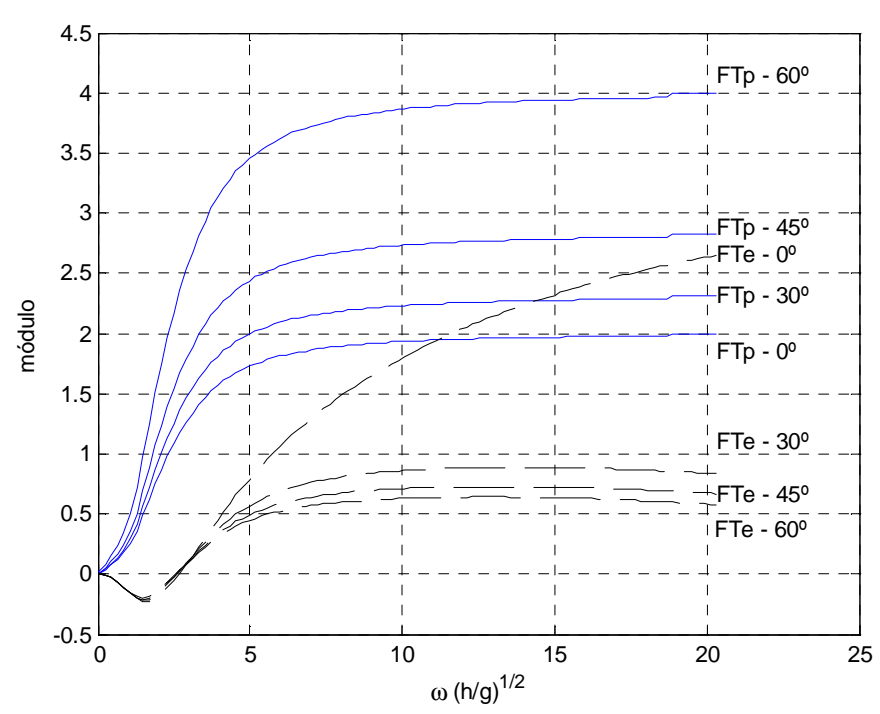

Figura 3.6. Funções de transferência - influência da direção de geração de ondas. 


\subsubsection{Função de transferência mecânica}

$\mathrm{Na}$ prática de projeto de geradores de ondas deste tipo, geralmente o ponto de conexão entre o mecanismo atuador e o flap acontece em um ponto acima da linha de água. Por conta disso, existe uma função de transferência que, no trabalho, é chamada de função de transferência mecânica que precisa ser compensada para que o deslocamento seja transferido corretamente do atuador mecânico $\left(S_{a}\right)$, à linha de água $\left(S_{0}\right)$. Veja a Figura 3.7.

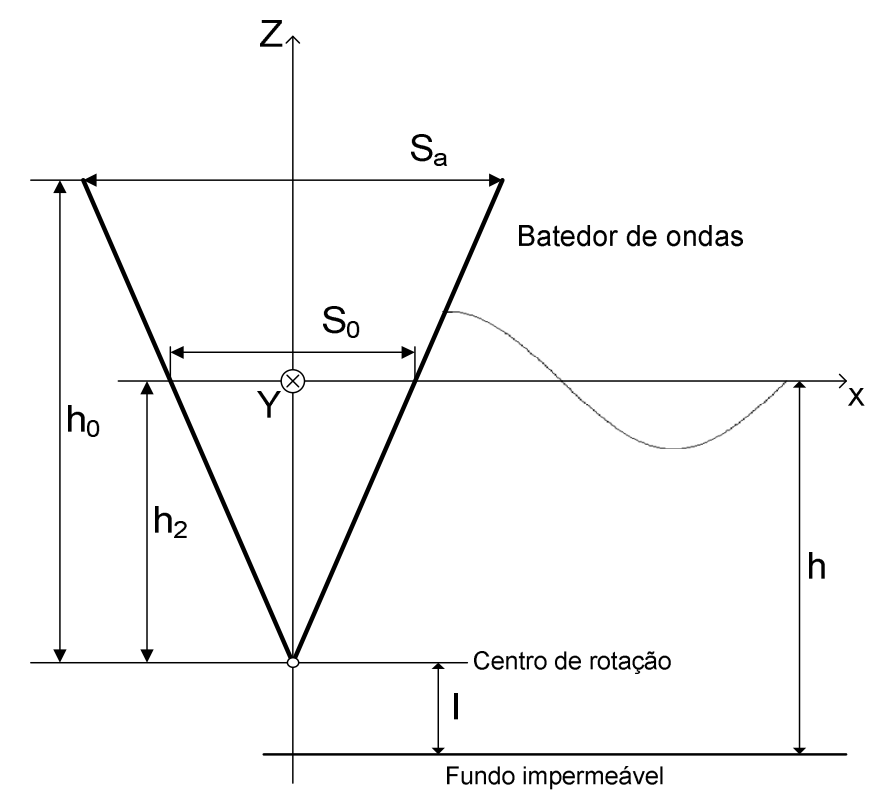

Figura 3.7. Função de transferência mecânica.

Compensando o deslocamento no braço de acionamento $\left(S_{a}\right)$, a função de transferência mecânica é:

$F T_{M}=\frac{s_{0}}{S_{a}}=\frac{h_{2}}{h_{0}}$

onde $S_{0}=S$ mostrado no restante do trabalho. 


\subsubsection{Efeito da largura finita dos batedores de ondas}

A solução linearizada da geração de ondas não leva em consideração o efeito da discretização dos batedores de ondas. Veja a Figura 3.4, onde não existem descontinuidades nos batedores na direção $y$. Batedores de ondas com largura infinitesimal são impraticáveis devido ao elevado número de atuadores; portanto, foi adotada no Calibrador Hidrodinâmico uma largura padrão para os flaps: 0,36 metro.

Segundo Biesel (1954), existe um ajuste na função de transferência do gerador de ondas para corrigir a altura das ondas oblíquas progressivas geradas. Além do mais, o autor mostra que existe um limite para que as ondas progressivas sejam geradas sem ocorrência das chamadas ondas espúrias próximas ao gerador de ondas. No trabalho de Quadrante (2011), as deduções feitas por Biesel (1954) foram verificadas numericamente e confrontadas com o simulador hidrodinâmico WAMIT, para simular o campo de ondas no Calibrador Hidrodinâmico. Os resultados mostram que a correção para geração de ondas oblíquas é necessária e apresenta bons resultados se comparada ao WAMIT.

O modelo linear apresentado no tópico 3.2.1 mostra uma correção angular baseada no ajuste geométrico em planta, dado pelo ângulo entre a direção normal do flap e a direção de geração da onda progressiva, presente na equação (3.27). O desenvolvimento de Biesel (1954) leva em consideração a largura finita dos flaps (veja na Figura 3.8). Nesta condição, o potencial de velocidades, após o desenvolvimento algébrico usando técnica de perturbação avaliando a estabilidade das soluções em função da largura do flap, leva a um resultado diferente da equação (3.27):

$\frac{H}{S}=c_{0} \frac{\operatorname{sen} \tau}{\tau \cos \theta}$

onde $\tau$ é:

$\tau=\frac{1}{2} \cdot k \cdot l \cdot \operatorname{sen} \theta$

onde $l$ é a largura do flap.

A coordenada $y$ avança agora em posição discreta com comprimento $l$ dado pela largura do flap. A posição central do batedor é agora a referência de posição em $y$. 


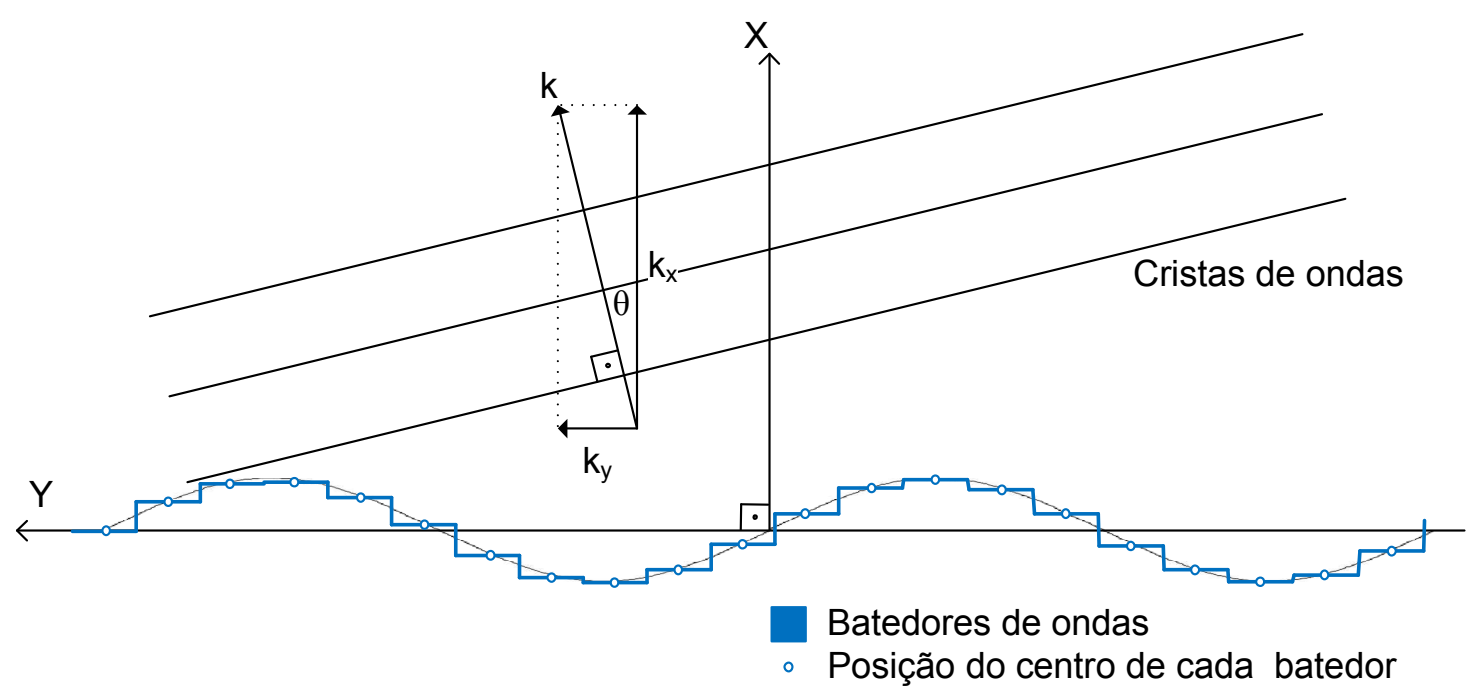

Figura 3.8. Discretização espacial dos batedores de ondas.

A equação (3.37) em baixa frequência tende assintoticamente a equação (3.27). Em alta frequência, ela atinge uma singularidade em que o seu valor tende a infinito. Essa singularidade também indica que existe um limite para a geração de ondas baseado na relação entre o comprimento de ondas, largura do flap e ângulo de geração de ondas, o chamado Limite de Biesel.

Biesel (1954) estabelece, então, uma relação entre os parâmetros citados no parágrafo anterior e define analiticamente a região de geração de ondas sem a ocorrência de ondas espúrias e que não se propagam ao longe do gerador de ondas:

$l<\frac{L}{1+|\operatorname{sen} \theta|}$

A relação limita para uma dada largura de batedor o menor comprimento de onda possível de ser gerado em determinado ângulo.

O autor faz uma análise desse limite. Se o ângulo for $90^{\circ}$ o comprimento de ondas limite será $2 l$. Nessa condição, a defasagem de um batedor ao próximo será de $180^{\circ}$. Com esta defasagem em contrafase, uma onda propagando pode ter dois sentidos: $-90^{\circ}$ e $+90^{\circ}$. Ondas propagando em duas direções é uma condição indesejada. Para tanto, o limite teórico estabelecido seria muito brando e também deixaria ocorrer muitas descontinuidades na superfície formada pelos batedores. $\mathrm{O}$ autor, então, restringe o limite analiticamente de forma que os termos espúrios tenham valor menor que os progressivos, o que resulta na forma final do limite atribuído a Biesel: 
$l<\frac{L}{\sqrt{2}+|\operatorname{sen} \theta|}$

Cabe lembrar que este limite é definido semi empiricamente e não tem transição brusca. Deve ser analisado e verificado empiricamente no gerador de ondas. Graficamente ele pode ser descrito para o tanque do Calibrador Hidrodinâmico na Figura 3.9. A largura do batedor é de 0.36 metro. Com esta informação, é possível definir melhor os limites de operação do tanque de ondas. É preciso lembrar que, como o Limite de Biesel foi definido para ângulos agudos usando uma definição teórica para fins práticos, no caso não oblíquo não há restrição de geração de ondas, embora analiticamente exista. As regiões demarcadas na Figura 3.9 indicam quais laterais estão aptas para gerar ondas individualmente. Quando, para um determinado ângulo, uma lateral está excedendo o limite, a próxima lateral na sequência, por sua vez, não está excedendo o limite. Abaixo de 1,34 Hz não há restrição alguma em todo o tanque (área em azul) e em $45^{\circ}$ da direção de cada lateral ocorre o cruzamento da geração entre as laterais em 1,43 Hz. A área marcada em marrom indica quando o limite foi excedido, onde não é possível gerar ondas sem a ocorrência de ondas espúrias.

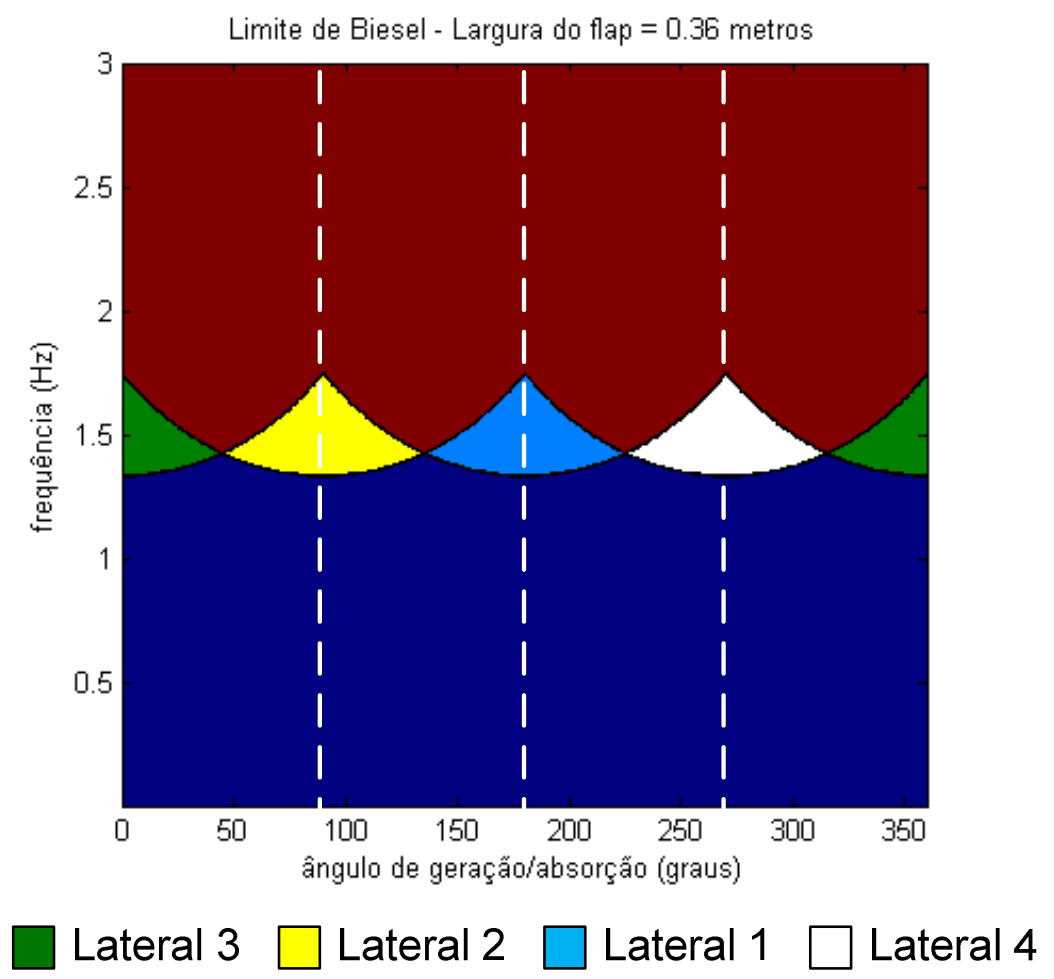

Figura 3.9. Limite de Biesel para o Calibrador Hidrodinâmico. 


\subsection{TR - Time reversal e focalização espacial}

Originalmente, a técnica de TR foi desenvolvida para ser aplicada no tratamento de sinais acústicos. Ela vem se desenvolvendo ao longo dos anos e ganhando um maior número de aplicações, tais como na formação e reconstrução de imagens, na geofísica, na comunicação submarina e em ensaios não destrutivos. Foi proposta pela primeira vez por Mathias Fink como uma forma de focalização espacial em meios não homogêneos (FINK, 1992). Iterativamente realizada, pode focalizar a pressão acústica em um ponto do espaço. Ela é realizada pela re-emissão revertida no tempo de ecos acústicos; assim, ela funciona analogamente a um espelho óptico, focalizando energia pontualmente e resolvendo, desta forma, um problema inverso diretamente.

Os problemas inversos são estudados relativamente há pouco tempo. Maiores informações a esse respeito podem ser encontradas em Campos Velho (2003). Simplificadamente, os problemas podem ser classificados de dois modos: direto ou inverso. Os problemas diretos têm causas perfeitamente modeladas e estudadas (características de um sistema, por exemplo), que levam a uma solução única e correta do problema, ou seja, o efeito como resultado. Em um problema inverso, quando não se tem o sistema completamente estudado, pela alta complexidade, por exemplo, o que se faz é observar os efeitos para estimar as causas conhecidas que originaram tal efeito. É fácil notar que o campo de aplicação da técnica é vasto e interdisciplinar, estendendo-se a diferentes áreas do conhecimento. Sob o ponto de vista do problema proposto por Fink (1992), a modelagem do sistema é complexa devido à natureza da aplicação. Nesse caso, usando a técnica de TR, a focalização de energia, como objetivo imposto, é obtida. Outros exemplos de aplicações podem ser vistos em Campos Velho (2003).

Ondas acústicas emitidas em arrays de transdutores podem ser usadas para formar imagens por ultrassom e focalizar energia em pontos específicos do espaço. Usando a técnica de retardo temporal e somatório dos sinais adquiridos é possível detectar ecos refletidos de interfaces de materiais acusticamente distintos. O retardo aplicado aos sinais muda o ponto de focalização espacial, analogamente a uma lente convergente em óptica. Esta técnica é usada em várias aplicações de formação de imagens por ultrassom. Uma limitação pode ocorrer na abordagem quando os meios por onde a onda acústica se propaga têm características acústicas distintas, pois as velocidades de 
propagação são diferentes em cada um dos meios. O foco é deteriorado nestes casos, pois o retardo é especificado para uma determinada velocidade de propagação. Da mesma forma, com a transmissão usando retardo de fase em arrays de transdutores de ultrassom, pode-se fazer o foco em um ponto específico do espaço, concentrando energia acústica. Nesse caso, a focalização com meios de propagação muito diferentes fica prejudicada.

A vantagem do método de TR é que, ao receber o sinal do eco, revertê-lo no tempo e emiti-lo novamente, fazemos com que a concentração ocorra novamente, no ponto em que foi originado o eco. O retardo do sinal será nulo no ponto que originou o eco; portanto, a pressão acústica será concentrada no ponto. Segundo Fink (1992), repetindo iterativamente o processo, ocorre a concentração de energia somente no ponto que tem o maior eco acústico. A técnica concentra energia mesmo que o meio seja não homogêneo, o que representa uma vantagem em relação aos métodos convencionais.

A técnica de TR pode ser aplicada para ondas na água usando geradores de ondas para concentrar energia em pontos específicos do espaço. Da mesma forma que aplicada para ultrassom, a técnica de TR tem boa resposta para um sistema linear, invariante no tempo e determinístico. $\mathrm{O}$ fato de as ondas de gravidade serem dispersivas (eq. 3.8) impõe que cada comprimento de onda que esteja presente em um registro de elevação da superfície livre tenha velocidades de fase e de grupo diferentes. A propagação pode ser resolvida pela técnica de TR para focalizar um somatório de várias frequências de ondas em um ponto específico do espaço. No caso de propagação de ondas em duas dimensões, como em um tanque oceânico, a concentração pode ser feita usando-se diferentes direções de propagação. Assim, a técnica pode concentrar energia tanto em ondas que apresentam dispersão direcional como também em ondas de gravidade que apresentam dispersão em frequências.

A técnica foi estudada numericamente em diversos trabalhos em que foram usados modelos de propagação de ondas de gravidade, entre eles o modelo de Boussinesq de águas rasas, para modelar as ondas de gravidade. No trabalho de Fouque, Garnier et al. (2004) foi simulada numericamente a focalização na transmissão e na reflexão de ondas propagando por sobre um fundo com profundidade aleatória com ondas unidirecionais. Em (FOUQUE e NACHBIN, 2003) foi feito o estudo da mesma propagação sobre um fundo aleatório usando-se a teoria de ondas não lineares para águas rasas. No trabalho de Fouque, Garnier e Nachbin (2004) novamente foram estudadas ondas dispersivas 
propagando sobre um fundo aleatório e plano. Os três trabalhos abordam diferentes aspectos da simulação numérica de TR para focalização de ondas propagando por sobre um fundo aleatório ou plano para ondas unidirecionais. O papel da profundidade aleatória é criar interferência na propagação da onda, pois faz com que ela seja afetada pelo fundo.

No caso de um fundo plano e do uso de frequências de ondas caracterizadas em águas profundas (Tabela 3.1), não irá ocorrer influência do fundo na propagação. Por outro lado, se a profundidade for variável e aleatória, o cálculo de uma função para focalizar energia analiticamente se tornará mais complexo e, então, a teoria descrita pelos três trabalhos acima se tornará essencial. Outro aspecto destes trabalhos é que eles abordam ondas propagando e não tratam do gerador de ondas que as gerou.

No caso de aplicações experimentais em um tanque oceânico, a influência da profundidade não afeta a propagação das ondas por se tratar de um tanque suficientemente profundo. Mas ao se colocar na linha de água objetos que alterem a propagação das ondas por efeito da difração e irradiação, como uma forma de criar diferentes "caminhos" para a passagem da onda, o uso de TR pode resolver o efeito destas interferências diretamente.

Quanto à forma para se criar a perturbação inicial na água, isso pode se dar de duas maneiras. A primeira delas é usar um ou mais batedores de ondas para criar uma onda. A outra forma é fazer um objeto cair na água para criar uma onda circular que incidirá nas laterais do tanque. Nos dois casos, a perturbação é lida pelos sensores de ondas dos batedores, que depois gerarão a onda revertida da perturbação.

Matematicamente, o fenômeno pode ser descrito como a resposta impulsiva de um sistema linear. O sistema dito linear é composto pela resposta do batedor, o meio líquido por onde a onda propaga e o sensor que adquire a altura da onda. A resposta total do sistema para uma entrada arbitrária $x(t)$ de movimento do batedor pode, então, ser descrita pela convolução da entrada pela resposta impulsiva do sistema como:

$y(t)=x(t) \otimes h(r, t)=\int_{-\infty}^{\infty} x(\tau) \cdot h(r, t-\tau) d \tau$

onde $r$ é a distância entre o ponto de entrada e a saída. 
No domínio da frequência a resposta pode ser descrita pelo produto simples entre entrada e resposta impulsiva:

$Y(\omega)=X(\omega) \cdot H(r, \omega)$

Para realizar o TR é preciso obter a resposta impulsiva $h(r, t)$ emitindo um delta de Dirac entre o batedor e o ponto de medição da superfície livre e depois inverter no tempo, ou seja, fazer $h(r,-t)$. Como o sistema é causal, na verdade o que se obtém é $h(r, T-t)$, onde $T$ é a duração do sinal adquirido. Se houver quaisquer translações do sinal no tempo, elas não afetarão a resposta, pois o sistema é invariante no tempo.

Ao emitir novamente a resposta impulsiva no sistema, obtém-se:

$y(t)=h(r, T-t) \otimes h(r, t)=\int_{-\infty}^{\infty} h(r, \tau) \cdot h(r, t-T+\tau) d \tau$

A equação 3.43 é, portanto, a função de autocorrelação de $h(r, t)$. O máximo dela ocorre quando $t-T=0$, ou seja, no instante final da série temporal. O tamanho dela não importa. Assim, no domínio da frequência a resposta é:

$Y(r, \omega)=H(r, \omega) \cdot H^{*}(r, \omega) \exp j \omega T$

O produto conjugado tem o efeito de cancelamento das fases para cada frequência envolvida e $T$ é um retardo total à resposta. Desta forma, o máximo ocorre em $T$, que é justamente quando todas as fases são nulas.

O objetivo da aplicação da técnica é realizar a focalização de ondas em determinadas posições do tanque de provas mesmo na presença de obstáculos e elementos que afetem sua propagação. A expectativa é que o método tenha desempenho de focalização melhor se comparado à focalização realizada pela geração de onda transiente. Esta última é modelada pela distância entre fonte e recepção e não pressupõe a diferença de trajeto em função de obstáculos nem de mudança de batimetria. Para tanto, seria preciso resolver efeitos de fundo, difração e refração da onda. Estes efeitos não modelados são diretamente "resolvidos" pela realização de TR empiricamente. No capítulo 6 serão mostrados experimentos realizados no tanque de provas que mostram as vantagens de se utilizar o método na focalização espacial de ondas. 


\section{Implementação do tanque de provas}

Neste capítulo é apresentado o desenvolvimento do sistema de controle do tanque de provas, também detalhado em De Mello et al. (2011), assim como a definição do sistema, o sistema elétrico desenvolvido, o sensoriamento de ondas por ultrassom, o sistema de automação utilizando CLP, uma breve descrição do mecanismo do atuador e o sensoriamento de ondas por sensores capacitivos.

\subsection{Definições}

Com o objetivo de criar um padrão para todo o sistema do gerador de ondas, em que são identificados os equipamentos elétricos, mecânicos, sensores e alocação física no prédio, foram feitas as seguintes definições:

- Divisão dos equipamentos do tanque em 4 lados.

- Grupos de atuadores mecânicos e sensores de ondas de batedores do tipo flap em grupos de 5 unidades.

- Dois painéis com servo-drivers por lateral do tanque; 8 ao total.

- Um painel com as CPUs de controle locado próximo à sala de controle.

- Um painel elétrico de distribuição de energia locado próximo ao centro de cargas elétricas.

- Sistema de coordenadas do tanque em acordo com a regra da mão direita $(\mathrm{x}, \mathrm{y}, \mathrm{z})$ com o eixo $\mathrm{x}$ alinhado longitudinalmente ao prédio.

- Numeração única de flaps, motores, servo-drivers e sensores de ondas.

A Figura 4.1 ilustra as características do tanque usando tais premissas. Cada flap tem 0,36 metro de largura e, como existem cantos retos, dois flaps são bloqueados por canto. Estes flaps não têm mecanismo atuador, mas apresentam sensores de ondas em um deles (veja na Figura 4.1). Optou-se por bloquear dois flaps das laterais 2 e 4 para que as laterais 1 e 3 ficassem completas e, assim, pudessem atuar como um canal de ondas, evitando a difração de ondas nos cantos quando fossem geradas ondas entre as laterais 1 e 3 .

O sistema de referências do tanque pode ser visto na Figura 4.2. Existem dois referenciais: um fixo no modelo e outro fixo no tanque (vistos na Figura 4.1 e na Figura 
4.2). As ondas também seguem esta regra, usada nas definições dos algoritmos de geração de ondas desenvolvidos no trabalho.

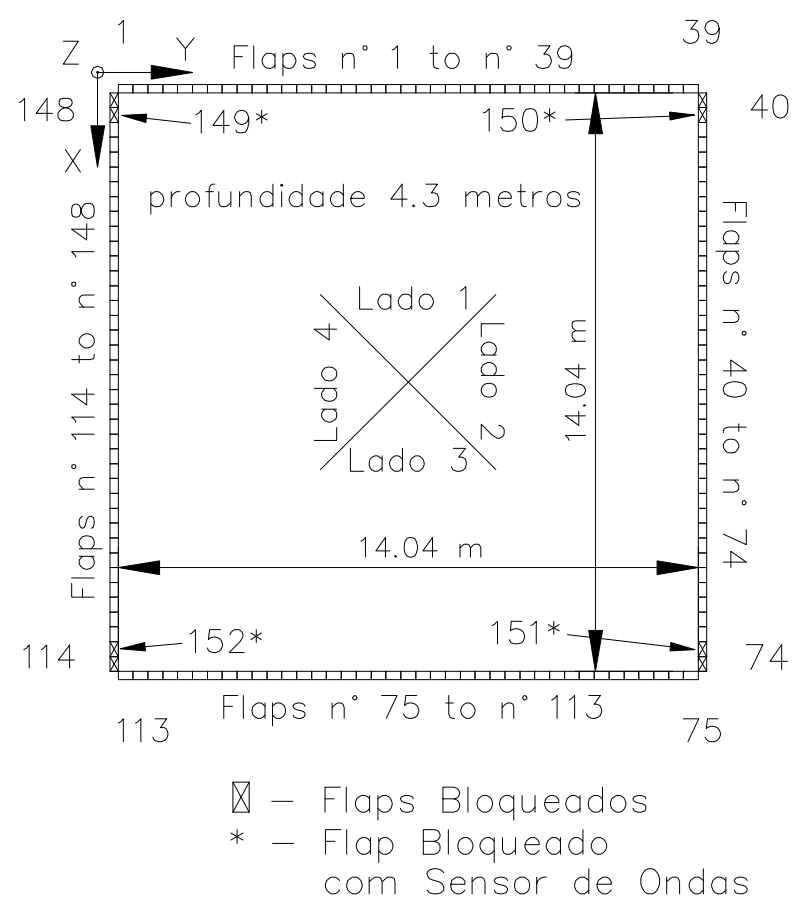

Figura 4.1. Definições de coordenadas e características do tanque.

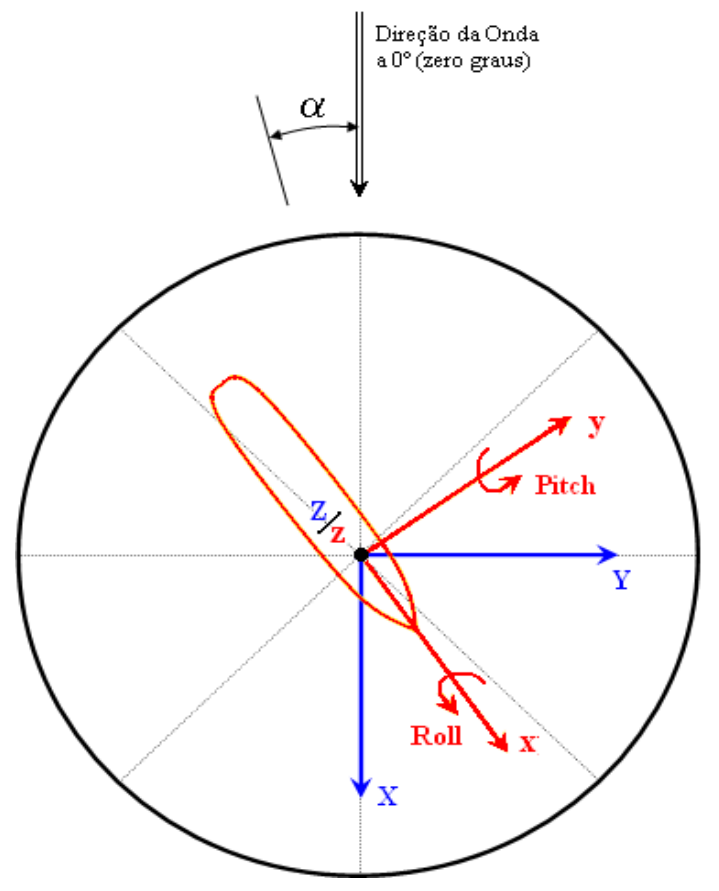

Figura 4.2. Sistema de coordenadas para modelos em teste. 


\subsection{Sistema elétrico}

O sistema elétrico utilizado é composto por equipamentos diversos integrados de forma a operar em conjunto. Foram montadas placas de circuitos de condicionamento de sinais, para o medidor de altura de ondas ultrassônico, específicas para o projeto do tanque, assunto do próximo tópico. Foram adquiridos, a partir de uma detalhada especificação, equipamentos de automação industrial, montados e programados para automatizarem o sistema. O controle destes equipamentos é tratado no tópico 4.4.

Para que a integração do sistema não fosse afetada por ruídos eletromagnéticos, foi feito um estudo destes efeitos. Utilizando-se blindagem elétrica, isolação galvânica, acoplamentos ópticos e alocação correta da posição dos equipamentos, o ruído se torna pouco influente. As medidas adotadas são listadas na Tabela 4.1 abaixo:

Tabela 4.1. Medidas adotadas para evitar ruídos eletromagnéticos.

\begin{tabular}{|c|c|c|c|c|}
\hline 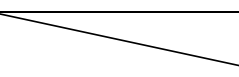 & $\begin{array}{c}\text { Circuito dos } \\
\text { medidores de ondas }\end{array}$ & Cabos elétricos & Eletrocalhas & Servo-drivers \\
\hline Medidas adotadas & $\begin{array}{l}\text { - Isolação galvânica da } \\
\text { fonte de alimentação. } \\
\text { - Opto acopladores } \\
\text { nos sinal de controle } \\
\text { e saídas analógicas. } \\
\text { - Acondicionamento } \\
\text { em caixas metálicas } \\
\text { aterradas. } \\
\text { - Montagem próximo } \\
\text { ao tanque para evitar } \\
\text { ruídos } \\
\text { eletromagnéticos. }\end{array}$ & $\begin{array}{l}\text { - Cabos de sinais } \\
\text { separados de cabos } \\
\text { de alimentação. } \\
\text { - Cabos blindados para } \\
\text { motores e sinais } \\
\text { analógicos. } \\
\text { - Aterramento } \\
\text { individual das } \\
\text { blindagens dos } \\
\text { cabos. }\end{array}$ & $\begin{array}{l}\text { - Eletrocalhas } \\
\text { metálicas de boa } \\
\text { qualidade com tampa } \\
\text { de acabamento. } \\
\text { - Dois conjuntos: um } \\
\text { para passagem de } \\
\text { cabos de potência e } \\
\text { outro para cabos de } \\
\text { sinais analógicos e } \\
\text { de controle. } \\
\text { - Cabo de aterramento } \\
\text { passando por todas } \\
\text { as eletrocalhas } \\
\text { ligadas a hastes de } \\
\text { terra para aterrar } \\
\text { todo o sistema do } \\
\text { gerador de ondas. }\end{array}$ & $\begin{array}{l}\text { - Montados em painéis } \\
\text { metálicos. } \\
\text { - Usam aterramento } \\
\text { individual. } \\
\text { - Placa de montagem } \\
\text { galvanizada para } \\
\text { manter contato com a } \\
\text { carcaça dos servo- } \\
\text { drivers e demais } \\
\text { equipamentos. } \\
\text { - Filtros supressores } \\
\text { de RF e IEM foram } \\
\text { usados para filtrar a } \\
\text { alimentação dos } \\
\text { mesmos. } \\
\text { - Sinais elétricos } \\
\text { acoplados por relés } \\
\text { de interface. }\end{array}$ \\
\hline & Motores & CPUs de comando & Sinais de comando & Sinais analógicos \\
\hline Medidas adotadas & $\begin{array}{l}\text { - Aterramento } \\
\text { individual ligado } \\
\text { entre motor e servo- } \\
\text { driver. } \\
\text { - Uso de cabos de } \\
\text { encoder com } \\
\text { comunicação } \\
\text { redundante. }\end{array}$ & $\begin{array}{l}\text { - Aterramento } \\
\text { individual e } \\
\text { centralizado. } \\
\text { - Placa de montagem } \\
\text { galvanizada para } \\
\text { manter contato com a } \\
\text { carcaça das CPUs. } \\
\text { - Fontes de } \\
\text { alimentação } \\
\text { individuais por tipo } \\
\text { de serviço. } \\
\text { - Sinais elétricos } \\
\text { acoplados por relés } \\
\text { de interface. } \\
\text { - Uso de isolação } \\
\text { galvânica. }\end{array}$ & $\begin{array}{l}\text { - Acoplados por relés } \\
\text { e fontes de } \\
\text { alimentação } \\
\text { setorizadas. } \\
\text { - Preferência por uso } \\
\text { de redes de } \\
\text { comunicação com } \\
\text { cabos ópticos. }\end{array}$ & $\begin{array}{l}\text { - Aterramento } \\
\text { individual e } \\
\text { centralizado. } \\
\text { - Acoplados por opto } \\
\text { acopladores. } \\
\text { - Fontes de } \\
\text { alimentação } \\
\text { individuais. }\end{array}$ \\
\hline
\end{tabular}


Conforme foi mencionado anteriormente, o sistema é dividido em 10 painéis elétricos. Cada painel acomoda um tipo de equipamento. Outras 32 caixas metálicas contêm os circuitos condicionadores de sinais dos medidores de ondas. Elas devem estar perto da borda do tanque para que fiquem o mais próximo possível dos transdutores de ultrassom, suscetíveis a ruídos eletromagnéticos. Foram divididas em grupos de 5 flaps para que acompanhassem o agrupamento dos acionadores mecânicos. Os medidores podem ser vistos na Figura 4.25. A Figura 4.3 ilustra a distribuição dos flaps referenciando sensores e CPUs de controle de motores. Estas são mostradas no tópico 4.2.3.

LADO 3

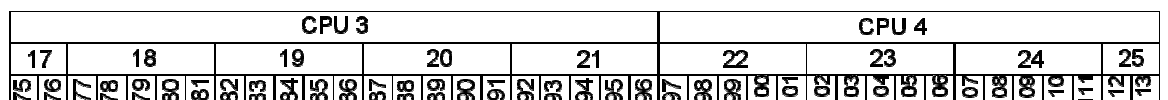

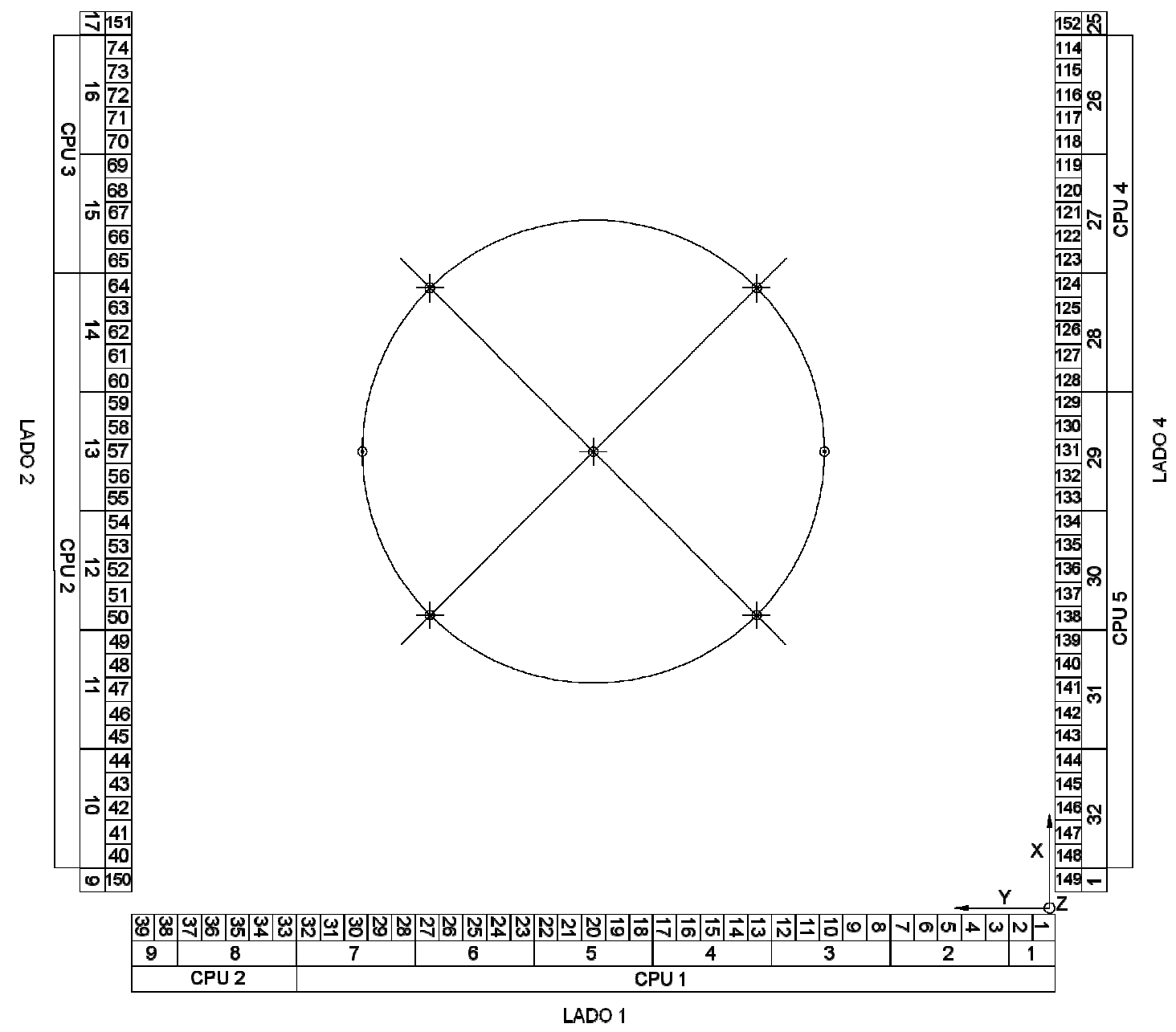

Figura 4.3. Numeração dos flaps (interna), as caixas de sensores (centro) e CPUs (externa). 
Foi definido que em cada lateral do tanque e na sala de controle houvesse um botão de emergência que desliga todos os motores manualmente por usuários do tanque. Foi também instalada uma sinaleira com luz piscante e cigarra sonora para indicar a operação do gerador de ondas. A Figura 4.4 mostra a localização dos painéis elétricos no andar térreo do prédio, bem como os botões de emergência e o poste de sinalização de operação no andar superior, onde se encontra o tanque de provas.

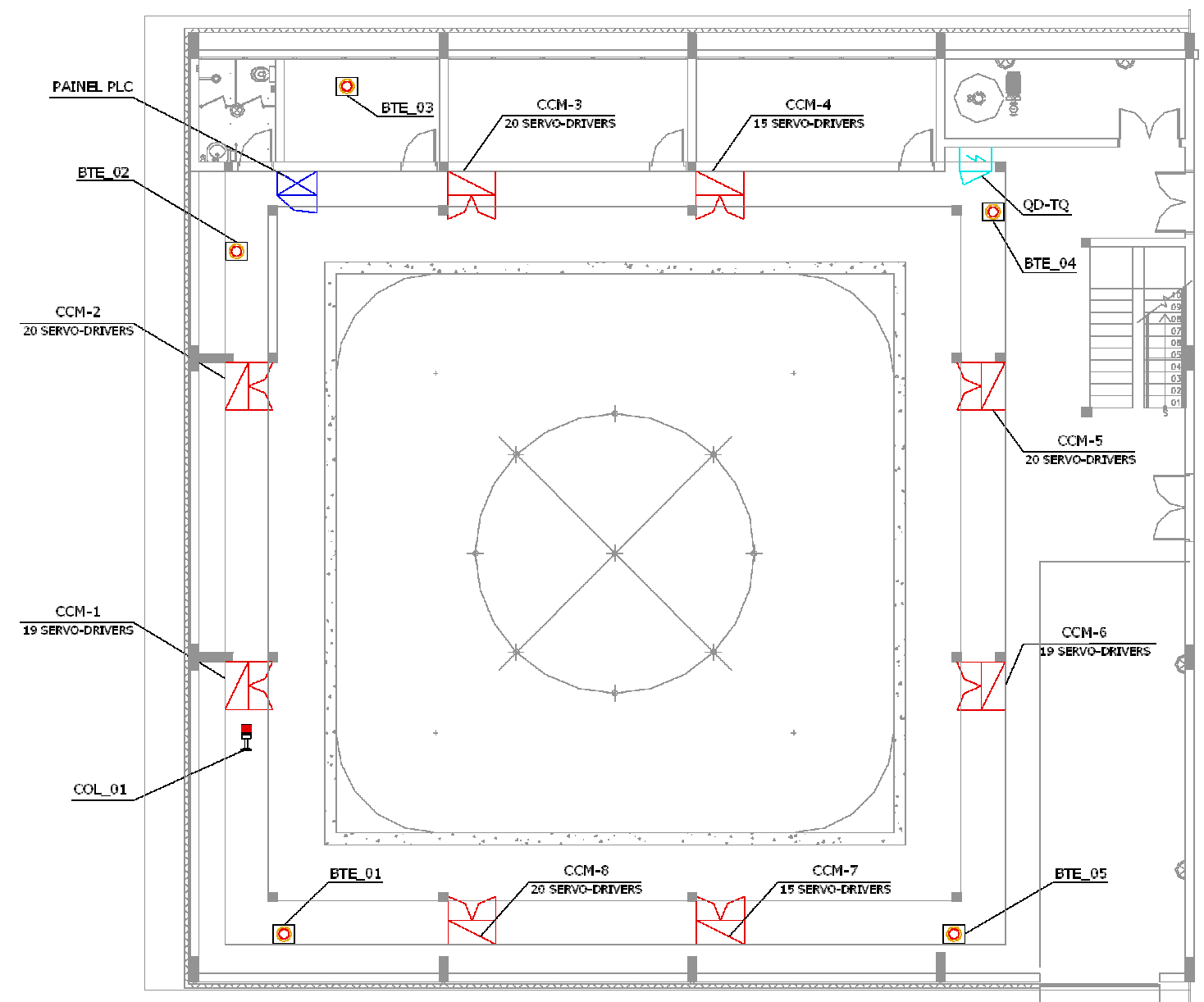

Figura 4.4. Localização dos principais equipamentos elétricos no tanque de ondas.

\subsubsection{Painel de distribuição de energia}

O painel de alimentação do gerador de ondas distribui a energia elétrica ao sistema. Ele é composto por um disjuntor geral, disjuntores de alimentação dos circuitos alimentadores de cada painel de controle de motores (CCM) e circuito alimentador do painel de CPUs de controle. O painel possui uma proteção contra descargas atmosféricas e de linha de alimentação a varistor para proteger o sistema elétrico. A 
potência total instalada é composta primordialmente por acionamento eletromecânico. Desta forma, a potência total pode ser obtida através do consumo dos servo-drivers de acionamento. Cada servo-driver tem $750 \mathrm{~W}(\approx 1 \mathrm{CV})$, considerando alimentação trifásica e reserva para $300 \%$ do torque nominal; segundo manual de operação (MITSUBISHI, 2007), a potência elétrica aparente de alimentação é de 1,3KVA. Assim a potência total instalada é aproximadamente:

$P_{t} \approx \sqrt{3} \cdot V_{L} \cdot I_{L}=\sqrt{3} \cdot 220 \mathrm{~V} \cdot(148 \cdot 3,4)=191 \mathrm{KVA}$

A demanda do sistema é bem difícil de mensurar pelo fato de que o consumo varia muito em função do tipo de aplicação. O máximo consumo só ocorreria com todos os motores a plena carga a todo instante. No caso do gerador de ondas, nem todos os motores estão em torque máximo a todo instante, existindo duas circunstâncias possíveis. Na primeira, uma lateral está gerando ondas e a outra absorvendo, enquanto as outras duas estão paradas. Na segunda circunstância, duas laterais geram ondas para serem absorvidas nas outras duas. Neste caso, o movimento dos flaps é feito para gerar ondas em ângulo, o chamado snake. Como o movimento é defasado entre eles, dependendo do comprimento de ondas, há uma variação em torno de um certo valor médio. Assim, a demanda para condições de geração máxima deve ser de no mínimo 0,5 até o valor nominal de projeto (eq. 4.1). Mas é claro que, em se tratando de ondas normais de ensaios, estes valores em geral não são atingidos. Optou-se, portanto, por usar a potência instalada para dimensionamento como precaução para uma operação segura. A Figura 4.5 ilustra o painel de distribuição de energia. 


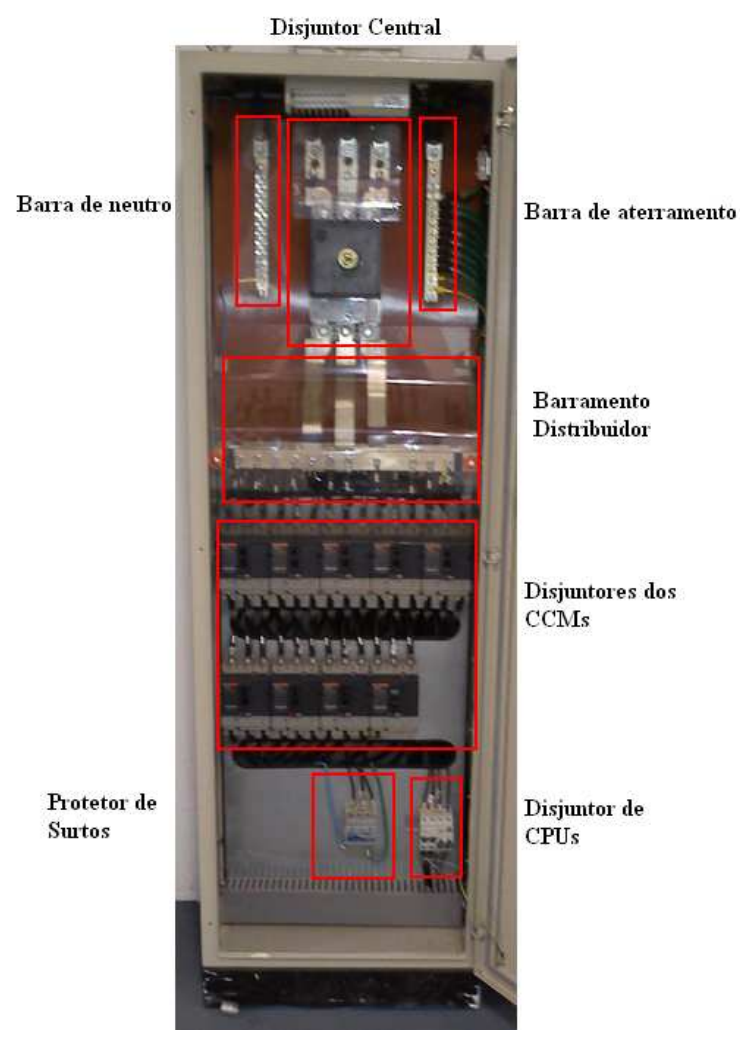

Figura 4.5. Painel de distribuição.

\subsubsection{Painéis de controle de motores}

Os painéis de controle de motores, ou CCM, têm espaço para colocação de 20 servo-drivers cada. Cada lateral do tanque tem 39 flaps nos lados ímpares e 35 flaps nos lados pares; assim, alguns painéis têm espaços vazios. Na lateral do tanque um dos painéis tem 20 servo-drivers e o outro tem 15 (lados pares) ou 19 (lados ímpares) servodrivers. Eles têm recursos, conforme mencionado na Tabela 4.1, para evitar ruídos elétricos e interfaces de comunicação simplificadas. Recebem alimentação trifásica em 220vac e possuem comunicação óptica de controle que percorre os servo-drivers em grupos de 16 por cabo óptico em rede token-ring. Recebem também dois comandos de controle da alimentação elétrica de potência, com interface a relé, vindos das CPUs de controle. Os detalhes do controle via rede de comunicação são abordados no tópico 4.4 e a Figura 4.6 mostra o interior dos painéis de controle de motores.

A proteção contra IEM (interferências eletromagnéticas) e de IRF (interferências de rádio frequência) é feita por filtros supressores instalados na alimentação trifásica em 
grupos de 10 servo-drivers. Eles evitam que ruídos de chaveamento dos servo-drivers interfiram na rede de alimentação fora dos painéis. Estas apresentam filtragem de modo comum entre fases e modo assimétrico entre fases, além de bloquear RF induzida e conduzida entre a entrada e a saída.

Os servo-drivers receberam proteção individual por disjuntores contra curtocircuito interno. No caso de problemas de curto-circuito ou sobrecargas nos motores dos servo-drivers, através de relés de interfaces, é acionado o sistema de proteção que desliga a alimentação de potência do painel em grupos de 10 servo-drivers. Estes alarmes são visualizados através do sistema de controle, que pode então providenciar o rearme ou indicar onde é necessário se fazer manutenção. A proteção interna do servodriver também atua caso o curso dos mecanismos exceda o valor máximo de deslocamento, usando chaves de final de curso dos dois limites mecânicos. As chaves de final de curso são magnéticas por proximidade com lógica NF (normalmente fechadas) e NPN (saída em coletor aberto drenando a terra). Elas estão localizadas do mecanismo de atuação dos flaps para detectar o bloco mecânico da castanha do fuso de esferas (veja os mecanismos no tópico 4.5). No conector de I/O (CN3) dos servodrivers, mostrado na Figura 4.8, os sinais das chaves de limite liberam a operação (pinos 2 e 12). O pino 15 indica alarmes internos do servo-driver que desligam a alimentação dos grupos de servo-drivers. A lógica usada de entrada e saída é normalmente fechada, pois caso algum sinal não esteja presente, a operação é interrompida. Normalmente, em casos de problemas de operação, existem fios soltos ou mal conectados.

A proteção atua com lógica E mostrada na Figura 4.9. É necessário que esteja presente o sinal externo no relé RL2, o disjuntor Q esteja acionado e os servos sem alarme, através dos relés KA, para que manualmente pela botoeira do painel (B2 e B4) ou pelo relé RL1 a alimentação seja acionada pelo contator KM. A manutenção da alimentação é feita pelo contato de selo de KM. A interrupção ocorre por qualquer estado anormal destes dispositivos. Outra botoeira serve para desarme manual no painel (B1 e B3). 


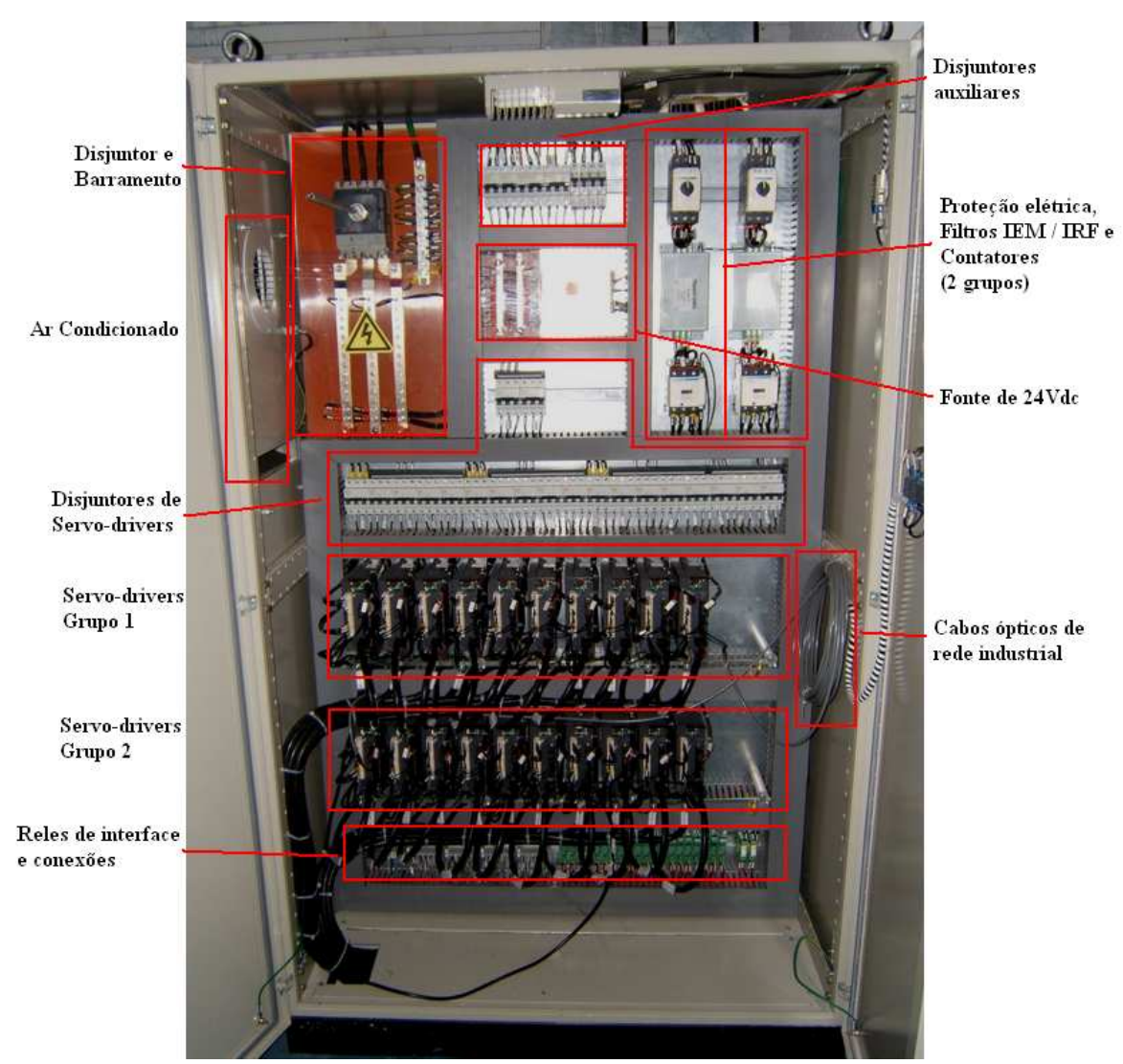

Figura 4.6. Painel de controle de motores (CCM).

A Figura 4.7 mostra por onde caminham os sinais externos aos painéis. A cor verde indica que os cabos passam pela eletrocalha de sinais e a cor vermelha indica que passam pela eletrocalha de cabos de potência.

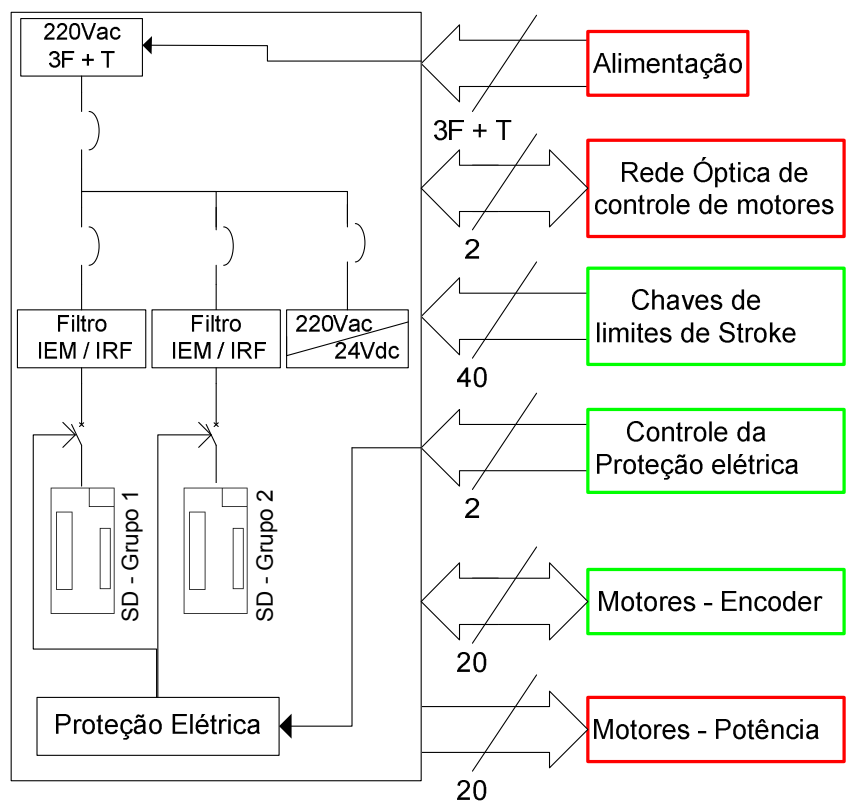

Figura 4.7. Esquema funcional do CCM. 


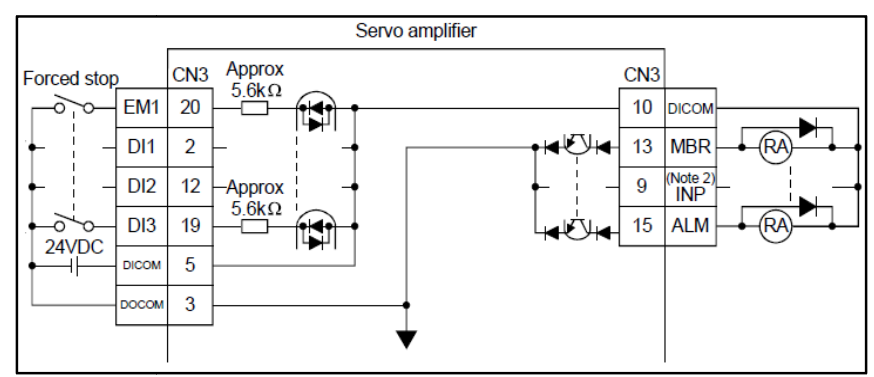

Figura 4.8. Conector de I/O do servo-driver.

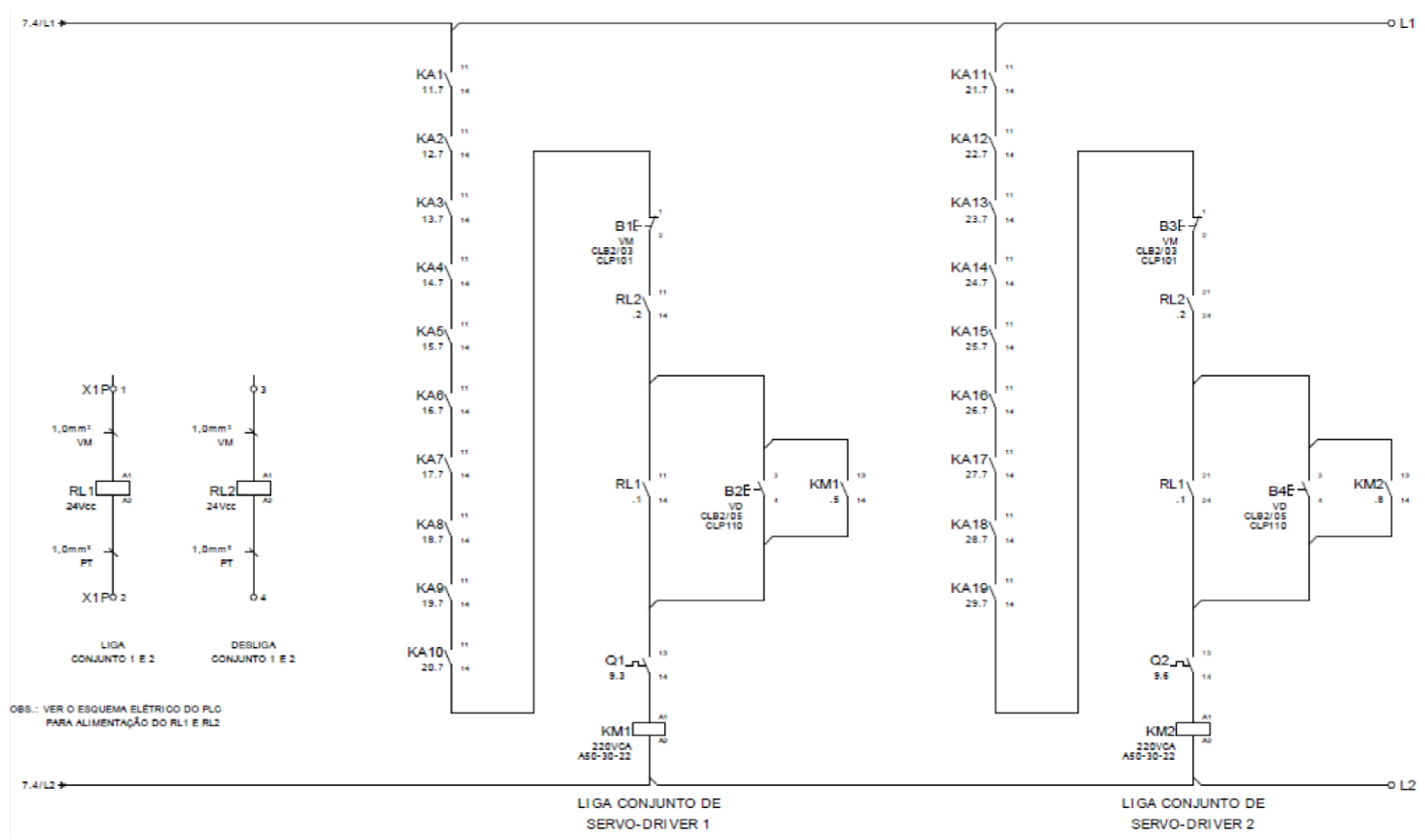

Figura 4.9. Diagrama de atuação da proteção elétrica dos servo-drivers.

\subsubsection{Painel de CPUs de controle}

O painel de CPUs centraliza o controle do gerador de ondas. Nele estão dispostos três CLPs (controlador lógico programável) que controlam os motores e fazem a leitura dos sensores de ondas ultrassônicos de flaps. As CPUs são modulares, de forma que é possível montar com os cartões de diversas funções uma solução de automação de acordo com as necessidades. A Figura 4.10 mostra este painel.

O CLP $\mathrm{n}^{\circ} 1$ é composto de uma CPU de controle programada em linguagem Ladder que controla outras três CPUs (em cartões) controladoras de motores e que são programadas em linguagem SFC (Sequential Function Chart). Cada CPU de controle de motores, através de rede industrial óptica token-ring em anel, se conecta a 32 servo- 
drivers. Toda a operação e o controle dos servo-drivers são feitos pela CPU. Portanto, o CLP $\mathrm{n}^{\circ} 1$ controla 96 flaps. O CLP $\mathrm{n}^{\circ} 2$ é semelhante ao primeiro e aciona os 52 eixos restantes usando duas CPUs de controle de motores, uma com 32 flaps e a outra com 20 flaps. O agrupamento destas pode ser visto na Figura 4.3.

O CLP no 3 é responsável pela leitura dos sensores de ondas ultrassônicos e por executar tarefas auxiliares. A leitura dos sensores é feita por corrente analógica no padrão 4 a 20 mA. Cada cartão de leitura tem 8 canais analógicos, optoacoplados em relação ao terra elétrico; este recurso evita interferências eletromagnéticas. No total, são 19 cartões para coletar os 152 sensores de ondas. Maiores detalhes sobre a transmissão de sinais dos sensores são apresentados no tópico 4.3.1.4. Quatro saídas de comando, uma para cada lateral do tanque, acionam os circuitos medidores de ondas instalados nos flaps, mostrados na Figura 4.25. Outras tarefas auxiliares são executadas pelo CLP número 3, tais como ligar a sinaleira de indicação de operação (luz piscante), a cigarra sonora e fazer a coordenação de proteção dos painéis de servo-drivers. Foram montadas em campo cinco botoeiras de emergência (Figura 4.4) que, quando acionadas, desligam todos os motores do gerador de ondas através das entradas de emergência localizadas nas CPUs de controle de motores.

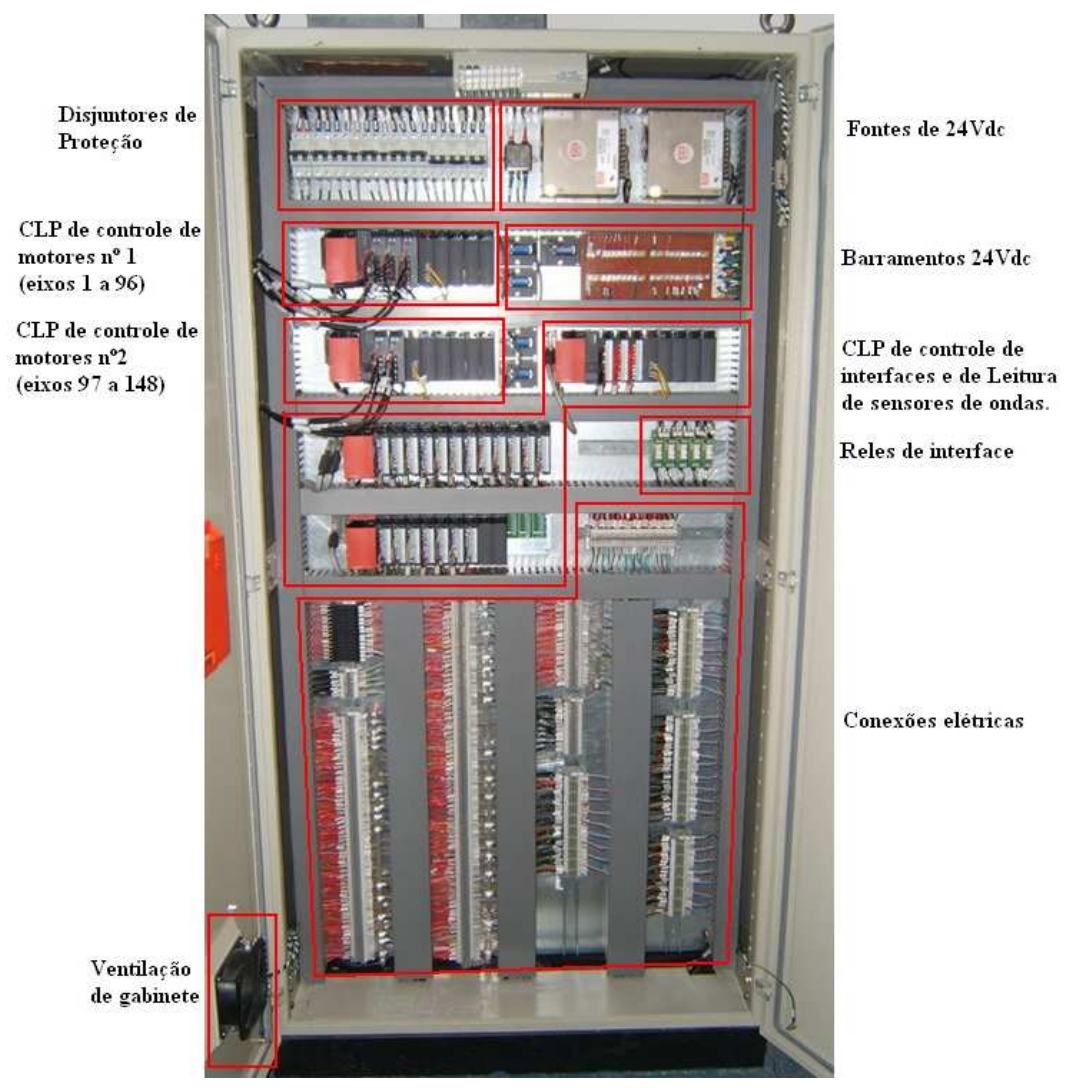

Figura 4.10. Painel de CPUs de controle. 
Todos os dados que são transmitidos no sistema passam por uma rede industrial que interconecta os CLPs ao PC (computador pessoal) de operação. Cada CLP tem um cartão de rede e o PC possui uma placa de barramento PCI; todos estão interligados com cabos ópticos a uma taxa de transmissão de $1 \mathrm{~GB}$ por segundo. A rede é redundante com dois sentidos de comunicação em forma de anel duplo e é do tipo token-ring. Esta rede é o ponto principal do sistema, pois é através dela que o controle em tempo real de execução é feito. O funcionamento da automação é descrito em detalhes no tópico 4.4.

O painel de CPU centraliza a alimentação dos medidores de ondas ultrassônicos, feita em 220vac, e, como já foi mencionado, o controle de acionamento dos mesmos. A alimentação das interfaces analógicas em corrente 4 a $20 \mathrm{~mA}$ dos sensores é feita por uma fonte de alimentação $24 \mathrm{vdc}$ localizada no painel. Outra fonte de alimentação de $24 \mathrm{vdc}$ serve de alimentação às interfaces. Ela alimenta o acionamento do controle de potência dos painéis de servo-drivers, o acionamento dos circuitos dos sensores de ondas, a sinaleira (sonora e visual) e os botões de emergência.

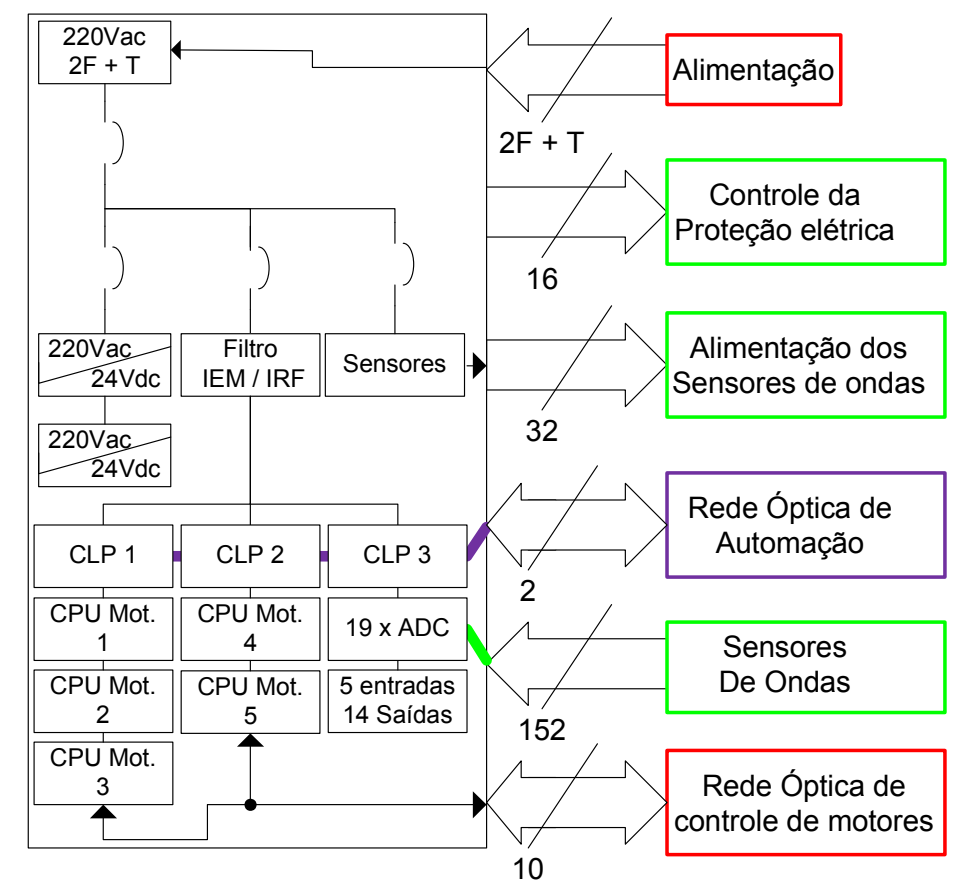

Figura 4.11. Esquema funcional do painel de CPU.

O diagrama da Figura 4.11 mostra as ligações externas do painel de CPU. Os cabos na cor vermelha seguem pela eletrocalha de potência e os cabos na cor verde seguem pela eletrocalha de sinais. Já os cabos ópticos, em azul escuro, seguem para o 
computador de operação na sala de controle do tanque de provas. A Tabela 4.2 mostra o resumo dos sinais manipulados pelo CLP $\mathrm{n}^{\mathrm{o}} 3$ que podem ser controlados na execução de programas de automação do tanque.

Tabela 4.2. Resumo das entradas e saídas usadas no CLP n 3 .

\begin{tabular}{|l|l|l|l|l|}
\hline \multirow{5}{*}{ Entrada } & Nome & End. físico & End. lógico & Descrição \\
\hline \multirow{5}{*}{ Saída } & BTE_01 & Slot 0 TB01 & X01 & Botoeira emer. 01 \\
\cline { 2 - 4 } & BTE_02 & Slot 0 TB02 & X02 & Botoeira emer. 02 \\
\cline { 2 - 4 } & BTE_03 & Slot 0 TB03 & X03 & Botoeira emer. 03 \\
\cline { 2 - 4 } & BTE_04 & Slot 0 TB04 & X04 & Botoeira emer. 04 \\
\cline { 2 - 4 } & BTE_05 & Slot 0 TB05 & X05 & Botoeira emer. 05 \\
\hline & Liga CCM01 e CCM02 & Slot 1 TB01 & Y10 & Liga potência lado 1 \\
\cline { 2 - 4 } & Desliga CCM01 e CCM02 & Slot 1 TB03 & Y11 & Desliga potência lado 1 \\
\cline { 2 - 4 } & Liga CCM03 e CCM04 & Slot 1 TB05 & Y12 & Liga potência lado 2 \\
\cline { 2 - 4 } & Desliga CCM03 e CCM04 & Slot 1 TB07 & Y13 & Desliga potência lado 2 \\
\cline { 2 - 4 } & Liga CCM05 e CCM06 & Slot 1 TB09 & Y14 & Liga potência lado 3 \\
\cline { 2 - 4 } & Desliga CCM05 e CCM06 & Slot 1 TB11 & Y15 & Desliga potência lado 3 \\
\cline { 2 - 4 } & Liga CCM07 e CCM08 & Slot 1 TB13 & Y16 & Liga potência lado 4 \\
\cline { 2 - 4 } & Desliga CCM07 e CCM08 & Slot 1 TB15 & Y17 & Desliga potência lado 4 \\
\cline { 2 - 4 } & Hab. Caixas 1 a 9 & Slot 2 TB01 & Y20 & Liga sensores lado 1 \\
\cline { 2 - 4 } & Hab. Caixas 10 a 16 & Slot 2 TB03 & Y21 & Liga sensores lado 2 \\
\cline { 2 - 4 } & Hab. Caixas 17 a 25 & Slot 2 TB05 & Y22 & Liga sensores lado 3 \\
\cline { 2 - 4 } & Hab. Caixas 26 a 32 & Slot 2 TB07 & Y23 & Liga sensores lado 4 \\
\cline { 2 - 4 } & Flash-light & Slot 2 TB09 & Y24 & Liga Flash-light \\
\cline { 2 - 4 } & Sirene & Slot 2 TB11 & Y25 & Liga Sirene \\
\hline
\end{tabular}

\subsection{Sensoriamento de altura de ondas por ultrassom}

Baseada na experiência do Laboratório de Sensores e Atuadores do Departamento de Engenharia Mecatrônica e Sistemas Mecânicos da EPUSP, foi desenvolvida uma nova versão de medidor de altura de ondas por ultrassom. Apresentada pela primeira vez em Carneiro (2007), foi desenvolvida como opção para a realimentação da malha de controle de absorção em um gerador de ondas. Os sensores ficam instalados nos flaps do gerador de ondas, medindo a altura da coluna de água.

Existem vários outros tipos de medidores de ondas utilizados em tanques e canais de ensaios. Os dois tipos mais comuns são os medidores por resistividade (condutividade) e por capacitância. Nos dois casos, existem fios paralelos que servem de haste de medição da resistência elétrica ou da capacitância em função do nível de água imerso. O sensor capacitivo tem um revestimento dielétrico nos fios, diferentemente do resistivo; funciona por contato direto com a água. Ambos apresentam problemas de variação de ganho e deriva de offset em função de mudanças físicoquímicas da água e da temperatura de operação tanto do condicionador de sinais quanto da água. Outro problema que ocorre com os dois tipos de sensores é a histerese causada 
pela tensão superficial da água em torno dos fios. Pode ser vista em Wilner (1960) uma análise destes problemas envolvendo sensores capacitivos. Problemas eletrônicos também ocorrem com os dois tipos de sensores, tais como interferência, leitura cruzada (cross-talk) entre canais e ruídos eletromagnéticos. Por conta disso, eles precisam de isolação galvânica entre os sensores e o restante do sistema elétrico.

O sensor de ondas por ultrassom apresenta diversas vantagens se comparado aos sensores resistivos e capacitivos. A adoção do sensor ultrassônico no gerador de ondas do Calibrador Hidrodinâmico deve-se ao fato de ele não precisar de ajustes e calibrações frequentes, além de possuir boa resolução e boa imunidade elétrica. Uma vez que ele esteja montado nos flaps do gerador de ondas, é necessário saber apenas a velocidade de propagação do som na água para calcular a leitura da coluna líquida. Para tanto, mede-se a temperatura da água, que não apresenta grandes variações ao longo de horas e até mesmo dias, e calcula-se a velocidade de propagação acústica.

O trabalho de Martins et al (2007) mostra um levantamento dos tipos de sensores testados no laboratório acadêmico da Engenharia Naval da EPUSP e dá maiores detalhes sobre as características e os problemas destes sensores. Um breve comparativo entre os tipos de sensores pode ser visto na Tabela 4.3 abaixo.

Tabela 4.3. Características dos sensores de ondas do tipo capacitivo, resistivo e ultrassônico.

\begin{tabular}{|c|c|c|c|}
\hline $\begin{array}{l}\text { Tipo de } \\
\text { sensor }\end{array}$ & $\begin{array}{l}\text { Princípio de } \\
\text { funcionamento }\end{array}$ & Prós & Contra \\
\hline Capacitivo & $\begin{array}{l}\text { Capacitância elétrica entre } \\
\text { duas hastes revestidas e } \\
\text { imersas na água. }\end{array}$ & $\begin{array}{l}\text { Escala de medição } \\
\text { continua. } \\
\text { Fácil montagem. } \\
\text { Fácil conexão ao sistema de } \\
\text { aquisição de dados. }\end{array}$ & $\begin{array}{l}\text { Necessita isolação galvânica. } \\
\text { Precisam de calibração para o uso. } \\
\text { Sofrem com histerese por tensão } \\
\text { superficial da água. } \\
\text { Sujeira que adere nas hastes provoca } \\
\text { erro de medição. }\end{array}$ \\
\hline Resistivo & $\begin{array}{l}\text { Resistência elétrica entre } \\
\text { duas hastes imersas na } \\
\text { água. }\end{array}$ & $\begin{array}{l}\text { Escala de medição } \\
\text { continua. } \\
\text { Fácil montagem. } \\
\text { Fácil conexão ao sistema de } \\
\text { aquisição de dados. }\end{array}$ & $\begin{array}{l}\text { Necessita isolação galvânica. } \\
\text { Precisam de calibração para o uso. } \\
\text { Sofrem com histerese por tensão } \\
\text { superficial da água. } \\
\text { Sujeira que adere nas hastes provoca } \\
\text { erro de medição. }\end{array}$ \\
\hline Ultrassônico & $\begin{array}{l}\text { Tempo de voo de pulso- } \\
\text { eco acústico dentro de } \\
\text { uma guia de ondas imersa } \\
\text { na água. }\end{array}$ & $\begin{array}{l}\text { Calibração simplificada; a } \\
\text { partir da velocidade de } \\
\text { propagação do som na } \\
\text { água. } \\
\text { Estável eletricamente e com } \\
\text { a característica físico- } \\
\text { química da água. }\end{array}$ & $\begin{array}{l}\text { Necessita uso de guia de ondas. } \\
\text { Sensível à desalinhamentos de } \\
\text { montagem. } \\
\text { Amplitude do eco é sensível à } \\
\text { propagação do som dentro da guia de } \\
\text { ondas. } \\
\text { Menisco da superfície da água pode } \\
\text { causar atenuação no eco acústico. } \\
\text { Sujeira e bolhas de ar dentro da guia de } \\
\text { ondas provocam atenuação acústica, } \\
\text { ocasionando perda de leitura ou leitura } \\
\text { falsa da linha de água. }\end{array}$ \\
\hline
\end{tabular}




\subsubsection{Sensor ultrassônico do Calibrador Hidrodinâmico}

O principal ganho no desenvolvimento do sensor de ondas para ser usado no Calibrador Hidrodinâmico, em comparação com outros modelos usados no Laboratório de Sensores e Atuadores, foi melhorar a precisão e fazer a integração ao sistema de aquisição do gerador de ondas. Para tanto, foi definido que a placa de circuito fosse composta por seis canais de aquisição e uma fonte de alimentação única. No entanto, são usados simultaneamente cinco canais, restando um como reserva, no caso de problemas com um deles. A fonte da placa de circuitos, a partir de um transformador $220 \mathrm{vac} / 24 \mathrm{vac}$, gera quatro saídas de alimentação. Uma tensão de 240vdc é usada para o circuito pulsador gerar pulsos no transdutor de ultrassom, a parte analógica usa tensão simétrica de $12 \mathrm{vdc}$ e a parte digital (microcontrolador) usa $5 \mathrm{vdc}$ como alimentação.

O sensor será apresentado em quatro partes distintas:

- Transdutor e guia de ondas.

- Pulsador, amplificador e comparador.

- Microcontrolador e software de tratamento de sinais.

- Saída analógica.

\subsubsection{Transdutor e guia de ondas}

Fisicamente, o sensor por ultrassom é composto de apenas três partes: transdutor, guia de ondas e circuito condicionador de sinais.

O transdutor de ultrassom converte os sinais elétricos em pressão mecânica e vice-

versa. É composto de uma cerâmica piezelétrica que tem a propriedade de converter campo elétrico em pressão mecânica e tem a sua espessura dimensionada para trabalhar em uma frequência de sintonia. Na parte de trás da cerâmica fica a retaguarda ou backing, que serve de camada de absorção acústica. Na frente da cerâmica fica a camada de casamento de impedância acústica ou matching, cuja função é melhor transferir a pressão acústica entre a cerâmica e o meio; no caso, a água. Quanto mais banda larga for o transdutor, mais curto será o pulso que ele pode transmitir ou receber. Isso é importante, pois permite uma melhor resolução de recepção acústica. 
O sensor de ondas por ultrassom faz uso da técnica de pulso-eco para medir a altura da coluna líquida. Essa técnica consiste em medir o tempo de viagem que um pulso acústico de ultrassom demora a percorrer, entre a ida e a volta, a distância entre o transdutor e a linha de água. Segundo Carneiro (2007), a diferença entre as impedâncias acústicas de dois meios nos fornece o coeficiente de reflexão de uma onda de pressão acústica. Como a água e o ar têm impedâncias muito diferentes, a onda acústica reflete de volta o pulso quase totalmente, não transmitindo pressão para o ar. Considerando-se a massa específica da água a $20^{\circ} \mathrm{C}$ como $998,2 \mathrm{Kg} / \mathrm{m}^{3}$ e do ar como $1,204 \mathrm{Kg} / \mathrm{m}^{3}$ e as velocidades de propagação do som na água a $20^{\circ} \mathrm{C}$ como $1482,3 \mathrm{~m} / \mathrm{s}$ e no ar como $343,4 \mathrm{~m} / \mathrm{s}$, as impedâncias acústicas são:

$$
\begin{aligned}
& Z_{a g}=\rho_{\text {água }} \cdot c_{\text {água }}=1,48 \cdot 10^{6}(\mathrm{Kg} / \mathrm{m} \cdot \mathrm{s}) \\
& Z_{a r}=\rho_{a r} \cdot c_{a r}=413,45(\mathrm{Kg} / \mathrm{m} \cdot \mathrm{s})
\end{aligned}
$$

Portanto, o coeficiente de reflexão $R$ é:

$R=\frac{z_{a r}-Z_{a g}}{z_{a r}+Z_{a g}}=-0,999$

Pode-se notar que quase o total da pressão acústica retorna de volta. O sinal negativo indica que a fase entre o pulso incidente e o refletido é invertida.

O tempo que o pulso acústico leva para percorrer a distância entre a linha de água e o transdutor, entre ida e volta, pode ser obtido de forma simples por:

$t_{v}=\frac{2 \cdot d}{c}$

onde $d$ é a distância entre o transdutor e a linha de água e $c$ é a velocidade de propagação do som na água.

A técnica funciona bem quando a linha de água é estática e quando não há inclinação da frente de onda incidindo na interface água e ar. O pulso acústico retorna em linha reta ao transdutor. No caso do sensor de ondas, foi especificada uma guia de ondas acústica. Ela tem o papel de manter o pulso acústico em uma trajetória de retorno ao transdutor mesmo que a linha de água esteja inclinada. Segundo a lei de Snell que rege o fenômeno, a onda acústica vai ser refletiva para a direção simetricamente oposta à normal da superfície. Também se deve notar que o sensor é solidário ao flap, que se 
inclina, podendo ocorrer reflexão em ângulo mesmo que não existam ondas no tanque. A Figura 4.12 ilustra a guia de ondas acústica, mostrando o efeito da reflexão na interface água e ar.

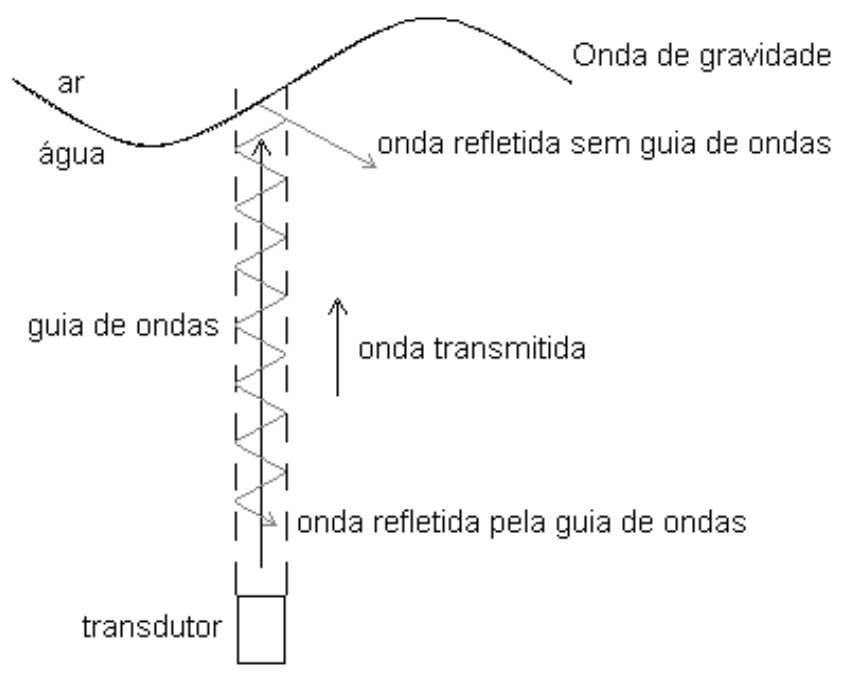

Figura 4.12. Guia de ondas acústica.

Para que a guia de ondas possa resolver o problema da reflexão em ângulos do pulso acústico, ela deve atender a requisitos hidrodinâmicos também. A água tem que poder entrar na guia de ondas com rapidez. Se ocorrer resistência à passagem da água, o nível de água dentro da guia será menor e terá um atraso em relação à face do flap, não representando o nível real da coluna líquida. Para resolver esse problema, foi especificada pela equipe envolvida no projeto uma parede frontal da guia de ondas com perfurações oblongas opostas nas bordas de forma intercalada, para evitar interrupções na continuidade da linha de água. Esta parede é coincidente com a face do flap. As outras faces da guia de ondas são lisas e ficam internas ao flap. Este formato de seção retangular foi testado em Carneiro (2007) e apresentou um bom desempenho em ensaios dinâmicos por excitação forçada da guia de ondas incidindo verticalmente na água. Apresentava dimensões de $10 \mathrm{~mm}$ de profundidade por $14 \mathrm{~mm}$ de largura das seções transversais e a distância entre transdutor e linha de água era de aproximadamente 275 mm. Foram testadas diversas frequências e amplitudes de excitação com bom desempenho dinâmico. Os resultados foram apresentados também em Martins (2007).

Para o Calibrador Hidrodinâmico foi especificada uma guia de ondas com dimensões transversais de aproximadamente $14 \mathrm{~mm}$, que era a largura externa do transdutor. O comprimento total da guia de ondas foi de $775 \mathrm{~mm}$. O transdutor foi especificado com frequência de ressonância de $2 \mathrm{MHz}$ no modo de espessura da 
cerâmica piezelétrica. A frequência adotada foi a mesma dos outros trabalhos relatados. O ideal seria que essa frequência fosse menor para uma boa propagação dentro da guia de ondas, mas a fabricação do transdutor seria prejudicada, pois teria de ter um diâmetro maior. Com o diâmetro maior do transdutor e da guia de ondas, a propagação seria pior. Dessa forma, em função do compromisso de projeto, a frequência foi fixada. A guia de ondas, assim, deve ser dimensionada para um bom funcionamento do sensor.

$\mathrm{Na}$ verdade, um estudo mais aprofundado deveria ser feito no projeto da guia de ondas. É apresentada a seguir uma breve explicação dos problemas enfrentados com a guia de ondas que foi utilizada até o momento no Calibrador Hidrodinâmico e que indica algumas maneiras de se melhorar o desempenho da mesma.

Originalmente apresentada em Carneiro (2007), a guia de ondas utiliza, entre outras referências, a teoria apresentada em Redwood (1963). Aplicou-se a teoria descrita em Redwood (1963) para a guia de ondas fabricada para o Calibrador Hidrodinâmico, que entre outros problemas observados não tinha as dimensões inicialmente previstas. A Figura 4.13 mostra a guia de ondas estudada. Ela apresenta comprimento de $775 \mathrm{~mm}$ com $16 \mathrm{~mm}$ de seção na profundidade e $14 \mathrm{~mm}$ de seção na largura. As paredes não são precisamente paralelas e tampouco planas. Apresentam variações dimensionais e de formato devido ao processo de fabricação. As perfurações oblongas têm as mesmas dimensões dos trabalhos anteriores. A chapa perfurada foi soldada na chapa dobrada, que forma as outras três paredes da guia de ondas, com desalinhamento, ocasionando assimetria entre as laterais.

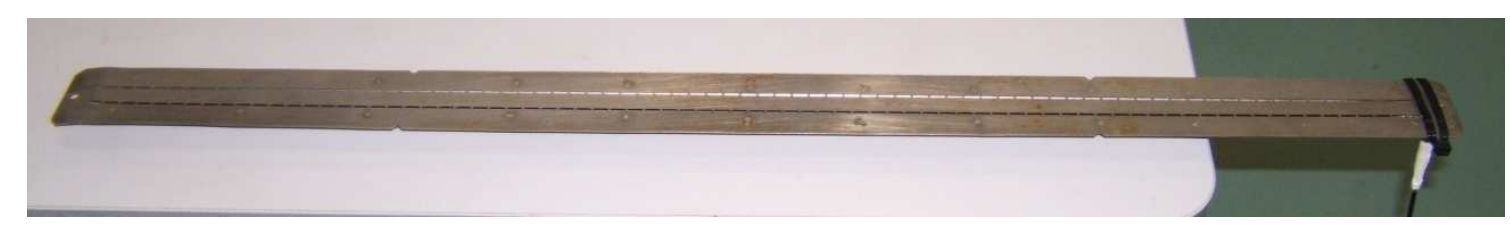

Figura 4.13. Guia de ondas e transdutor (à direita) inicialmente usado no Calibrador Hidrodinâmico.

As suas características foram analisadas para um melhor casamento com o projeto da eletrônica do condicionador de sinais. Usando a teoria apresentada em Redwood (1963), pode-se afirmar que, devido ao pequeno comprimento de onda em relação à dimensão das seções da guia de ondas, existirão muitos modos de propagação dentro da guia de ondas. Eles são excitados, pois quando ocorre a reflexão acústica na linha de água, mesmo com a onda incidente sendo homogênea e plana, devido ao complexo 
formato da interface, a reflexão não é um fenômeno de fácil entendimento. Existem vários fenômenos envolvidos.

A reflexão ocorre em ângulo por conta da inclinação da linha de água em ondas e também pelo ângulo que o flap pode adquirir. As perfurações para equalização do nível de água ao longo de toda a guia de ondas aumentam a atenuação acústica. A tensão superficial na interface água e ar cria uma superfície de reflexão irregular, modificando a frente de ondas refletidas. Ocorre também, assim como em sensores resistivos e capacitivos, histerese da subida e descida da água nas paredes da guia de ondas, neste caso, alterando a amplitude e a fase do eco de retorno acústico.

Segundo Redwood (1963), ao se utilizar onda acústica pulsada, que é o caso, ocorre dispersão em frequências por se tratar de velocidades de propagação de fase e de grupo diferentes. Por conta desse efeito, os modos de propagação interagindo criam zonas de interferências destrutivas e construtivas que podem atenuar a pressão acústica dependendo da posição dentro da guia de ondas. Portanto, trata-se de dois efeitos: interação entre modos de propagação de mesma frequência e dispersão em frequências.

De acordo com a teoria exposta em Redwood (1963), existe a propagação de uma onda plana, mas há também a propagação em ziguezague de ondas planas com diferentes modos de propagação proporcionais a meio comprimento de onda. A onda plana sem ângulo pode propagar sem limitação de frequência com velocidade de propagação semelhante a uma onda sem guia de ondas.

Segundo a teoria, para uma frequência de $2 \mathrm{MHz}$ com velocidades de propagação do som na água a $20^{\circ} \mathrm{C}$ como $1482,3 \mathrm{~m} / \mathrm{s}$, o comprimento de ondas é igual a $\lambda=0,741$ mm. O número de modos de propagação que existem na guia de ondas pode ser calculado através de:

$\cos \theta=m \cdot\left(\frac{\lambda}{2} \cdot D\right)$

onde $\theta$ é o ângulo de propagação dentro da guia de ondas, $m$ é um número inteiro e indica o modo de propagação, $\lambda$ é o comprimento de ondas e $D$ é a largura da guia de ondas. Aplicando-se ao modelo de guia adotada, com ângulo de corte $\theta=0^{\circ}$, portanto direção transversal à guia de ondas e nas duas medidas de seção, os modos possíveis de propagação são: 
$1=m \cdot\left(\frac{0,741 m m}{2} \cdot 16 m m\right) \rightarrow m=43$

$1=m \cdot\left(\frac{0,741 m m}{2} \cdot 14 m m\right) \rightarrow m=37$

Portanto, grosso modo, existem muitos modos de propagação. Por um lado é bom, pois permite a propagação com ângulos extremos; mas, por outro lado, a interação entre modos aumenta muito, ocasionando atenuações no eco de retorno. Cada modo tem uma velocidade de propagação específica de fase e de grupo.

Para entender e estabelecer uma definição para o projeto da eletrônica, a medida adotada foi montar uma guia de ondas e medir a atenuação acústica com a distância de água imersa. A guia usada foi mostrada na Figura 4.13. O transdutor foi encaixado na extremidade da guia de ondas e o conjunto colocado em um tubo de PVC para ser imerso em água. O transdutor foi alinhado para evitar propagação em ziguezague na onda transmitida. A altura imersa foi alterada para avaliar a atenuação na vertical e a $20^{\circ}$ de inclinação, com o primeiro eco sendo refletido na face com perfurações. A escolha da face perfurada visou reproduzir a pior situação de teste, comprovada por ensaios anteriores na guia de ondas curta, usada no protótipo do gerador de ondas. A Figura 4.14 mostra a montagem para teste de atenuação da amplitude do eco do ultrassom. A eletrônica que foi utilizada no teste estava sendo desenvolvida e será explicada na próxima seção do texto.
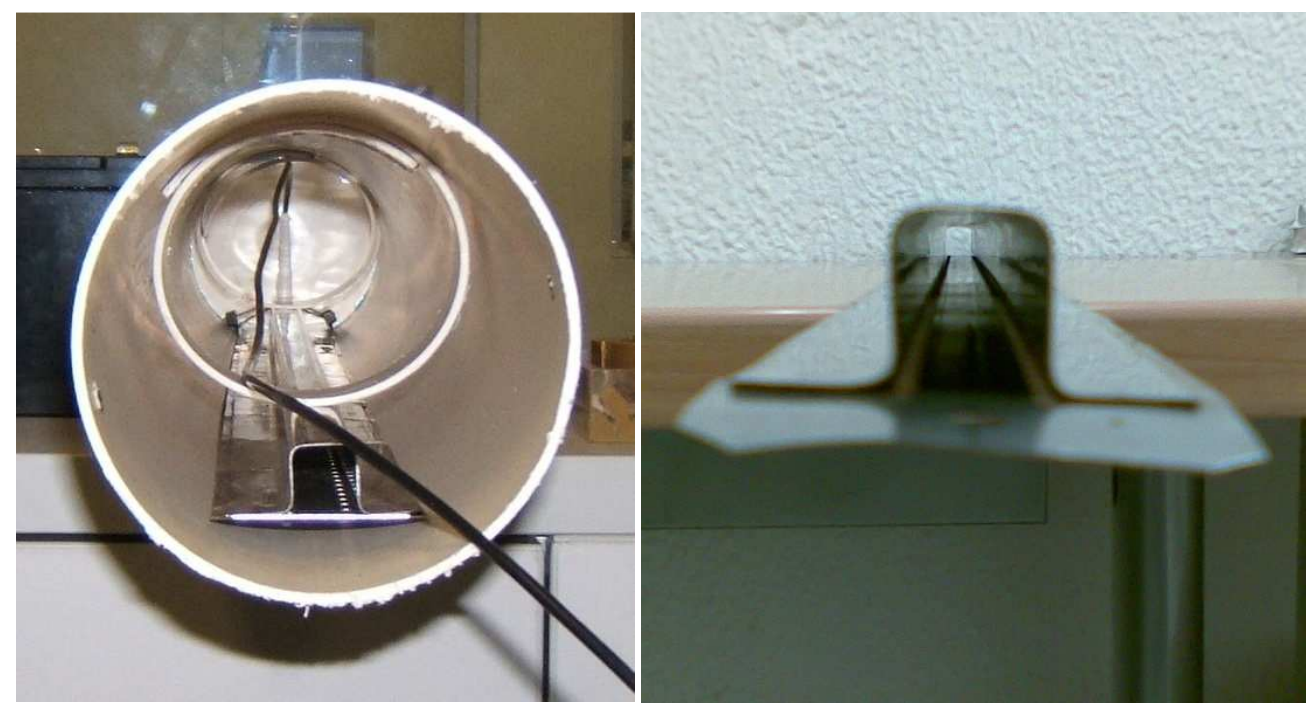

Figura 4.14. Montagem para testar a atenuação da guia de ondas e visão ampliada da guia de ondas testada, respectivamente. 
Durante o alinhamento do conjunto no tubo foi observado que existiam muitas modulações no formato do eco recebido. Dependendo do ângulo em que se colocava a guia de ondas, a amplitude era atenuada e pouco concentrada. Por conta desse efeito, foi comparado o resultado com o observado no protótipo do gerador de ondas, descrito por Carneiro (2007); foi realizado um ensaio de captura do sinal de eco, via sistema de aquisição de dados adquirindo a uma taxa de $5 \mathrm{MHz}$. Podem-se observar na Figura 4.15 quatro momentos diferentes da medição de uma onda regular de $0,5 \mathrm{~Hz}$ com aproximadamente $74 \mathrm{~mm}$ de altura na face do flap.

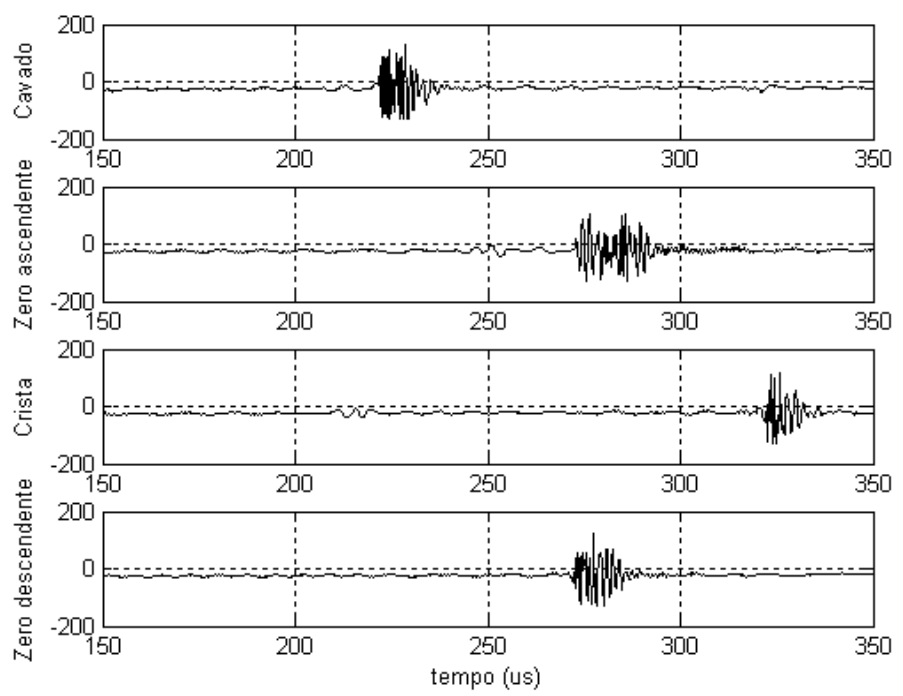

Figura 4.15. Eco recebido pelo sensor de ultrassom.

Observa-se que o eco tem um formato irregular e que muda a todo instante. No cavado da onda, a concentração é maior. No cruzamento por zero o eco é diferente entre subida e descida, pois, devido à tensão superficial, o menisco da água tem formato diferente. Assim como na inversão do movimento, também ocorre a inversão do menisco. O que importa para a medição de altura de ondas é o tempo de chegada da frente de ondas do eco, ou seja, a menor trajetória de retorno é também a altura da coluna líquida com maior precisão. Neste caso, ela pode ser alterada pelo fato de estas modulações ocorrerem com o eco.

No sensor testado, a tentativa foi alinhar o melhor possível o tubo de teste com a guia de ondas imersa, para se obter um eco concentrado e com melhor amplitude da frente de ondas. Com um correto alinhamento de transdutor à guia de ondas, procurouse evitar modos de propagação superiores. Em seguida, realizaram-se várias medições da amplitude do eco variando-se a coluna imersa com a guia de ondas na vertical e a $20^{\circ}$ 
de inclinação. O circuito pulsador, amplificador e detector de eco usado no teste foi a primeira versão da placa de circuitos que estava em desenvolvimento. A Figura 4.16 mostra os resultados obtidos no teste. Por comparação a atenuação acústica na água a 20 ${ }^{\circ} \mathrm{C}$ para frequência de $2 \mathrm{MHz}$ e 1 atm em propagação livre é mostrada. Segundo Kinsler et al. (2000), a atenuação pode ser calculada como:

$\alpha=25 \cdot 10^{-15} \cdot f^{2}[\mathrm{~Np} / \mathrm{m}]$

onde $\alpha$ é a atenuação em $N p / m$, em $d B / m$ é:

$\alpha_{d B}=8,7 \cdot \alpha[d B / m]$

Neste caso:

$\alpha_{d B}=0,87[d B / m]$

\section{Atenuação acústica - guia de ondas}
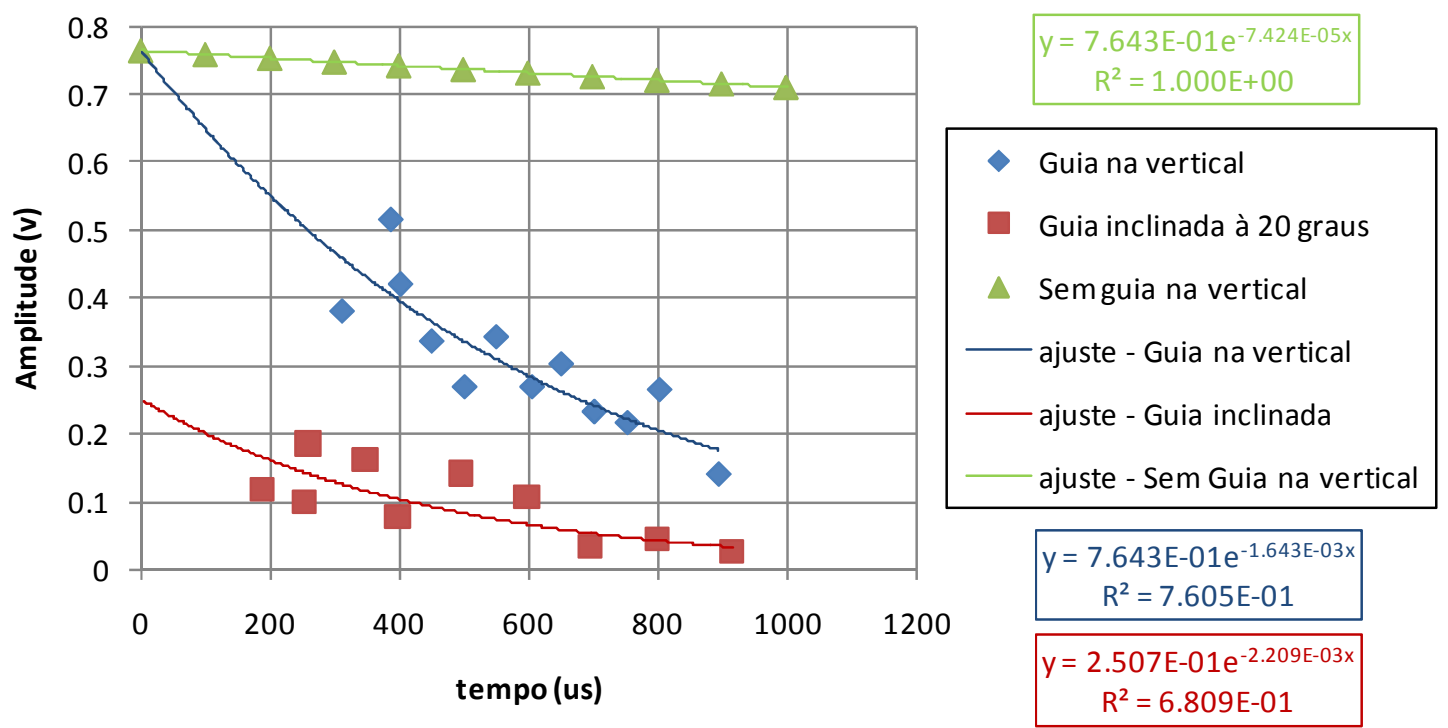

Figura 4.16. Atenuação acústica devida ao uso da guia de ondas.

Observa-se que a atenuação acústica é aproximadamente 3,05 vezes maior com a guia inclinada comparando o termo que multiplica o exponencial da curva de ajuste, ou seja, 7,64/2,51 =3,05. Da mesma forma, o expoente muda pouco entre os testes, assim pode-se considerar a atenuação em função do tempo como no pior caso um expoente igual a $e^{-0,002 t}$. 
Como a resposta atenuada da guia de ondas apresentava característica exponencial, o projeto do amplificador e detector foi feito em função disto. $\mathrm{O}$ amplificador passou a amplificar o sinal e, na sequência, o detector de limiar registrou o momento em que ocorreu a chegada do eco de retorno.

\subsubsection{Pulsador, amplificador e comparador}

O pulsador tem o papel de enviar ao transdutor um pulso de alta tensão elétrica para a transmissão do sinal acústico. Ele foi otimizado em relação às versões anteriores do circuito usando-se simulação elétrica de respostas transientes no software OrCadv9.2. O objetivo foi fazer a taxa de subida da tensão $(d V / d t)$ ser a maior possível para que a amplitude do sinal acústico transmitido pelo transdutor piezelétrico tivesse a maior pressão mecânica, de acordo com a sua função transferência eletromecânica. Outro ganho obtido foi na adoção de um indutor em paralelo com o transdutor, para que a impedância elétrica entre os dois fosse a mais próxima possível de um circuito resistivo, existindo, portanto, um bom casamento de impedâncias. Isto porque o transdutor tem forte característica capacitiva. O indutor fez com que a energia acumulada pela capacitância do transdutor durante o pulso fosse dissipada pela formação de um circuito RLC ressonante, juntamente com resistência de entrada do amplificador. Extinguiu-se, assim, a tensão residual na entrada da placa de circuitos em poucos microssegundos. $\mathrm{O}$ indutor, filtrando também as baixas frequências na entrada, previne ruídos elétricos.

Para este sistema optou-se por fazer um nível de limiar de detecção de eco variante no tempo. Ele decai exponencialmente na mesma taxa de atenuação da guia de ondas. Dessa forma, o comportamento é equivalente a um ganho variável com o tempo. A idéia é poder detectar somente o eco de retorno e tentar evitar falsos ecos provenientes de sujeiras, bolhas de ar e partículas no interior da guia de ondas refletindo a pressão acústica. Isso aumenta a robustez do sistema.

Outro ponto pesquisado foi o detector por limiar. Como poderia ocorrer a perda de detecção do primeiro ciclo do sinal de retorno usando-se apenas a detecção pela amplitude positiva do eco, optou-se por fazer uma detecção dupla usando também a amplitude negativa. Assim, o detector de limiar na verdade atua em torno de uma janela 
de tensão próxima do zero. Dessa forma, caso não ocorra detecção no primeiro semiciclo do sinal de retorno, o detector pode registrar o próximo semiciclo negativo. $\mathrm{O}$ transdutor usado tem frequência de $2 \mathrm{MHz}$ e $\lambda=0,741 \mathrm{~mm}$. Caso ocorra a perda de um ciclo e somente ocorra detecção no seguinte, o erro da altura lida é de 1 comprimento de onda, ou 0,74 mm. No caso de se usar também detecção no semiciclo negativo seguinte, o erro obtido é de meio comprimento de onda, ou $0,37 \mathrm{~mm}$. Ganha-se, dessa forma, robustez no funcionamento do sistema, minimizando problemas de leitura de alturas com grandes variações, no caso de falha de detecção de um semiciclo de eco. A Figura 4.17 ilustra o detector definido para o medidor de ondas.

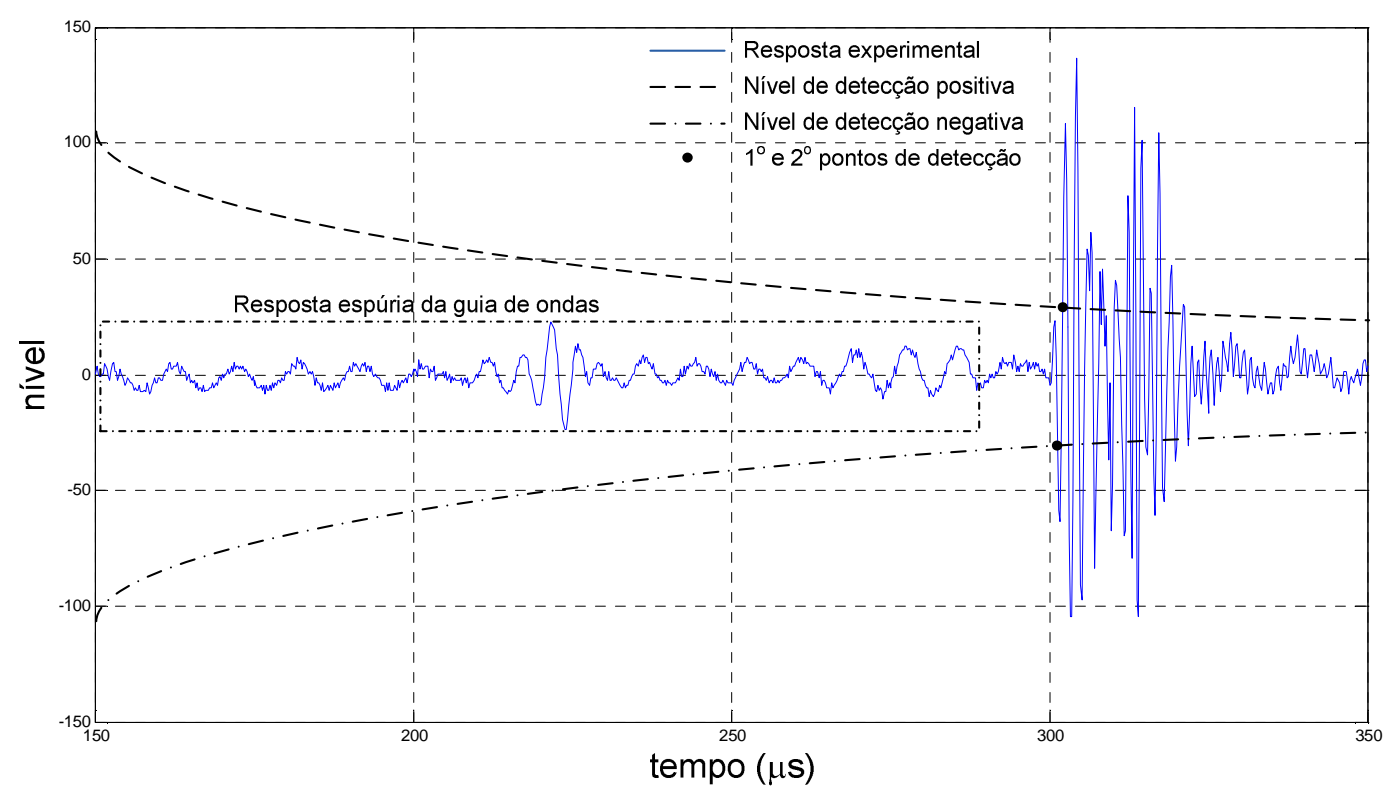

Figura 4.17. Detector de sinais de ultrassom.

A curva de decaimento do nível do detector ao longo do tempo pode ser obtida usando-se um circuito RC em carga com tensão contínua. O circuito montado tem resposta dada pela equação abaixo:

$V_{R}=V o \cdot\left(e^{-\frac{1}{R C} \cdot t}\right)$

Aplicando para os parâmetros de decaimento da guia de ondas fixando $C=$ $330 n F$ o valor de $R=1844 \Omega$ e $V o=5 V$ conseguimos uma curva equivalente do detector, vista na Figura 4.18. Resta ajustarmos o ganho do amplificador para que o valor da amplitude do sinal seja maior que o nível do detector para todas as condições de funcionamento. 


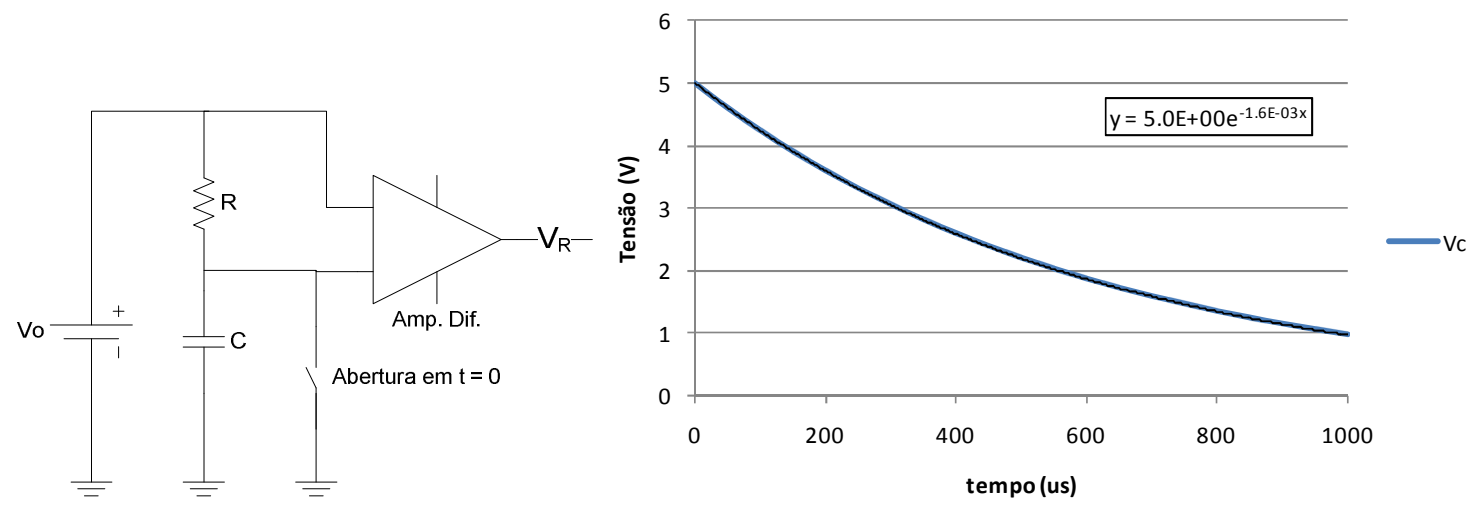

Figura 4.18. Resposta de um circuito RC.

Usando-se uma amplificação do sinal para o pior caso, quando a guia de ondas está inclinada a $20^{\circ}$ e na maior distância, obtemos o seguinte ganho:

$A_{70^{\circ}}=1 \mathrm{~V} / 27 \mathrm{mV}=37 \mathrm{~V} / \mathrm{V}$

Como existem grandes incertezas sobre o funcionamento da guia de ondas, foi estabelecido que o ganho deveria ser muito maior que este mínimo. Assim, o ganho foi ajustado em $A=82 \mathrm{~V} / \mathrm{V}$ que é o valor máximo do amplificador; ou seja, o dobro da pior condição encontrada. A Figura 4.19 ilustra a condição de operação do detector de eco e as curvas de resposta da guia de ondas amplificadas. A figura mostra a parte negativa do detector e a saturação da saída do amplificador. A saturação do amplificador não interfere na faixa dinâmica pretendida para uma boa operação.

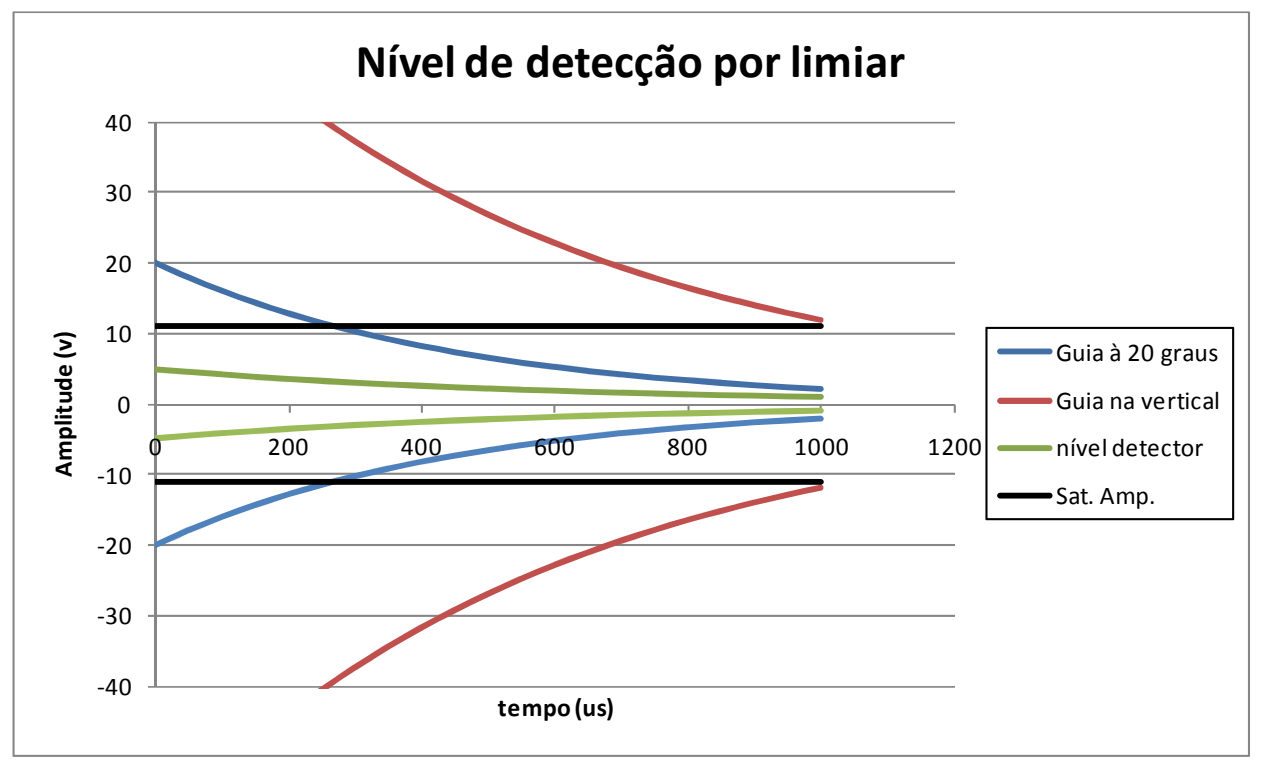

Figura 4.19. Níveis de detecção do eco no condicionador de sinais. 
O setor analógico do circuito pode ser visto na Figura 4.20. As duas rampas de limiares com decaimento exponencial e o sinal do eco vindo do amplificador entram no detector de janela por limiar. Quando o eco é maior que um dos dois limiares, a saída do detector transita de nível lógico 1 para 0 . Na sequência, o registrador (latch) composto por um flip-flop D operando em modo RS recebe o sinal do detector e transita para 1 sempre que ocorrer detecção. O sinal de habilitação (HAB), ativo em nível lógico 1, permite que o registrador funcione somente durante o período de interesse. Quando habilitado, o registrador transita a saída $\bar{Q}$ para zero quando ocorre o primeiro eco e mantém o estado até ser desabilitado.

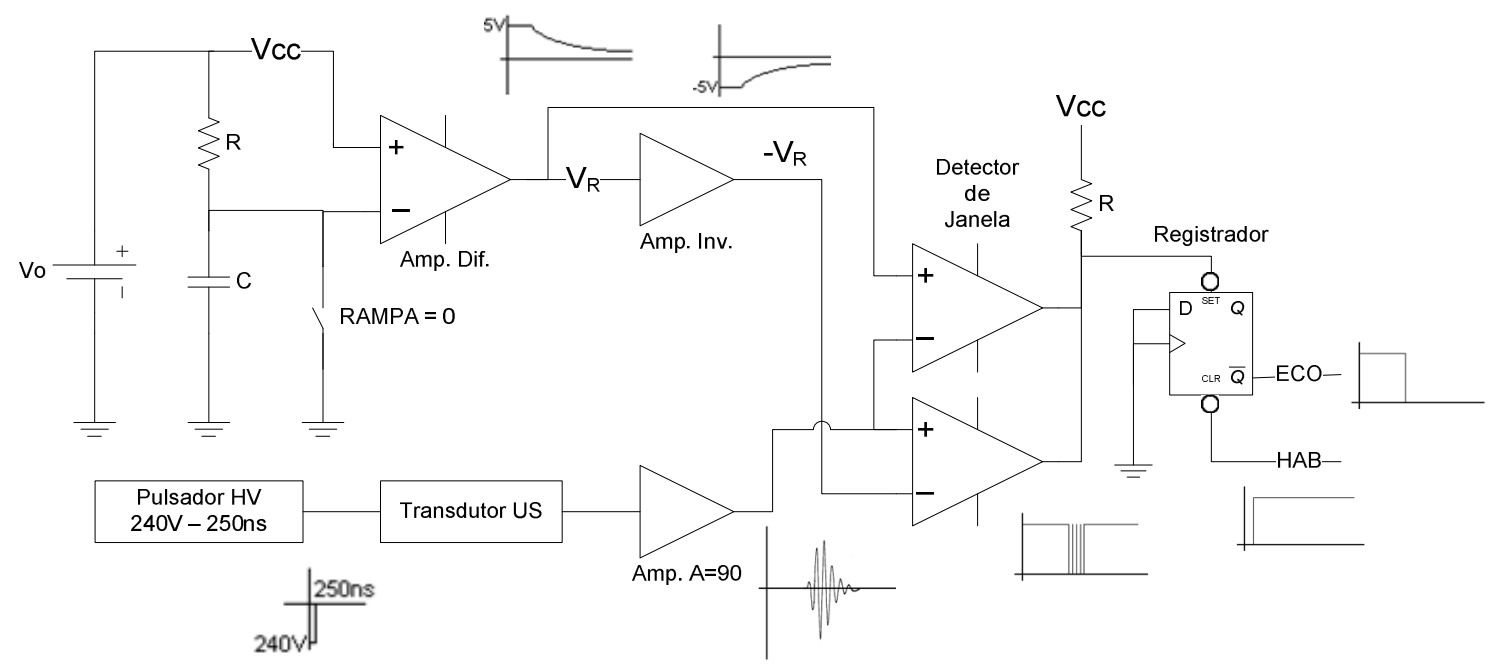

Figura 4.20. Esquema elétrico do circuito condicionador analógico do medidor de ondas por ultrassom.

A contagem do tempo de retorno do eco (sinal ECO) e o fluxo das operações do circuito são controlados por um microcontrolador. A sua operação será descrita no próximo tópico.

\subsubsection{Microcontrolador e software de tratamento de sinais}

O microcontrolador usado é um PIC 18F1220-I/P. Na placa de circuito existem 5 destes. O microcontrolador do primeiro canal, chamado de Mestre, roda uma base de tempo de $104 \mathrm{~Hz}$ baseada em temporizador, que os outros microcontroladores Escravos 
usam para gerar os pulsos sincronamente. $\mathrm{O}$ sincronismo é feito de Mestre para Escravo através de um sinal chamado SYNC. Os pulsos devem ocorrer juntos para que não exista interferência entre canais, uma vez que, ao pulsar, o ruído eletromagnético gerado é sentido entre canais; é o chamado cross-talk.

Existe um sinal externo à placa com isolação por optoacoplador que libera o funcionamento de todos os canais (sinal ENABLE). Ele é usado para liberar a leitura dos sensores vinda do sistema de controle do gerador de ondas.

A contagem de tempo do eco é feita internamente por um contador por captura. Assim que habilitado após o pulso, uma base de tempo dada pelo cristal de $10 \mathrm{MHz}$ incrementa um contador de 16 bits que interrompe a contagem assim que o eco é registrado (sinal ECO). Como a base de tempo é de $1 / 10 \mathrm{MHz}=100 \mathrm{~ns}$ a resolução do contador, usando a equação 4,5 a $20^{\circ} \mathrm{C}$, é de aproximadamente $0,074 \mathrm{~mm}$.

A Figura 4.21 mostra o fluxograma que os microcontroladores executam. A seleção entre Mestre e Escravo é feita por um pino do microcontrolador. O soquete da posição do primeiro canal tem sinal lógico diferente dos demais; uma vez lido pelo programa, o canal 1 executa as tarefas Mestre e nos outros canais restantes as tarefas Escravo.

Um atraso de $97 \mu$ s foi colocado após o pulso do transdutor porque nesta região existem reverberações acústicas no transdutor e há também o efeito do campo próximo acústico. Na região do campo próximo, as ondas acústicas emitidas pela borda do transdutor interagem com a onda emitida na superfície da cerâmica, descrita pelo modelo de pistão plano. Quando as ondas se sobrepõem a certa distância do transdutor, ocorre um ponto de valor máximo e a onda de pressão torna-se plana, o chamado campo distante. Na prática, a região de campo próximo não é adequada para medição, tornando-se uma zona morta. O campo próximo pode ser calculado, segundo Kinsler et al. (2000) por:

$N F=\frac{a^{2}}{\lambda}=\frac{0,005^{2}}{0,000741}=33,7 \mathrm{~mm}$

onde $a$ é o raio da cerâmica e $\lambda$ o comprimento de onda acústica. Dessa forma, usandose a equação (4.5) resulta um intervalo de tempo de:

$t=\frac{2 \cdot 33,7 \mathrm{~mm}}{1482 \mathrm{~m} / \mathrm{s}}=45,5 \mu \mathrm{s}$ 
Desse modo, o tempo de $97 \mu$ s evita a região de campo próximo com sobras.

Na sequência da execução, a captura do registrador é habilitada e inicia-se o contador de tempo. O programa fica esperando por $1 \mathrm{~ms}$ até que ocorra um eco válido. $\mathrm{O}$ valor lido é então avaliado; será é considerado bom se o tempo estiver no intervalo de $10 \mu \mathrm{s}<$ tempo $<1 \mathrm{~ms}$. Novamente usando a equação (4.5), o intervalo equivale em distância a 79,3 mm < distância $<812,9 \mathrm{~mm}$, considerando-se os $97 \mu$ s iniciais.

Sendo válido, o valor é lido, a escala de saída é ajustada e o valor é carregado no conversor digital-analógico (DAC) para transmissão da leitura ao sistema de controle. Caso ocorra um valor inválido, o dado transmitido será o da leitura anterior. Se ocorrerem 25 leituras inválidas sequencialmente, o valor de erro será enviado ao conversor analógico-digital. O valor de erro é uma corrente de saída do DAC de 3,5mA. Esta corrente abaixo do mínimo válido de $4 \mathrm{~mA}$ é reconhecida pelo sistema de controle como falha do sensor de ondas. As 25 amostras correspondem a 240ms de tempo sem leitura. Se o sensor voltar a ler um eco válido, a contagem de erros será reiniciada. 


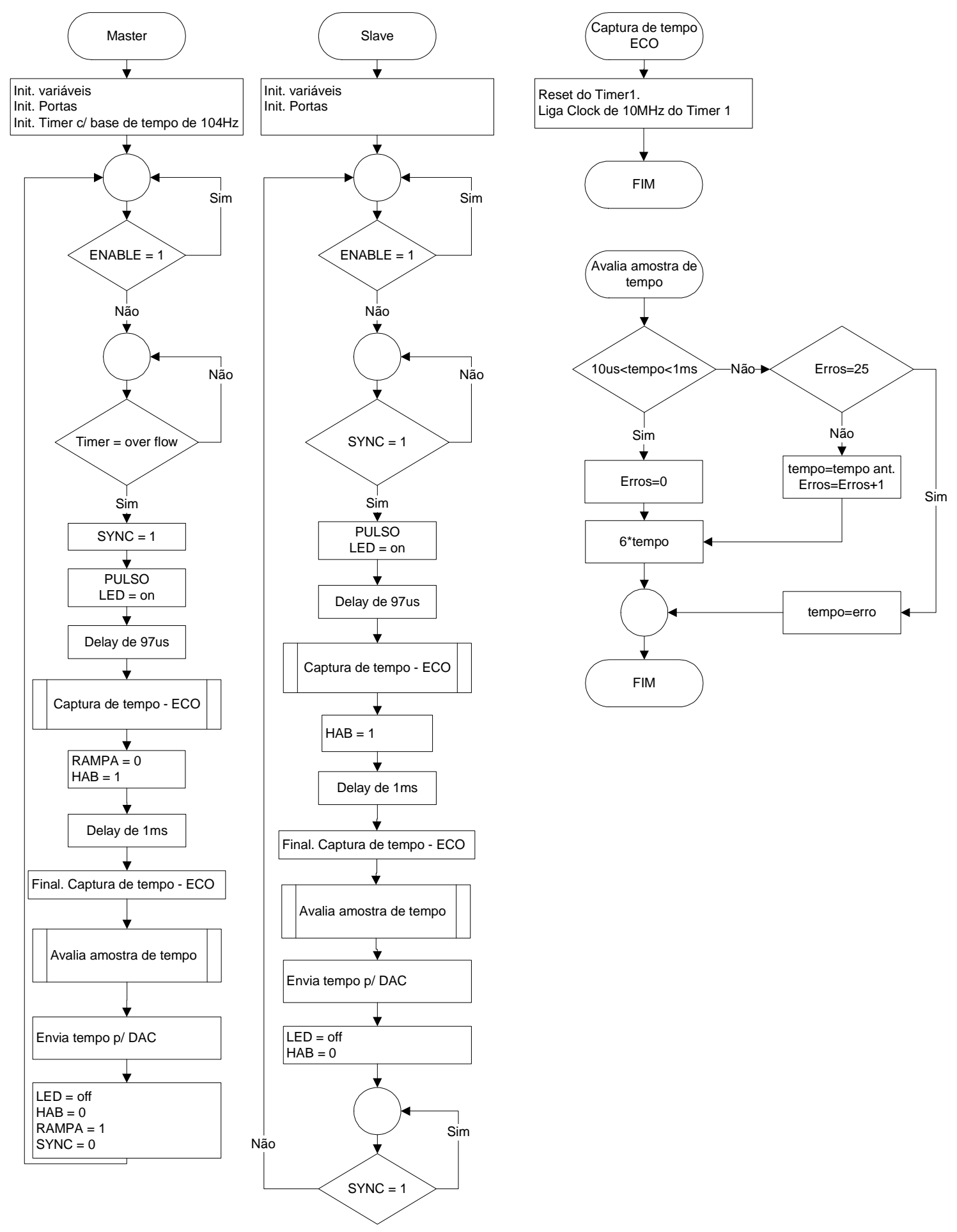

Figura 4.21. Fluxograma dos microcontroladores dos medidores de ondas por ultrassom.

\subsubsection{Saída analógica}

A saída analógica para os sensores foi escolhida para que todas as 32 placas de circuitos, contendo cinco sensores cada, em um total de 152 flaps monitorados, fossem 
lidas simultaneamente pelos cartões conversores analógico-digitais (ADC) dos CLPs. Estes executam leituras de forma assíncrona entre si, pois não existe sincronismo entre as diversas placas de circuitos dos sensores. Para que estes cartões, sendo assíncronos, não afetem a fase das leituras de ondas, é necessário que sua taxa de leitura seja mais rápida que a dos outros fenômenos envolvidos. Para o modelo escolhido Q68ADV, do mesmo fabricante dos controladores (CLP), o tempo de conversão cíclica para os 8 canais do cartão é de $800 \mu$ s. O valor lido é, então, disponibilizado para a CPU do PLC. São $80 \mu$ s de tempo de leitura entre canais e mais $160 \mu$ s ao final do ciclo para compensação de temperatura do cartão.

Da mesma forma, os conversores digital-analógicos das placas de circuitos devem ser mais rápidos que os fenômenos envolvidos. Por essa razão foi selecionado o DAC AD421, que possui internamente vários circuitos necessários à conversão digital em corrente padrão industrial 4 a 20mA. Eles recebem o valor de corrente vindos do microcontrolador por comunicação serial SPI por 3 linhas optoacopladas (clock, data e latch). Outra vantagem explorada é o fato de se poder usar a corrente da linha de corrente para alimentar o circuito DAC e usar optoacopladores para isolar o restante da placa de circuitos dos cartões do PLC e fonte de alimentação da linha em 24vdc. Assim os ruídos são suprimidos entre os vários componentes do sistema, como discutido no tópico 4.2 sobre o sistema elétrico.

Como foi mencionado, os DACs apresentam também tempo de conversão. Para o caso de transição entre 4 a 20mA, equivalente a 0x0000 a 0xFFFF (HEX) de dados de entrada em 16bits, o tempo de subida é de $8 \mathrm{~ms}$, limitando portanto a taxa de $125 \mathrm{~Hz}$. Mas como a taxa de subida habitual para leitura de ondas é sempre muito inferior ao fundo de escala, o conversor foi testado para verificar quaisquer atrasos de fase.

Para o caso da transição entre mínimo e máximo, foi testado o transiente de subida. Usando um resistor de aproximadamente $100 \Omega$ para converter 4 a $20 \mathrm{~mA}$ em 0,43 a 2,05volts e a leitura realizada por um osciloscópio com captura, a rampa foi avaliada. A Figura 4.22 mostra esse teste. Observou-se que existe um pequeno degrau de $350 \mu$ s durante a transmissão dos dados entre o microcontrolador e o DAC. Esse degrau é relatado aqui, mas não influenciou o desempenho final do sistema. Após esse teste somente foi aumentada a velocidade da transmissão para reduzir o tempo deste degrau para $250 \mu \mathrm{s}$. A sua causa provavelmente está associada ao consumo de energia 
pelo DAC, pelos inversores TTL de buffer dos sinais e pelos optoacopladores durante a transmissão dos dados.

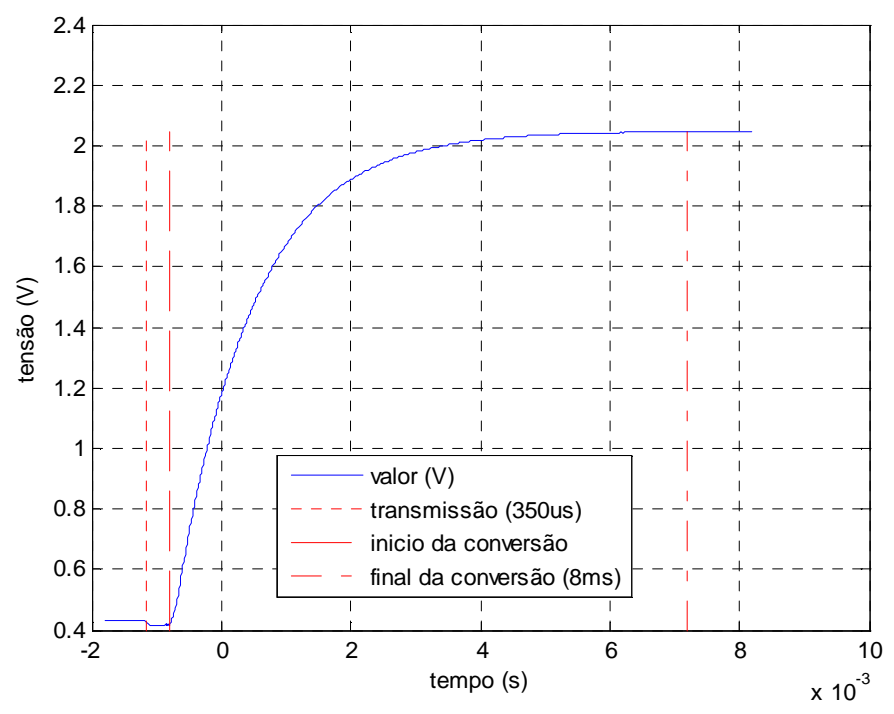

Figura 4.22. Rampa de conversão dos circuitos do DAC.

Para avaliar o atraso efetivo do DAC, foi feito um programa para o microcontrolador transmitir um sinal senoidal de $1 \mathrm{~Hz}$ por 35447 dígitos pico-a-pico com 50 divisões temporais. Outro sinal digital usado como referência, gerado em um pino do microcontrolador, com valor 1 no semiciclo positivo e 0 no semiciclo negativo também foi adquirido com a senóide pelo osciloscópio para verificar a fase relativa. Foi feita uma análise por FFT para medir a fase relativa entre os sinais. A Tabela 4.4 mostra quatro testes feitos usando 1000 pontos temporais via osciloscópio usando taxa de amostragens variadas. A Figura 4.23 mostra um dos testes realizados. Nota-se que apesar de se usar taxas de amostragem variadas, o atraso da senóide é semelhante. O tempo médio de atraso observado é $8,455 \mathrm{~ms}$. O resultado é pouco maior que o observado anteriormente de $8 \mathrm{~ms}$ no DAC somado de $350 \mu$ s da transmissão.

Tabela 4.4. Teste de atraso do DAC.

\begin{tabular}{|c|c|c|c|c|}
\hline Teste & Frequência $(\mathrm{Hz})$ & Frequência de amostragem $(\mathrm{Hz})$ & Atraso de fase (graus) & Atraso da fase (ms) \\
\hline 1 & 1 & 500 & 3,0398 & 8,444 \\
\hline 2 & 1 & 100 & 3,0455 & 8,460 \\
\hline 3 & 1 & 50 & 3,0483 & 8,468 \\
\hline 4 & 1 & 50 & 3,0416 & 8,449 \\
\hline
\end{tabular}



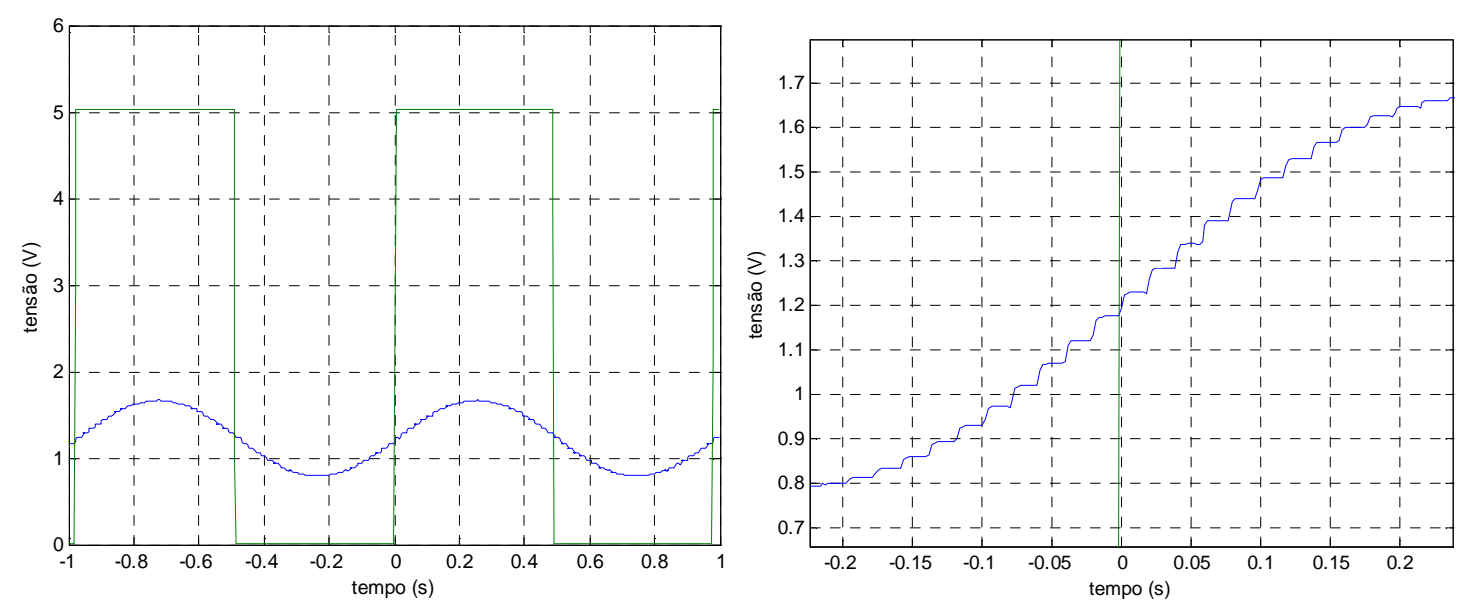

Figura 4.23. Teste de resposta do DAC.

Desta forma, pode-se concluir que o atraso total do sistema de medição é a soma da taxa de aquisição $(9,6 \mathrm{~ms})$ acrescida do tempo de atraso do DAC $(8,3 \mathrm{~ms}$ após ajuste na taxa de transmissão), num total de 17,9ms.

O fator de escala total do sistema pode, então, ser calculado usando-se os parâmetros observados no desenvolvimento do circuito do sensor com o fator de escala de conversão do cartão ADC do PLC. O cartão lê o valor de tensão de 1 a 5 volts convertido de 0 a 12000 dígitos. Usando um resistor de precisão de $250 \Omega$ na entrada do cartão, pela $1^{a}$ lei de Ohm, o valor em tensão 1 a 5 volts corresponde a 4 a 20mA. Para aperfeiçoar a faixa dinâmica da escala do ADC, optou-se por multiplicar a quantidade de dígitos adquiridos pelo contador de tempo de eco (base de $100 \mathrm{~ns}$ ) por 6 . Isto porque, pela resolução de distância da guia de ondas, são necessários 10458 dígitos para apresentar os $775 \mathrm{~mm}$ do comprimento da guia de ondas. Assim, a leitura de altura medida pode ser convertida a partir dos dígitos do cartão ADC como:

dist $=(I-4 m A) \cdot \frac{c \cdot 100 n s \cdot 2^{16}}{2 \cdot 6 \cdot 16 m A}=\left(\frac{16 m A}{12000} \cdot D i g-4 m A\right) \cdot \frac{c \cdot 100 n s \cdot 2^{16}}{2 \cdot 6 \cdot 16 m A}$

Descartando o offset do sensor, o ganho total é:

dist $=\left(\frac{16 m A}{12000} \cdot \mathrm{Dig}\right) \cdot \frac{c \cdot 100 \mathrm{~ns} \cdot 2^{16}}{2 \cdot 6 \cdot 16 \mathrm{~mA}}=\mathrm{Dig} \cdot \mathrm{c} \cdot 45,511 \cdot 10^{-9}(\mathrm{~m})$

onde dist é a altura medida em metros, $c$ é a velocidade de propagação do som na água e Dig é a leitura do ADC. 
A leitura de distância foi aferida e apresentou diferenças muito pequenas em relação à curva teórica. A curva teórica é a saída esperada calculada com velocidade do som na água igual a $c=1482 \mathrm{~m} / \mathrm{s}$. O teste foi feito no tanque do IPT com distância de medição de até 1,62 metros. Para obter a distância de medição ampliada, o ganho aplicado aos dígitos da escala de tempo foi 2 no microcontrolador. O sistema de medição era analógico com resistor de precisão de $250 \Omega$ convertendo a saída em tensão. O sistema de aquisição usado foi um Lynx Aqdados com medição de $-5 \mathrm{~V}$ a $5 \mathrm{~V}$ com 16 bits de resolução. A diferença de ganho obtido é de 0,06 \% com boa linearidade total.

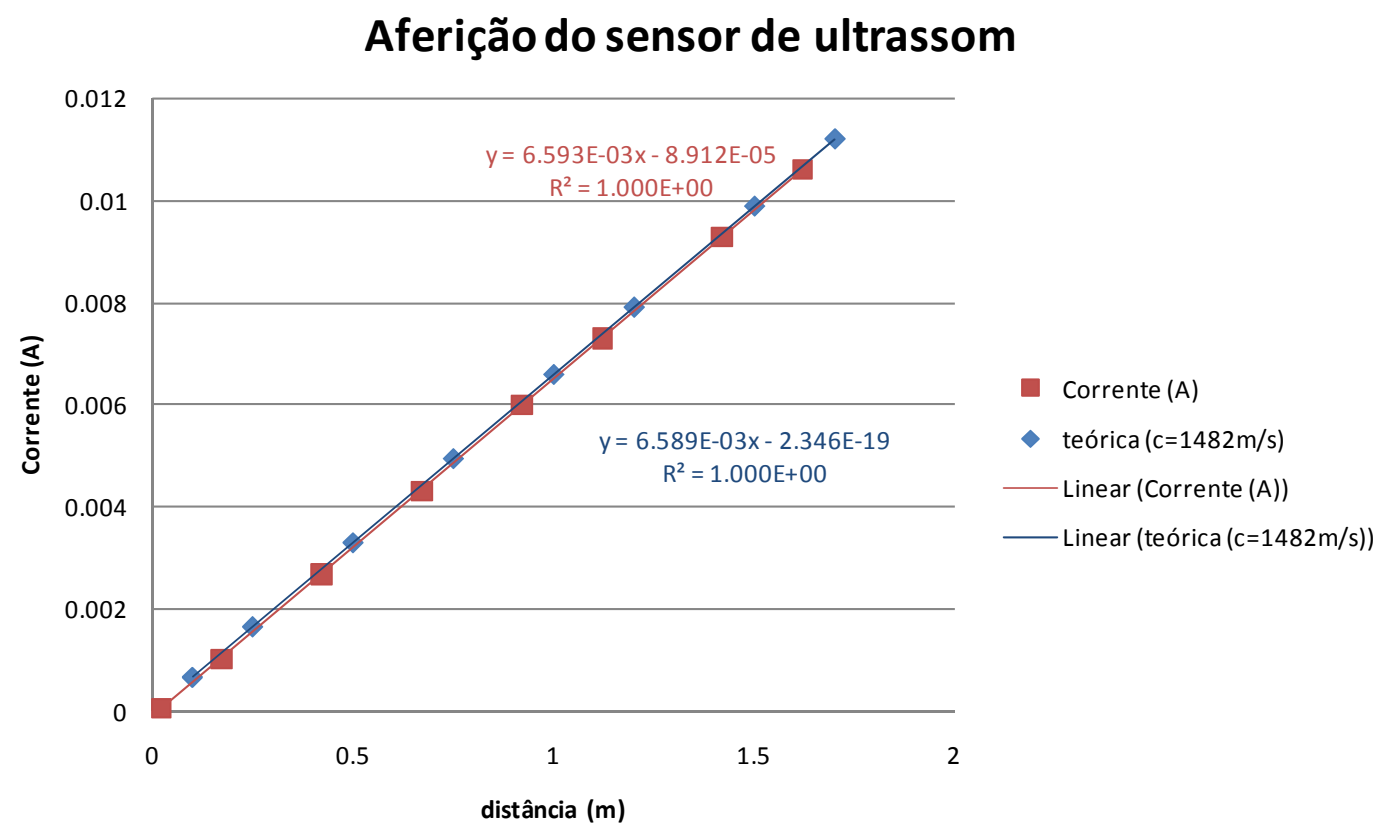

Figura 4.24. Leitura do sensor de ondas observada.

A placa de circuitos foi projetada de acordo com as definições do sistema elétrico e foi feito o seu layout para comportar os 6 canais (1 de reserva). Foi montada ao lado dos motores, próxima da borda do tanque e, para evitar ruídos elétricos, colocada dentro de uma caixa metálica. Os transdutores, portanto, ficaram o mais próximo possível da placa. A alimentação foi feita por transformador 220vac / 24vac dentro da caixa.

Por uma questão de correção do circuito, foram feitas duas versões de placa. A primeira sofreu algumas alterações no layout e nos circuitos. A segunda versão foi definitiva. A Figura 4.25 mostra os setores da placa e, em seguida, a placa montada dentro da caixa. 

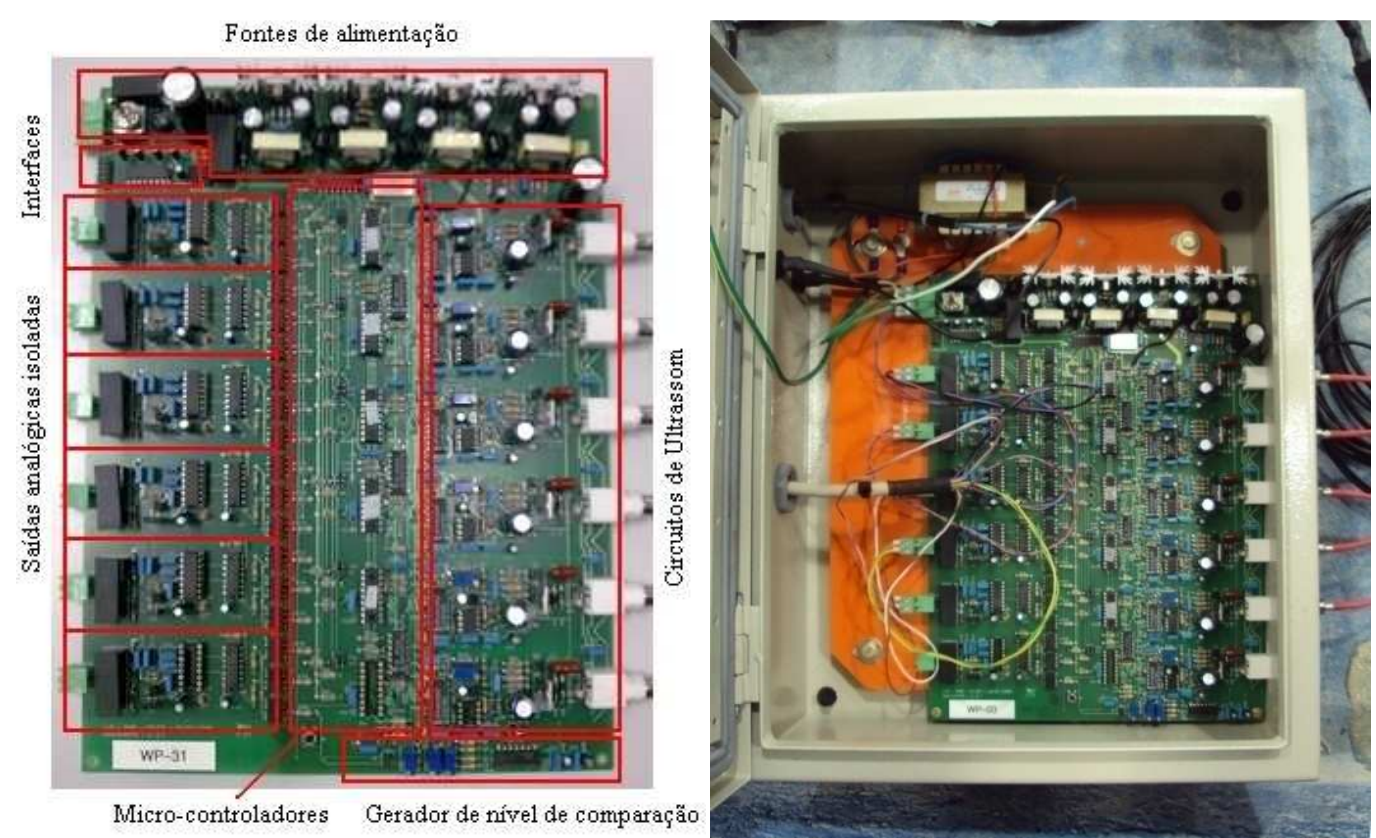

Figura 4.25. Circuito do medidor de ondas.

\subsection{Automação e controle}

A arquitetura de controle implementada no sistema do gerador de ondas é baseada em equipamentos de padrão industrial. Nos dias atuais, novas gerações de equipamento destinadas à automação industrial têm evoluído de forma consistente em capacidade, escalabilidade, modularidade e flexibilidade para atender à demanda atual da indústria. Da mesma forma, computadores pessoais têm melhorado o desempenho lançando mão principalmente da utilização de processamento paralelo em computadores multi-cores e processamento em GPU. Assim sendo, o que antes seria feito em um hardware especificamente projetado para aplicação de um gerador de ondas, por exemplo, pode ser feito com tais equipamentos, especificados criteriosamente.

O hardware foi descrito no tópico 4.2. No tópico atual será mostrada a programação da automação realizada pelas CPUs de controle. Primeiramente foi feita a especificação dos requisitos desejados. Os principais objetivos eram:

- Taxa de amostragem de $20 \mathrm{~ms}$.

- $\quad$ Troca de amostras sincronamente.

- $\quad$ Uso da rede entre CPUs como base de sincronismo do sistema.

- $\quad$ Processamento descentralizado com carga computacional equilibrada. 
- $\quad$ Todos os 148 flaps comandados e a posição real destes lida em cada amostra no tempo.

- $\quad$ Os 152 sensores de ondas lidos em cada amostra no tempo.

- Uso de um computador de controle para operação do gerador de ondas.

- Sistema com interface de operação e manutenção que também proporcionasse fácil desenvolvimento de algoritmos de controle.

Visando atingir tais metas de funcionamento, foi adotado um modelo baseado em redes de comunicação. O modelo usado conta com duas redes de comunicação ópticas distintas: uma interligando os CLPs de execução industriais ao PC de controle, outra interligando as CPUs de controle de motores aos servo-drivers, que acionam os motores. Foram usados três CLPs de execução industrial, dois controlando a movimentação dos flaps e o terceiro adquirindo a leitura dos sensores de ondas dos flaps. Os CLPs são programados em linguagem ladder e as CPUs de controle de motores em linguagem SFC (Sequential Function Chart).

Cada um dos três CLPs conta com uma interface de comunicação via rede do tipo Melsecnet/G, token-ring de 1 Gbps de velocidade. Cada estação na rede tem uma área reservada de endereços onde os dados são gravados e que são lidos pelas outras estações na rede. Essa rede é a responsável por integrar todos os dados que são escritos e lidos no PC de controle. Como ela é a rede de mais alto nível do sistema, é por ela que ocorre o sincronismo via base de tempo de execução entre os CLPs e o PC. A base de tempo é única no sistema e é gerada por um timer no CLP de execução número 1. A Figura 4.26 ilustra o sistema de automação.

\subsubsection{Temporização do sistema}

Primeiramente foi analisada a temporização dos equipamentos utilizados. A grande maioria dos CLPs trabalha com o conceito de execução em escada, traduzindo ladder do inglês, fazendo analogia com os diagramas elétricos de contatos de bobinas de relés, temporizadores e contatores. As lógicas de acionamento são dispostas em linhas de execução. Cada linha resulta em um estado de saída, ligado ou desligado, de acordo 
com a leitura das entradas atuais. Cada uma dessas linhas é executada sequencialmente da primeira à última. Quando uma saída é alterada como resultado de uma operação lógica, nas linhas subsequentes este novo estado é válido e pode ser novamente alterado. Mas diferentemente do que possa parecer, a saída física externa ao CLP só será alterada assim que todo o programa for executado, ao final de todas as linhas de ladder. O tempo necessário para se executar todas as linhas de ladder é chamado de tempo de scan. Outro recurso, criado em CLPs mais modernos, é usar instruções que alterem imediatamente o estado de uma saída. Este recurso geralmente leva mais tempo de execução, pois interrompe o fluxo de execução normal para fazer acesso ao hardware. Outro conceito importante é que se pode executar instruções de cálculos aritméticos e manipular valores de 16 bits ou 32 bits em ladder. Como em outras linguagens de programação, para controlar o fluxo de execução é possível executar controles de fluxo, da mesma forma que se usam instruções WHILE, FOR, IF, interrupções e chamadas de funções. Pode-se também usar chamadas de execução de programas e configurações em outros cartões de CPU ligados ao CLP principal.

Desta forma, os diversos hardwares de um CLP, dispostos em cartões, executam uma tarefa com um tempo de scan diferente entre si. Geralmente a CPU do CLP é que acessa os dados de cada um deles ao final do seu ciclo de scan. Como as tarefas executadas ao final do ciclo são muitas, existem configurações bastante específicas para isso, chamadas de end processing tasks. São definidos quais dados entre a CPU e seus cartões e entre CPU e redes serão atualizados. No início de um ciclo de scan, os dados de entrada são todos novos. Assim sendo, para se saber qual o tempo total despendido na execução de uma automação em tempo real, é necessário contabilizar todos os tempos envolvidos: tempo de scan de programa, tempo de end processing tasks, tempos de execução dos hardwares de cartões, tempos de atualização de rede, tempos de execução de cálculos matemáticos, tempos de respostas dinâmicas etc. Cada tempo envolvido deve ser, a priori, menor que o tempo total de execução desejado com uma reserva de tempo como folga.

O diagrama da Figura 4.26 demonstra com detalhes os principais tempos envolvidos nos diversos equipamentos do gerador de ondas. Cada qual tem um ciclo de operação que necessariamente não está sincronizado com os outros. O que foi usado como meta é que se deve ter uma base de tempo real de operação que faça sincronamente a troca de dados. Como pode ser percebido pelo diagrama, a rede 
industrial entre CLPs e PC é o ponto de conexão desta base da troca de dados. Para que isso seja possível, é necessário que os tempos de atraso dos componentes do sistema não sejam superiores ao tempo de execução desejado. A meta de taxa de amostragem é de $20 \mathrm{~ms}(50 \mathrm{~Hz})$.

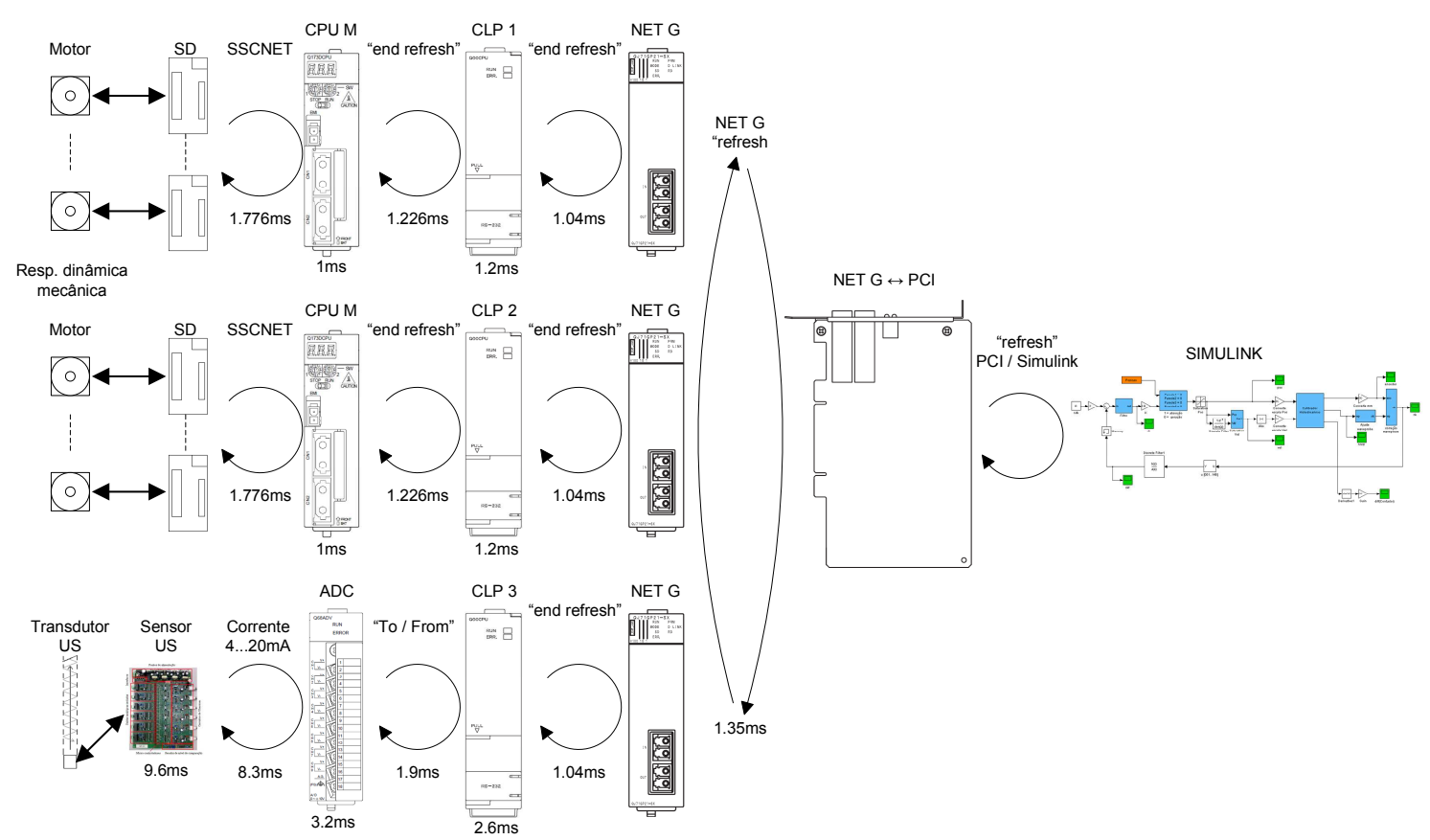

Figura 4.26. Tempos de respostas dos hardwares do gerador de ondas.

Os tempos de atraso obtidos para cada um dos CLPs podem ser calculados. Os dois CLPs de controle de motores têm tempos semelhantes, apesar de terem diferentes números de eixos. A rede de controle de motores SSCNET (Servo System Controller NETwork) da Mitsubishi tem tempo de scan fixo, tabelado pelo fabricante, em função do sistema operacional que a CPU de controle de motor está usando. No caso do tipo do sistema operacional, fica disponível certo número de recursos e instruções de movimentação de motores. Neste caso, o sistema é o mais simples, modelo SV13QB. O tempo de scan é de $1,77 \mathrm{~ms}$. O programa que é executado para controle de motores, descrito no tópico 4.4.2, tem um tempo de execução monitorado de $1 \mathrm{~ms}$. O CLP de controle de motores, por sua vez, tem um tempo de $1,226 \mathrm{~ms}$ de troca de dados com as três CPUs de controle de motores, acrescido no end processing tasks, e mais um tempo de execução das instruções de $1,2 \mathrm{~ms}$. Novamente um tempo de troca de dados com o cartão de rede. 
Usando a mesma análise para o CLP número 3, desde o sensor de ondas até a rede de comunicação pode-se calcular o atraso. Os detalhes sobre o tempo de atraso dos circuitos do sensor de ondas podem ser vistos no tópico 4.3.1. O ADC que trabalha em conjunto com o CLP tem tempo de conversão de $0,8 \mathrm{~ms}$, mas como ele executa média móvel de 4 amostras entre entrada e saída para atenuação de ruídos, o tempo total é de $3,2 \mathrm{~ms}$. Este tempo não representa um atraso temporal significativo e foi desconsiderado na análise. A leitura do ADC é feita pela instrução FROM no programa do CLP de forma imediata em 1,9ms. A transferência para a rede é feita via end processing tasks e o programa tem tempo de scan de $2,6 \mathrm{~ms}$.

O tempo de troca de dados via end processing foi calculado usando-se as fórmulas dadas pelos manuais de usuário dos equipamentos (MITSUBISHI, 2008). Os tempos de transações via rede NET G foram obtidos graças aos mesmos manuais. Resumidamente pode-se concluir que o atraso de comunicação entre os CLPs e os motores e sensores é:

$T_{C L P 1 M}=1,776+1+1,23(\mathrm{~ms})=4,01(\mathrm{~ms})$

$T_{C L P 2 M} \approx T_{C L P 1}$

$T_{C L P 3 S}=9,6+8,3(\mathrm{~ms})=17,9(\mathrm{~ms})$

Estes tempos demonstram que a leitura dos sensores de ondas tem um atraso de quase um ciclo de rede $(17,9 \mathrm{~ms} / 20 \mathrm{~ms}=0,9)$. Mas é possível realizar a comunicação entre os CLPs e o PC com ciclo de comunicação menor que $20 \mathrm{~ms}$, porque o tempo de atraso de rede é suficientemente rápido para isso. Analisando o atraso para realizar um ciclo de comunicação:

$T_{C L P 1}=1,35+1,04+1,2+1,04+1,35(\mathrm{~ms})=5,98(\mathrm{~ms})$

$T_{C L P 2} \approx T_{C L P 1}$

$T_{C L P 3}=1,35+1,04+1,9+2,6+1,04+1,35(m s)=9,28(m s)$

Com essa margem de folga, é possível executar uma máquina de estados cíclica via rede de comunicação. A base de tempo do sistema foi implementada por um temporizador no CLP número 1. Ele foi escolhido por apresentar um tempo de atraso menor que o CLP 3.

A rede de comunicação Melsecnet G, também designada CC-Link IE, tem a característica de operar por memória compartilhada. São configuradas faixas de endereços de variáveis de 16 bits chamadas de W (word) e de bits chamados B (bits), 
em que cada nó da rede pode escrever. A leitura é comum para todos os nós. Um dos nós, no caso a placa PCI instalada no computador, faz o papel de gerenciador mestre da rede. Para o caso desta aplicação, o tempo de atualização da rede é $1,35 \mathrm{~ms}$. Tanto no computador quanto nos CLPs existe o atraso devido à replicação da memória para a área de usuário dos programas, respectivamente, <1ms e 1,04ms para o computador e CLPs. O atraso no PC é mostrado no software de configuração em dígitos inteiros em milissegundos. No caso, foi indicado um tempo menor que $1 \mathrm{~ms}$.

No computador foi utilizado um programa de usuário escrito em linguagem $C$ que faz a troca de dados entre a placa PCI de comunicação de rede e o Simulink no MatLab® . O Simulink foi escolhido por propiciar um ambiente de desenvolvimento adequado para os algoritmos de controle e de automação do gerador de ondas. Assim, foi usado o recurso chamado de $S$-function, em que o usuário pode escrever códigos em linguagem $C$ dentro de um bloco do Simulink. No código em $C$ é possível executar a biblioteca de comunicação com a placa PCI fornecida pelo fabricante. Uma vez compilada a $S$-function, esta é incorporada ao Simulink e fornece a comunicação com o hardware.

A máquina de tempo real síncrona funciona da forma que se segue. Cada nó da rede tem um contador local iniciado em zero. Quando o usuário tecla no computador no início da simulação do Simulink, o programa de usuário liga o bit de rede B0. O contador local do computador é, então, incrementado. Quando os CLPs de controle de motores leem este novo valor, eles realizam a troca dos dados de posição e velocidade aos servo-drivers que estão na rede e incrementam ao final o seu contador local. Da mesma forma, o CLP de leitura de sensores lê os dados de medição de onda e os grava na rede. Ao final, incrementam o seu contador local. O CLP 1 incrementa o contador de base de tempo na rede assim que o temporizador local gera um novo passo. Enquanto isso, no computador, o programa de usuário lê os dados da rede e aguarda em um semáforo de software que todos os CLPs atualizem os contadores. Quando isto ocorre, foi finalizada a transferência dos dados e a base de tempo foi incrementada. Neste momento, acontece a transferência dos dados para o Simulink, que roda um novo passo temporal e devolve os dados de posições novas - assim sucessivamente, até que ocorra o final da simulação no Simulink. Nesse caso, o bit de rede B0 é desligado e o contador local é zerado. Então os CLPs param a troca de dados e zeram os seus contadores. A Tabela 4.5 ilustra as principais variáveis de controle da comunicação da rede. 
Na Figura 4.27 podem ser vistos os diagramas de estados desenvolvidos para controlar ciclicamente a comunicação. Foi introduzido um contador no computador para que, caso os CLPs parem de responder, em 60 segundos a simulação no Simulink seja finalizada automaticamente, mecanismo introduzido dentro do semáforo de software. Da maneira como foi especificado o sistema, o computador passou a ser a interface e o elemento de cálculo matemático e os CLPs ficaram responsáveis pela execução da automação em tempo real.

Como o comportamento foi equilibrado, pôde ser constatado pelo uso do sistema que o tempo de amostragem podia ser reduzido, visto que os tempos da equação 4.15 permitem isso. Dos $20 \mathrm{~ms}$ originais, passou-se a trabalhar a $12 \mathrm{~ms}(83,33 \mathrm{~Hz})$ de taxa de amostragem. Isso foi possível porque a comunicação cíclica da rede foi, segundo a equação 4.15, de 9,28ms de tempo máximo. Assim, o restante do tempo foi gasto pelo Simulink ao executar os cálculos de controle. O teste de desempenho foi feito avaliando-se a derivada do contador de tempo CBT no Simulink. Caso o valor fosse diferente de 1 , o passo de execução da máquina de estados estaria maior que o passo de tempo de amostragem. Assim foi observado que a operação se manteve estável com $12 \mathrm{~ms}$. Usando-se $10 \mathrm{~ms}$, por algumas vezes ocorria a perda de sincronismo.

Desta forma, o tempo de acionamento de motores é calculado pela soma de tempo abaixo dos CLPs, assim como o tempo de sensoriamento de ondas, excluindo-se o tempo da rede já calculado.

Tabela 4.5. Variáveis de controle da rede

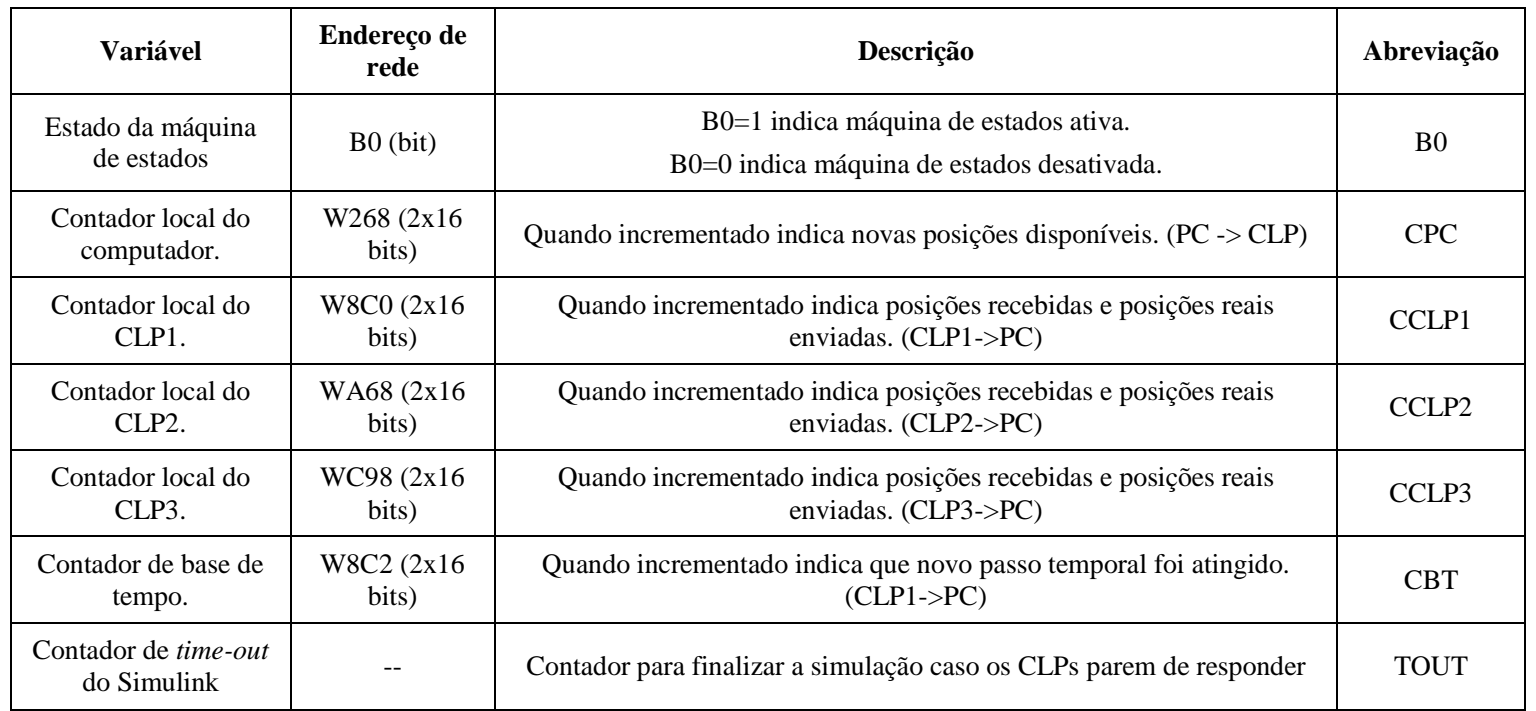




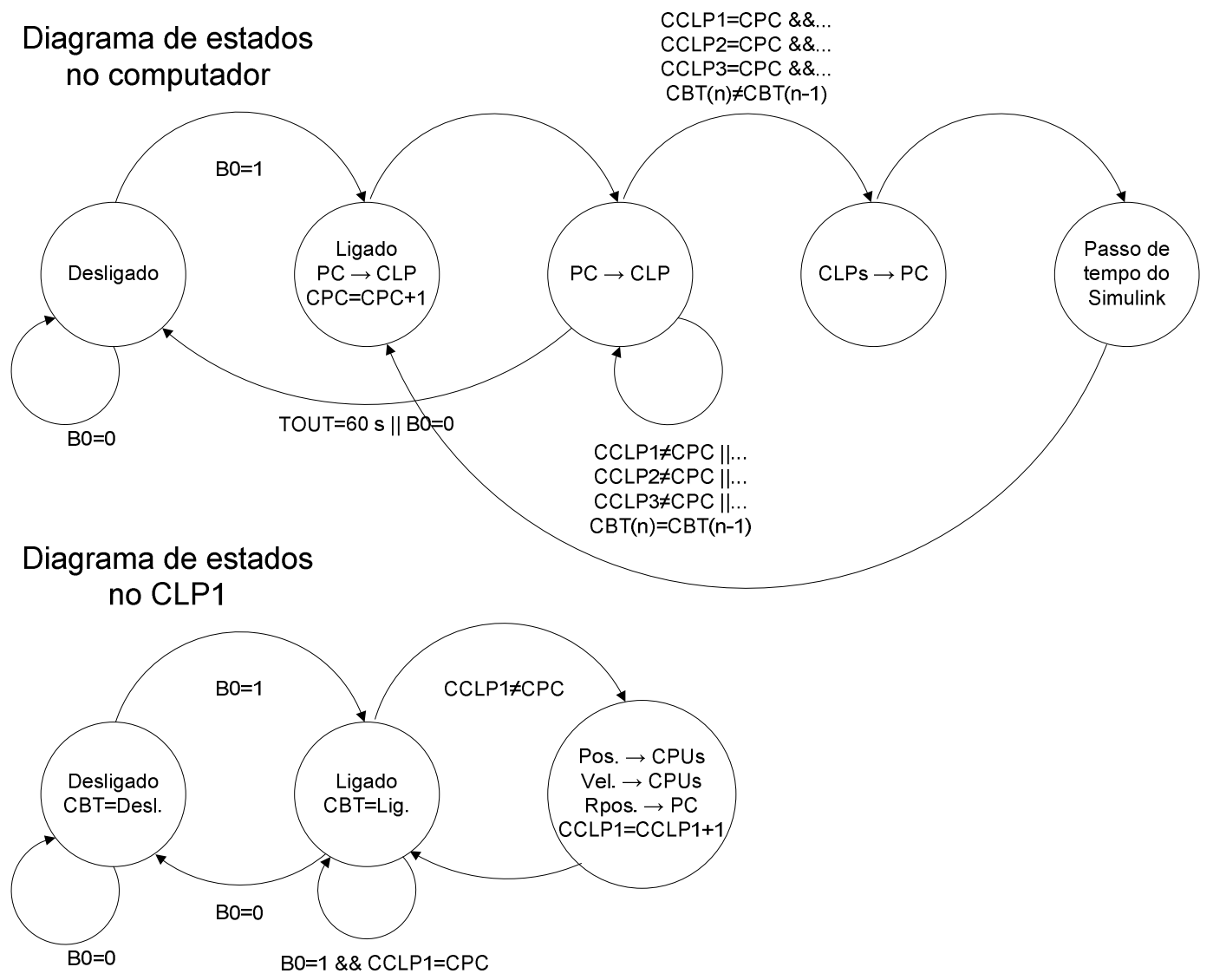

Diagrama de estados no CLP2

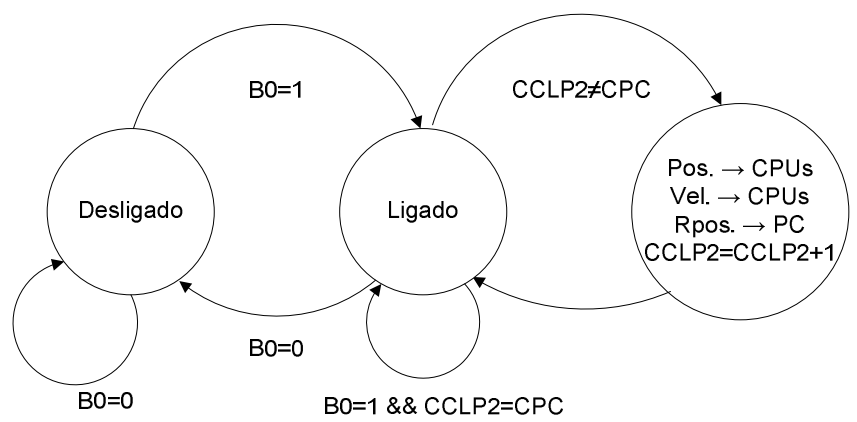

Diagrama de estados no CLP3

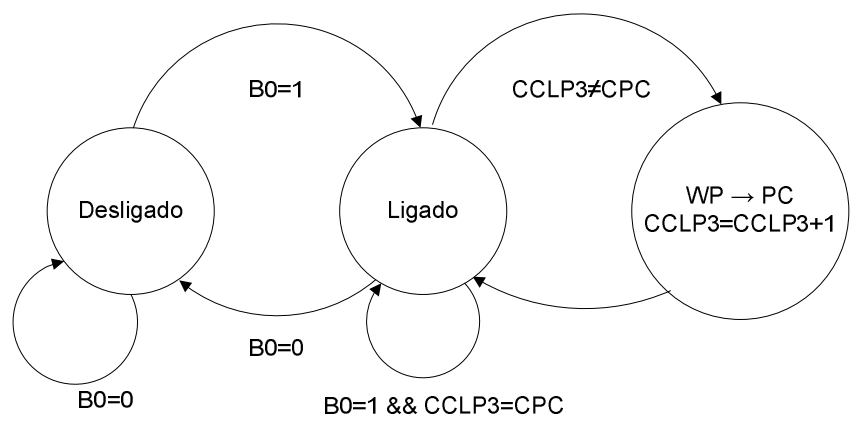

Figura 4.27. Diagrama de estados de rede. 


\subsubsection{Controle de motores}

A Figura 4.28 ilustra a arquitetura do controle de movimento dos flaps. Cada CPU de movimento é conectada a até 32 servo-drivers de controle de posição. Sinais de controle, status e alarmes também passam por ela.

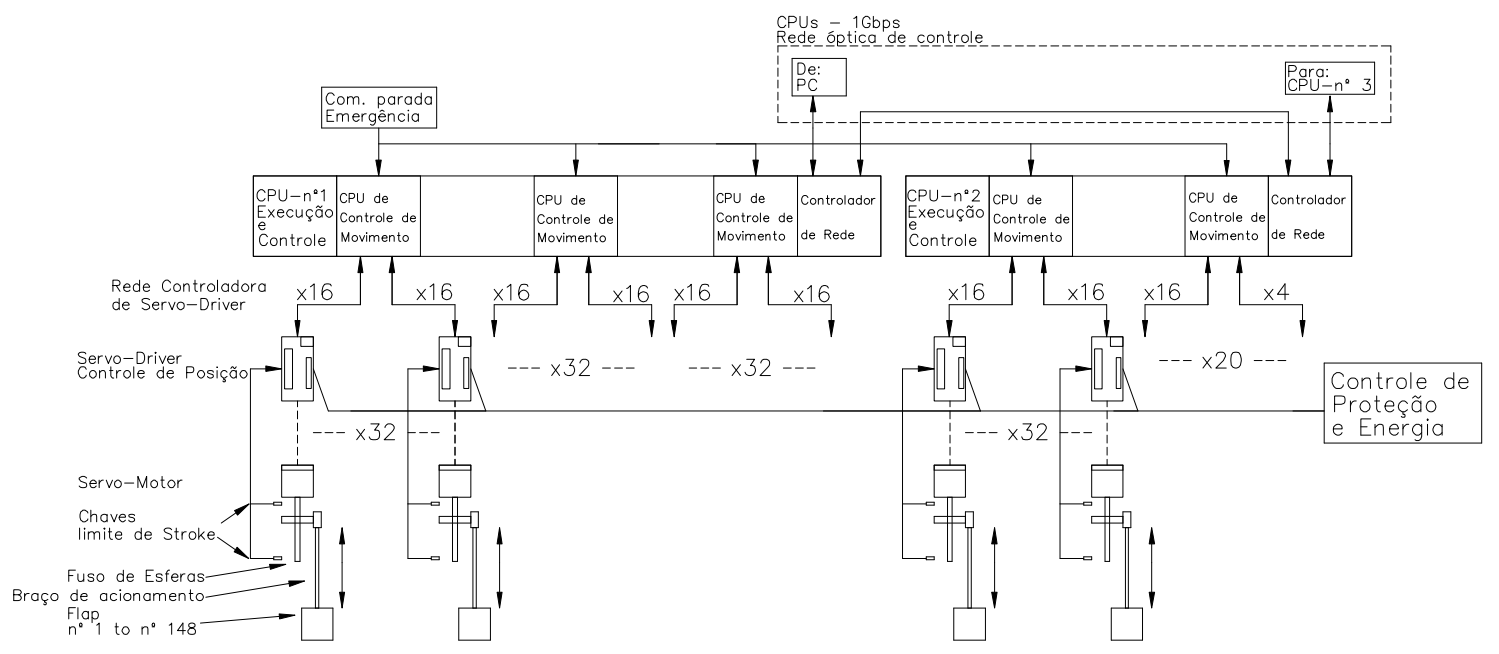

Figura 4.28. Sistema de controle de motores.

As CPUs de movimento executam programas em SFC (Sequential Function Chart); em um nível mais baixo, executam os chamados programas de movimentação. Estes são programas pré-definidos pelo sistema operacional e executam tarefas específicas de controle de motores na CPU. O programa de usuário em SFC faz as chamadas destes e manipula as variáveis dos vários motores ligados à CPU. A maior parte dos intertravamentos (interlocks) e automações ocorrem aqui. Destacam-se entre as automações e controles: proteção por chaves de fim de curso para o limite de curso, referenciamento do zero dos flaps usando as chaves de fim de curso, JOG de movimentação manual, retorno para zero automático no início de operação e limites de curso por software, velocidade e torque. Um conjunto de bits foi usado para controlar os estados do programa da CPU para que se inicie a geração de ondas somente quando não há problemas nos mecanismos e para que os erros sejam reportados ao CLP. Foi introduzido um retorno para a posição vertical dos flaps sempre que se inicia a geração de ondas, visando prevenir possíveis desalinhamentos nos batedores de ondas.

A malha de posição dos flaps é executada no servo-driver, recebida da rede SSCNET. O comando externo, basicamente, é de posição e velocidade. O retorno é a 
posição real do flap obtida do encoder do motor. O comando de posição é executado com a velocidade imposta simultaneamente de cada segmento de movimento para evitar vibrações mecânicas e para se ter uma maior rigidez de controle. A Figura 4.29 mostra a malha de controle interna do servo-driver.

O controlador de posição conta com três malhas (loops), uma interna à outra: torque, velocidade e posição. A taxa de operação das malhas de controle é $900 \mathrm{~Hz}$. O controle de torque atua sobre o motor usando a corrente como realimentação. A malha de velocidade aplica torque ao motor usando a velocidade dada pela derivada da posição do encoder como realimentação. Por sua vez, a malha de posição aplica velocidade para controle e usa o encoder como realimentação. O controle de posição conta com um controlador PID, que conta também com um ganho feed-forward para minimizar problemas de atraso de fase na posição final. Esse problema pode afetar a resposta final do sistema. Esta realimentação aplica em paralelo ao PID de posição o erro de posição diretamente à malha de velocidade. Em paralelo ao controlador existe um observador do sistema que é usado para ajustar automaticamente os parâmetros dos controladores. Ele é chamado de auto-tunning. Foi feita a opção de se usar o ajuste automático do ganho da malha de posição e de velocidade simultaneamente ao controle feed-forward, para prevenir atrasos de fase da resposta dinâmica.

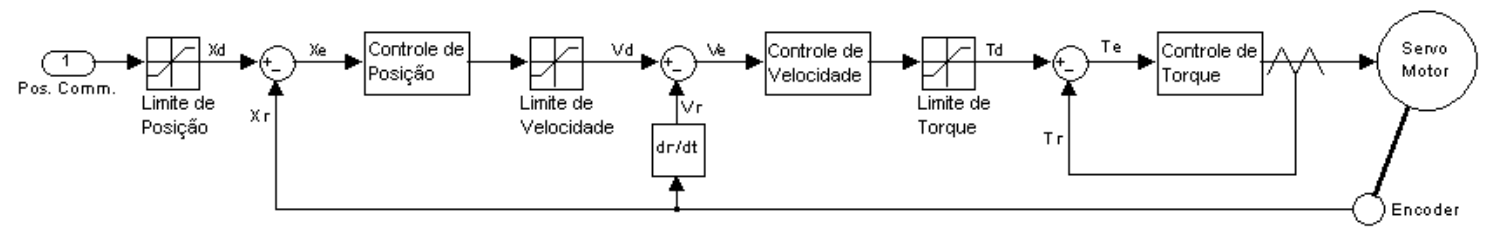

Figura 4.29. Malha de controle de posição dos servo-drivers.

\subsubsection{Leitura dos sensores de ondas}

Os sinais adquiridos dos sensores de ondas instalados nos flaps do gerador de ondas são feitos no CLP número 3. Ele está equipado com 152 canais de entrada de sinais analógicos em corrente padrão 4 a 20mA. O sinal é lido em corrente e convertido em tensão por resistores de precisão instalados em paralelo aos cartões ADC. Neles, são lidos os sinais provenientes dos circuitos condicionadores dos sensores. Foi selecionado 
nos cartões um filtro de média móvel que a cada 4 leituras a $800 \mu$ s resulta em uma amostra - portanto, a uma taxa de $3,2 \mathrm{~ms}$.

Foi incorporada ao processamento deste CLP a leitura do calado médio da água do tanque. Isso foi feito para se poder medir o calado do tanque para vias de controle do nível via válvula de liberação de água da rede, no futuro. Quando as leituras de ondas são feitas, o valor da linha de água é subtraído da amostra e o computador recebe o valor em torno do zero, que passa a ser o calado do flap. A média é calculada no CLP com a mesma taxa de $12 \mathrm{~ms}(83,3 \mathrm{~Hz})$ usada no controle. Quando requisitada a medição do calado, os sensores são acionados e após 5 segundos a leitura é feita por 10 segundos. Em seguida, o valor médio é calculado e salvo em uma variável para posterior uso no controle do gerador de ondas.

Algumas outras automações ela também executa, tais como sinalização luminosa e sonora, reconhecimento de emergências, controle de alimentação de energia e interface externa para intertravamentos e sincronismos para sistema de aquisição de dados nos ensaios do tanque de provas (triggers). A Figura 4.30 ilustra o CLP número 3.

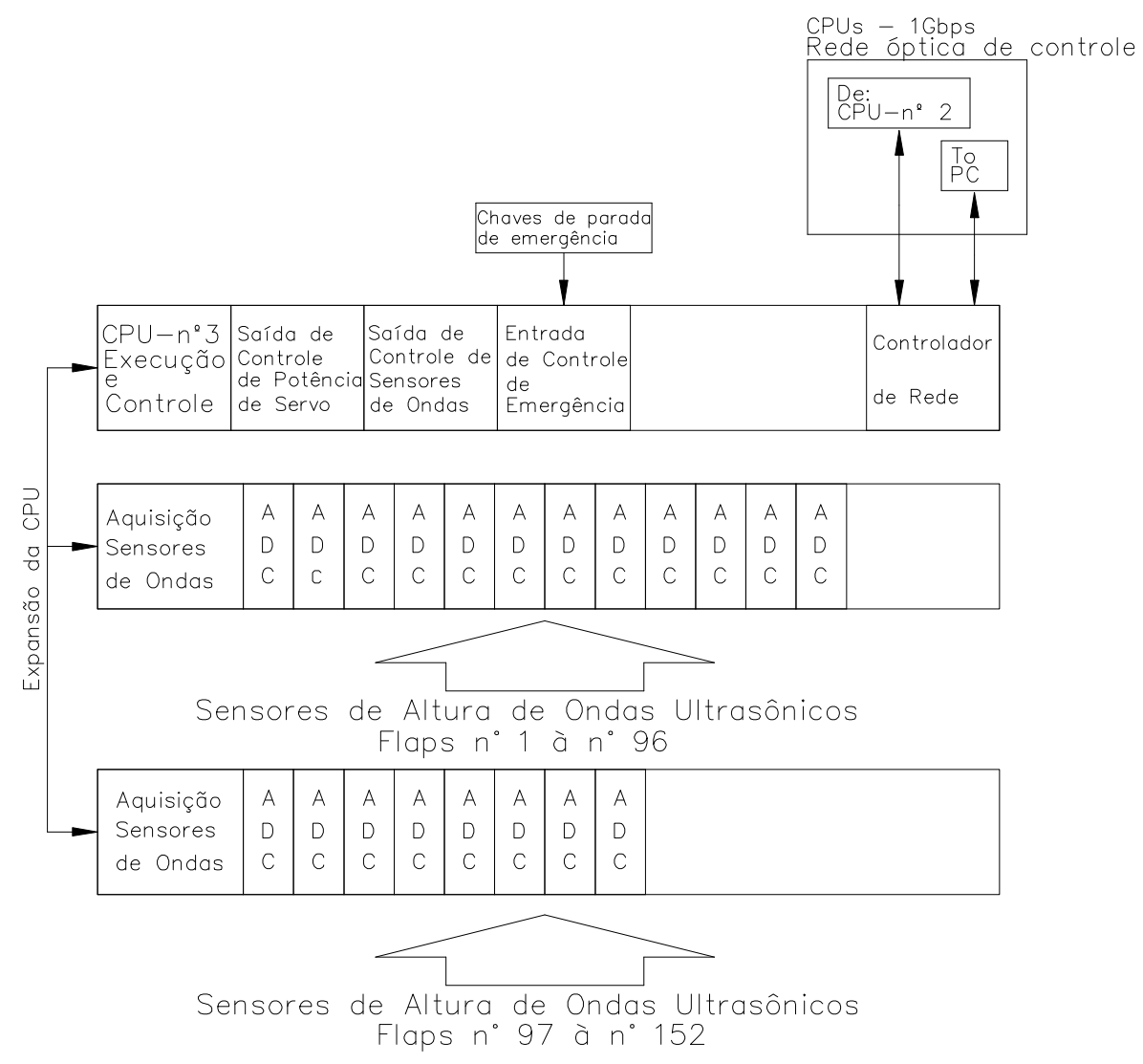

Figura 4.30. CLP de aquisição dos sensores de ondas. 


\subsubsection{Software de interface e controle}

Para servir de interface de todos os sinais via rede no PC de controle, um software em $C$ foi escrito como uma S-function do Simulink do MatLab®. Esse software funciona como um driver de interface para os sinais de rede ao Simulink.

Foi observado que todas as trocas de dados via rede puderam ser feitas em 10ms $(100 \mathrm{~Hz})$. Mas ao operar nessa taxa de amostragem por vezes ocorriam perdas de tempo real de execução (perda de passos de tempo), por questão de estabilidade foi estipulada uma taxa de $12 \mathrm{~ms}(83,3 \mathrm{~Hz})$, para uma operação segura. Portanto, o tempo de execução das operações da malha de controle dentro do Simulink foi feita em até $2 \mathrm{~ms}$. O computador usado nos testes foi um Workstation quad-core de 3,3 GHz. O MatLab® usa apenas um dos núcleos para processamento, pois as tarefas de interface e cálculos no Simulink não são multitarefas. Apesar disso, pode-se em um futuro próximo utilizar multiprocessamento e processamento em GPU usando-se as $S$-functions, caso seja necessário mais carga computacional.

A interface de operação atual, portanto, é o Simulink, mostrado na Figura 4.31; nele pode ser observado um bloco chamado "Calibrador Hidrodinâmico" que faz a conexão entre o hardware e o diagrama de blocos do Simulink. Operações de conversão de escala e tratamento dos dados são feitas de forma simples. Quando a simulação é iniciada, os set-points de posição e velocidades são enviados aos CLPs, a leitura da posição real, altura de ondas e base de tempo são adquiridos. A malha de controle de absorção de ondas para o tanque é então executada.

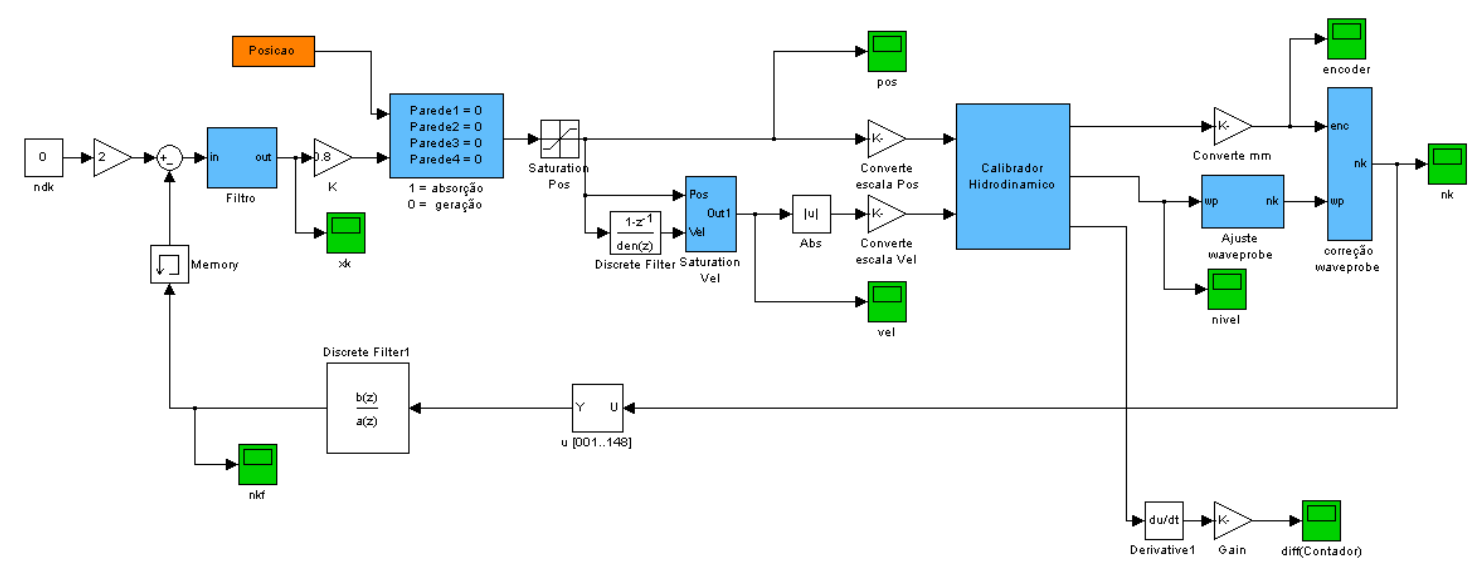

Figura 4.31. Tela do Simulink com controle do gerador de ondas. 


\subsection{Descrição do mecanismo atuador}

O mecanismo atuador é composto pelo servo-motor, fuso de esferas recirculantes, guia linear de apoio, braço de conexão ao flap, o flap propriamente dito e o mancal de apoio. Todo o conjunto atuador foi disposto em grupos de cinco montados sobre um quadro de apoio fixado sobre a laje de concreto próximo da borda do tanque de provas. O projeto do grupo atuador não é o foco deste trabalho. Somente será apresentado o funcionamento do mesmo. A Figura 4.32 mostra a mecânica do gerador de ondas. Maiores detalhes sobre o mecanismo podem ser visto em De Mello, Carneiro et al. (2007).

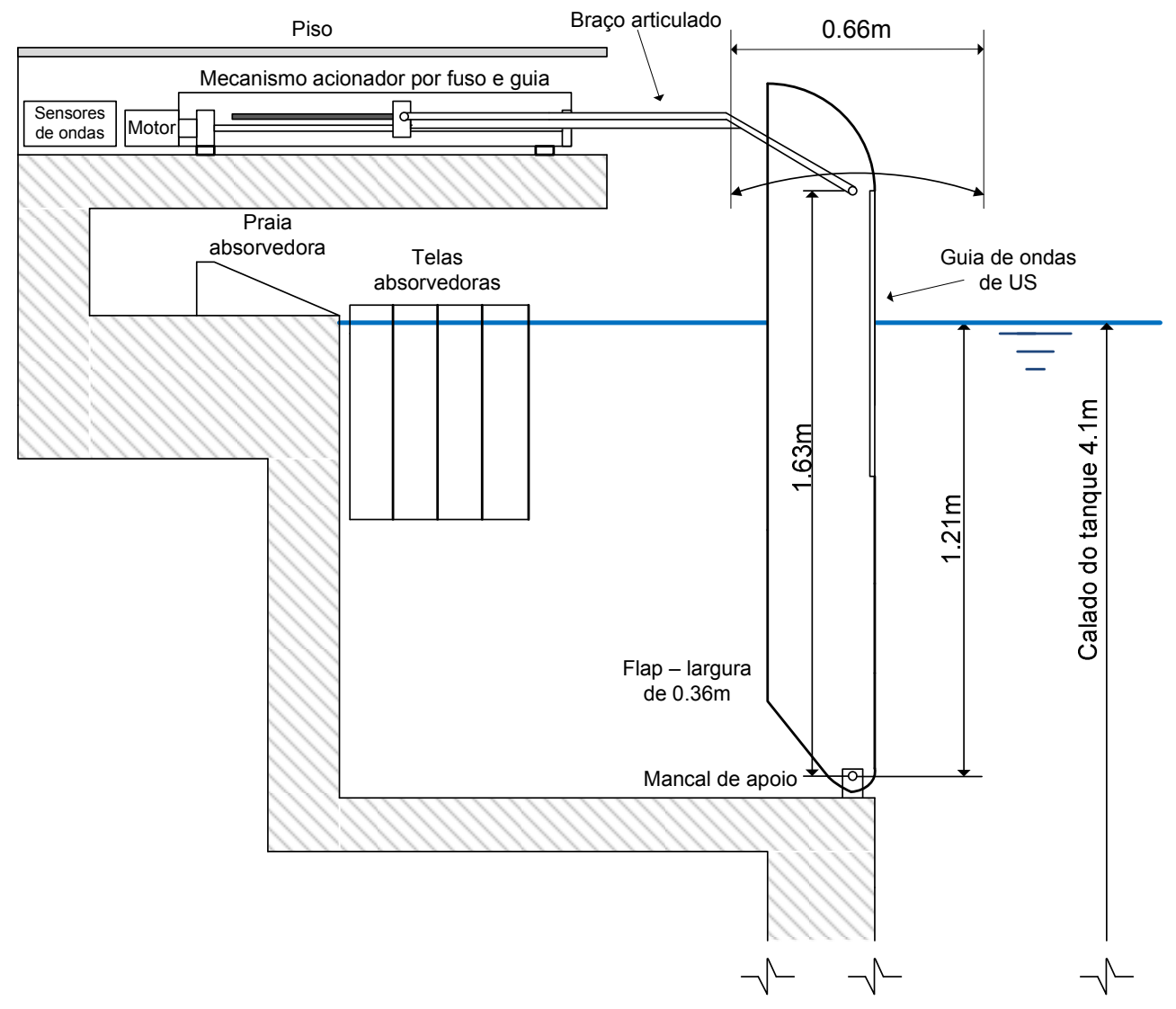

Figura 4.32. Atuador eletromecânico do gerador de ondas.

As paredes frontais e laterais do flap foram confeccionadas em fibra de vidro laminada sobre placas de poliuretano expandido com reforços internos, formando colmeias quadradas. Na parte posterior dos flaps, ligando a parede frontal e as laterais, foram feitos reforços de formato $\mathrm{X}$ e transversais para dar rigidez ao conjunto. Como as 
paredes e reforços foram feitos com as placas compostas de fibra de vidro e poliuretano, a resistência é grande enquanto o peso total é pequeno, cerca de $40 \mathrm{~kg}$. Na parte frontal do flap foi feito um corte vertical para encaixar as guias de ondas do medidor de ondas ultrassônicos centralizado no meio do seu eixo de medição. Embaixo do flap existem duas travas de eixo flangeadas presas às laterais do flap que suportam o eixo de fixação conectado a dois mancais de apoio com buchas poliméricas presas ao piso. A fixação dos mancais ao piso é feita em um trilho preso ao concreto por chumbadores que suportam vários flaps. Na parte superior dois mancais flangeados com rolamentos são fixados às laterais do flap e suportam o eixo superior do flap.

Ao eixo superior é conectado o braço articulado através de um garfo feito de alumínio fundido. O braço tem uma dobra para se adequar à altura da laje da borda do tanque. O braço articulado se conecta ao mecanismo atuador através de uma unidade de rolamento que provê movimento de rotação e giro lateral ao braço em caso de desalinhamento entre atuador e flap. A unidade de rolamento se conecta a um bloco de conexão de ferro fundido que é apoiado ao bloco móvel da guia linear e também ao bloco móvel do fuso de esferas recirculantes. O passo do fuso de esferas é de $5 \mathrm{~mm} / \mathrm{rev}$. e este é apoiado à mesa do atuador por dois mancais. O mancal frontal somente apoia $\mathrm{o}$ fuso radialmente e o posterior faz também a fixação axial. Devido ao tipo de apoio, a velocidade máxima do fuso, devido à vibração mecânica, é de aproximadamente 3000RPM. A mesa do mecanismo é de ferro fundido e usinada nos pontos de conexão mecânicos. Ao final fica posicionado o servo-motor conectado à mesa por um flange suporte a $90^{\circ}$ e conectado ao fuso de esferas por um acoplamento sem folgas de fole de aço. Os mecanismos atuadores, em grupos de cinco, são fixados a um quadro suporte. Finalmente o quadro é fixado à laje de concreto por 4 parafusos com espaçadores de borracha e uma barra em cada lateral do quadro horizontalmente à viga de alvenaria na parte traseira. As barras horizontais garantem rigidez para o quadro devido aos esforços da reação de força dos flaps no sentido horizontal. A Figura 4.33 mostra o detalhamento do sistema mecânico. Através de dois furos oblongos na mesa, os dois sensores de fim de curso magnéticos foram posicionados para detectar o máximo curso do bloco de conexão móvel. Quando excedido o limite de curso, os sensores freiam o movimento pelo controle de posição do servo-driver. 


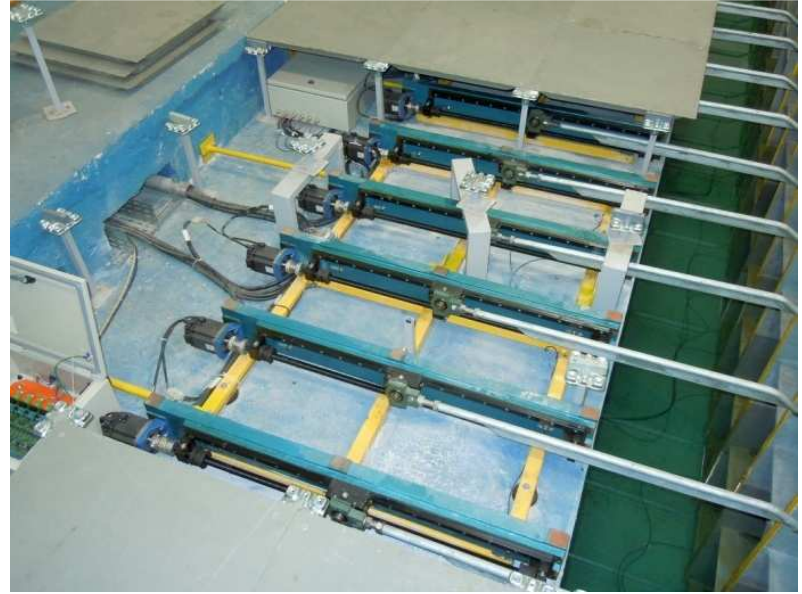

(a) - Quadro com 5 mecanismos atuadores montados no tanque de provas.

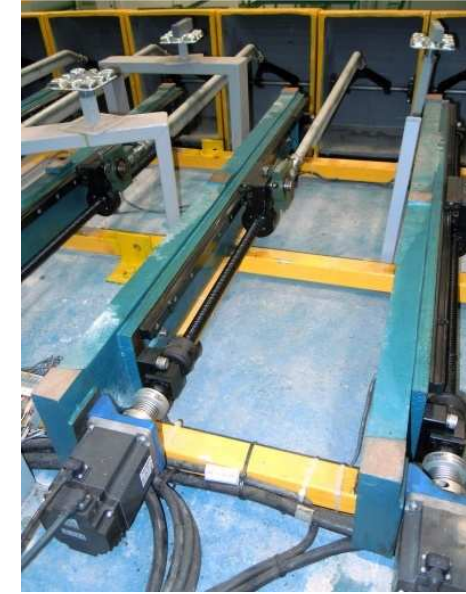

(b) - Detalhe de um dos atuadores.

Figura 4.33. Foto do mecanismo atuador.

Foi dada uma especial atenção aos absorvedores de ondas passivos traseiros aos flaps durante a concepção do gerador de ondas. As ondas geradas para trás dos flaps rebatem na parede de alvenaria traseira e retornam aos flaps formando uma caixa ressonante. O retorno da água aos flaps na parte traseira provoca um impacto indesejado que aumenta a fadiga mecânica dos equipamentos. Para evitar o impacto da água na parte traseira dos flaps foram tomadas duas medidas: a colocação de uma caixa com algum tipo de material poroso dentro que promova a absorção viscosa da energia das ondas e uma praia acima na mureta de alvenaria para absorver a energia das ondas mais altas. O Apêndice A mostra o desenvolvimento destes dispositivos para o tanque oceânico, mostrado na Figura 4.34.
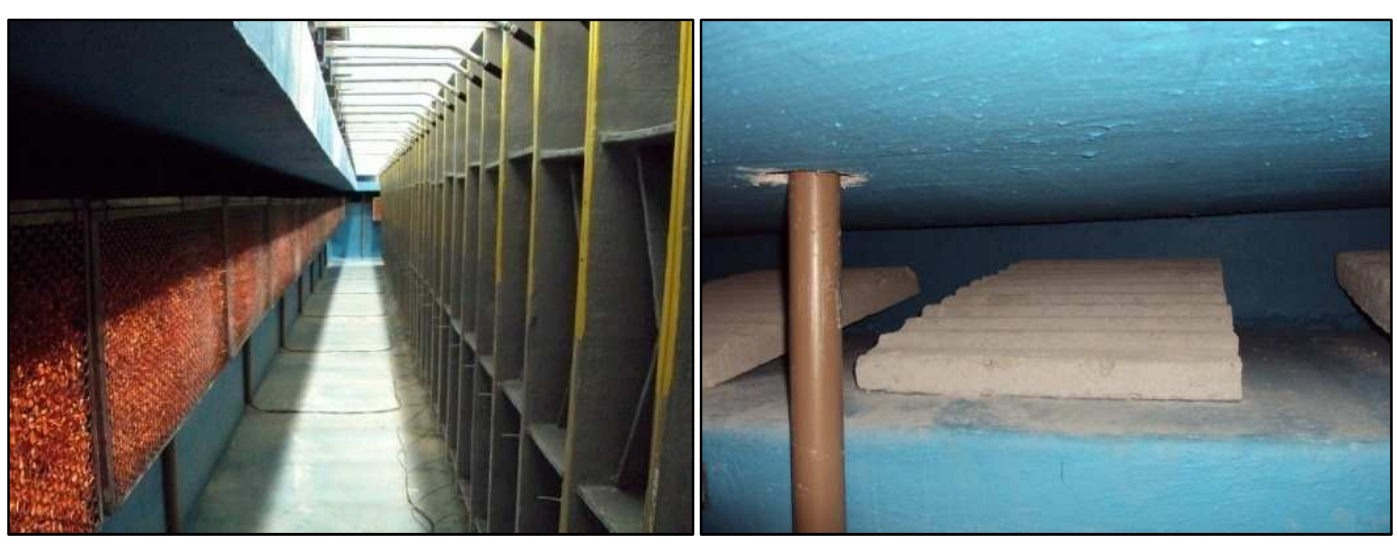

Figura 4.34. Absorvedores de ondas passivos. 


\subsection{Sensoriamento de altura de ondas por sensores capacitivos}

Os sensores de ondas capacitivos foram adotados para medir as ondas no interior do tanque de provas. Como foi mencionado anteriormente, sensores desse tipo apresentam histerese causada pela tensão superficial no fio revestido Wilner (1960); por essa razão o fio tem que ser o mais fino possível para minimizar tal efeito. Outro problema que ocorre é o ruído elétrico e a interferência cruzada entre sensores, o chamado cross-talk. Para evitar tal problema são usados isoladores galvânicos nos condicionadores de sinais em cada canal. Estas medidas foram adotadas nos sensores desenvolvidos para medição de ondas. O condicionador de sinais dos sensores é do tipo Sitron SC-404 com modificação de resposta dinâmica do filtro passa-baixas de saída, acrescido de isoladores de sinais de corrente 4 a 20mA com resposta dinâmica de $50 \mathrm{~Hz}$ por canal.

Como no tanque oceânico é necessário medir ondas de diversas direções, o suporte do fio sensor não deve provocar perturbação na superfície da água pela passagem da onda em qualquer direção de propagação. Foi usado, então, um tubo de aço inox cilíndrico de $8 \mathrm{~mm}$ de diâmetro servindo de suporte e terra ao sensor. O fio sensor é paralelo ao suporte com uma distância de 10mm. Veja a Figura 4.35.

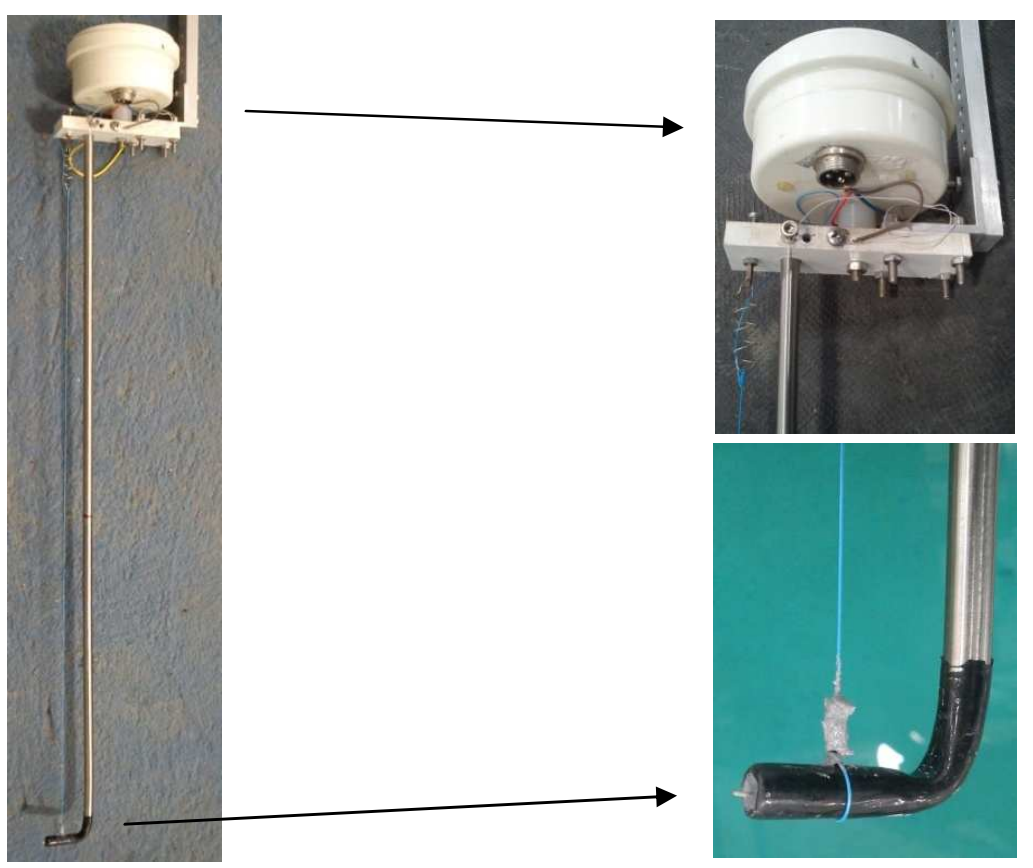

Figura 4.35. Sensor de ondas capacitivo. 
O fio usado foi do tipo wire-wrap, que é muito frágil. O revestimento do fio é de polipropileno. Se ele for tracionado excessivamente poderá se romper. Para tanto foi adicionada uma mola em série para mantê-lo esticado. Ao ser abalroado, a mola cede evitando a quebra, retornando à tensão normal após ser liberado. Na parte inferior do fio (dentro da água) o revestimento da capa é vedado com silicone.

Para garantir que as medições de ondas realizadas no tanque de provas tenham o desempenho aceitável para ensaios, uma série de testes nos sensores foi executada para avaliação. O primeiro deles foi a calibração estática. Seguindo uma metodologia padrão, foi montado um suporte para o sensor com graduação de $10 \mathrm{~mm}$ com um recipiente de água embaixo (veja Figura 4.36). A calibração foi feita nas posições: 0, $\pm 50, \pm 100$ e $\pm 150 \pm 200(\mathrm{~mm})$. Foram feitas três repetições em um total de 49 pontos. O instrumento de medida de tensão elétrica de saída era o HBM MX-840, adquirindo uma amostra de tensão em cada posição.

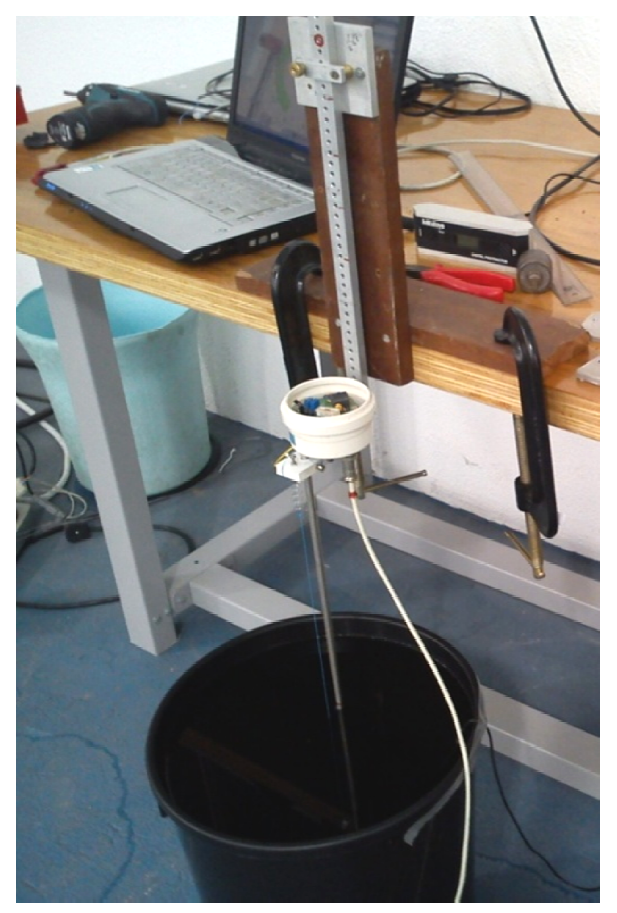

Figura 4.36. Arranjo experimental usado para calibração estática de sensor capacitivo.

O objetivo do teste era obter uma correlação quadrática ao ajuste a uma função linear que fosse melhor que 0,9999. A Figura 4.37 mostra o resultado da calibração 
estática, em que o valor da correlação quadrática obtida foi de 0,9999886; portanto, acima da meta pré-estabelecida.

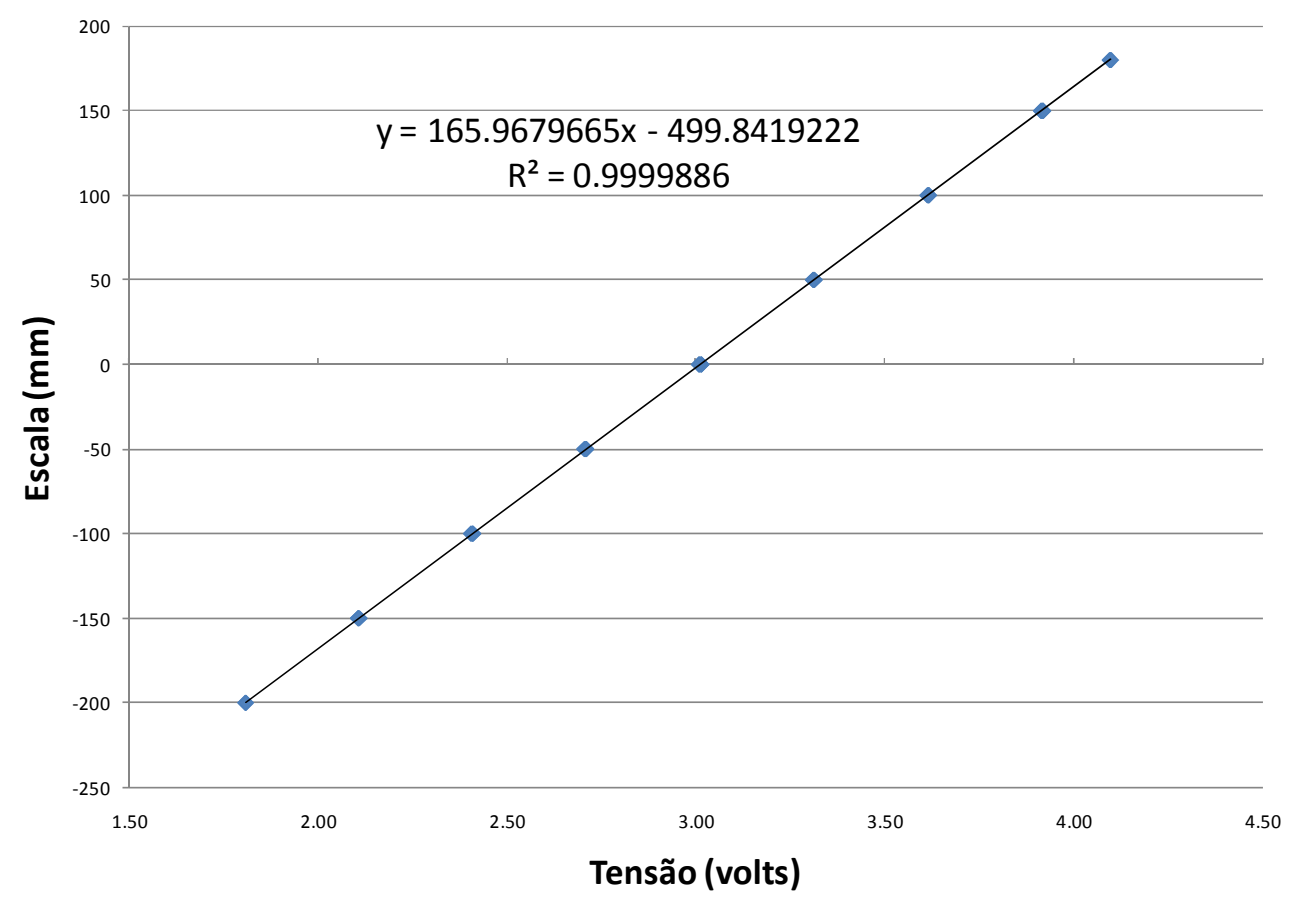

Figura 4.37. Regressão linear para ajuste de calibração estática de sensor capacitivo.

A segunda etapa da calibração foi a execução de testes para avaliar a resposta dinâmica do sensor. A faixa de utilização de ondas no tanque de provas tem frequências entre $0,5 \mathrm{~Hz}$ e $3 \mathrm{~Hz}$. Assim, foi usado um mecanismo atuador eletromecânico de um grau de liberdade acionado por servo-driver e motor brushless de $400 \mathrm{~W}$ com movimento harmônico simples que opera de $0,1 \mathrm{~Hz}$ até $2,5 \mathrm{~Hz}$, pouco abaixo da máxima frequência de ondas. Veja a Figura 4.38. O atuador conta com uma rampa linear de inicialização de um ciclo de oscilação. Caso o movimento oscilatório começasse de forma brusca, efeitos transitórios poderiam contaminar o resultado do teste.

O atuador eletromecânico, por sua vez, tem resposta dinâmica com tendência de perda de amplitude com o aumento da frequência. Sendo assim, foi usado um potenciômetro multivoltas de precisão para medir a posição real do atuador através de uma roldana, com um cabo ligado à estrutura do atuador. Durante os ensaios, o valor da posição dada pelo potenciômetro foi calibrado, bem como o do sensor capacitivo, usando a mesma escala milimétrica. Os dois sensores foram adquiridos pelo sistema de aquisição de dados HBM MX-840. 
Para o teste da tendência dinâmica definiram-se as seguintes frequências de oscilação: 0,1 - 0,5 - 1,0 - 1,5 - 2,0 - 2,5 (Hz), para alturas de: $10-20-40(\mathrm{~mm})$. Foram usados 60 ciclos de oscilações por frequência e altura; foram analisadas as alturas por espectro cruzado de 60 ciclos de oscilação de cada frequência entre o potenciômetro e no sensor capacitivo. Portanto o que foi obtido é a função de transferências entre o potenciômetro (posição real) e o sensor capacitivo.

A calibração estática foi feita para determinar o ganho dos sensores antes do início do teste para as mesmas distâncias do teste estático, mas somente com uma repetição. A regressão linear estática dos sensores foi feita simultaneamente e resultou em correlações quadráticas de 0,9999971 no sensor capacitivo e 0,9999534 no potenciômetro. Em seguida o teste dinâmico foi executado. O valor da perda de amplitude ocasionada pela resposta dinâmica do atuador foi então considerado na análise, ou seja, os pontos experimentais foram ajustados para que a perda dinâmica do atuador fosse subtraída da resposta dinâmica do sensor. Na Figura 4.39 o resultado da função de transferência do sensor é apresentado em valor percentual para comparação direta entre as diferentes alturas ensaiadas.

Nota-se que percentualmente a perda de altura lida é praticamente a mesma, no pior caso com $3,47 \%(H=40 \mathrm{~mm})$ e no melhor caso com 3,17 \% $(H=10 \mathrm{~mm})$ para a frequência de $2,5 \mathrm{~Hz}$. A fase tem resposta semelhante nos três casos. O resultado indica que o efeito da tensão superficial é pequeno, caso contrário os valores percentuais seriam discrepantes entre si. A altura de ondas com 10mm apresenta o menor desvio, com $0,32 \mathrm{~mm}$; o maior desvio é de $1,4 \mathrm{~mm}$ com a onda de $40 \mathrm{~mm}$. Os condicionadores de sinais usados neste teste apresentam resposta dinâmica de $50 \mathrm{~Hz}$. A resposta do atraso do condicionador acrescido de problemas inerentes ao método de medição descrito em Wilner (1960), como por exemplo, histereses no fio sensor, somadas linearmente resultam nas curvas obtidas. 


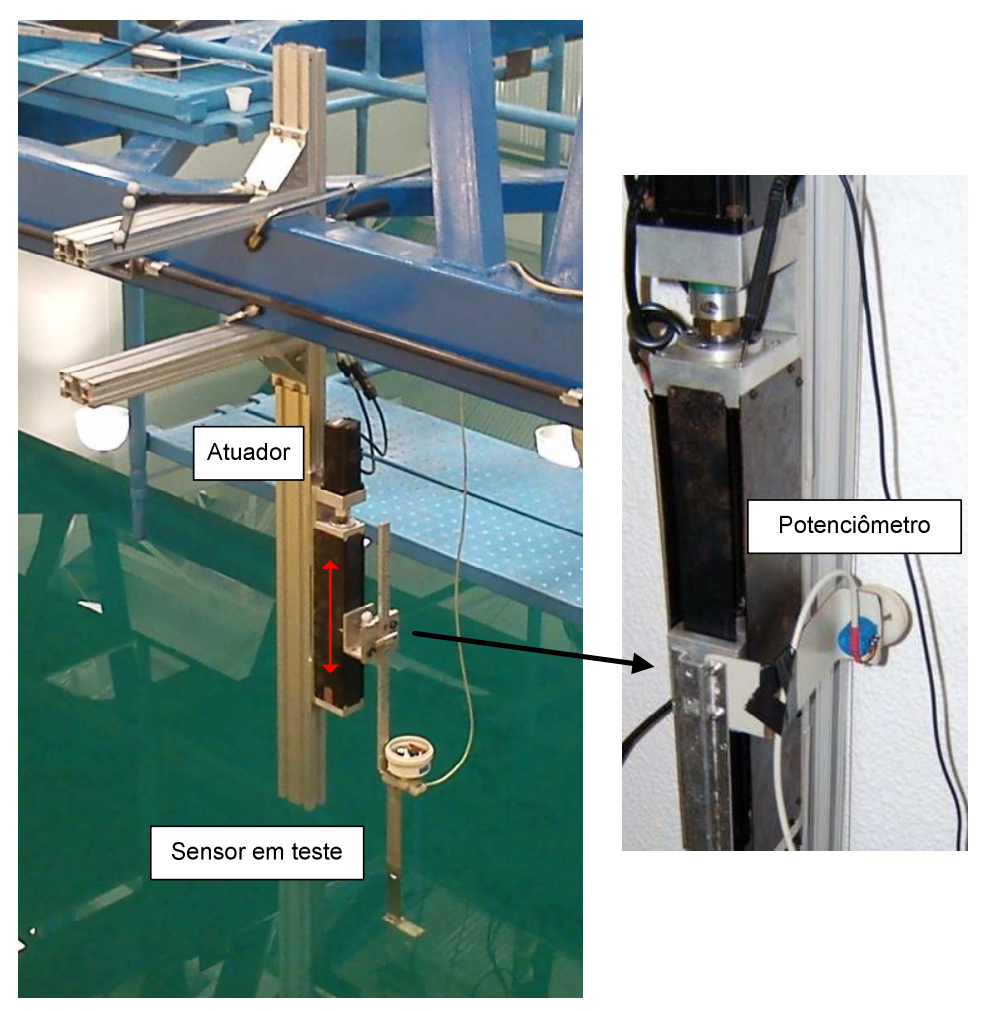

Figura 4.38. Arranjo experimental utilizado na avaliação da resposta dinâmica do sensor de ondas capacitivo.
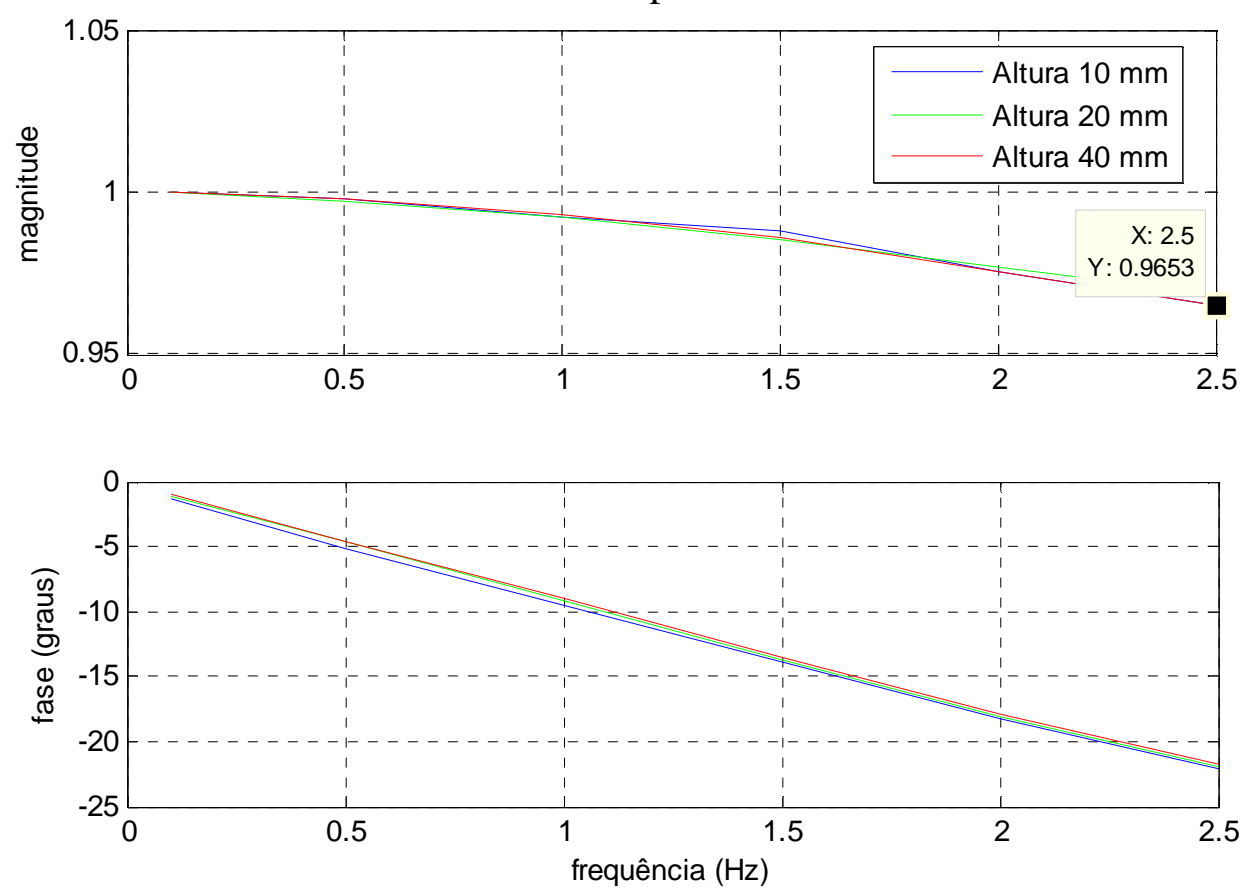

Figura 4.39. Resultado obtido no teste de calibração dinâmica - valor normalizado. 


\section{Procedimentos para a geração de ondas}

As teorias de ondas aqui apresentadas foram estudadas visando a aplicação ao caso específico do Calibrador Hidrodinâmico. O tanque para testes hidrodinâmicos foi concebido para ser multidirecional e com formato quadrado. Neste capítulo, é mostrada a teoria de ondas necessária para os mais variados ensaios com modelos, como foi discutido no capítulo 3. No capítulo 4, especificamente nos tópicos 4.1 e 4.5 , é apresentado o sistema de referências utilizado no tanque de provas, bem como a numeração dos flaps, as dimensões e os aspectos mecânicos.

A seguir, são apresentadas as técnicas de geração de ondas aplicadas ao Calibrador Hidrodinâmico. Os ensaios realizados utilizando tais técnicas são mostrados no capítulo 6.

\subsection{Ondas regulares}

Utilizando a função de transferência de ondas progressivas deduzida no capítulo anterior (eq. 3.26) e as definições do tanque do Calibrador Hidrodinâmico, será mostrada a aplicação ao caso do Calibrador Hidrodinâmico. Todas as quatro laterais do tanque devem absorver as ondas para evitar reflexões de ondas e ressonâncias no tanque. A Figura 5.1 ilustra tais situações.

No caso de geração por uma única lateral, o lado oposto deve absorver as ondas a $0^{\circ}$, enquanto as laterais, nesse caso específico, devem absorver somente as ondas irradiadas por um modelo sendo ensaiado, pois as ondas progressivas estão a 90 graus. A priori, pelo fato de a onda ser paralela às laterais, não é possível absorvê-la nem tampouco gerá-la.

No caso oblíquo, duas laterais geram e absorvem ondas e as outras duas laterais absorvem. Nesse caso, o movimento do gerador adquire a forma descrita na Figura 3.8 e o número de ondas é decomposto em duas projeções ortogonais. Da mesma forma, a absorção de tais ondas deve considerar ajustes na função de absorção para levar em consideração o ângulo de incidência da onda e absorvê-la corretamente. 


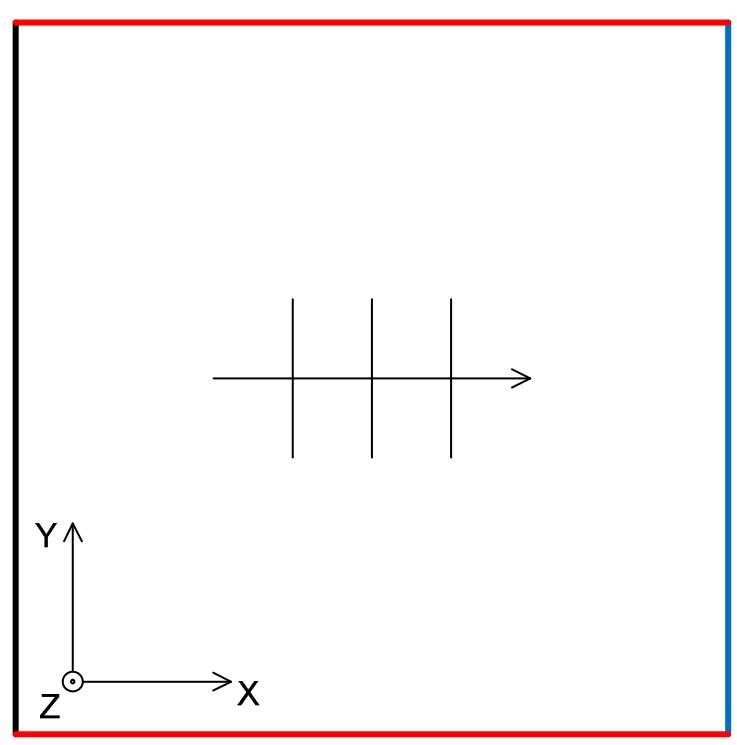

(a) - Caso não oblíquo

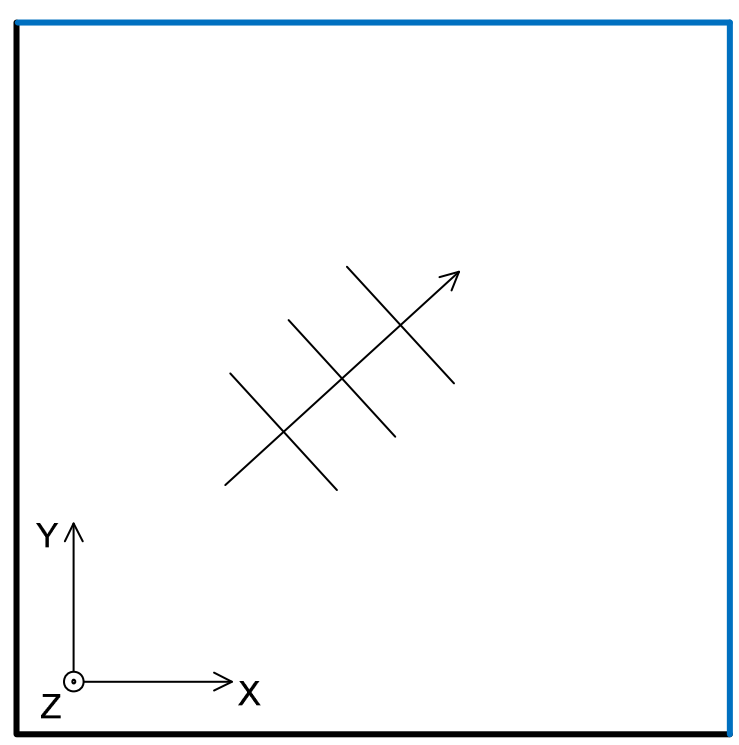

(b) - Caso oblíquo

Figura 5.1. Ilustração de geração de ondas no tanque.

As séries temporais são calculadas em função da posição do flap no tanque e da direção de geração de ondas. Fazendo uso de defasagem entre os flaps para obter ondas oblíquas (BIESEL, 1954), que aparece explícita na equação (3.16), podem-se criar tais fases a partir da posição dos flaps no tanque. A equação citada revela que se deve defasar pela distância da crista ao flap na direção de propagação da onda. Assim podese obter a série temporal de todos os flaps do gerador de ondas. Neste caso o movimento é igual ao modelo cinemático de geração e absorção descrito por Newman (2008), em que os flaps em absorção devem ter fase inversa da geração para poder absorver as ondas. Pode-se ilustrar o conceito da fase da onda nas posições dos flaps na Figura 5.2. 


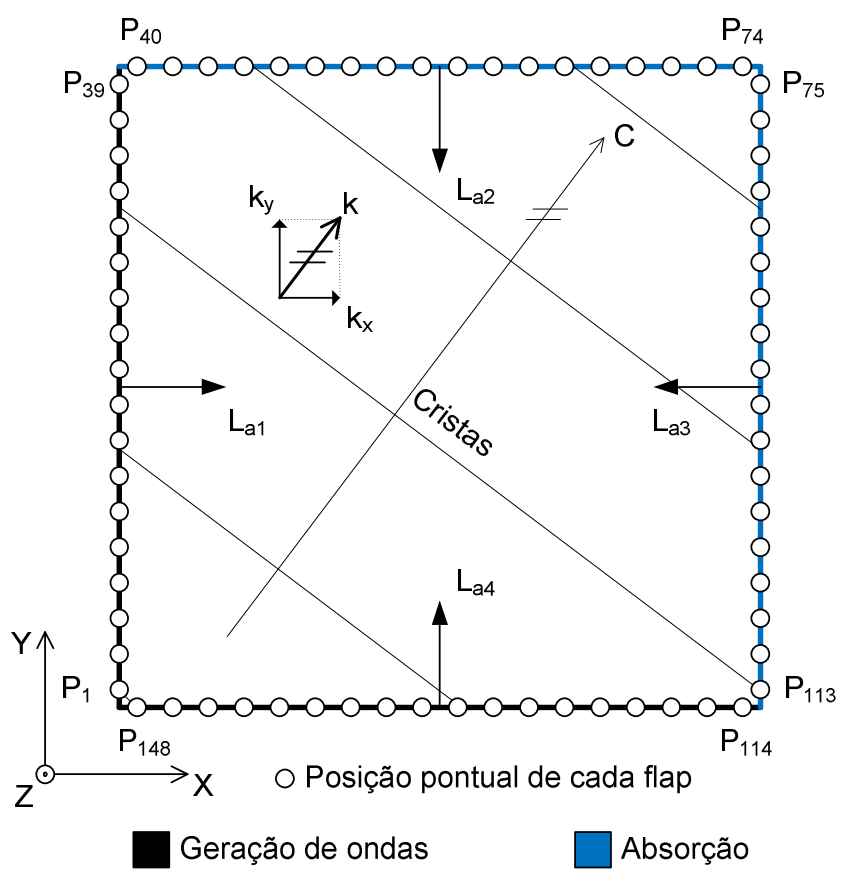

Figura 5.2. Onda regular propagando através do tanque oceânico.

A posição pontual de cada flap é a posição do centro de cada flap de forma discreta. Os flaps do Calibrador Hidrodinâmico têm $0.36 \mathrm{~m}$ de largura. Portanto, para as ondas regulares, pode-se descrever a série temporal de geração de ondas como:

$X_{0 j}=\frac{A_{j}}{c_{0}} \frac{\tau_{\mathrm{j}} \cos \theta_{\mathrm{j}}}{\operatorname{sen} \tau_{\mathrm{j}}} \frac{H}{2} \cos \left(-\omega t+k_{x} P_{x j}+k_{y} P_{y j}\right)$

onde $j$ é o índice do número de flap. As posições dos flaps em planta são $P_{x j}$ e $P_{y j}$. Somente resta demonstrar a seleção dos flaps que atuaram em função do arranjo físico incorporado no termo $A_{j}$, dado pela equação (5.2). A direção de $L_{a}$ pode ser vista na Figura 5.2.

$A_{j}\left(L_{a}, k\right)= \begin{cases}A_{j}=1, & \left|L_{a} \angle k\right|=\theta_{\mathrm{j}}<90^{\circ} \\ A_{j}=0, & \left|L_{a} \angle k\right|=\theta_{\mathrm{j}} \geq 90^{\circ}\end{cases}$

Sempre que $A_{j}\left(L_{a}, k\right)=1$ o ângulo $\theta_{\mathrm{j}}$ terá valor real, caso contrário será nulo. $\mathrm{O}$ ângulo $\theta_{\mathrm{j}}$ é aplicado na equação (5.1) e no cálculo de $\tau_{\mathbf{j}}$.

Antes de gerar uma onda, a verificação do Limite de Biesel é feita em cada lateral para garantir que não ocorra a geração de ondas espúrias no tanque. Caso não atenda ao 
critério, a onda não pode ser gerada. Caso o ângulo de geração seja zero, a parcela do ganho em função de teta $(\theta)$ é descartada.

Outro ponto que mereceu estudo foi como fazer uma rampa gradual de inicialização e finalização do acionamento. $\mathrm{O}$ modelo utilizado é simplificado e visa somente evitar o surgimento de efeitos transitórios na geração de ondas. Além de fazer uma rampa com aumento linear de alguns segundos de duração no início da geração, foi feito um atraso gradual para que a onda começasse a ser gerada a partir da primeira aresta de onde a onda ira surgir no interior do tanque de provas. Assim, as cristas das ondas começam a ser geradas no flap mais distante do centro do tanque na direção das cristas das ondas, garantindo que o campo de ondas sempre esteja homogêneo no centro do tanque desde os primeiros ciclos de ondas. A Figura 5.3 ilustra uma onda regular a $45^{\circ}$ passando pelo centro do tanque em linha usando tal técnica. O efeito criado é como se a onda propagasse através das fronteiras do tanque para dentro dele.

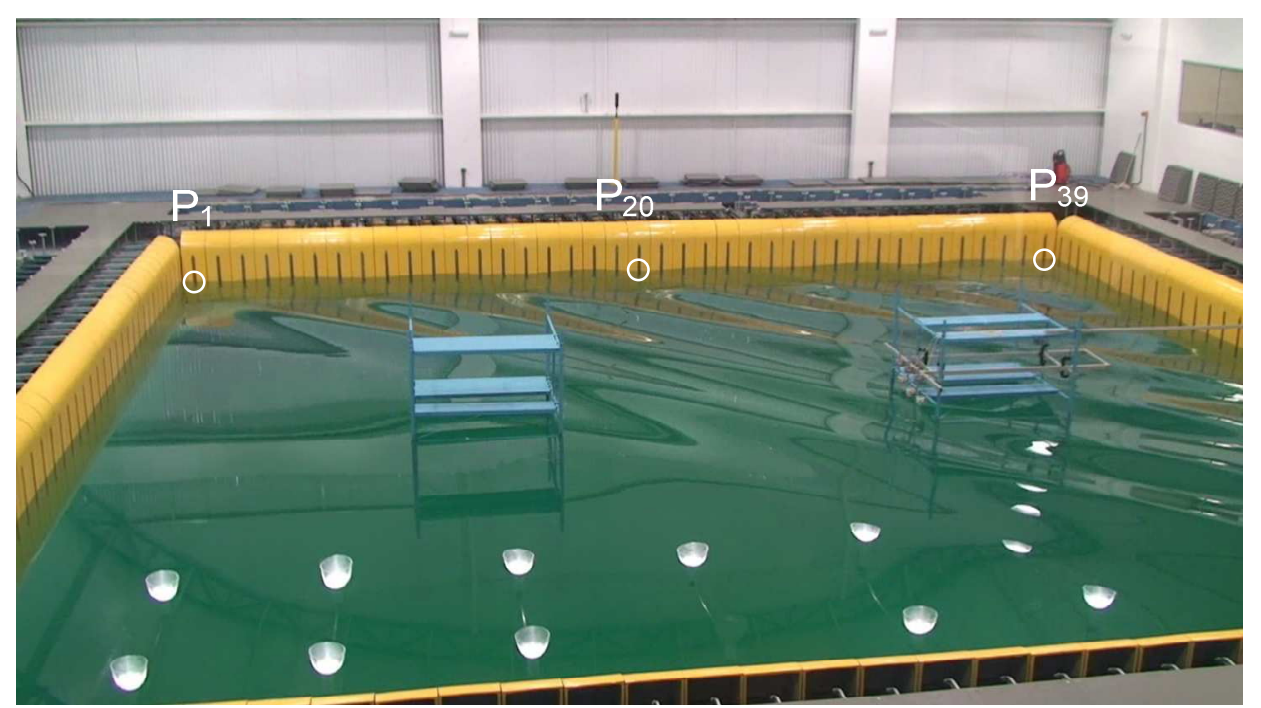

Figura 5.3. Inicialização da onda em geração de onda de $1 \mathrm{~Hz}$ com $40 \mathrm{~mm}$ de altura a $45^{\circ}$.

O atraso temporal necessário para que a onda comece a ser gerada na fronteira anterior do tanque é calculado primeiramente com o atraso temporal a partir da fase da onda em cada flap:

Atrasofase $_{j}=\frac{k_{x} P_{x j}+k_{y} P_{y j}}{\omega}(s)$ 
onde $j$ denota o índice de cada flap. Em seguida, a partir da relação entre velocidade de fase e de grupo (eq. 3.11), calcula-se o atraso do início do "pacote" de ondas:

Atrasogrupo $_{j}=\frac{\text { Atrasofase }_{j}}{n}(s)$

Normalmente, para grande parte das ondas utilizadas no tanque, a relação entre a celeridade de fase e a de grupo leva a valores de $n \approx 0.5$; portanto, a velocidade de grupo muitas vezes é metade da velocidade de fase. No trabalho o valor de $n$ é sempre calculado em função da frequência da onda e da sua profundidade. Finalmente ajusta-se o tempo de atraso em relação ao flap inicial:

Atraso $_{j}=$ Atrasogrupo $_{j}-\min \left(\right.$ Atrasogrupo $\left._{j}\right)(s)$

Após aplicar este atraso a cada flap, uma rampa suave de ganho variando de 0 a 1 é feita por alguns segundos para prevenir efeitos transitórios e o surgimento de ondas livres no início da propagação da onda. Outra rampa decrescente é adicionada ao final da série temporal para que o movimento não termine bruscamente. A Figura 5.4 mostra o resultado do método.
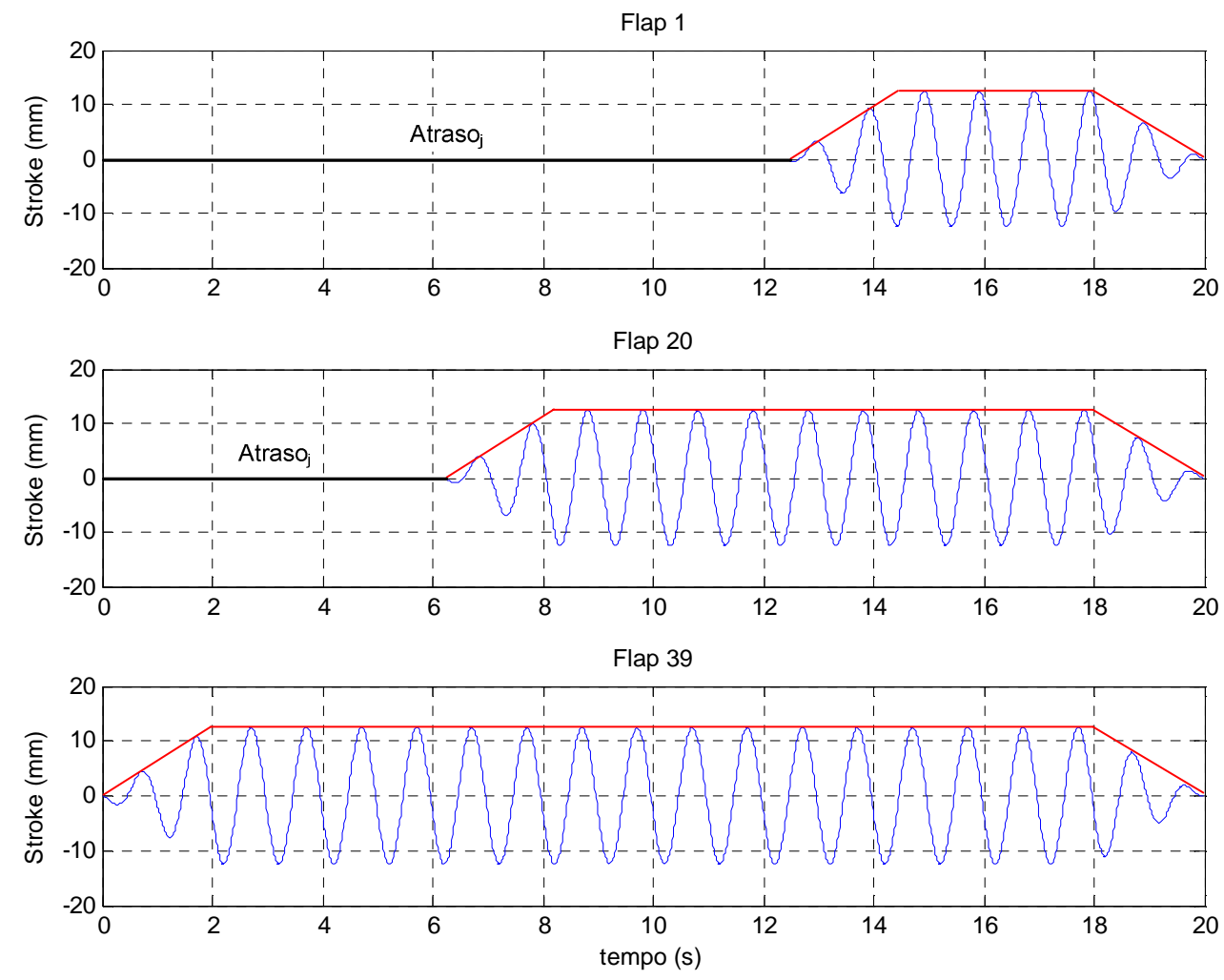

Figura 5.4. Série temporal de deslocamento para 3 flaps com onda de $1 \mathrm{~Hz}$ por $40 \mathrm{~mm}$ a $45^{\circ}$. 


\subsubsection{Estimativa de ondas nos batedores}

Os trabalhos de Maeda (2004), Zhang (2005) e depois Zhang, Schäffer e Jakobsen (2007) mostram que existem dois métodos para se abordar a absorção de ondas. A absorção ativa de ondas não é o foco deste trabalho; mas o segundo método, chamado por Zhang (2005) de dual mode, é bastante interessante de ser abordado, pois tem características que podem melhorar a qualidade das ondas geradas no tanque de provas. O método funciona da seguinte maneira: enquanto o gerador de ondas executa uma série temporal de deslocamento para gerar uma onda progressiva, uma segunda série temporal da estimativa da onda que deve existir nos sensores instalados em cada batedor é carregada pelo sistema de geração e absorção. A estimativa de onda é subtraída do sinal dos sensores e a diferença desta elevação de onda é usada para se fazer a absorção de ondas. Toda vez que existir reflexão de ondas incidindo em determinado flap, o valor da elevação poderá ser determinado e a absorção será feita. A reação para absorver essa onda é então somada ao deslocamento enviado ao flap. O sistema torna-se uma malha fechada com dois sinais de entrada pré-carregados: o deslocamento e a estimativa de onda causada por esse deslocamento.

Uma vez que o tanque tem que gerar e absorver ondas simultaneamente, a absorção ativa precisa operar integrada à geração. Dessa forma, neste trabalho, foi pesquisado o método de síntese da série temporal da estimativa de onda no flap, chamada aqui de $n d$.

O seu valor é determinado pela reação do flap. Aplicando a função de transferência total da equação (3.35), obtém-se o valor de $n d$ :

$n d_{j}=X_{0 j} \cdot F T$

A função de transferência utilizada leva em consideração as parcelas progressivas e evanescentes de onda; desse modo, o módulo e a fase da onda regular no batedor são dados pela resposta mostrada na Figura 5.5. Para uma dada frequência de onda, o módulo e a fase têm o comportamento mostrado em relação ao deslocamento dado. 
$\mathrm{Na}$ série temporal de $n d$ também são aplicadas as funções de atraso temporal e suavização utilizadas no início e no final da série temporal de deslocamento do atuador. A comparação do resultado experimental da medição de onda nos sensores de ondas dos flaps com a curva teórica serve de validação de funcionamento do sistema gerador de ondas. Esta análise será apresentada no capítulo 6.
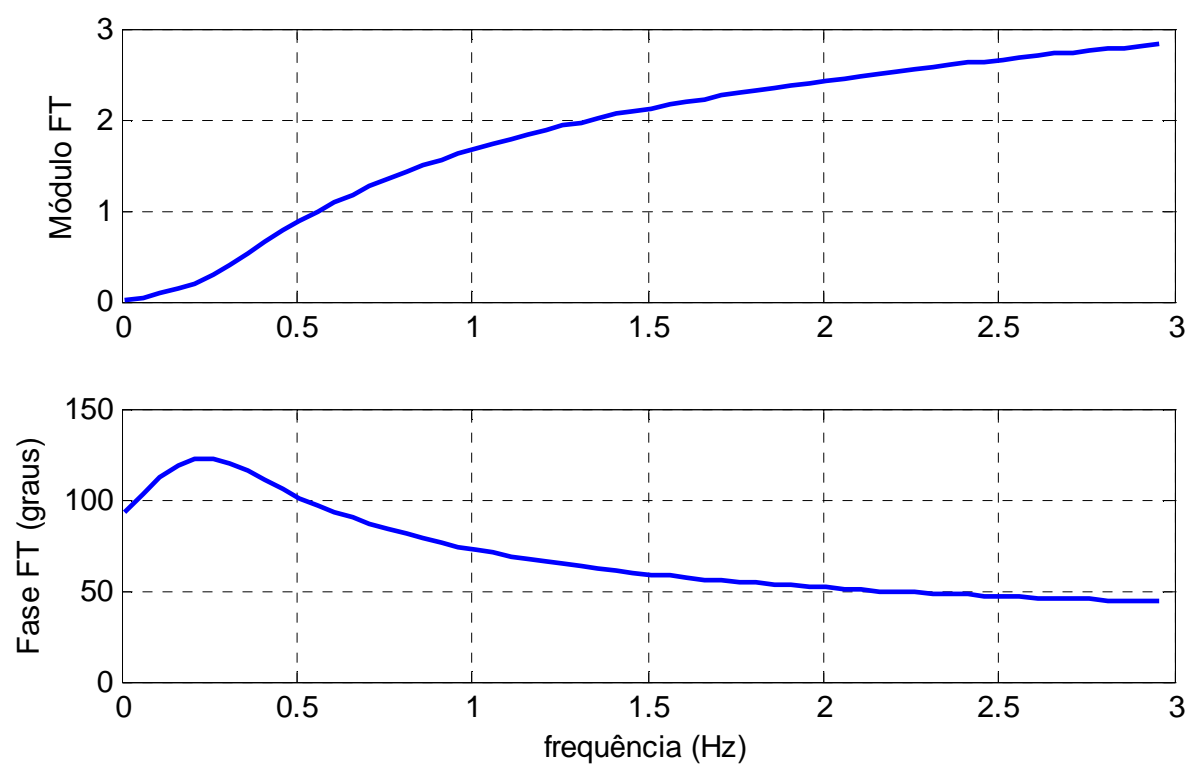

Figura 5.5. Função de transferência (FT) nos batedores de ondas.

\subsection{Ondas irregulares}

A onda irregular tem como característica ser de natureza aleatória; é originada pela ação do vento sobre a superfície livre da água e tem como força restauradora a gravidade. Devido à característica aleatória da sua natureza, as ondas irregulares têm alturas, períodos e direções de propagação que variam ao longo do tempo. Assim sendo, na literatura científica, foram definidos diversos parâmetros estatísticos para modelar as ondas de um mar real. A partir de diversas observações da natureza, feitas por diferentes métodos que evoluíram ao longo do tempo, foram definidos diversos "estados de mar" para diferentes regiões do mundo. A importância destes estudos é grande, pois as ondas irregulares têm grande relevância nas pesquisas de engenharia oceânica.

Normalmente uma amostra de medição de mar, que representa uma tempestade ou um evento específico, busca ser representativa para descrever sua característica. Descrevendo o mar por parâmetros estatísticos, dificilmente ele terá todas as 
características de um determinado evento (onda), mas é assumido como tal, estatisticamente estacionário (dentro da amostra) e homogêneo no tempo e no espaço, ou seja, estocástico e ergódico.

Em ITTC (2002) podem ser vistas diversas recomendações acerca da simulação de mares, bem como recomendações para a realização de mares em tanques para ensaios com modelos em escala reduzida. Para aplicação offshore, deve-se usar um registro de ao menos 100 ciclos de ondas de maior período observado para a convergência da estatística do mar. Normalmente usa-se um tempo de registro equivalente a 3 horas em escala real, pois esse é o tempo característico de uma tempestade e que garante um número elevado de ciclos de ondas. O estudo também mostra possíveis fontes de incertezas e erros relatadas por diversos autores que lidam com a realização de tais experimentos - desde recomendações sobre métodos de criação de séries temporais até problemas mecânicos em geradores de ondas que acarretam a incorreta reprodução dos movimentos necessários nos experimentos.

São usados diversos parâmetros estatísticos para se definir um mar característico para um ensaio, bem como métodos de análise de mares. Em Chakrabarti (1987) pode ser encontrada uma série de tipos de análises de mares. Um importante aspecto dos mares é a sua distribuição de energia em função da frequência, o chamado espectro de densidade de potências. Definido de forma paramétrica, baseia-se em observações de mares reais. Existem também modelos paramétricos de espalhamento direcional de energia, usados para definir mares do tipo cristas curtas (short-crested). Análises direcionais mais complexas podem ser vistas em Mitsuyasu, Tasai et al. (1975), em Hasselmann, Dunckel e Ewing (1980) e em Mendes (2005) sobre espalhamento direcional, as quais foram utilizadas neste trabalho.

$\mathrm{Na}$ prática de uso em geradores de ondas, as ondas irregulares normalmente são sintetizadas de diversas maneiras. O trabalho de Miles e Funke (1989) apresenta alguns exemplos de métodos que podem ser utilizados. O método mais difundido é também o mais simples: é o método das fases aleatórias. Simplesmente se faz uma somatória de diferentes frequências harmônicas com amplitudes dadas pelas componentes de um espectro de potências do mar real que se quer sintetizar. As fases das componentes harmônicas recebem uma "semente" aleatória que faz com que a série temporal tenha um comportamento similar ao das ondas irregulares. $\mathrm{O}$ custo computacional desse método, no entanto, é muito alto. 
Outros métodos tendem a ser aplicados por conta do custo computacional, como, por exemplo, o da filtragem do ruído branco. Nesta abordagem uma sequência randômica de números sem distribuição de valores é filtrada por um filtro digital passabanda com o formato do espectro de potências. O filtro tem um ganho diferente para cada frequência, de forma que o espectro da série temporal obtida é semelhante ao requerido. Dessa forma, o resultado é uma série temporal da elevação da superfície livre.

Outro método que tem rapidez de processamento é o das fases aleatórias com aplicação feita por FFT, chamada de coeficientes randômicos de Fourier. Usando a amplitude do espectro e uma semente aleatória, criam-se duas componentes de amplitude aleatórias. Em seguida, é feita a transformada inversa de Fourier resultando na série temporal de onda.

Em (Chakrabarti, 1987) é mostrado o método das fases aleatórias e dos coeficientes randômicos de Fourier. Segundo o autor, para uma devida representação da distribuição gaussiana da elevação do mar, o método usando FFT é citado como mais adequado, pois o método das fases aleatórias pode apresentar erros na distribuição gaussiana da superfície livre. Por outro lado, o autor diz que esses erros ocorrem com séries temporais com pouca resolução e duração e não é consenso na literatura que tais erros sejam consideráveis.

Novamente no trabalho de Miles e Funke (1989) é feita a comparação das resoluções de tais métodos. Somando-se muitas componentes harmônicas ao sintetizar tais séries temporais, pela análise de espectros cruzados analiticamente em diferentes posições espaciais, pode-se garantir que o método das fases aleatórias tenha boa estatística, estacionária temporalmente e espacialmente. A conclusão obtida pelo autor foi de que para simular um mar deve-se ter um $\Delta f$ inversamente proporcional ao tempo total da série temporal e é preciso que existam ao menos 32 componentes direcionais em mares de cristas curtas (com espalhamento direcional). A definição de $\Delta f$ é premissa para a transformada de Fourier; mas, devido ao elevado custo computacional, pela grande quantidade de componentes em frequências, algumas vezes poder-se-ia optar por utilizar um $\Delta f$ maior que o recomendado. Assim, o autor faz uma análise para verificar as implicações dessa opção, que, no caso, causa problemas de convergência estatística da série temporal gerada. 
Neste trabalho, foi feita a opção por utilizar o método das fases aleatórias. O método é também o mais simples para se trabalhar. Essa opção, usando as recomendações apontadas acima no texto, tem um desempenho semelhante ao dos outros métodos, segundo os trabalhos pesquisados. A aplicação do método é uma expansão da teoria de ondas regulares descrita no tópico 5.1, agora para espectro de energia e espalhamento direcional. As expansões serão apresentadas separadamente no trabalho. O tempo computacional foi comparado e concluiu-se que, devido à maior capacidade dos computadores atuais, não existe um impacto grande no tempo de processamento. O estudo da otimização dos algoritmos para aumento da velocidade de processamento fica como recomendação de desenvolvimento futuro. Outra vantagem do método é que se pode fazer, de forma simples, a criação da série temporal da estimativa de onda nos batedores de ondas, chamada de $n d$ no tópico 5.1.1, de forma simples.

Uma vez definido o método de expansão harmônica e direcional, restam ser definidos o modelo de espectro de energia paramétrico e o modelo de espalhamento direcional que serão adotados ao longo do trabalho.

Entre os modelos de espectro de energia, foi experimentado o modelo do tipo JONSWAP (Joint North Sea Wave Atmosphere Program), que normalmente é utilizado para representar um mar típico da costa brasileira de pista limitada. Outros modelos podem ser vistos em Chakrabarti (1987). A sua formulação pode ser escrita, ajustada para a costa brasileira, segundo Petrobras (2005), como:

$S(\omega)=\alpha g^{2} \omega^{-5} \exp \left[-1,25\left(\omega / \omega_{0}\right)^{-4}\right] \gamma^{\exp \left[-\frac{\left(\omega-\omega_{0}\right)^{2}}{2 \tau^{2} \omega_{0}^{2}}\right]}$

onde:

$S(\omega)$ - Espectro de energia $\left(m^{2} s\right)$

$\alpha=5,0609 \frac{H_{S}^{2}}{T_{p}^{4}}[1-0287 \ln \gamma]$

$H_{S}$ - Altura significativa de ondas

$T_{p}$ - Período de pico do espectro

$\omega_{0}-$ Frequência de pico $\left(\omega_{0}=2 \pi / T_{p}\right)$

$\tau=0,07 \rightarrow \omega \leq \omega_{0}$ ou $\tau=0,09 \rightarrow \omega>\omega_{0}$ 
$\gamma$-Define o formato do pico. Varia de 1 a 7 em geral

Ainda segundo Petrobras (2005) o valor de $\gamma$ é ajustado por:

$\gamma=6,4 \cdot T_{p}^{-0,491}$

O formato típico do espectro de JONSWAP pode ser visto na Figura 5.6 para um $T_{p}=16,6 s, H_{s}=9,2 m$ e $\gamma=1,611$. O espectro é definido em $\mathrm{rad} / \mathrm{s}$. Caso as raias de frequência do espectro sejam definidas em $\mathrm{Hz}$, a amplitude do espectro deve ser dividida por $2 \pi$ para manter a equivalência em $\mathrm{rad} / \mathrm{s}$ da energia por raia.

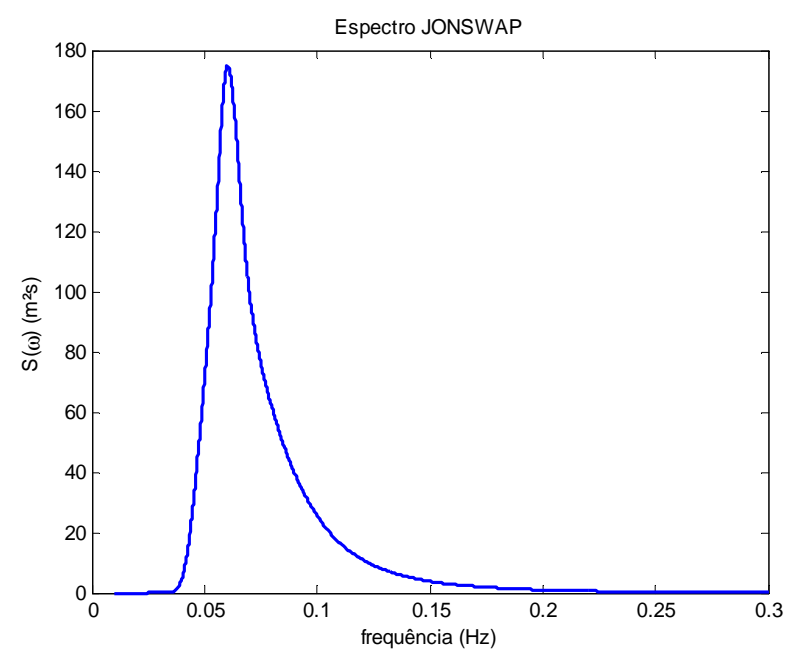

Figura 5.6. Espectro do tipo JONSWAP.

Um modelo de espalhamento direcional paramétrico bastante difundido é mostrado por Ochi (1998), o chamado modelo $\cos ^{2 s}$. Ele se baseia somente na definição da concentração da energia através do valor de $s$. Quando $s=\infty$ o espectro não tem espalhamento algum recaindo em um mar chamado de cristas longas (longcrested). Quando $s=1$ o mar é espalhado ao máximo, de $-\pi(\mathrm{rad})$ a $+\pi(\mathrm{rad})$ em torno da direção principal a $0^{\circ}$. Ele é representado por:

$D(f, \theta)=G(s) \cos ^{2 s}\left[\frac{\theta-\theta_{0}}{2}\right]$

$G(s)=\frac{2^{2 s}}{2 \pi} \cdot \frac{\Gamma^{2}(s+1)}{\Gamma(2 s+1)}$

onde $\theta$ é a direção de cada componente do mar, $\theta_{0}$ é a direção média do mar e $D(f, \theta)$ é a função de espalhamento direcional. Ela é normalizada em nível de energia: 
$\int_{-\pi}^{+\pi} D(f, \theta) d \theta=1$

A Figura 5.7 mostra o valor de $D(f, \theta)$ para diferentes valores de $s$. O modelo prevê espalhamento igual para todas as frequências do espectro. Notadamente podem-se adotar outros modelos de espalhamento. Nos trabalhos de Mitsuyasu, Tasai et al. (1975) e Hasselmann, Dunckel e Ewing (1980) pode ser vista uma proposta de espalhamento com dependência com a frequência. Próximo da frequência de pico $\left(f_{p}=1 / T_{p}\right)$ o espalhamento é mínimo ( $s$ é máximo) e em outras regiões o espalhamento aumenta ( $s$ pequeno), segundo a formulação:

$s\left(f, f_{0}\right)=\left\{\begin{array}{r}s_{m}\left(f / f_{p}\right)^{5}, f \leq f_{p} \\ s_{m}\left(f / f_{p}\right)^{-2,5}, f>f_{p}\end{array}\right.$

Segundo Goda, 1999, apud Mendes, 2005, p.13 é bem difundida na engenharia para classificar o espalhamento para mar local e swell como:

$s_{m}= \begin{cases}10, & \text { mar local } \\ 25, & \text { swell de geração próxima } \\ 75, & \text { swell de geração distante }\end{cases}$

Um mar do tipo swell foi gerado por vento a uma grande distante do ponto onde se está medindo. Dessa forma, em posições próximas entre si não se observam diferenças de direção de propagação. As cristas são paralelas, embora não estejam sempre equidistantes. Este mar é chamado de cristas longas (long-crested). Assim o valor de $s$ é alto. Se o ponto de medição estiver próximo de onde o vento está soprando, típico de uma tempestade, as cristas das ondas têm um comportamento espalhado sem uma direção bem definida. Nesse caso o mar é local e chamado de cristas curtas (shortcrested) com espalhamento direcional grande em torno da direção principal das ondas. Por esta razão o valor de $s$ é pequeno.

A Figura 5.8 mostra um exemplo de espalhamento para $f_{p}=0,3 \mathrm{~Hz}, s_{m}=10 \mathrm{e}$ $\theta_{0}=0$. No trabalho de Mendes (2005) podem ser encontrados mais exemplos de modelos de espalhamento. 


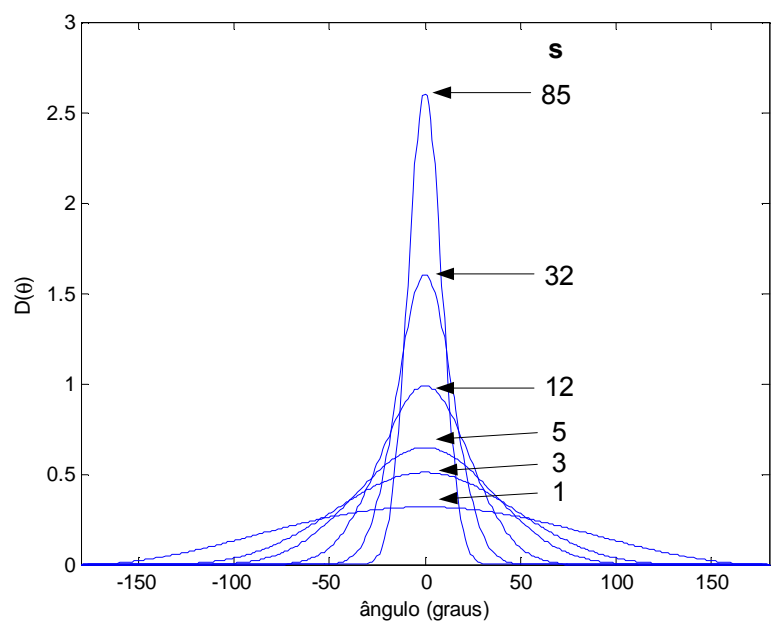

Figura 5.7. Curvas de $D(f, \theta)$ para diversos $s$ em $\theta_{0}=0$.

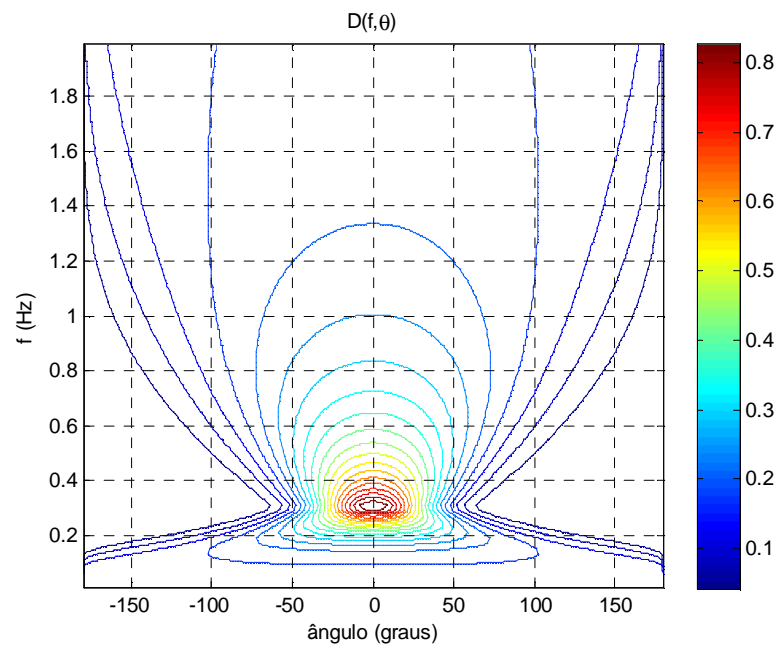

Figura 5.8. Função de espalhamento direcional de mar local dependente da frequência.

Outra forma de criar os mares com diversas direções e espalhamentos é fazer uma análise não paramétrica e usar diretamente dados reais de mares medidos (dado pelo espectro $S(f, \theta)$ ), sintetizar a série temporal de deslocamento e executar no gerador de ondas. A composição de mais de um mar também pode ser usada para representar um determinado estado de mar, por exemplo, o bimodal (dois mares), que ocorre com bastante frequência em algumas regiões do planeta. 


\subsubsection{Mares de cristas longas (Long-crested)}

Os mares de cristas longas são normalmente empregados em ensaios em tanques por apresentarem uma única direção de propagação. Os geradores de ondas não segmentados podem gerá-los; desta forma, constituem o primeiro tipo de simulação de mar a ser realizado. Fazendo uso de um gerador de ondas com a característica do Calibrador Hidrodinâmico, pode-se explorar a possibilidade de mudar a direção da onda sem ter que mudar o aproamento de um modelo ensaiado. Normalmente as forças resultantes de um mar desse tipo, ao incidir em um modelo, resultam em forças maiores do que usando-se um mar de cristas curtas. Por isso ele pode ser usado para se obter um esforço maior no modelo ITTC (2002). Assim, considerando uma única direção, tal como nas ondas regulares, podemos obter as séries temporais de onda a partir de diversas ondas harmônicas sobrepostas.

Segundo foi dito em Miles e Funke (1989), sobre as raias de frequência:

$\Delta f=1 / t_{\text {total }}$

onde $t_{\text {total }}$ é o tempo total da série temporal. Portanto, pode-se escrever o deslocamento do gerador de ondas dos mares de cristas longas:

$X_{0 j}=\sum_{m=1}^{M} \frac{A_{j}}{c_{0 m}} \frac{\tau_{\mathrm{j}} \cos \theta_{\mathrm{j}}}{\operatorname{sen} \tau_{\mathrm{j}}} a_{m} \cos \left(-\omega_{m} t+k_{x m} P_{x j}+k_{y m} P_{y j}+\varphi_{m}\right)$

onde $A_{j}$ é dada pela equação (5.2) usando um único $k_{m}$ pois só existe uma única direção. $\mathrm{O}$ índice $m$ indica as componentes em frequência. Da mesma forma que nas ondas regulares, os $k_{m}$ são projetados nas direções das coordenadas $x$ e $y$. As frequências angulares usadas $\left(\omega_{m}\right)$ são calculadas com a equação (5.14) e estabelecendo a máxima frequência harmônica, normalmente a máxima frequência que o gerador de ondas pode gerar, neste caso foi definida para $4 \mathrm{~Hz}$. A amplitude de cada componente espectral é dada por:

$a_{m}=\sqrt{2 S(\omega) \Delta \omega}$

onde $\Delta \omega=2 \pi \Delta f$. As fases aleatórias são os termos $\varphi_{m}$ calculados aleatoriamente entre $[0,2 \pi]$ para cada componente em frequência harmônica. O termo $c_{0 m}$ é a função de 
transferência progressiva do gerador de ondas usando a equação (3.24) para todas as frequências harmônicas envolvidas na somatória.

Caso o Limite de Biesel não possa ser atendido em determinadas direções (regiões da Figura 3.9), as frequências do espectro acima do limite são desativadas, fazendo-se ganho nulo.

Após definido o equacionamento resta somente fazer uma rampa gradual de inicialização e finalização com alguns segundos usando um ganho variável de 0 a 1 . A frequência de amostragem temporal é definida de acordo com o máximo possível do gerador de ondas e também deve ser duas vezes o valor da máxima frequência que existe na série temporal $X_{0 j}$, de acordo com a lei de Nyquist, que pode ser vista em Oppenheim, Schafer e Buck (1998).

A verificação da simulação da onda progressiva resultante deste método de criação de elevação de onda pode ser vista na Figura 5.9. Eliminando o ganho angular e a função de transferência do gerador de ondas na equação (5.15), ela se torna a elevação de superfície livre. O exemplo de criação da elevação de onda da Figura 5.9 tem $T_{p}=1,66 s, H_{s}=0,092 \mathrm{~m}, \gamma=1,611$ e $t_{\text {total }}=1080 \mathrm{~s}$. Em Chakrabarti (1987) e também em Malta (2010) podem ser vistos maiores detalhes sobre as análises feitas na série temporal sintetizada. Nela, são comparados diversos parâmetros estatísticos com as respectivas curvas teóricas. Acima na Figura 5.9 é mostrada a série temporal da onda. Na segunda fileira vê-se a distribuição das amostras discretas da onda, caracterizada por uma curva gaussiana dada pela média nula e pelo desvio padrão das amostras. Em seguida, é mostrada a distribuição de amplitude pelo modelo de Rayleigh de espectros de banca estreita. Na terceira fileira estão, respectivamente, os espectros de energia ( $1^{\text {a }}$ ordem) e o espectro de grupo ( $2^{\mathrm{a}}$ ordem). Destas comparações, o espectro de grupo obtido apresenta valor menor em baixa frequência, que é atribuído à pouca energia presente nesta região. O espectro de grupo é importante para se analisar o comportamento de deriva lenta de uma embarcação em teste, excitando movimentos de deriva lenta quando as frequências naturais da ancoragem da embarcação coincidem com as frequências dos grupos de ondas, provocando ressonância de baixa frequência na posição da embarcação ancorada. 


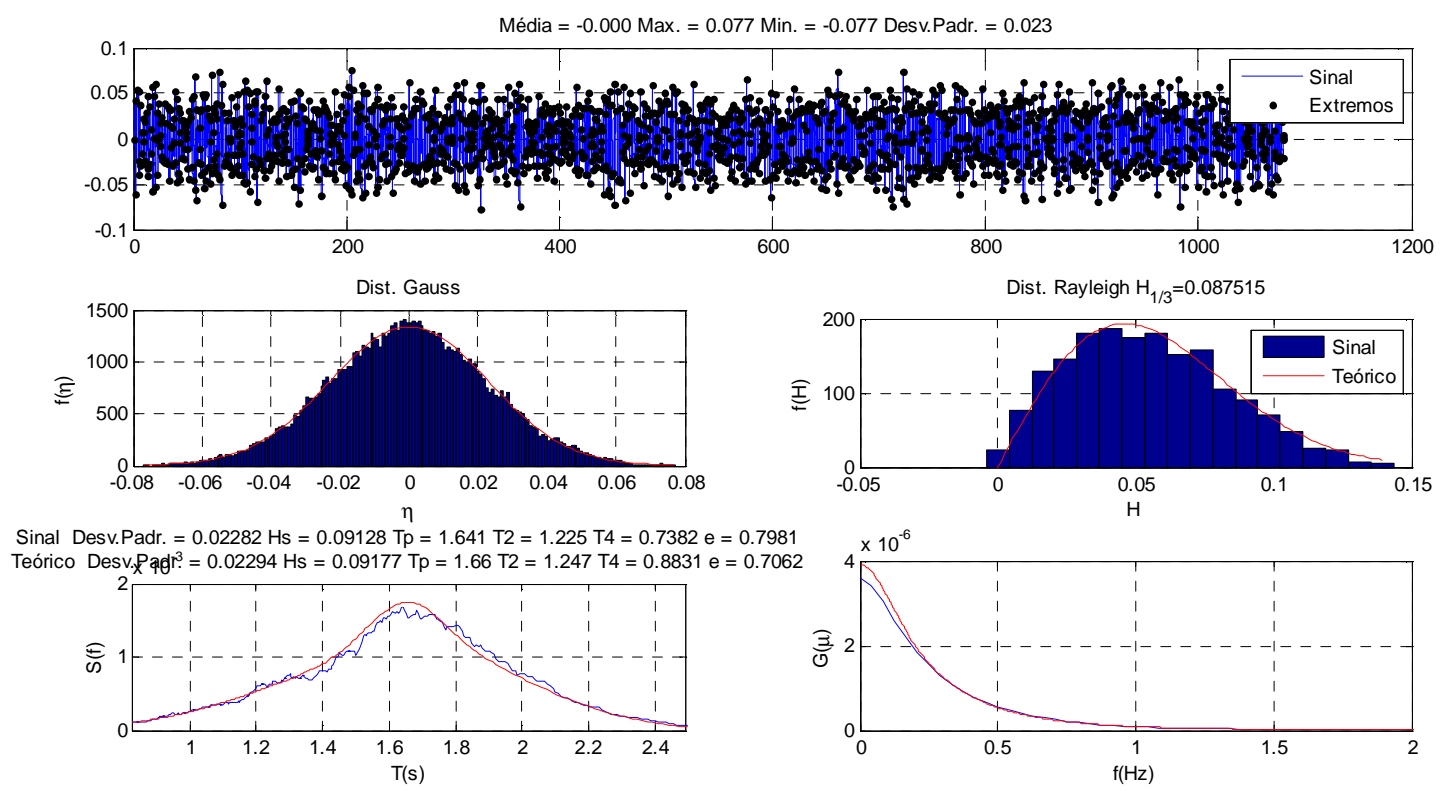

Figura 5.9. Análise de simulação de mar irregular long-crested.

Da mesma maneira que as ondas regulares, a estimativa de ondas nos batedores foi criada. Nesse caso usaram-se diversas frequências que acarretam diferentes amplitudes e fases de ondas somadas. Considerando pequenas amplitudes de ondas, ou seja, ondas lineares, é possível a sobreposição de diversas ondas harmônicas na somatória feita nos batedores de ondas. A equação (5.6) torna-se uma somatória de harmônicas com módulo e fases da forma da Figura 5.5:

$n d_{j}=\sum_{m=1}^{M} X_{0 j m} \cdot F T_{m}$

\subsubsection{Mares de cristas curtas (Short-crested)}

Os mares de cristas curtas são os mais semelhantes aos mares reais, pois têm espalhamento direcional além de espectro em frequências. Os mares reais têm espalhamento direcional por serem gerados pelo vento soprando em diferentes direções e em rajadas, o que resulta na seguinte característica: uma direção principal com um espalhamento direcional em torno dela. Para tanto, analisando as recomendações de Miles e Funke (1989), baseadas em análises usando espectros cruzados em vários pontos no espaço, deve-se ter ao menos 32 direções e frequências dadas pela equação (5.14). O modelo de geração do mar da equação (5.15) é expandido agora em direções, resultando em: 
onde $A_{j}\left(L_{a}, k_{n}\right)$ é a equação (5.2) calculada para cada direção (índice $n$ ). Os termos $A_{j}\left(L_{a}, k_{n}\right) \cdot \cos \theta_{j}$ resultam na expansão mostrada na Figura 5.10.

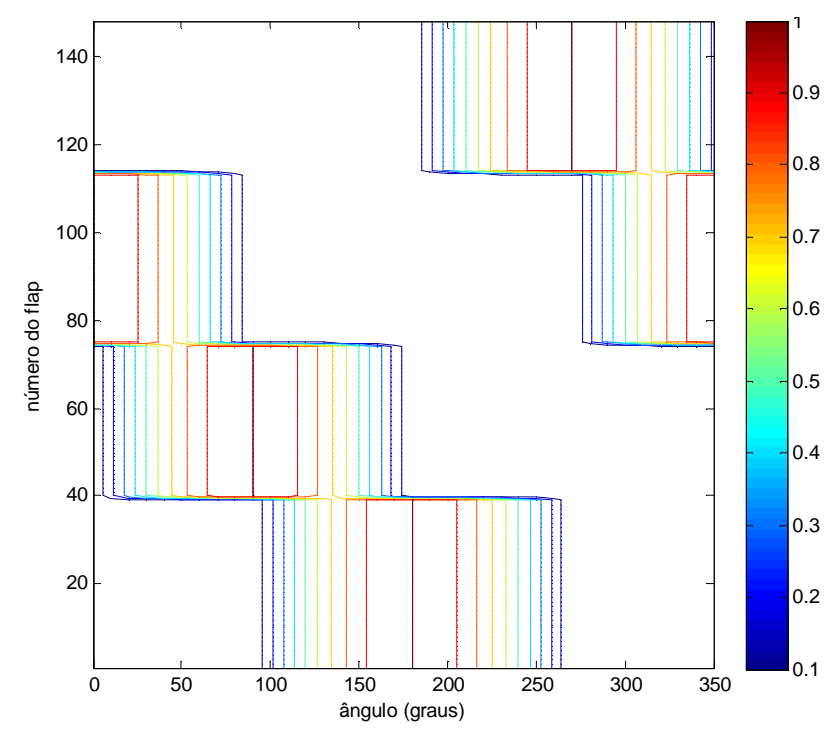

Figura 5.10. Equação $A_{j}\left(L_{a}, k_{n}\right) \cdot \cos \theta_{j}$ para direção principal de $180^{\circ}$ do referencial do tanque de provas (Figura 4.1).

A "semente" aleatória de fases $\left(\varphi_{m n}\right)$ agora tem duas dimensões, em função da frequência e da direção. O termo $a_{m n}$ das amplitudes das harmônicas é dado por:

$a_{m n}=\sqrt{2 \cdot S(\omega) \cdot \mathrm{D}(f, \theta) \cdot \Delta \omega \Delta \theta}$

onde $\Delta \omega=2 \pi \Delta f$ e $\Delta \theta$ é dado em radianos. O espectro direcional resulta, portanto, em:

$S(\omega, \theta)=S(\omega) \cdot D(f, \theta)$

Da mesma forma que nos mares de cristas largas, caso uma componente exceda o Limite de Biesel, ela será anulada (regiões da Figura 3.9).

Podem-se estimar as ondas presentes nos batedores usando a mesma técnica descrita na síntese das equações (5.6) e (5.17), do que resulta uma dupla somatória:

$n d_{j}=\sum_{m=1}^{M} \sum_{n=1}^{N} X_{0 j m n} \cdot F T_{m n}$ 
Caso o espectro direcional seja o modelo de $s$ invariante com a frequência resulta no exemplo da Figura 5.11a e com variação segundo o modelo de Mitsuyasu resulta na Figura 5.11b, considerando $s, H_{s}$ e $T_{p}$ iguais nos dois casos.

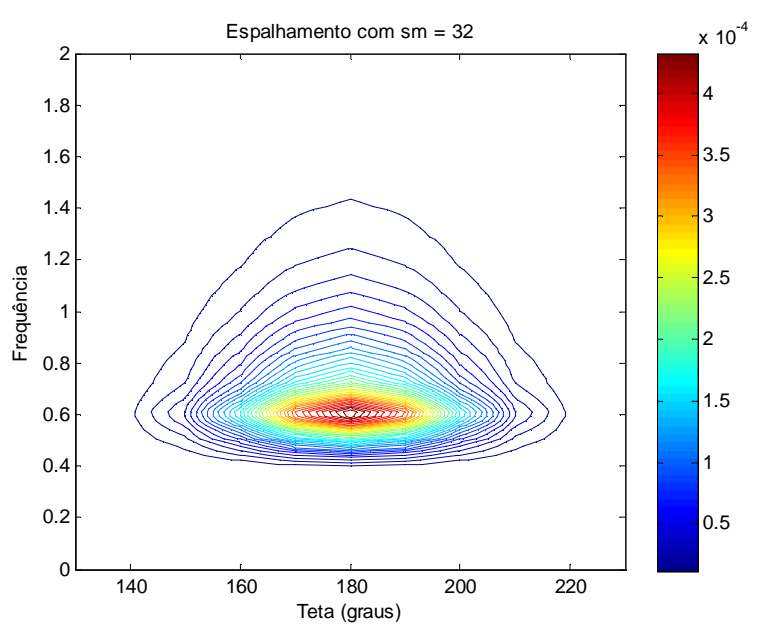

(a) Espetro direcional com $s$ constante.

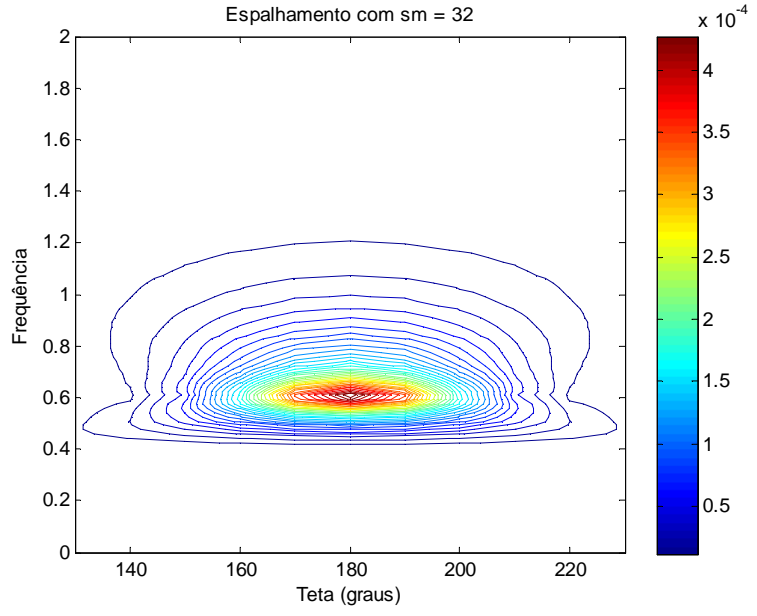

(b) Espectro direcional com dependência da frequência.

Figura 5.11. Espectros direcionais.

O cálculo da série temporal de geração de ondas recai em um problema de grande gasto computacional envolvendo a soma de todos os flaps, frequências harmônicas, direções de propagação e amostras temporais, como foi relatado em De Mello, Carneiro et al. (2010). Foi observado também que, ao se criar espectros com espalhamento direcional do modelo de Mitsuyasu, ocorre a criação de componentes direcionais muito espalhados; fora da região de maior energia existe um grande aumento do número de componentes de espectro direcional e que quase sempre vão de $-180^{\circ}$ a $+180^{\circ}$, com grande custo computacional. O problema do custo computacional foi observado por Nohara, Yamamoto e Matsuura (1996) e Nohara (2000), em que foi usado processamento em DSP com um algoritmo otimizado para a realização dos cálculos em tempo real durante a geração das ondas.

Neste trabalho, optou-se por realizar as séries temporais em pré-processamento (antes do ensaio). O tempo de processamento necessário para criar as séries temporais pode ser visto na Tabela 5.1. O software, para gerar séries temporais regulares, tem um tempo de processamento pequeno. Para as ondas irregulares unidirecionais, o tempo necessário sofre um incremento, mas que não torna a execução inviável. No caso das ondas multidirecionais o tempo necessário é elevado. Assim, foi pesquisado um método para aperfeiçoar o desempenho usando-se um processamento paralelo em mais de um 
processador do computador. As rotinas de processamento criam as séries temporais de cada batedor uma a uma por meio da instrução for. Cada loop da instrução for executado para cada batedor não usa variáveis de outro, ou seja, eles são independentes entre si; portanto, têm um processamento paralelizável. Existe no Matlab ${ }^{\circledR}$ um recurso de processamento paralelo que permite executar várias instâncias do Matlab ${ }^{\circledR}$ no mesmo computador ou em diversos computadores em rede. Chamado de matlabpool, ele cria outros executáveis escravos que processam em paralelo dados "despachados" pelo Matlab ${ }^{\circledR}$ mestre. O meio para se paralelizar o programa é substituir a instrução for pela instrução parfor (paralel for). Desta forma, as outras instâncias do Matlab ${ }^{\circledR}$ executam independentemente as instruções contidas no parfor e as enviam de volta ao mestre.

Para gerar os dados da Tabela 5.1 foi usado um computador portátil com processador de dois núcleos do tipo Intel Core Duo T2600 - 2,16GHz. Os três tempos apresentados para as ondas multidirecionais foram obtidos com uma instância, duas instâncias e quatro instâncias de processamento, respectivamente. A diferença de tempos ao se usar duas ou quatro instâncias é pequena, pois o computador tem dois núcleos e as instâncias acabam concorrendo entre si. Com processadores de quatro núcleos a ocupação de processamento é total, o que faz com que os tempos totais diminuam. Caso o matlabpool não esteja ativo, a execução ocorre normalmente, como no caso de processamento não paralelo.

Tabela 5.1. Tempo de processamento necessário para se criar séries temporais.

\begin{tabular}{|c|c|c|c|c|c|c|c|}
\hline Tipo de onda & Ângulo & $\begin{array}{c}\text { Amostragem } \\
\text { temporal }\end{array}$ & $\begin{array}{c}\text { Número de } \\
\text { frequências }\end{array}$ & $\begin{array}{c}\text { Número de } \\
\text { direções }\end{array}$ & $\begin{array}{c}\text { Número de } \\
\text { batedores }\end{array}$ & $\begin{array}{c}\text { Tamanho da } \\
\text { série temporal }\end{array}$ & $\begin{array}{c}\text { Tempo de } \\
\text { processamento }\end{array}$ \\
\hline \multirow{2}{*}{ Regular } & $0^{\circ}$ & $12 \mathrm{~ms}$ & 1 & 1 & 39 & $120 \mathrm{~s}$ & $2,1 \mathrm{~s}$ \\
\cline { 2 - 8 } & $45^{\circ}$ & $12 \mathrm{~ms}$ & 1 & 1 & 74 & $120 \mathrm{~s}$ & $2,6 \mathrm{~s}$ \\
\hline $\begin{array}{c}\text { Irregular cristas } \\
\text { longas }\end{array}$ & $0^{\circ}$ & $12 \mathrm{~ms}$ & 720 & 1 & 39 & $120 \mathrm{~s}$ & $25 \mathrm{~s}$ \\
\cline { 2 - 8 } & $45^{\circ}$ & $12 \mathrm{~ms}$ & 720 & 1 & 74 & $120 \mathrm{~s}$ & $45 \mathrm{~s}$ \\
\hline $\begin{array}{c}\text { Irregular cristas } \\
\text { curtas }\end{array}$ & $0^{\circ}$ & $12 \mathrm{~ms}$ & 720 & 36 & 109 & $120 \mathrm{~s}$ & $457 \mathrm{~s} / 291 \mathrm{~s} / 259 \mathrm{~s}$ \\
\cline { 2 - 8 } & $45^{\circ}$ & $12 \mathrm{~ms}$ & 720 & 36 & 74 & $120 \mathrm{~s}$ & $400 \mathrm{~s} / 215 \mathrm{~s} / 220 \mathrm{~s}$ \\
\hline
\end{tabular}




\section{Procedimentos experimentais}

Neste capítulo serão apresentados os resultados obtidos em diversos testes realizados com o intuito de validar o tanque de provas e os diversos equipamentos, bem como obter a resposta hidrodinâmica do gerador de ondas.

\subsection{Validação da resposta dinâmica mecânica}

Visando obter o comportamento dos atuadores e do movimento dos batedores do tanque de provas, foi feita uma série de testes para caracterizar a função de transferência entre o comando de posição fornecido aos servo-atuadores e a posição efetiva alcançada pelos mesmos. A posição do batedor é medida por meio dos encoders instalados no próprio servo-motor, que é utilizado pelo servo-driver para realimentar a malha interna de controle de posição, como pode ser visto na Figura 4.29. Dessa forma é enviada a posição comandada em milímetros e a resposta é também dada em milímetros diretamente na conexão do patim oscilante ao braço de acionamento. A resposta foi medida entre o comando dado e a resposta obtida através do programa de controle (Simulink). Por esta razão, quando a amostra do comando é enviada, espera-se que exista um atraso de uma amostra devido à rede de comunicação discutida no capítulo 4 e que é de $12 \mathrm{~ms}$.

Primeiramente foi aferida a resposta ao degrau para a execução de ajustes internos do servo-driver. Estes ajustes foram feitos com o software MR-Configurator e salvos diretamente no servo-driver via rede de comunicação dos PLCs. Após os ajustes de calibração, a resposta ao degrau obtida é mostrada na Tabela 6.1 e na Figura 6.1. O tempo de subida é aproximado, pois o passo temporal de $12 \mathrm{~ms}$ tem pouca resolução frente à taxa de subida. $\mathrm{O}$ tempo de subida considerado foi o instante quando a curva de subida ultrapassava o valor comandado. 
Tabela 6.1. Resposta em degrau dos servo-drivers.

\begin{tabular}{|c|c|c|c|c|}
\hline $\begin{array}{c}\text { Altura do } \\
\text { degrau }(\mathrm{mm})\end{array}$ & $\begin{array}{c}\text { Batedores } \\
\text { testados }\end{array}$ & $\begin{array}{c}\text { Tempo de atraso do início da } \\
\text { subida médio }(\mathrm{ms})\end{array}$ & $\begin{array}{c}\text { Tempo de subida } \\
\text { médio }(\mathrm{ms})\end{array}$ & $\begin{array}{c}\text { Sobressinal } \\
(\%)\end{array}$ \\
\hline+1 & 1 a 39 & 12 & 35,0 & 5,0 \\
\hline+2 & 1 a 39 & 12 & 32,5 & 5,0 \\
\hline+4 & 1 a 39 & 12 & 35,5 & 3,5 \\
\hline+6 & 1 a 39 & 12 & 48,0 & 3,0 \\
\hline+6 & 1 a 39 & 12 & 48,0 & 3,0 \\
\hline
\end{tabular}
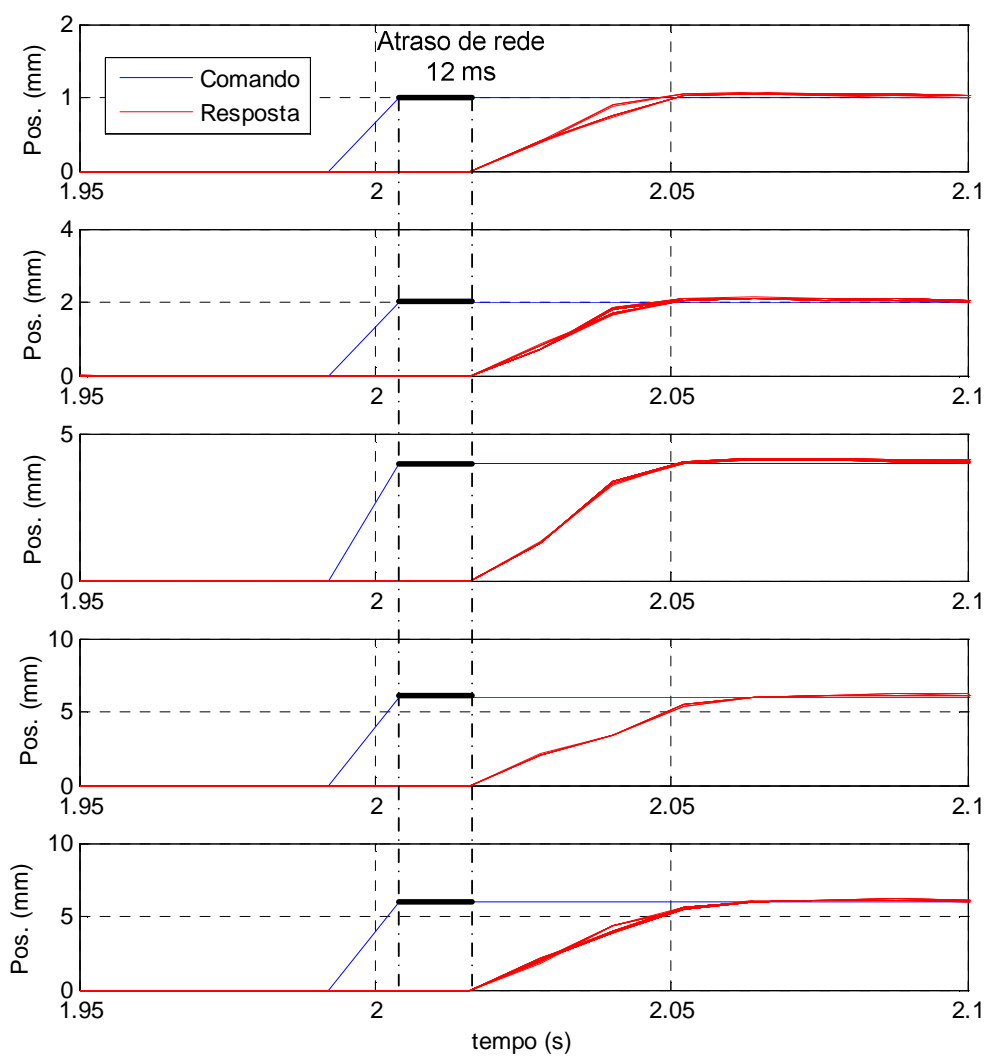

Figura 6.1. Resposta em degrau dos batedores segundo a sequência da Tabela 6.1

Pode ser comprovado o atraso de rede de comunicação de $12 \mathrm{~ms}$ no início da subida da resposta em degrau. $\mathrm{O}$ atraso de subida foi verificado e devido ao servo-driver contar com um controlador PID com feed-forward, a resposta não apresentava atraso elevado nem sobressinal significativo. O resultado obtido confirma a resposta mais rápida da malha PID do servo-driver (1,1ms segundo Mitsubishi, 2007) frente à taxa de amostragem do sistema (12ms). Não foi testada altura de degrau maior para não causar danos aos mecanismos dos acionamentos e batedores.

Como a intenção era caracterizar a resposta dinâmica em diversas frequências, o sistema foi então modelado por uma função de transferência de $2^{\mathrm{a}}$ ordem e aferido com outros dois testes dinâmicos. O atraso de rede de comunicação de $12 \mathrm{~ms}$ ocorre entre o 
comando dado e a resposta obtida no Simulink; portanto, este atraso foi compensado com o avanço da resposta obtida em um passo de rede $(12 \mathrm{~ms})$ para avaliar a resposta dinâmica do servo-driver e do mecanismo.

O primeiro teste de resposta dinâmica dos batedores foi feito com uma função delta de dirac. Como não era necessário aferir com infinitas frequências, o que tornaria o pulso muito estreito frente às respostas mecânicas, o delta de Dirac foi escrito por uma função sinc. Uma maneira de se obter a função é executar uma somatória de cossenos até a máxima frequência que se pretende utilizar. Foi definida a maior frequência em $4 \mathrm{~Hz}$ e a altura máxima do movimento em 10mm. A função utilizada pode ser vista na Figura 6.2.
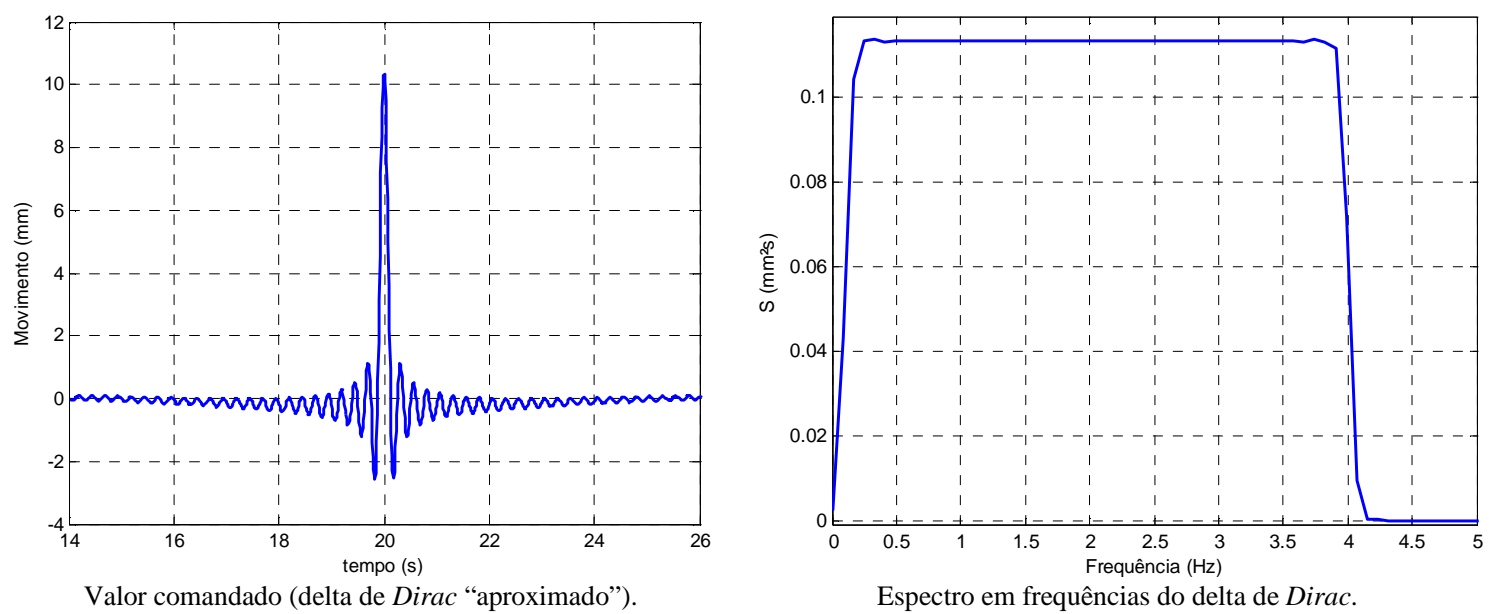

Figura 6.2. Função sinc.

O modelo utilizado para a resposta do motor foi de $2^{\mathrm{a}}$ ordem. Uma rotina no MatLab® faz o ajuste dos parâmetros do modelo para obter a regressão da resposta em frequências com a resposta experimental. O módulo do modelo de $2^{\mathrm{a}}$ ordem para o motor é:

$|M(\omega)|=\frac{1}{\sqrt{\left(1-\left(\omega / \omega_{n}\right)^{2}\right)^{2}+\left(2 \psi \omega / \omega_{n}\right)^{2}}}$

onde $\psi$ é o amortecimento e $\omega_{n}$ é a frequência angular não amortecida.

Após a aplicação do comando sinc nos batedores da lateral 1 (batedores 1 a 39), a resposta obtida foi tratada por FFT para se obter a resposta em frequências. Foi feito o espectro cruzado com alisamento entre os sinais, verificando-se que o valor do módulo é semelhante para todos os batedores envolvidos. A média destes possibilitou se obter a 
resposta experimental. O modelo teórico foi comparado ao experimental, mostrado na Figura 6.3, em que se apresentam também o amortecimento e a frequência angular não amortecida do ajuste feito. Pode-se notar que a fase tem um comportamento próximo do linear na faixa de frequência avaliada e que o módulo apresenta pouca atenuação aproximadamente $2 \%$ em $3 \mathrm{~Hz}$. O modelo foi ajustado pelo módulo da resposta, mas foi manipulado o algoritmo de regressão para que as fases convergissem limitando-se à faixa de ajuste do amortecimento. Com mais de uma repetição do ensaio a resposta foi semelhante. Foi feito então um segundo teste com o motor usando varredura em frequências.

O teste usando varredura em frequências contou com cinco realizações, de acordo com a Tabela 6.2. Somente alguns batedores foram selecionados para o teste, pois poderiam ocorrer danos mecânicos nas diversas realizações propostas; além disso, uma onda seria criada no tanque e poderia contaminar o resultado. Para avaliar se a resposta do sistema seria linear, foram feitos três testes com amplitude de posição constante e dois com amplitude de velocidade constante, não excedendo o limite de posição do acionamento.
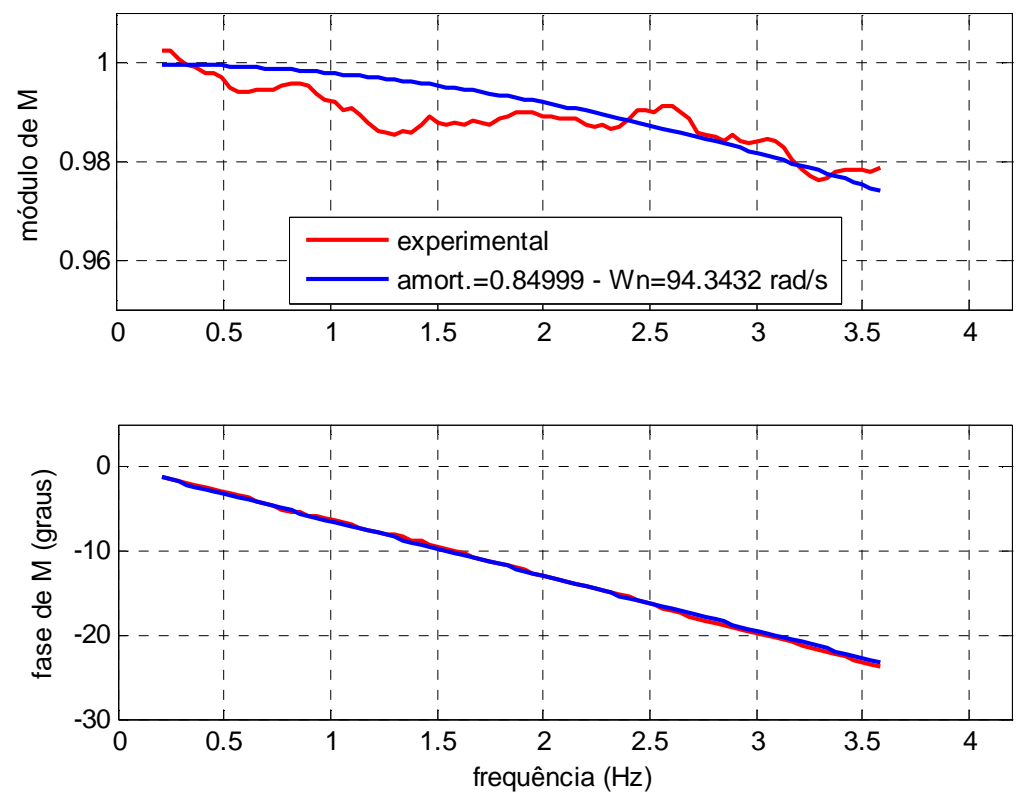

Figura 6.3. Resposta impulsiva dos batedores. 
Tabela 6.2. Testes de resposta em frequência dos batedores.

\begin{tabular}{|c|c|}
\hline Batedores testados & $13-26-51-63-87-100-125-137$ \\
\hline Frequência inicial & $0,05 \mathrm{~Hz}$ \\
\hline Frequência final & $3,6 \mathrm{~Hz}$ \\
\hline Tempo de varredura & $240 \mathrm{~s}$ \\
\hline Amplitudes constantes & $5 \mathrm{~mm}-10 \mathrm{~mm}-15 \mathrm{~mm}$ \\
\hline Velocidades constantes & $109 \mathrm{~mm} / \mathrm{s}-218 \mathrm{~mm} / \mathrm{s}$ \\
\hline
\end{tabular}

O resultado do teste pode ser visto na Tabela 6.3, abaixo. Na regressão foi imposto que $0,5<\psi<1,1$ e o ajuste foi feito usando o módulo. Mesmo desconsiderando a fase na regressão, a fase do modelo se aproximou da fase experimental com pouca diferença. A fase experimental em função da frequência é semelhante para a resposta impulsiva e para a resposta com varredura. O módulo obtido para a varredura foi ligeiramente menor do que o obtido para o impulso. Os dois módulos obtidos têm comportamento semelhante, mas o método por varredura apresenta melhor aderência. O resultado foi muito próximo para todos os tipos de testes; portanto, o sistema de acionamento pode ser modelado como linear e invariante no tempo. O amortecimento resultante foi próximo de 1, ou seja, o sistema é quase criticamente amortecido - um resultado muito bom como resposta dinâmica. A Figura 6.4 mostra o resultado do teste com velocidade constante de $218 \mathrm{~mm} / \mathrm{s}$.

Tabela 6.3. Resultado do teste de resposta em frequência dos batedores.

\begin{tabular}{|c|c|c|}
\hline Tipo do teste & $\omega_{n}(\mathrm{rad} / \mathrm{s})$ & $\psi$ \\
\hline Amplitude constante $-5 \mathrm{~mm}$ & 114,59 & 0,97 \\
\hline Amplitude constante $-10 \mathrm{~mm}$ & 114,10 & 0,98 \\
\hline Amplitude constante $-15 \mathrm{~mm}$ & 114,27 & 0,98 \\
\hline Velocidade constante $-109 \mathrm{~mm} / \mathrm{s}$ & 113,45 & 0,97 \\
\hline Velocidade constante $-218 \mathrm{~mm} / \mathrm{s}$ & 114,62 & 0,98 \\
\hline
\end{tabular}



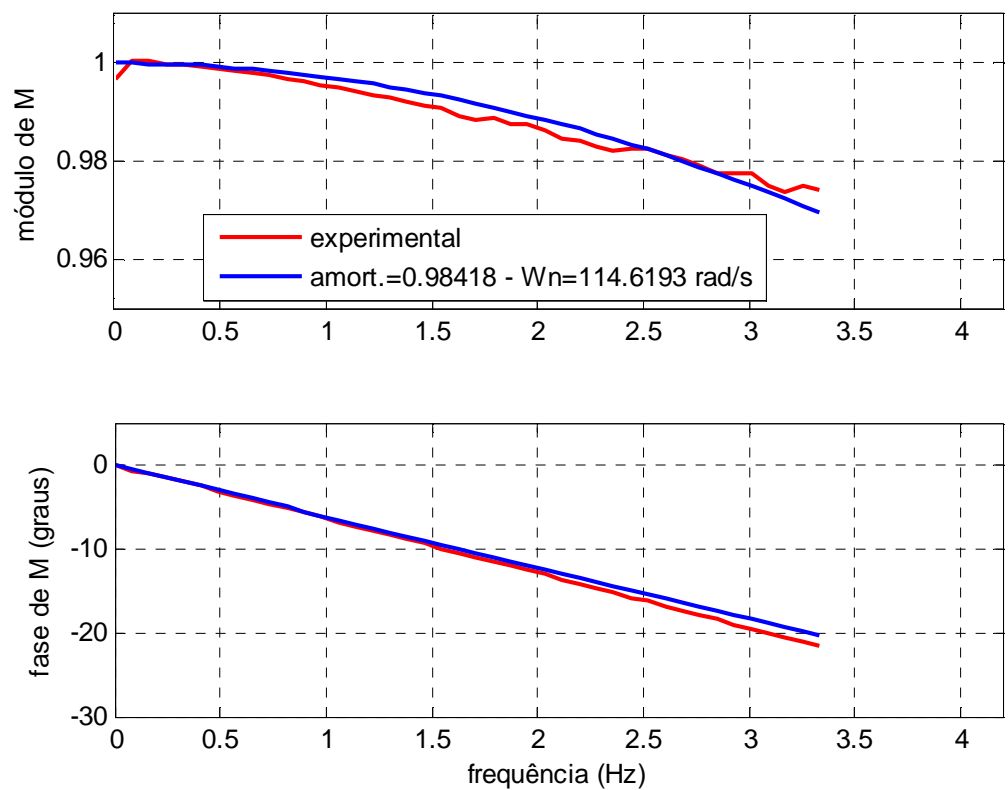

Figura 6.4. Resposta em frequência dos batedores.

$\mathrm{O}$ resultado dos testes usando comando sinc e varredura em frequências cobre uma faixa dinâmica muito pequena; dever-se-iam usar frequências mais altas, o que poderia causar avarias no mecanismo; portanto, não foi tentado. Assim sendo, acreditase que, usando uma série temporal de maior duração que apresente um grande número de harmônicos, seja mais conveniente para, usando FFT, se obter a resposta dinâmica mais precisa na pequena faixa dinâmica disponível para realizar testes com o mecanismo. Mesmo que não se possa expandir a faixa dinâmica, a faixa de frequências de utilização do mecanismo está bem descrita. Assim optou-se por considerar a resposta da varredura como definitiva, apesar de ambas serem bem próximas.

$\mathrm{O}$ sistema de $2^{\mathrm{a}}$ ordem obtido tem tempo de resposta pequeno se comparado ao tempo de resposta do sistema. Por essa razão o teste ao impulso tem baixa resolução para efeito de comparação. Na fase da resposta dinâmica estão incorporados todos os atrasos do sistema de controle, que são mostrados na equação (4.14), entre os CLPs e os servo-drivers. $\mathrm{O}$ atraso de rede $(12 \mathrm{~ms})$ foi compensado na análise entre o comando e a resposta obtida. 


\subsection{Validação de geração de ondas regulares}

Os resultados apresentados a seguir abrangem a execução de testes de resposta para ondas nos batedores (ondas progressivas e evanescentes) e em uma posição próxima do centro do tanque (ondas progressivas) para ondas não-oblíquas. As leituras das ondas evanescentes foram realizadas pelos sensores de ondas ultrassônicos dos batedores e as ondas progressivas no interior do tanque pelos sensores capacitivos.

Testes para medição do campo de ondas regulares progressivas oblíquas na região central do tanque fizeram uso de uma matriz 4 x 4 com 16 sensores capacitivos para medir ondas em diferentes direções de propagação.

\subsubsection{Ondas unidirecionais não-oblíquas}

Uma campanha de calibração de ondas foi feita para a obtenção da função de transferência do gerador de ondas. Para tanto foram ensaiadas diversas alturas de ondas com diferentes frequências no Calibrador Hidrodinâmico.

A campanha experimental contou com duas etapas: uma para medição de ondas na face do flap (função de transferência total), usando os sensores de ultrassom, e outra para caracterizar as ondas no centro do tanque (função de transferência de ondas progressivas).

\subsubsection{Ondas nos batedores de onda}

Como dito anteriormente, usando os sensores dos batedores foi possível verificar a qualidade das ondas nos batedores, confrontadas com a teoria esperada. Estes testes realizados no período de verificação inicial dos equipamentos do gerador de ondas foram importantes para um levantamento dos atrasos e das respostas de todo o sistema de automação e controle. As ondas regulares ensaiadas, em um total de 24, são mostradas na Tabela 6.4: 
Tabela 6.4. Ondas regulares ensaiadas.

\begin{tabular}{|c|c|c|c|}
\hline Frequência (Hz) & Declividade de onda (\%) & $\mathrm{L}(\mathrm{m})$ & $t_{C_{g}}(s)$ \\
\hline 1,67 & $2,3,4,6$ & 0,56 & 60,0 \\
\hline 1,25 & $2,3,4,6$ & 1,00 & 45,0 \\
\hline 1,00 & $2,3,4,6$ & 1,56 & 36,0 \\
\hline 0,83 & 3 e 6 & 2,25 & 30,0 \\
\hline 0,71 & 3 e 6 & 3,06 & 25,7 \\
\hline 0,63 & $2,3,4,6$ & 4,00 & 22,5 \\
\hline 0,56 & 2,3 & 5,06 & 20,0 \\
\hline 0,50 & 2 & 6,25 & 18,0 \\
\hline 0,45 & 2 & 7,54 & 16,4 \\
\hline
\end{tabular}

O termo $t_{C_{g}}$ mostrado na Tabela 6.4 é o tempo necessário para a onda percorrer duas vezes a distância do tanque $(d=2 \cdot 14,04 \mathrm{~m})$ antes que a reflexão de onda volte à lateral que a gerou - veja a equação (6.2). Dessa forma, a janela temporal de análise de dos sinais não pode ultrapassar estes instantes, dependentes da frequência da onda.

$t_{C_{g}}=\frac{d(m)}{C_{g}(m / s)}(s)$

O teste consistiu em executar ondas na lateral 1 do tanque e absorvê-las na lateral 3; segundo o referencial do tanque, ondas com incidência de $180^{\circ}$, ou seja, constituindo uma geração de ondas não-oblíquas. Os sinais de encoder e os sensores de flap foram usados para medir experimentalmente a função de transferência do gerador de ondas. Foi feito o espectro cruzado entre os sinais usando o método de welch com 1024 pontos, sobreposição de janelas temporais de 512 pontos e janela temporal do tipo hanning. A taxa de amostragem usada é dada pelo sistema gerador de ondas: 83,3 Hz.

O sinal de entrada foi o encoder dos motores, que fornecem a posição real dos batedores, livre do atraso ocasionado pela função de transferência de motor e pelo atraso de rede de comunicação (12ms). Depois de obter a função de transferência de cada batedor $\left(F T \cdot F T_{M}=H / S\right)$ o valor médio era obtido com a lateral toda. No caso nãooblíquo pode-se fazer a média da lateral toda, pois os sinais de comando são todos iguais e nesse caso evitam-se flutuações no valor obtido. A função de transferência 
levantada incorpora a função de transferência mecânica do motor à linha de água $\left(F T \cdot F T_{M}\right)$. A Figura 6.5 mostra a função de transferência obtida.

Como esperado, havia um atraso no sinal retornado pelos sensores de ondas ultrassônicos por conta do tempo de execução da amostra e pelo tempo de conversão analógica $(D A C)$ e digital novamente $(A D C)$. Para tanto foi necessário compensar este tempo, que é de $17,9 \mathrm{~ms}$. Na análise dos sinais esse atraso temporal foi subtraído e resultou em um ajuste adequado das curvas características da função de transferência de ondas nos batedores $(F T)$ comparado ao experimental. A Figura 6.6 mostra o resultado obtido. Nota-se que não existe influência da declividade das ondas na resposta apresentada.

Na Figura 6.7 pode ser vista a resposta completa do sistema de automação e controle do gerador de ondas. Considerando-se os atrasos do sistema e a resposta dinâmica mecânica, o sistema pode ser caracterizado e as respostas, quando necessário, podem ser compensadas.
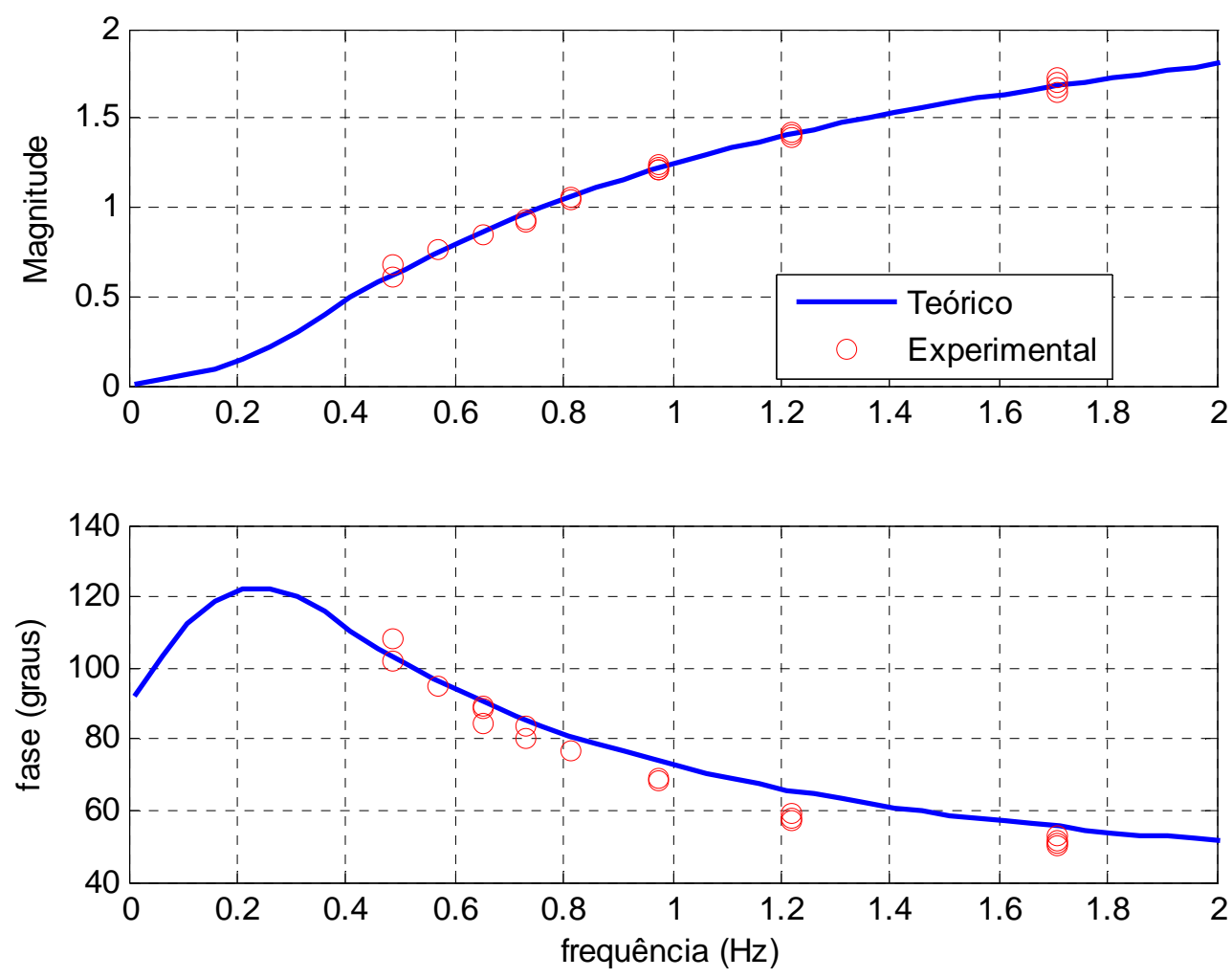

Figura 6.5. Função de transferência (FT) experimental x teórica. 

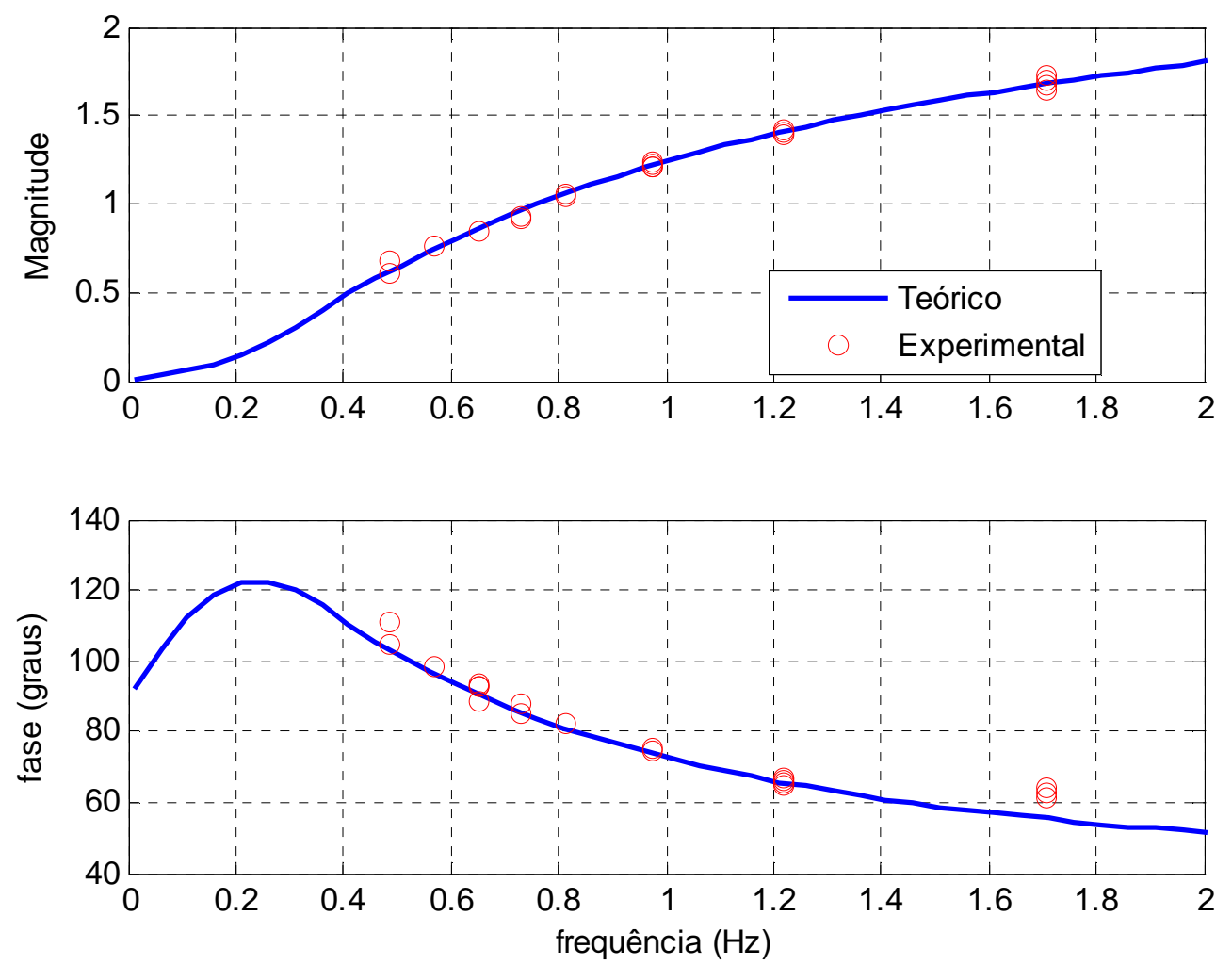

Figura 6.6. Função de transferência (FT) experimental com atrasos temporais x teórica.

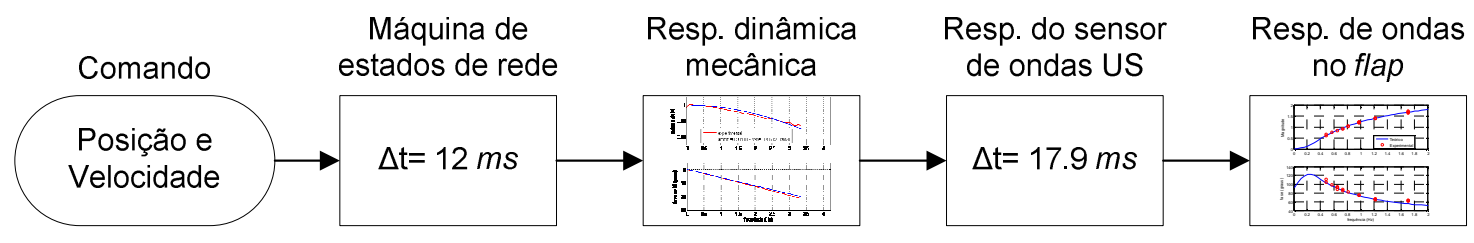

Figura 6.7. Resposta do sistema de automação e controle do gerador de ondas.

\subsubsection{Ondas progressivas}

Os ensaios com ondas regulares têm como objetivo avaliar a função de transferência progressiva do gerador de ondas $\left(F T_{p}\right)$, a estabilidade das ondas e também a eficiência da absorção ativa de ondas. Foram realizadas diversas configurações experimentais para comparação de resultados. As ondas ensaiadas foram inicialmente calibradas e depois repetidas com a absorção ativa acionada na lateral que estava gerando ondas. 
As características das ondas ensaiadas são apresentadas na Tabela 6.5. Elas contemplam três frequências, cada qual com três declividades. As ondas foram sempre geradas na lateral 1 propagando-se no sentido da lateral 3 (ver Figura 6.8).

Tabela 6.5. Ondas regulares ensaiadas

\begin{tabular}{|c|c|c|c|c|c|}
\hline $\mathbf{T}(\mathbf{s})$ & $\mathbf{f}(\mathbf{H z})$ & Declividade $(\boldsymbol{\%})$ & $\mathbf{L}(\mathbf{m})$ & $\mathbf{H}(\mathbf{m m})$ & $\mathbf{A}(\mathbf{m m})$ \\
\hline 1,428571 & 0,70 & 2,5 & 3,185 & 79,6 & 39,8 \\
\hline 1,428571 & 0,70 & 3,3 & 3,185 & 106,2 & 53,1 \\
\hline 1,428571 & 0,70 & 5,0 & 3,185 & 159,3 & 79,6 \\
\hline 1 & 1,00 & 2,5 & 1,561 & 39,0 & 19,5 \\
\hline 1 & 1,00 & 3,3 & 1,561 & 52,0 & 26,0 \\
\hline 1 & 1,00 & 5,0 & 1,561 & 78,1 & 39,0 \\
\hline 0,769231 & 1,30 & 2,5 & 0,924 & 23,1 & 11,5 \\
\hline 0,769231 & 1,30 & 3,3 & 0,924 & 30,8 & 15,4 \\
\hline 0,769231 & 1,30 & 5,0 & 0,924 & 46,2 & 23,1 \\
\hline
\end{tabular}

A medição de ondas foi feita através de três sensores de ondas capacitivos (veja descrição destes no tópico 4.6) posicionados segundo a Figura 6.8. Usando este arranjo e o método proposto por Mansard \& Funke (ver, p. ex., ISAACSON, 1991), foi feita a separação das parcelas incidente e refletida das ondas, para uma estimativa do coeficiente de reflexão e para se verificar a estabilidade das ondas. As informações das três alturas (WP1, WP2 e WP3) e das duas defasagens entre sensores ( $\Delta 1$ e $\Delta 2)$ são usadas para determinar as ondas incidente (Lateral $1 \rightarrow$ Lateral 3) e refletida (Lateral 3 $\rightarrow$ Lateral 1) usando o método de Mansard \& Funke implementado por De Mello (2006).

O método de Mansard \& Funke apresenta singularidades na relação entre comprimento de ondas e a distância entre os sensores; deste modo, resultaram 2 arranjos distintos de sensores para se evitar tais singularidades: um para ondas de $0,7 \mathrm{~Hz}$ e $1,0 \mathrm{~Hz}$ $(\Delta 1=0,6 \mathrm{~m}$ e $\Delta 2=1,2 \mathrm{~m})$ e outro para ondas de $1,3 \mathrm{~Hz}(\Delta 1=0,6 \mathrm{~m}$ e $\Delta 2=0,74 \mathrm{~m})$. O sensor WP2 foi alocado sempre na posição central do tanque $(x=7,02 \mathrm{~m} ; \mathrm{y}=7,02 \mathrm{~m})$. De acordo com o método implementado, os três sensores têm que estar menos de um comprimento de ondas distantes entre si. Isto foi conseguido nos testes. Cada onda que passava pelos sensores tinha o coeficiente de reflexão estimado. Dessa forma foi possível notar o instante em que a frente de ondas incidente chegava aos sensores e, melhor que isso, o 
instante em que a reflexão chegava aos sensores. Com esta informação é possível avaliar a estabilidade do campo de ondas.

Os sinais dos sensores de ondas foram adquiridos pelo módulo de aquisição MX840 da HBM a uma taxa de $50 \mathrm{~Hz}$. Para melhor tratar os sinais, um canal de sincronismo entre o gerador de ondas e o módulo da HBM foi usado para que o início da aquisição ocorresse junto com o início da geração de ondas. A calibração estática dos sensores foi feita sempre com a correlação quadrática acima de 0,9999 na regressão linear.

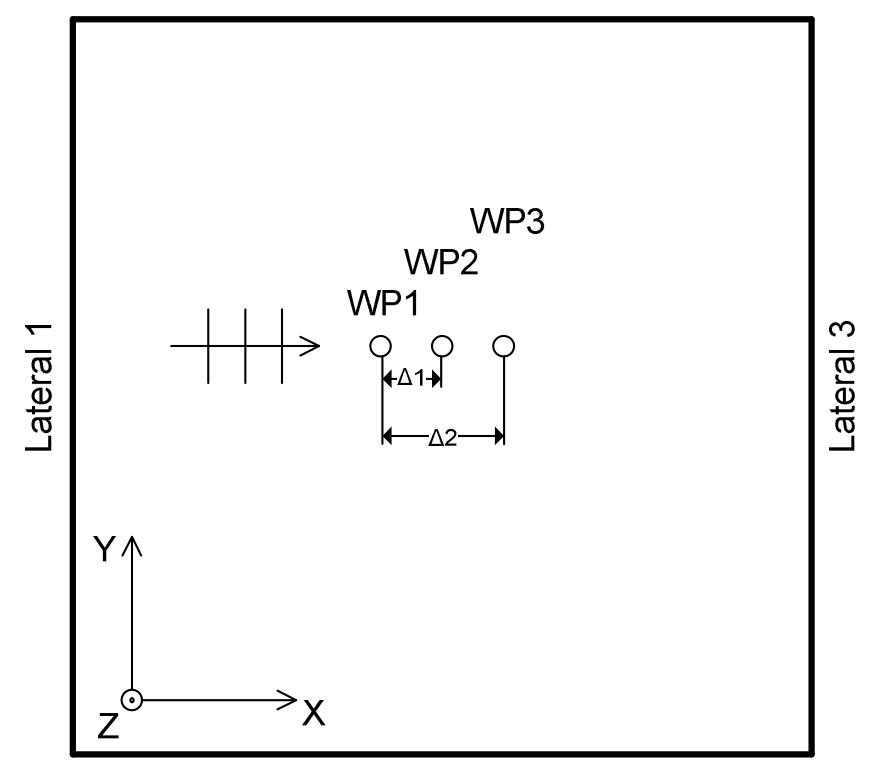

Figura 6.8. Disposição dos três sensores de ondas (WPx) no interior do tanque para avaliar ondas regulares.

Os ensaios de ondas regulares foram executados em duas etapas, listadas na Tabela 6.6. As diferenças entre as etapas dizem respeito ao esquema de absorção empregado: absorção em uma ou nas duas laterais. O esquema adotado de absorção na lateral 1 foi do tipo dual mode, discutido no tópico 5.1.1. Para tanto foi necessário compensar as respostas do sistema de automação (veja a Figura 6.7). No princípio de funcionamento dual mode, são geradas duas séries temporais: de deslocamento do atuador $\left(X_{0 j} / F T_{M}\right)$ e da elevação de ondas esperada nos flaps $\left(n d_{j}\right)$. No deslocamento do atuador é compensado o módulo da resposta dinâmica mecânica. No $n d_{j}$ são compensados o atraso da rede de comunicação $(\Delta t=12 \mathrm{~ms})$, a fase da resposta dinâmica mecânica e o atraso de leitura dos sensores de ondas ultrassônicos $(\Delta t=$ 17,9 $\mathrm{ms}$ ). A Figura 6.9 ilustra a estrutura do controle utilizado. 


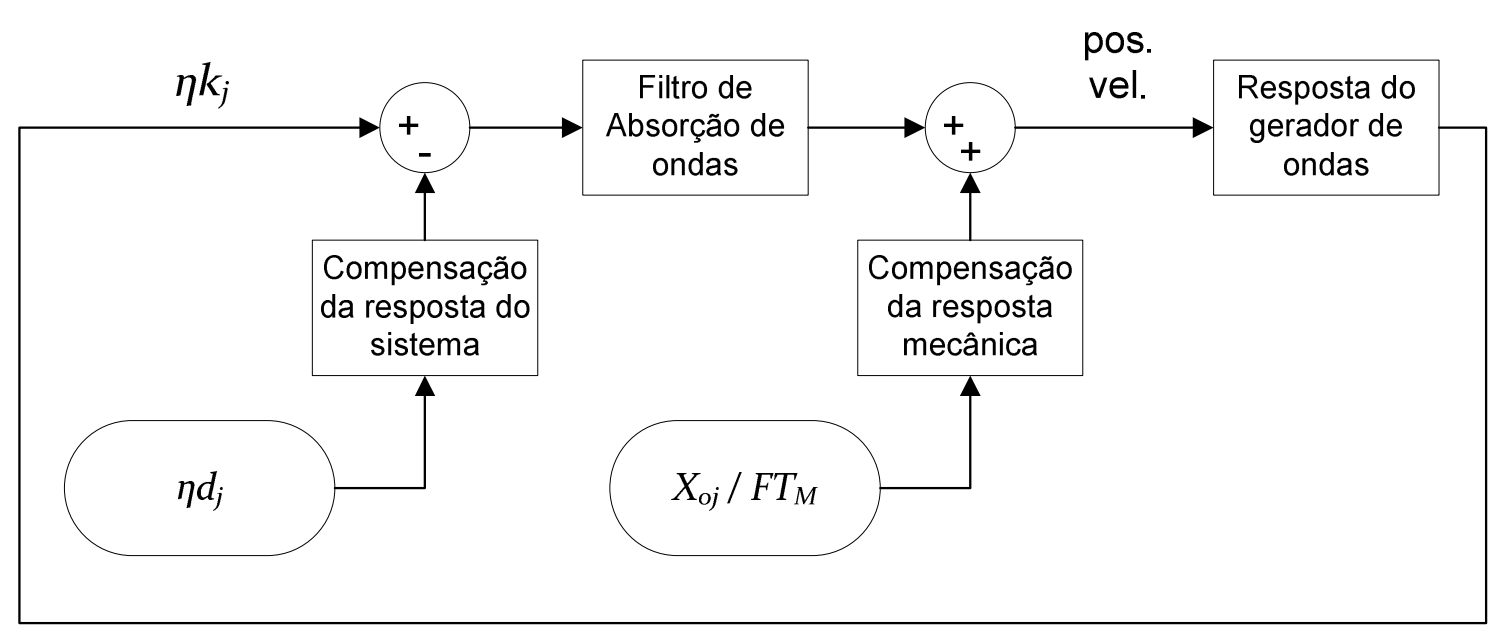

Figura 6.9. Sistema de controle dual mode.

Onde $\eta k_{j}$ é a leitura dos sensores de ondas ultrassônicos dos flaps. Assim, quando não houver reflexão de ondas em um determinado flap, o resultado de $\eta k_{j}-$ $\eta d_{j}$ será nulo e não haverá absorção a ser feita. Quando existe onda refletida incidindo no flap, o sinal resultante é não-nulo; e após passar pelo filtro de absorção, será somado ao sinal de deslocamento de comando de geração de ondas e enviado ao sistema de automação e controle. Assim, sempre que houver alguma diferença da onda esperada em frente a algum flap, uma compensação será feita pelo sistema, alterando o movimento do flap.

Tabela 6.6. Descrição dos ensaios com ondas regulares.

\begin{tabular}{|l|c|c|c|c|c|c|}
\hline \multirow{2}{*}{ Nome } & \multirow{2}{*}{ Descrição } & \multirow{2}{*}{ Geração } & \multicolumn{4}{|c|}{ Absorção } \\
\cline { 4 - 7 } & & & Lado 1 & Lado 2 & Lado 3 & Lado 4 \\
\hline C001 & Calibração de ondas & Lado 1 & & & $\mathrm{X}$ & \\
\hline C002 & Repetição com geração e absorção & Lado 1 & $\mathrm{X}$ & & $\mathrm{X}$ & \\
\hline
\end{tabular}

O trecho inicial das séries temporais foi usado para comparação de altura com o valor requerido para a mesma. Este trecho temporal evitava a reflexão das ondas a partir do cálculo da equação (6.2) usando a distância de $d=14,04-0,6(m)$. O sensor WP2 (centro do tanque) era a referência de medição e a altura foi calculada por zeros ascendentes das cristas e cavados. Inicialmente a função de transferência da parcela progressiva, mostrada na figura 6.10 , foi avaliada somente com geração de ondas na lateral 1. Observa-se que a resposta apresenta atenuação em todas as ondas sem influência das respectivas declividades. O erro encontrado de $F T_{p}$ situou-se no intervalo 
de $5,1<E(\%)<9,3$. Nesse caso foi feita a calibração das ondas aplicando-se um ganho linear para cada onda, que depois de aplicado resultou em erros de no máximo 1,05 mm. Esse resultado é mostrado na Tabela 6.7 (teste C001).

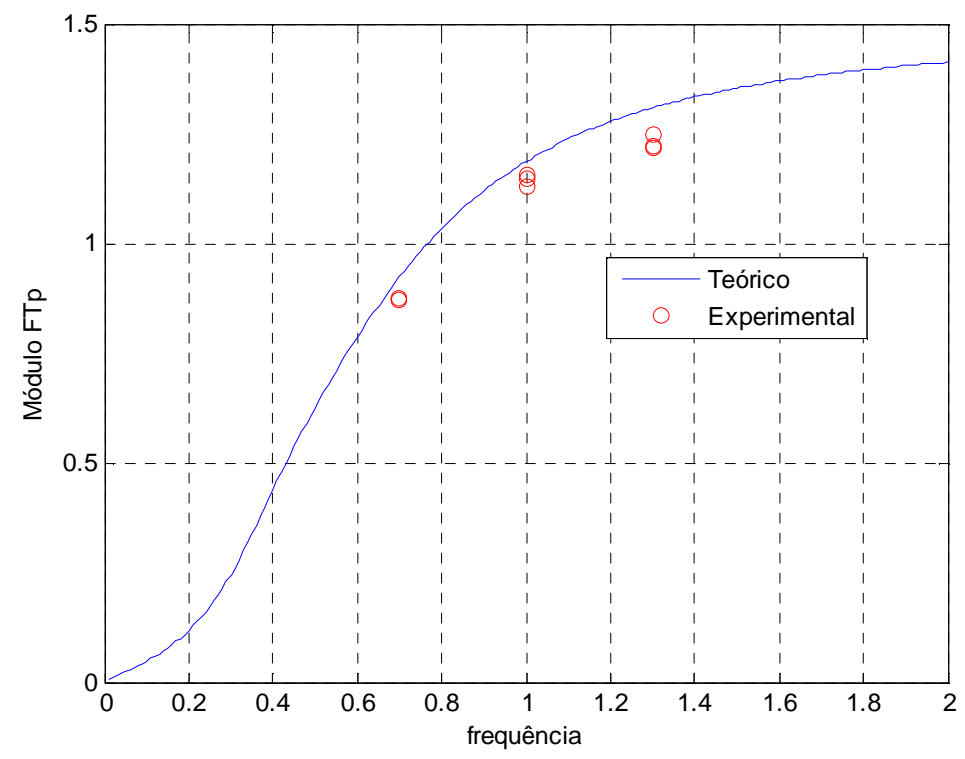

Figura 6.10. Resposta de ondas progressivas do gerador de ondas.

Para comparação entre as duas configurações experimentais, a Tabela 6.7 apresenta as estatísticas do mesmo trecho do sinal de ondas para cada uma das duas diferentes repetições. A Tabela 6.8, por sua vez, traz os valores das diferenças máximas de altura encontradas neste mesmo trecho, para cada uma das repetições.

Tabela 6.7. Trecho inicial das ondas regulares - Onda incidente.

\begin{tabular}{|c|c|c|c|}
\hline $\mathbf{f}(\mathbf{H z})$ & H Teo. $(\mathbf{m m})$ & $\mathbf{C 0 0 1}(\mathbf{m m})$ & $\mathbf{C 0 0 2}(\mathbf{m m})$ \\
\hline 0,70 & 79,6 & 79,6 & 82,3 \\
\hline 0,70 & 106,2 & 106,3 & 109,0 \\
\hline 0,70 & 159,3 & 159,9 & 162,8 \\
\hline 1,00 & 39,0 & 38,9 & 39,2 \\
\hline 1,00 & 52,0 & 52,1 & 52,9 \\
\hline 1,00 & 78,1 & 78,2 & 79,9 \\
\hline 1,30 & 23,1 & 22,1 & 23,2 \\
\hline 1,30 & 30,8 & 30,4 & 30,5 \\
\hline 1,30 & 46,2 & 45,1 & 45,7 \\
\hline
\end{tabular}


Tabela 6.8. Diferença no trecho inicial - Onda incidente.

\begin{tabular}{|c|c|c|c|}
\hline $\mathbf{f}(\mathbf{H z})$ & H Teo. $(\mathbf{m m})$ & $\mathbf{C 0 0 1}(\mathbf{m m})$ & $\mathbf{C 0 0 2}(\mathbf{m m})$ \\
\hline 0,70 & 79,6 & 0,00 & 2,71 \\
\hline 0,70 & 106,2 & 0,11 & 2,85 \\
\hline 0,70 & 159,3 & 0,68 & 3,50 \\
\hline 1,00 & 39,0 & $-0,12$ & 0,19 \\
\hline 1,00 & 52,0 & 0,08 & 0,82 \\
\hline 1,00 & 78,1 & 0,09 & 1,85 \\
\hline 1,30 & 23,1 & $-0,98$ & 0,14 \\
\hline 1,30 & 30,8 & $-0,34$ & $-0,32$ \\
\hline 1,30 & 46,2 & $-1,05$ & $-0,51$ \\
\hline
\end{tabular}

O erro máximo observado em altura calibrada foi de $-1,05 \mathrm{~mm}$ (valor negativo indica altura menor que o requerido) na onda de $1,3 \mathrm{~Hz}$ com altura de 46,2 $\mathrm{mm}$. O erro percentual máximo foi de 4,2\% na onda de $1,3 \mathrm{~Hz}$ com altura de 23,1 mm.

Ao se ativar a geração com absorção ativa na lateral 1, as diferenças nas ondas de 1 e $1,3 \mathrm{~Hz}$ diminuíram. Nas ondas de $0,7 \mathrm{~Hz}$ houve aumento no erro, mas somente para a onda de $79,6 \mathrm{~mm}$ o erro ultrapassou $3 \%$, sendo de $3,41 \%$. No geral, com a absorção e geração simultâneas na lateral 1, ocorreu uma melhora dos valores das alturas.

A reflexão medida, proveniente da absorção ativa da lateral 3, pode ser avaliada na Tabela 6.9. O coeficiente de reflexão é semelhante, independentemente do esquema de absorção; com o aumento da declividade, a reflexão aumenta para os dois casos, com e sem absorção na lateral 1. Os valores máximos de coeficiente de reflexão se situam na faixa dos $10 \%$, e estão de acordo com as previsões teóricas para o sistema de absorção empregado. 
Tabela 6.9. Coeficientes de reflexão medidos nos ensaios com onda regular.

\begin{tabular}{|c|c|c|c|}
\hline $\mathbf{f}(\mathbf{H z})$ & H Teo. $(\mathbf{m m})$ & $\mathbf{C r} \mathbf{C 0 0 1}(\boldsymbol{\%})$ & $\mathbf{C r} \mathbf{C 0 0 2}(\boldsymbol{\%})$ \\
\hline 0,70 & 79,6 & 7,98 & 7,82 \\
\hline 0,70 & 106,2 & 9,16 & 8,89 \\
\hline 0,70 & 159,3 & 10,40 & 9,59 \\
\hline 1,00 & 39,0 & 6,50 & 7,18 \\
\hline 1,00 & 52,0 & 7,42 & 8,10 \\
\hline 1,00 & 78,1 & 10,14 & 9,23 \\
\hline 1,30 & 23,1 & 6,02 & 6,79 \\
\hline 1,30 & 30,8 & 7,48 & 7,32 \\
\hline 1,30 & 46,2 & 7,88 & 10,72 \\
\hline
\end{tabular}

Na Figura 6.11, vê-se que, mesmo com a altura de ondas nos sensores estando modulada em função da sobreposição das ondas incidente e refletida (gráfico superior), a altura da onda incidente apontada permanece estável apesar da reflexão (gráfico inferior). Desta forma, podemos fazer comparações sobre a reflexão das ondas em diferentes trechos no tempo - antes da onda refletida chegar aos sensores e depois de ocorrer uma ou mais reflexões (a re-reflexão na lateral geradora, por ex.).
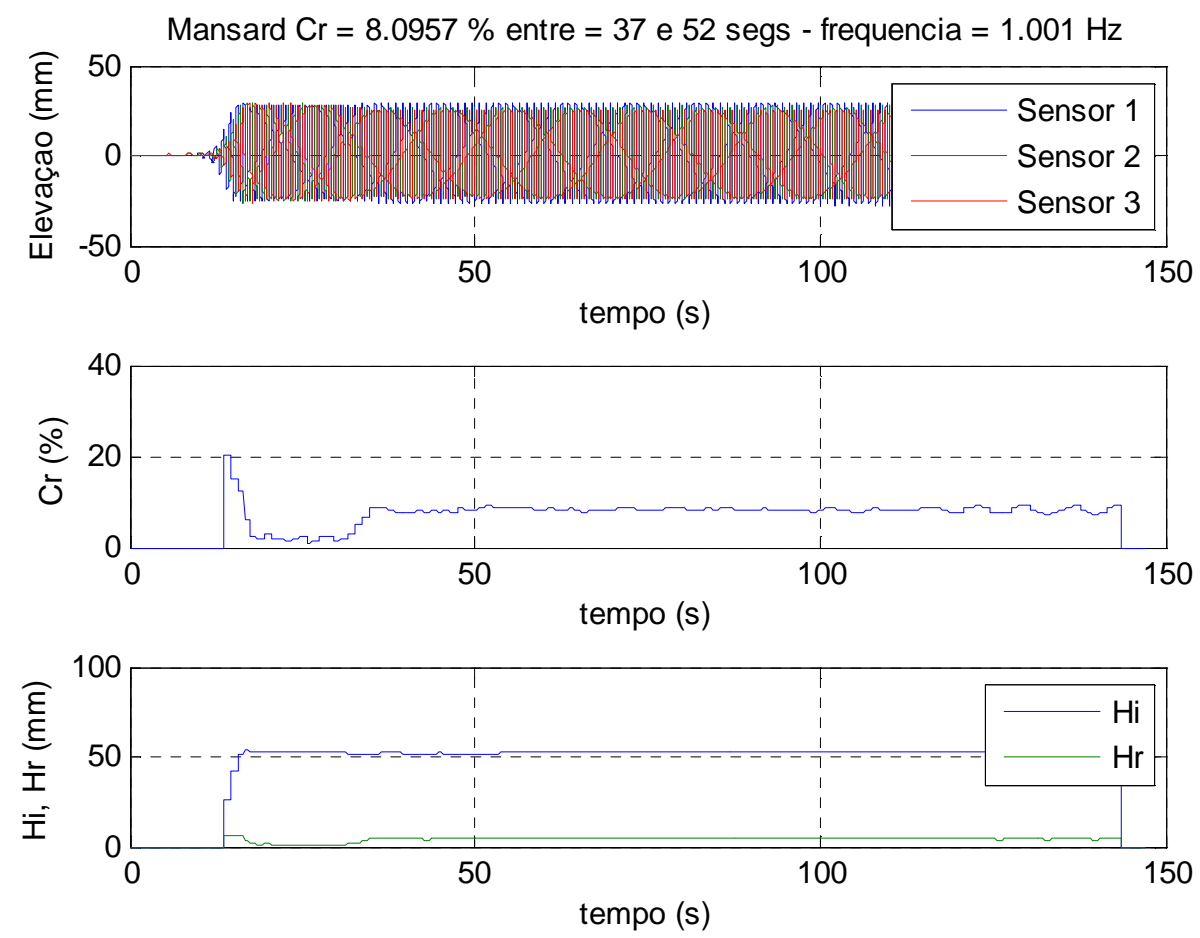

Figura 6.11. Análise de reflexão de onda para a frequência de $1.0 \mathrm{~Hz}$ com H=52mm do ensaio C002. 
Primeiramente pode-se comparar a estabilidade da onda incidente em diferentes trechos de sinal e com isso analisar o efeito da re-reflexão de ondas na lateral 1 usando os dados dos testes C001 e C002. Se a lateral 1 estiver gerando e absorvendo, a onda refletida da lateral 3 pode ser absorvida e não mais retornar ao tanque. Assim, a onda incidente não apresentará modulações com maior tempo de ensaio.

A Figura 6.12 mostra a onda com $0,7 \mathrm{~Hz}$ e 106,2mm de altura, destacando os trechos sem reflexão, com uma reflexão e com duas reflexões, respectivamente. Os trechos foram selecionados a partir da velocidade de grupo de ondas na equação (6.2). Este foi um resultado recorrente nos testes, evidenciado na Tabela 6.10. A altura de ondas incidente é estimada pelo método de Mansard \& Funke e revela que, quando o gerador da lateral 1 está também absorvendo, a altura gerada é um pouco maior para as ondas de $0,7 \mathrm{~Hz}$ (como mostra a Tabela 6.7). Isto mostra que, como procedimento padrão, deve-se sempre calibrar as ondas com a absorção ativa no gerador, para se obter os melhores resultados. A análise da variação das alturas nos diferentes trechos destacados na Figura 6.12 resulta nos dados da Tabela 6.11.

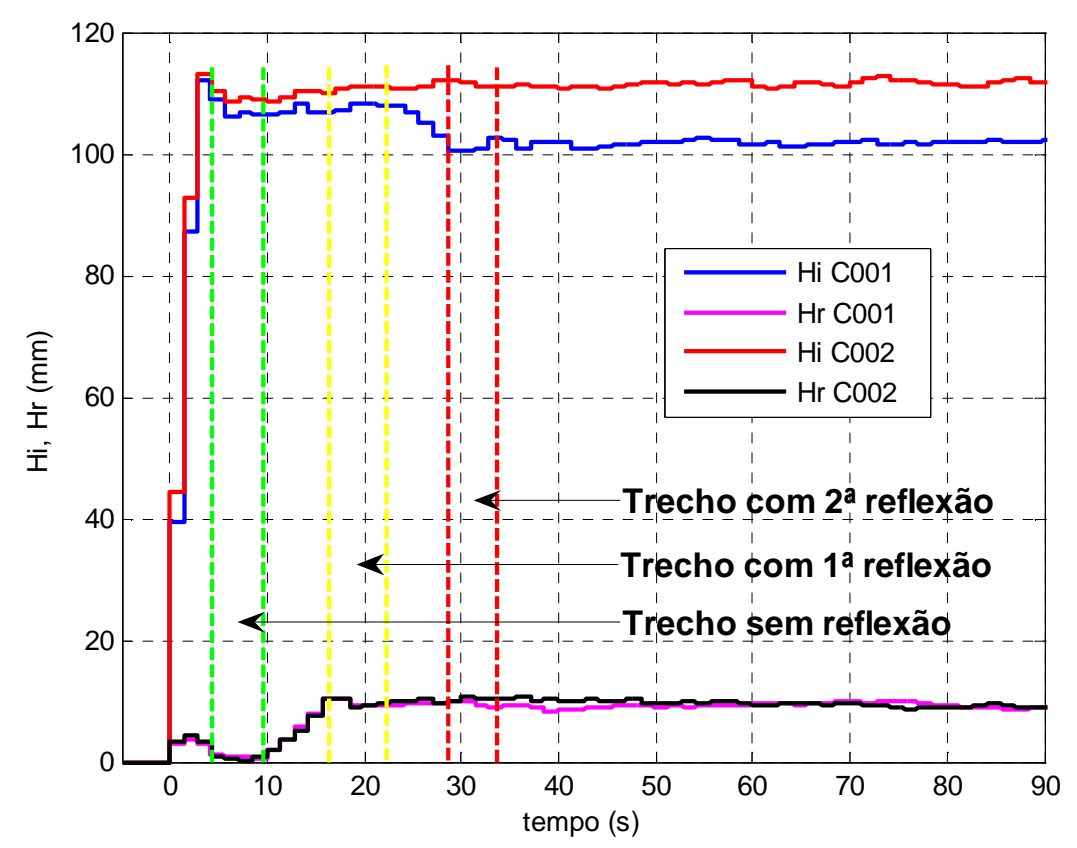

Figura 6.12. Comparação da estabilidade da onda incidente com uma lateral e duas absorvendo ondas (ensaios C001 e C002). 
Tabela 6.10. Altura de ondas regulares incidentes por trechos temporais.

\begin{tabular}{|c|c|c|c|c|c|c|c|}
\hline \multirow[b]{2}{*}{$\mathbf{f}(\mathbf{H z})$} & \multirow{2}{*}{$\begin{array}{c}\text { H Teo. } \\
(\mathbf{m m})\end{array}$} & \multicolumn{3}{|c|}{ C001 } & \multicolumn{3}{|c|}{ C002 } \\
\hline & & $\begin{array}{l}\text { Hi ini. } \\
(\mathbf{m m})\end{array}$ & $\begin{array}{c}\text { Hi } 1^{\text {a }} \text { ref. } \\
(\mathbf{m m})\end{array}$ & $\begin{array}{c}\text { Hi } 2^{\mathrm{a}} \text { ref. } \\
\quad(\mathrm{mm})\end{array}$ & $\begin{array}{l}\text { Hi ini. } \\
\text { (mm) }\end{array}$ & $\begin{array}{c}\text { Hi } 1^{\text {a }} \text { ref. } \\
(\mathbf{m m})\end{array}$ & $\begin{array}{c}\text { Hi } 2^{\mathrm{a}} \text { ref. } \\
(\mathrm{mm})\end{array}$ \\
\hline 0,70 & 79,6 & 80,1 & 79,1 & 75,04 & 82,6 & 81,0 & 81,7 \\
\hline 0,70 & 106,2 & 107,0 & 105,6 & 101,5 & 109,4 & 111,1 & 111,0 \\
\hline 0,70 & 159,3 & 161,3 & 157,5 & 147,6 & 163,1 & 161,5 & 162,0 \\
\hline 1,00 & 39,0 & 38,9 & 38,0 & 35,4 & 39,4 & 38,7 & 38,9 \\
\hline 1,00 & 52,0 & 52,3 & 51,1 & 48,1 & 52,8 & 51,8 & 52,3 \\
\hline 1,00 & 78,1 & 78,8 & 76,9 & 76,6 & 80,1 & 79,1 & 79,2 \\
\hline 1,30 & 23,1 & 22,3 & 22,3 & 23,5 & 23,4 & 23,3 & 24,0 \\
\hline 1,30 & 30,8 & 30,7 & 30,6 & 32,9 & 30,9 & 30,8 & 31,5 \\
\hline 1,30 & 46,2 & 45,1 & 45,4 & 46,1 & 45,8 & 45,7 & 46,1 \\
\hline
\end{tabular}

Tabela 6.11. Diferença de altura de ondas regulares incidentes por trechos temporais (medidas em relação às alturas requeridas).

\begin{tabular}{|c|c|c|c|c|c|c|c|}
\hline \multirow[b]{2}{*}{$\mathbf{f}(\mathbf{H z})$} & \multirow{2}{*}{$\begin{array}{c}\text { H Teo. } \\
\text { (mm) }\end{array}$} & \multicolumn{3}{|c|}{ C001 } & \multicolumn{3}{|c|}{ C002 } \\
\hline & & $\begin{array}{l}\text { Hi ini. } \\
(\mathrm{mm})\end{array}$ & $\begin{array}{c}\text { Hi } 1^{\text {a }} \text { ref. } \\
(\mathrm{mm})\end{array}$ & $\begin{array}{c}\text { Hi } 2^{\mathrm{a}} \text { ref. } \\
(\mathbf{m m})\end{array}$ & $\begin{array}{l}\text { Hi ini. } \\
(\mathbf{m m})\end{array}$ & $\begin{array}{c}\text { Hi } 1^{\text {a }} \text { ref. } \\
(\mathbf{m m})\end{array}$ & $\begin{array}{c}\text { Hi } 2^{a} \text { ref. } \\
(\mathbf{m m})\end{array}$ \\
\hline 0,70 & 79,6 & 0,5 & $-0,5$ & $-4,56$ & 3 & 1,4 & 2,1 \\
\hline 0,70 & 106,2 & 0,8 & $-0,6$ & $-4,7$ & 3,2 & 4,9 & 4,8 \\
\hline 0,70 & 159,3 & 2 & $-1,8$ & $-11,7$ & 3,8 & 2,2 & 2,7 \\
\hline 1,00 & 39,0 & $-0,1$ & -1 & $-3,6$ & 0,4 & $-0,3$ & $-0,1$ \\
\hline 1,00 & 52,0 & 0,3 & $-0,9$ & $-3,9$ & 0,8 & $-0,2$ & 0,3 \\
\hline 1,00 & 78,1 & 0,7 & $-1,2$ & $-1,5$ & 2 & 1 & 1,1 \\
\hline 1,30 & 23,1 & $-0,8$ & $-0,8$ & 0,4 & 0,3 & 0,2 & 0,9 \\
\hline 1,30 & 30,8 & $-0,1$ & $-0,2$ & 2,1 & 0,1 & 0 & 0,7 \\
\hline 1,30 & 46,2 & $-1,1$ & $-0,8$ & $-0,1$ & $-0,4$ & $-0,5$ & $-0,1$ \\
\hline
\end{tabular}

Pode ser observado que, sem a absorção em dois lados opostos do tanque (C001), efeitos de re-reflexão das ondas criam variações na onda incidente com vários milímetros de diferença. A Tabela 6.12 quantifica estes efeitos, comparando percentualmente a variação entre trechos com relação à onda incidente do primeiro trecho.

Pode-se concluir, portanto, que se deve utilizar absorção de ondas em lados opostos e recomenda-se que a calibração de ondas seja sempre realizada com a absorção ativada na lateral geradora. 
Tabela 6.12. Variação de altura de onda percentual entre a onda incidente inicial e os trechos com uma e duas reflexões.

\begin{tabular}{|c|c|c|c|c|c|}
\hline \multicolumn{3}{|c|}{ C001 } & \multicolumn{3}{|c|}{$\mathrm{COO2}$} \\
\hline Hi ini. (mm) & $\Delta H i 1^{a}$ ref. (\%) & $\Delta H_{i} 2^{\mathrm{a}}$ ref. (\%) & Hi ini. (mm) & $\Delta$ Hi $1^{\text {a }}$ ref. $(\%)$ & $\Delta \mathrm{Hi} 2^{\mathrm{a}}$ ref. (\%) \\
\hline 80,1 & 1,25 & 6,32 & 82,6 & 1,94 & 1,09 \\
\hline 107,0 & 1,31 & 5,14 & 109,4 & 1,55 & 1,46 \\
\hline 161,3 & 2,36 & 8,49 & 163,1 & 0,98 & 0,67 \\
\hline 38,9 & 2,31 & 9,00 & 39,4 & 1,78 & 1,27 \\
\hline 52,3 & 2,29 & 8,03 & 52,8 & 1,89 & 0,95 \\
\hline 78,8 & 2,41 & 2,79 & 80,1 & 1,25 & 1,12 \\
\hline 22,3 & 0,00 & 5,38 & 23,4 & 0,43 & 2,56 \\
\hline 30,7 & 0,33 & 7,17 & 30,9 & 0,32 & 1,94 \\
\hline 45,1 & 0,67 & 2,22 & 45,8 & 0,22 & 0,66 \\
\hline
\end{tabular}

Quanto às alturas de ondas refletidas $\left(\mathrm{H}_{\mathrm{R}}\right)$ pela lateral 3, foi observada discreta variação entre os testes C001 e C002. Isto porque a altura da $2^{a}$ reflexão é atenuada ao incidir novamente na lateral 3, resultando em variações de altura de ondas refletida muito pequenas. A descrição do efeito se mostra coerente para explicar por que no teste C001, após a $2^{\mathrm{a}}$ reflexão, as variações na onda incidente diminuem (veja a Figura 6.12).

\subsubsection{Ondas unidirecionais oblíquas}

As ondas regulares progressivas oblíquas ensaiadas no tanque foram as mesmas dos testes não-oblíquos, geradas agora em diferentes ângulos: $180^{\circ}\left(0^{\circ}\right), 210^{\circ}\left(30^{\circ}\right), 225^{\circ}$ $\left(45^{\circ}\right), 240^{\circ}\left(60^{\circ}\right), 270^{\circ}\left(90^{\circ}\right)$. O teste é uma varredura angular da lateral 1 para a lateral 4. As ondas foram realizadas com absorção ativa em todas as laterais, com exceção das ondas em $180^{\circ}$, que foram executadas sem absorção nas laterais (laterais 2 e 4). As ondas com direção de $270^{\circ}$ foram realizadas com absorção ativa nas laterais 1 e 3, com o objetivo de atenuar eventuais efeitos de tridimensionalidade causados pelos dois flaps bloqueados nas extremidades das laterais geradoras (neste caso, as laterais 2 e 4). No total foram realizadas 45 ondas, cujas características são relacionadas na Tabela 6.13.

Para se avaliar a qualidade dos campos de onda gerados nas diferentes direções, optou-se por fazer um mapeamento de uma área de $9 \mathrm{~m}^{2}(3 \mathrm{~m} \times 3 \mathrm{~m})$ com centro 
coincidente com o centro do tanque, representativa da área mais provável para os ensaios. Para tanto, foi construído um dispositivo que permitiu a fixação de 16 sensores de onda, para medidas de onda simultâneas nas diferentes posições.

Os 16 sensores de ondas capacitivos utilizados foram montados em um dispositivo para calibração de forma a realizar a calibração simultânea de todos os sensores. O dispositivo tem ajuste linear de altura e permite um posicionamento preciso no sentido vertical. Foram usados 7 pontos de altura $(-150,-100,-50,0,50,100$ e 150 $\mathrm{mm}$ ) realizados duas vezes para traçar a reta de calibração. O valor da correlação quadrática da regressão dos sensores foi sempre maior que 0,9999. A calibração foi repetida diversas vezes para se aferir o valor do ganho ao longo do tempo.

A instrumentação utilizada neste ensaio foi a mesma das anteriores, dois módulos MX-840 da HBM (2 x 8 canais) foram montados em paralelo para adquirir os 16 sensores. Devido à falta de um canal de sincronismo com o gerador de ondas, a análise dos sinais foi feita usando-se um recurso que será explicado à frente, no texto. 
Tabela 6.13. Ondas regulares oblíquas.

\begin{tabular}{|c|c|c|c|c|c|c|}
\hline index & $\mathbf{T}(\mathbf{s})$ & $\mathbf{f}(\mathbf{H z})$ & Declividade (\%) & Direção (graus) & $\mathbf{L}(\mathbf{m})$ & $\mathbf{H}(\mathbf{m m})$ \\
\hline 1 & 1,43 & 0,70 & 2,5 & 180 & 3,19 & 79,6 \\
\hline 2 & 1,43 & 0,70 & 3,3 & 180 & 3,19 & 106,2 \\
\hline 3 & 1,43 & 0,70 & 5,0 & 180 & 3,19 & 159,3 \\
\hline 4 & 1,00 & 1,00 & 2,5 & 180 & 1,56 & 39,0 \\
\hline 5 & 1,00 & 1,00 & 3,3 & 180 & 1,56 & 52,0 \\
\hline 6 & 1,00 & 1,00 & 5,0 & 180 & 1,56 & 78,1 \\
\hline 7 & 0,77 & 1,30 & 2,5 & 180 & 0,92 & 23,1 \\
\hline 8 & 0,77 & 1,30 & 3,3 & 180 & 0,92 & 30,8 \\
\hline 9 & 0,77 & 1,30 & 5,0 & 180 & 0,92 & 46,2 \\
\hline 10 & 1,43 & 0,70 & 2,5 & 210 & 3,19 & 79,6 \\
\hline 11 & 1,43 & 0,70 & 3,3 & 210 & 3,19 & 106,2 \\
\hline 12 & 1,43 & 0,70 & 5,0 & 210 & 3,19 & 159,3 \\
\hline 13 & 1,00 & 1,00 & 2,5 & 210 & 1,56 & 39,0 \\
\hline 14 & 1,00 & 1,00 & 3,3 & 210 & 1,56 & 52,0 \\
\hline 15 & 1,00 & 1,00 & 5,0 & 210 & 1,56 & 78,1 \\
\hline 16 & 0,77 & 1,30 & 2,5 & 210 & 0,92 & 23,1 \\
\hline 17 & 0,77 & 1,30 & 3,3 & 210 & 0,92 & 30,8 \\
\hline 18 & 0,77 & 1,30 & 5,0 & 210 & 0,92 & 46,2 \\
\hline 19 & 1,43 & 0,70 & 2,5 & 225 & 3,19 & 79,6 \\
\hline 20 & 1,43 & 0,70 & 3,3 & 225 & 3,19 & 106,2 \\
\hline 21 & 1,43 & 0,70 & 5,0 & 225 & 3,19 & 159,3 \\
\hline 22 & 1,00 & 1,00 & 2,5 & 225 & 1,56 & 39,0 \\
\hline 23 & 1,00 & 1,00 & 3,3 & 225 & 1,56 & 52,0 \\
\hline 24 & 1,00 & 1,00 & 5,0 & 225 & 1,56 & 78,1 \\
\hline 25 & 0,77 & 1,30 & 2,5 & 225 & 0,92 & 23,1 \\
\hline 26 & 0,77 & 1,30 & 3,3 & 225 & 0,92 & 30,8 \\
\hline 27 & 0,77 & 1,30 & 5,0 & 225 & 0,92 & 46,2 \\
\hline 28 & 1,43 & 0,70 & 2,5 & 240 & 3,19 & 79,6 \\
\hline 29 & 1,43 & 0,70 & 3,3 & 240 & 3,19 & 106,2 \\
\hline 30 & 1,43 & 0,70 & 5,0 & 240 & 3,19 & 159,3 \\
\hline 31 & 1,00 & 1,00 & 2,5 & 240 & 1,56 & 39,0 \\
\hline 32 & 1,00 & 1,00 & 3,3 & 240 & 1,56 & 52,0 \\
\hline 33 & 1,00 & 1,00 & 5,0 & 240 & 1,56 & 78,1 \\
\hline 34 & 0,77 & 1,30 & 2,5 & 240 & 0,92 & 23,1 \\
\hline 35 & 0,77 & 1,30 & 3,3 & 240 & 0,92 & 30,8 \\
\hline 36 & 0,77 & 1,30 & 5,0 & 240 & 0,92 & 46,2 \\
\hline 37 & 1,43 & 0,70 & 2,5 & 270 & 3,19 & 79,6 \\
\hline 38 & 1,43 & 0,70 & 3,3 & 270 & 3,19 & 106,2 \\
\hline 39 & 1,43 & 0,70 & 5,0 & 270 & 3,19 & 159,3 \\
\hline 40 & 1,00 & 1,00 & 2,5 & 270 & 1,56 & 39,0 \\
\hline 41 & 1,00 & 1,00 & 3,3 & 270 & 1,56 & 52,0 \\
\hline 42 & 1,00 & 1,00 & 5,0 & 270 & 1,56 & 78,1 \\
\hline 43 & 0,77 & 1,30 & 2,5 & 270 & 0,92 & 23,1 \\
\hline 44 & 0,77 & 1,30 & 3,3 & 270 & 0,92 & 30,8 \\
\hline 45 & 0,77 & 1,30 & 5,0 & 270 & 0,92 & 46,2 \\
\hline
\end{tabular}

Os sensores foram colocados em quatro traves de suporte horizontais para montagem do arranjo em matriz 4 x 4 elementos no centro do tanque. A distância entre 
sensores foi de 1 metro. A Figura 6.13 mostra o arranjo montado no tanque de provas, com detalhe da numeração dos sensores de ondas.

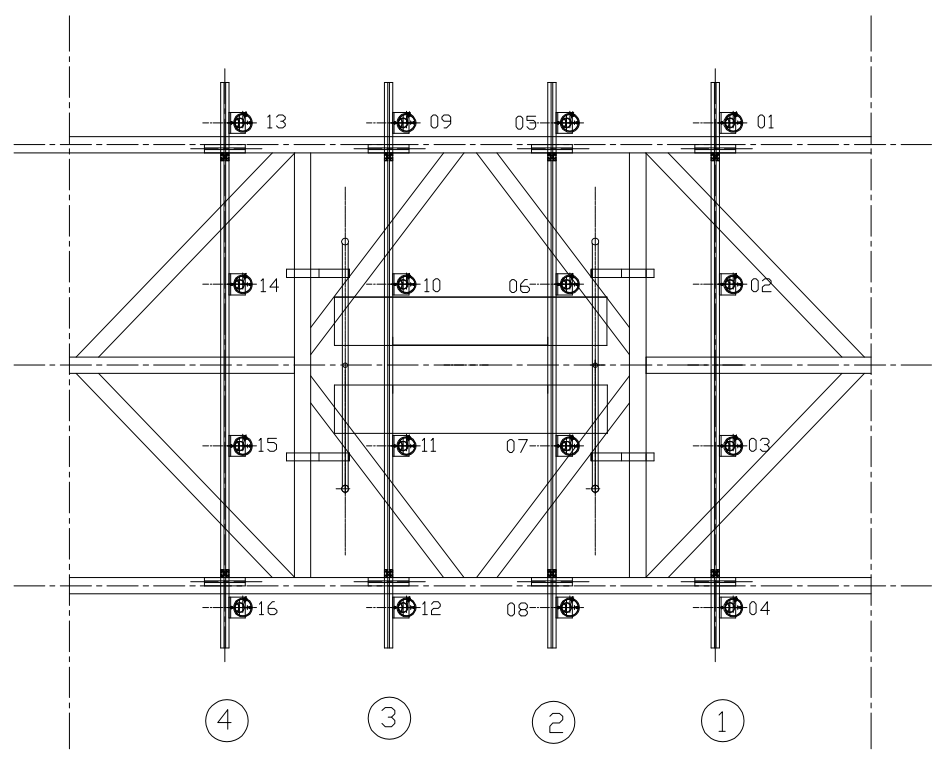

(a) - Concepção do arranjo matricial de sensores.

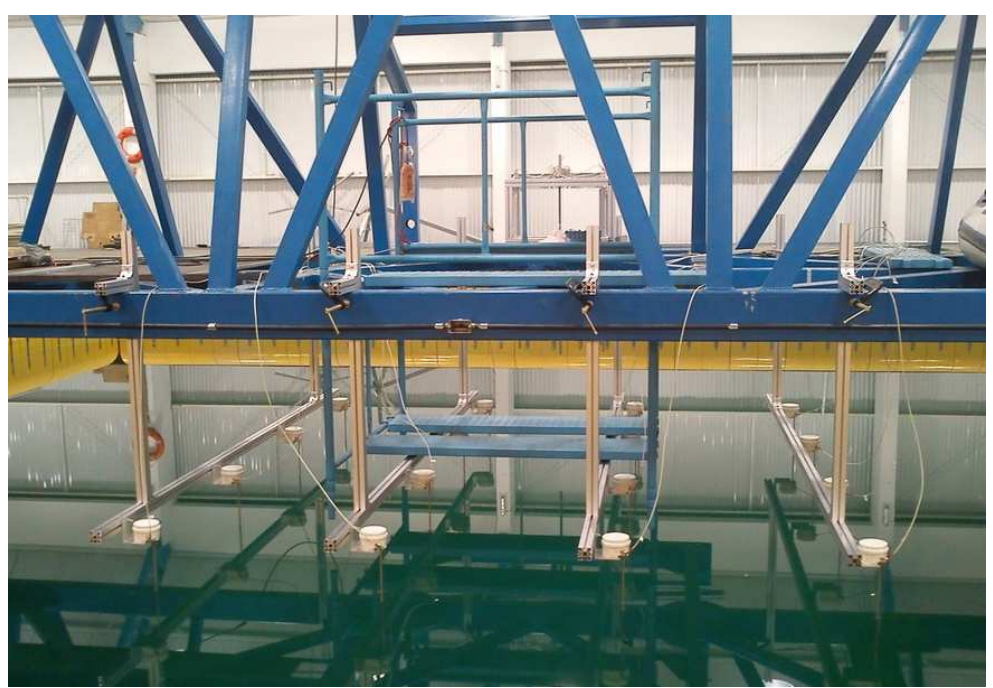

(b) - Arranjo de sensores montado no tanque de provas.

Figura 6.13. Matriz de sensores 4 x 4 montada no tanque de provas.

A posição de medição dos sensores é mostrada na Tabela 6.14, em relação ao sistema de coordenadas do tanque. Na coordenada $\mathrm{X}$ a matriz ficou centralizada em $\mathrm{X}=$ $6,865 \mathrm{~m}$, ou seja, apenas $0,155 \mathrm{~m}$ fora do centro, em virtude da interferência dos suportes com a ponte de instrumentação. 
Tabela 6.14. Posições dos sensores na matriz espacial.

\begin{tabular}{|c|c|c|c|c|}
\hline Coordenadas & $\mathrm{Y}=5,52 \mathrm{~m}$ & $\mathrm{Y}=6,52 \mathrm{~m}$ & $\mathrm{Y}=7,52 \mathrm{~m}$ & $\mathrm{Y}=8,52 \mathrm{~m}$ \\
\hline $\mathrm{X}=5,365 \mathrm{~m}$ & WP1 & WP2 & WP3 & WP4 \\
\hline $\mathrm{X}=6,365 \mathrm{~m}$ & WP5 & WP6 & WP7 & WP8 \\
\hline $\mathrm{X}=7,365 \mathrm{~m}$ & WP9 & WP10 & WP11 & WP12 \\
\hline $\mathrm{X}=8,365 \mathrm{~m}$ & WP13 & WP14 & WP15 & WP16 \\
\hline
\end{tabular}

Um procedimento padrão foi adotado para a análise das séries temporais de todas as ondas. Visando analisar as primeiras ondas que passam por cada sensor, as séries temporais foram sincronizadas pela envoltória da frente de ondas, ou seja, as ondas analisadas foram sempre as primeiras ondas após a chegada da frente de ondas em cada sensor. A Figura 6.14 mostra, como exemplo, uma das ondas na direção $45^{\circ}$ analisada por esse procedimento. A seguir, foram definidas as janelas temporais sem reflexão de ondas do lado oposto para levantamento da estatística de altura média por zeros ascendentes. Como início da janela temporal, foi escolhido o instante seguinte da passagem da frente inicial, que normalmente apresenta alguma flutuação transitória. Na sequência, o valor das alturas das ondas na matriz foi analisado em relação ao desvio do valor requerido. Foi avaliada também a máxima variação percentual e o desvio padrão de cada sensor em relação ao valor médio da altura na matriz. Esta última análise é essencial para se avaliar a variação espacial do campo de ondas e sua homogeneidade. Quanto ao desvio em relação à altura requerida, o erro é facilmente minimizado com a devida calibração da altura com uma nova repetição da onda de calibração. Assim sendo, a Tabela 6.15 mostra os resultados das análises das 45 ondas; o desvio percentual de altura média em relação ao requerido (coluna 5), o desvio padrão da altura amostrada entre os 16 sensores de ondas (coluna 6) e também a maior variação percentual de altura de onda entre os 16 sensores (coluna 7).

A direção de propagação das ondas foi medida experimentalmente e também é mostrada na Tabela 6.15. A direção foi avaliada por meio de um método de medição da combinação de sensores de ondas. Foi adotado o arranjo mostrado na Figura 6.15, a partir da leitura de 9 dos 16 sensores disponíveis nos testes. Os espectros de densidade de energia cruzados entre as 9 combinações de sensores utilizadas são aplicados a um algoritmo que gera o espectro direcional de ondas $(S(\omega, \theta))$ a partir do método de máxima entropia. A implementação e aplicação deste método de estimação de direção de ondas pode ser visto em Tannuri, De Mello et al. (2007). 
$\mathrm{Na}$ aplicação a este experimento, foram feitos os espectros usando o método de welch. Devido à reflexão das ondas, o trecho temporal utilizado era reduzido e não forneceria uma resposta adequada; assim, foi utilizado um trecho maior, que apresenta reflexão de ondas. O método não prevê a existência de ondas em sentidos opostos $\left(180^{\circ}\right)$, que são interpretadas como sendo uma única direção. Se for avaliada a direção média pela energia total do espectro, a direção da onda não tem variação no valor estimado. Portanto, o método pode ser utilizado.

O trabalho de Nwogu (1989) mostra, aplicado a um array de 5 sensores (um sensor central com 4 perimetrais com raio constante em relação ao sensor central), que existe uma faixa de medição de frequência ideal para um dado raio do array circular. Segundo o autor, a faixa ideal de medição é dada por:

$0,05<\frac{R_{a}}{L}<0,5$
$\frac{R_{a}}{L}=0,15 \rightarrow$ relação ideal

onde $R_{a}$ é o raio do array e $L$ é o comprimento de ondas em uma dada frequência. Assim observa-se que, dependendo da frequência, poderá ocorrer uma piora na estimação da direção. As ondas de $1 \mathrm{~Hz}$ e 1,3 Hz não atendem ao critério recomendado com a distância entre os sensores de 1 metro e 1,41 metros. Consequentemente, a dispersão direcional da energia obtida foi pior com tais ondas, mas os valores dos picos dos espectros direcionais $(S(\omega, \theta))$ estavam preservados. Assim foi buscado o pico do espectro, que é a direção correta da onda. O método utiliza uma malha em duas dimensões, em frequência e direção. Se a malha for demasiadamente pequena não é viável realizá-la computacionalmente, com um tempo de processamento elevado. Assim sendo, foi definida em direção a resolução de 1 grau. As estimativas das direções são apresentadas na Tabela 6.15. Como o único objetivo desta análise era indicar a direção de pico de ondas regulares, isto foi possível de ser feito, apesar da faixa de utilização não ser a melhor possível por limitação do arranjo experimental. 


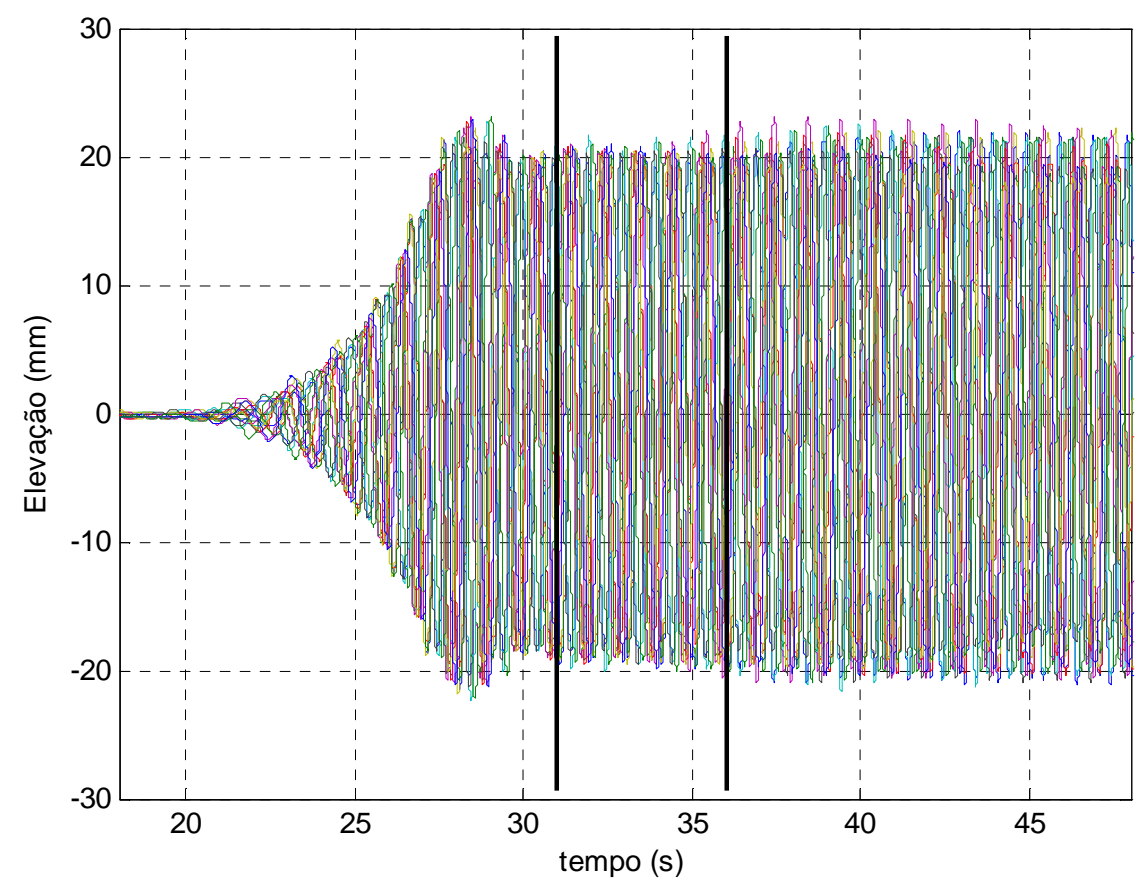

Figura 6.14. Elevação de onda dos 16 sensores sincronizados no tempo da onda de $1 \mathrm{~Hz}$ com $2,5 \%$ de declividade (destacado o trecho analisado).

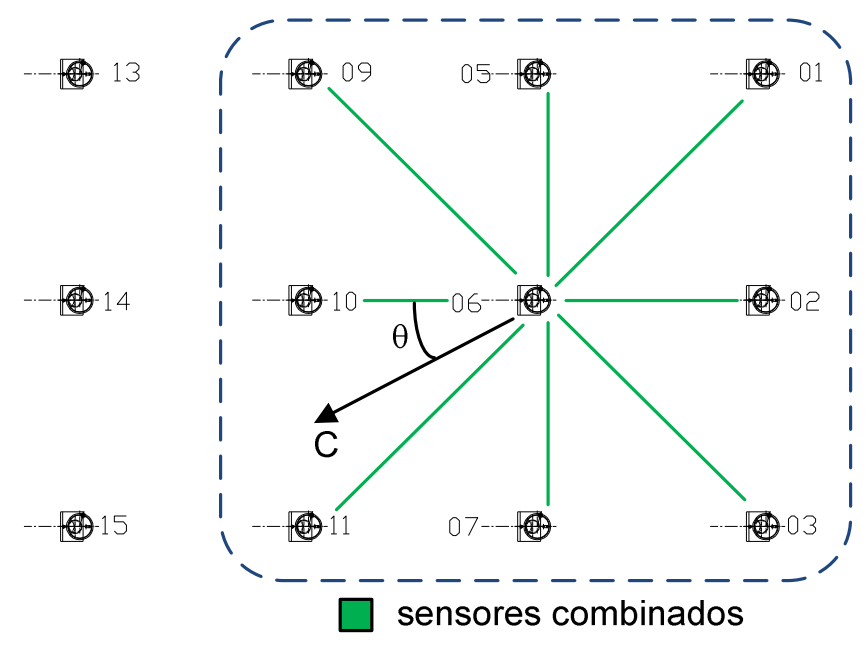

- 16 - 12

Figura 6.15. Sensores utilizados para medição direcional de ondas. Em destaque o referencial angular adotado. 
Tabela 6.15. Desvio entre valor de altura requerida e altura média na matriz de sensores.

\begin{tabular}{|c|c|c|c|c|c|c|c|}
\hline index & $\mathbf{f}(\mathbf{H z})$ & Direção (graus) & $\mathbf{H}(\mathbf{m m})$ & $\mathrm{H}_{\text {erro }}$ Matriz (\%) & oH Matriz (mm) & $\Delta \mathbf{H}$ Matriz $(\%)$ & Direção ME (graus) \\
\hline 1 & \multirow{3}{*}{0,70} & \multirow{9}{*}{180} & 79,6 & 6,24 & 1,12 & \begin{tabular}{|l|}
4,96 \\
\end{tabular} & \begin{tabular}{|c|}
$-0,67$ \\
\end{tabular} \\
\hline 2 & & & 106,2 & 7,02 & 1,49 & 4,63 & $-0,65$ \\
\hline 3 & & & 159,3 & 6,20 & 3,17 & 6,27 & $-1,53$ \\
\hline 4 & \multirow{3}{*}{1,00} & & 39,0 & 3,82 & $\mathbf{0 , 8 7}$ & 6,66 & $-0,75$ \\
\hline 5 & & & 52,0 & 4,52 & $\mathbf{0 , 8 4}$ & 5,28 & $-0,70$ \\
\hline 6 & & & 78,1 & 5,33 & 1,02 & 3,93 & $-0,37$ \\
\hline 7 & \multirow{3}{*}{1,30} & & 23,1 & 4,22 & $\mathbf{0 , 8 1}$ & 10,99 & $0 *$ \\
\hline 8 & & & 30,8 & 6,00 & 0,92 & 10,49 & 0* \\
\hline 9 & & & 46,2 & 5,31 & 1,51 & 9,64 & 0* \\
\hline 10 & \multirow{3}{*}{0,70} & \multirow{9}{*}{210} & 79,6 & 3,05 & 2,88 & 13,39 & 28,98 \\
\hline 11 & & & 106,2 & 3,01 & 3,79 & 12,99 & 29,15 \\
\hline 12 & & & 159,3 & 4,22 & 4,47 & 9,63 & 30,06 \\
\hline 13 & \multirow{3}{*}{1,00} & & 39,0 & 1,70 & 1,22 & $\mathbf{9 , 5 8}$ & $29 *$ \\
\hline 14 & & & 52,0 & 1,11 & 1,59 & 10,84 & $29 *$ \\
\hline 15 & & & 78,1 & 1,12 & 3,97 & 19,45 & 29* \\
\hline 16 & \multirow{3}{*}{1,30} & & 23,1 & 4,59 & 2,43 & 30,52 & 30* \\
\hline 17 & & & 30,8 & 6,04 & 3,23 & 28,83 & 30* \\
\hline 18 & & & 46,2 & 3,82 & 4,44 & 23,64 & $30 *$ \\
\hline 19 & \multirow{3}{*}{0,70} & \multirow{9}{*}{225} & 79,6 & 4,17 & 2,28 & 11,15 & 43,86 \\
\hline 20 & & & 106,2 & 4,21 & 3,58 & 13,46 & 43,95 \\
\hline 21 & & & 159,3 & 2,13 & 5,43 & 13,19 & 44,19 \\
\hline 22 & \multirow{3}{*}{1,00} & & 39,0 & 0,64 & 1,12 & 10,51 & $44 *$ \\
\hline 23 & & & 52,0 & 1,21 & 1,65 & 10,62 & 44* \\
\hline 24 & & & 78,1 & $-0,16$ & 1,87 & 8,46 & $44 *$ \\
\hline 25 & \multirow{3}{*}{1,30} & & 23,1 & 0,55 & 1,48 & 20,35 & $43 *$ \\
\hline 26 & & & 30,8 & 3,93 & 1,78 & 18,52 & $43 *$ \\
\hline 27 & & & 46,2 & 1,19 & 2,80 & 18,15 & $44 *$ \\
\hline 28 & \multirow{3}{*}{0,70} & \multirow{9}{*}{240} & 79,6 & 2,14 & 5,19 & 18,16 & 61,54 \\
\hline 29 & & & 106,2 & 1,64 & 7,37 & 21,42 & 61,09 \\
\hline 30 & & & 159,3 & 0,77 & 9,34 & 17,17 & 60,85 \\
\hline 31 & \multirow{3}{*}{1,00} & & 39,0 & 2,73 & 3,18 & 27,92 & $62 *$ \\
\hline 32 & & & 52,0 & 2,20 & 4,43 & 30,64 & $63^{*}$ \\
\hline 33 & & & 78,1 & $-0,19$ & 4,91 & 23,51 & $63^{*}$ \\
\hline 34 & \multirow{3}{*}{1,30} & & 23,1 & 0,47 & 4,17 & 58,35 & 61* \\
\hline 35 & & & 30,8 & 0,62 & 5,35 & $\begin{array}{l}5,57 \\
\end{array}$ & 61* \\
\hline 36 & & & 46,2 & $-2,29$ & 7,34 & 49,48 & $63 *$ \\
\hline 37 & \multirow{3}{*}{0,7} & \multirow{9}{*}{270,0} & 79,6 & 7,90 & 5,88 & 21,56 & 86,34 \\
\hline 38 & & & 106,2 & 7,91 & 7,32 & 20,50 & 87,12 \\
\hline 39 & & & 159,3 & 7,48 & 10,26 & 18,04 & 85,65 \\
\hline 40 & \multirow{3}{*}{1,0} & & 39,0 & 0,23 & 3,66 & 34,57 & 89,67 \\
\hline 41 & & & 52,0 & 1,11 & 5,05 & 35,59 & 89,97 \\
\hline 42 & & & 78,1 & 1,76 & 7,32 & 31,38 & 90,13 \\
\hline 43 & \multirow{3}{*}{1,3} & & 23,1 & 6,36 & 3,48 & 45,80 & 89* \\
\hline 44 & & & 30,8 & 6,74 & 4,58 & 47,81 & 89* \\
\hline 45 & & & 46,2 & 5,32 & 5,63 & 50,05 & 89* \\
\hline
\end{tabular}

$(*)$ - Estimado pelo valor de pico do espectro direcional

Percebe-se pelos resultados de $H_{\text {erro }}$ que os valores obtidos em geral apresentam variações positivas, que equivalem então a valores maiores do que os requeridos. Valores negativos indicam altura menor que a esperada. $O$ resultado é uma indicação de que a altura média nos sensores varia em cada posição de medição. Dessa forma, deve- 
se sempre calibrar as alturas das ondas na posição desejada através de um sensor de ondas. $\mathrm{O}$ fato de existirem 2 flaps bloqueados nas laterais pares do tanque (laterais $2 \mathrm{e}$ 4) causa a maior parte dos problemas relativos à uniformidade do campo de ondas na região de medição. Problemas estes que se intensificam com o aumento do ângulo de geração de ondas (em relação às direções 0 ou 180 graus). Pode-se avaliar a uniformidade pela análise do desvio padrão e da variação máxima percentual em cada sensor de ondas.

$\mathrm{O}$ desvio padrão $(\sigma H)$ indica variações crescentes de $0^{\circ}$ seguido de $45^{\circ}, 30^{\circ}, 60^{\circ} \mathrm{e}$ $90^{\circ}$. O caso a $45^{\circ}$ tem variação menor que a $30^{\circ}$. Quanto maior o ângulo, maior a importância das laterais pares, que têm justamente flaps bloqueados nas laterais.

A variação máxima percentual $(\Delta H)$ encontrada na matriz de sensores tem tendência semelhante ao desvio padrão. As variações aumentam, com o aumento do ângulo e com a frequência da onda, condizente com o que foi dito acima no texto. A tendência dos dados aponta que a influência da declividade de onda não é predominante, pois a variação máxima encontrada é semelhante em todas as três declividades. $\mathrm{O}$ desvio padrão (em milímetros) crescente em declividade reforça este fato. Adicionalmente, as ondas de $1,3 \mathrm{~Hz}$ apresentam maiores variações, pois quanto menor o comprimento de ondas mais próximo do Limite de Biesel o gerador de ondas opera. $\mathrm{O}$ Limite de Biesel define o limiar entre gerar ondas progressivas e gerar ondas espúrias que não se propagam além do gerador de ondas (veja no tópico 3.2.3).

O ângulo de propagação de onda tende ao requerido, mas na direção das laterais pares o erro é maior. Nesses casos existem maiores variações no campo de ondas, assim como na direção de propagação de ondas estimada.

Nas figuras seguintes (Figura 6.16 a Figura 6.24) são apresentadas as análises da distribuição espacial das alturas de ondas medidas nos diferentes sensores, na forma de mapas de contorno em cores em cada ângulo de propagação. As setas pretas indicam o sentido de propagação das ondas nas figuras. 


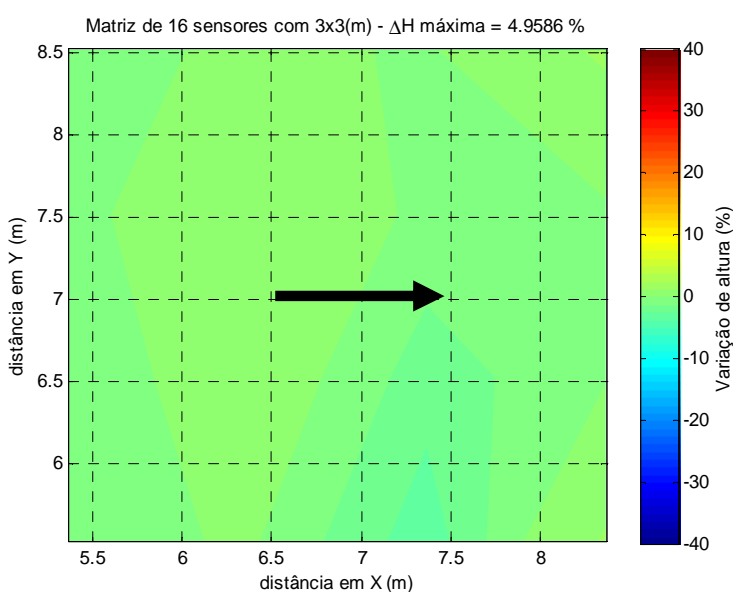

(a) $-180^{\circ}$

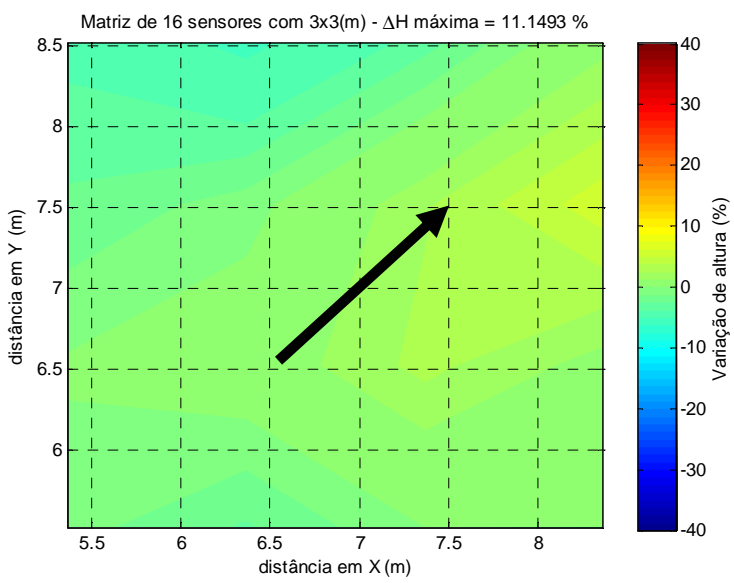

(c) $-225^{\circ}$

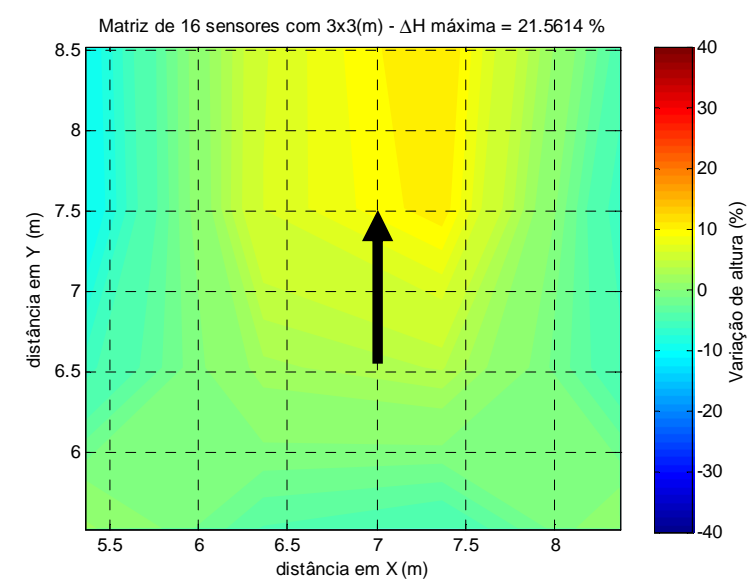

(e) $-270^{\circ}$

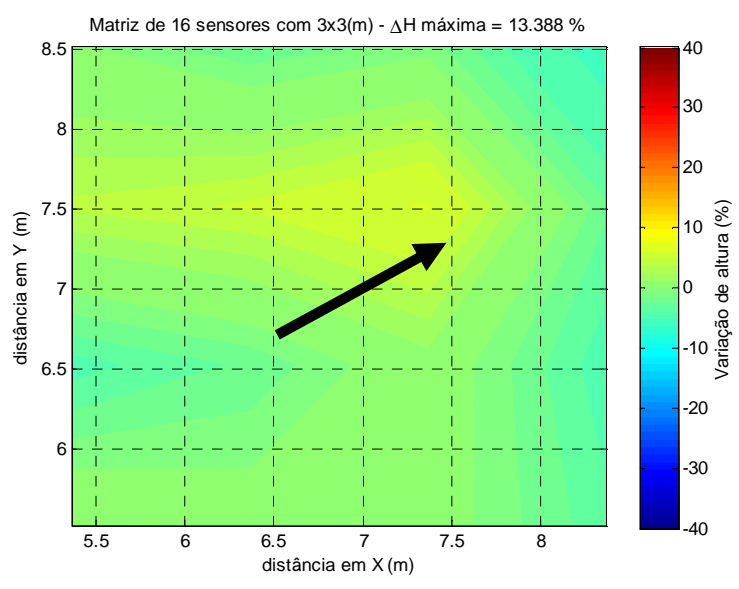

(b) $-210^{\circ}$

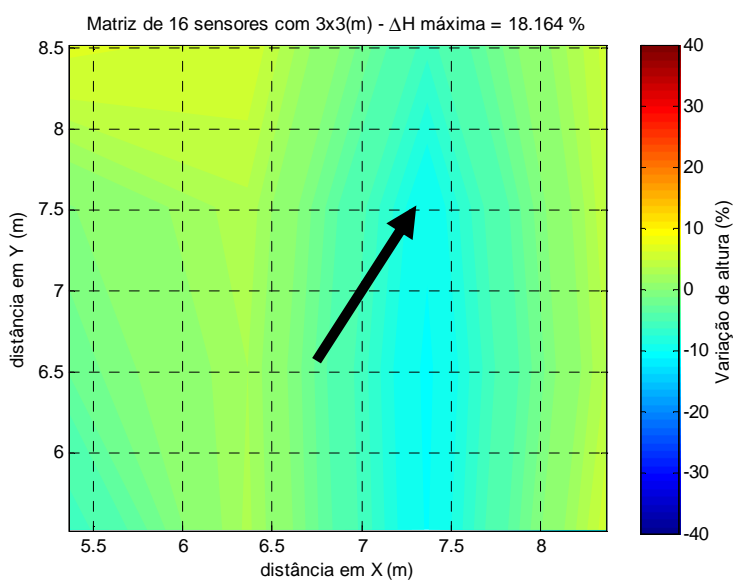

(d) $-240^{\circ}$

Figura 6.16. Onda regular de $0,7 \mathrm{~Hz}$ com $2,5 \%$ de declividade. 


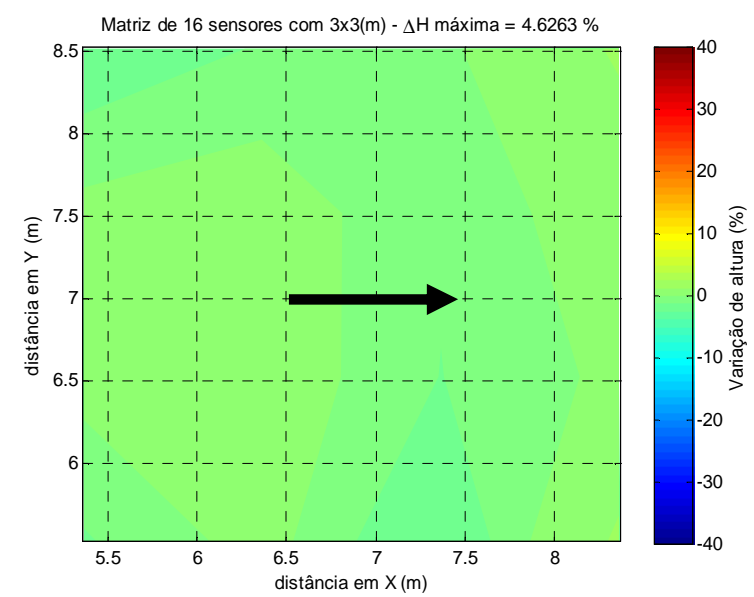

(a) $-180^{\circ}$

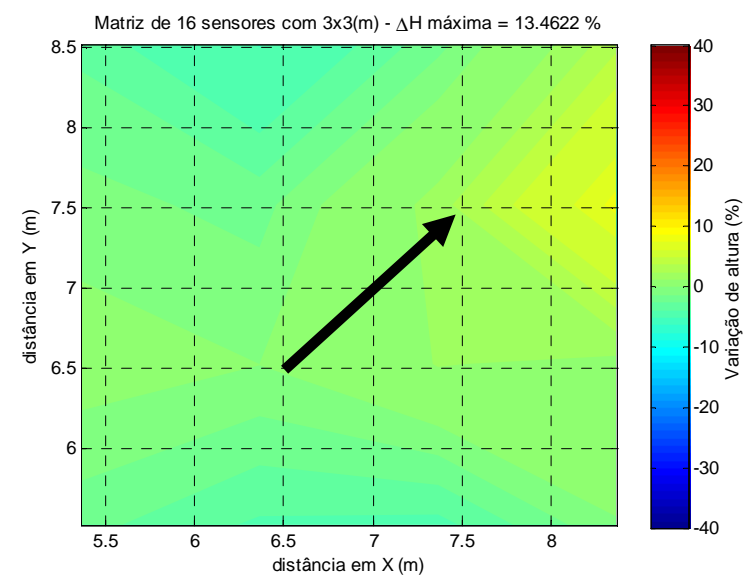

(c) $-225^{\circ}$

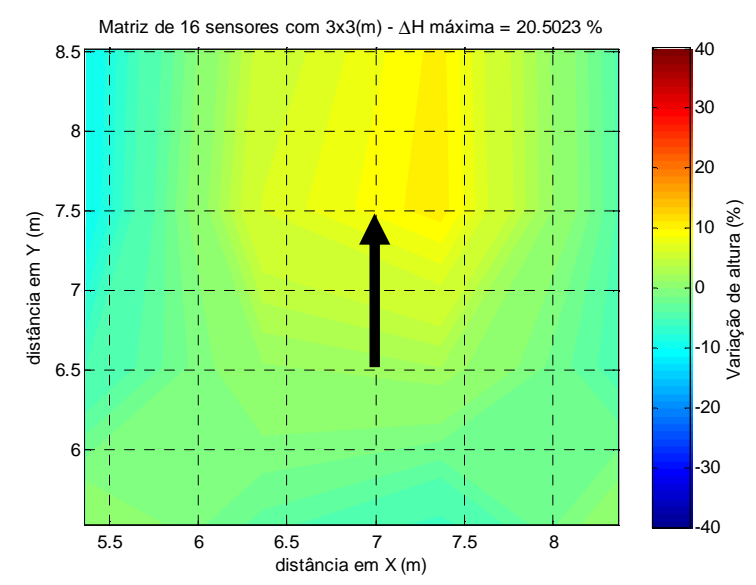

(e) $-270^{\circ}$

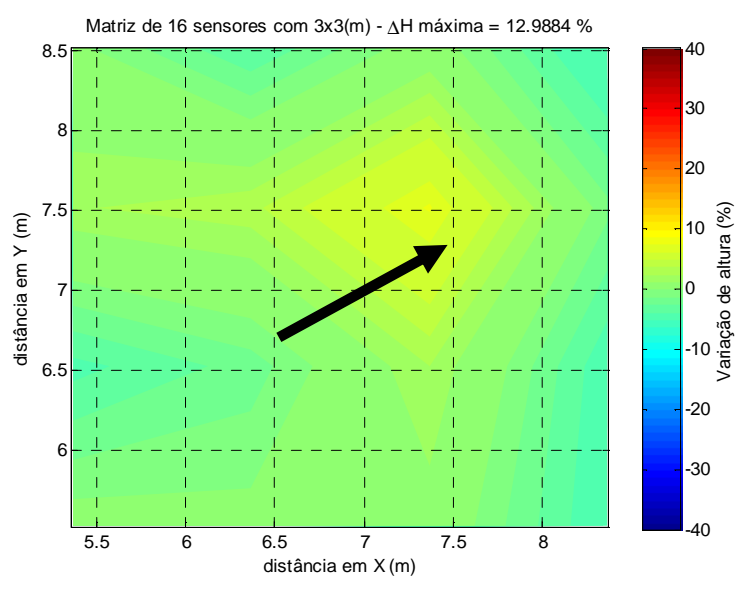

(b) $-210^{\circ}$

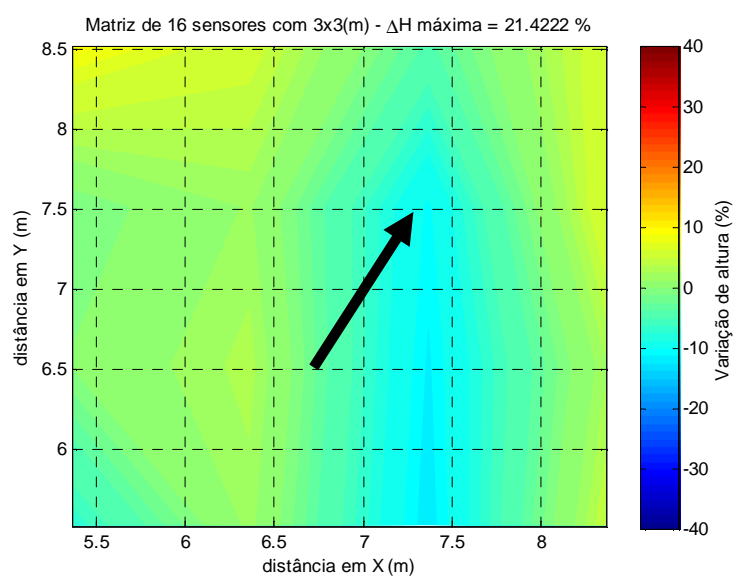

(d) $-240^{\circ}$

Figura 6.17. Onda regular de $0,7 \mathrm{~Hz}$ com $3,3 \%$ de declividade. 


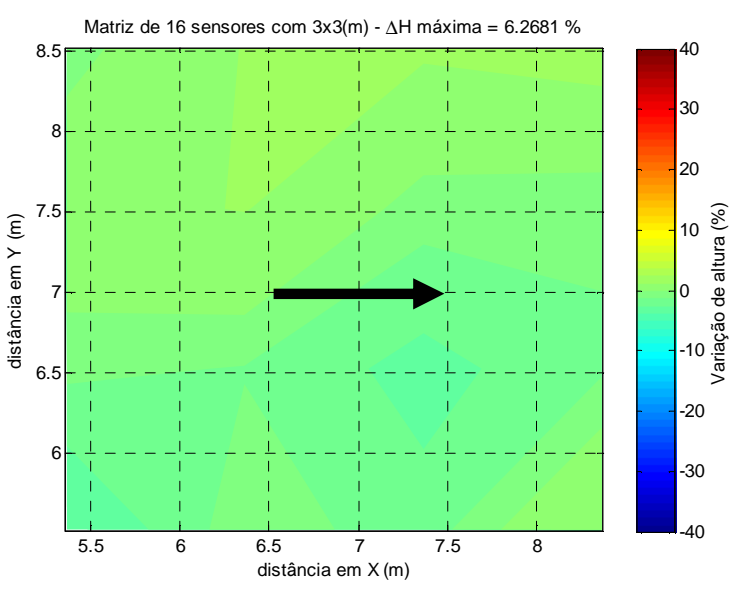

(a) $-180^{\circ}$

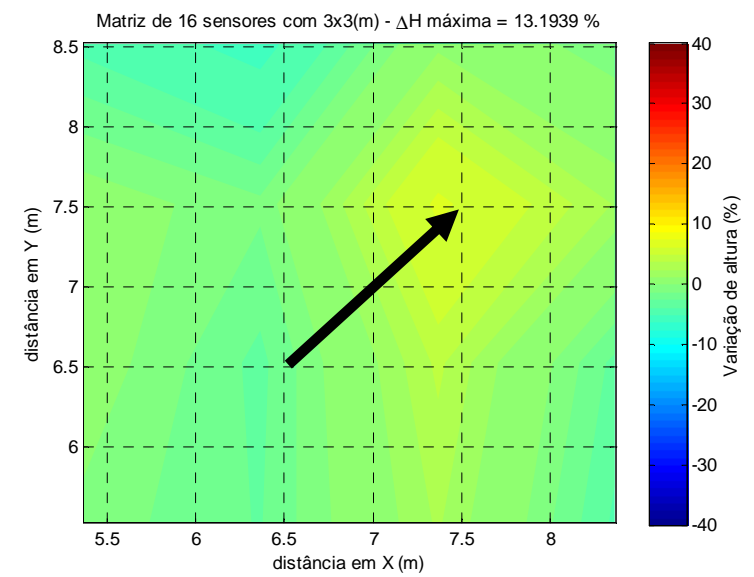

(c) $-225^{\circ}$

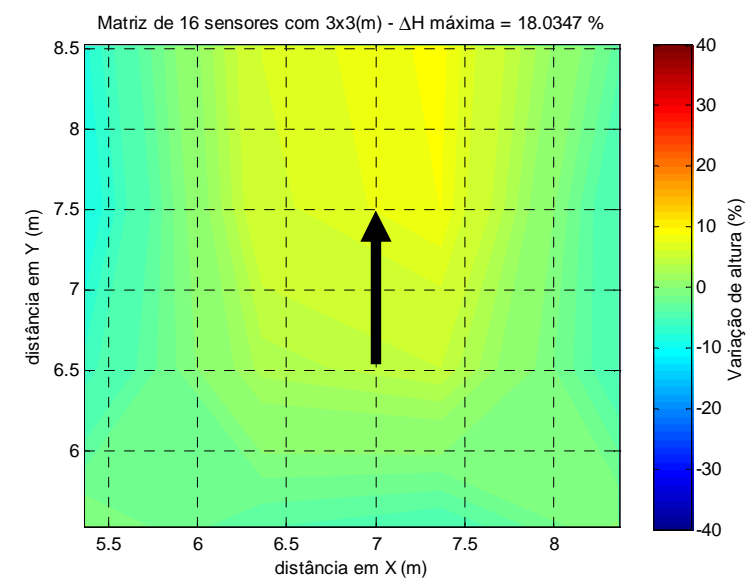

(e) $-270^{\circ}$

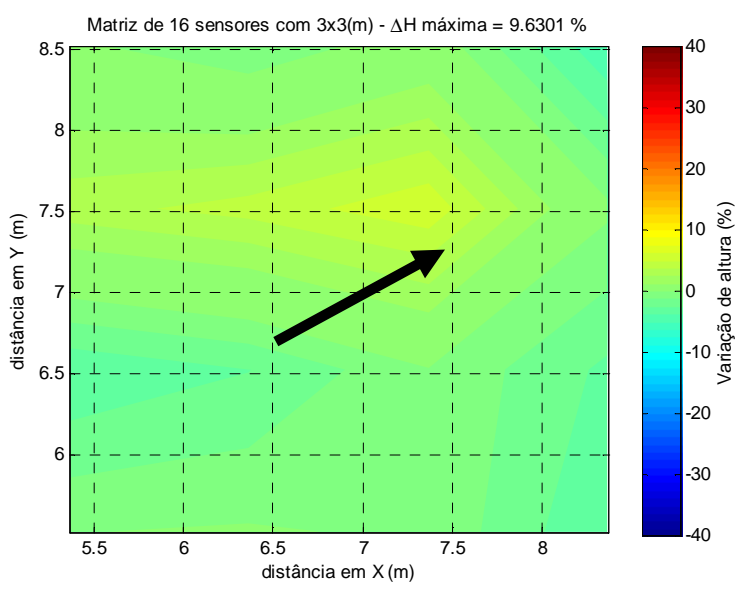

(b) $-210^{\circ}$

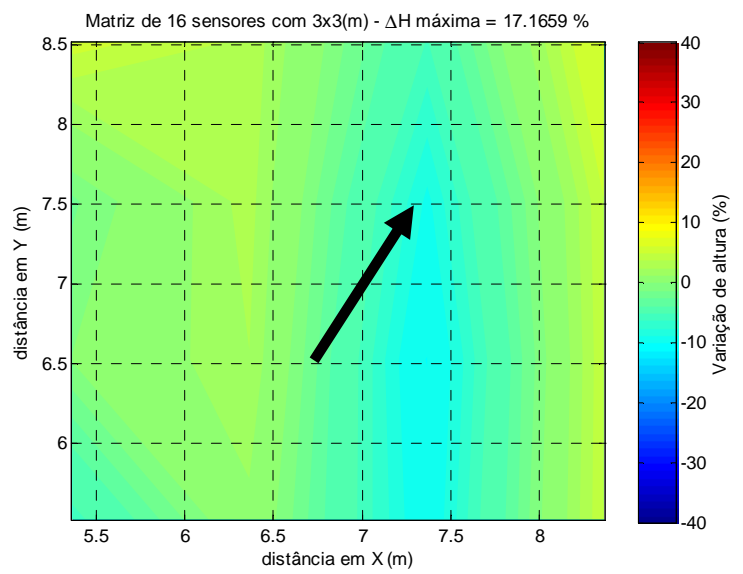

(d) $-240^{\circ}$

Figura 6.18. Onda regular de $0,7 \mathrm{~Hz}$ com $5,0 \%$ de declividade. 


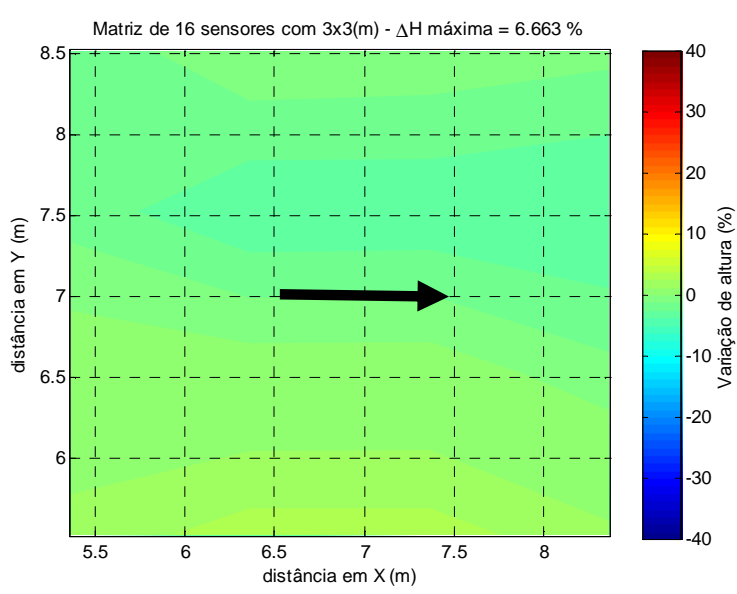

(a) $-180^{\circ}$

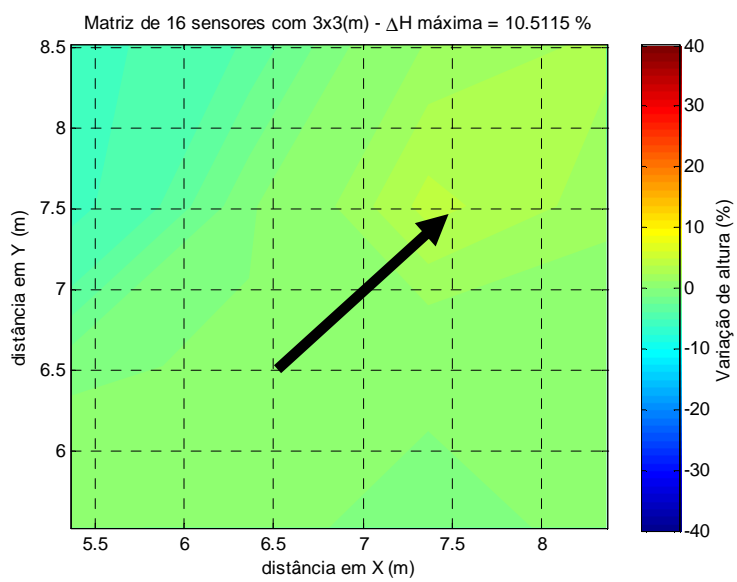

(c) $-225^{\circ}$

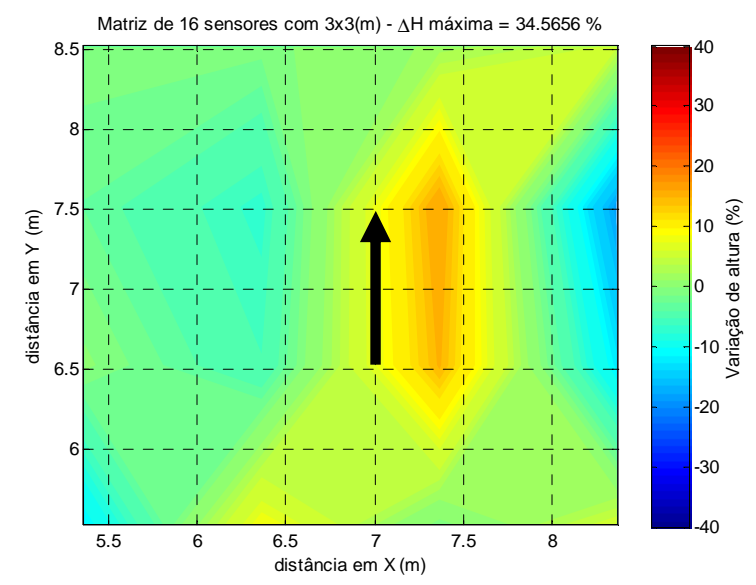

(e) $-270^{\circ}$

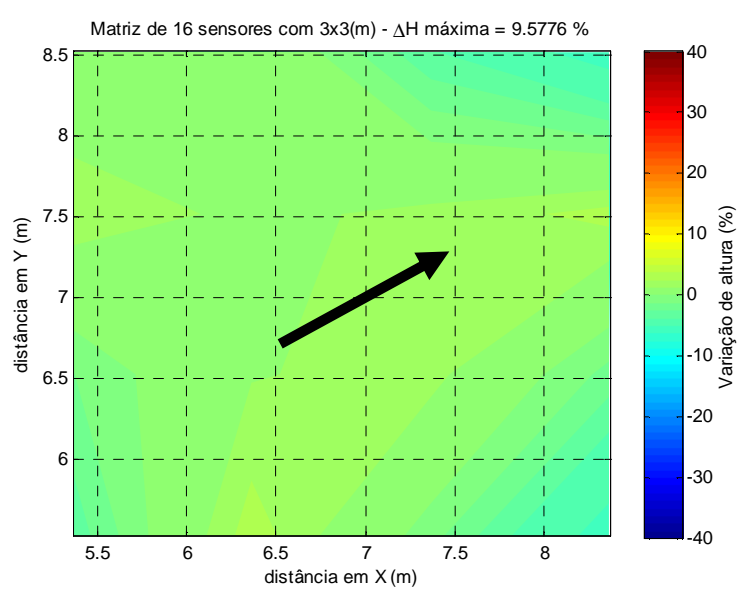

(b) $-210^{\circ}$

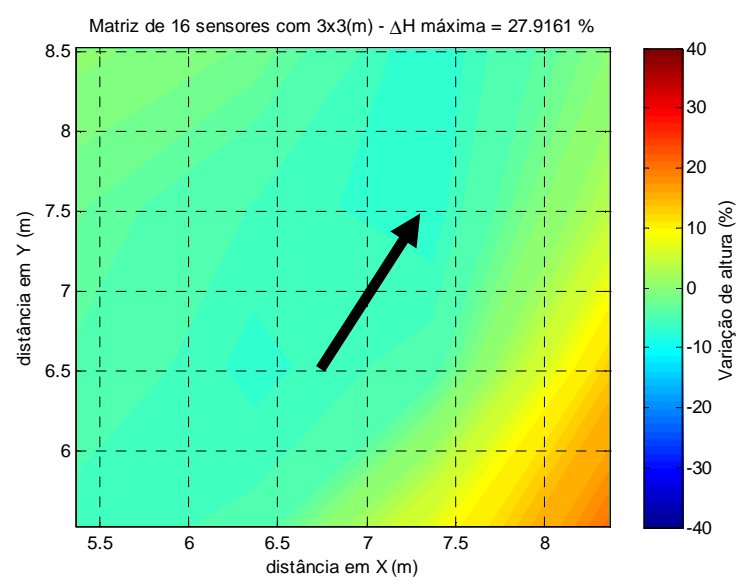

(d) $-240^{\circ}$

Figura 6.19. Onda regular de $1,0 \mathrm{~Hz}$ com $2,5 \%$ de declividade. 


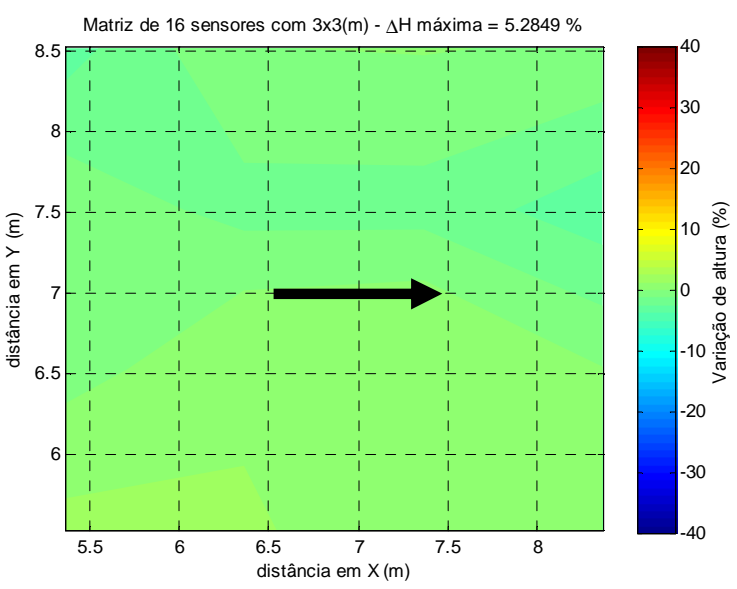

(a) $-180^{\circ}$

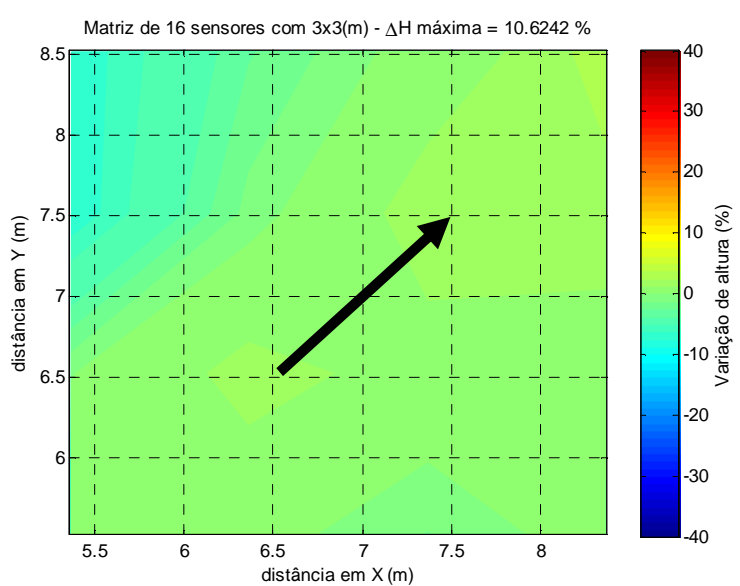

(c) $-225^{\circ}$

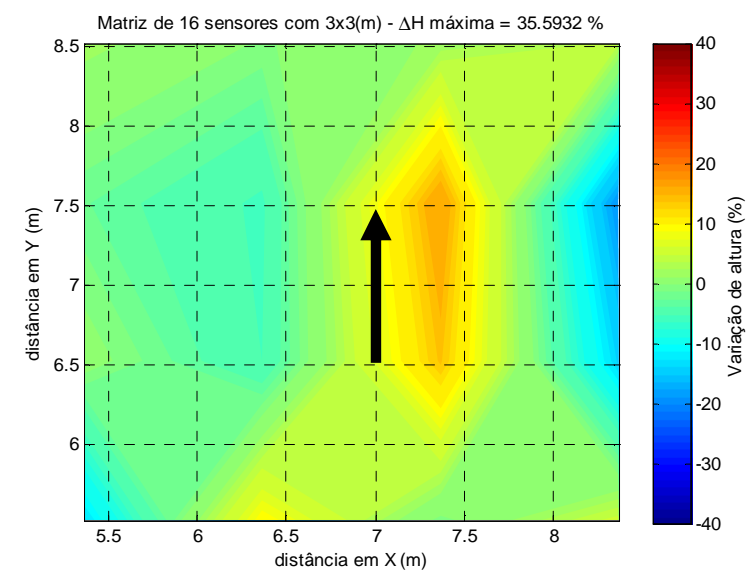

(e) $-270^{\circ}$

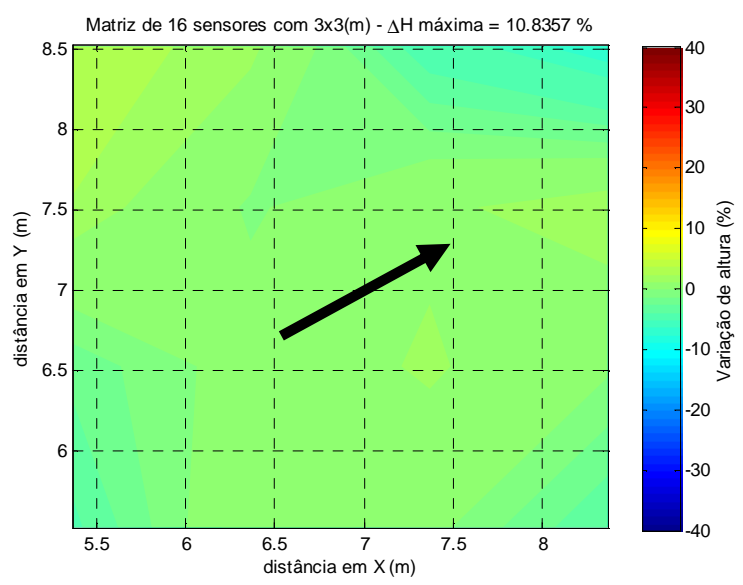

(b) $-210^{\circ}$

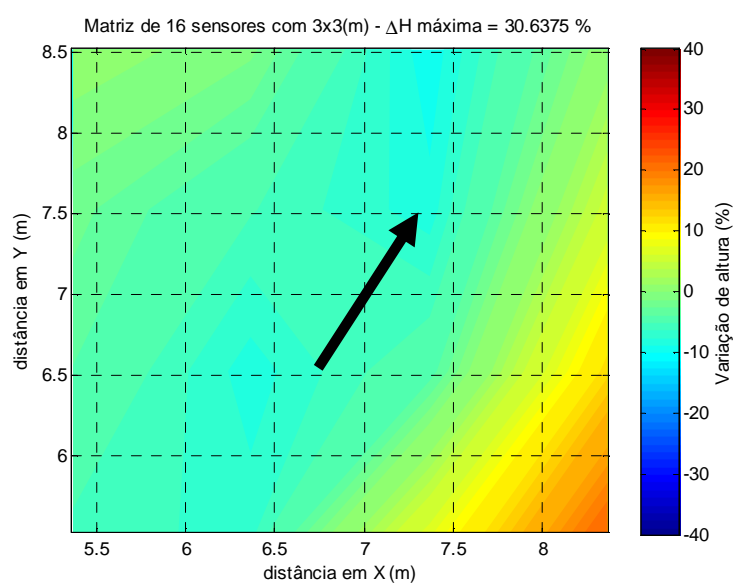

(d) $-240^{\circ}$

Figura 6.20. Onda regular de $1,0 \mathrm{~Hz}$ com $3,3 \%$ de declividade. 


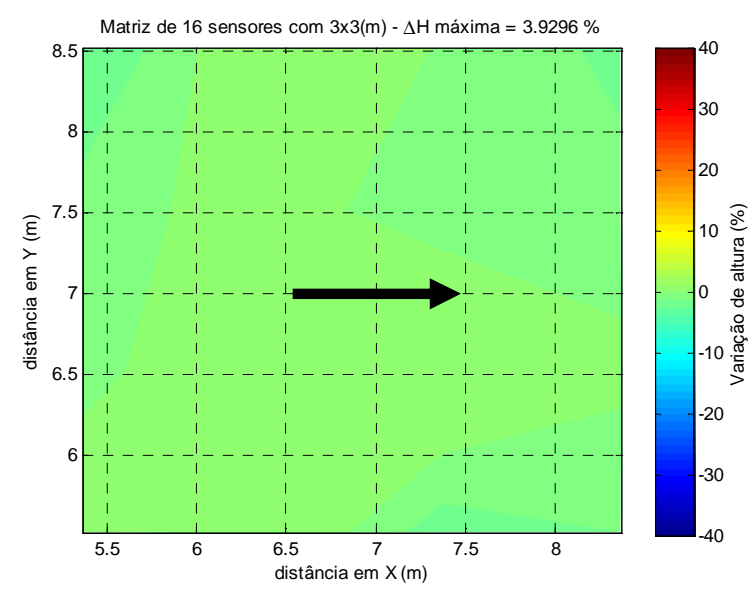

(a) $-180^{\circ}$

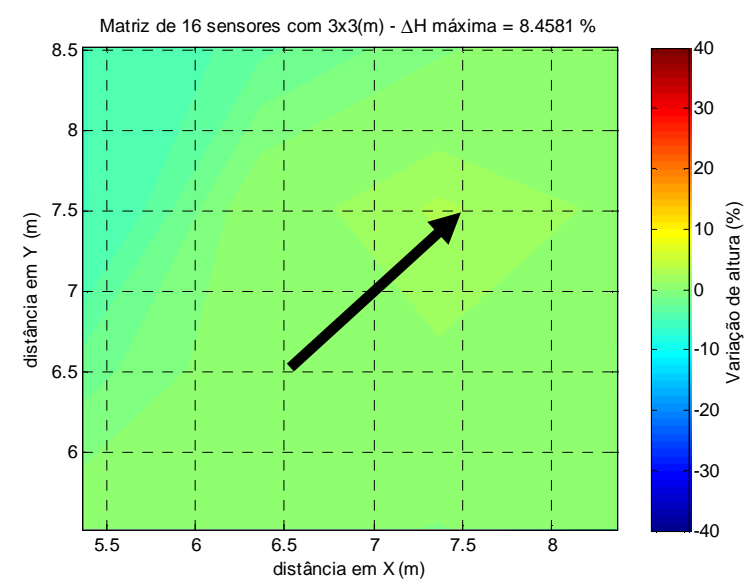

(c) $-225^{\circ}$

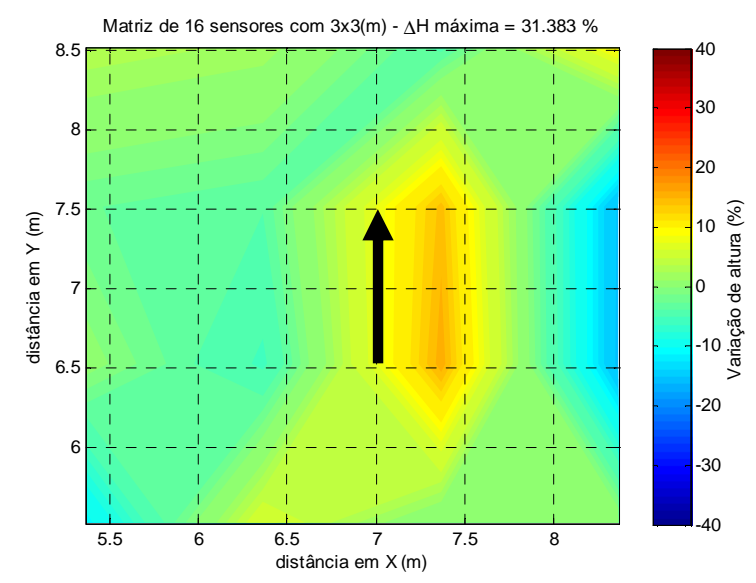

(e) $-270^{\circ}$

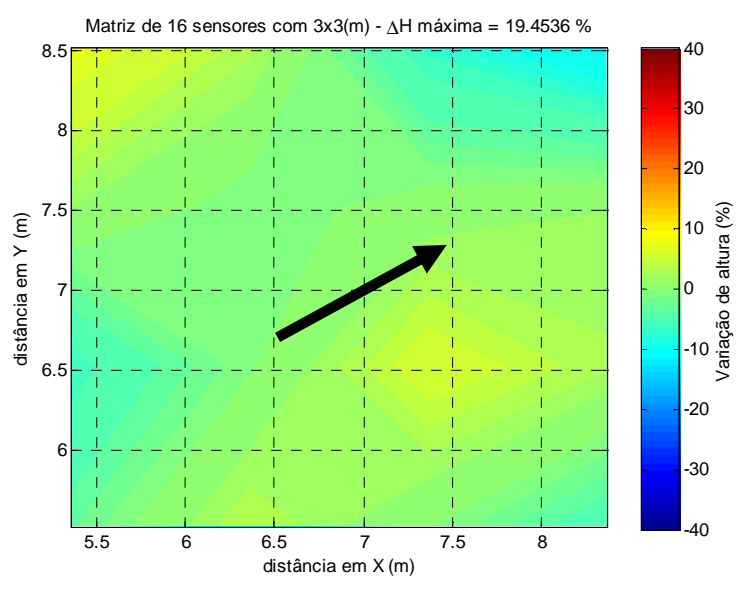

(b) $-210^{\circ}$

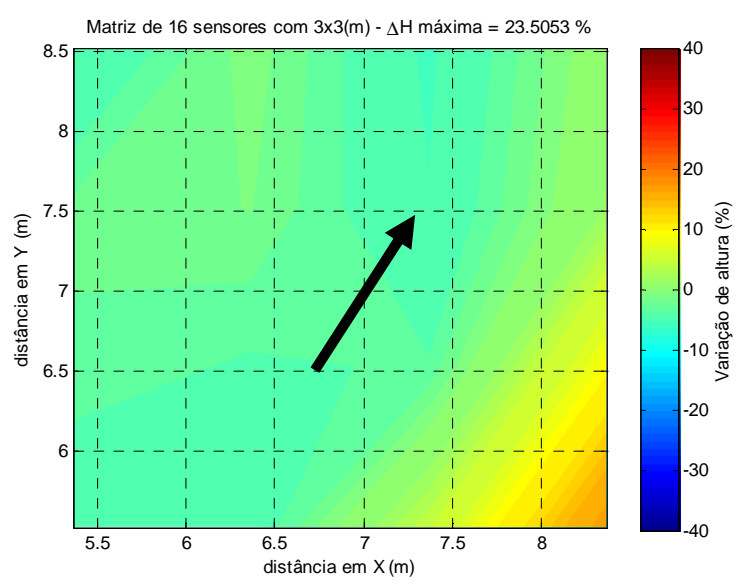

(d) $-240^{\circ}$

Figura 6.21. Onda regular de 1,0Hz com 5,0\% de declividade. 


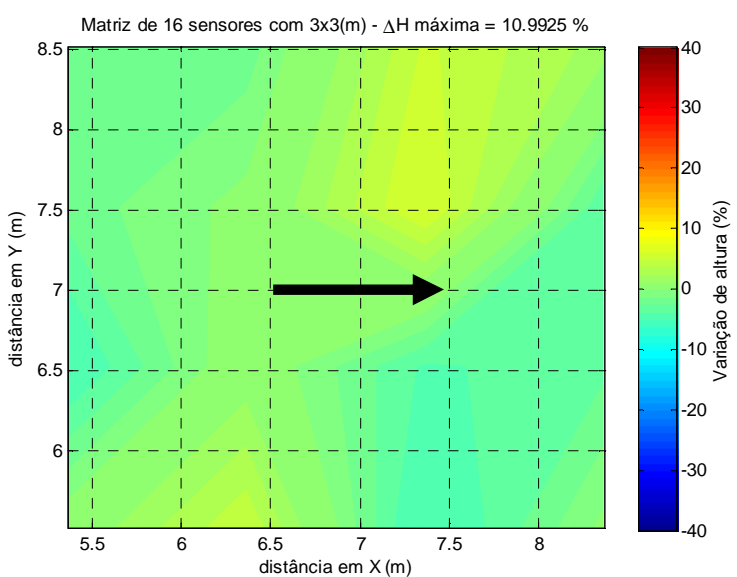

(a) $-180^{\circ}$

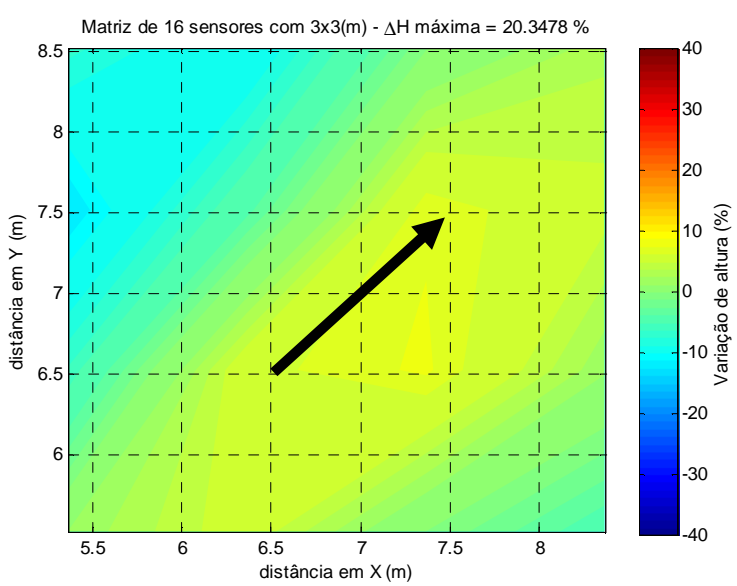

(c) $-225^{\circ}$

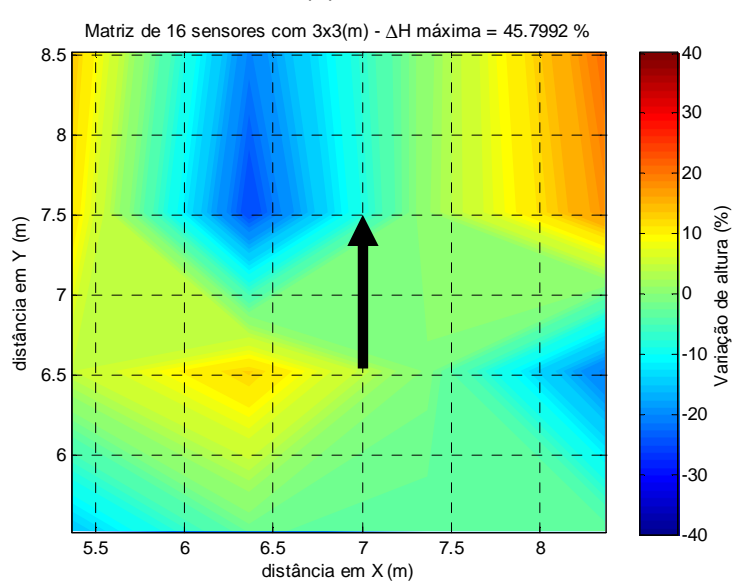

(e) $-270^{\circ}$

Figura 6.22. Onda regular de $1,3 \mathrm{~Hz}$ com $2,5 \%$ de declividade.

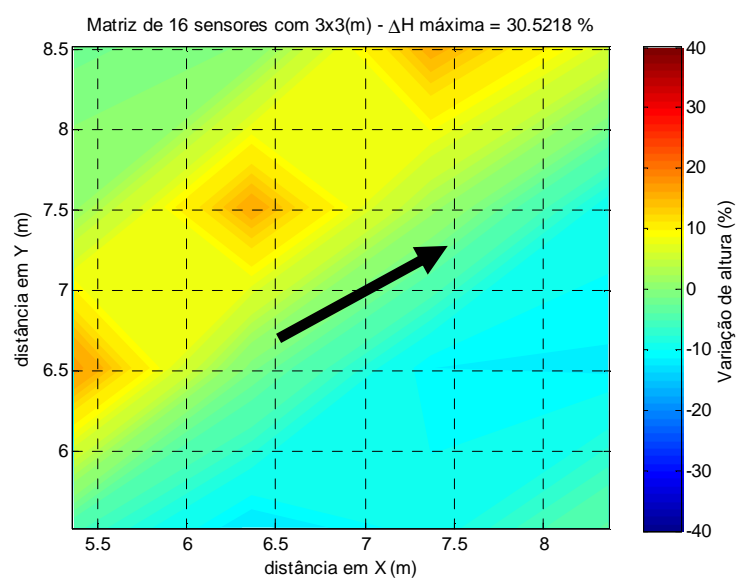

(b) $-210^{\circ}$

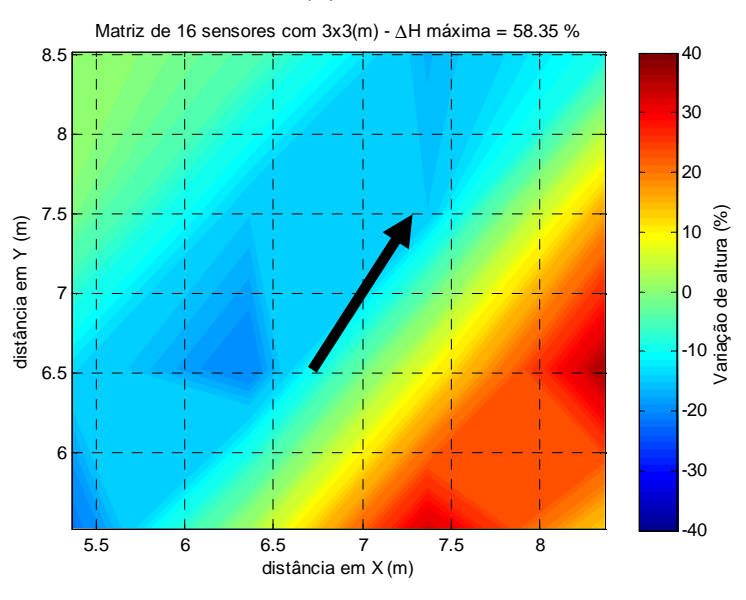

(d) $-240^{\circ}$ 


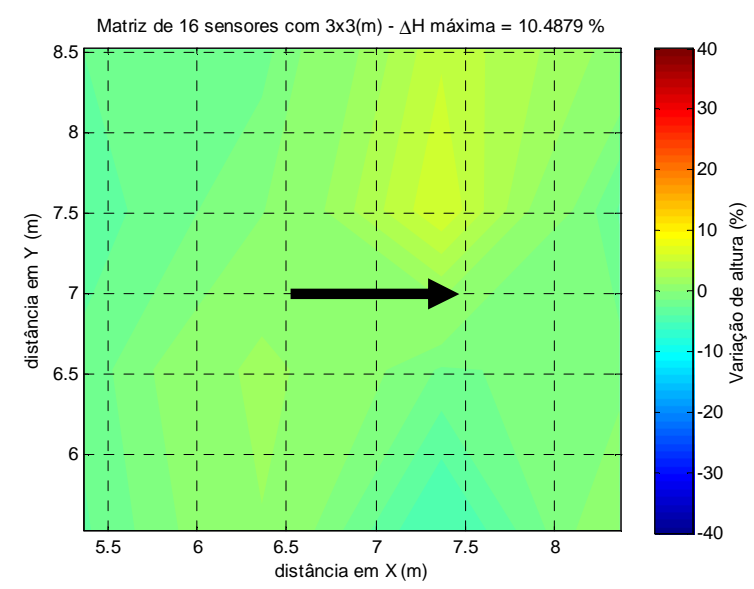

(a) $-180^{\circ}$

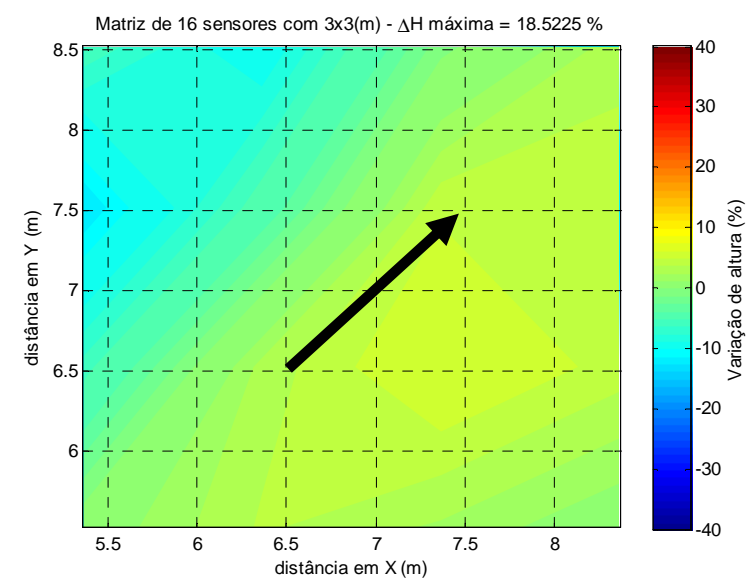

(c) $-225^{\circ}$

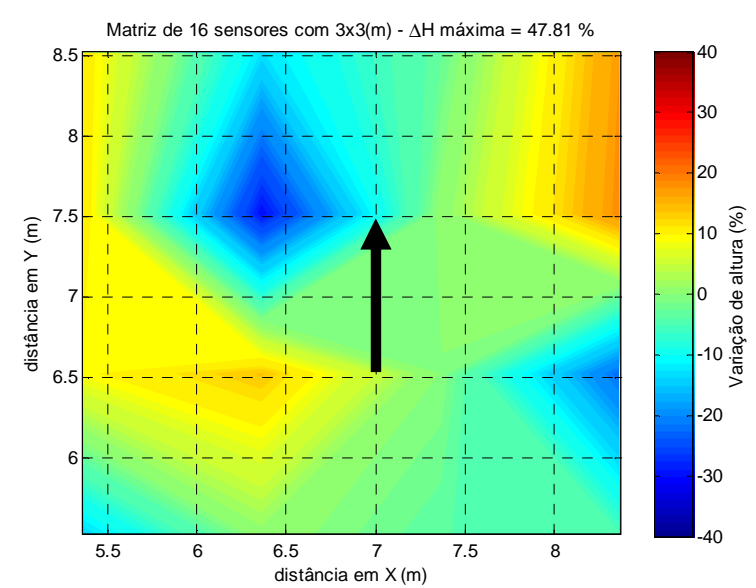

(e) $-270^{\circ}$

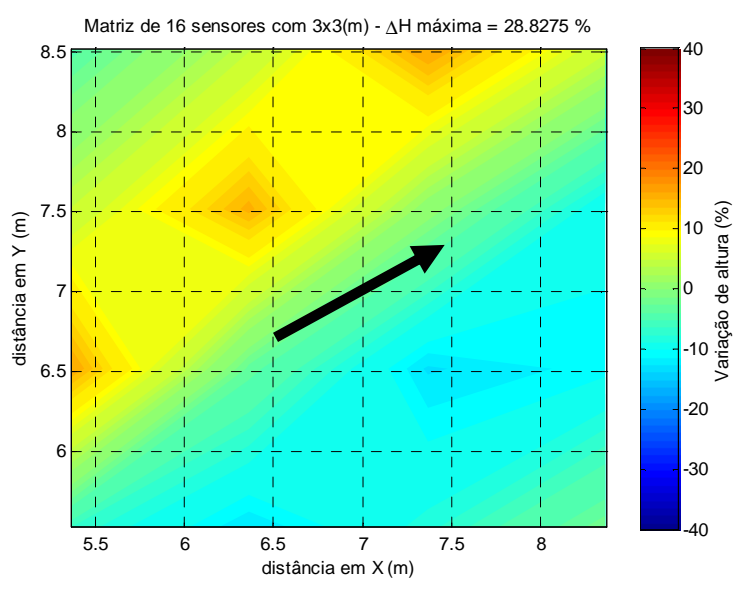

(b) $-210^{\circ}$

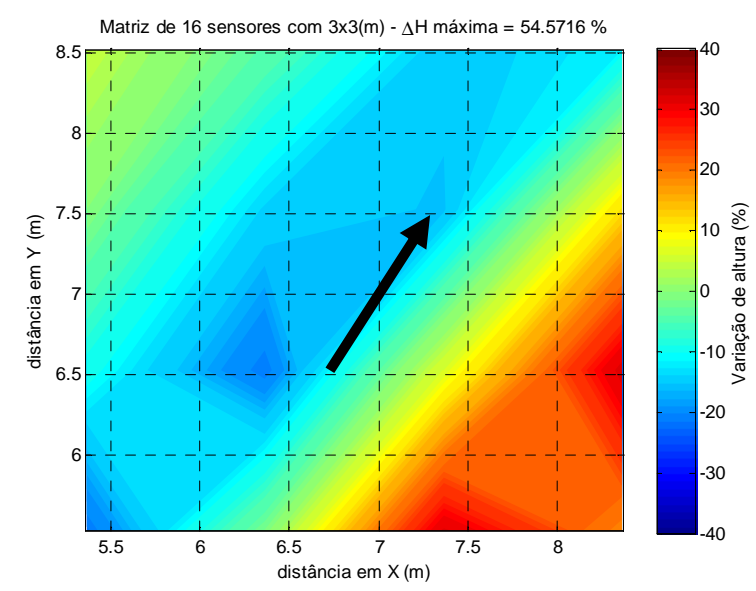

(d) $-240^{\circ}$

Figura 6.23. Onda regular de $1,3 \mathrm{~Hz}$ com $3,3 \%$ de declividade. 


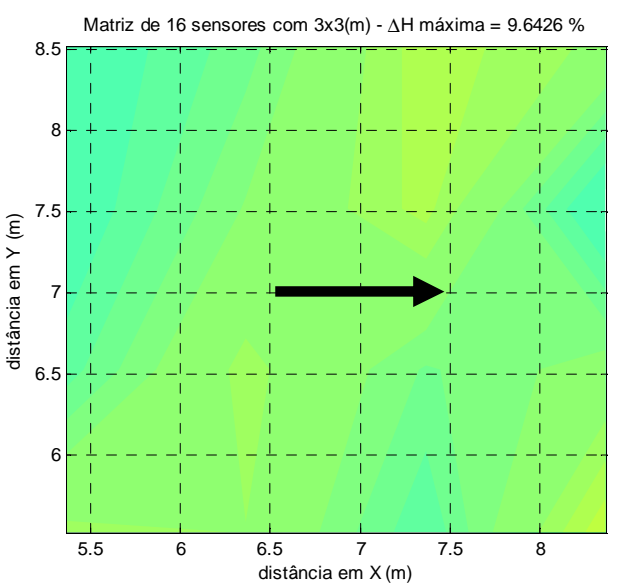

(a) $-180^{\circ}$

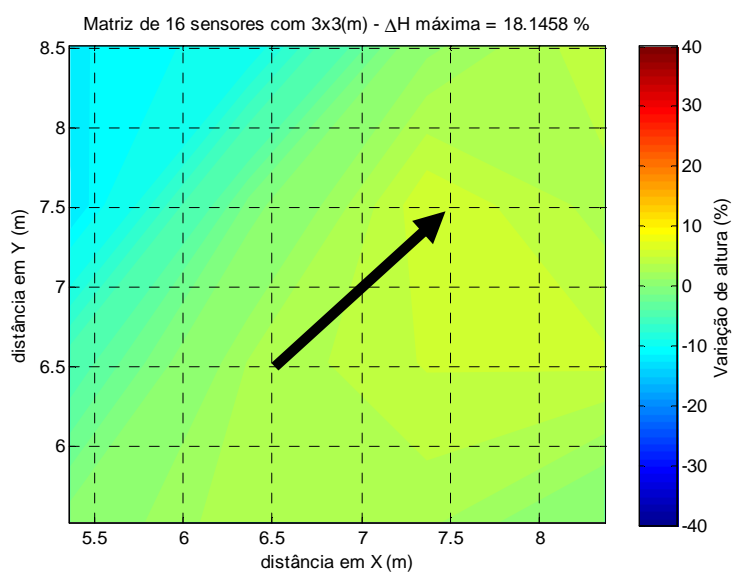

(c) $-225^{\circ}$

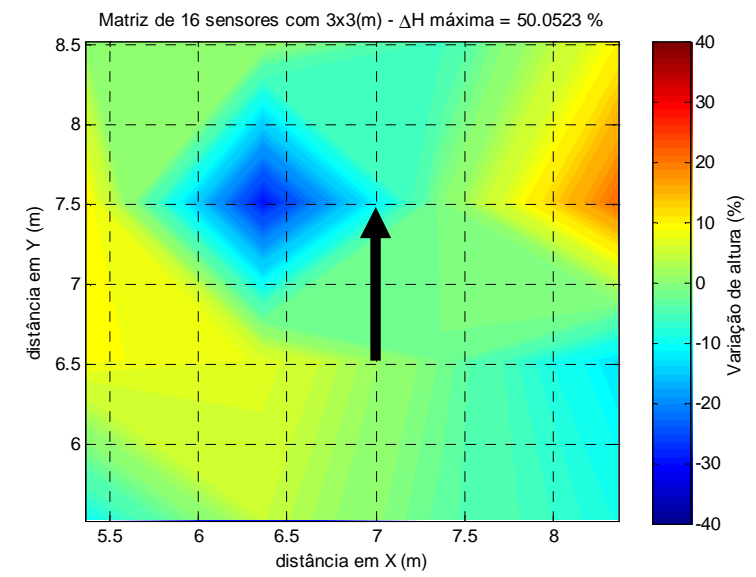

(e) $-270^{\circ}$

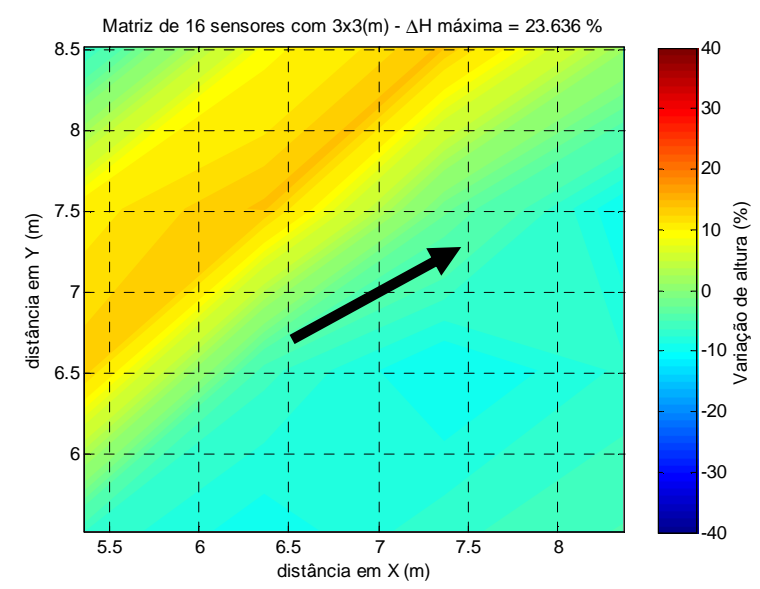

(b) $-210^{\circ}$

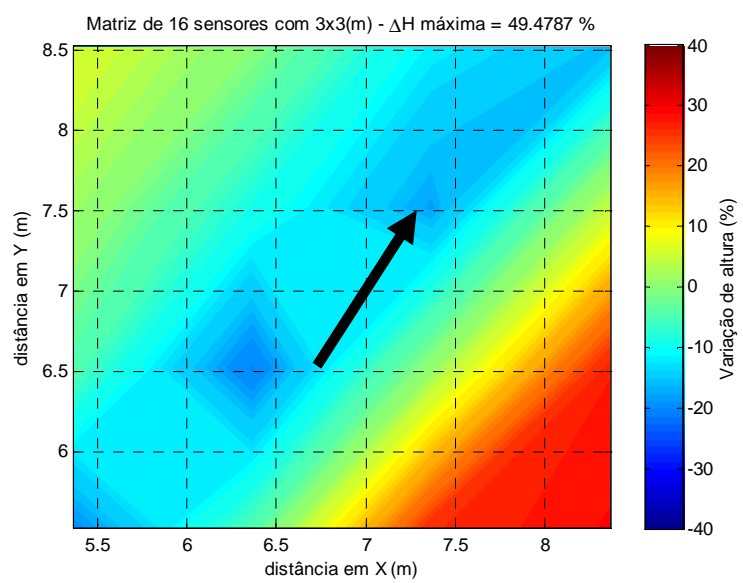

(d) $-240^{\circ}$

Figura 6.24. Onda regular de 1,3Hz com 5,0\% de declividade.

De forma geral, os resultados mostram que há uma variação excessiva da altura de ondas dentro da área de medição para ângulos acima de 225 graus. Como dito anteriormente, a principal razão para isso decorre da influência dos 4 flaps inoperantes 
(dois flaps nos limites extremos das laterais 2 e 4) sobre a geração do campo de ondas com ângulos de propagação entre 225 e 270 graus.

Operando da forma como se encontra o gerador de ondas, é recomendável não utilizar ondas com ângulo maior que $45^{\circ} \mathrm{em}$ torno das laterais ímpares. Duas melhorias podem ser feitas para minimizar tal problema: ativar os atuadores inoperantes e decidir quais deles serão ativados, de acordo com as necessidades do ensaio experimental; realizar um estudo de otimização de movimentos dos atuadores atualmente em operação para que compensem a falta dos que se encontram bloqueados, tendo como meta um campo de ondas homogêneo em uma dada região do tanque de provas. Este método será apresentado nas recomendações futuras do trabalho.

\subsection{Validação de geração de ondas irregulares unidirecionais}

Os ensaios com ondas irregulares têm como objetivo avaliar a capacidade de geração de mares que emulem condições típicas da costa brasileira. As ondas ensaiadas foram inicialmente executadas e depois repetidas para definir um procedimento de análise e calibração.

As ondas ensaiadas são apresentadas na Tabela 6.16. Elas contemplam mares decenais e centenários selecionados da Bacia de Campos, segundo Petrobras (2005) (o fator de escala 1:100 foi adotado como típico), e da Bacia de Santos, segundo Petrobras (2008) (neste caso, dadas as maiores alturas de ondas, optou-se por um fator de escala 1:120), locais típicos onde existem plataformas de petróleo em operação.

As ondas foram, mais uma vez, geradas da lateral 1 para a lateral 3, sem qualquer efeito de espalhamento direcional na geração. Tem-se, portanto, condições de mar conhecidas como "mares de cristas longas" ou long-crested seas, na denominação em inglês. 
Tabela 6.16. Ondas irregulares ensaiadas no tanque de provas.

\begin{tabular}{|c|c|c|c|c|c|c|c|c|c|}
\hline \multirow{2}{*}{ index } & \multicolumn{4}{|c|}{ Escala real } & \multicolumn{5}{c|}{ Escala do modelo } \\
\cline { 2 - 11 } & Tp (s) & Hs (m) & gama & Duração (s) & escala & Tp (s) & fp (Hz) & Hs (mm) & duração (s) \\
\hline Campos10 & 11,00 & 6,26 & 1,972 & 10800 & $1: 100$ & 1,100 & 0,909 & 62,60 & 1080,0 \\
\hline Campos100 & 15,55 & 7,84 & 1,664 & 10800 & $1: 100$ & 1,555 & 0,643 & 78,40 & 1080,0 \\
\hline Santos10 & 10,00 & 8,01 & 2,066 & 10800 & $1: 120$ & 0,913 & 1,095 & 66,75 & 985,9 \\
\hline Santos100 & 15,50 & 11,11 & 1,666 & 10800 & $1: 120$ & 1,415 & 0,707 & 92,58 & 985,9 \\
\hline
\end{tabular}

A medição de ondas se deu por três sensores de ondas capacitivos posicionados segundo a Figura 6.8. A instrumentação foi a mesma usada nos testes com ondas regulares, incluindo o sincronismo entre gerador de ondas e instrumentação eletrônica. Usando este arranjo e aplicando o método de Goda \& Suzuki (ver, p. ex., Chakrabarti, 1987), foi feita a separação das parcelas incidente e refletida das ondas para cálculo do coeficiente de reflexão. A informação de duas alturas (WPx, WPy) e de 1 defasagem entre sensores ( $\Delta x y)$ é usada para determinar a onda incidente (Lateral $1 \rightarrow$ Lateral 3) e a refletida (Lateral $3 \rightarrow$ Lateral 1 ). Usando os três sensores disponíveis com três diferentes combinações entre eles foi possível ampliar o alcance em frequência do método, que é dependente da distância entre os mesmos. Foram adotadas as distâncias entre sensores de $\Delta 1=17,1 \mathrm{~cm}$ e $\Delta 2=34,4 \mathrm{~cm}$ para um melhor alcance em frequências, sempre mantendo o sensor WP2 no centro do tanque (X=7,02 $\mathrm{m}: \mathrm{Y}=7,02 \mathrm{~m})$.

Dados os resultados obtidos nos ensaios em ondas regulares (discutidos no tópico 6.2.1.2), todas as ondas já foram calibradas usando-se absorção ativa na lateral geradora, ou seja, gerando e absorvendo na lateral 1 e absorvendo na lateral 3. O princípio de operação da absorção de ondas dual mode foi adotado nestes ensaios. A Figura 6.25 mostra o início e o final das séries temporais de $\eta d_{j}$ e $\eta k_{j}$ em duas ondas irregulares. Nos instantes iniciais não existe reflexão de onda no flap; portanto, os sinais são semelhantes. Nos instantes finais, devido à reflexão proveniente do lado oposto do tanque, o sinal de $\eta k_{j}$ é diferente do sinal de $\eta d_{j}$. Quando o gerador termina a série temporal (em $t=1080 \mathrm{~s}$ ), o gerador de ondas continua absorvendo a onda refletida que ainda propaga no tanque de provas. 


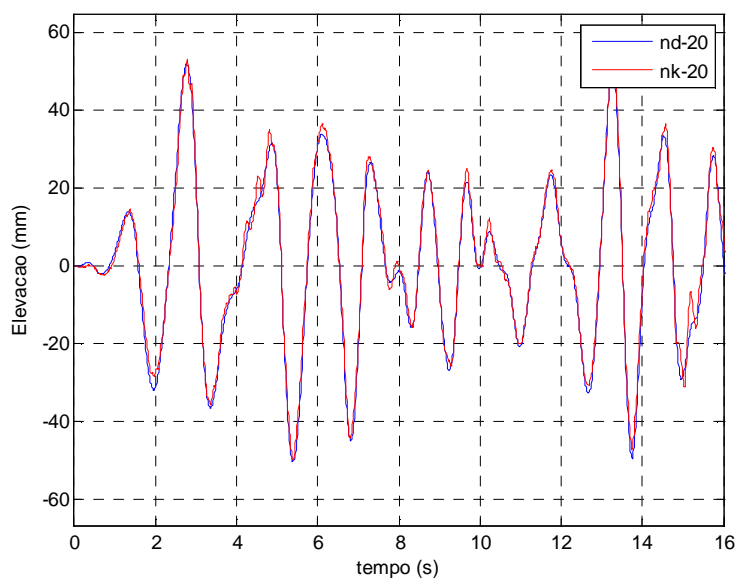

(a) - Início da onda Campos centenária

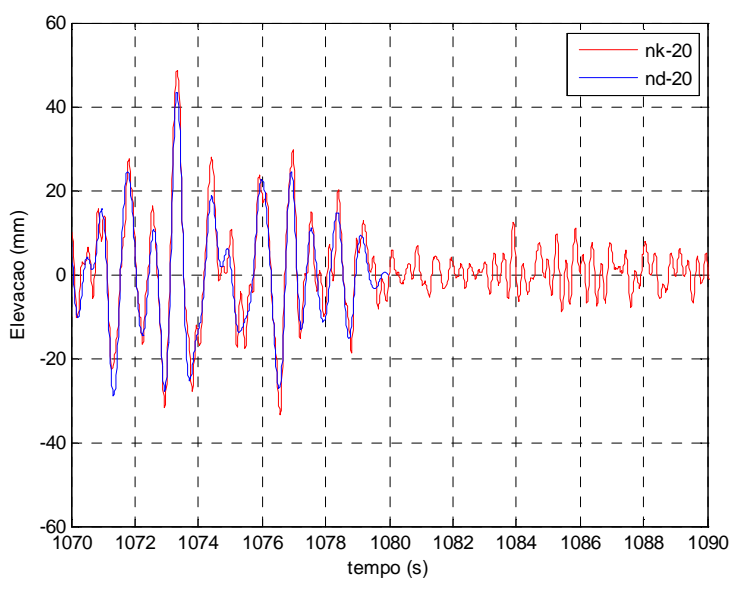

(b) - Final da onda Campos decenária

Figura 6.25. Início de final das séries temporais de $\eta d_{j}$ e $\eta k_{j}$ no flap número 20.

Para cada onda gerada, o espectro de energia foi levantado com base nas medidas do sensor de ondas central (WP2). Na primeira rodada de geração, os espectros não eram satisfatórios e, portanto, foram realizadas novas rodadas de calibração. $\mathrm{O} T_{p} \mathrm{e}$ o $H_{s}$ desde a primeira rodada de ondas já apresentavam valores próximos do requerido; assim, um fator de correção foi introduzido para corrigir o espectro em uma nova realização. A fase aleatória das componentes em frequência foi mantida nas novas rodadas de calibração; somente um ganho em frequências foi ajustado.

Seguindo as recomendações da ITTC, a melhor forma de análise, visando a calibração de um mar irregular, é comparar o espectro de energia teórico com o experimental. A partir do espectro medido, um ganho linear no espectro era aplicado a cada raia em frequência para corrigir a sua energia. $\mathrm{O}$ fator de ganho usado é a relação entre espectro teórico e experimental, ou seja:

$$
A(f)=\frac{S_{t e o}(f)}{S_{\exp }(f)}
$$

A diferença em relação à calibração de ondas regulares é que o ganho é aplicado ao espectro e não à altura da onda. Assim sendo, ele não é linear em altura.

As duas primeiras ondas (Bacia de Campos) foram realizadas três vezes, até que as estatísticas fossem consideradas adequadas. As ondas da Bacia de Santos foram realizadas duas vezes para a calibração. A Figura 6.26 mostra um trecho da série temporal e o espectro de energia de cada realização da onda da Bacia de Campos centenária (Campos100) durante a calibração. Nota-se que as variações das raias de 
frequências diminuem a cada realização da onda durante a calibração. A série temporal sofre pequenas variações entre as realizações, grande parte causada pela mudança do ganho em cada raia de frequências.

A Figura 6.27 mostra os espectros de energia das quatro ondas irregulares, obtidos pelo método de welch e com valores dados na escala do modelo. A Tabela 6.17 mostra os resultados obtidos da calibração de $T_{p}$ e $H_{s}$, com valores já convertidos para a escala real. O resultado completo dos parâmetros estatísticos de cada uma das ondas é apresentado nas figuras seguintes (Figura 6.28 a Figura 6.31). Nestas, são mostradas diversas estatísticas das ondas, sempre comparando o resultado esperado com o resultado obtido: série temporal com as cristas e os cavados detectados, distribuição gaussiana do registro temporal, distribuição de Rayleigh das alturas das ondas detectadas, espectro de energia de $1^{\mathrm{a}}$ ordem calculado pelo método de média móvel e espectro dos grupos de ondas ( $2^{\mathrm{a}}$ ordem), calculado a partir do espectro de $1^{\mathrm{a}}$ ordem. 

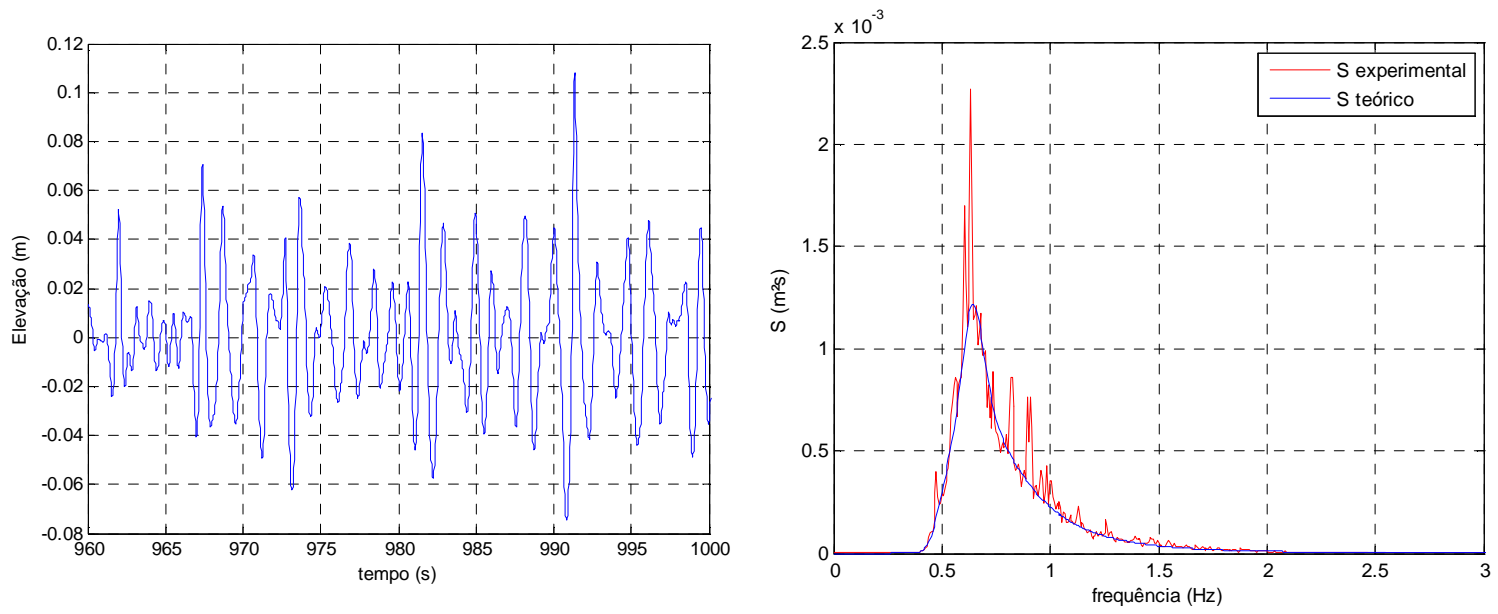

$1^{\mathrm{a}}$ repetição
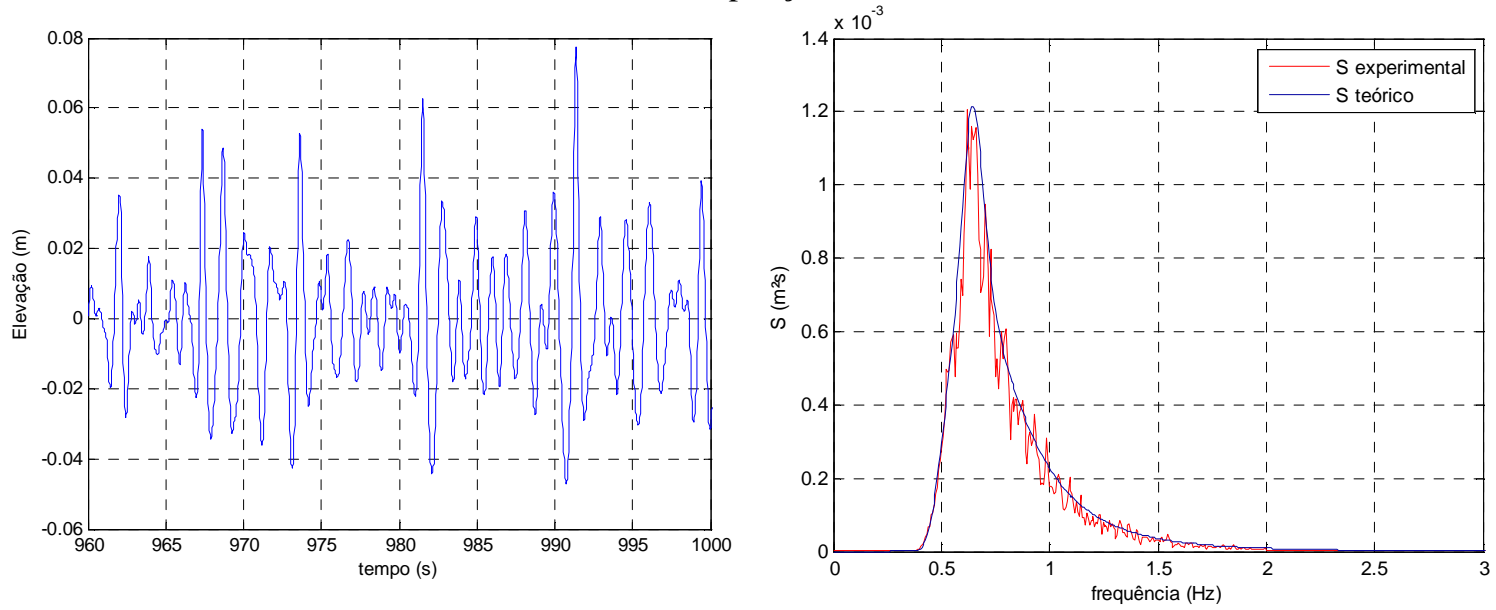

$2^{\mathrm{a}}$ repetição
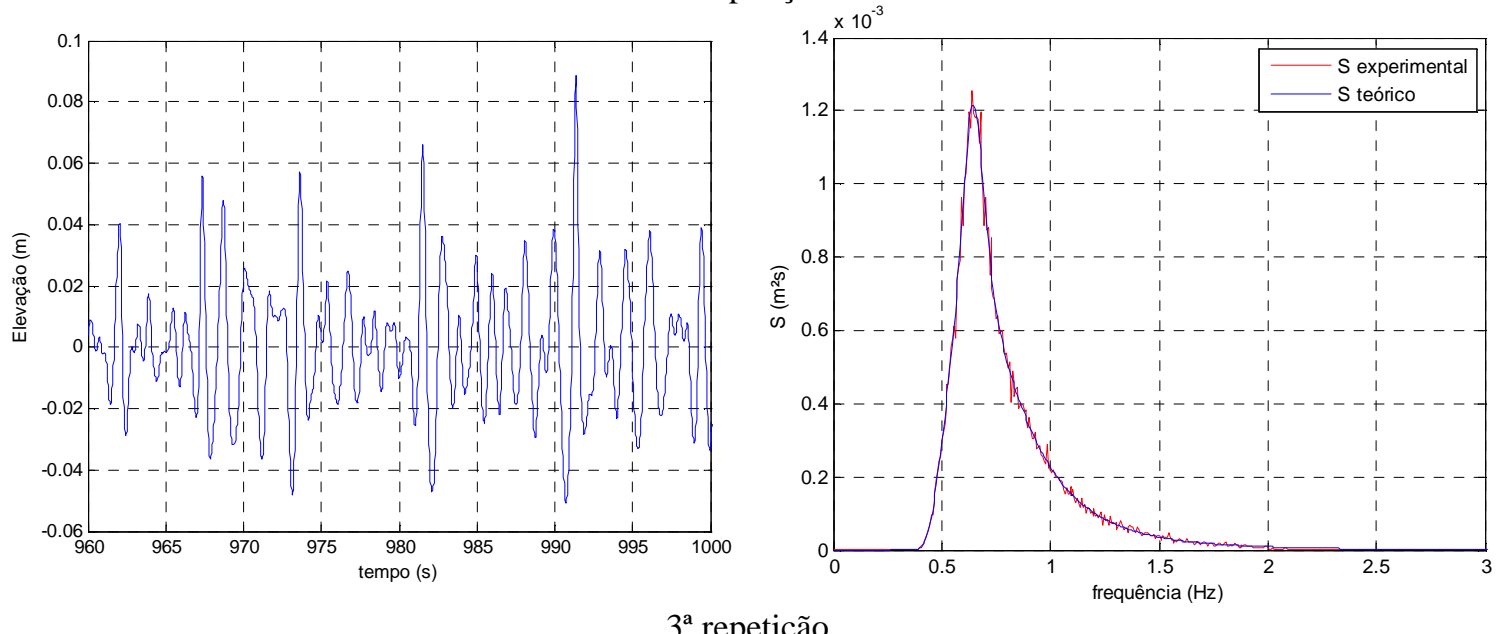

$3^{\mathrm{a}}$ repetição

Figura 6.26. Calibração de mar irregular de cristas largas da Bacia de Campos centenária. 


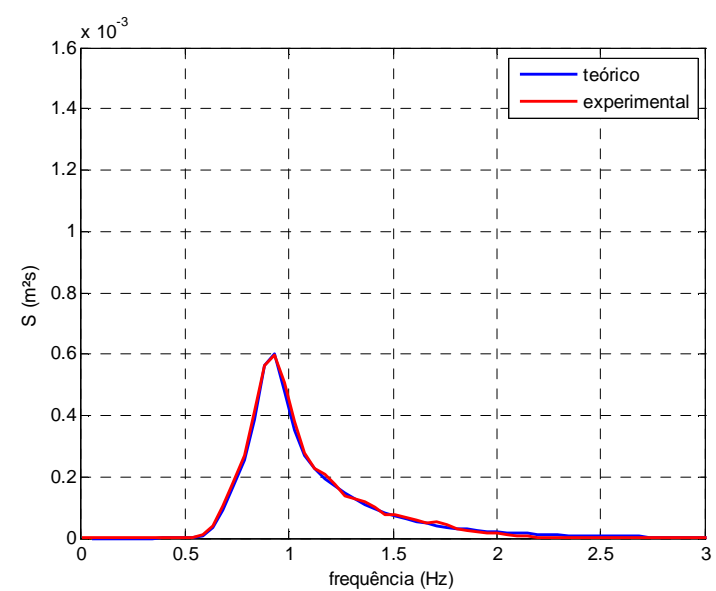

Campos decenária

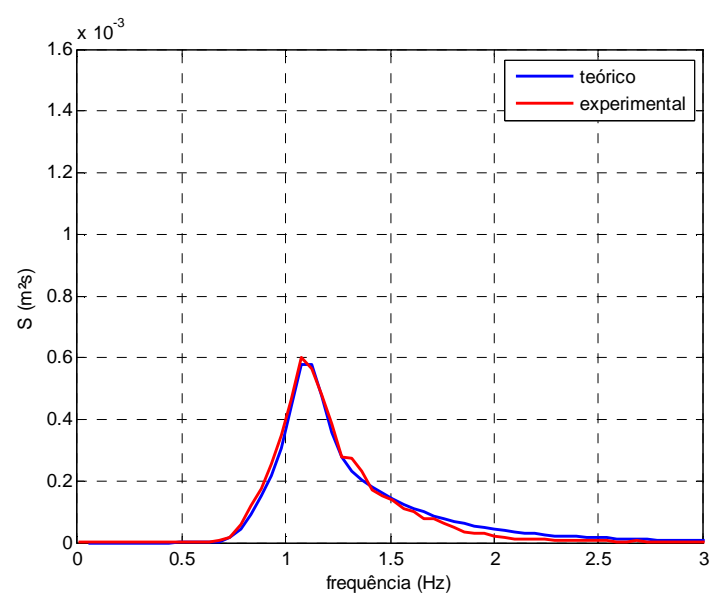

Santos decenária

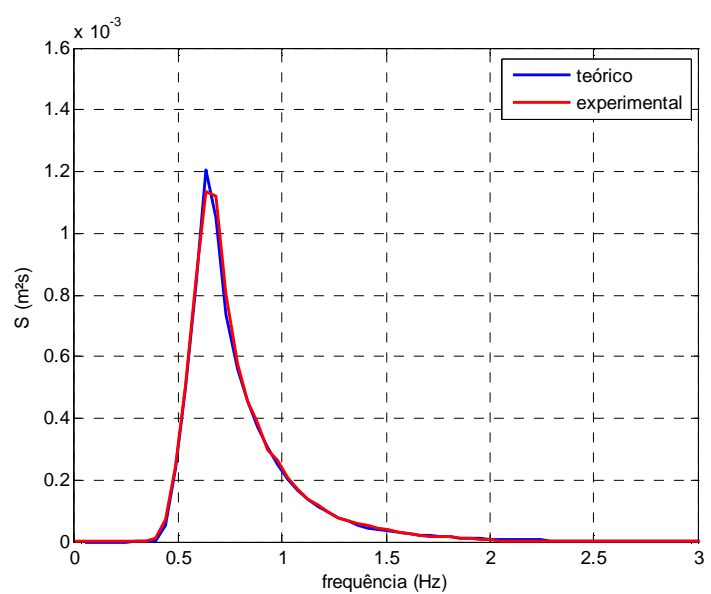

Campos centenária

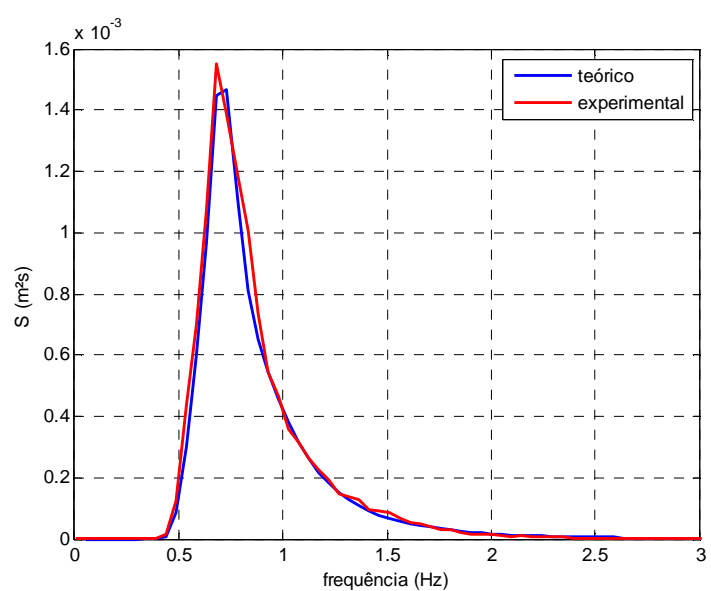

Santos centenária

Figura 6.27. Espectros de potências das ondas irregulares calibradas.

Tabela 6.17. Resultados experimentais da calibração das ondas irregulares.

\begin{tabular}{|c|c|c|c|c|c|c|}
\hline \multirow{2}{*}{ Nome } & \multicolumn{2}{|c|}{ Requerido } & \multicolumn{2}{c|}{ Experimental } & \multicolumn{2}{c|}{ Erro } \\
\cline { 2 - 7 } & Tp (s) & Hs (m) & Tp (s) & Hs (m) & Tp (s) & Hs (\%) \\
\hline Campos10 & 11,00 & 6,26 & 11,07 & 6,17 & 0,07 & 1,50 \\
\hline Campos100 & 15,55 & 7,84 & 15,60 & 7,81 & 0,05 & 0,45 \\
\hline Santos10 & 10,00 & 8,01 & 10,03 & 7,91 & 0,03 & 1,29 \\
\hline Santos100 & 15,50 & 11,11 & 15,54 & 11,38 & 0,04 & 2,39 \\
\hline
\end{tabular}



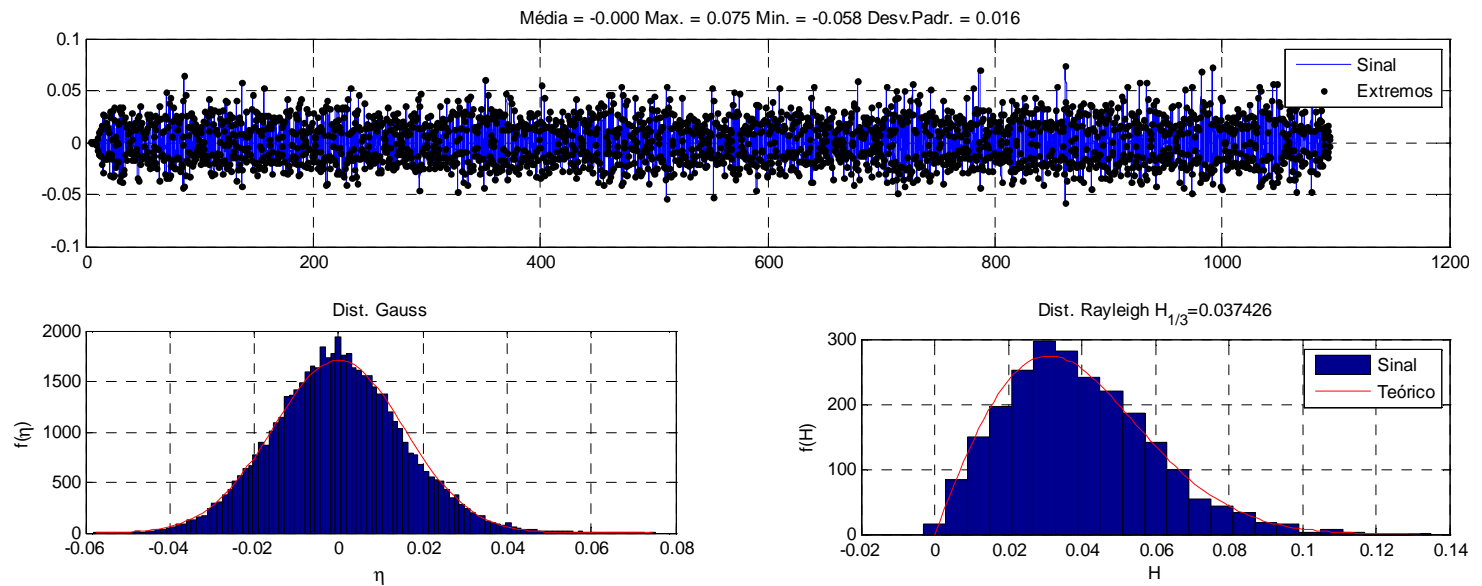

Sinal Desv.Padr. $=0.01557 \mathrm{Hs}=0.06227 \mathrm{Tp}=1.093 \mathrm{~T} 2=0.8773 \mathrm{~T} 4=0.6389 \mathrm{e}=0.6853$ Teórico Desv.Padr $=0.01562 \mathrm{Hs}=0.06248 \mathrm{Tp}=1.1 \mathrm{~T} 2=0.8386 \mathrm{~T} 4=0.5938 \mathrm{e}=0.7061$
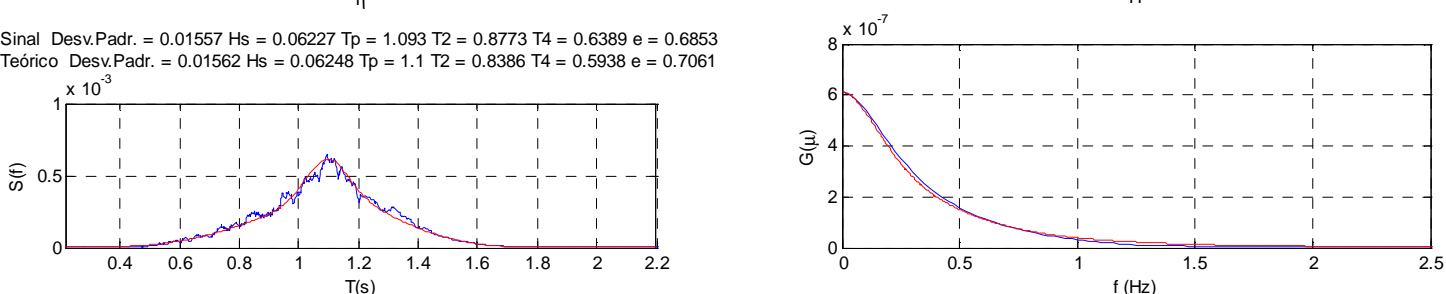

Figura 6.28. Estatística do mar decenário da Bacia de Campos.
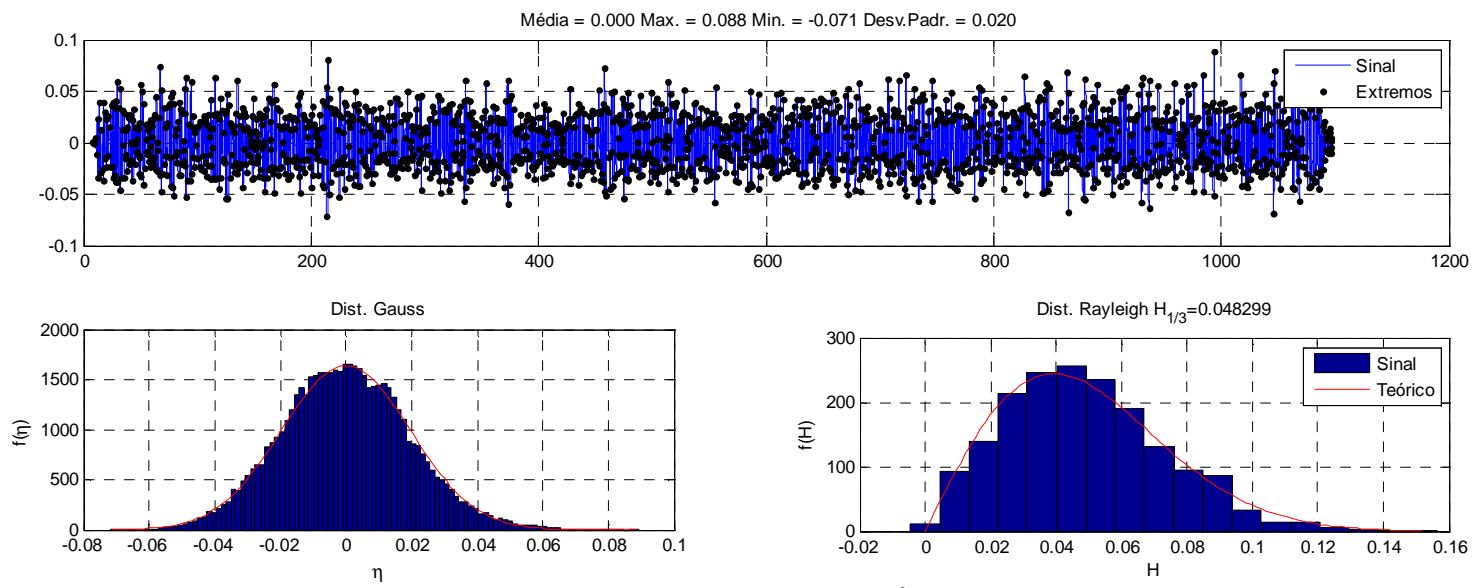

Sinal Desv.Padr. $=0.0198 \mathrm{Hs}=0.07921 \mathrm{Tp}=1.51 \mathrm{~T} 2=1.192 \mathrm{~T} 4=0.8588 \mathrm{e}=0.6934$ Teórico Desv.Padr. $=0.01955 \mathrm{Hs}=0.07821 \mathrm{Tp}=1.555 \mathrm{~T} 2=1.171 \mathrm{~T} 4=0.8291 \mathrm{e}=0.7062$
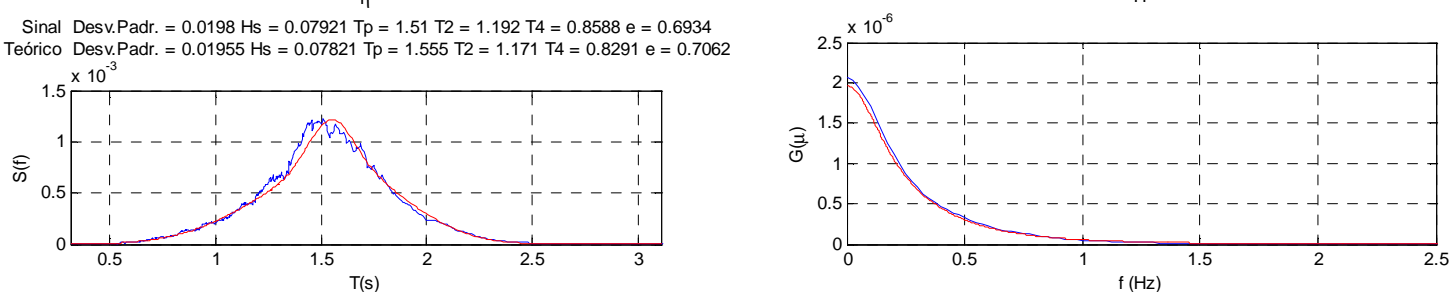

Figura 6.29. Estatística do mar centenário da Bacia de Campos. 

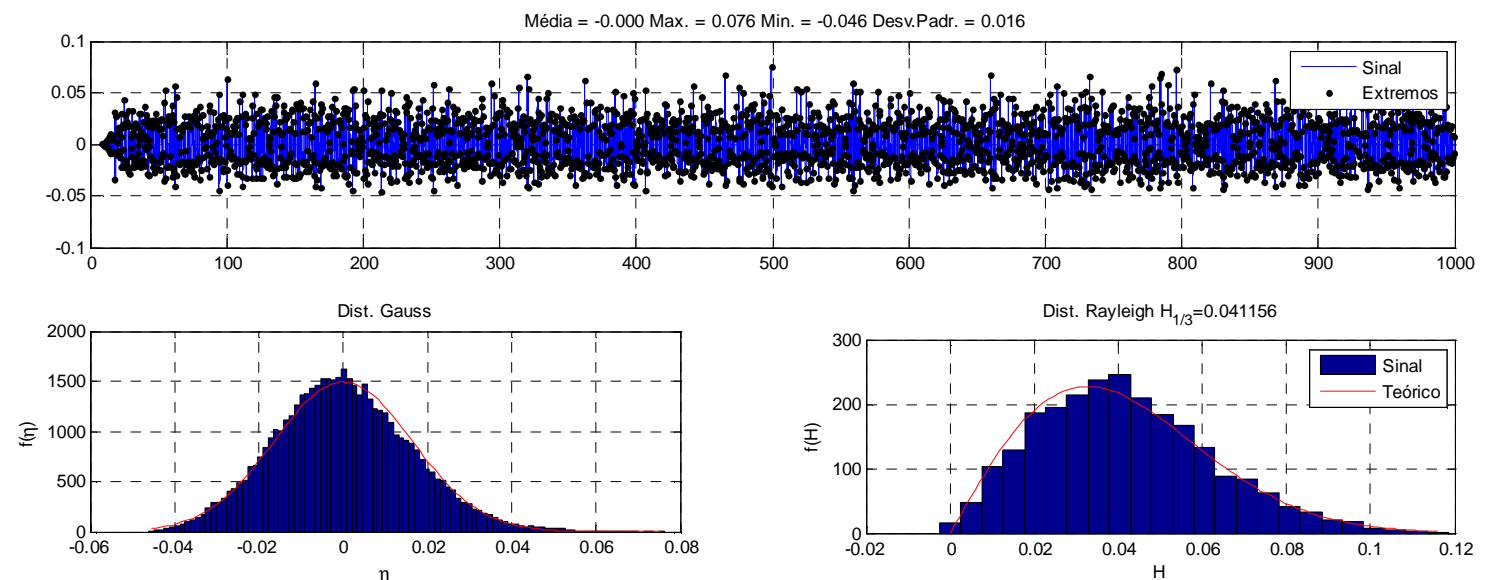
$\begin{aligned} & \text { Sinal Desv.Padr. }=0.0162 \mathrm{Hs}=0.0648 \mathrm{Tp}=0.9262 \mathrm{~T} 2=0.764 \mathrm{~T} 4=0.5448 \mathrm{e}=0.7012 \\ & \text { Teórico Desv.Padr. }=0.01666 \mathrm{Hs}=0.06663 \mathrm{Tp}=0.913 \mathrm{~T} 2=0.6984 \mathrm{~T} 4=0.4946 \mathrm{e}=0.706\end{aligned}$
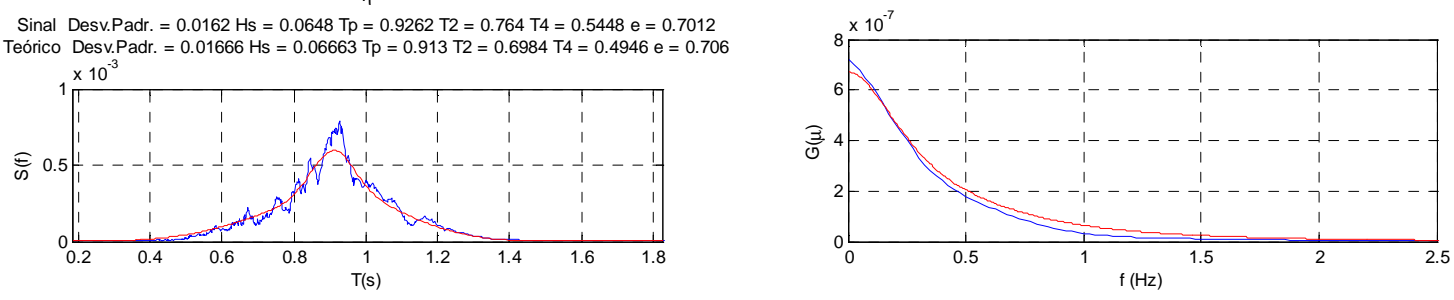

Figura 6.30. Estatística do mar decenário da Bacia de Santos.
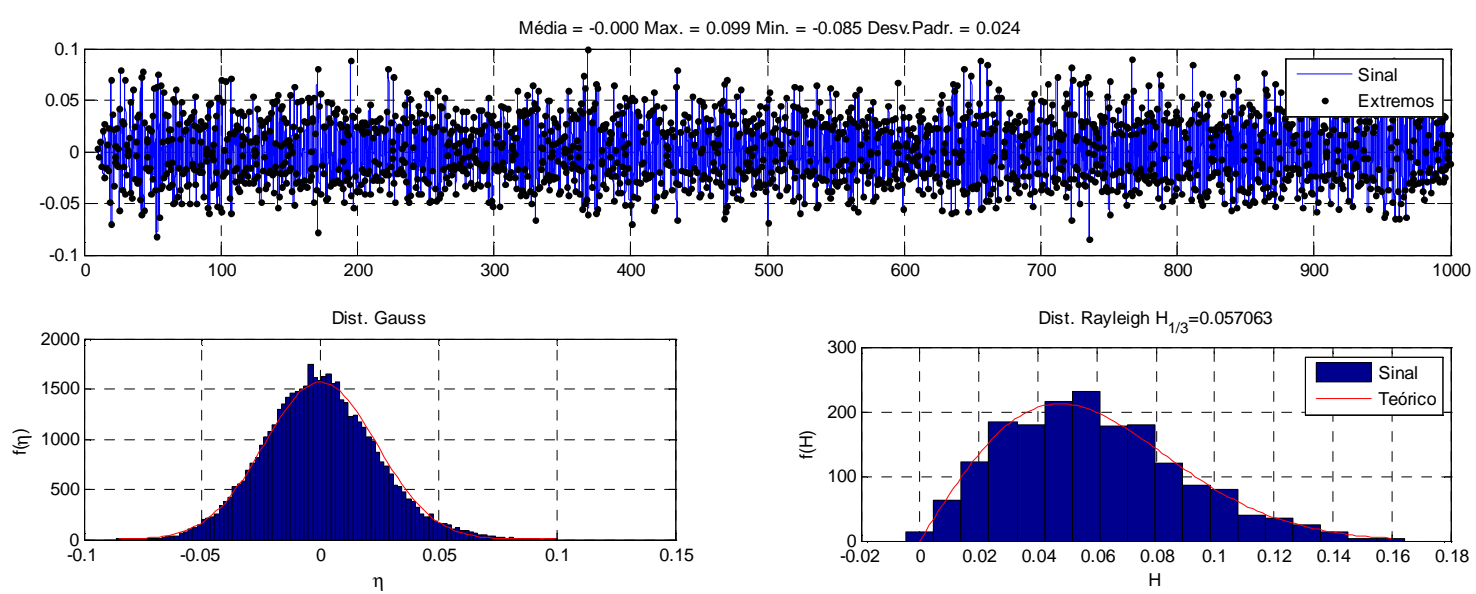

Sinal Desv.Padr. $=0.0236 \mathrm{Hs}=0.0944 \mathrm{Tp}=1.436 \mathrm{~T} 2=1.084 \mathrm{~T} 4=0.7118 \mathrm{e}=0.7544$ Teórico Desv.Padr. $=0.02309 \mathrm{Hs}=0.09235 \mathrm{Tp}=1.415 \mathrm{~T} 2=1.066 \mathrm{~T} 4=0.7545 \mathrm{e}=0.7062$
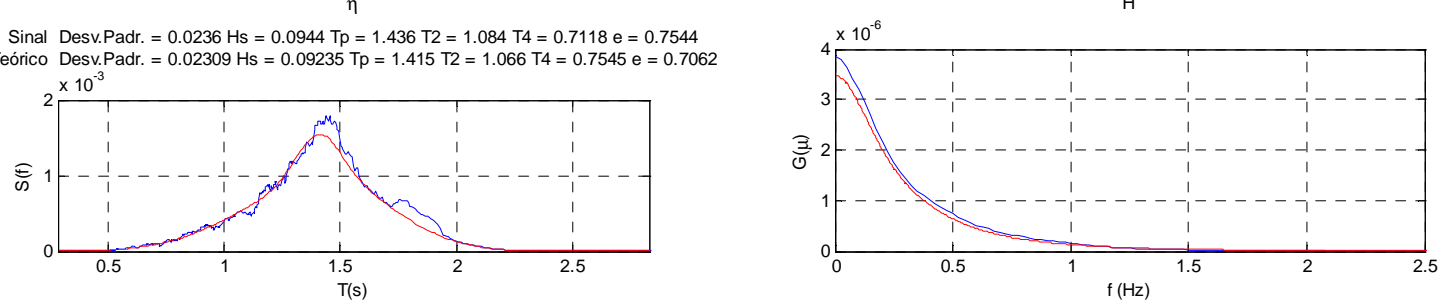

Figura 6.31. Estatística do mar centenário da Bacia de Santos.

Visando avaliar o espectro de energia das ondas refletidas provenientes da lateral 3 e calcular os coeficientes de reflexão, o método de Goda \& Suzuki, 1976, foi usado com os dados dos três sensores capacitivos posicionados no centro do tanque. Foi possível fazer três combinações diferentes de sensores, o que muda a faixa de 
frequências de medição. Dependendo das frequências do espectro e da distância entre os sensores, ocorrem singularidades no método que implicam em erros na avaliação das parcelas incidente e refletida.

Fazendo-se uma verificação dos espectros, nota-se que quanto maior a energia em determinada raia de frequências, mais bem comportada tende a ser a estimativa do coeficiente de reflexão. Ao contrário, quando há pouca energia, a estimativa do coeficiente de reflexão tende a ser maior e com mais variações. Optou-se, então, por usar uma faixa de frequências contínua e centralizada na raia com maior parcela de energia, geralmente próxima do pico do espectro. Dessa forma, foi utilizado somente um arranjo de sensores por onda irregular e com o coeficiente de reflexão médio calculado entre uma frequência inicial e uma final. A Tabela 6.18 mostra o resultado obtido do coeficiente de reflexão de todas as ondas utilizando o procedimento descrito acima.

A Figura 6.32 mostra a análise de reflexão das 4 ondas irregulares ensaiadas. A faixa de frequências entre as barras pretas verticais delimita a região livre das singularidades do método de Goda \& Suzuki. Os espectros mostrados são de densidade de energia e o coeficiente de reflexão é calculado em altura de onda, portanto em escala de energia o valor da onda refletida $\left(H_{r}\right)$ é quadrático e muito menor em relação ao espectro incidente $\left(H_{i}\right)$. Assim sendo, manteve-se a análise do coeficiente de reflexão em altura de onda, pois o resultado é similar à análise realizada com as ondas regulares.

Tabela 6.18. Coeficientes de reflexão experimental.

\begin{tabular}{|c|c|c|c|c|c|c|c|}
\hline \multirow{2}{*}{ Nome } & \multirow{2}{*}{\multicolumn{2}{|c|}{ Arranjo }} & \multicolumn{2}{|c|}{$\begin{array}{c}\text { Faixa de } \\
\text { frequências }\end{array}$} & \multirow{3}{*}{$\begin{array}{c}\text { Cr médio (\%) } \\
10,69\end{array}$} & \multirow{3}{*}{$\begin{array}{l}\text { Cr máximo }(\%) \\
15,60 \text { em } 1,24 \mathrm{~Hz}\end{array}$} & \multirow{3}{*}{$\begin{array}{c}\text { Cr mínimo (\%) } \\
6,86 \text { em } 0,9 \mathrm{~Hz}\end{array}$} \\
\hline & & & $\mathrm{f}_{\mathrm{i}}(\mathrm{Hz})$ & $\mathrm{f}_{\mathrm{o}}(\mathrm{Hz})$ & & & \\
\hline Campos10 & WP1 & WP3 & 0,67 & 1,25 & & & \\
\hline Campos 100 & WP1 & WP3 & 0,46 & 1,24 & 10,15 & $14,90 \mathrm{em} 1,24 \mathrm{~Hz}$ & 4,30 em $0,67 \mathrm{~Hz}$ \\
\hline Santos 10 & WP1 & WP2 & 0,82 & 1,34 & 9,75 & $14,39 \mathrm{em} 1,28 \mathrm{~Hz}$ & $6,80 \mathrm{em} 1,09 \mathrm{~Hz}$ \\
\hline Santos 100 & WP1 & WP3 & 0,54 & 1,20 & 8,04 & $13,37 \mathrm{em} 1,04 \mathrm{~Hz}$ & 4,00 em $0,74 \mathrm{~Hz}$ \\
\hline
\end{tabular}



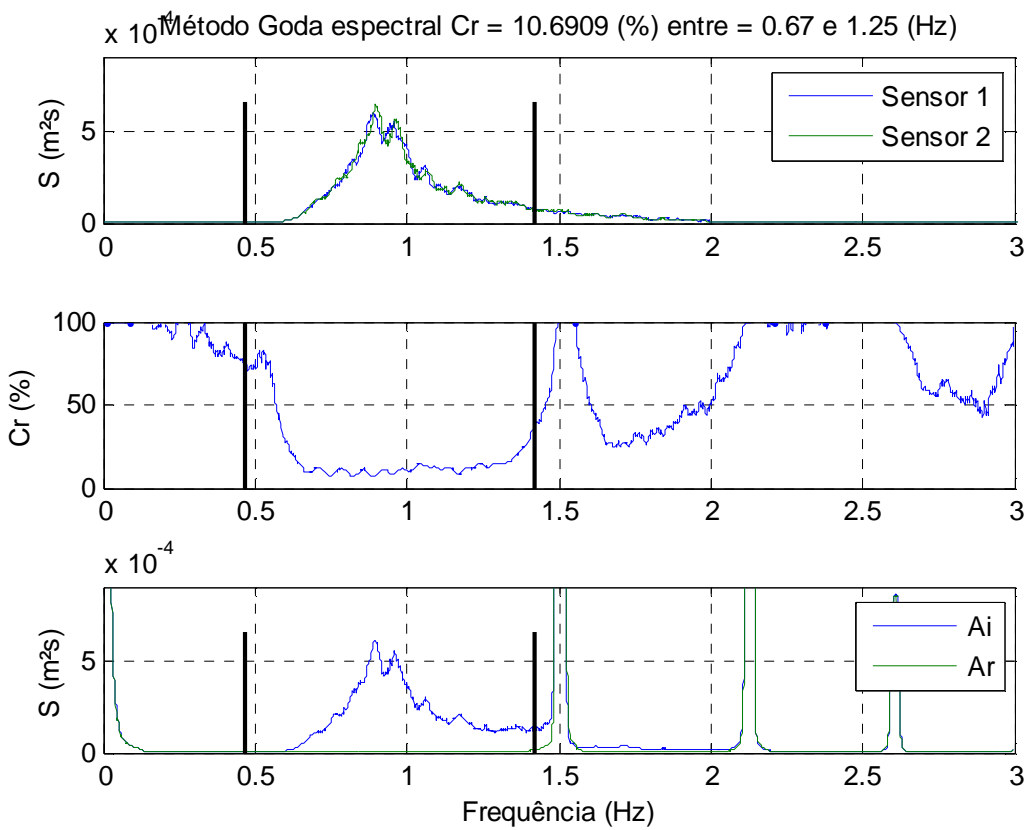

(a) - Campos decenária
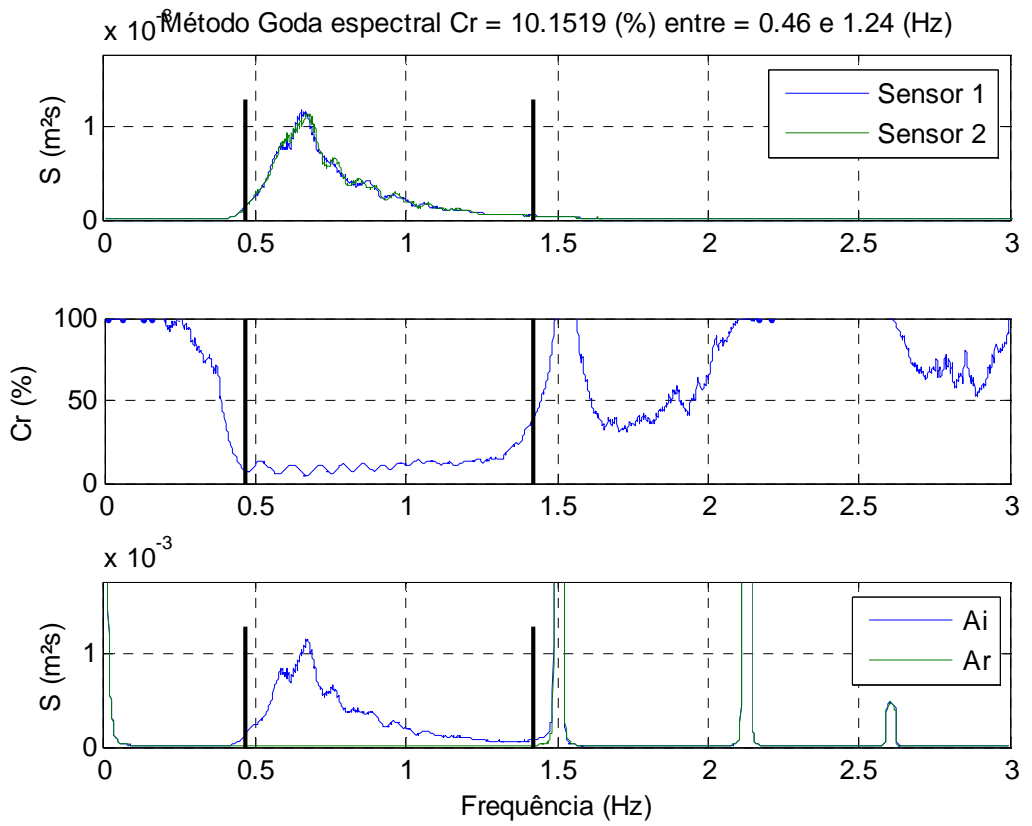

(b) - Campos centenária 

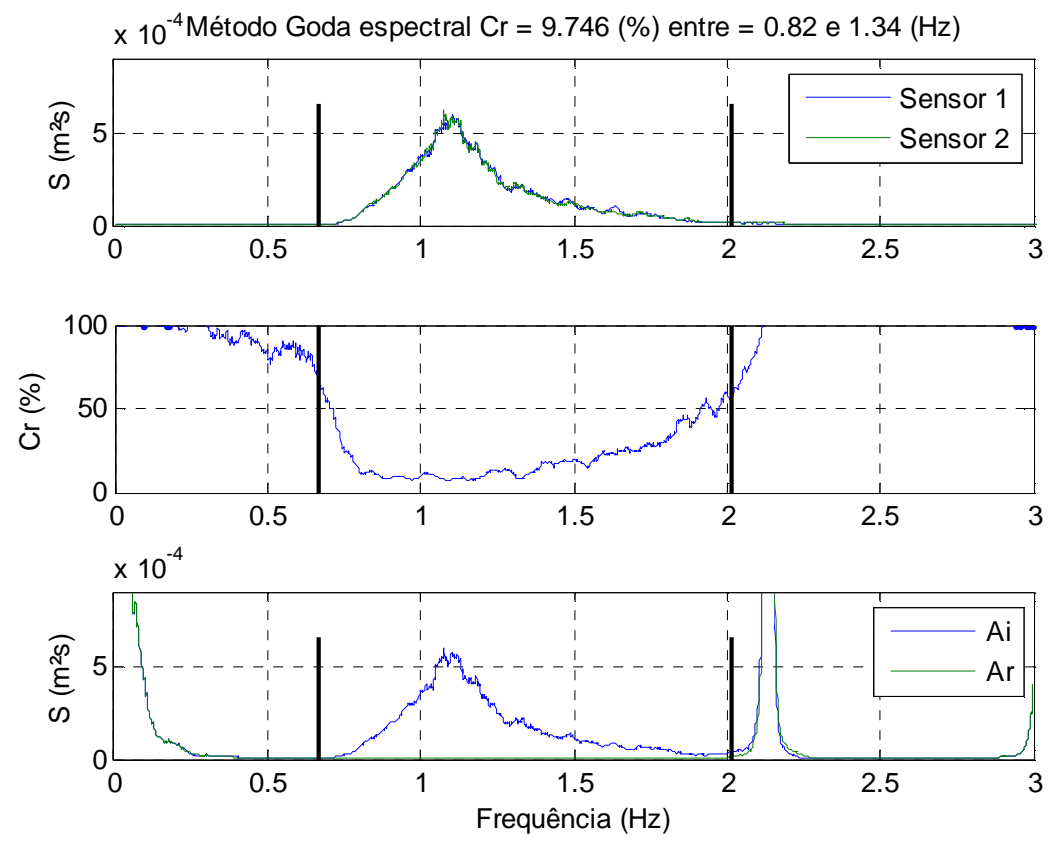

(c) - Santos decenária
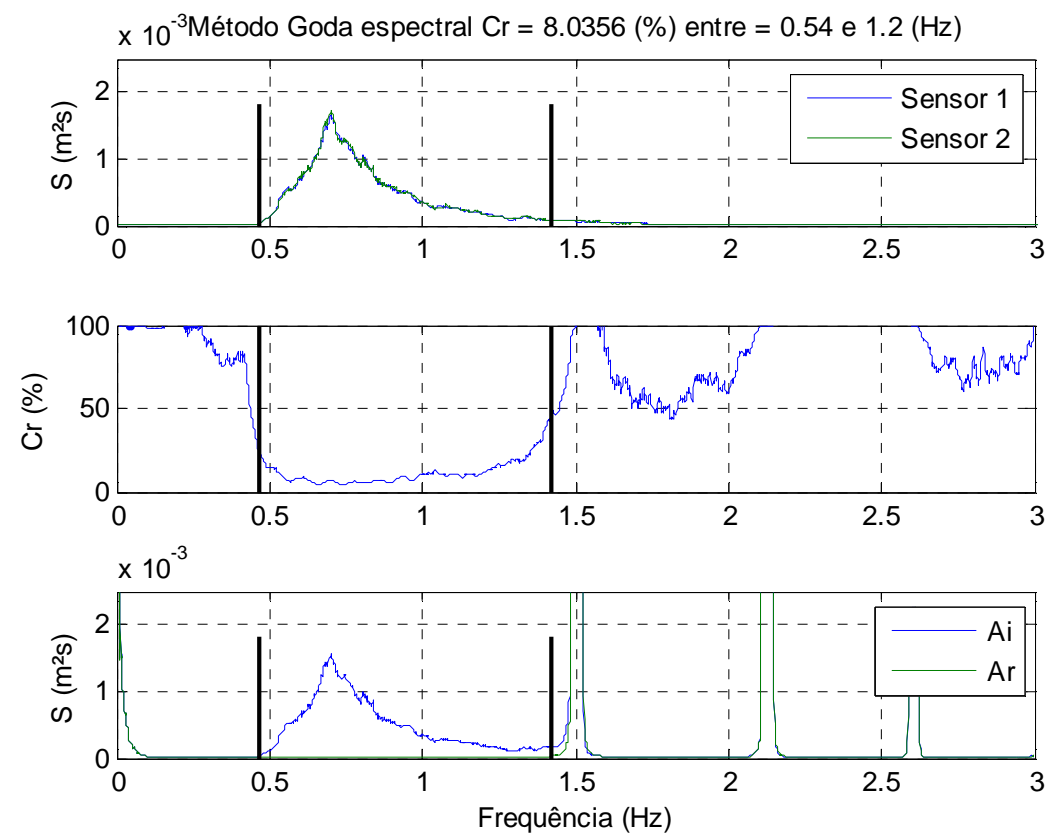

(d) - Santos centenária

Figura 6.32. Análise de reflexão feita para as ondas irregulares.

O coeficiente de reflexão estimado é coerente para todas as ondas e também se comparado aos valores estimados para as ondas regulares (ver Tabela 6.9). Observa-se que, quanto maior a frequência, maior é o $\mathrm{Cr}$ e a dispersão dos espectros incidentes e refletidos, com valores médios na faixa de $10 \%$. Dado que a absorção no gerador foi mantida ativada durante os ensaios, não se observou influência significativa da re- 
reflexão de ondas no gerador sobre os resultados, assim como no teste com ondas regulares.

Ressalta-se também que, como as maiores taxas de reflexão ocorrem nas frequências mais elevadas, o que fica evidente nas ondas da Tabela 6.18 e na Figura $6.32 c$, deve-se evitar grande energia espectral em tal faixa. Para tanto, é recomendável limitar as frequências de pico a valores abaixo de $1,5 \mathrm{~Hz}$.

\subsection{Aplicação da técnica de TR no tanque de provas}

A técnica de TR foi experimentada no tanque de provas para, em um estágio inicial de testes, avaliar o comportamento do tanque com fontes de sinais impulsivos e com diferentes fontes de emissão. Para tanto foram feitos experimentos usando um impulso inicial e em seguida executando ondas com o gerador de ondas revertido no tempo.

Os experimentos foram divididos em três grupos: fonte impulsiva por um objeto lançado contra a água, fonte impulsiva feita por um batedor de ondas e recepcionada por um sensor de ondas e fonte impulsiva feita por um batedor de ondas e recepcionada por outro batedor de ondas.

O objetivo dos experimentos foi estudar como a técnica se comporta para ondas de superfície. Para tanto foram usados os sensores de ondas dos batedores, os batedores como fonte de perturbação, sensores de ondas (a mesma matriz de sensores descrita no tópico 6.2.2) para medir as ondas no interior do tanque e filmagens em vídeo dos testes. A seguir, os experimentos são apresentados em três grupos distintos.

\subsubsection{Lançamento de objeto na superfície da água}

Nestes testes foi usado um objeto cilíndrico para criar uma perturbação na água. Em seguida foi feita a reversão temporal para avaliar a focalização reversa dessa perturbação. Em um segundo teste uma antepara foi colocada próxima do centro do tanque para obstruir a passagem da onda e assim fazer uma variação do experimento 
para avaliar a resposta da focalização reversa em um meio com efeito de difração de ondas em torno da antepara.

\subsubsection{Tanque de provas sem obstáculo}

Neste teste foi usada a matriz de sensores da foto da Figura 6.13 para medir a onda gerada pela queda de um objeto na água. A Figura 6.33 mostra o arranjo do ensaio.

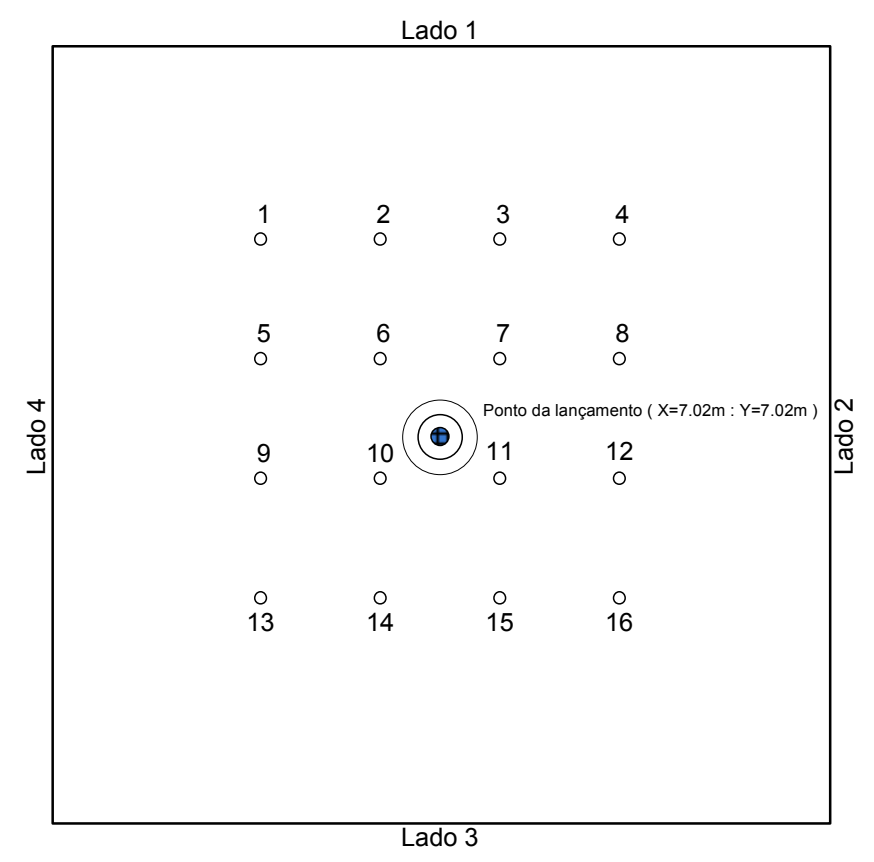

Figura 6.33. Arranjo experimental de lançamento (sem escala).

O objeto lançado é cilíndrico, com os cantos arredondados, medindo $100 \mathrm{~mm}$ de diâmetro com $180 \mathrm{~mm}$ de altura e pesando $2,175 \mathrm{Kg}$. Um olhal na parte de cima foi usado para, com um cabo de náilon passando por uma roldana fixa na ponte de instrumentação, fazer o lançamento na posição central do tanque em duas alturas diferentes acima da água: 0,5 metro (LAN01) e 1,0 metro (LAN02). O cabo de náilon era solto e liberava o objeto que caia até o fundo do tanque de provas.

A Tabela 6.19 mostra os testes realizados. O lançamento era feito com duas alturas e com duas repetições cada (LAN01 e LAN01a, LAN02 e LAN02a). No momento do lançamento os sensores de ondas capacitivos (WPC) adquiriam a onda produzida. O gerador de ondas não gerava onda alguma, somente adquiria as ondas que incidiam sobre a face dos batedores através dos sensores de ondas ultrassônicos. 
Tabela 6.19. Características dos testes de lançamento de objeto na água.

\begin{tabular}{|c|c|c|c|c|}
\hline Nome do teste & $\begin{array}{c}\text { Altura de } \\
\text { lançamento }\end{array}$ & Estado dos WPC & Estado dos WPU & $\begin{array}{c}\text { Estado do } \\
\text { gerador }\end{array}$ \\
\hline LAN01 & $0,5 \mathrm{~m}$ & Adquirindo & Adquirindo & Não utilizado \\
\hline LAN01a & $0,5 \mathrm{~m}$ & Adquirindo & Adquirindo & Não utilizado \\
\hline LAN02 & $1,0 \mathrm{~m}$ & Adquirindo & Adquirindo & Não utilizado \\
\hline LAN02a & $1,0 \mathrm{~m}$ & Adquirindo & Adquirindo & Não utilizado \\
\hline TR de LAN01 & $0,5 \mathrm{~m}$ & Adquirindo & Não utilizado & Atuando \\
\hline TR de LAN01a & $0,5 \mathrm{~m}$ & Adquirindo & Não utilizado & Atuando \\
\hline TR de LAN02 & $1,0 \mathrm{~m}$ & Adquirindo & Não utilizado & Atuando \\
\hline TR de LAN02a & $1,0 \mathrm{~m}$ & Adquirindo & Não utilizado & Atuando \\
\hline
\end{tabular}

Analisando, nos sensores capacitivos, a onda produzida (Figura 6.35a) nota-se que os sensores mais próximos do ponto de lançamento têm maior concentração de energia, enquanto os mais distantes têm energia mais dispersa. As ondas de gravidade são dispersivas. Avaliando este resultado, pode-se afirmar que no ponto de lançamento a energia é mais concentrada.

\subsection{Correção espacial nos WPC}

Duas correções foram aplicadas à leitura dos sensores capacitivos para comparar os 16 sinais adquiridos. A primeira delas corrige a concentração da energia em função da dispersão das ondas. A celeridade de onda depende do período da mesma (eq. 3.10). A partir da celeridade de onda e da distância entre o ponto de lançamento e a posição de cada sensor, pode-se calcular o atraso temporal em função da frequência entre cada sensor e o ponto de lançamento:

$\frac{\Delta S_{k}(m)}{C_{j}(m / s)}=\Delta t_{j k}(s)$

onde $k$ e $j$ são os índices de sensor e frequência, respectivamente. O termo $\Delta S$ é a distância entre o ponto de lançamento e cada sensor. O termo $\Delta t$ é o atraso temporal entre o ponto de lançamento e cada sensor. A Figura 6.34 mostra graficamente este resultado para o experimento realizado. Ao aplicar este atraso à leitura dos sensores de forma inversa, compensando o atraso ao ponto de lançamento usando a propriedade de 
atraso temporal com FFT (Oppenheim, Schafer e Buck, 1998), a energia da onda volta a ser concentrada (focalizada).

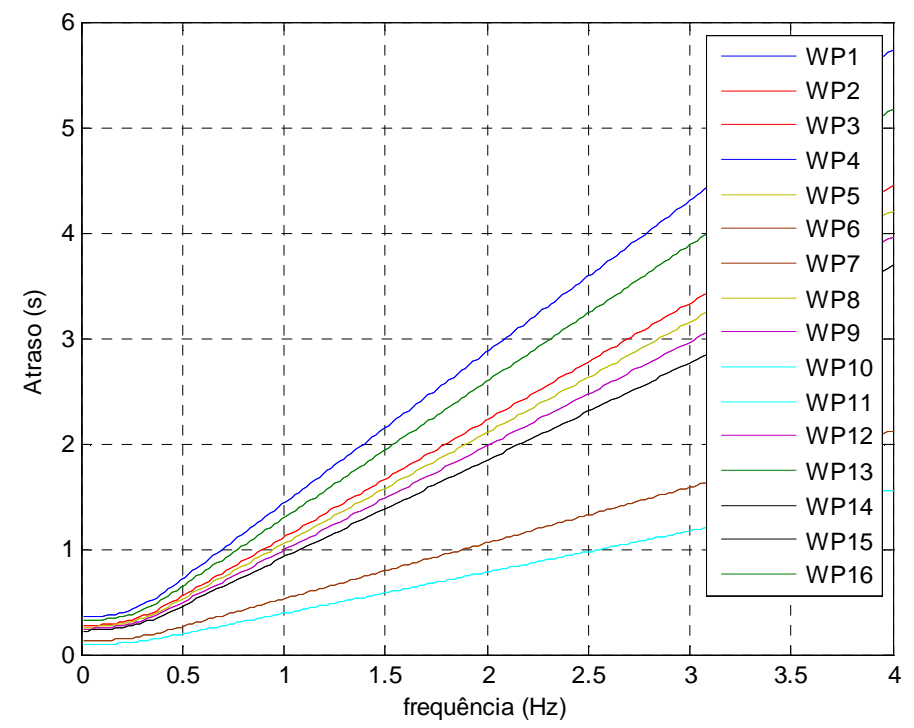

Figura 6.34. Atraso temporal em função da frequência nos sensores de ondas capacitivos.

A segunda correção diz respeito à altura de ondas concêntrica. Segundo Hirayama, 1994 apud Quadrante, 2011, p. 45, as ondas concêntricas têm um fator de atenuação em função do raio para conservar a energia das ondas, que atenuam em função do raio $(r)$ :

$A_{c}(r)=A_{0} \cdot \frac{1}{\sqrt{\pi r}}$

onde $A_{0}$ é a altura inicial. Utilizando o raio dado pela distância entre o ponto de lançamento e os sensores aplicada à correção de altura de ondas concêntricas, obtém-se a altura de ondas no ponto de lançamento. $\mathrm{O}$ resultado das duas correções aplicadas à leitura dos sensores pode ser vista na Figura $6.35 b$. A Figura 6.36 mostra a leitura dos sensores em detalhes com a correção espacial de ondas. As duas correções aplicadas têm o objetivo de normalizar a leitura dos sensores, sem a pretensão de estimar a energia ou o fenômeno da queda de um objeto na água. 

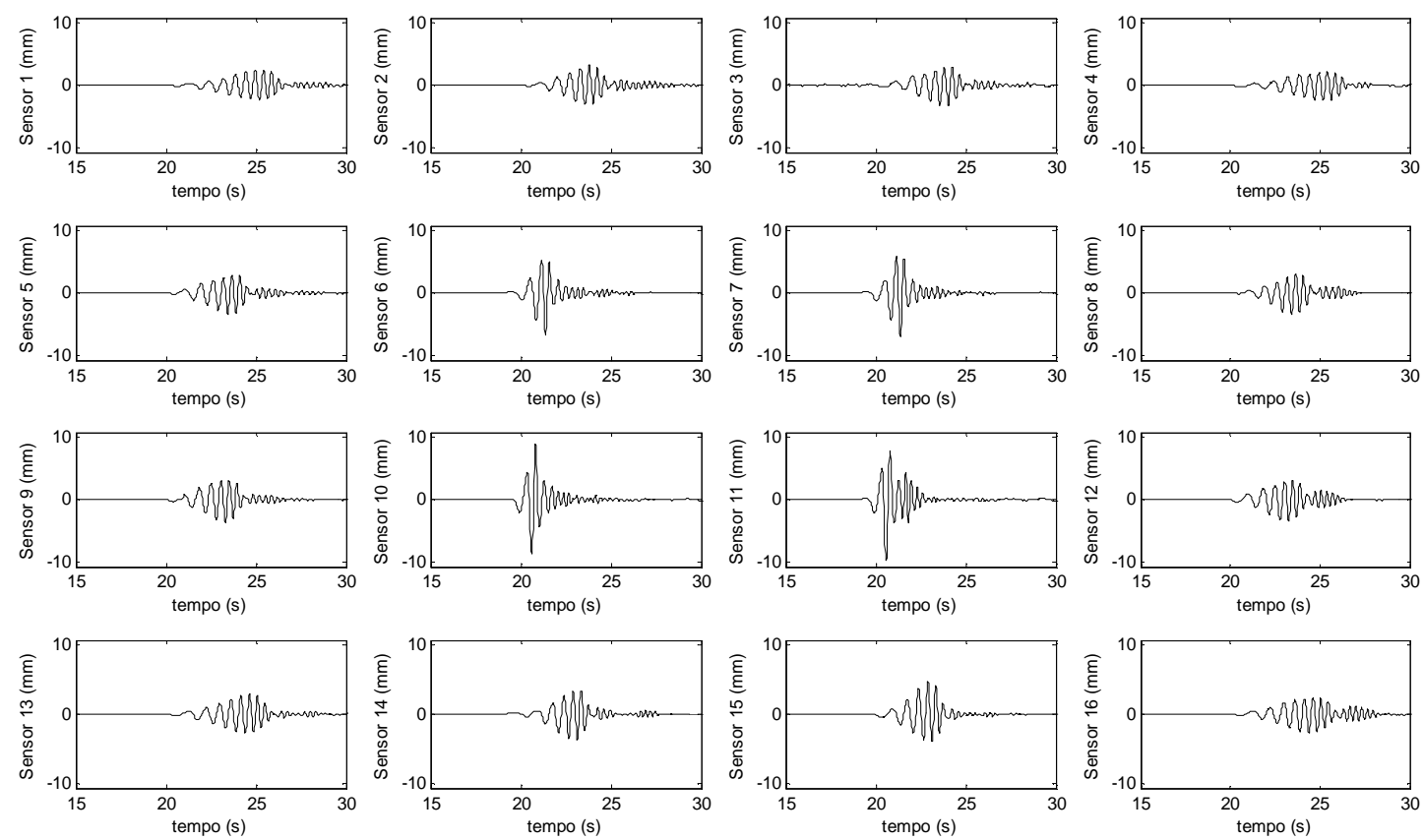

(a) - Leitura de onda no lançamento 01 .
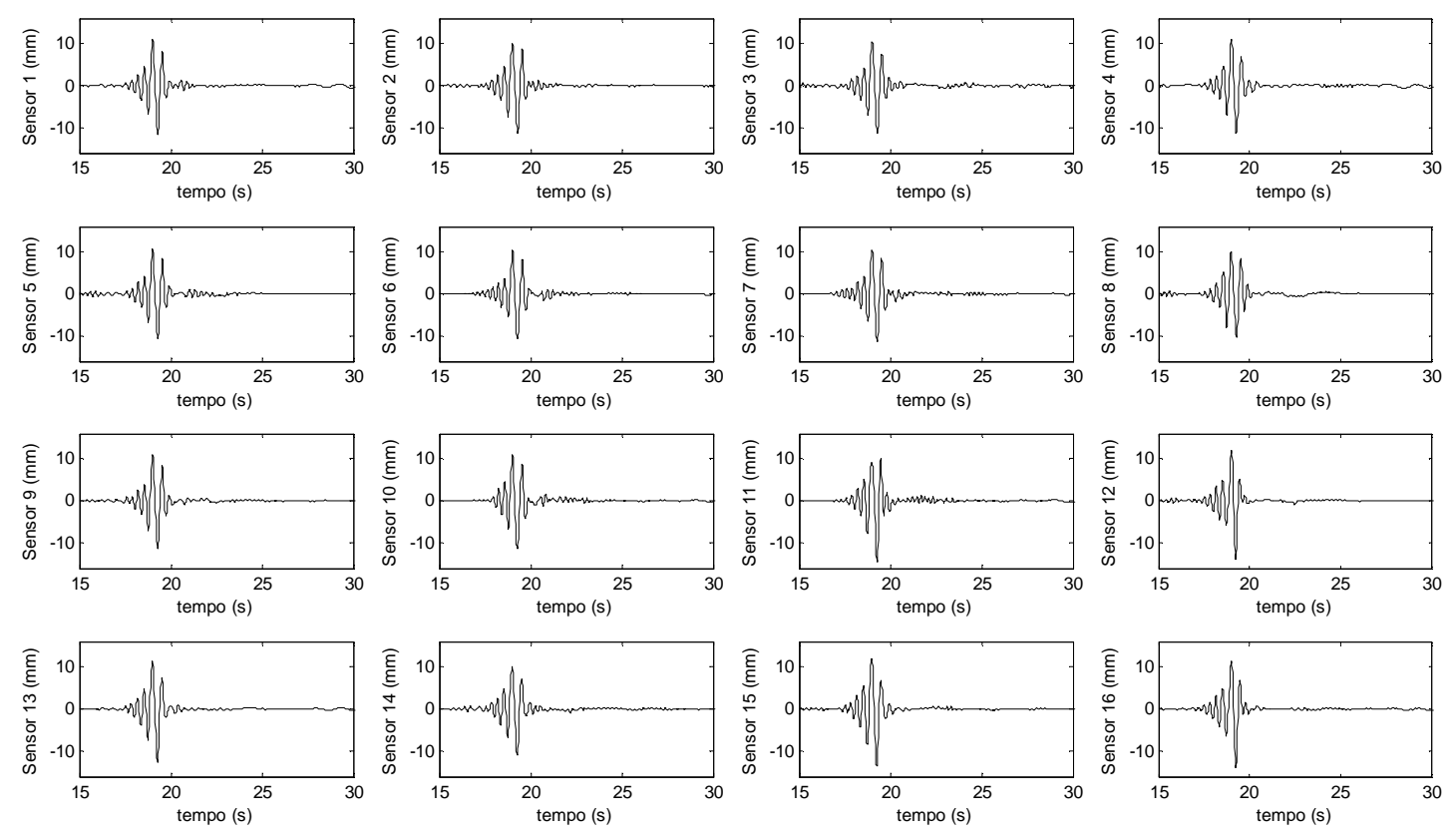

(b) - Leitura de onda com correção espacial.

Figura 6.35. Onda lida nos sensores capacitivos do lançamento 01. 


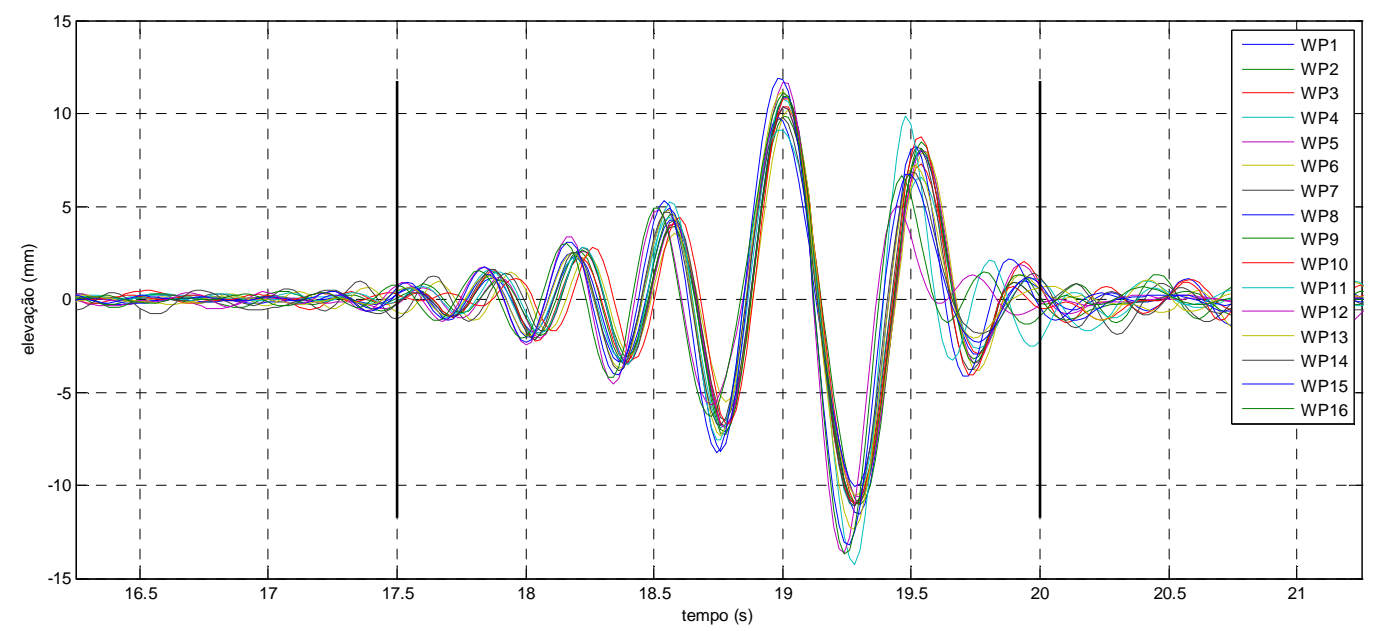

Figura 6.36. Sinais dos sensores de onda com correções espaciais.

Fazendo uso do método definido acima, ocorrem ainda algumas flutuações de altura e do instante da focalização entre os sensores de ondas, mas pode-se concluir que a energia no ponto de lançamento apresenta concentração de energia, ou seja, representa uma fonte impulsiva. Aplicando o procedimento aos quatro lançamentos realizados, observa-se o mesmo comportamento. A Tabela 6.20 compara os quatro lançamentos.

Tabela 6.20. Resultado das análises de lançamentos realizados.

\begin{tabular}{|c|c|c|c|c|}
\hline Nome do teste & $\boldsymbol{H}_{\boldsymbol{r m s}}(\mathbf{m m})$ & $\boldsymbol{\sigma} \boldsymbol{H}_{\boldsymbol{r m s}}(\mathbf{m m})$ & $\boldsymbol{H}_{\boldsymbol{m a x}}(\mathbf{m m})$ & $\boldsymbol{\sigma}_{\boldsymbol{m a x}}(\mathbf{m m})$ \\
\hline LAN01 & 4,498 & 0,203 & 22,325 & 1,691 \\
\hline LAN01a & 4,532 & 0,240 & 22,254 & 1,305 \\
\hline LAN02 & 5,687 & 0,184 & 27,103 & 1,307 \\
\hline LAN02a & 5,513 & 0,189 & 25,553 & 1,267 \\
\hline
\end{tabular}

O valor médio quadrático e o valor máximo de altura de onda apresentados são o valor médio dos 16 sensores. Para tanto, são apresentados os desvios padrão entre os sensores. Os valores foram obtidos do trecho temporal em que ocorreu a concentração com a correção espacial aplicada, como mostrado na Figura 6.36. Observa-se que ocorre a repetição dos resultados e que a energia nos lançamentos não é proporcional à energia potencial inicial do objeto antes de lançado. 


\subsection{Reversão temporal dos lançamentos de objeto}

$\mathrm{Na}$ sequência do teste, foi feito o tratamento da leitura dos sensores de ondas ultrassônicos dos batedores de ondas para realizar a reversão temporal. Foram utilizados todos os 148 batedores de ondas nos testes. O trecho temporal que continha a onda proveniente do lançamento foi selecionado. As ondas concêntricas geradas incidem nas laterais do tanque de provas e refletem novamente no interior do tanque com alturas cada vez menores. Como as ondas são dispersivas, as ondas de maior frequência demoram mais tempo para atingir as laterais do tanque, enquanto as ondas de frequências mais baixas já refletiram diversas vezes. Selecionando um trecho com duração elevada é possível focalizar as ondas contendo elevada "reverberação", em analogia com as ondas acústicas. Em contrapartida, se o trecho for muito longo, pode conter excesso de ruído em função da resolução dos sensores de ondas. A Figura 6.37 ilustra o início do trecho temporal adquirido em diversos dos sensores dos batedores de ondas. Nota-se que inicialmente as ondas longas incidem nas laterais do tanque e as ondas curtas posteriormente. A altura obtida é menor que no centro do tanque (sensores capacitivos) devido à atenuação concêntrica. $O$ trecho temporal recortado tem 20 segundos de duração a partir do sinal dos sensores ultrassônicos.

A leitura dos sensores sofreu um ajuste para a re-emissão devido à reflexão na face do batedor. Um meio de explicar a reflexão das ondas é considerar a fase de duas ondas em sentidos opostos nula na face do batedor; assim, seria como se existisse a sobreposição de duas ondas em sentidos opostos. Considerando tal situação, um sensor medindo a altura da água na face do batedor terá o dobro da altura da onda incidente ao batedor. Em planta, ocorrerá a reflexão da onda segundo a Lei de Snell: a onda oblíqua terá reflexão simétrica em relação à normal da face do batedor. Assim sendo, a elevação de ondas nos batedores terá a metade da altura lida nos sensores. Essa característica melhora, inclusive, a relação sinal ruído (dos sistemas eletrônicos) na medição das ondas. 

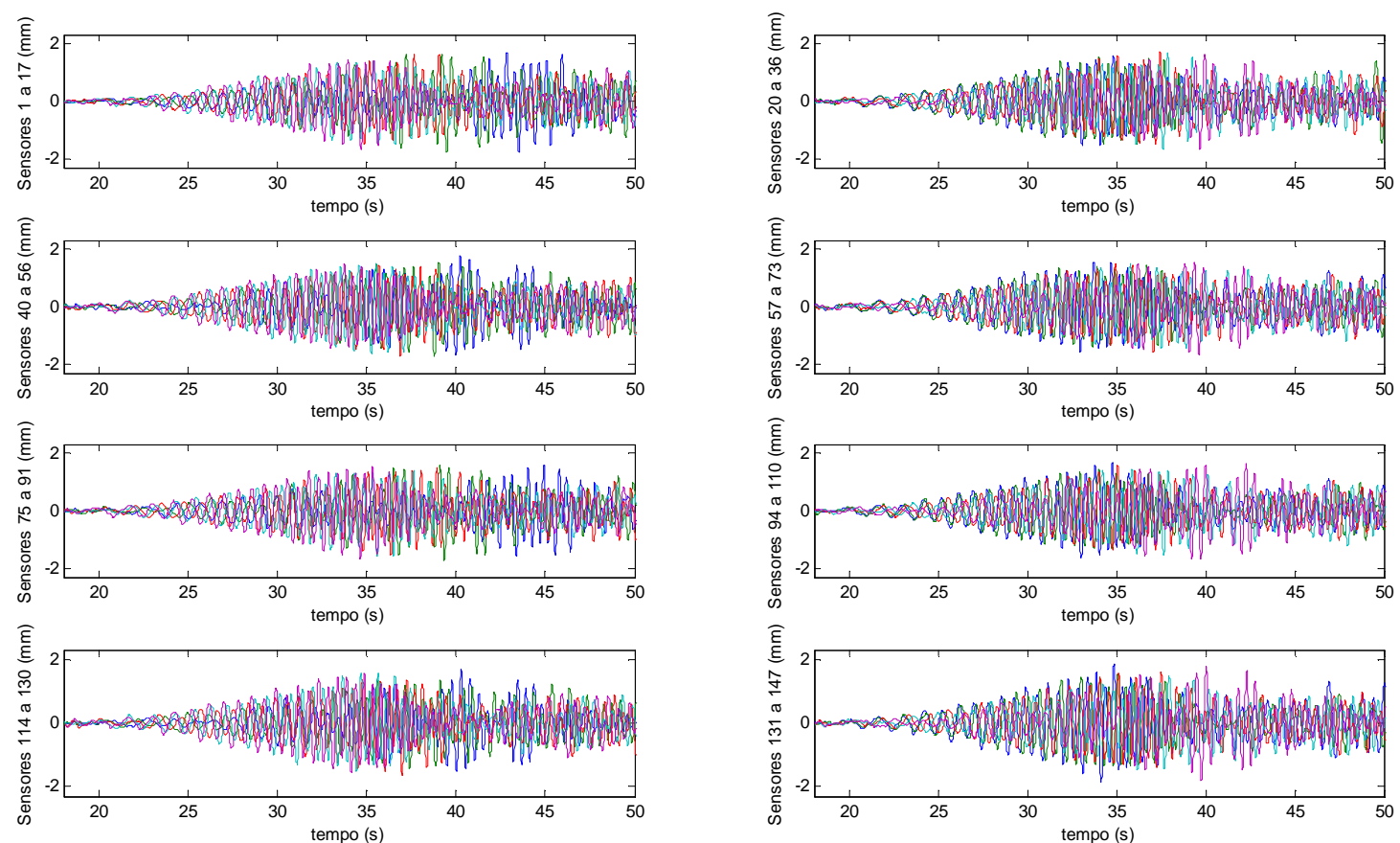

Figura 6.37. Onda do lançamento 1 adquirida nos sensores de ondas ultrassônico.

O fator importante para que a aplicação de TR funcione diz respeito à fase da onda; a concentração depende da repetibilidade do sistema (invariância temporal do sistema). A altura das ondas lidas nos batedores será revertida no tempo e reenviada como deslocamento no mesmo. Não é necessário que seja feito um ajuste de amplitude no gerador de ondas. Portanto, não foi aplicada a função de transferência do batedor de ondas do tipo flap nas ondas revertidas no tempo. Dessa forma, não se espera que as alturas de ondas no ponto de lançamento sejam recuperadas. A Figura 6.38 mostra o deslocamento feito nos batedores para a reversão temporal. 

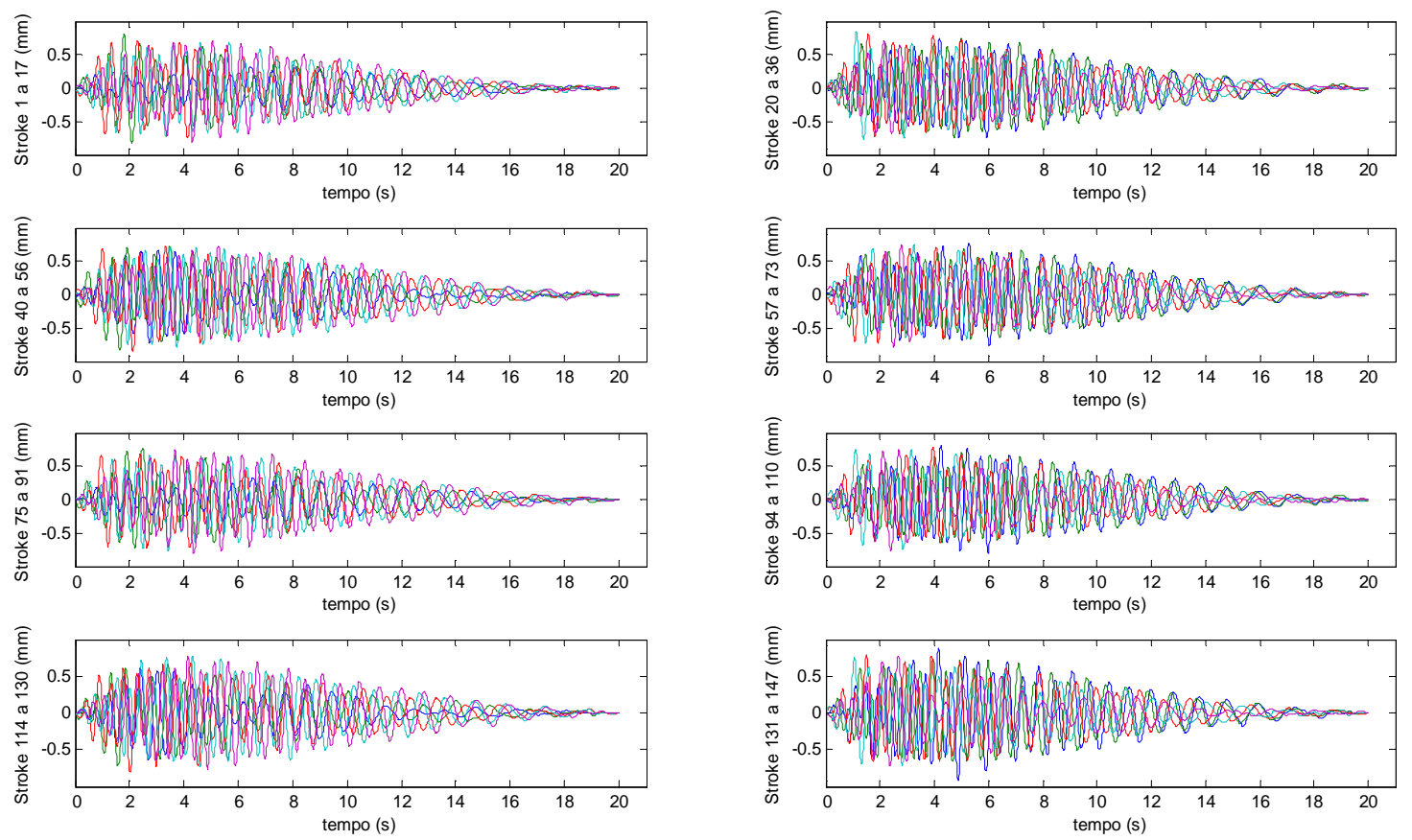

Figura 6.38. Deslocamento realizado na reversão temporal do lançamento 01 (trecho de 20 segundos ).

A Figura $6.39 a$ mostra a onda revertida no tempo nos sensores de ondas capacitivos. Existem dois "pacotes" de ondas passando pelos sensores. No primeiro deles, observa-se que a onda é menor nos sensores de ondas mais distantes do ponto de lançamento e que as ondas mais longas agora passam depois pelos sensores, resultado inverso do lançamento do objeto. Após elas passarem pelos sensores, ocorre outro "pacote" de ondas que tem o mesmo formato do teste de lançamento do objeto. Portanto pode-se concluir que ocorreu a concentração de ondas em algum local do tanque nos instantes de tempo entre os dois "pacotes". Aplicando-se a correção da dispersão das ondas no sentido inverso - ou seja, considerando que a onda concêntrica propaga para o ponto de lançamento - e a correção de concentricidade da onda, resultam os sinais da Figura 6.39b. O primeiro "pacote" se concentra e o segundo dispersa mais ainda. A Figura 6.40 mostra o trecho do primeiro "pacote" de ondas. O resultado foi semelhante em todas as aplicações de TR dos lançamentos 1 e 2. 

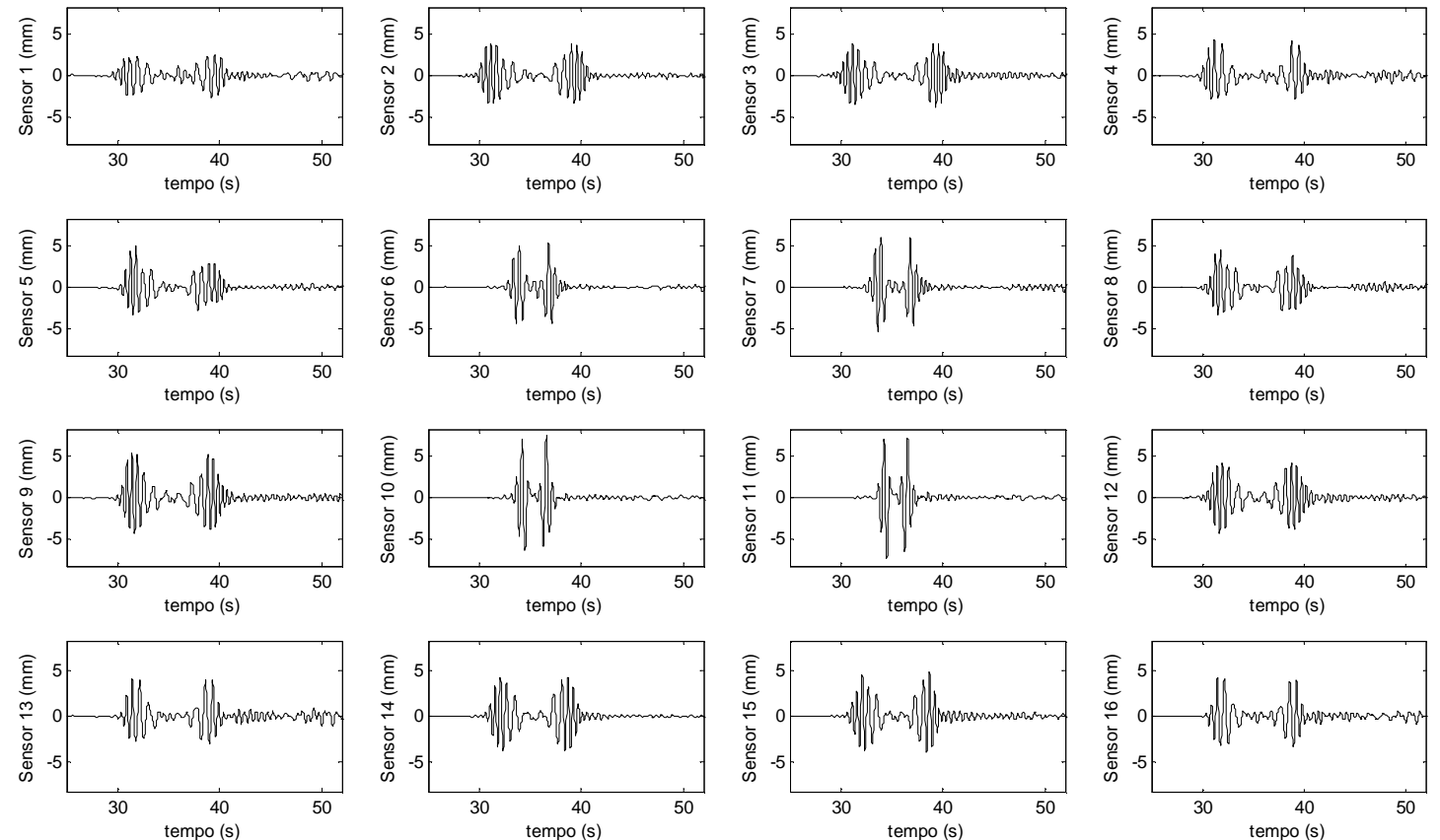

(a) - Leitura de onda da reversão temporal do lançamento 01.
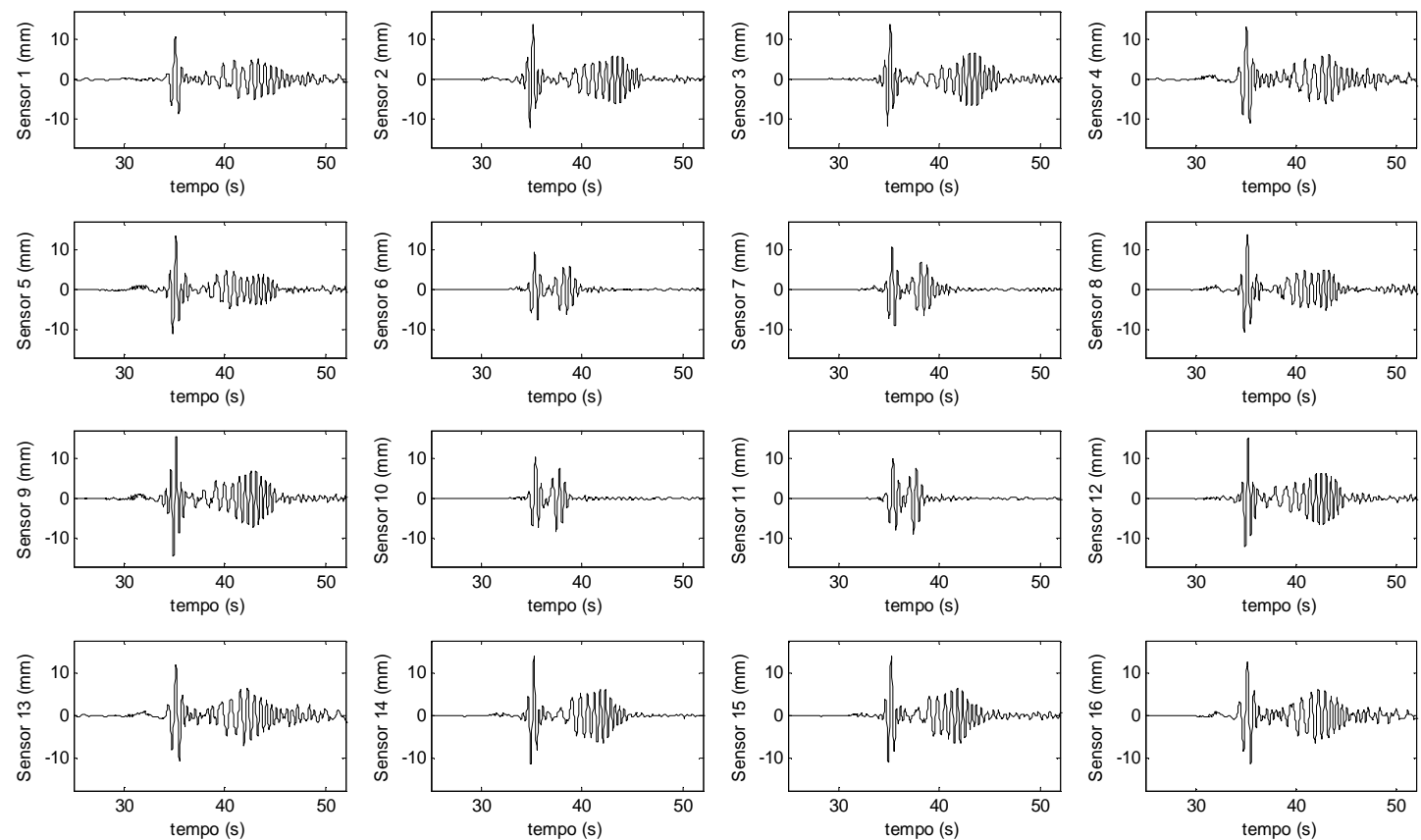

(b) - Leitura de onda com correção espacial.

Figura 6.39. Onda lida nos sensores capacitivos na reversão temporal do lançamento 01. 


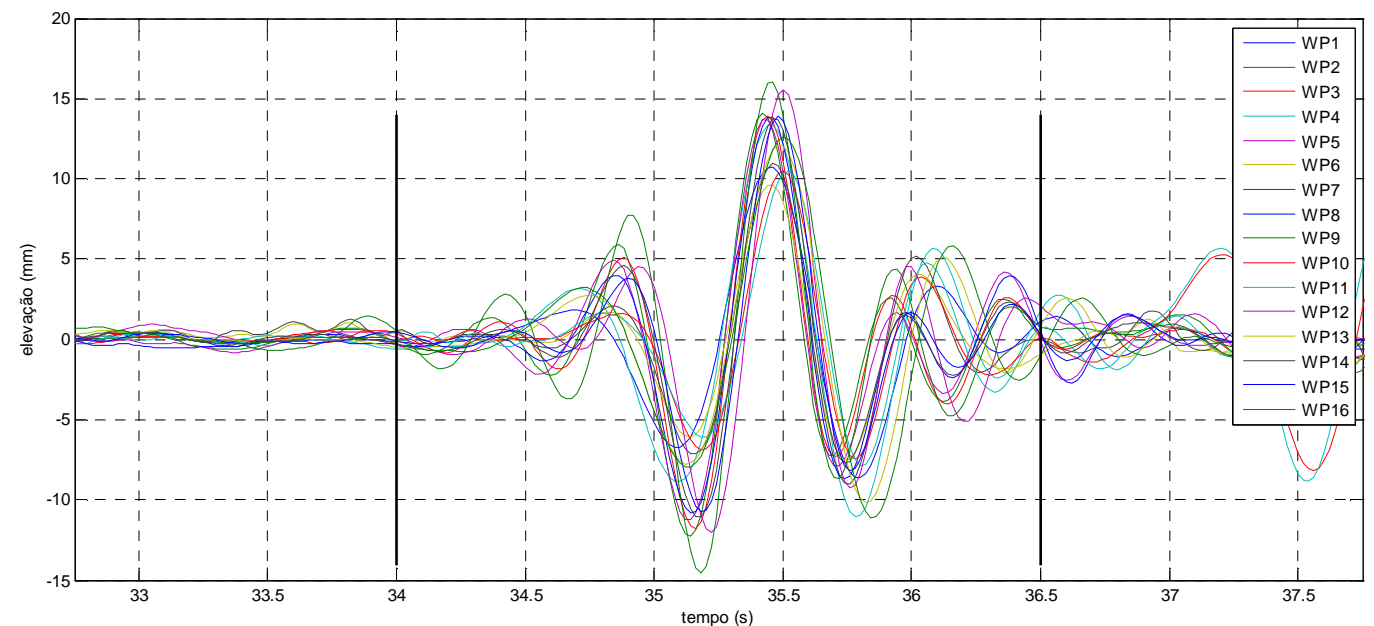

Figura 6.40. Leitura dos sensores de onda com correções espaciais.

Avaliando o trecho de onda concentrada de forma semelhante à da Tabela 6.20, resultam nos dados apresentados na Tabela 6.21. Os resultados mostram diferenças pequenas, apesar de a função de transferência do gerador de ondas não ter sido aplicada. No caso da maior onda detectada, a diferença é menor que $1 \mathrm{~mm}$. Os outros parâmetros mostrados apresentam diferenças maiores. A Figura 6.41 mostra 4 instantes diferentes na onda revertida concentrando no ponto de lançamento original. Os dois últimos instantes mostram a onda totalmente concentrada, formando um cavado e, em seguida, uma crista com a máxima elevação observada; em seguida esta se desfaz e forma uma nova onda concêntrica, semelhante ao que mostra a Figura 6.40. Nota-se que nas filmagens a onda concentrada tem um diâmetro pequeno no ponto de foco, embora ele não tenha sido medido. A julgar pela imagem, o diâmetro é inferior a 1 metro.

Tabela 6.21. Resultado da aplicação de TR aos lançamentos 1 e 2.

\begin{tabular}{|c|c|c|c|c|}
\hline Nome do teste & $\boldsymbol{H}_{\boldsymbol{r m} \boldsymbol{s}}(\mathbf{m m})$ & $\boldsymbol{\sigma}_{\boldsymbol{r m s}}(\mathbf{m m})$ & $\boldsymbol{H}_{\boldsymbol{m a x}}(\mathbf{m m})$ & $\boldsymbol{\sigma H}_{\boldsymbol{m a x}}(\mathbf{m m})$ \\
\hline TR de LAN01 & 4,779 & 0,691 & 21,468 & 2,399 \\
\hline TR de LAN01a & 4,783 & 0,711 & 21,423 & 2,658 \\
\hline TR de LAN02 & 6,006 & 0,851 & 25,769 & 3,089 \\
\hline TR de LAN02a & 6,273 & 0,751 & 27,196 & 2,942 \\
\hline
\end{tabular}




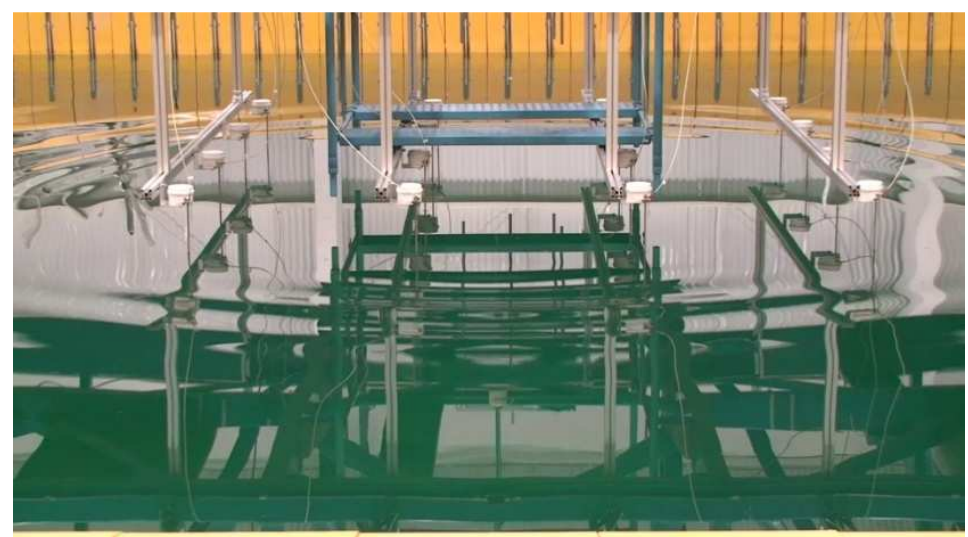

(a) $t=t_{c}-6,33 \mathrm{~s}$

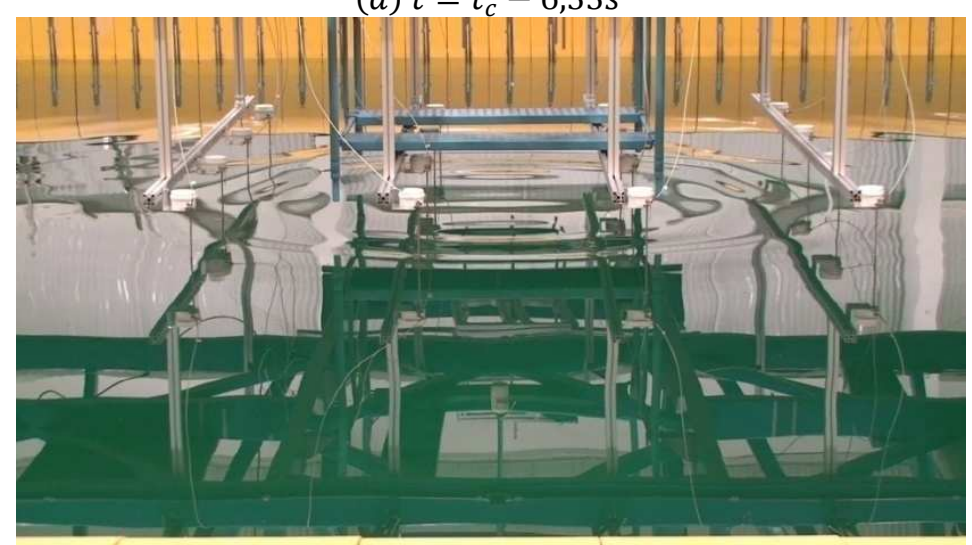

(b) $t=t_{c}-2,93 \mathrm{~s}$
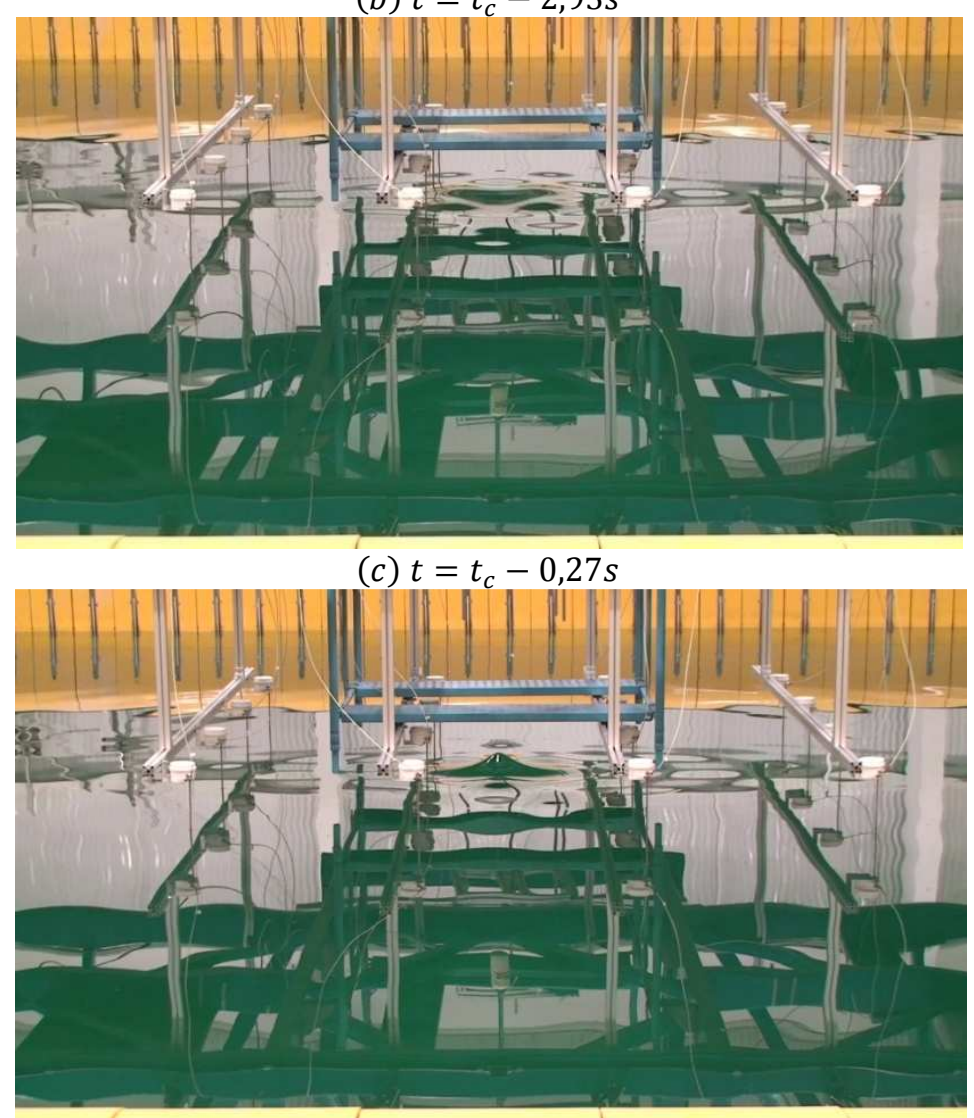

(d) $t=t_{c}-0 s$

Figura 6.41. Onda concentrada no instante $t_{c}=0 s$ usando TR do lançamento 02. 


\subsubsection{Tanque de provas com obstáculo}

Neste teste foi montada uma antepara próxima do centro do tanque de provas para servir de obstáculo à propagação das ondas. Utilizando a técnica de TR, os lançamentos descritos no tópico anterior foram repetidos para avaliar a capacidade do método em focalizar as ondas no ponto de interesse, no caso, o ponto de lançamento. A Figura 6.42 mostra o aparato experimental montado. A profundidade da antepara era de $426 \mathrm{~mm}$. Usou-se uma antepara suficientemente rígida para que não se movesse ou vibrasse com a incidência de ondas; no entanto ela não era muito profunda. Por essa razão a ocorrência de difração em torno da antepara poderia não acontecer com ondas longas.

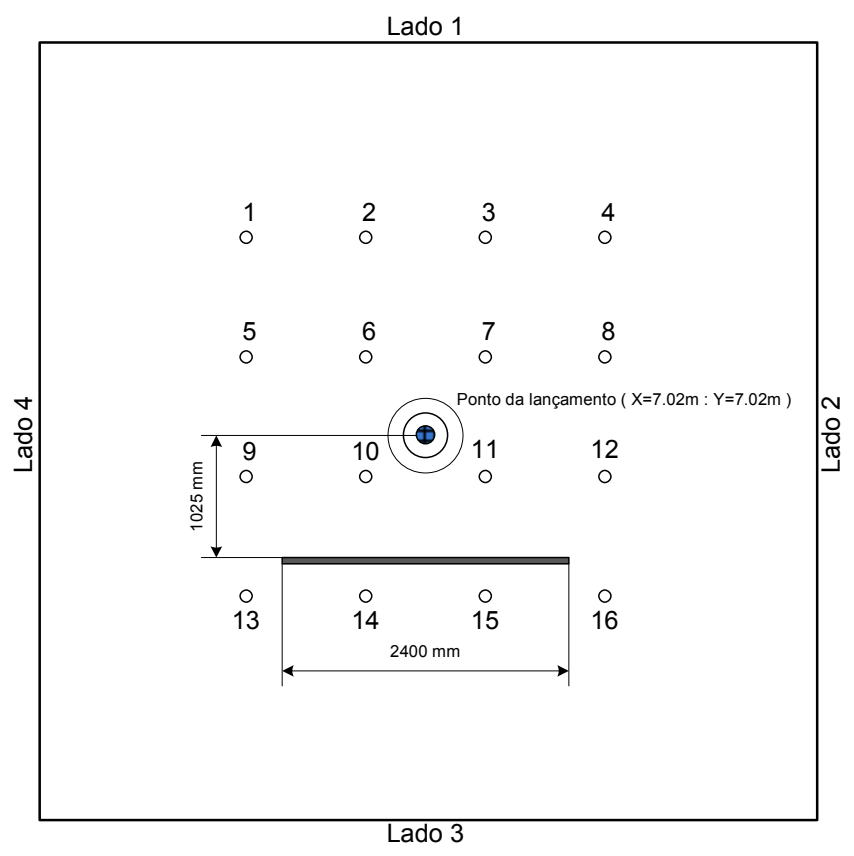

Figura 6.42. Arranjo experimental de lançamento (sem escala).

A Figura 6.43 mostra dois instantes de um lançamento com a antepara presente no tanque de provas. Como o estudo agora tem o objetivo de verificar a focalização reversa de ondas com obstáculos, os lançamentos foram repetidos com o gerador de ondas ativado uma lateral por vez, alguns batedores por vez e ao final com todas as laterais. A Tabela 6.22 mostra os testes realizados. 

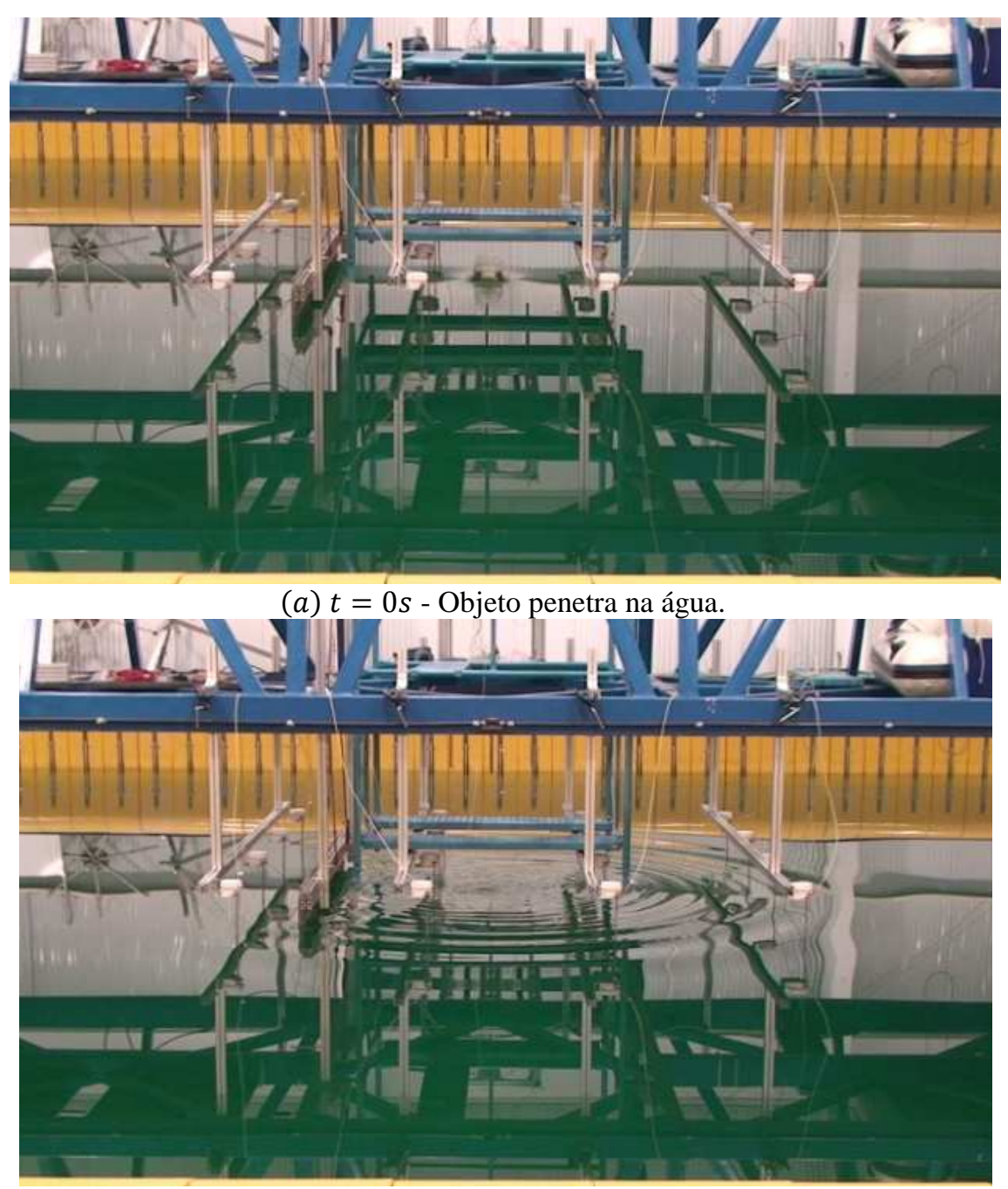

(b) $t=4,6 s$ - Onda gerada reflete na antepara.

Figura 6.43. Lançamento 04a com a antepara presente no tanque de provas.

O lançamento 4 foi repetido também com um número reduzido de batedores na lateral 3 para avaliar o efeito da antepara obstruindo a propagação da onda criada, que nesse caso reflete para as outras laterais do tanque e só depois incide nesta região. A Figura 6.44 mostra a leitura dos sensores capacitivos no lançamento 4. Nota-se que nos sensores à frente da antepara existe um "pacote" de ondas mais alongado e maior, enquanto que os posteriores (entre o ponto de lançamento e a antepara) apresentam uma leitura bastante pequena. Isto mostra que está coerente com a Figura $6.43 \mathrm{~b}$, dado que a antepara bloqueia a passagem das ondas e reflete para outras direções as ondas produzidas. 
Tabela 6.22. Características dos testes de lançamento de objeto na água.

\begin{tabular}{|c|c|c|c|c|}
\hline Nome do teste & Altura & Estado dos WPC & Estado dos WPU & Estado do gerador \\
\hline LAN03 & $0,5 \mathrm{~m}$ & Adquirindo & Adquirindo & Não utilizado \\
\hline LAN03a & $0,5 \mathrm{~m}$ & Adquirindo & Adquirindo & Não utilizado \\
\hline LAN04 & $1,0 \mathrm{~m}$ & Adquirindo & Adquirindo & Não utilizado \\
\hline LAN04a & $1,0 \mathrm{~m}$ & Adquirindo & Adquirindo & Não utilizado \\
\hline TR de LAN03 L1 & - & Adquirindo & Não utilizado & Atuando flaps 1 a 39 \\
\hline TR de LAN03 L2 & - & Adquirindo & Não utilizado & Atuando flaps 40 a 74 \\
\hline TR de LAN03 L3 & - & Adquirindo & Não utilizado & Atuando flaps 75 a 113 \\
\hline TR de LAN03 L4 & - & Adquirindo & Não utilizado & Atuando flaps 114 a 148 \\
\hline TR de LAN03 L1 a L4 & - & Adquirindo & Não utilizado & Atuando flaps 1 a 148 \\
\hline TR de LAN04 L1 & - & Adquirindo & Não utilizado & Atuando flaps 1 a 39 \\
\hline TR de LAN04 L2 & - & Adquirindo & Não utilizado & Atuando flaps 40 a 74 \\
\hline TR de LAN04 L3 & - & Adquirindo & Não utilizado & Atuando flaps 75 a 113 \\
\hline TR de LAN04 L4 & - & Adquirindo & Não utilizado & Atuando flaps 114 a 148 \\
\hline TR de LAN04 L1 a L4 & - & Adquirindo & Não utilizado & Atuando flaps 1 a 148 \\
\hline TR de LAN04 L3R & - & Adquirindo & Não utilizado & Atuando flaps 92 a 97 \\
\hline TR de LAN04 L3F94 & - & Adquirindo & Não utilizado & Atuando flap 94 \\
\hline
\end{tabular}
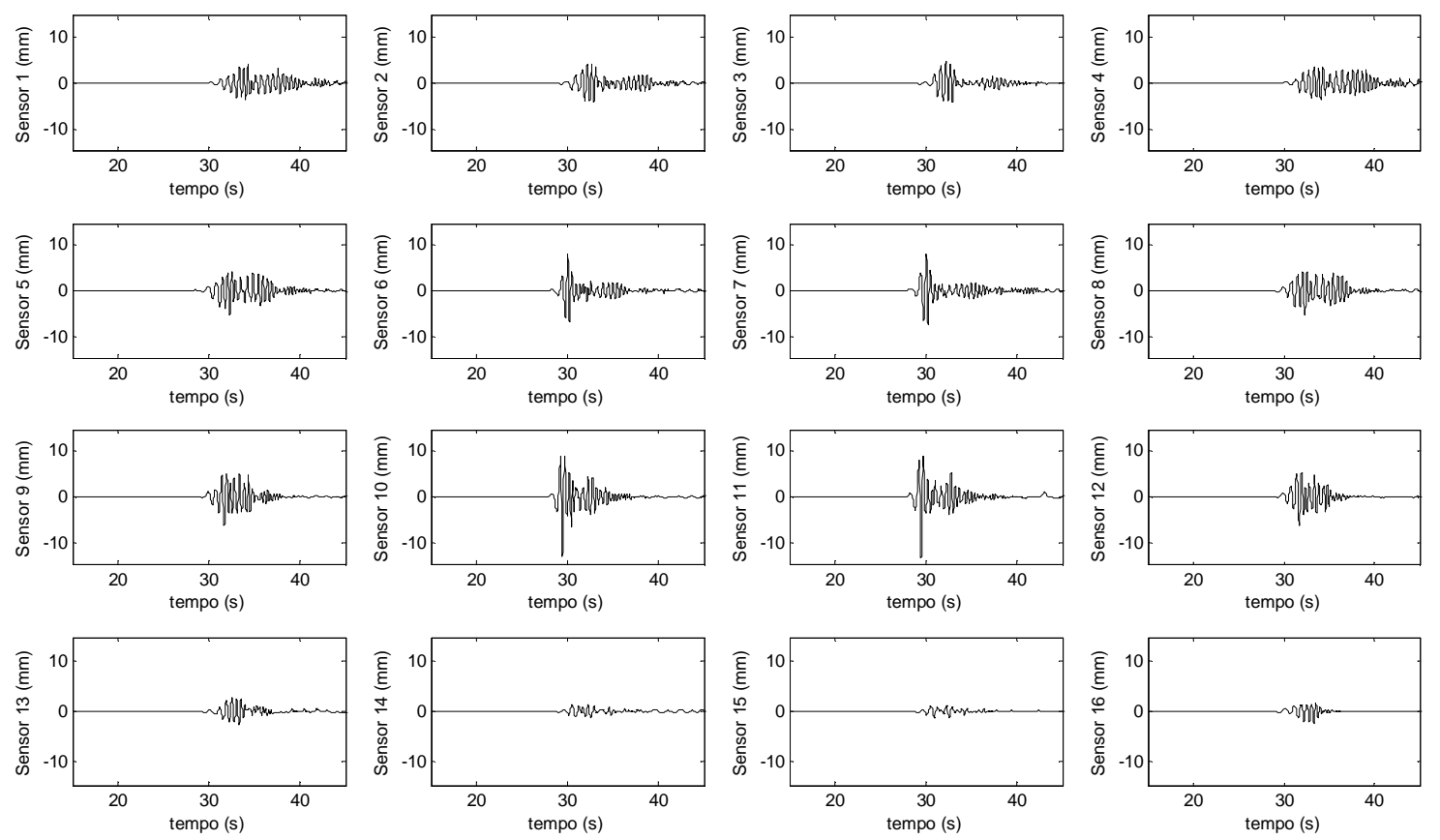

Figura 6.44. Onda lida nos sensores capacitivos do lançamento 04. 
A Figura 6.45 mostra a leitura dos sensores de ondas dos batedores e sustenta o resultado observado no parágrafo anterior. Os sensores da lateral 1 apresentam as maiores alturas de ondas e a lateral 3 as menores. As laterais pares alternam este resultado; quanto mais próximo da lateral 1, maior é a altura de onda nas laterais pares. Como os resultados dos novos lançamentos se repetem, foram feitas repetições reversas apenas da primeira execução do lançamento (veja na Tabela 6.22).
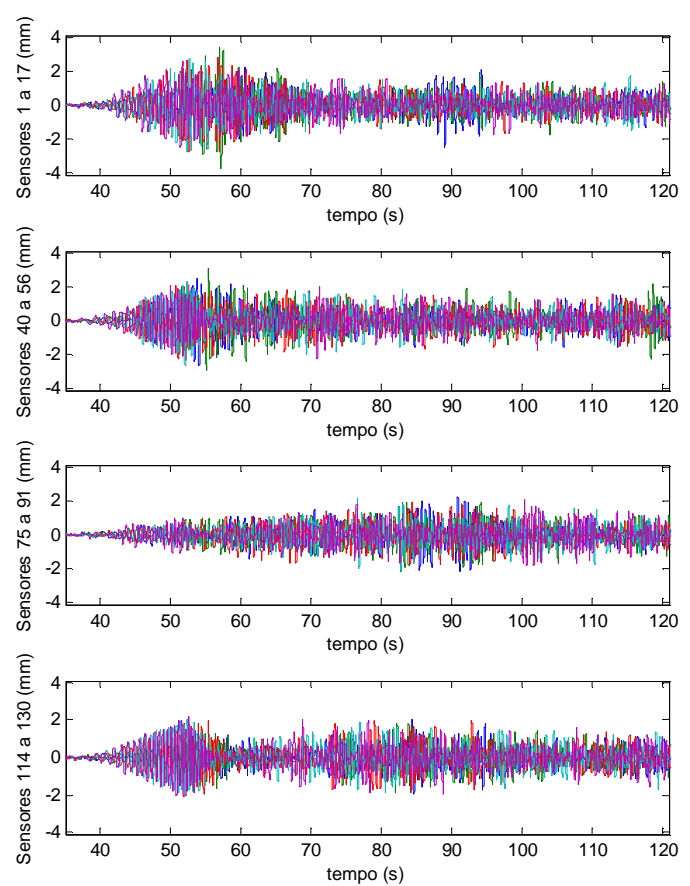
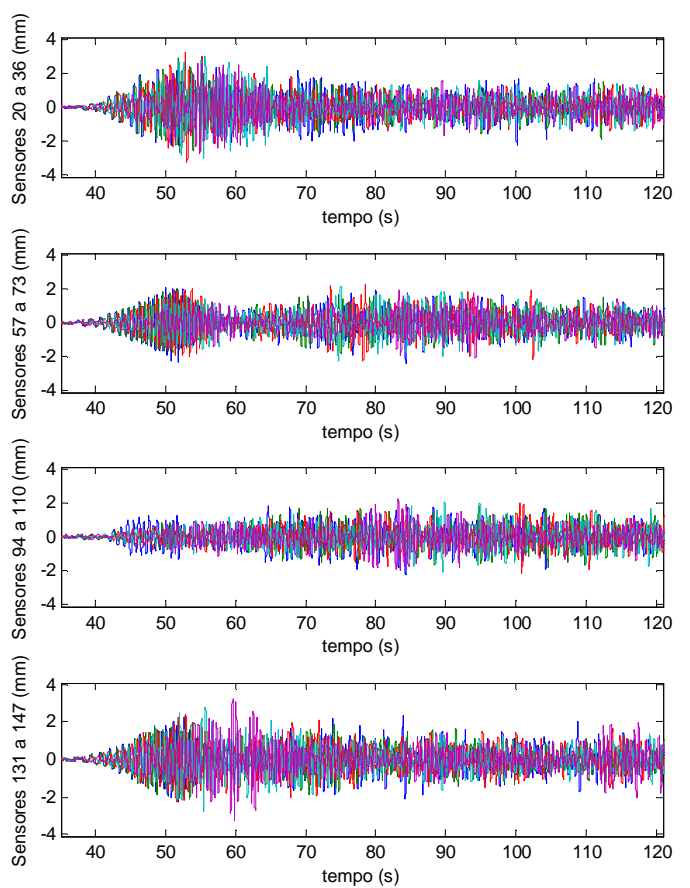

Figura 6.45. Onda do lançamento 4 adquirida nos sensores de ondas ultrassônico.

Nos testes de TR (reversão temporal) foram usados 86 segundos (veja na Figura 6.45) dos sinais dos sensores de ondas para garantir que tenham ocorrido múltiplas reflexões de ondas no interior do tanque, ou seja, "reverberação". No ponto de concentração foi posicionado o sensor de ondas 11 (WP11) para medir a onda. Este foi realocado para tal finalidade. É necessário neste teste um sincronismo entre o gerador de ondas e o sistema de aquisição da HBM para adquirir os sinais nos sensores capacitivos sincronamente com o deslocamento produzido. Para tanto, o canal do sensor 4 (WP4) foi usado como sincronismo; a onda nesta posição deixou de ser medida. O arranjo experimental pode ser visto na Figura 6.46. 


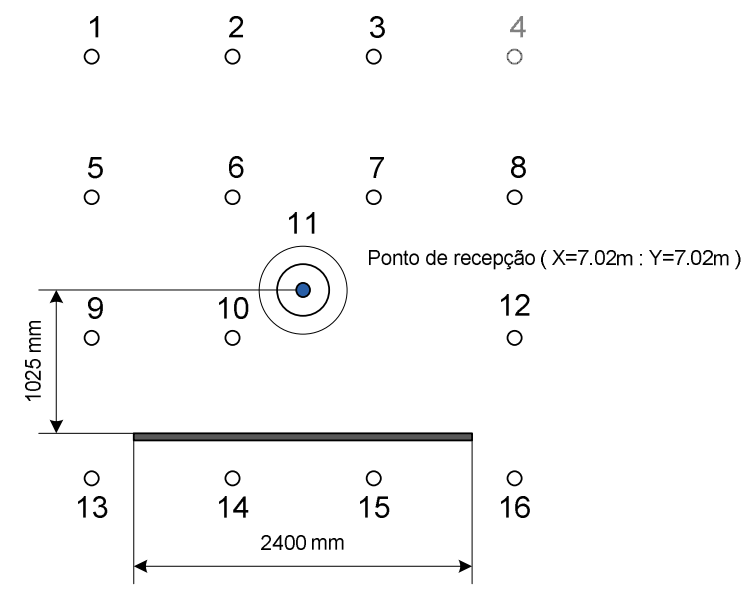

Figura 6.46. Ponto de recepção dos lançamentos 3 e 4 com o WP11 medindo a onda concentrada.

Pode ser observado na Figura 6.47 que ocorre a concentração no instante $t_{c}=$ $86,46 s$ com elevada altura de ondas no sensor 11 . Nos outros sensores não existe elevação neste instante, o que mostra que toda a energia de ondas está concentrada no ponto de foco, pois é neste instante que as fases de todas as frequências do sistema são zero e o módulo é máximo.

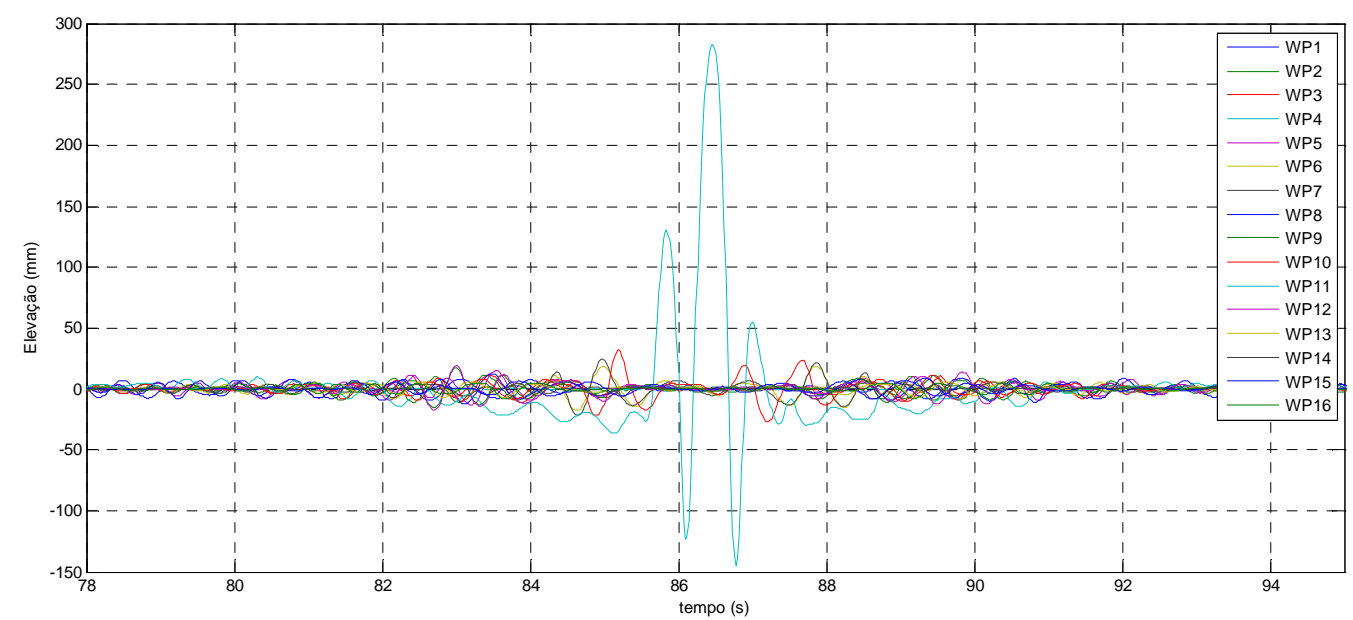

Figura 6.47. Elevação de ondas nos sensores de ondas na reversão temporal do lançamento 04.

Avaliando a leitura do sensor 11 para as diversas laterais, observa-se que ocorre a concentração sempre no mesmo instante de tempo. A Figura 6.48 mostra este resultado no lançamento 4. A altura da onda difere em função da lateral e do número de batedores envolvidos, mas o instante no tempo é o mesmo. 


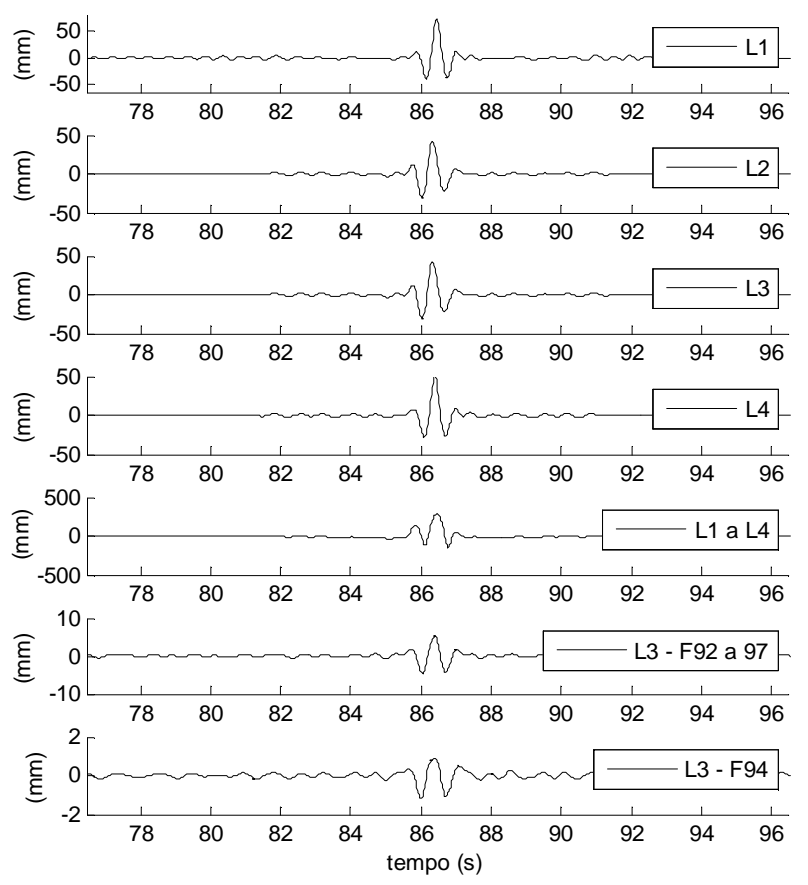

Figura 6.48. Elevação de onda no sensor 11 no instante da focalização em todos os testes do lançamento 4.

A Tabela 6.23 compara a onda focalizada nas diferentes realizações. As colunas são, respectivamente, da esquerda para a direita: o nome, a altura máxima medida na amostra, a amplitude de pico da concentração, o instante da concentração e a largura da amplitude máxima entre dois zeros consecutivos.

Tabela 6.23. Resultado da aplicação de TR aos lançamentos 3 e 4.

\begin{tabular}{|c|c|c|c|c|}
\hline Nome & $\boldsymbol{H}_{\boldsymbol{m a x}}(\mathrm{mm})$ & $\boldsymbol{A}_{\boldsymbol{m a x}}(\mathrm{mm})$ & $\boldsymbol{t}_{\boldsymbol{c}}(\mathrm{s})$ & $\boldsymbol{\Delta t}_{\boldsymbol{c}}(\mathrm{s})$ \\
\hline TR de LAN03 L1 & 64,12 & 42,17 & 85,16 & 0,322 \\
\hline TR de LAN03 L2 & 39,44 & 25,10 & 85,15 & 0,327 \\
\hline TR de LAN03 L3 & 30,54 & 17,66 & 85,23 & 0,382 \\
\hline TR de LAN03 L4 & 43,49 & 26,94 & 85,15 & 0,320 \\
\hline TR de LAN03 L1 a L4 & 255,30 & 175,40 & 85,25 & 0,394 \\
\hline TR de LAN04 L1 & 112,63 & 74,24 & 86,45 & 0,336 \\
\hline TR de LAN04 L2 & 66,67 & 43,21 & 86,33 & 0,347 \\
\hline TR de LAN04 L3 & 61,13 & 37,62 & 86,40 & 0,360 \\
\hline TR de LAN04 L4 & 79,39 & 51,82 & 86,40 & 0,325 \\
\hline TR de LAN04 L1 a L4 & 428,55 & 282,90 & 86,46 & 0,473 \\
\hline TR de LAN04 L3R & 9,52 & 5,24 & 86,40 & 0,363 \\
\hline TR de LAN04 L3F94 & 1,95 & 0,86 & 86,40 & 0,403 \\
\hline
\end{tabular}


Pode-se concluir pelo resultado que a focalização utilizando o procedimento descrito foi atingida. Quando realizada uma lateral por vez, a sequência crescente entre as laterais se mantém nas duas alturas de lançamento. Existe uma diferença entre as laterais pares; a lateral 4 tem altura maior com os dois lançamentos realizados. A lateral 1, que recebeu mais ondas diretamente, resulta em alturas maiores na reversão. A altura resultante da lateral 3 é menor devido à obstrução da antepara.

No geral, a altura observada com todas as laterais ativas não é a soma das laterais individuais. Isto porque quando cada lateral gera a onda, ela reflete nas laterais restantes e aí sim propaga para a posição de focalização. É dessa forma que a lateral 3 atinge a posição de focalização, visto que com apenas um batedor (flap 94) a focalização é obtida. Estas múltiplas reflexões só são possíveis usando um trecho temporal longo o suficiente para que indiretamente o foco ocorra. Neste caso, foi utilizado um trecho de 86 segundos. Por esse motivo a soma das alturas de cada lateral não resulta na altura com todas as laterais ativas. Com as múltiplas reflexões ocorridas no interior do tanque, cada vez que a onda reflete em um batedor a elevação lida no sensor da face do batedor resulta em uma elevação que será revertida no tempo, amplificando a reversão temporal.

Comparando com a focalização dos lançamentos 1 e 2, embora exista a antepara no tanque e a medição de onda realizada agora seja indireta, as alturas aqui são maiores, pois foi usado mais tempo; anteriormente foi utilizado um trecho temporal de 20 segundos, em que a reverberação era menor. Em acústica de ultrassom em cavidades metálicas, o tamanho do trecho temporal utilizado na realização de TR contendo reverberação é assunto de discussão na literatura. Neste trabalho, fica a sugestão para que somente em pesquisas futuras isso seja feito, devido à grande demanda de tempo para a realização de tais testes sistemáticos.

O instante temporal em que ocorre a concentração foi semelhante para cada lateral ativa nos testes, como mostrado na Figura 6.48, confirmando as expectativas quanto ao resultado do ensaio. Quanto à largura da maior crista, a lateral 3, por estar obstruída pela antepara, era a maior, pois era obtida por trajetórias indiretas entre a lateral e o ponto de foco. Quando todas as laterais estão ativas, a largura também é maior, devido principalmente à elevada altura de onda concêntrica atingida. 


\subsubsection{Fonte impulsiva com um ponto de recepção indireto}

$\mathrm{O}$ teste de emissão usando um batedor de ondas como origem foi feito na sequência do tópico 6.4.1.2. O arranjo experimental foi o mesmo da Figura 6.46; a diferença fica por conta de que a origem da perturbação na água é agora o batedor de ondas número 1. A função sinc foi usada como fonte de perturbação no deslocamento do batedor. A amplitude foi de $40 \mathrm{~mm}$ com faixa de frequência de 0,001 a 3,5 Hz. A Figura 6.49 mostra a série temporal e o espectro de frequências da função aplicada.

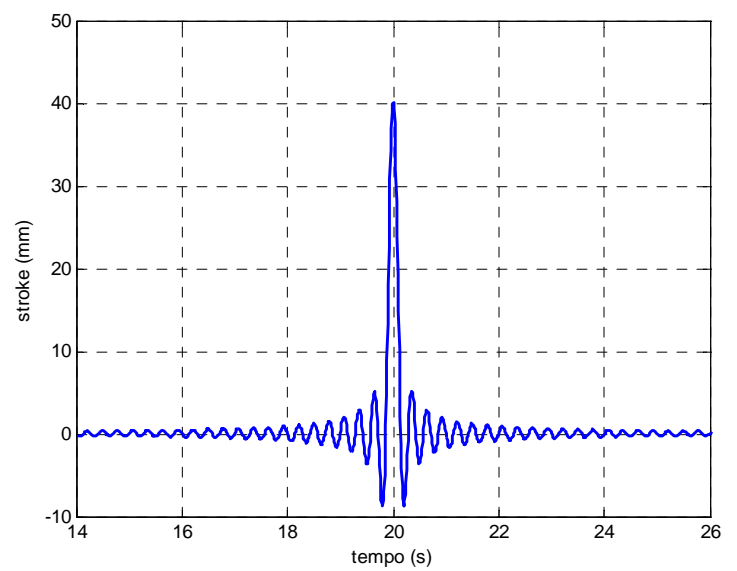

Valor comandado (delta de dirac "aproximado").

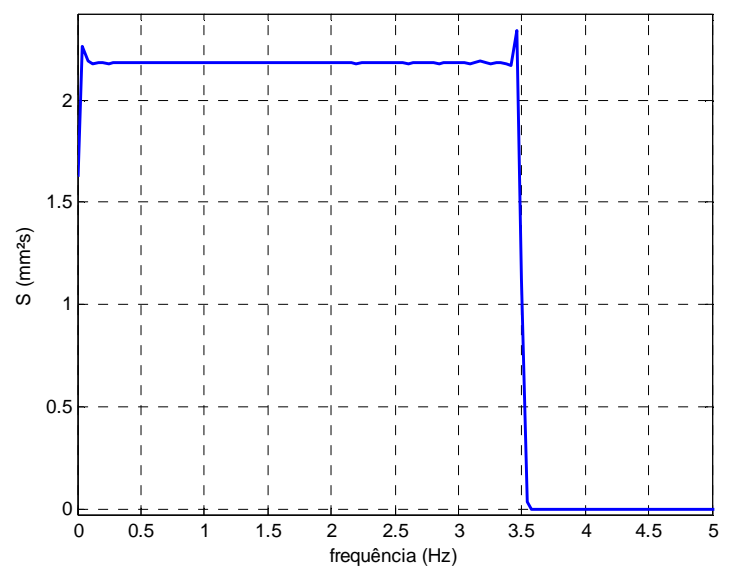

Espectro em frequências do delta de dirac.

Figura 6.49. Função sinc.

A função sinc, ao ser aplicada no gerador de ondas, vai ter sua resposta afetada pela função de transferência dinâmica mecânica (descrita no tópico 6.1), ocasionando perdas no módulo e atraso na fase. A resposta dinâmica afetará a onda na água. A onda irá propagar até a posição do sensor de ondas. Por sua vez, o sensor de ondas capacitivo tem sua resposta característica (descrita no tópico 4.6). Quando a reversão temporal for feita com o batedor como origem e novamente o sensor capacitivo como receptor, todos os atrasos serão compensados e espera-se ter a função impulso original criada na posição do sensor de ondas. O módulo, como foi discutido anteriormente, sofrerá atenuação da resposta dinâmica mecânica, alteração em função da resposta dinâmica de ondas progressivas no batedor, atenuação em função da resposta dinâmica do sensor de ondas e efeitos causados na propagação da onda.

Os efeitos da propagação da onda são causados, como foi dito no tópico 6.4.1.2, pelo tamanho do trecho temporal alterando a "reverberação" e a disposição física dos 
elementos no tanque de provas. Dessa forma, foi escolhido o sensor número 15 (WP15) como ponto de recepção, pois este se encontra na "sombra" da antepara. As ondas tiveram, portanto, que percorrer o tanque refletindo diversas vezes nas laterais até atingirem o sensor de ondas no momento da reversão temporal. Os testes foram conduzidos segundo a Tabela 6.24. Primeiramente foi feito o impulso no flap 1 do gerador. A seguir a resposta medida foi revertida. Como o nível do sinal era muito pequeno (visto na Figura 6.51), este foi corrigido para que tivesse o mesmo valor $r m s$ do impulso inicial; para tanto foi aplicado um ganho ao sinal de $A=18,75$ vezes. Após esta execução foi feita outra com o valor 5 vezes maior. A Figura 6.50 mostra o deslocamento executado nos três testes e a Figura 6.51 as três leituras realizadas pelo sensor de ondas 15. A Figura 6.52 mostra o espectro de densidade de energia no sensor 15 do teste T01. Nota-se que houve grande atenuação da onda propagada em relação ao impulso no batedor e que acima de $2,5 \mathrm{~Hz}$ há muito pouca energia de ondas.

Tabela 6.24. Características dos testes com fonte impulsiva.

\begin{tabular}{|c|c|c|c|c|c|}
\hline Nome & Stroke $_{\text {rms }}$ & $\begin{array}{c}\text { Estado do } \\
\text { gerador }\end{array}$ & $\begin{array}{c}\text { Estado dos } \\
\text { WPC }\end{array}$ & $\begin{array}{c}\text { Trecho temporal usado } \\
\text { para TR }\end{array}$ & $\begin{array}{c}\text { Estado dos } \\
\text { WPU }\end{array}$ \\
\hline T01 & $2,402 \mathrm{~mm}$ & Flap 1 atuando & Adquirindo & -- & Não utilizado \\
\hline T02 & $2,402 \mathrm{~mm}$ & Flap 1 atuando & Adquirindo & $\begin{array}{c}\text { Trecho de 24 a 186 } \\
\text { segundos de T01 } \\
\text { reverso no tempo }\end{array}$ & Não utilizado \\
\hline T03 & $12,011 \mathrm{~mm}$ & Flap 1 atuando & Adquirindo & $\begin{array}{c}\text { Trecho de 24 a 186 } \\
\text { segundos de T01 } \\
\text { reverso no tempo }\end{array}$ & Não utilizado \\
\hline
\end{tabular}
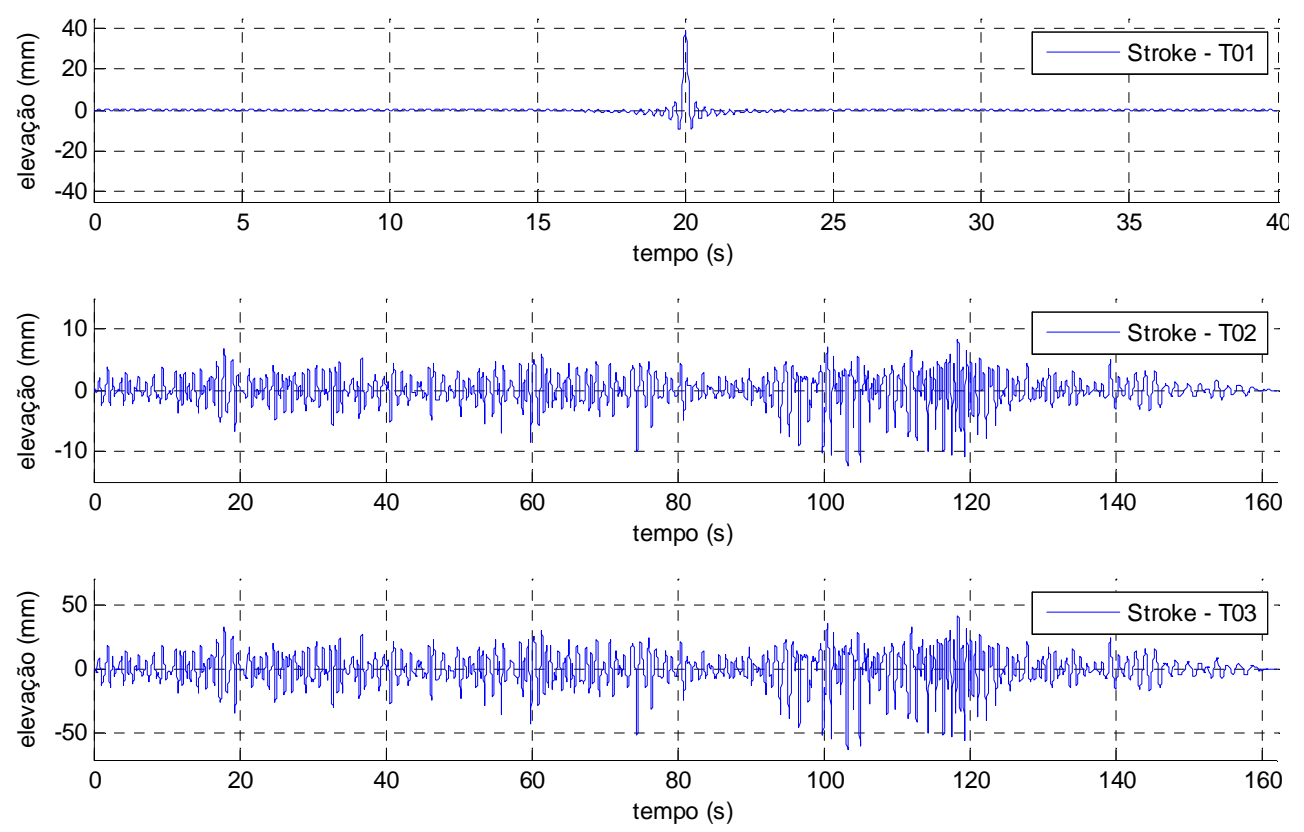

Figura 6.50. Deslocamento executado no flap 1. 

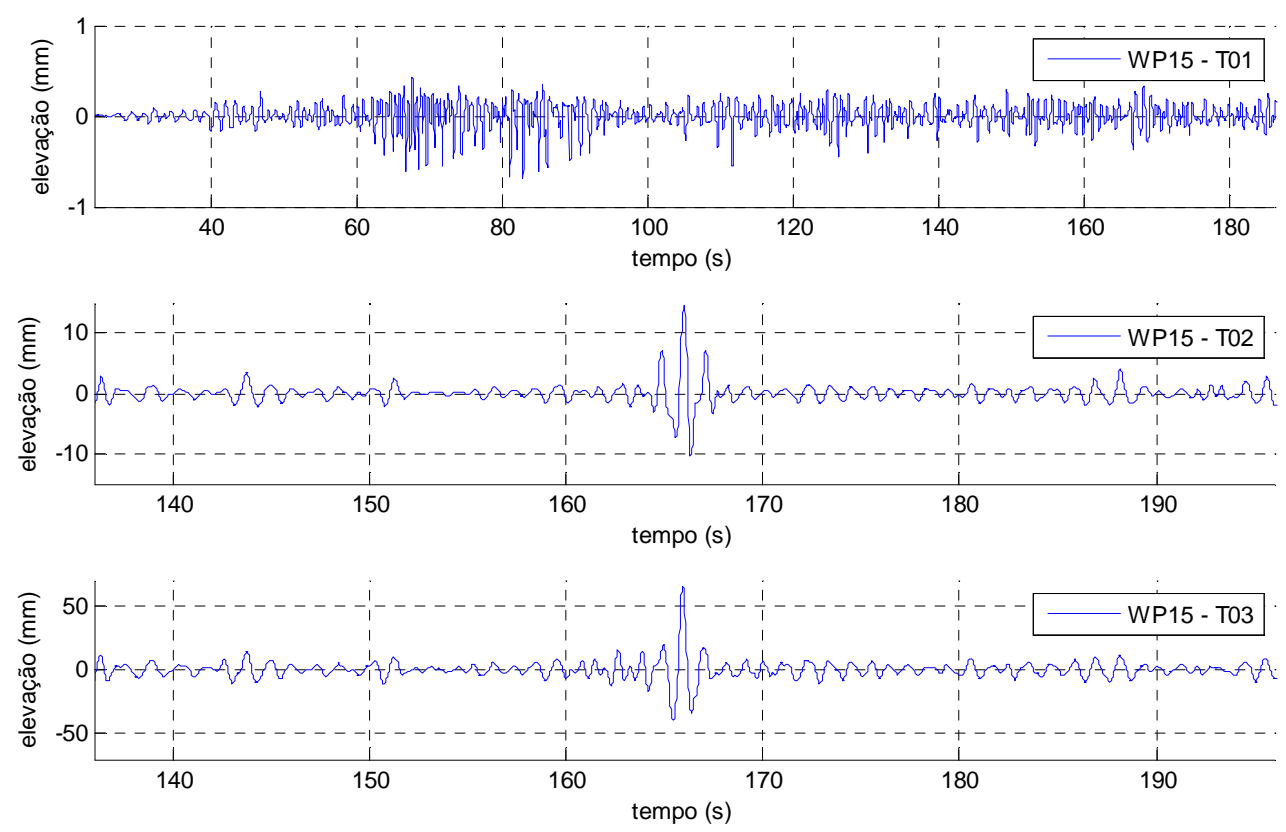

Figura 6.51. Leitura do sensor de ondas 15 (WP15).

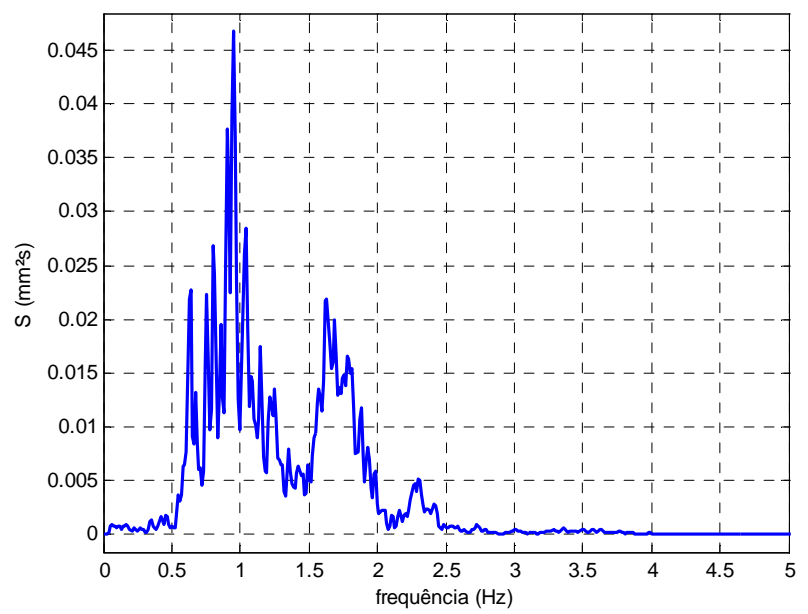

Figura 6.52. Espectro do impulso sinc feito no batedor 1 visto nos sensores WP15 (trecho de 24 a 186 segundos do sensor).

A concentração de ondas experimental ocorre no instante 166 segundos. Como a perturbação foi emitida no flap em $t=20 \mathrm{~s}$, embora o trecho temporal usado fosse de $t_{i}=24 \mathrm{~s}$ a 186s, o instante de concentração é $t_{c}=186-20=166 \mathrm{~s}$. O tempo de concentração será o intervalo de tempo entre o impulso e o instante final do registro da série temporal adquirida. Neste caso foi descartado o trecho entre 20 e 24 segundos, pois não existia elevação de onda no registro, o que não afeta o instante da concentração. A Tabela 6.25 mostra o resultado obtido no sensor 15 nos três testes. 
Tabela 6.25. Resultados dos testes com fonte impulsiva no WP15.

\begin{tabular}{|c|c|c|c|c|c|}
\hline Nome do teste & $\boldsymbol{W P 1 5}_{\boldsymbol{r m s}}(\mathbf{m m})$ & $\boldsymbol{H}_{\boldsymbol{m a x}}(\mathbf{m m})$ & $\boldsymbol{A}_{\boldsymbol{m a x}}(\mathbf{m m})$ & $\boldsymbol{t}_{\boldsymbol{c}}(\mathbf{s})$ & $\boldsymbol{\Delta t}_{\boldsymbol{c}}(\mathbf{s})$ \\
\hline T01 & 0,1281 & 0,9557 & 0,4372 & -- & -- \\
\hline T02 & 1,365 & 25,118 & 14,674 & 166,00 & 0,437 \\
\hline T03 & 5,964 & 99,553 & 65,418 & 165,93 & 0,482 \\
\hline
\end{tabular}

Nota-se que a altura de ondas máxima e a amplitude de onda máxima não são proporcionais ao ganho de 5 vezes aplicado entre os ensaios T02 e T03, indicando que entre os ensaios a resposta não é mais linear, embora continue ocorrendo a concentração de energia nos ensaios.

A Figura 6.53 mostra 3 instantes do vídeo realizado nos testes. Foi observado que surgiram duas frentes de ondas em sentidos opostos lateralmente à antepara, instantes antes de a concentração de ondas ocorrer no sensor 15. Quando as duas frentes chegaram ao sensor, ocorreu o impulso na posição do mesmo, detectado na série temporal adquirida. Em seguida, as duas frentes de ondas dispersaram novamente em sentidos opostos. 


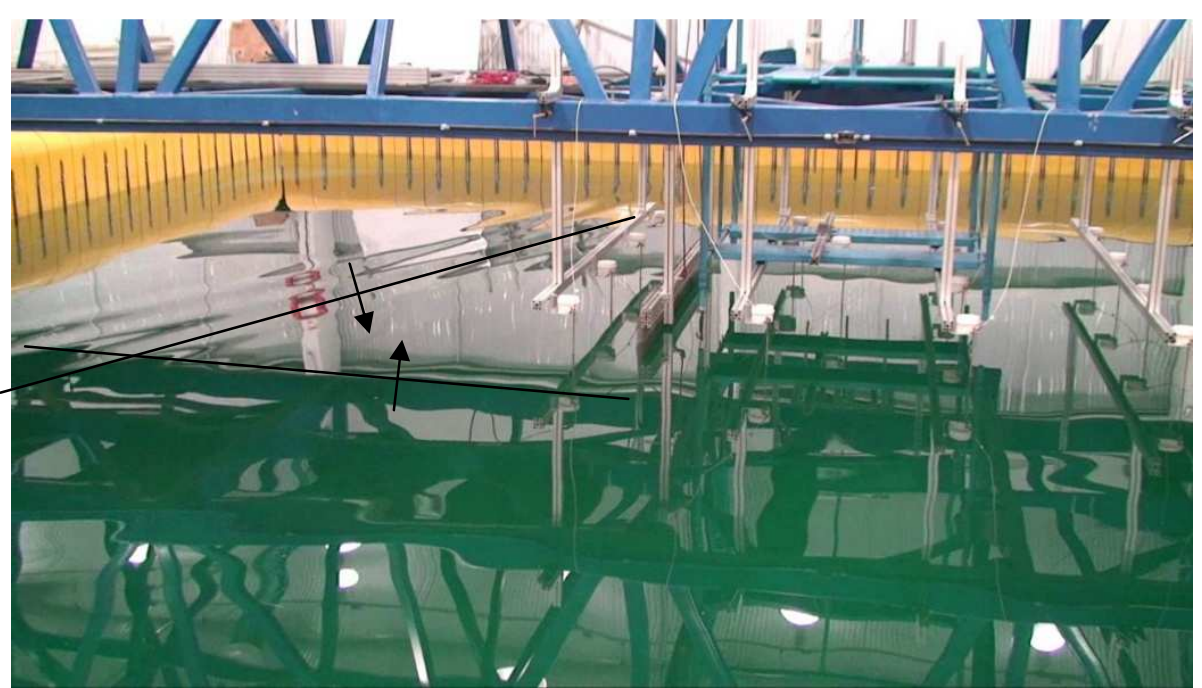

(a) $t=161,0 \mathrm{~s}$
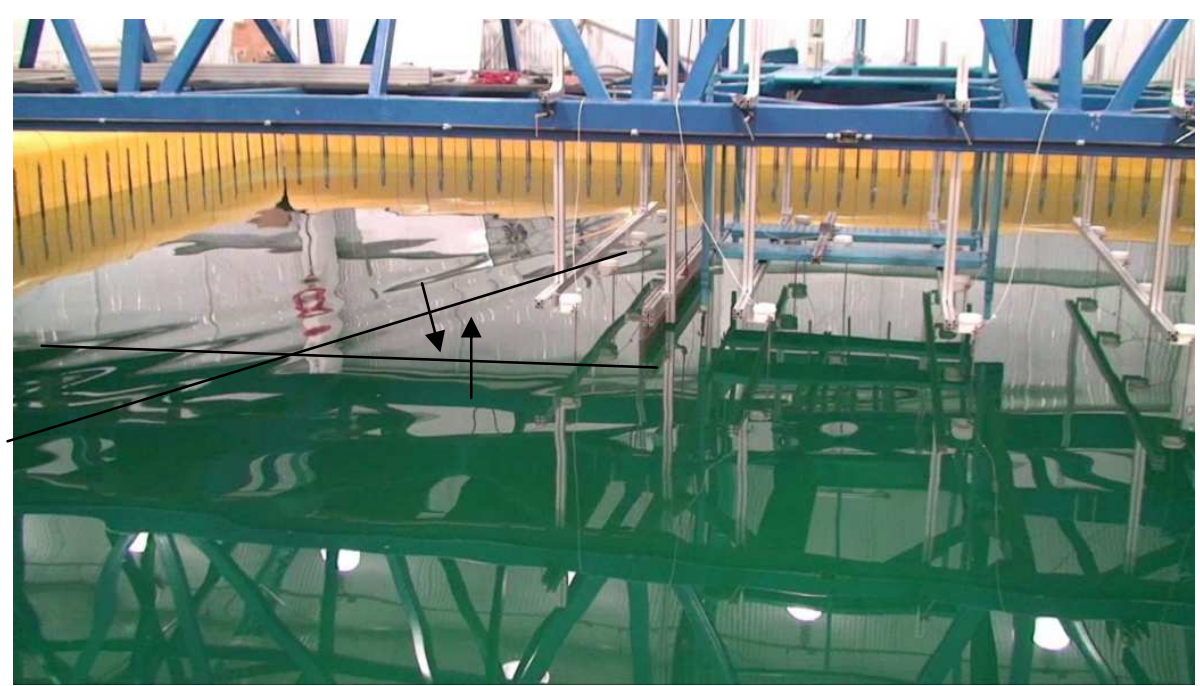

(b) $t=162,7 \mathrm{~s}$

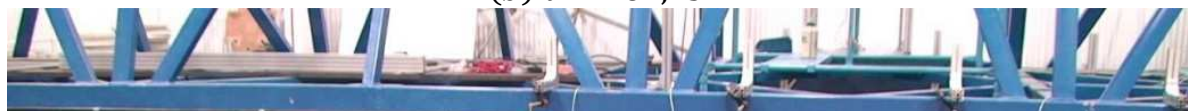

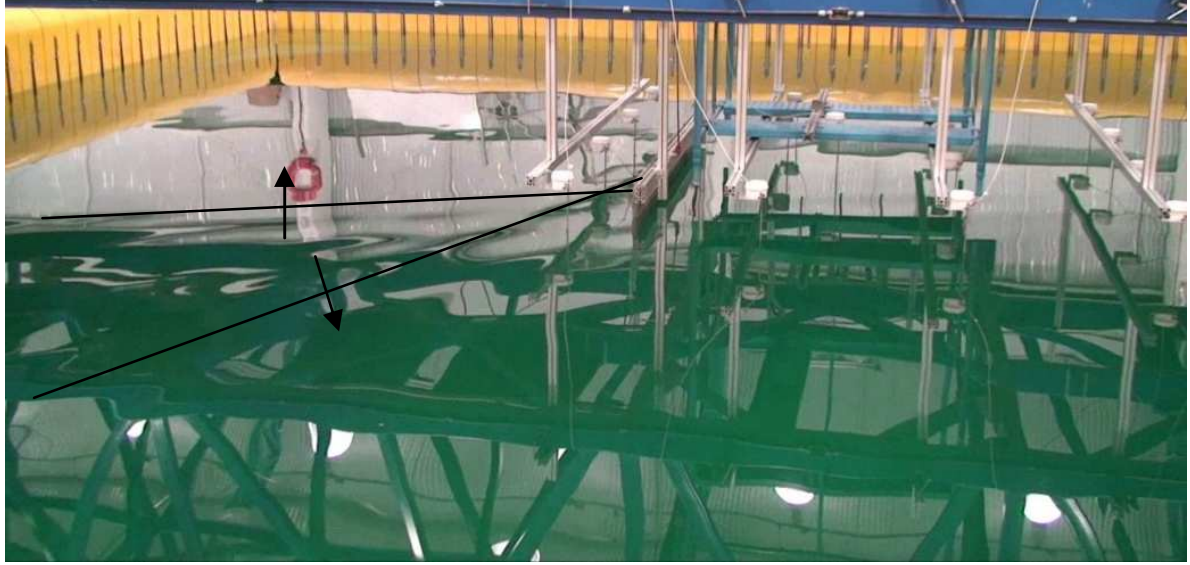

(c) $t=166,0 \mathrm{~s}$

Figura 6.53. Imagem de três instantes da concentração do teste T02 destacando as frentes de ondas incidindo no sensor 15. 


\subsubsection{Fonte impulsiva feita por um par de batedores}

Nestes testes foram realizados experimentos usando os batedores de ondas como fonte e também receptores das perturbações na água. Os sensores capacitivos foram usados para monitorar as ondas no centro do tanque de provas. Um único batedor foi usado para criar a perturbação e a antepara foi usada para obstruir a propagação das ondas no teste com obstáculos. A fonte de perturbação foi a mesma função sinc utilizada nos testes de recepção no sensor capacitivo 15, como mostrou o tópico 6.4.2.

\subsubsection{Tanque de provas sem obstáculo}

Nos experimentos foi usado o aparato mostrado na Figura 6.54. Os sensores capacitivos foram usados para estimar a característica da onda progressiva que atravessou a região central do tanque. O flap 94 recepcionou a perturbação produzida pelo flap 20. A perturbação medida foi revertida no tempo e reenviada novamente no flap 20. Em seguida essa mesma leitura foi reenviada no flap 94; no final, todos os flaps das laterais 2, 3 e 4 foram usados para enviar de forma reversa as suas leituras de perturbação. A Tabela 6.26 mostra os testes realizados.

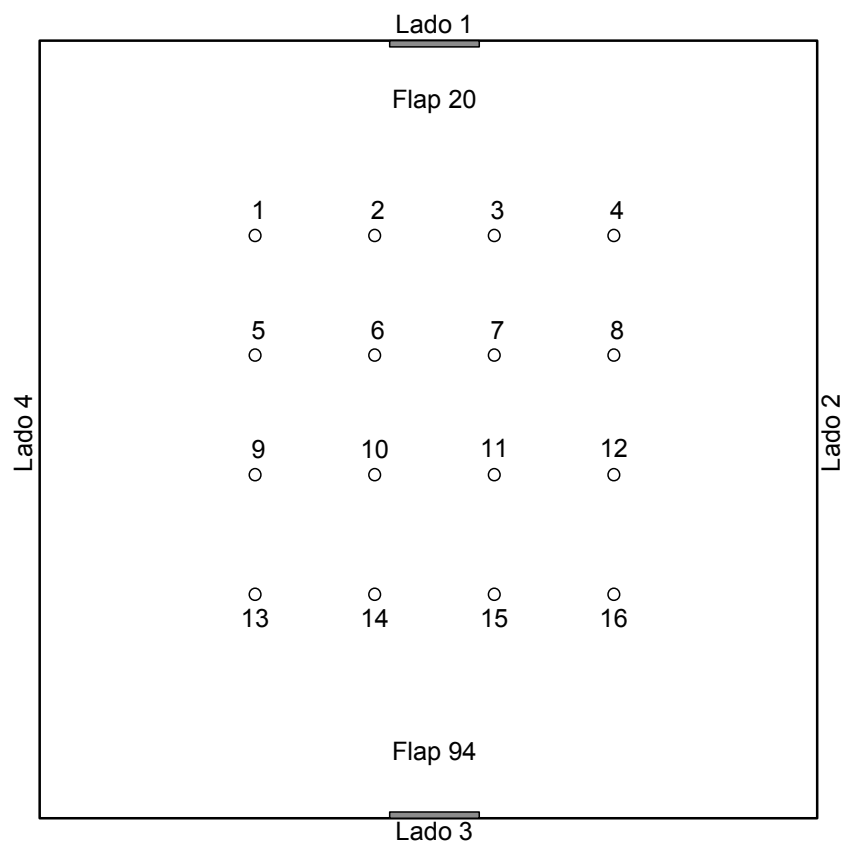

Figura 6.54. Arranjo experimental de emissão usando o batedor 20 (sem escala). 
Tabela 6.26. Testes realizados de emissão e recepção entre batedores de ondas.

\begin{tabular}{|c|c|c|c|c|c|}
\hline Nome & Stroke & $\begin{array}{c}\text { Estado do } \\
\text { gerador }\end{array}$ & $\begin{array}{c}\text { Estado dos } \\
\text { WPC }\end{array}$ & $\begin{array}{c}\text { Trecho temporal } \\
\text { usado para TR }\end{array}$ & $\begin{array}{c}\text { Estado dos } \\
\text { WPU }\end{array}$ \\
\hline EM01 & $2,402 \mathrm{~mm}_{r m s}$ & $\begin{array}{c}\text { Flap } 20 \\
\text { atuando }\end{array}$ & Adquirindo & - & Adquirindo \\
\hline EM01Rev & $2,402 \mathrm{~mm}_{r m s}$ & $\begin{array}{c}\text { Flap } 20 \\
\text { atuando }\end{array}$ & Adquirindo & $\begin{array}{c}\text { Trecho de } 20 \text { a } 65 \\
\text { segundos de EM01 } \\
\text { reverso no tempo }\end{array}$ & Adquirindo \\
\hline EM01Ret & $2,402 \mathrm{~mm}_{r m s}$ & $\begin{array}{c}\text { Flap } 94 \\
\text { atuando }\end{array}$ & Adquirindo & $\begin{array}{c}\text { Trecho de } 20 \text { a } 65 \\
\text { segundos de EM01 } \\
\text { reverso no tempo }\end{array}$ & Adquirindo \\
\hline EM01RetA & WPU reverso & $\begin{array}{c}\text { Flaps } 40 \mathrm{a} \\
148 \text { atuando }\end{array}$ & Adquirindo & $\begin{array}{c}\text { Trecho de 23 a 77 } \\
\text { segundos de EM01 } \\
\text { reverso no tempo }\end{array}$ & Adquirindo \\
\hline
\end{tabular}

Primeiramente a perturbação foi emitida e capturada pelos sensores de ondas. A leitura dos sensores capacitivos foi analisada pelo mesmo método descrito no tópico 6.4.1.1. Mas como dessa vez a emissão foi feita por um batedor de ondas, a função de correção da amplitude de onda era ajustada, segundo Quadrante (2011), por um semicírculo, pois a fonte concêntrica emite sua energia em $180^{\circ}$ em torno do ponto de emissão:

$A_{c}(r)=A_{0} \cdot \frac{1}{\sqrt{\frac{\pi r}{2}}}$

A coordenada do ponto de emissão usada foi a posição do centro dos flaps, ou seja, flap $20(x=0,00 m: y=7,02 m)$ e flap $94(x=14,04 m: y=7,02 m)$. Após realizar a emissão, verificou-se a característica da onda emitida através dos sensores dos batedores da lateral 1 e da leitura dos sensores capacitivos com correção espacial, como é apresentado na Figura 6.55. 

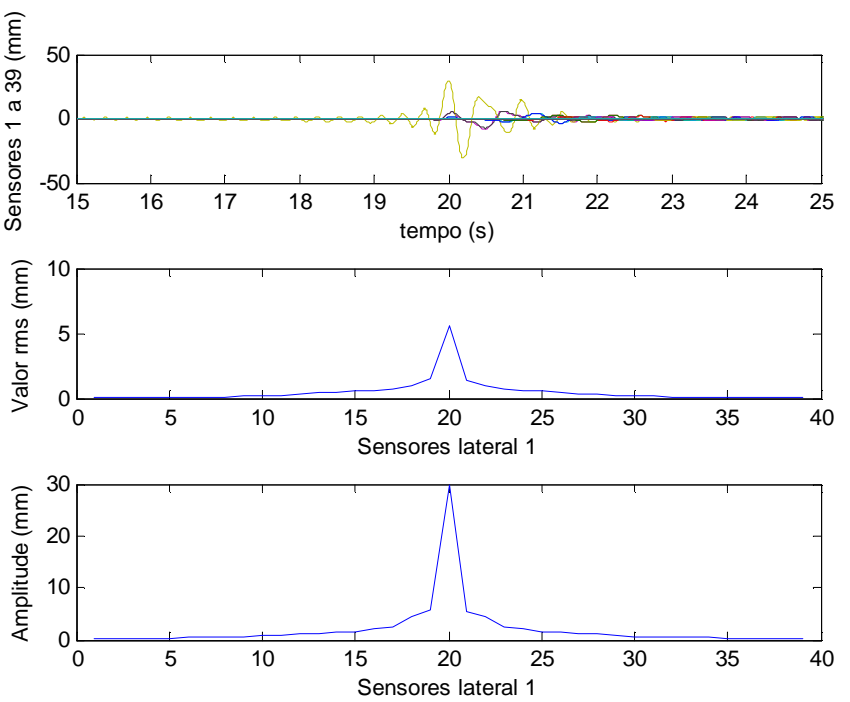

(a) - Resposta de onda impulsiva nos sensores de ondas dos batedores (flap 20 em amarelo)

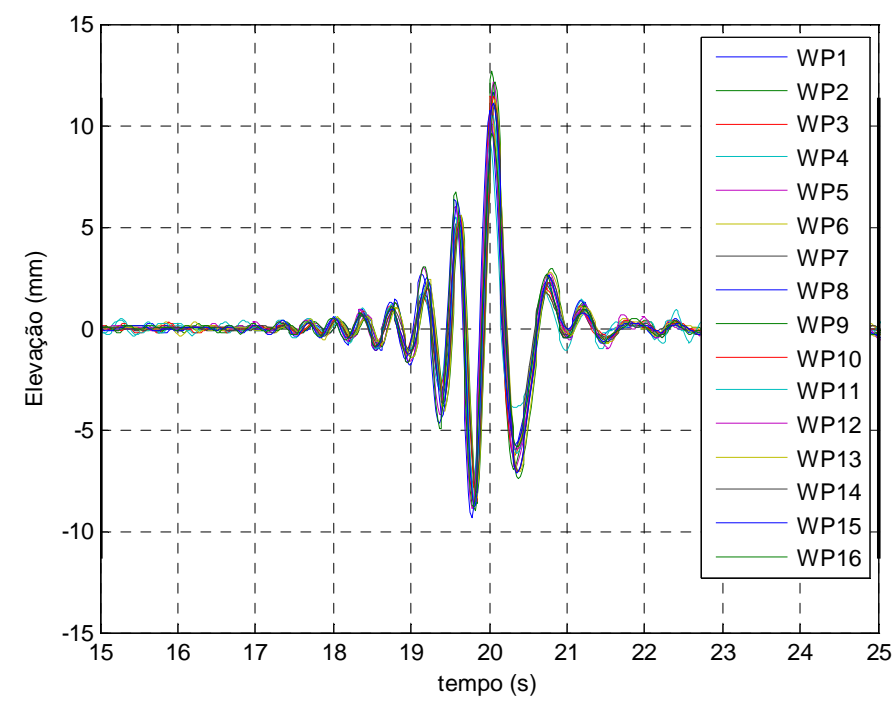

(b) - Resposta impulsiva vista pelos sensores capacitivos

Figura 6.55. Onda impulsiva realizada pelo batedor 20 .

Nota-se que a onda na lateral 1 tem a altura reduzida rapidamente devido à dispersão em frequências e em direção, medida a partir dos sensores laterais ao flap emissor. A elevação de onda lida pelos sensores capacitivos referente à parcela progressiva da onda apresenta baixa dispersão temporal, indicando que a onda propagou a partir do flap concentricamente com direção radial bem definida. A Figura 6.56 mostra a elevação de ondas nos sensores dos batedores de ondas. Nas laterais pares, quanto mais próximo da lateral 1, mais concentrada era a onda; na lateral 3 a dispersão era maior. 

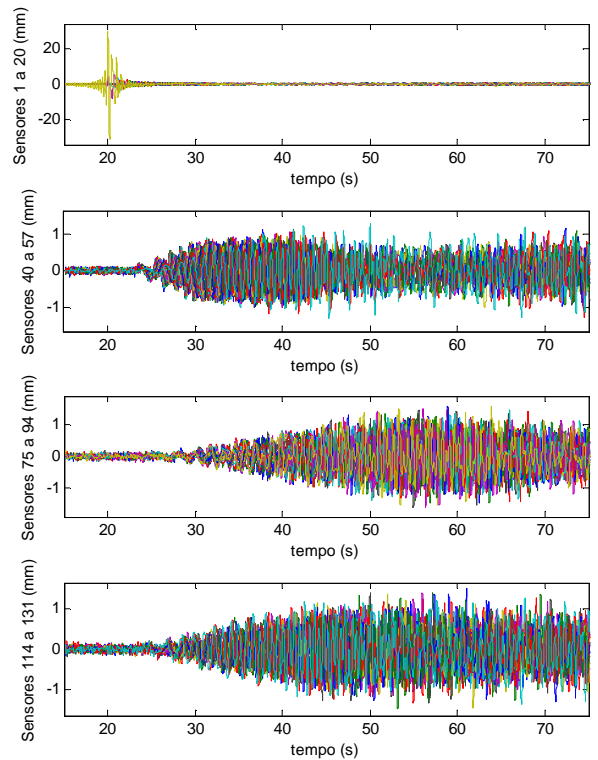
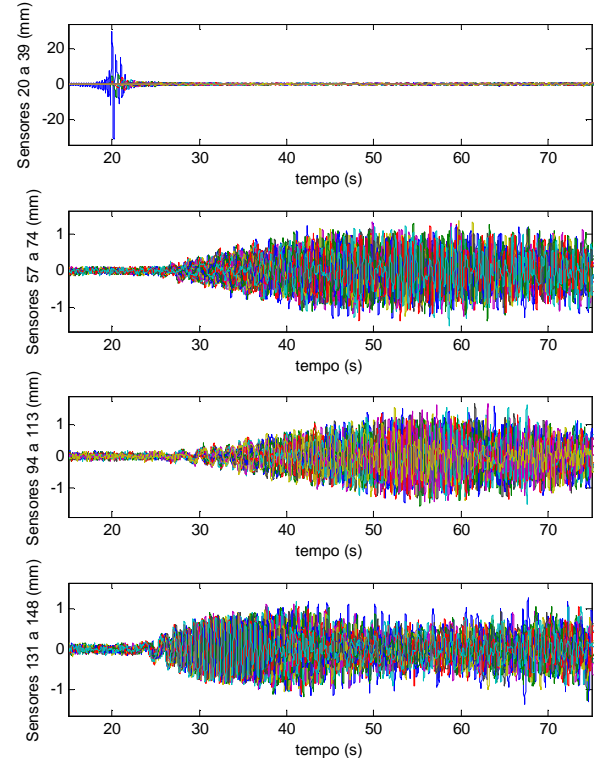

Figura 6.56. Onda emitida no batedor 20 adquirida nos sensores de ondas ultrassônico.

A leitura do sensor do batedor 94 apresentava amplitude máxima de 1,58mm e 0,4977 $\mathrm{mm}_{r m s}$. Um ganho de 4,83 vezes foi aplicado à leitura para que a série temporal revertida de deslocamento tivesse o mesmo valor médio quadrático do impulso sinc original. O deslocamento revertido no tempo foi então repetido no flap 20 e no flap 94 para a realização de dois testes de concentração simétricos. A Figura 6.57 e a Tabela 6.27 mostram esta comparação. As elevações nos batedores de ondas apresentaram resultado inverso entre as realizações (Figura $6.57 a$ e $b$ ). Uma onda em fase, de aproximadamente um quarto do valor da onda concentrada, aparece no batedor do lado emissor. A elevação de onda no batedor não tem o aspecto de uma função sinc, diferentemente dos outros resultados obtidos até então. A amplitude da onda concentrada foi maior na recepção da lateral 1 , apresentando um pico mais pronunciado nos gráficos dessa lateral. 


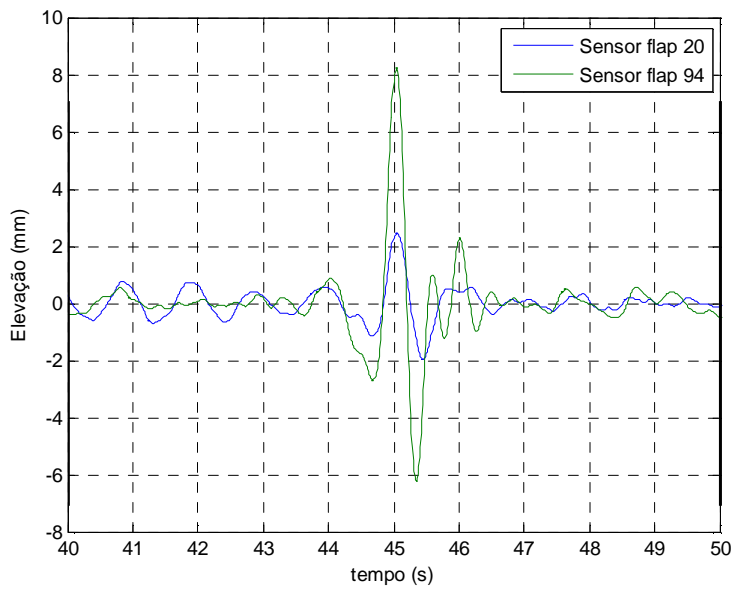

(a) - Elevação no teste EM01Rev
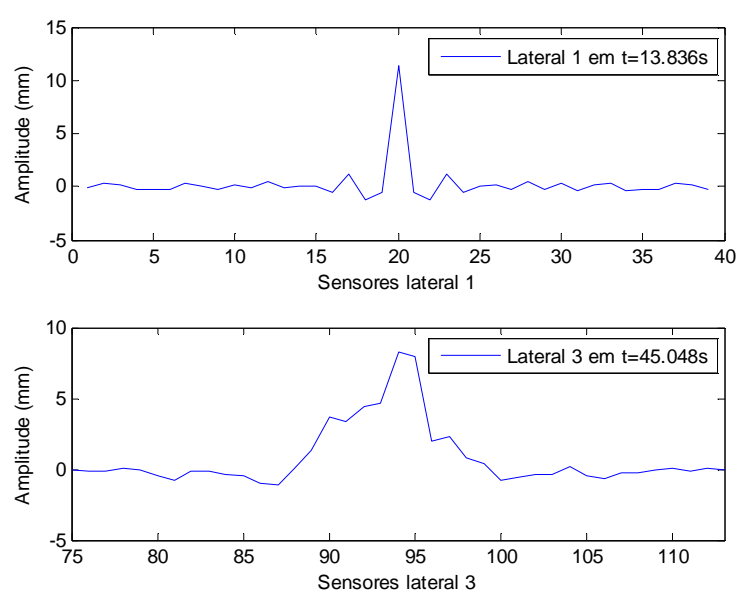

(c) - Elevação nas laterais no instante de máxima elevação nos sensores 20 e 94 no teste EM01Rev

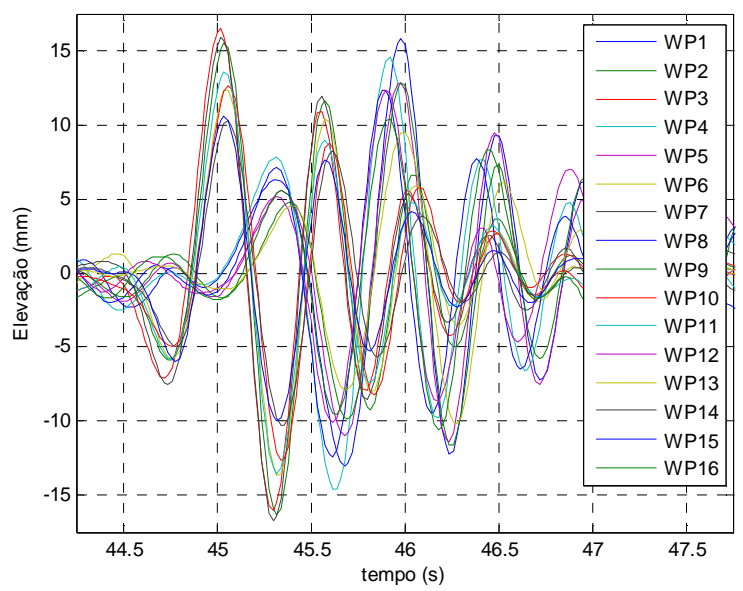

(e) - Elevação nos WPC no teste EM01Rev

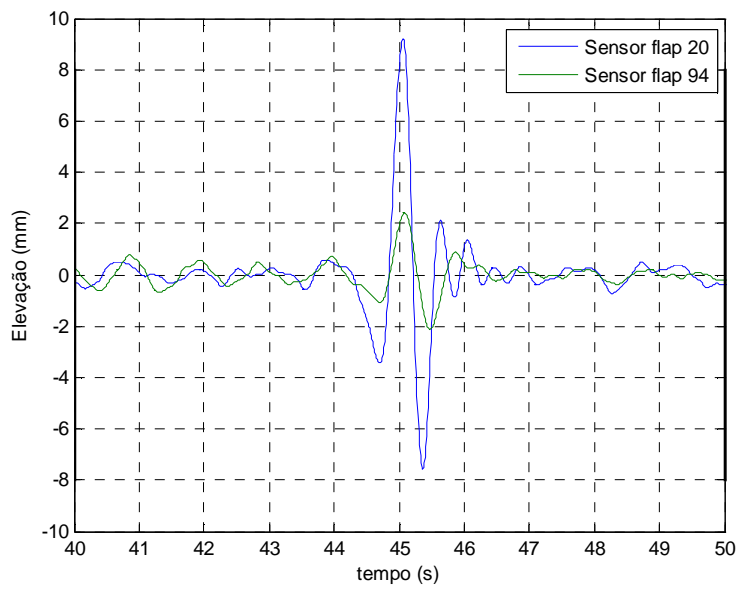

(b) - Elevação no teste EM01Ret
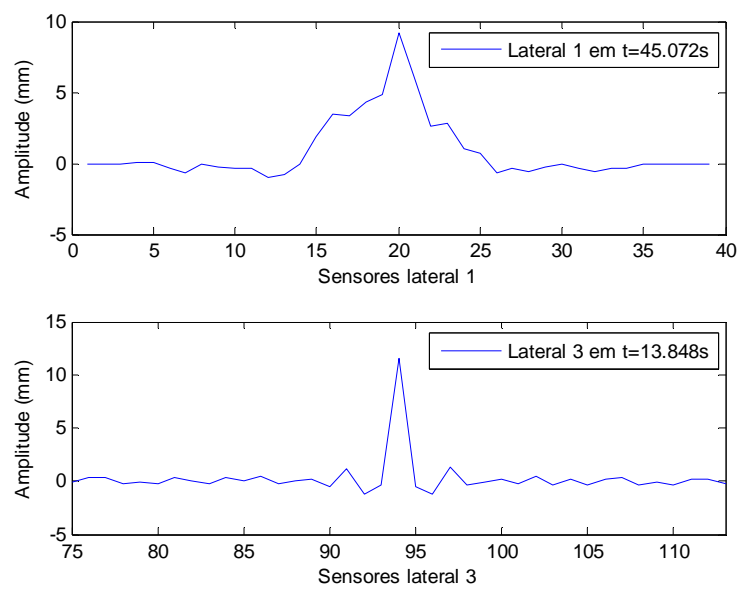

(d) - Elevação nas laterais no instante de máxima elevação nos sensores 20 e 94 no teste EM01Ret

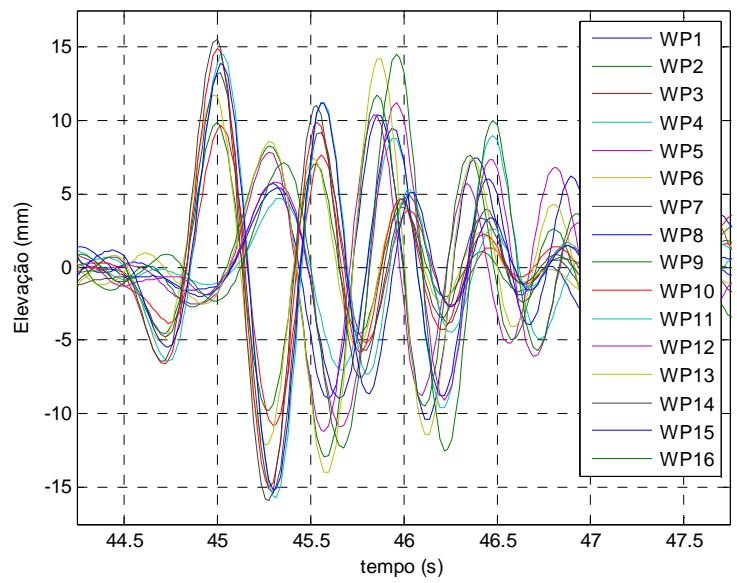

(f) - Elevação nos WPC no teste EM01Ret

Figura 6.57. Comparação de resultados dos testes de reversão temporal entre dois batedores de ondas.

Na comparação da elevação de ondas nos sensores das laterais (Figura $6.57 c$ e $d$ ), a elevação máxima nos sensores que recebem a concentração de altura ocorre em $t_{c} \sim 45 s=65 s-20 s$, confirmando o instante de concentração. Outro dado revelado, 
analisando o instante em que ocorre o valor de pico dos sinais nas laterais, é que as amplitudes de ondas na emissão são maiores que na recepção. Este resultado é esperado, pois o flap emissor, seja ele o $n^{\circ} 20$ ou o $n^{\circ} 94$, emite ondas concêntricas. Se por um lado a tendência da aplicação de TR é concentrar as elevações no receptor no domínio da frequência em uma linha reta entre os flaps, por outro lado o fato de as ondas serem concêntricas acarreta a perda de concentração ao dispersar espacialmente as ondas na emissão. Dentro do tanque, onde são possíveis inúmeras reflexões, ao se tomar um trecho temporal elevado é possível, após diversas reflexões (reverberação), amplificar a elevação de ondas no receptor. O efeito amplificador da reverberação, citado no tópico 6.4.1.2, não foi verificado neste teste e fica agora como sugestão para testes futuros no tanque de provas, usando-se diferentes tamanhos de trecho temporal.

Avaliando os resultados da Figura 6.57 e e $f$, observa-se que existe uma dispersão direcional na onda ao se usar um ponto focal espacial na posição do receptor. Existem dois grupos de sensores com comportamento semelhante. Os sensores que se concentram em um primeiro instante são os sensores próximos da linha central do tanque ao longo do eixo $X$; são eles os sensores 2, 3, 6, 7, 10, 11, 14 e 15. Estes sensores estão a 0,5 metro da linha de centro, os demais estão a 1,5 metros. A correção espacial atua com o efeito semelhante a uma lente óptica convergente: se a trajetória das ondas medidas não converge para a posição focalizada, em analogia com a óptica, a imagem se forma em um ponto diferente do esperado, que, no caso das ondas, é um instante diferente no tempo. Assim se confirma a concentricidade da onda a partir do flap emissor.

Tabela 6.27. Resultado dos testes de emissão e recepção por um par de batedores de ondas.

\begin{tabular}{|c|c|c|c|c|c|c|}
\hline \multirow{2}{*}{ Nome } & \multicolumn{3}{|c|}{ Flap 20 } & \multicolumn{3}{c|}{ Flap 94 } \\
\cline { 2 - 7 } & $\boldsymbol{H}_{\boldsymbol{r m s}}(\mathbf{m m})$ & $\boldsymbol{A}_{\boldsymbol{m a x}}(\mathbf{m m})$ & $\boldsymbol{H}_{\boldsymbol{m a x}}(\mathbf{m m})$ & $\boldsymbol{H}_{\boldsymbol{r m s}}(\mathbf{m m})$ & $\boldsymbol{A}_{\boldsymbol{m a x}}(\mathbf{m m})$ & $\boldsymbol{H}_{\boldsymbol{m a x}}(\mathbf{m m})$ \\
\hline EM01Rev & 0,574 & 2,447 & 4,423 & 1,468 & 8,261 & 14,480 \\
\hline EM01Ret & 1,679 & 9,227 & 16,806 & 0,571 & 2,443 & 4,575 \\
\hline
\end{tabular}

Por conta do efeito concêntrico de um emissor único, a onda concentra no receptor, mas com amplitude atenuada espacialmente. Se todos os batedores de ondas do tanque, porém, atuarem para concentrar ondas no receptor usando TR, a onda produzida será contínua espacialmente; ocorrerá então a amplificação da altura no 
receptor, tal como no caso do lançamento de objetos na água. Isto foi feito na sequência dos testes. A onda revertida foi executada (EM01RetA) três vezes e sempre ocorreu perda da leitura do sensor de ondas do flap 20 por conta da elevada amplitude de onda resultante. Mesmo com este fato foi possível comprovar o resultado do teste. Os resultados observados foram semelhantes nas três realizações. Quando o sensor de ondas ultrassônico perde uma amostra, ele a substitui pela anterior. Ao voltar a medir, passa a operar normalmente. Portanto, as amostras próximas da que foi perdida têm a medida correta da elevação para questões quantitativas.

A Figura 6.58 mostra o resultado observado no teste de reversão temporal usando todos os flaps atuando na concentração. O instante da concentração foi confirmado em $t_{c} \sim 77 \mathrm{~s}-20 \mathrm{~s}=57 \mathrm{~s}$. Nos sensores ultrassônicos dos batedores de ondas pode-se notar que no instante da concentração ocorre a diminuição da elevação de ondas nas laterais 2, 3 e 4, bem como nos sensores mais afastados do sensor 20 na lateral 1 (Figura 6.58 a). Este é um indicativo de que as ondas estão concentradas nos sensores centrais da lateral 1. Avaliando a leitura dos sensores capacitivos (Figura $6.58 d$ ) com correção espacial focando na posição do flap 20, observa-se que existe uma onda concêntrica propagando para aquele ponto com pouca dispersão no tempo e na amplitude. Analisando somente a lateral 1 (Figura $6.58 \quad b \quad \mathrm{e} c$ ), nota-se que o valor médio quadrático, a amplitude máxima e também a amplitude no instante de concentração apontam que o flap 20 é o centro do foco com altura de ondas bastante elevada. Apesar da falha do sensor, é possível afirmar que existe uma alta concentração da onda no flap 20. Infelizmente neste teste não foi feita a gravação em vídeo para estimar visualmente a concentração de ondas. A Tabela 6.28 mostra o resultado dos testes.

A reversão temporal executada tem valor $r m s$, a maior altura e a maior amplitude detectadas, um valor aproximadamente 3 vezes maior que que aquele da emissão anteriormente executada. Existem dois motivos principais para isso: a função de transferência do flap não foi considerada nos testes e a leitura da onda nos flaps não foi ajustada dividindo-se por 2 na reversão temporal. No futuro novos testes poderão ajudar no estudo de TR considerando um maior número de parâmetros, de forma a se obter uma reversão temporal com a resposta mais próxima da perturbação inicial. 

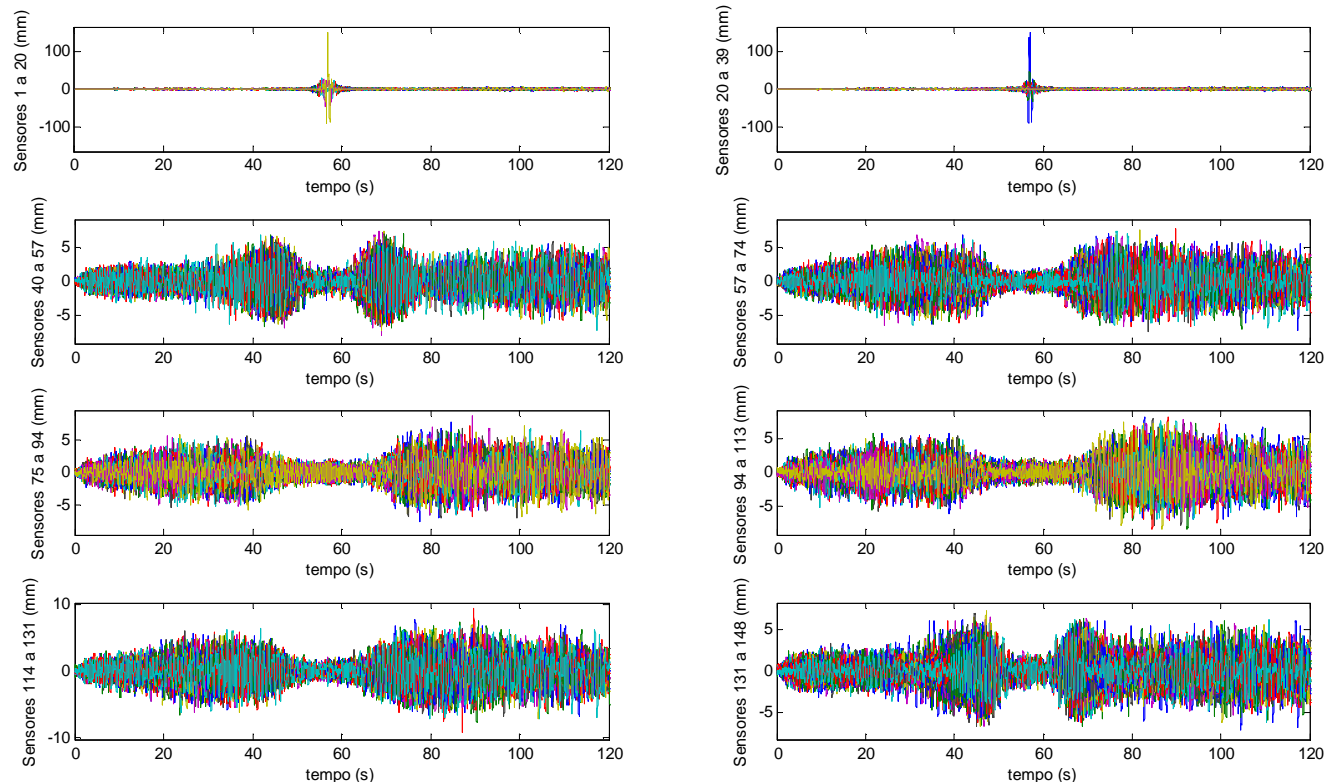

(a) - Elevação de onda nos sensores ultrassônicos.
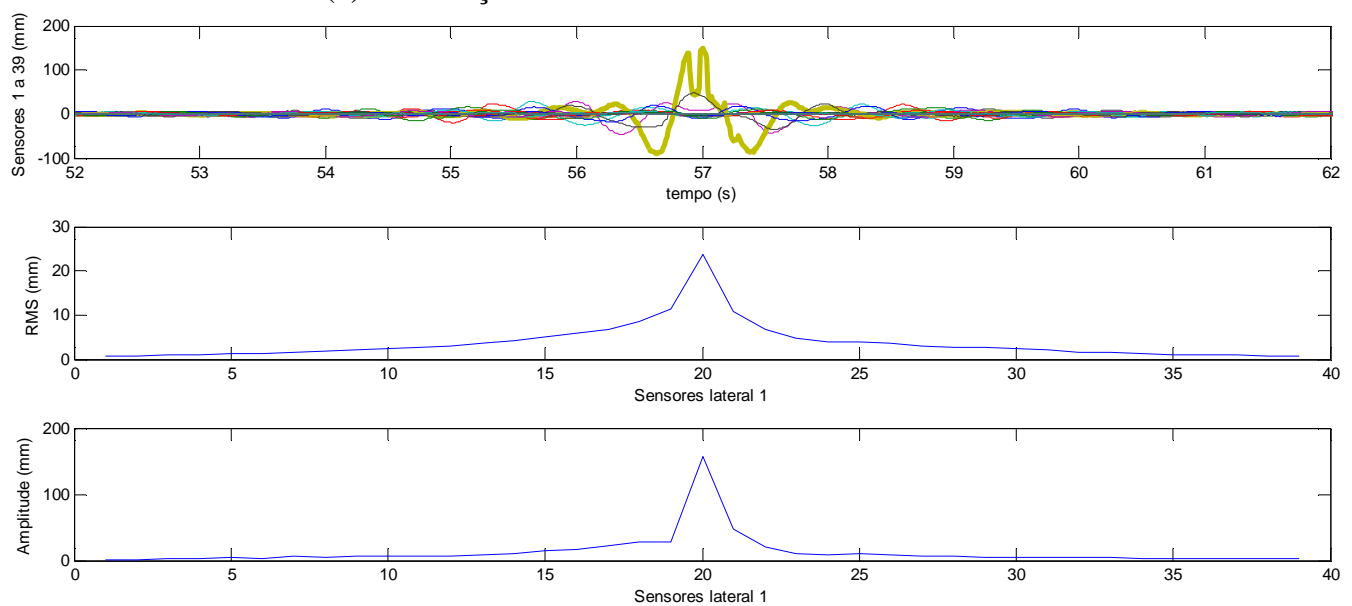

(b) - Análise da elevação de onda nos sensores ultrassônicos da lateral 1 (flap 20 em amarelo).

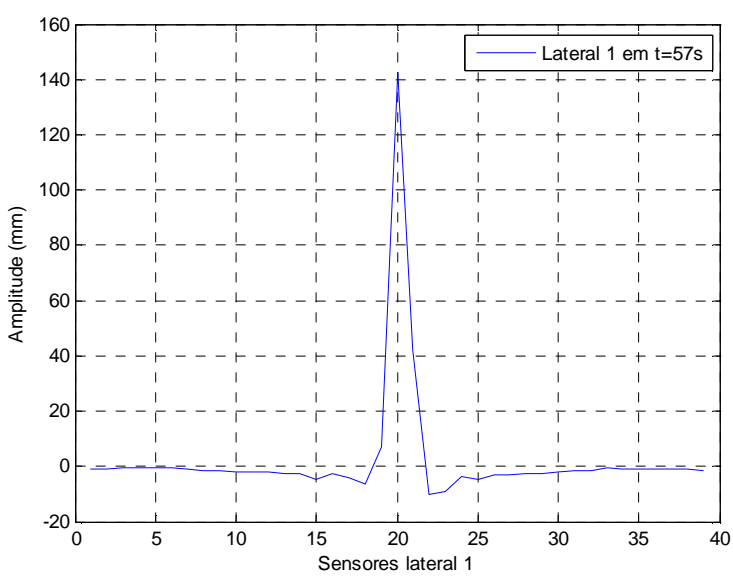

(c) - Elevação no WPU da lateral 1.

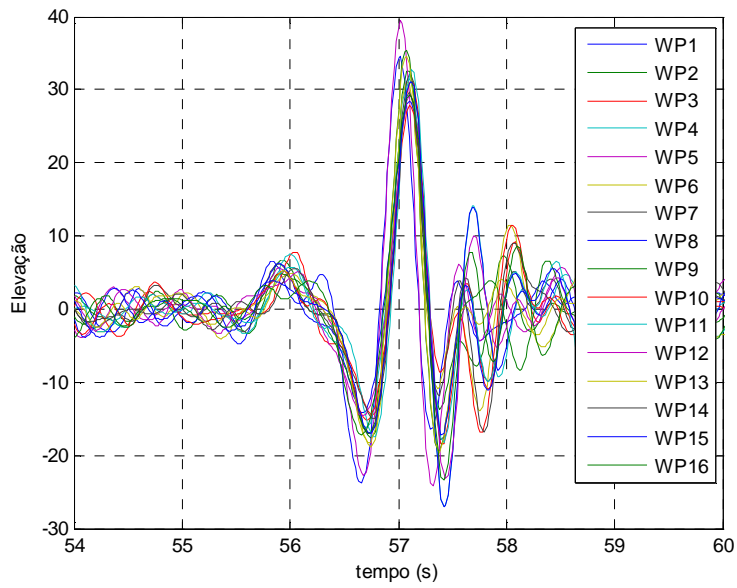

(d) - Elevação nos WPC com correção espacial.

Figura 6.58. Resultado da reversão temporal do teste EM01RetA. 
Tabela 6.28. Resultado da análise dos sensores capacitivos da reversão temporal entre um batedor de ondas emissor e os demais batedores.

\begin{tabular}{|c|c|c|c|c|c|c|}
\hline Nome & $\begin{array}{c}\boldsymbol{H}_{\boldsymbol{r m s}} \\
(\mathbf{m m})\end{array}$ & $\begin{array}{c}\boldsymbol{\sigma} \boldsymbol{H}_{\boldsymbol{r m s}} \\
(\mathbf{m m})\end{array}$ & $\begin{array}{c}\boldsymbol{H}_{\max } \\
(\mathbf{m m})\end{array}$ & $\begin{array}{c}\boldsymbol{\sigma} \boldsymbol{H}_{\max } \\
(\mathbf{m m})\end{array}$ & $\begin{array}{c}\boldsymbol{A}_{\max } \\
(\mathbf{m m})\end{array}$ & $\begin{array}{c}\boldsymbol{\sigma} \boldsymbol{A}_{\max } \\
(\mathbf{m m})\end{array}$ \\
\hline EM01 & 1,984 & 0,134 & 17,366 & 1,698 & 10,944 & 0,972 \\
\hline EM01RetA repetição 1 & 6,044 & 0,4324 & 51,081 & 5,858 & 31,930 & 3,016 \\
\hline EM01RetA repetição 2 & 5,946 & 0,511 & 50,156 & 6,626 & 31,373 & 2,974 \\
\hline EM01RetA repetição 3 & 6,321 & 0,755 & 54,114 & 8,080 & 33,532 & 4,139 \\
\hline
\end{tabular}

\subsubsection{Tanque de provas com obstáculo}

Nestes experimentos foi usado o aparato experimental com antepara, mostrado na Figura 6.59. Os sensores capacitivos foram usados para estimar a característica da onda progressiva que atravessou a região central do tanque. O flap 94 recepcionou a perturbação produzida pelo flap 20. A perturbação medida foi revertida no tempo e reenviada novamente no flap 20. Em seguida, essa mesma leitura foi reenviada agora no flap 94 e, ao final, todos os flaps das laterais 2, 3 e 4 foram usados para enviar de forma reversa as suas leituras de perturbação. A Tabela 6.29 mostra os testes realizados.

Estes experimentos foram similares ao do teste sem obstáculo, mas o trecho temporal usado foi maior para que, usando a reverberação das ondas, a concentração de energia no ponto de foco fosse otimizada. Após realizar a emissão, verificou-se a característica da onda emitida através dos sensores dos batedores da lateral 1 e da leitura dos sensores capacitivos. A característica da emissão nos sensores da lateral 1 foi semelhante à do teste sem obstáculos. No centro do tanque pode ser visto que a elevação de ondas nos sensores à frente da antepara foi mais intensa pela reflexão de ondas na antepara e que nos sensores atrás da antepara a elevação foi atenuada (Figura 6.60a). Nos sensores de ondas da lateral 3 a elevação de ondas tem, devido à simetria do experimento, maior valor $r m s$ nos sensores laterais e no sensor central (94), enquanto os sensores em torno do centro apresentam regiões com elevações reduzidas (Figura 6.60b). Isto revela que, apesar de o sensor central estar na "sombra" da antepara e o teste ser simétrico, as ondas incidentes puderam incidir nele devido ao trecho de tempo longo o suficiente para ocorrer a reverberação. 


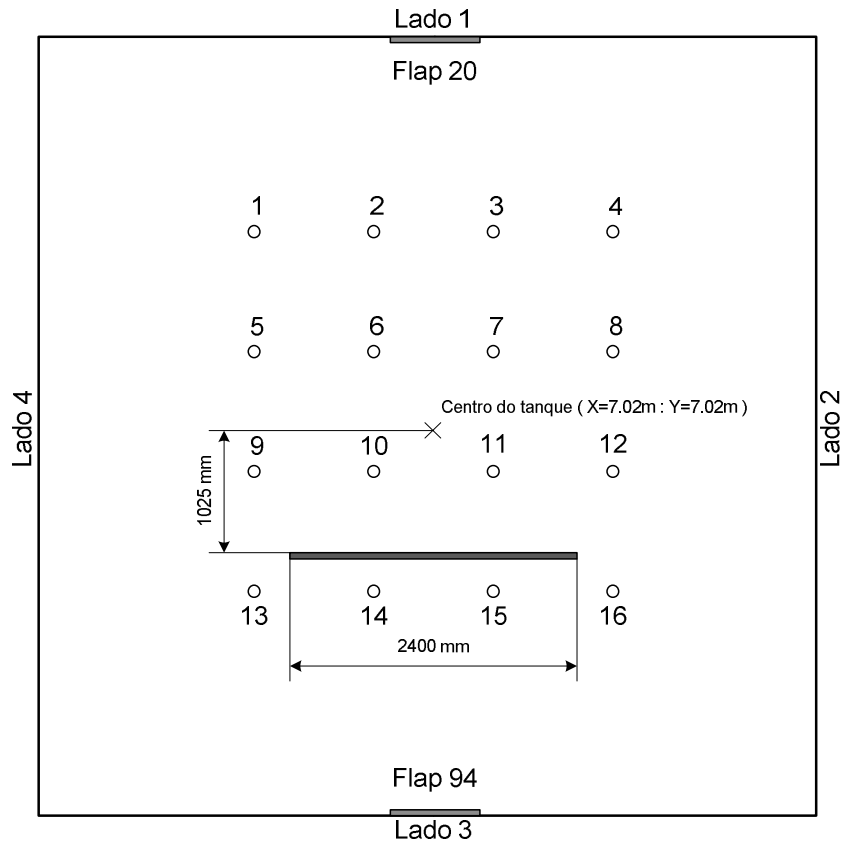

Figura 6.59. Arranjo experimental de emissão usando o batedor 20 (sem escala).

Tabela 6.29. Testes realizados de emissão e recepção entre batedores de ondas.

\begin{tabular}{|c|c|c|c|c|c|}
\hline Nome & Stroke & $\begin{array}{c}\text { Estado do } \\
\text { gerador }\end{array}$ & $\begin{array}{c}\text { Estado dos } \\
\text { WPC }\end{array}$ & $\begin{array}{c}\text { Trecho temporal } \\
\text { usado para TR }\end{array}$ & $\begin{array}{c}\text { Estado dos } \\
\text { WPU }\end{array}$ \\
\hline EM02 & $2,402 \mathrm{~mm}_{r m s}$ & $\begin{array}{c}\text { Flap } 20 \\
\text { atuando }\end{array}$ & Adquirindo & -- & Adquirindo \\
\hline EM02Rev & $2,402 \mathrm{~mm}_{r m s}$ & $\begin{array}{c}\text { Flap } 20 \\
\text { atuando }\end{array}$ & Adquirindo & $\begin{array}{c}\text { Trecho de } 23 \text { a } 130 \\
\text { segundos de EM01 } \\
\text { reverso no tempo }\end{array}$ & Adquirindo \\
\hline EM02Ret & $2,402 \mathrm{~mm}_{r m s}$ & $\begin{array}{c}\text { Flap } 94 \\
\text { atuando }\end{array}$ & Adquirindo & $\begin{array}{c}\text { Trecho de } 23 \text { a } 130 \\
\text { segundos de EM01 } \\
\text { reverso no tempo }\end{array}$ & Adquirindo \\
\hline EM02RetA & $W P U_{R E V E R S O} / 2$ & $\begin{array}{c}\text { Flaps } 40 \text { a } \\
148 \text { atuando }\end{array}$ & Adquirindo & $\begin{array}{c}\text { Trecho de } 23 \text { a } 130 \\
\text { segundos de EM01 } \\
\text { reverso no tempo }\end{array}$ & Adquirindo \\
\hline
\end{tabular}



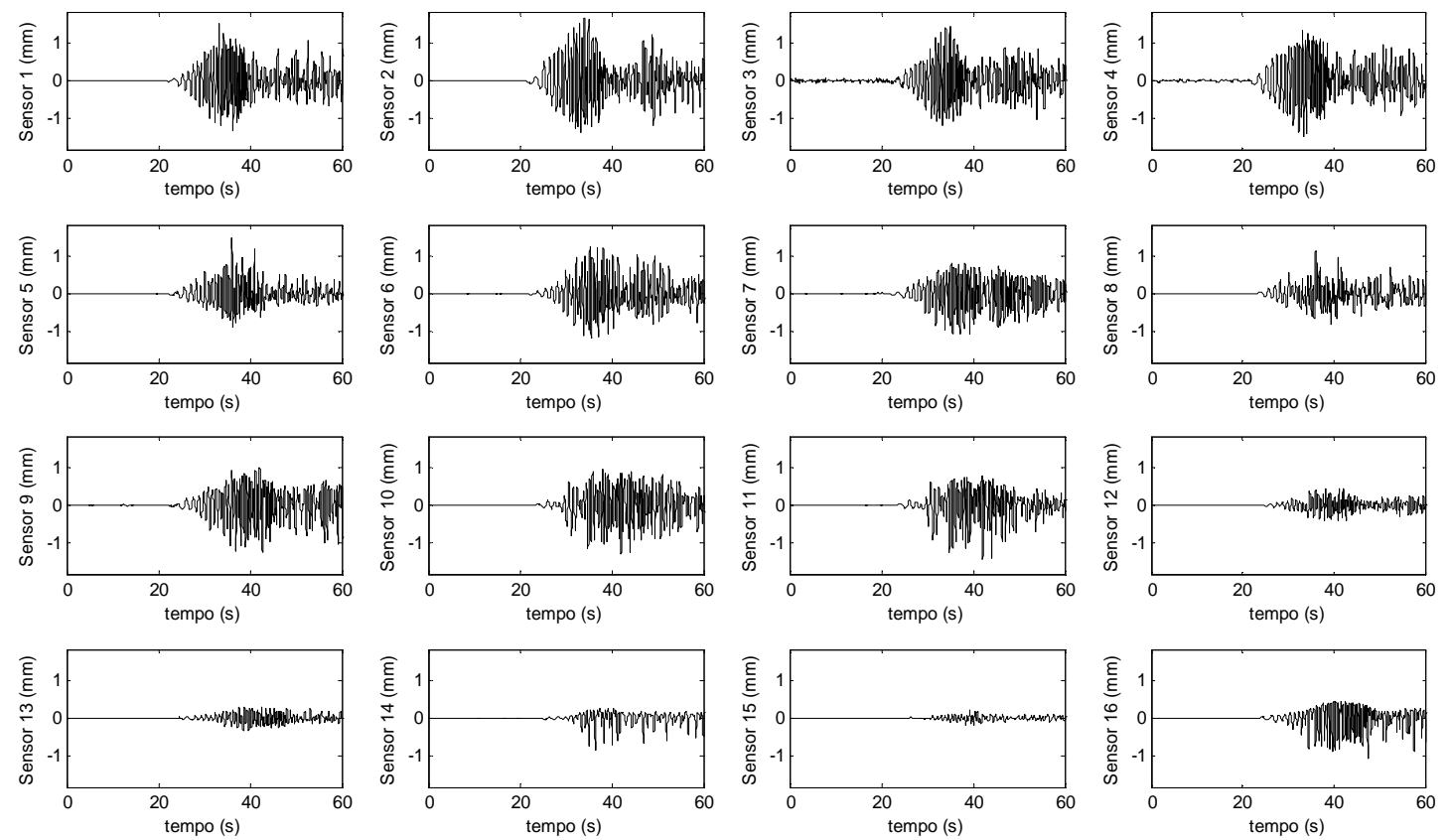

(a) - Resposta impulsiva vista pelos sensores capacitivos.
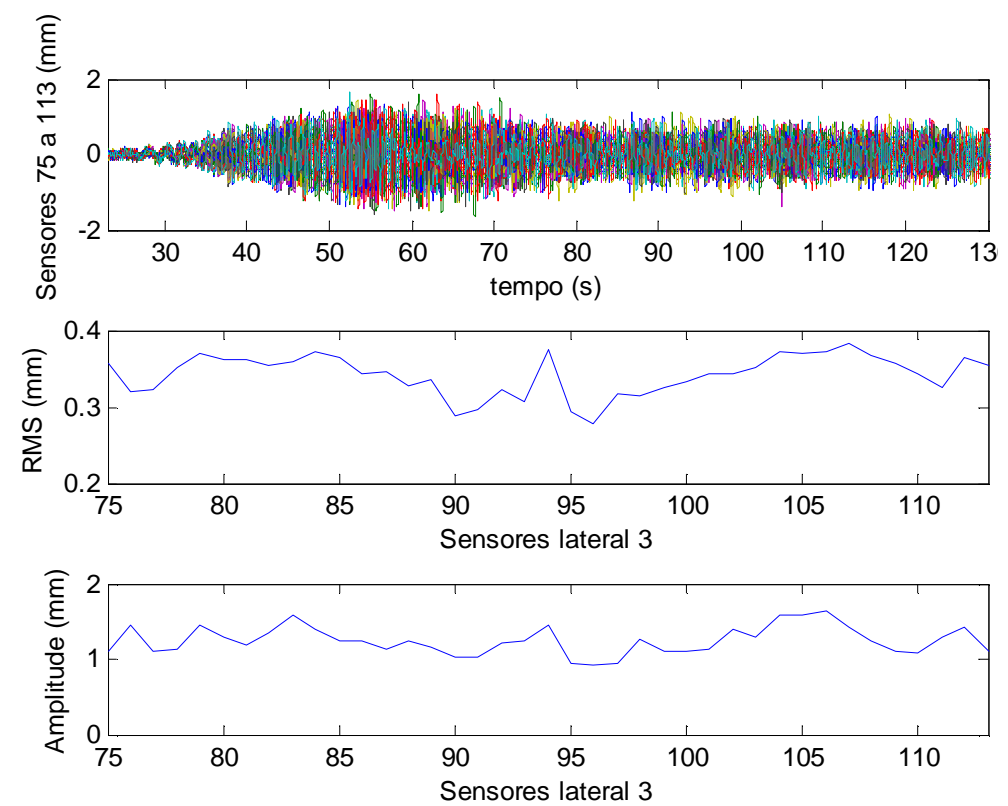

(b) - Onda recepcionada nos sensores da lateral 3.

Figura 6.60. Onda impulsiva realizada pelo batedor 20 .

A elevação da onda no batedor 94 apresentava valor médio quadrático igual a $0,364 \mathrm{~mm}_{r m s}$. O ganho de 6,5995 vezes foi aplicado à leitura para que a série temporal revertida de deslocamento tivesse o mesmo valor médio quadrático do impulso sinc original. O deslocamento revertido no tempo foi então repetido nos batedores 20 e 94 para se realizar dois testes de concentração simétricos. A Figura 6.61 e a Tabela 6.30 mostram esta comparação. As elevações nos batedores de ondas apresentaram resultado 
inverso entre as realizações (Figura $6.61 a$ e $b$ ). Uma onda em fase, pouco menor que um quinto do valor da onda concentrada, aparece no batedor do lado emissor. Diferentemente do teste sem obstáculo, a elevação de ondas concentrada tem um aspecto mais próximo de uma função sinc.

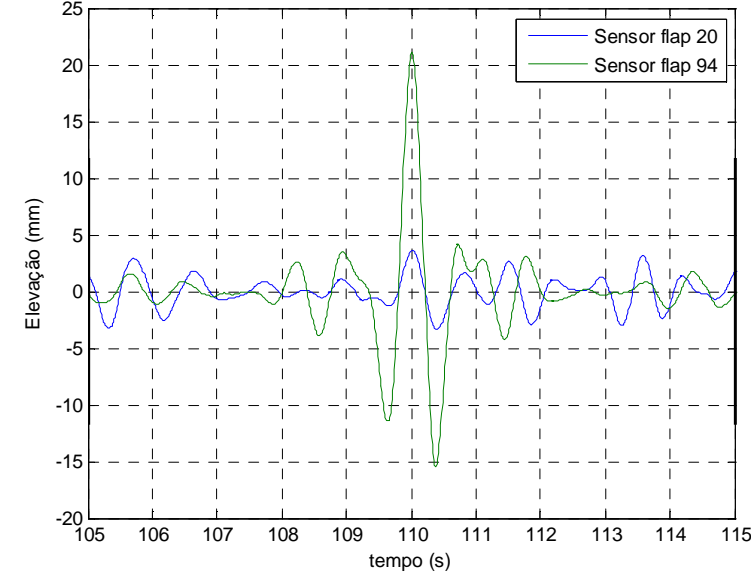

(a) - Elevação no teste EM02Rev.
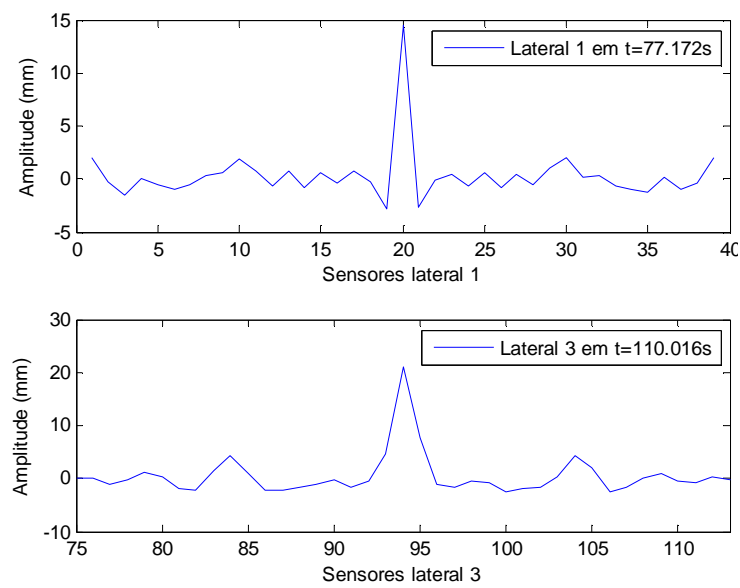

(c) - Elevação nas laterais no instante de máxima elevação nos sensores 20 e 94 no teste EM02Rev.

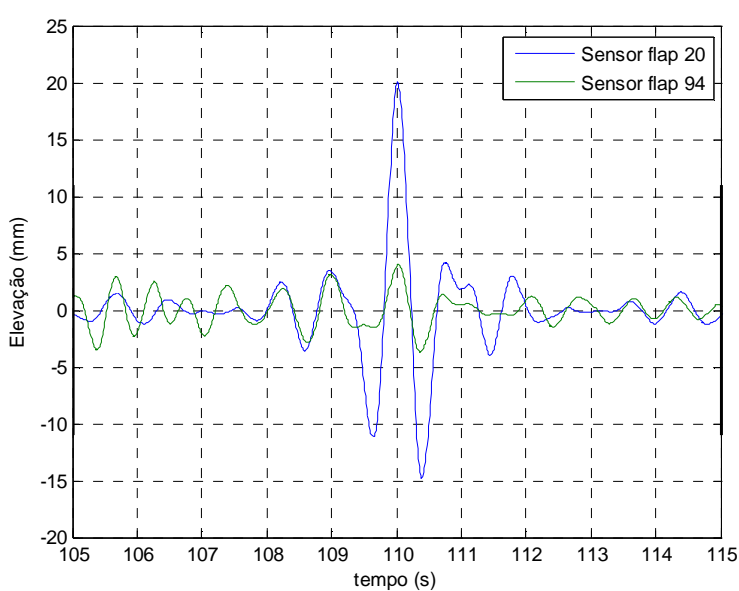

(b) - Elevação no teste EM02Ret.
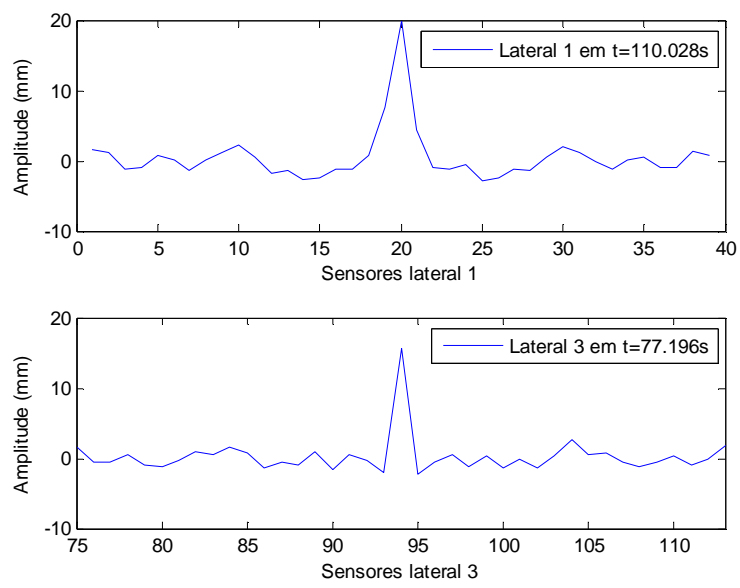

(d) - Elevação nas laterais no instante de máxima elevação nos sensores 20 e 94 no teste EM02Ret.

Figura 6.61. Comparação de resultados dos testes de reversão temporal entre dois batedores de ondas.

Na comparação da elevação de ondas nos sensores das laterais (Figura $6.61 c$ e $d$ ), a elevação máxima nos sensores que recebem a concentração de altura ocorre em $t_{c} \sim 110 s=130 s-20 s$, confirmando o instante de concentração. Diferentemente do teste sem obstáculos, a elevação máxima na emissão sempre foi menor que na recepção; daí se conclui que, o trecho temporal sendo maior, ocorrem mais reflexões no interior do tanque, graças ao efeito amplificador da elevação das ondas. Comparando-se a concentração da elevação de ondas no receptor, fica evidente que os sensores laterais ao central têm amplitude muito menor que no teste sem obstáculos, em que o trecho 
temporal foi demasiadamente curto; isso revela o efeito de aumento de foco da energia no receptor em decorrência das múltiplas reflexões ocorridas no segundo teste.

Tabela 6.30. Resultado dos testes de emissão e recepção por um par de batedores de ondas.

\begin{tabular}{|c|c|c|c|c|c|c|}
\hline \multirow{2}{*}{ Nome } & \multicolumn{3}{|c|}{ Flap 20 } & \multicolumn{3}{c|}{ Flap 94 } \\
\cline { 2 - 7 } & $\boldsymbol{H}_{\boldsymbol{r m s}}(\mathbf{m m})$ & $\boldsymbol{A}_{\boldsymbol{m a x}}(\mathbf{m m})$ & $\boldsymbol{H}_{\boldsymbol{m a x}}(\mathbf{m m})$ & $\boldsymbol{H}_{\boldsymbol{r m s}}(\mathbf{m m})$ & $\boldsymbol{A}_{\boldsymbol{m a x}}(\mathbf{m m})$ & $\boldsymbol{H}_{\boldsymbol{m a x}}(\mathbf{m m})$ \\
\hline EM02Rev & 1,439 & 3,617 & 6,987 & 4,168 & 21,061 & 36,551 \\
\hline EM02Ret & 4,065 & 20,016 & 34,809 & 1,436 & 3,999 & 7,710 \\
\hline
\end{tabular}

No último teste realizado, todos os batedores das laterais 2, 3 e 4 foram usados para emitir a onda reversa no tempo. A onda revertida foi executada (EM02RetA) com metade da elevação medida nos sensores de ondas dos batedores, diferentemente do que foi feito no teste sem obstáculos. Mesmo com emissão menor, ocorreu perda da leitura do sensor de ondas do flap 20 por conta da elevada amplitude na recepção.

A Figura 6.62 mostra o resultado observado no teste de reversão temporal usando todos os flaps atuando na concentração. $\mathrm{O}$ instante da concentração foi confirmado em $t_{c} \sim 130 s-20 s=110 s$. A Figura $6.62 a$ revela o mesmo comportamento do teste sem obstáculos, com as elevações menores nas laterais afastadas do ponto de concentração. Analisando somente a lateral 1 (Figura $6.62 b$ e $c$ ), nota-se que o valor médio quadrático, a amplitude máxima e também a amplitude no instante de concentração apontam que o flap 20 é o centro do foco com altura de ondas bastante elevada. O valor da maior amplitude encontrada foi de 127,27 mm. A Figura 6.63 mostra seis instantes do vídeo realizado ao longo do ensaio. Foi possível notar que no instante da concentração ocorreu a máxima elevação da onda fora da posição do sensor de ondas em uma posição fora do centro do flap. A causa dessa ocorrência é desconhecida; mas assim, o sensor pode não ter medido o máximo da onda por estar fora da posição. Estimar a elevação pela imagem pode induzir a erros de efeito óptico, mas para relato das observações experimentais isso foi feito e resultou em uma elevação de $186,2 \mathrm{~mm}$. 

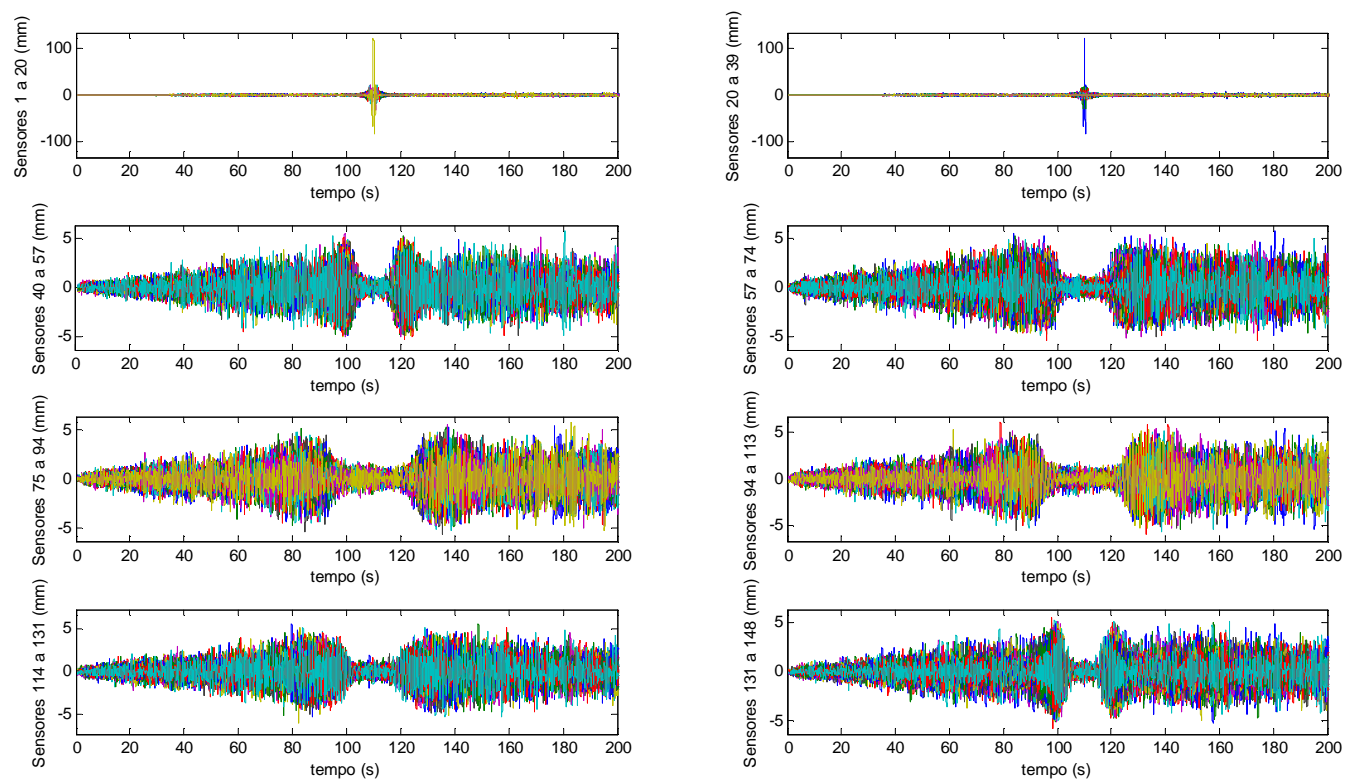

(a) - Elevação de onda nos sensores ultrassônicos.
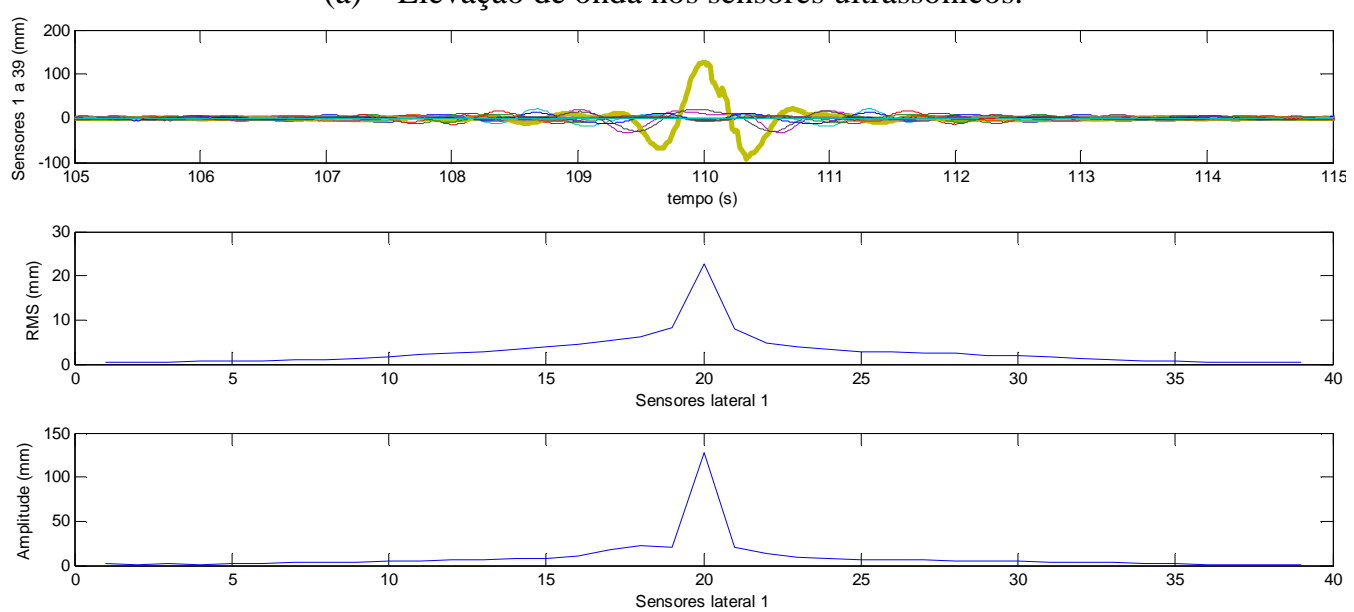

(b) - Análise da elevação de onda nos sensores ultrassônicos da lateral 1 (flap 20 em amarelo).

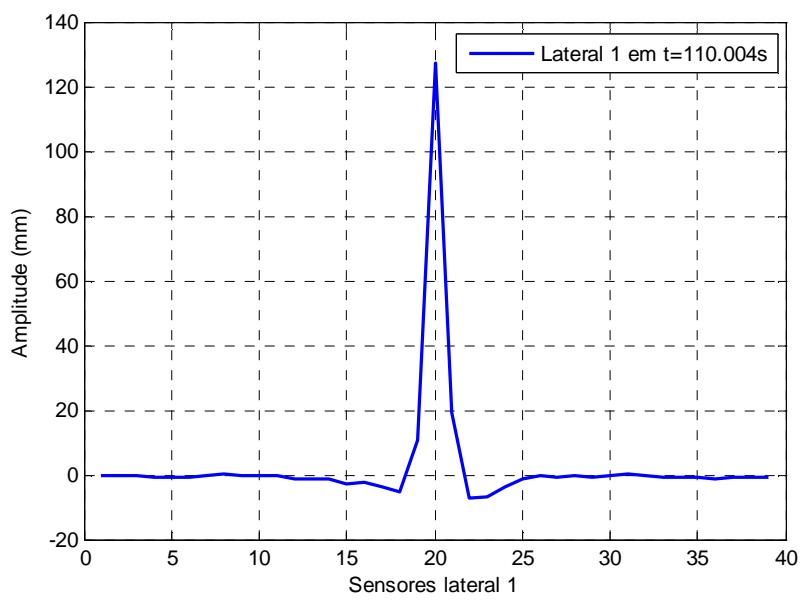

(c) - Elevação no WPU da lateral 1.

Figura 6.62. Resultado da reversão temporal do teste EM02RetA. 


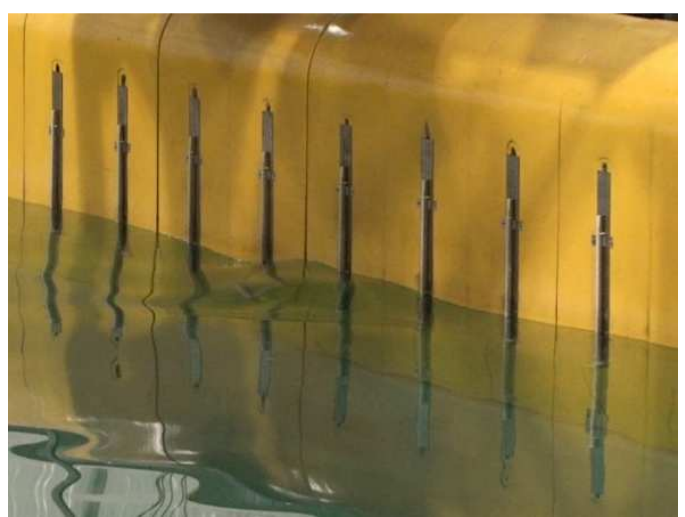

(a) $t=109,2 s$

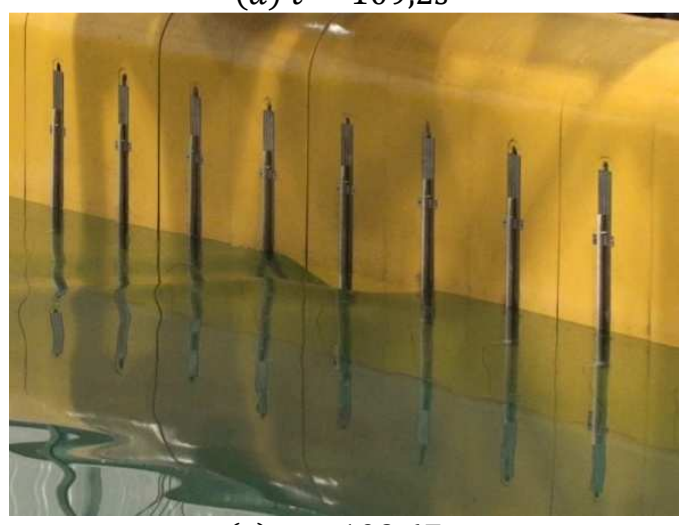

(c) $t=109,67 \mathrm{~s}$

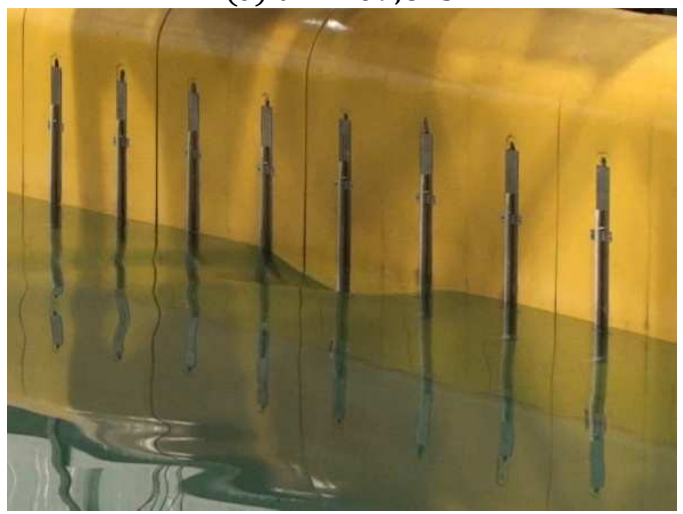

(e) $t=110,34 \mathrm{~s}$

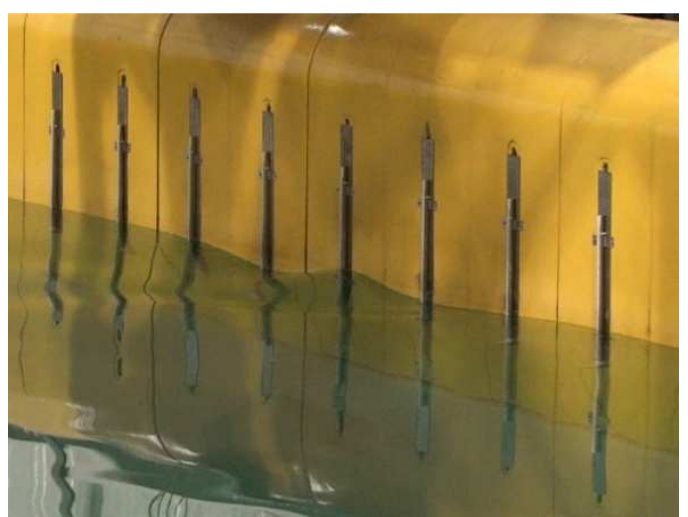

(b) $t=109,34 s$

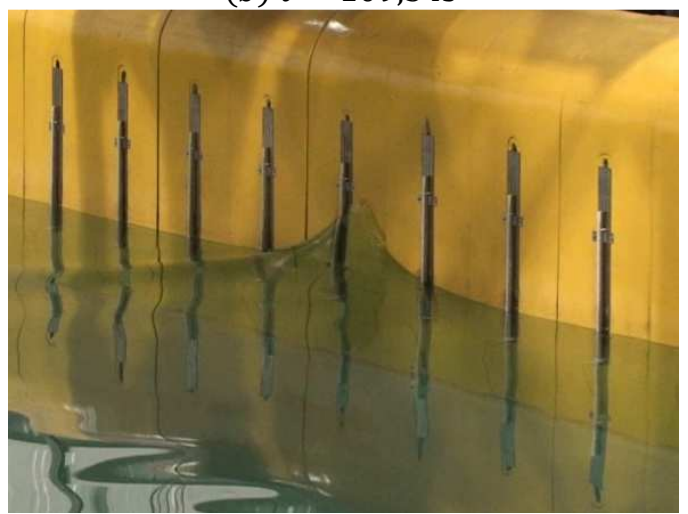

(d) $t=t_{c}=110,0 \mathrm{~s}-A_{\max }=186,2 \mathrm{~mm}$

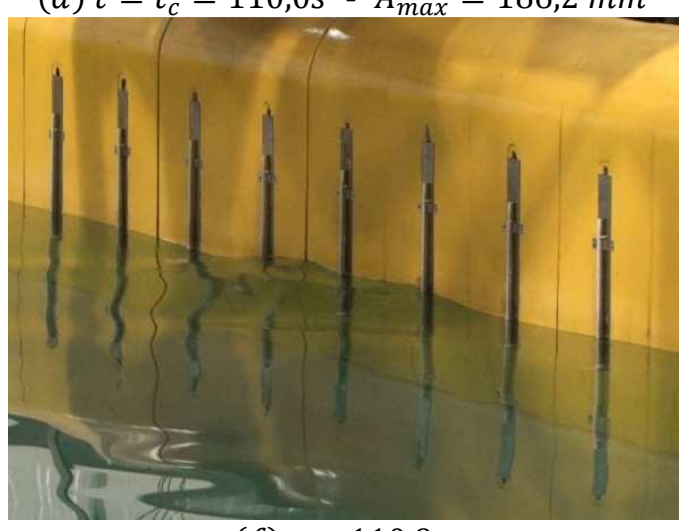

(f) $t=110,9 \mathrm{~s}$

Figura 6.63. Instantes destacados da concentração de ondas ocorrida no ensaio EM02RetA.

\subsubsection{Conclusões acerca dos ensaios de TR}

A partir do resultado do experimento, pode-se afirmar que o tamanho do trecho temporal é importante tanto para amplificar a elevação de onda na reversão temporal quanto para melhorar a focalização espacial. Em futuros experimentos um estudo sistemático do assunto poderá mostrar como de dá o comportamento da concentração de ondas em função do tamanho dos trechos temporais utilizados. 
A quantidade de atuadores envolvidos tem impacto na amplitude da onda concentrada. Com poucos atuadores é possível focalizar ondas em diferentes direções de propagação incidindo no ponto de concentração; nesse caso, porém, a quantidade de reflexões nas laterais (reverberação) tem grande impacto no resultado. Com um número maior de atuadores, mais direções de incidência sob o ponto de concentração são obtidas.

A função de transferência do flap poderá ser mais bem estudada para ser introduzida no estudo de TR, de modo a reproduzir melhor as ondas na reversão temporal. Os sensores dos atuadores medem a elevação da onda na face; no entanto, quando o atuador se move, a elevação de onda incorpora a influência da função de transferência característica.

Na realização da reversão temporal, o ponto de concentração no meio líquido tem elevação muito alta em uma região do espaço bastante restrita. No tempo, o instante da concentração é bem definido e apresenta pouco espalhamento. Foi comprovado que a concentração ocorre sempre no instante previsto e que o sistema é linear, para que grande parte das ondas presentes no tanque de provas se concentre na posição prevista.

O método de focalização espacial usando os sensores capacitivos fornece uma boa estimativa da onda no ponto de concentração, mas não pode prever como a onda realmente é tanto na emissão quanto na recepção. A estimativa fornecida é baseada na onda progressiva que passa no centro do tanque e não prevê os fenômenos que acontecem na face do batedor de ondas nem no local em que um objeto é lançado na água. Este estudo pode ser aproveitado para análises de formação de imagens em meios dispersivos, tal qual se faz em ultrassonografia.

O método de TR provou que pode concentrar ondas em regiões com aparatos que causem difração e reflexão presentes e que afetem a propagação das ondas. Pode-se prever ensaios com outros tipos de aparatos e geometrias mais complexas para analisar a resposta da técnica de TR. 


\section{Conclusões}

Esse trabalho apresenta o desenvolvimento de um sistema de automação e controle para tanques oceânicos com múltiplos atuadores visando possibilitar a geração e absorção ativa de ondas. O desenvolvimento compreende: a implementação e validação do sistema de automação e controle para o tanque de provas; o desenvolvimento de algoritmos para geração de ondas com batedores do tipo flap, para atender os casos tipicamente utilizados em ensaios de estruturas oceânicas, tais como ondas regulares e irregulares, com ou sem espalhamento direcional. Para demonstrar a potencialidade do controlador do tanque, foi desenvolvida uma nova técnica para focalização de energia de ondas em tanque de provas, fundamentada na técnica de TR (time reversal) para concentrar ondas em pontos específicos do espaço. Essa técnica tem sido aplicada na focalização de ondas de pressão acústica na faixa de ultrassom, mas, devido à semelhança com as ondas de pressão acústicas, foi aplicada às ondas de superfície livre da água no tanque de provas desenvolvido.

O gerador de ondas do Calibrador Hidrodinâmico é composto de 148 elementos. Além de mover de forma controlada os atuadores (batedores de ondas do tipo flap) para gerar as ondas, permite a medição da posição dos atuadores e as elevações nos sensores de ondas dos atuadores em tempo real para realizar a absorção ativa a partir de um sistema de controle em malha fechada. Os tanques de provas existentes em outras instituições usam hardware de controle desenvolvido especificamente para a aplicação. O Calibrador Hidrodinâmico tem um dos primeiros geradores de ondas que utiliza equipamentos destinados à automação industrial. Essa abordagem propiciou uma grande flexibilidade no desenvolvimento do controlador e também diminuiu a fase de desenvolvimento de hardware do controlador. Assim sendo, boa parte do trabalho de desenvolvimento do gerador de ondas se concentrou na integração dos módulos e no desenvolvimento do software de controle. Por consequência, a grande flexibilidade do hardware possibilitou o desenvolvimento contínuo para a pesquisa atual e para pesquisas futuras no Calibrador Hidrodinâmico.

Foram utilizados controladores do tipo CLP (controlador lógico programável) em rede de comunicação usando troca de dados síncrona (dois níveis de rede), como uma solução robusta de automação. O ponto crítico para que o sistema apresente um 
funcionamento dentro dos requisitos técnicos necessários são as redes de comunicação industriais. Os atuadores do gerador de ondas são acionados pelos CLPs enquanto o computador executa os cálculos para a absorção ativa de ondas; os CLPs são interligados pelas redes industriais. A previsão inicial era operar em tempo real de execução com ciclo de amostragem de $20 \mathrm{~ms}$, que atenderia marginalmente aos requisitos, mas esse ciclo foi reduzido para $12 \mathrm{~ms}$ ao final do desenvolvimento.

As elevações de onda nos atuadores são medidas por sensores ultrassônicos desenvolvidos na Escola Politécnica da USP em paralelo com a implementação do gerador de ondas. Para isso, foi necessário o desenvolvimento de uma eletrônica de condicionamento de sinais para os sensores ultrassônicos passíveis de serem integradas ao hardware de controle. Os sensores foram caracterizados para vários tipos de ondas e mostraram-se adequados para a aplicação.

A verificação experimental do funcionamento do sistema de atuação, controle e sensoriamento foi realizada. Ela serviu para avaliar de forma completa o funcionamento do sistema. Foram também desenvolvidos sensores de ondas capacitivos que possibilitaram a confrontação de resultados com dois tipos de sensores e também para serem utilizados em ensaios no Calibrador Hidrodinâmico.

A geração de ondas regulares foi avaliada no tanque. Os testes com ondas regulares mostraram que a elevação das ondas medidas nos atuadores com os sensores ultrassônicos são muito próximas às previstas teoricamente. Esse resultado valida as análises dos subsistemas desenvolvidos.

As ondas progressivas geradas, medidas na região central do tanque, apresentaram pequena atenuação em relação às simulações teóricas. Esse comportamento, não explicado neste trabalho, será tema de trabalhos futuros. O coeficiente de reflexão experimental foi determinado usando-se um método de separação de ondas (incidentes e refletidas) a partir das ondas calibradas. Foi realizada uma análise da flutuação das ondas no interior do tanque devido à reflexão, que mostrou que, embora exista reflexão pouco abaixo de $10 \%$, a flutuação das ondas se mantém estacionária. As ondas não têm as suas características degradadas ao longo do tempo. A segunda reflexão não afeta o comportamento das ondas incidentes pelo uso de absorção nos dois lados opostos do tanque. 
As ondas regulares oblíquas produzidas no tanque, com medição por uma matriz composta de 16 sensores de ondas capacitivos no centro do tanque, resultaram em uma extensa investigação experimental. Se por um lado o resultado mostrou uma flutuação de até $58 \%$ no campo de ondas, por outro lado levou ao desenvolvimento de uma metodologia de avaliação empírica do campo de ondas e à realização de pesquisas destinadas a suprimir tais flutuações. A causa detectada foi a existência de atuadores bloqueados nos cantos do tanque de provas; eles não só deixam de gerar ondas, como também constituem descontinuidades nos cantos do tanque que criam difração nas ondas. A flutuação piora com o aumento da frequência das ondas (ondas de pequeno comprimento) e também com o aumento do ângulo de incidência (fazendo uso da lateral que tem atuadores bloqueados). Desta forma, a faixa angular em que a flutuação é menor que $30 \%$ fica restrita a um ângulo de $45^{\circ}$ em torno das laterais sem atuadores bloqueados (lados ímpares). Quando se usam somente as laterais sem atuadores bloqueados, a flutuação não passa de $11 \%$.

A geração de ondas irregulares no tanque de provas se mostrou adequada para a realização de ensaios experimentais. A devida calibração da energia de ondas por faixa de frequência contribuiu para que diversos parâmetros estatísticos de mares convergissem ao valor requerido. O uso de um método de separação de ondas (incidentes e refletidas) com sensores no centro do tanque apontou com razoável precisão o coeficiente de reflexão do filtro de absorção. $\mathrm{O}$ valor observado se mantém constante nas quatro ondas irregulares geradas, indicando estabilidade do campo de ondas. A segunda reflexão de ondas não afeta o resultado final, assim como acontece com as ondas regulares. Nesse trabalho foi avaliada somente a geração de mares nãooblíquos de cristas longas, mas é possível realizar, com os algoritmos desenvolvidos, ondas oblíquas e ondas de cristas curtas no tanque. Isso não foi contemplado neste trabalho devido à não disponibilidade de filtros de absorção ativa até o momento, para que se realizasse a absorção de ondas em todas as direções de propagação. Este é um assunto de maior complexidade; encontra-se em desenvolvimento e não faz parte deste trabalho.

O modelo de absorção de ondas dual mode utilizando ensaios com ondas regulares, regulares oblíquas e irregulares se mostrou eficaz para se realizar absorção ativa em lados opostos do tanque; ele cria um meio de se eliminar a segunda reflexão de ondas (ondas re-refletidas), conforme foi avaliado nos testes. 
A técnica de TR utilizada no trabalho para se concentrar ondas espacialmente é oriunda de pesquisas na área de propagação de ondas de ultrassom. O Calibrador Hidrodinâmico permitiu a aplicação da técnica de TR devido às suas características singulares: é equipado com sensores de ondas nos atuadores cobrindo todo o perímetro do tanque. As verificações experimentais com TR utilizaram a matriz de sensores de ondas capacitivos no centro do tanque para medir as ondas. Observou-se que a concentração foi obtida em todos os testes de reversão temporal realizados. $\mathrm{Na}$ análise dos testes constatou-se que havia dois fatores preponderantes na qualidade do "foco" da concentração de ondas: o tamanho do trecho temporal usado na reversão temporal e a quantidade de atuadores envolvidos nos testes. A concentração foi obtida mesmo usando-se um único atuador. Os ensaios experimentais mostraram que a técnica é robusta para se obter alta concentração de ondas em um ponto do espaço (focalização), mesmo usando-se anteparos para "forçar" a difração e a reflexão internas no tanque, efeitos estes que o método pode resolver intrinsecamente. Os resultados foram satisfatórios nas três variações experimentais realizadas.

\subsection{Trabalhos futuros}

Foi observada uma atenuação nas ondas regulares no centro do tanque. Uma investigação é recomendada para que as causas sejam determinadas. Existem trabalhos na literatura que mostram as vantagens de se utilizar uma teoria de geração de ondas de $2^{\mathrm{a}}$ ordem para geradores de ondas do tipo flap. Ao que tudo indica, teorias de $2^{\mathrm{a}}$ ordem são mais adequadas para tal aplicação, uma vez que a teoria utilizada no trabalho é simplificada para pequena altura de ondas e pequeno deslocamento do atuador.

Nos ensaios com ondas regulares oblíquas foi observada uma elevada variação espacial no campo de ondas. Uma medida futura apontada será ativar mais atuadores e reduzir o efeito de variação espacial verificado. Mesmo com a necessidade do aumento do número de atuadores, a arquitetura de sistema desenvolvida permite que isso seja feito de forma simples, demonstrando a flexibilidade obtida com o sistema de automação concebido. Outra medida futura de curto prazo para a redução da flutuação no campo de ondas, motivada a partir do resultado experimental, será fazer uso de simuladores hidrodinâmicos - tal qual em Quadrante (2011) - aliados a um método 
iterativo mostrado em (Matsumoto e Hanzawa, 1996); o objetivo é otimizar os deslocamentos dos atuadores. O método usa o simulador para propagar um campo de ondas, medido pela matriz de sensores, a partir dos batedores de ondas com amplitude de movimento ajustáveis pela otimização. Desse modo é possível minimizar as flutuações na matriz de sensores de ondas. Métodos iguais a estes podem ser facilmente aplicados no tanque de provas. Um teste inicial foi realizado acerca deste procedimento.

As ondas irregulares oblíquas, de cristas longas e cristas curtas não foram ensaiadas no tanque de provas. Assim que se dispuser de um filtro para realizar a absorção multidirecional de ondas, estes ensaios de validação de geração de ondas poderão ser realizados.

Nos testes de TR foi observado que, nas alturas de ondas obtidas, o trecho temporal, o número de atuadores e a função de transferência do flap têm efeito. Assim, fica como recomendação futura a realização de testes que usem tais fatores de forma sistemática para avaliar quais são suas implicações.

Os testes de TR já realizados podem ser utilizados como paradigma para a realização de comparações numéricas, estudos de propagação de ondas dispersivas concêntricas, estudos de formação de imagens (detecção do ponto de concentração e objetos na superfície da água) além da utilização para alguma finalidade prática de concentração de ondas em tanque de provas. 


\section{Referências bibliográficas}

BIESEL, F. Wave Machines. Proceedings 1st Conference on Ships and Waves, n. pp 288-304, 1954.

BRIGGS, M. J. IAHR Working Group on Multidirectional Waves - An Historical Overview. Proc. of IAHR Seminar on Multidirectional Waves and their Interaction with Structures, 27th IAHR Congress. San Francisco, CA, USA: pp. 1-13. 1997.

BROSSARD, J., DRUAUX, A. L., MARIN, F., \& TABET-AOUL, E. H. Fixed absorbing semi-immersed breakwater. Coastal Engineering, v. 49, 2003. pp. 25-41.

CAMPOS VELHO, H. F. Mini-Curso - Problemas inversos: conceitos básicos e aplicações. IV Encontro de Modelagem Computacional, Anais SBMAC. Nova Friburgo, RJ, p. 63-79. 2003. (Notas de curso).

CARNEIRO, M. L. Desenvolvimento de dispositivo de geração e absorção ativa de ondas para tanque de ensaios de estruturas oceânicas. São Paulo. 2007. 1v. Dissertação (mestrado) - Escola Politécnica, Universidade de São Paulo.

CARneiro, M. L., DE MEllo, P. C., TANNURI, E. A., \& SimOS, A. N. Experimental Validation of an Absorbing Wavemaker Controller. Proceedings of the ASME 28th International Conference on Ocean, Offshore and Arctic Engineering OMAE. Honolulu. 2009.

CASTRO, O. C. Active Reflection Absorption for a Three Dimensional Multidirectional Wave Generator. Tese (Doctor of Philosophy), Texas A\&M University. College Station, TX, USA, p. 153. 2009.

CEM. Coastal Engineering Manual. Washington, D.C. (em 6 volumes): U.S. Army Corps of Engineers, 2002.

CERDEIRA, V. S. R. Estudo sobre as Características Físicas de um Canal de Ondas. Rio de Janeiro. 2006. 1v. Disssertação (mestrado) - COPPE - Departamento de Engenharia Naval e Oceânica - Universidade Federal do Rio de Janeiro.

CHAKRABARTI, S. K. Hydrodynamics of Offshore Structures. Southampton, UK: WIT Press, 1987. 
CHAKRABARTI, S. K. Offshore Struture Modeling. Singapore: World Scientific Publishing Co. Pte. Ltd., v. 9 - Advanced Series on Ocean Engineering, 1994. ISBN ISBN 981-02-1512-6.

CHAN, A. T.; LEE, S. W. C. Wave characteristics past a flexible fishnet. Ocean Engineering, v. 28, pp. 1517-1529, 2001.

DE MELLO, P. C. Um aparato para redução da reflexão de ondas em praia Parabólica. Rio de Janeiro. 2006. 1v. Disssertação (mestrado) - COPPE Departamento de Engenharia Naval e Oceânica - Universidade Federal do Rio de Janeiro.

DE MEllo, P. C., CARneiro, M. L., CASETTA, L., SimOS, A. N., ADAMOWSKI, J. C., NISHIMOTO, K. Development of a Wave Tank With Active Absorption. Proc. of International Workshop on Applied Offshore Hydrodynamics. Rio de Janeiro: . 2007.

DE MELlO, P. C., CARNEIRO, M. L., TANNURI, E. A., \& NISHIMOTO, K. USP Active Absorption Wave Basin: From Conception to Commissioning. Proceedings of the ASME 29th International Conference on Ocean, Offshore and Arctic Engineering. Shanghai: ASME. 2010.

DE MEllo, P., CARNEIRO, M. L., TANNURI, E. A., ADAMOWSKI, J. C., KASSAB, F., MARQUES, R. P., NISHIMOTO, K. A control and automation system for wave basins. Mechatronics, 2011. (Submetido, em revisão).

DEAN, R. G.; DALRYMPLE, R. A. Water wave mechanics for engineers and scientists. Englewood Cliffs, New Jersey: Prentice-Hall, Inc., 1984.

FINK, M. Time Reversal of Ultrasonic Fields - Part I: Basic Principles. IEEE Transactions on Ultrasonics, Ferroelectrics, and Frequency Control, p. 555-566, vol. 39, n. 5, 1992.

FOUQUE, J. P., GARNIER, J., MUNOZ GRAJALES, J. C., \& NACHBIN, A. Time reversing solitary waves. Physical Review Letters, v. 92, Is. 9, 094502, 2004.

FOUQUE, J. P.; GARNIER, J.; NACHBIN, A. Time reversal for dispersive waves in random media. SIAM Journal on Applied Mathematics, v. 64, is. 5, pp. 1810-1838, 2004. 
FOUQUE, J. P.; NACHBIN, A. Time-reversed refocusing of surface water waves. SIAM Journal on Multiscale Modeling and Simulation, v. 1, is. 4, pp. 609-629, 2003.

GODA, Y. A Comparative Review On The Functional Forms Of The Directional Wave Spectrum Directional Wave Spectrum. Coastal Engineering Journal, vol. 41, Is. 1, pp. 1-20, 1999.

HASSELMANN, D. E.; DUNCKEL, M.; EWING, J. A. Directional Wave Spectra Observed during JONSWAP 1973. Journal of Physical Oceanography, Vol. 10, August 1980. pp. 1264-1280.

HAVELOCK, T. H. Forced surface waves on water. Phil. Mag., Vol. 8, pp. 569$576,1929$.

HAWKES, P. J., EWING, J. A., HARFORD, C. M., KLOPMAN, G., STANSBERG, C. T., BENOIT, M. BRIGGS, M. J. FRIGAARD, P. HIRAISHI, T. MILES, M. D. SANTAS, J. SCHÄFFER, H. A. Comparative Analyses of Multidirectional Wave Basin Data. Proceedings of the Second International Symposium OCEAN WAVE MEASUREMENT AND ANALYSIS. New Orleans, Louisiana, USA: Sponsored by the Waterways, Port, Coastal and Ocean Div., ASCE. 1993.

HIRAYAMA, T. Generation and Simulation of Multi-Directional Transient Water Waves in a Longitudinal Towing Tank. Japan Kansai Society of Naval Architeture, $n^{\circ} 222,1994$. pp. 203-209.

HUGHES, S. A. Physical models and laboratory techniques in coastal engineering. Singapore: World Scientific Co. Pte. Ltd., 1993.

ISAACSON, M. Measurement of Regular Wave Reflection. Journal of Waterway, Port, Coastal, and Ocean Engineering, 117, n. 6, pp. 553-569, 1991.

ITTC. 22rd International Towing Tank Conference. Proceedings of 22rd International Towing Tank Conference. Seoul and Shanghai: ITTC. 1999.

ITTC. 23rd International Towing Tank Conference. Proceedings of the 23rd ITTC. Veneza: ITTC. 2002.

KAWAGUCHI, T. Absorbing Wave Making System with Wave Sensor and Velocity Control. Mitsi Zosen Technical Review, No.128, pp.20-24, 1986. 
KINSLER, L. E. et al. Fundamentals of Acoustics. fourth edition. ed. [S.1.]: John Wiley \& Sons, 2000.

LABOCEANO. http://www.laboceano.coppe.ufrj.br:8080/laboceano/index.jsp, 2011. Acesso em: 11 Novembro 2011.

LEBEY, M.; RIVOALEN, E. Experimental study of the working principal and efficiency of a superposed inclined planes wave absorber. Ocean Engineering, v. 29, 2002. pp. 1427-1440.

LI, W.; WILLIAMS, A. N. Second-Order Three-Dimensional Wave Maker Theory with Side-Wall Reflection. Proc. of the Eighth International Offshore and Polar Engineering Conference. Montréal: Canada. 1998.

LI, Y. et al. The reflection of oblique incident waves by breakwaters with doublelayered perforated wall. Coastal Engineering, v. 50, 2003. pp. 47-60.

MADSEN, O. S. A Three Dimensional Wave Maker, Its Theory And Appication. Journal of Hydraulic Research, Vol. 12, Is. 2, pp. 205-222, 1974.

MADSEN, P. A.; BINGHAM, H. B.; LIU, H. A new Boussinesq method for fully nonlinear waves from shallow to deep water. Journal of Fluid Mechanics, v. 462, pp. $1-30,2002$.

MAEDA, K. . H. N. . T. K. . A. A. H. Wave Making Properties of Circular Basin. International Symposium on Underwater Technology, pp. 349-354, 2004.

MALTA, E. B. Métodos e processos para a análise experimental de sistemas oceânicos de produção de petróleo e gás. 1v. Dissertação (mestrado) - Escola Politécnica, Departamento de Engenharia Naval e Oceânica, Universidade de São Paulo. São Paulo, p. 188. 2010.

MARIN. Basins, 2011. Disponivel em: <http://www.marin.nl/web/FacilitiesTools/Basins.htm>. Acesso em: 17 Novembro 2011.

MARINTEK. The Ocean Basin Laboratory - SINTEF, 2011. Disponivel em: $<$ http://www.sintef.no/home/MARINTEK/Laboratories-at-MARINTEK/The-OceanBasin-Laboratory/>. Acesso em: 17 Novembro 2011.

MARTINS, J. A. A. Análise de ondas em tanque de dimensões reduzidas com vistas à engenharia oceânica. São Paulo. 2003. 1v. Tese (Doutorado) - Escola 
Politécnica da Universidade de São Paulo - Departamento de Engenharia Naval e Oceânica.

MARTINS, J. A. D. A. . DE MELLO P. C. . CARNEIRO M. L. . SOUZA C. A. G. F. . ADAMOWSKI, J. C. Laboratory Wave Probes Dynamic Performance Evaluation. Proceedings of XX COPINAVAL - Congresso PanAmericano de Engenharia Naval e Transportes Marítimos, n. São Paulo, Brazil, 2007.

MASSEL, S. R. On the largest wave height in water of constant depth. Journal of Ocean Engineering, v. 23, i. 7, pp. 553-573, 1996.

MENDES, A. L. T. Investigação Sobre a Dispersão Direcional de Ondas de Gravidade na Bacia de Campo. Dissertação (mestrado), COPPE - UFRJ Departamento de Eng. Naval e Oceânica - Universidade Federal do Rio de Janeiro. Rio de Janeiro, Brasil, p. 91. 2005.

MILES, M. D.; FUNKE, E. R. A Comparison of Methods for Synthesis of Directional Seas. Journal of Offshore Mechanical and Arctic Engineering, v. 111, is. 43, Fev 1989, 1989.

MILGRAM, J. H. Active water wave absorbers. Journal of Fluid Mechanics, Vol. 42, Is. 4, pp. 845-859, 1970.

MITSUBISHI. General-Purpose AC Servo Melservo J3 series - Instruction Manual. SH-NA-030051-C, Mitsubishi Electric Corporation, 2007.

MITSUBISHI. MELSECNET/G Network System Reference Manual (Controller Network). SH-080668ENG-C, Mitsubishi Electric Corporation, mar. 2008.

MITSUBISHI. Multiple CPU system - User's Manual. SH(NA)-080485ENG-H, Mitsubishi Electric Corporation, dez. 2008.

MITSUYASU, H. et al. Observations of the Directional Spectrum of Ocean Waves Using a Cloverleaf Buoy. Journal of Physical Oceanography, Vol. 5, October 1975. pp. 750-760.

MOERI, 2008. Disponivel em: <http://www.moeri.re.kr/kordi_daeduck/eng/study/institution03.jsp>. Acesso em: Dezembro 2011. 
MOOG. Whipping Up a Storm with Advanced Hydraulic Technology , 2008. Disponivel em: <http://www.ideasinmotioncontrol.com/2008/02/whipping-up-a-stormwith-advanced-hydraulic-technology.html\#more>. Acesso em: Dezembro 2011.

NAITO, S. Wave generation and absorption in wave basins: theory and application. Proceedings 16th International Offshore and Polar Engineering Conference, 2006.

NAITO, S. et al. A new configuration of wave basin and a control of wave generation and absorption - the case when an advancing ship comes across the given waves. Proceedings of the 4th Pacific/Asia Offshore Mechanics Symposium, Pusan, Korea, 226, n. pp. 207-212, 1996.

NAITO, S.; MINOURA, M.; OKUYAMA, E. Diffraction Force in Compact Basin with Absorbing Wave Maker. Proceedings of The Twelfth (2002) International Offshore and Polar Engineering Conference, Kitakyushu, Japan, pp. 399-405, May 26-312002.

NEWMAN, J. N. Analysis of wave generators and absorbers in basins. Estudo não publicado disponível em: www.wamit.com, Acesso em: 21 de dez. de 2010, 2008.

NMRI. http://www.nmri.go.jp/main/overview/facilities/facilities_e.html, 2011. Acesso em: 11 Novembro 2011.

NOHARA, B. T. A Survey of the Generation of Ocean Waves in a Test Basin. Journal of the Brazilian Society of Mechanical Science, Campinas, 2000. V. 22, n.2, p. 303-315.

NOHARA, B. T.; YAMAMOTO, I.; MATSUURA, M. The organized motion control of multi-directional wave maker. Proceedings of the 4th International Workshop on Advanced Motion Control, 2, n. pp. 470-475, 1996.

NWOGU, O. Maximum Eentropy estimation of directional wave spectra from an array of wave probes. Applied Ocean Reserch, Vol. 11 No. 4, 1989.

O`DEA, J. F.; NEWMAN, J. N. Numerical Studies of Directional Wavemaker Performance. 28th American Towing Tank Conference. Ann Arbor, Michigan: USA. 2007. 
OCHI, M. Ocean Waves: The Stochastic Approach. [S.1.]: Cambridge Univ. Press, v. 6 - Cambridge Ocean Tech. Series, 1998.

OPPENHEIM, A. V.; SCHAFER, R. W.; BUCK, J. R. Discrete-time signal processing. Upper Saddle River, New Jersey, USA: Prentice-Hall, Inc., 1998.

PARENTE, C. E. et al. Directional Wave Measurements in Rio de Janeiro coast. Proc. of the 23rd International Conference on Coastal Engineering. Veneza: p. 551-562. 1992.

PETROBRAS. Metocean data - CAMPOS BASIN. Petrobras. Rio de Janeiro. 2005. (I-ET-3000.00-1000-941-PPC-001).

PETROBRAS. METOCEAN DATA - SANTOS BASIN BM-S CLUSTER REGION. Petrobras. Rio de Janeiro. 2008. (I-ET-3A26.00-1000-941-PPC-001).

QUADRANTE, L. A. R. Desenvolvimento de um simulador simplificado para estudo de geração de ondas em tanques dotados de geradores segmentados. São Paulo. 2011. 1v. Tese (Mestrado) - Escola Politécnica da Universidade de São Paulo Departamento de Engenharia Naval e Oceânica.

REDWOOD, M. Ultrasonic Waveguide - A physical approach. Ultrasonics, Vol. 1, n. 2, pp. 993-105, 1963.

SALTER, S. H. Absorbing wave makers and wide tanks. Proc. Directional Wave Spectra Applications, Berkeley, CA, USA, 1981. pp. 185-202.

SALTER, S. H. Physical modeling of directional seas. Proc. Symp. Description and Modeling of Directional Seas, Copenhagen, Denmark, 1984. pp. D-74 - D-82.

SCHÄFFER, H. A. Second-order wavemaker theory for irregular waves. Ocean Engineering, Vol. 23, pp. 47-88, 1996.

SCHÄFFER, H. A. Active Wave Absorption in Flumes and 3D Basins. Proceedings of 4th Int. Symp. on Ocean Wave Measurement and Analysis, n. ASCE, pp. 1200-1208, 2001.

SCHAFFER, H.; KLOPMAN, G. Review of Multidirectional Active Wave Absorption Methods. Journal of Waterway, Port, Coastal, and Ocean Engineering, ASCE, Vol. 126, Is. 2, pp.88-97, 2000. 
SCHAFFER, H.; SKOURUP, J. Active absorption of multidirectional waves. Proc., 25th Int. Conf. on Coast. Engrg., ASCE, Orlando, FL., USA, pp. 55-66, 1996.

SERCOS. http://www.sercos.com/index.htm, 2011. Acesso em: 23 Novembro 2011.

SPINNEKEN, J.; SWAN, C. Second-order wavemaker theory using forcefeedback control. PartI: A new theory for regular wave generation. Ocean Engineering, Vol. 36, pp. 539-548, 2009a.

SPINNEKEN, J.; SWAN, C. Second-order wavemaker theory using forcefeedback control. PartII: An experimental verification of regular wave generation. Ocean Engineering, Vol. 36, pp. 549-555, $2009 \mathrm{~b}$.

STANSBERG, C. T. Statistical Properties of Directional Sea Measurements. ASME OMAE Journal, Vol. 9, No. 2, pp. 142-147, 1987.

STANSBERG, C. T. On the Fourier Series Decomposition of Directional Wave Spectra. Proc. of the 8th Int. Off. and Polar Eng. Conf. ISOPE98. Montréal, Canadá, May 24-29, pp.227-233: ISOPE. 1998.

SUliSZ, W.; HUDSPETH, R. T. Complete Second-Order Solution for Water Waves Generated in Wave Flumes. Journal of Fluids and Structures, v. 7, p. 253-268, 1993.

TANNURI, E. A. et al. Estimation of Directional Wave Spectrum Using a WaveProbe Array. Marine Systems \& Ocean Technology, v. 3, pp. 123-129, 2007.

TWU, S. W.; DUANN, J. J. An Approach For Eliminating Re Reflected Waves. Ocean Engineering, v. 22, n. 5, 1995. pp. 421-437.

TWU, S. W.; LIN, D. T. On a highly effective wave Absorber. Coastal Engineering, v. 15, p. 389-405, 1991.

TWU, S. W.; LIU, C. C.; TWU, C. W. Wave damping characteristics of vertically stratified porous structures under oblique wave action, v. 29, 2002. pp. 1295-1311.

WILNER, L. B. Variable Capacitance Liquid Level Sensors. Review of scientific Instruments, Vol. 31 number 5, Maio 1960.

WU, Y. C.; DALRYMPLE, R. A. Analysis of Wave Fields Generated by a Directional Wavemaker. Coastal Engineering, v. 11, pp. 241-261, 1987. 
YOUNG, I. R.; VERHAGEN, L. A. The growth of fetch limited waves in water of finite depth. Part 2. Spectral evolution. Coastal Engineering, v. 29, pp. 79-99, 1996.

ZHANG, H. A Deterministic Combination of Numerical and Physical Models for Coastal Waves. Tese (Doctor of Philosophy), Technical University of Denmark, Maritime and Structural Engineering. Lyngby, Denmark, p. 145. 2005.

ZHANG, H.; SCHÄFFER, H. A.; BINGHAM, H. B. A method for generating highly nonlinear periodic waves in physical wave basins. Proceedings of the $21 \mathrm{st}$ International Workshop on Water Waves and Floating Bodies. Loughborough, England: pp. 193-196. 2006.

ZHANG, H.; SCHÄFFER, H. A.; JAKOBSEN, K. P. Deterministic combination of numerical and physical coastal wave models. Journal of Coastal, Harbour and Offshore Engineer, v. 54, pp. 171-186, 2007.

ZHU, S.; CHWANG, A. T. Investigations on the reflection behaviour of a slotted seawall. Coastal Engineering, v. 43, 2001. pp. 93-104. 


\section{Apêndice A - Absorvedores passivos de ondas}

Ao rebater na cavidade formada pelos flaps e na parede traseira, a água é pressionada a passar pelo espaço entre os flaps e pode formar pequenas ondas de interferências de borda no interior do tanque. Estas ondas podem contaminar o campo de ondas e, no pior caso, influenciar na leitura dos sensores de flap. Em um cenário mais pessimista, elas podem ser lidas nos sensores e prejudicar o desempenho da absorção de ondas ou até mesmo provocar realimentação suficiente para criar uma vibração durante a absorção das ondas. Por isso devem ser evitadas.

Outro motivo para se evitar tais ondas é o fato de se ter estruturas de reforço expostas na parte traseira dos flaps. As ondas rebatidas podem prejudicar a vida útil dos flaps por fadiga repetitiva. Outro problema relacionado é o aumento da potência dispendida pelos servo-drivers para efetuar o posicionamento.

A distância horizontal do flap à parede traseira é de aproximadamente 1,5 metros. A rebatida de ondas será maior toda vez que ocorrer a ressonância da relação entre comprimentos de ondas e distância em relação à parede, formando ondas estacionárias. Segundo Dean e Dalrymple (1984), isso vai ocorrer sempre que:

$\lambda=\frac{2 \cdot L}{n}$

onde $\lambda$ é o comprimento de ondas, $L$ é o comprimento de cavidade ressonante, no caso 1,5 metros, e o número natural $\eta=1,2,3 \ldots$ indexando o modo de oscilação. Pode-se ver que existem inúmeras combinações de ressonância que amplificariam a amplitude das ondas atrás dos flaps. É importante observar que grande parte das ondas pretendidas no tanque gira em torno de $1 \mathrm{~Hz}$, o que equivale a um comprimento de onda $\operatorname{com} \lambda=1,56$ metros, praticamente igual ao comprimento da cavidade com modo de ressonância $\eta=2$. O mesmo acontece com outros modos e outros múltiplos de onda. Portanto, é fácil observar a importância de se contar com tais absorvedores.

Com esta finalidade, diversos tipos de absorvedores poderiam ser instalados na parede. Devido ao formato da mureta onde a praia foi colocada, o papel da praia se tornou secundário e ela só será atuante para ondas maiores. Daí a importância de um absorvedor fixado à parede. 
O trabalho de De Mello (2006) trata deste assunto e faz uma comparação entre métodos de absorção de ondas. No caso de aparatos que podem ser fixados a uma parede, os mais relevantes são os métodos que fazem uso da dissipação de energia por viscosidade e turbulência em vórtices. Um tipo interessante é descrito por Lebey e Rivoalen (2002). Ele faz uso de placas sobrepostas inclinadas em frente a uma parede vertical para dissipar energia por viscosidade da onda, vórtices na ponta das placas e ressonância devido à cavidade confinada entre as placas e a parede. Dependendo dos parâmetros testados, a reflexão pode ser próxima de zero, mas ela depende da ressonância e consequentemente da faixa de frequências das ondas.

Vários trabalhos analisam telas verticais com porosidades variáveis. Nos trabalhos de Twu e Lin (1991), Twu e Duann (1995), Twu, Liu e Twu (2002) e Chan e Lee (2001) existem diversas análises a respeito da porosidade e dos arranjos das telas, destinadas a verificar a reflexão, a transmissão e a dissipação ocasionadas.

O trabalho de Brossard, Druaux et al. (2003) se concentra na análise de desempenho de um absorvedor por telas em frente a uma parede impermeável. $\mathrm{O}$ resultado é o mesmo que aquele obtido anteriormente por Twu e Lin (1991), Zhu e Chwang (2001) e Li, Dong et al. (2003). Existe uma melhora na absorção somente quando a relação entre o comprimento de onda e a distância entre a tela e a parede é próxima de 0,25 - portanto, $1 / 4$ do comprimento da onda. Assim sendo, não funciona para uma boa faixa de frequências de ondas.

Chakrabarti (1994) cita um outro método, em que se usam telas com porosidades variáveis sequencialmente; é chamado de absorvedor progressivo. Nele são colocadas 24 placas com porosidades variáveis a distâncias menores que o comprimento das ondas. Esta é uma vantagem do arranjo: a eficiência é boa para uma grande faixa de frequências e ângulos de incidência.

Tomando por base este último exemplo, foi feita uma caixa para ser fixada à parede. Nela foram colocados materiais de diferentes porosidades, de modo a dissipar a energia das ondas. A caixa tem $55 \mathrm{~cm}$ de altura, estando $5 \mathrm{~cm}$ fora da água e $50 \mathrm{~cm}$ submersos. Resta, portanto, 1 metro de distância entre a caixa e o flap. As paredes (frontais, laterais e traseiras) são compostas por chapas perfuradas com furos redondos (chapa moeda) assim como em Brossard, Druaux et al. (2003). Mas neste caso foram feitas divisões internas ajustáveis, para se decidir qual seria o melhor arranjo interno 
com elementos de porosidades variáveis. A chapa tem furos de $20 \mathrm{~mm}$ de diâmetro com porosidade de $73,3 \%$.

Visando estudar o assunto, foi feito um arranjo experimental semelhante àquele mostrado em De Mello (2006), em que foi medido o índice de reflexão de praias passivas. No canal de ensaios do laboratório didático da EPUSP foi feito o ensaio em ondas para medir a absorção da caixa. O canal tem 27 metros de comprimento por 1 metro de largura e 0,8 de lâmina de água. De um dos lados do canal o protótipo do gerador de ondas descrito em Carneiro (2007) foi usado para gerar as ondas e, do outro lado do canal, foi montada a caixa absorvedora. A distância entre o gerador e a caixa absorvedora era de aproximadamente 20 metros. A caixa usada apresentava 50 centímetros de altura, estando 40 deles dentro da água. No centro do canal foi montado um arranjo de três sensores de ondas para medir a reflexão ocasionada pela caixa. $\mathrm{O}$ algoritmo de medição de reflexão usa a série temporal dos sensores para fazer estimativas, com ajuste pelo método de mínimos quadrados descrito por Isaacson (1991) e aplicado por De Mello (2006). Usa-se um trecho da série temporal da onda incidente sobreposta com a onda refletida pelo aparato propagando pelos sensores e faz-se a média do coeficiente de reflexão resultante.

Foram feitos vários pré-testes que resultaram em arranjos mais promissores. $\mathrm{O}$ primeiro foi executado com bolinhas plásticas usadas em máquinas de lavar roupas com diâmetro de $5 \mathrm{~cm}$ (Figura A.1). Devido às suas seções de corte, elas criam vórtices que dissipam a energia cinética do fluido ao passar ao seu redor.

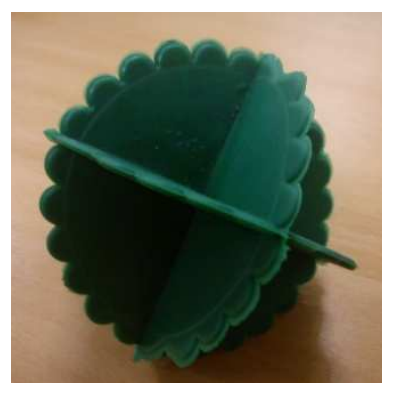

Figura A.1. Bolinha plástica usada para lavar roupas.

Usando-se quatro divisórias dentro da caixa, foi obtida a melhor absorção quando cada bolinha podia se deslocar livremente, sem que ficassem presas umas às outras. Assim, criaram-se quatro divisórias de 8 centímetros cada com o restante da distância livre até a parede. Foram feitas 4 alturas preenchidas com bolinhas nas divisórias; em 
relação à linha de água, a altura crescia gradativamente com -5, 0, 5 e 10 centímetros. Não foram providenciadas mais divisórias pela não disponibilidade de uma maior quantidade de bolinhas. A Figura A.2 mostra o arranjo da caixa no canal de ensaios.

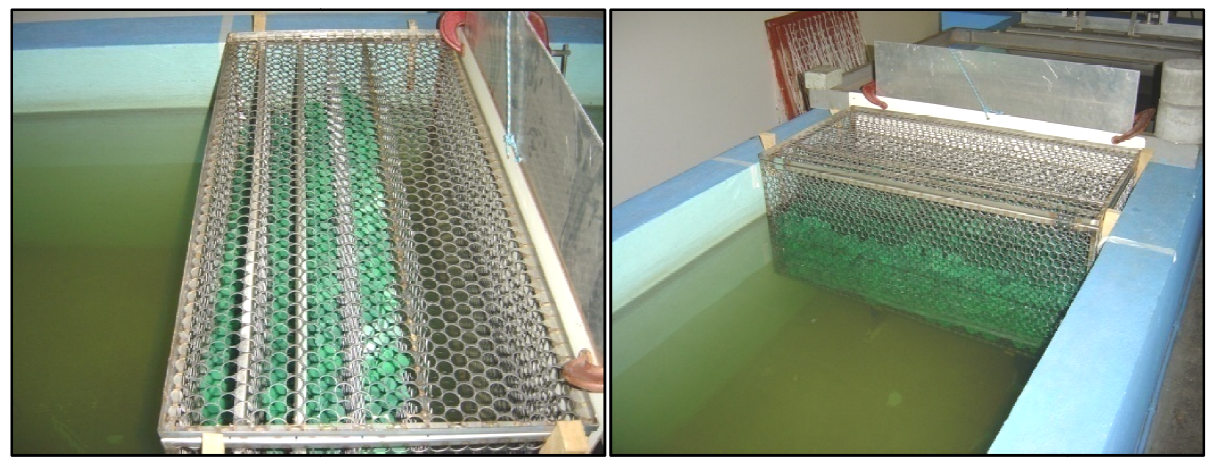

Figura A.2. Caixa porosa absorvedora de ondas.

Em uma nova experiência foram usadas telas plásticas no lugar das bolinhas. Mesmo tendo um melhor desempenho, as bolinhas exigem mais gastos ao serem usadas em grande quantidade no Calibrador Hidrodinâmico. As telas utilizadas no teste podem ser facilmente encontradas na construção civil: são telas tapume extrusadas com trama de $100 \times 50 \mathrm{~mm}$.

As telas foram testadas em duas configurações, alterando-se a quantidade por divisão da caixa. Elas foram colocadas em ziguezague dentro da divisória pelo lado de cima. A Tabela A.1 mostra a quantidade de tela por divisão e a altura preenchida, comparando-se com o teste das bolinhas.

Tabela A.1. Arranjo das divisórias dos absorvedores de ondas

\begin{tabular}{|c|c|c|c|}
\hline & Alturas $(\mathrm{cm})$ & Quantidade $(\mathrm{m})$ & Profundidade $(\mathrm{cm})$ \\
\hline Bolinhas & $(-5)-0-5-10$ & -- & $8-16-24-32$ \\
\hline Tela com baixa densidade & $(-5)-0-5-10$ & $3,5-4-4,5-6$ & $8-16-24-32$ \\
\hline Tela com alta densidade & $(-5)-0-5-10$ & $6-8-10-13$ & $8-16-24-32$ \\
\hline
\end{tabular}

Os resultados obtidos a partir dos testes com ondas podem ser vistos na Tabela A.2. A faixa de frequência do experimento foi limitada, pois não era necessário estudar uma grande quantidade de valores. As ondas de alta frequência apresentam baixa amplitude e as ondas de baixa frequência não representam um grande problema, pois o comprimento de onda é muito maior que a cavidade ressonante; assim, a onda não pode ser devidamente absorvida, mesmo que se tenha um grande aparato absorvedor. 
Tabela A.2. Resultado da caixa absorvedora.

\begin{tabular}{|c|c|c|c|c|}
\hline \multicolumn{2}{|r|}{ Frequências } & $0,50 \mathrm{~Hz}$ & $0,75 \mathrm{~Hz}$ & $1,00 \mathrm{~Hz}$ \\
\hline \multirow{12}{*}{ Arranjos } & Bolinhas: & & & \\
\hline & \multirow{3}{*}{$\begin{array}{r}\mathrm{Hi}(\mathrm{mm}) \\
\mathrm{Hr}(\mathrm{mm}) \\
\mathrm{Cr}(\%)\end{array}$} & 75,55 & 83,94 & 78,40 \\
\hline & & 30,07 & 12,73 & 08,62 \\
\hline & & 39,77 & 15,19 & 11,00 \\
\hline & Telas com baixa densidade: & & & \\
\hline & \multirow{2}{*}{$\begin{array}{l}\mathrm{Hi}(\mathrm{mm}) \\
\mathrm{Hr}(\mathrm{mm})\end{array}$} & 58,00 & 84,00 & 80,00 \\
\hline & & 36,50 & 26,00 & 15,25 \\
\hline & $\mathrm{Cr}(\%)$ & 62,36 & 29,55 & 19,65 \\
\hline & Telas com alta densidade: & & & \\
\hline & \multirow{2}{*}{$\begin{array}{l}\mathrm{Hi}(\mathrm{mm}) \\
\mathrm{Hr}(\mathrm{mm})\end{array}$} & 60,00 & 81,16 & 80,00 \\
\hline & & 27,00 & 8,21 & 11,50 \\
\hline & $\mathrm{Cr}(\%)$ & 40,30 & 10,11 & 15,50 \\
\hline
\end{tabular}

O resultado demonstra que as bolinhas obtiveram desempenho um pouco melhor em $1 \mathrm{~Hz}$ e pior em $0,75 \mathrm{~Hz}$. Mesmo que o resultado seja favorável, por conta do custo as bolinhas foram descartadas e optou-se pelas telas com alta densidade no Calibrador Hidrodinâmico. $\mathrm{O}$ resultado deteriora em $0,5 \mathrm{~Hz}$ para todos os arranjos, onde os comprimentos de ondas são bem maiores que o aparato absorvedor, diminuindo a eficiência de absorção. Para melhores resultados nas ondas longas, teria que ser usado um aparato mais profundo e mais alto, mas o espaço disponível é restrito. Desta forma, optou-se por usar esta concepção no tanque de provas porque a absorção obtida reduz em mais de $80 \%$ as ondas refletidas em frequências de $0,75 \mathrm{~Hz}$ e acima. A Figura A.3 abaixo mostra o arranjo final montado no tanque de provas.

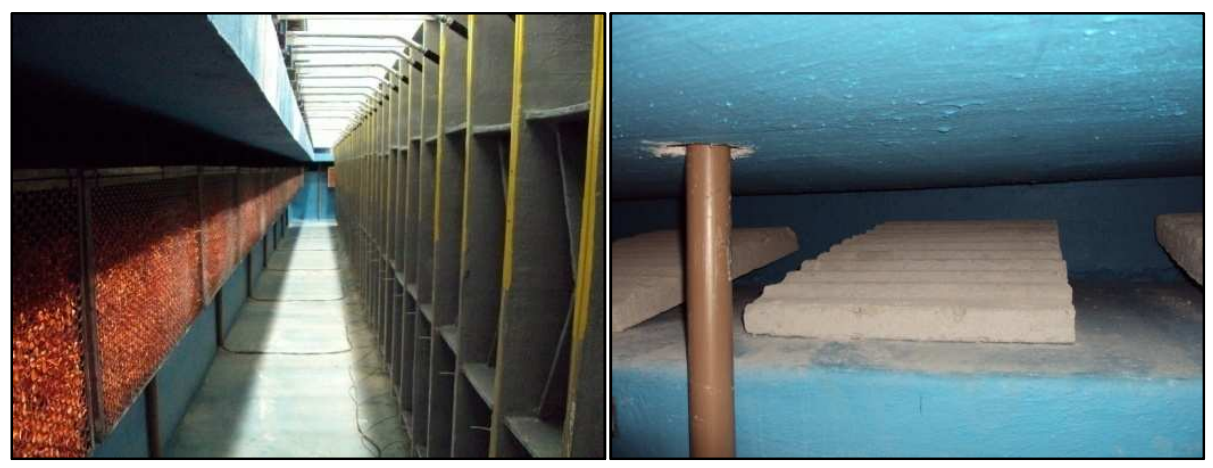

Figura A.3. Absorvedores de ondas passivos instalados no tanque de provas. 